\title{
B. Sehelle
}

\section{Die winterharten Nadelhôlzer}

\section{Mitteleuropas.'}

\section{0}

2

$5+1,184$

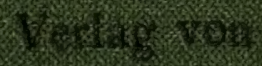

1) 

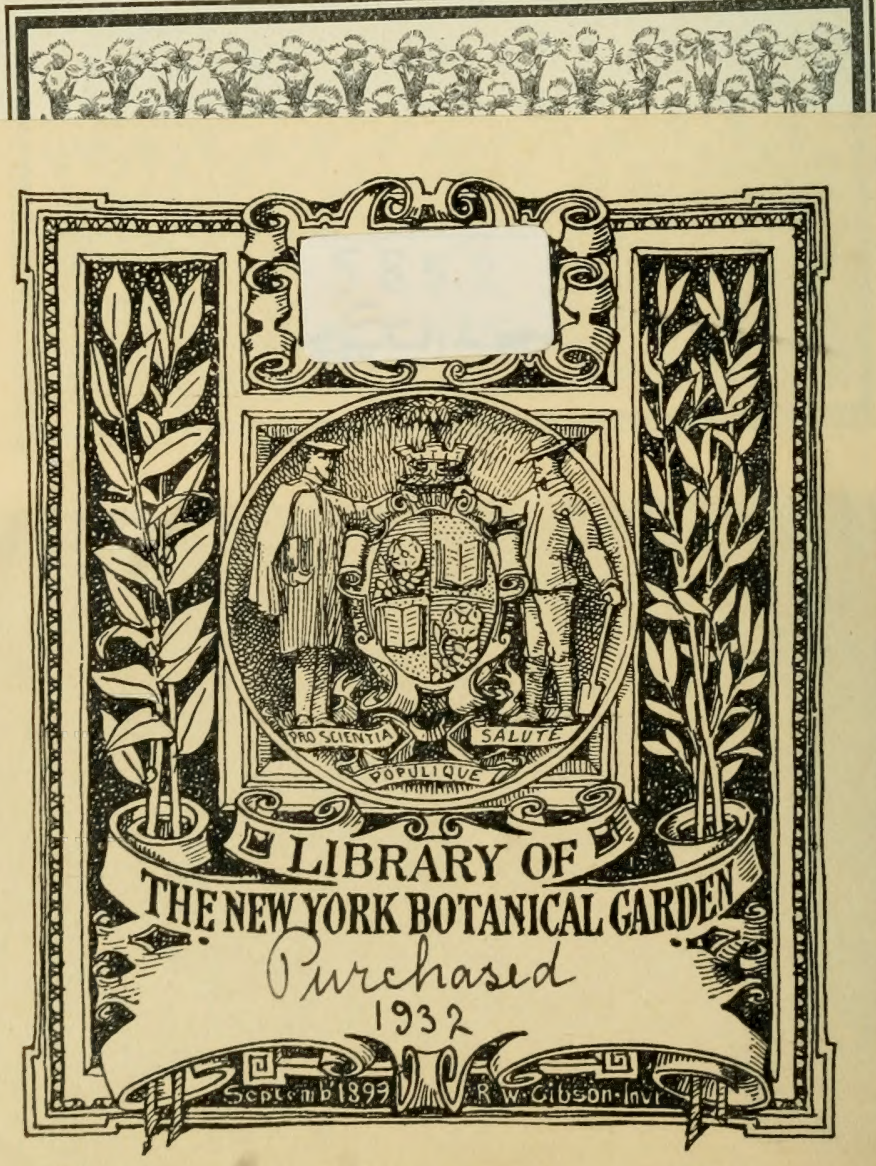


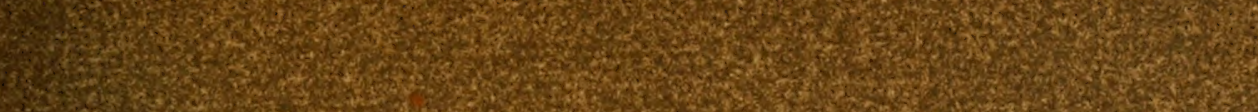

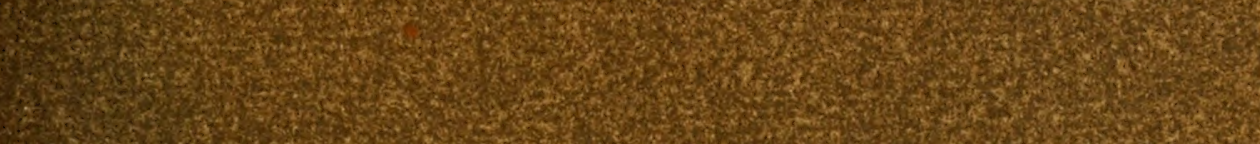

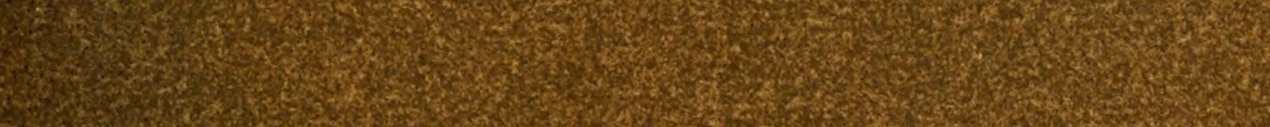

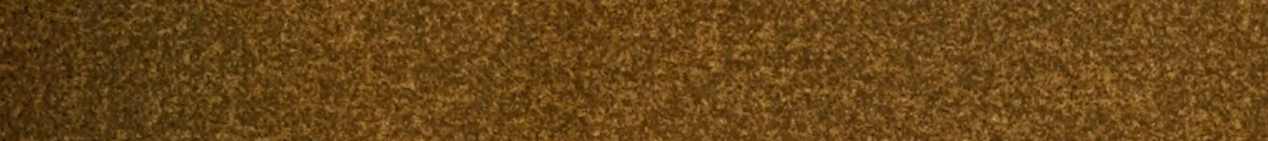

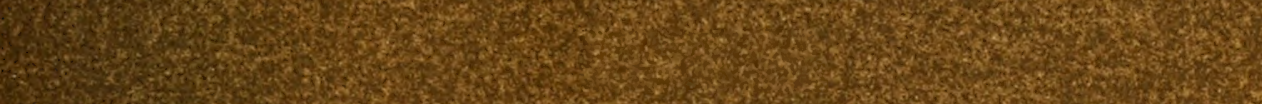

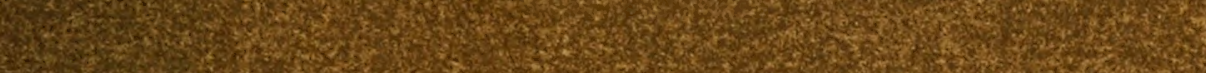

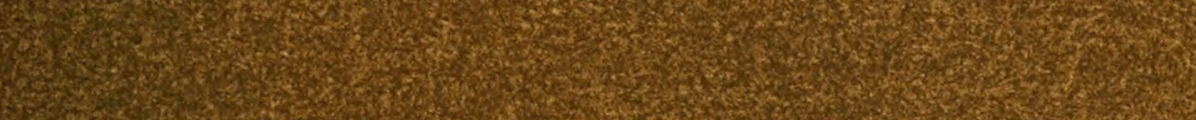

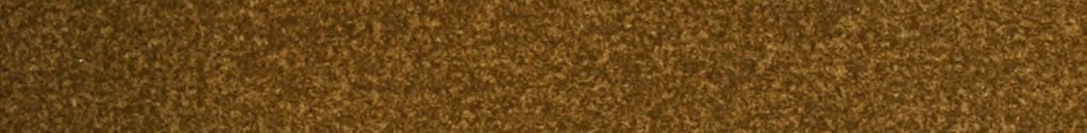

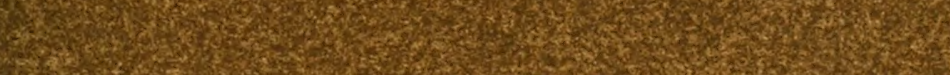

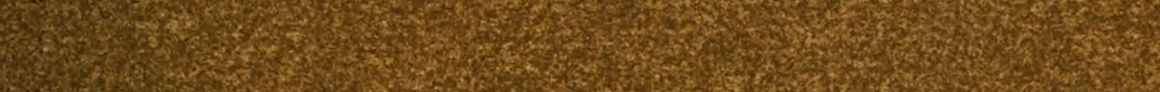

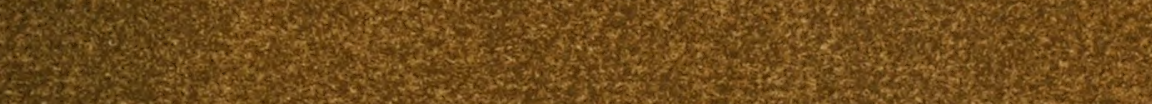
50.6. 6.1.7.

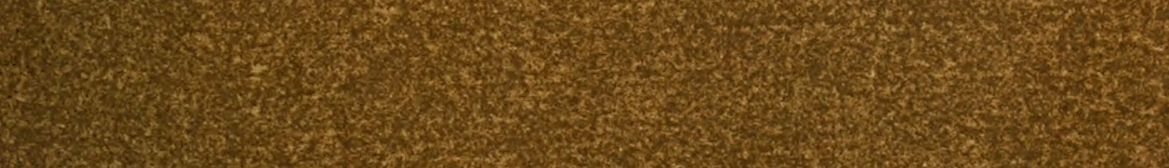
(1)

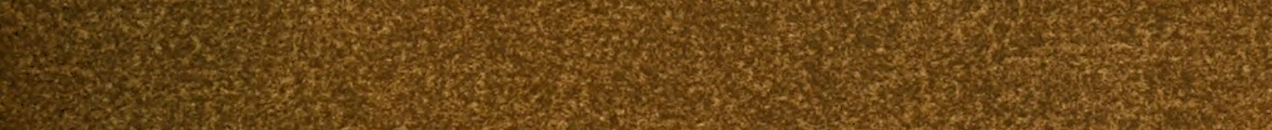
P.

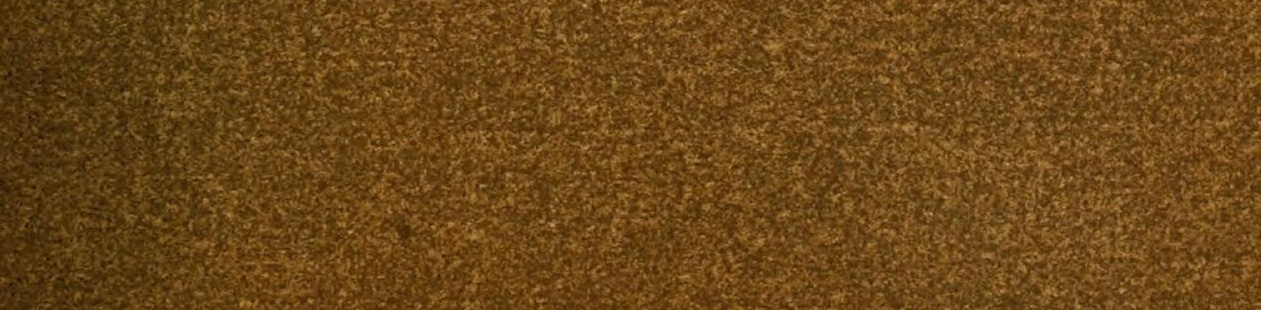

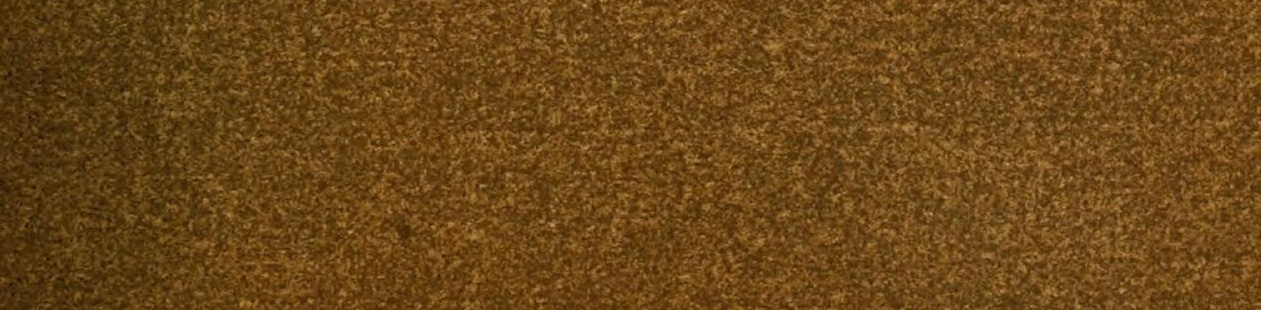


$24 \quad 43$

$4^{2}$ 


\section{Die winterharten Nadelhölzep Mitteleuropas.}

\section{Ein Handbuch für Gärtner und Gartenfreunde.}

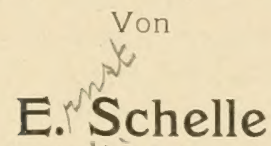

Kgl. Garteninspektor am botanischen Garten der Universitāt Tübingen.

Mit 173 Abbildungen, darunter 155 neue, nach der Natur aufgenommene Originalbilder und Federzeichnungen, sowie einer Tafel und einer geographischen Karte.

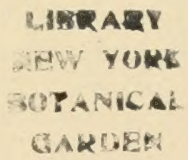

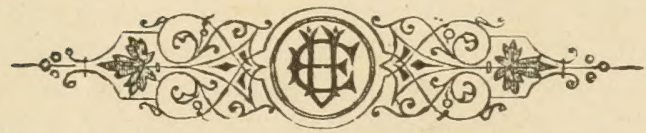

STUTTGART 1909.

VERLAGSBUCHHANDLUNG VON EUGEN ULMER.

Verlag für Landwirtschaft und Gartenbau. 


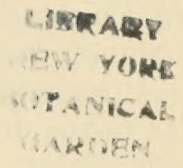

\section{Vorwort.}

Ein Buch für die Praxis soll das vorliegende Werk sein, dessen Bedürfnis von deutschen Praktikern seit mehr als einem Jahrzehnt ausgesprochen und anerkannt wurde.

Seit dem Erscheinen von Kochs, sowie Carrières „Dendrologie“, dann der vorzüglichen "Synopsis der Nadelhölzer" von Henkel und Hochstetter, sowie des letzteren kleinen Werkchens „Die Koniferen oder Nadelhölzer, welche in Mitteleuropa winterhart sind", ferner Lauches „Deutsche Dendrologie" und ähnliche Werke mehr, besonders aber seit dem auch in nomenklatorischer Hinsicht bahnbrechenden Buche Beißners „Handbuch der Nadelholzkunde", dem eine kleinere Arbeit: "Handbuch der Koniferenbenennung:" vorausgegangen war, und der kurz darauf erschienenen "Deutschen Dendrologie“ von Köhne, sowie Mayr „Fremdländische Wald- und Parkbäume“, welch allgenannte Werke - mit Ausnahme derjenigen von Beißner - in der Hauptsache nur die Koniferen - Arten behandelten und das Heer der Formen, besonders der neueren Formen übergingen, waren es neuerdings nur von Tubeuf „Die Nadelhölzer", sowie Hartwig "Illustrierte Gehölzzucht", welche neben den Arten auch eine größere Anzahl von Formen beschrieben hatten.

So war der Wunsch, ein nicht zu umfangreiches, der praktischen Arbeit dienendes Werk zu erhalten, welches Arten und Formen möglichst allseitig behandelte, gewiß begründet.

$\mathrm{Ob}$ es mir nun gelungen ist, diesem Wunsch mit meinem Buche wenigstens einigermaßen gerecht geworden zu sein, wage ich nicht zu beantworten; mein ständiges Bestreben aber war es bei der langjährigen Arbeit.

Eine Zeit lang beabsichtigte ich Hochstetters 1882 erschie$\propto$ nenes Werkchen neu herauszugeben, aber das seit jener Zeit $\$$ gewaltig angewachsene Material veranlaßte mich, die schon ziemlich weit vorangeschrittene Arbeit wieder beiseite zu legen und eine Neubearbeitung der Materie vorzunehmen.

Die Deutsche dendrologische Gesellschaft (in der Hauptsache hervorgegangen aus der Vereinigung deutscher 
Koniferenzüchter und -Kenner) hat die von Beißner aufgestellte, einheitliche Koniferenbenennung vollständig angenommen und erfolgreich durchgeführt, - (die Royal-Horticultural-Society in England folgte diesem Beispiel kurz darauf in fast übereinstimmender Weise) - der sich dann auch wohl alle Koniferenzüchter und -Kenner, ferner die größeren deutschen Baumschulen u. s. w. anschlossen, um so mehr, als die Mitglieder obengenannter, großen Gesellschaft die Mehrzahl der in Deutschland verbreiteten Koniferen- $\mathrm{Neuheiten}$ nur in ihrem eigerıen Organ, den „Mitteilungen der deutschen dendrologischen Gesellschaft" beschreiben und bestimmen.

Es war deshalb gewissermaßen selbstverständlich, daß auch ich als Mitbegründer und Ausschußmitglied genannter Gesellschaft deren Prinzipien strenge einhielt und bei meiner Arbeit dementsprechend Beißners Nomenklatur und Regelung der Nadelhölzer ebenfalls annahm und in ihr gleichartig durchführte, wodurch - so hoffe ich — die einheitliche Benennung der Koniferen immer mehr Gemeingut wird.

Hiedurch wurde ich aber zugleich einer umständlichen Arbeit enthoben, der Anführung synonymer Bezeichnungen, welche Beißner ja so eingehend behandelte. Nur in Fällen, in welchen die Synonymen zum genaueren Verständnis benötigt waren, wurden dieselben den gültigen Namen beigefügt.

Bemühte ich mich einerseits, möglichst alle für Deutschlands Klima in Betracht kommenden Nadelholz-Arten und Formen zu behandeln, so war ich doch andererseits, um den ohnehin weit gesteckten Rahmen des Buches nicht noch mehr dehnen zu müssen, gezwungen, die Beschreibung der Koniferen, unter besonderer Berücksichtigung der wichtigsten Kennzeichen, so knapp als irgend möglich auszuführen, was bei den Formen eben oft nur mit ein paar bestimmenden Worten geschehen mußte, immerhin - so glaube ich - aber doch genügend zur Beantwortung der ersten Fragen des Ratsuchenden.

Der Verleger meines Buches ist, davon ausgehend, daß ein gutes Bild sehr oft die längsten Beschreibungen mit einem Blick ersetzt, mir durch Anfertigung einer großen Anzahl prächtiger, von Material aus dem hiesigen botanischen Garten aufgenommener Abbildungen bei Ausführung meiner Arbeit sehr entgegengekommen, sodaß ich ihm hiefür, wie auch für die sonstige, schöne Ausstattung des Buches sehr verpflichtet meinen besten Dank ausdrücke.

Die Winterhärte-Notizen, in gleicher Weise durchgeführt wie im "Handbuch der Laubholzbenennung" sind einer ca. 30jährigen Arbeit entnommen. Bei immergrünen Gehölzen sind ja diesbezügliche, bestimmte Angaben weit schwieriger, als bei Laubhölzern; bei genauer Beachtung der für die Entwick- 
lung der Nadelhölzer so sehr wichtigen Verhältnisse des Standortes und der Bodenbeschaffenheit wird jedoch der wirklich erfahrene Beobachter meine nur in einer kleinen Anzahl noch wankenden Winterhärte-Bemerkungen als richtig bestätigen müssen. Eine Kenntnis der Winter-Ausdauer, bezw. KälteAusdauer der Nadelhölzer gehört bekanntlich zu den wichtigsten zu beobachtenden Faktoren bei der Anpflanzung der Koniferen, besonders in kälteren Gegenden und bei fremdländischen Gehölzen.

Wenn gar manche Art aufgenommen wurde, deren geringe Winterhärte eine Anpflanzung kaum oder nur in den klimatisch günstigsten Teilen Deutschlands zuläßt, so geschah dies besonders mit Rücksicht auf den Laien, welcher meist sehr geneigt ist, oft gerade mit diesen empfindlichen Arten Anpflanzungs-Versuche zu machen. -

Liegt mir nun auch der Gedanke fern, daß meine Arbeit der Kritik erfahrener Praktiker entgehen wird, so hoffe ich doch andererseits, daf das Gute, was das Werk in seinem umfangreichen Stoff enthält, berücksichtigt und wohlwollend beurteilt wird. - Vielleicht wird das Buch doch für Manchen das, als was ich es hätte gern bezeichnen mögen, als ein Vademekum, ein "Geh" mit mir" bei der Arbeit mit Nadelhölzern.

Tübingen, Sommer 1908. 



\section{Inhalts-Verzeichnis.}

1. Allgemeinel Teil

2. Die Heimat der Koniferen

und das Verhalten fremdländischer Arten in deutschen Klimaten

\section{sowie}

Schlüssel zu den Notizen über die Winterhärte der in Deutschland angepflanzten Nadelhölzer

3. Körperbau der Koniferen

Keimlinge

Wurzeln .

Holz

Äste

Zweige

Bau

Rinde

Borke.

Harzausscheidung

Knospen .

Blätter

Öldrüsen .

Spaltöfinungen

Blattstiele

Blattscheiden

Bliten

Zapfen

4. Kultur der Nadelhölzer . . . . . . . . . . . 20

Pflanzzeit . . . . . . . . . . . . . . . 20

Bodenbeschaffenheit . . . . . . . . . . . . . 20

Standort . . . . . . . . . . . . . . 20

Empfindlichkeit gegen Rauch und Staub . . . . . . . . 21

Pflanzung . . . . . . . . . . . . . . . . 21

Pflege der grösseren Koniferen . . . . . . . . . . 22

Schnitt der Koniferen . . . . . . . . . . . . . 23

Schutz gegen Schädlinge . . . . . . . . . . . 23 
a) Pflanzliche Schädlinge. . . . . . . . 24

b) Tierische Schädlinge ... . . . . . . . 26

5. Vermehrung der Nadelhölzer

und Pflege der jungen Pflanzen . . . . . . . . . 30

Samen . . . . . . . . . . . . . . . 30

Stecklinge. . . . . . . . . . . . . . . . . 33

Ableger oder Senker. . . . . . . . . . . . . . 35

Pfropfung . . . . . . . . . . . . . . . . 35

6. Grössere Nadelholzanpflanzungen in Deutschland . . . . . 37

7. Einteilung der Koniferen. . . . . . . . . . . . . . . . 41

8. Beschreibung der Koniferen . . . . . . . . . . . . . . $4 t$

\begin{tabular}{|c|c|c|c|c|c|c|c|c|c|c|c|c|c|c|c|}
\hline Abies & - & & & • & & - & $\begin{array}{r}\text { Seite } \\
. \quad 125\end{array}$ & Larix . & & & & & & & $\begin{array}{r}\text { Seite } \\
\text { - } \quad 161\end{array}$ \\
\hline Actinostrobus & & • & & . & 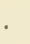 & . & . 261 & Libocedrus & & & & . & & & $26 ;$ \\
\hline Agathis & . & . & . & 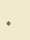 & . & - & 67 & Microcachrys & & & & . & 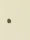 & & \\
\hline Araucaria & . & . & & $\cdot$ & . & 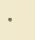 & $6 s$ & Phyllocladus & & & & - & • & & \\
\hline Arthrotaxis & . & . & . & . & . & . & . $\quad 249$ & Picea . & & & & . & 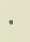 & & \\
\hline Biota . & - & . & & & . & . & . $\quad 265$ & Pinus . & & & & • & & & 18 \\
\hline Callitris & . & . & & & . & . &.$\quad 261$ & Podocarpus & & & & 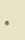 & & & \\
\hline Cedrus & 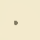 & . & & & . & . & 174 & Pseudolarix & & & & 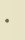 & 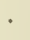 & & 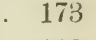 \\
\hline Cephalotaxus & & . & & & . & 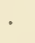 & 52 & Pseudotsuga & & & & . & $\cdot$ & • & 11 \\
\hline Chamaecypar & & . & & & . & - & 289 & Saxegothaea & - & & & & & & \\
\hline Cryptomeria & & . & & & · & - & . 250 & Sciadopitys & - & & & & & . & 24 \\
\hline Cunninghamia & & . & . & & . & . & . 244 & Sequoia. & 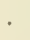 & & & 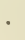 & 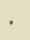 & . & $2-1$ \\
\hline Cupressus & - & . & . & . & . & . & . .241 & Taxodium & . & . & & 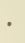 & - & • & . \\
\hline Dacrydium & . & - & $\cdot$ & $\cdot$ & . & 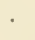 & วิ & Taxus & 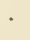 & . & & & · & . & \\
\hline Fitzroya & . & . & $\cdot$ & $\cdot$ & . & . & 262 & Thuya & $\cdot$ & 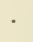 & & 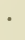 & . & $\cdot$ & 27 \\
\hline Ginkgo & · & $\cdot$ & . & ${ }^{\circ}$ & 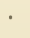 & . & 44 & Thuyopsis & & . & & 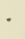 & - & . & 21 \\
\hline Juniperus & . & . & . & 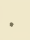 & . & 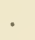 & - $\quad: 3117$ & Torreya & * & . & & 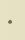 & - & . & 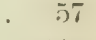 \\
\hline Keteleeria & . & & & 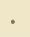 & . & . & . 162 & Tsuga & & & & & & & . \\
\hline
\end{tabular}

9. Alphabetisches Inhaltsverzeichnis . . . . . . . . . 330 


\section{Allgemeiner Teil.}

Foniferen und Palmen sind wohl die edelsten Gew ïchse unserer Erde. Wird die Palme als die Königin der Pflanzen tropischer Kilinaten bezeichnet, so kam die Tamme als solche der Pflanzen kalter Zonen genannt werden.

Der. Wald mit seinen mächtigen Laub- und Nadelbäumen galt schon unseren Vorfahren als heilig und auch wir können uns in einem alten, mit mächtigen Bäumen hestockten Walde oder waldihhnlichem Parke eines gewissen Schanerns nicht erwehren, wenn wir auch andererseits uns gerade dort der Allmntter Natur so iiberaus nahe füllen, dort unser Geist und Körper erfrischt, ja verjüngt wird.

Doch ist es nicht nu' der Wald in seiner' Gesantheit. der' auf' uns einwirkt, sondern jeder einzelne Baum erweckt unser Schönheitsgefiihl, besonder's wenn derselbe unbeengt durch seinesgleichen oder andere Baumarten sich frei entwickeln konnte und herrlich in seiner Vollpracht vor uns steht, er, der vielleicht schon manche Generation der grofen, menschlichen - Zwerge an seinem Stamme bewundernd stehen sah.

Freilich, die grandiosen Biider urwäldlicher Gegenden fremder Länder zu selıen, das ist wenig Gliicklichen vergünnt, aber auch in deutschen Gauen liömnen wir noch urwiichsige Waldgegenden in grofer Anzahl finden, wie ebenso in den Parks reicher Personen, besonders Fürstlichkeiten, deren Vorfahren schon in vielen Fïllen durch praktische, weitzigige Anpflanzungen von Nadel- und Laubbaiunen unserer Heimat, wie auch solcher aus fernen Ländern, den Wuchs dieser Bäume in ungehinderter. Weise, ohne Krampf mit seinesgleichen oder anderen Bäumen zur vollen Pracht sich entfalten liefen, welche num jetzt unser ehrwiirdiges Staunen erwecken.

Doch die Bewundertung herrlicher Bïume und die Liebe zu den Bäumen ist ja Gemeingut aller edleren Menschen, was W under, daß auch jeder, dem das Gliick hold ist, sich in den Besitz eines mehr oder minder großen Gartens zu setzen bestrebt ist, wemn iroend möglich cine Anzahl seiner Lieblinge muter den iibrigen Biumen und Sträuchern seines Besitztums 
anzupflanzen. Selbst der kleinste Garten birgt, wenn nicht ausladende Laubbäume, so doch Vertreter unserer Nadelhäume. Neben dem dichten, heiteren Griin des Laubgehölzes, das uns aber Winters verläit, verlangt unser Gefiihl das ernste, ständige Griun des Nadelholzes, das anch in der Eintönigkeit des Winters unser Auge erfreut. Und gibt es einen schineren schmuck unserer letzten Ruhestiitte, als das Simbild der immergrünen, nie ersterbenden Natur - die Konifere!

Aber nicht nur idealen Zwecken dienen die Nadelhölzer, eminenten Nutzen erbringen sie dem ganzen Menschengeschlecht.

So ist schon die Wurzel verschiedener Arten neben ihrem TTert als Brenmmaterial, offizinell im Gebrauch, wie sie auch fermer vielfach zähes Flechtmaterial ergibt.

Ist es wohl notwendig, den Nutzen des Holzes als Brenn-. Ban- und Werkholz, sowie zur Papierfabrikation u. s. w. näher zu erläutern? Die hohen Ziffern der Millionen von Mark, die holıen Zinserträge suter Wialder, alles aus dem Verkauf des Holzes, sind wohl die sichersten Belege hiefiur.

Ferner licfern aber noch einige Arten teines Material zu MLusikinstrumenten, dem Splint der"Tamen wird "Coniferin" :ihnlichen Zivecken wie Vanille dienend - entnommen, anilere Arten enthalten speziell im Harz zuckerhaltige Substanzen und derol. Aufierlem aber grewinnt man aus dem Koniferenholz: Terpentin, Pech, Harz als eßbares Produkt, als Ränchermosund Firnismaterial, oder zu offizincllem Gehrauch. In gleicher TTeise dient das Sandarak. Harz und Terpentin werden wieder zu Firnissen, Titte, Harzseifen, Siegellack und feinerem IIaterial zum Auftragen von Farben auf Porzellan und Metall verwendet. So ist besonders auch der Dammaralack ron Wichtigkeit fiir Finnisse, in der mikroskopischen Technik und in ähnlichen Fïllen. Grof ist anch der Wert an Balsam. Dam sei der ätherischen Öle gedacht, welche besonder's in den Blittern und jungen Trieben stark vorhanden sind und vielseitig, besonder's in der Heilkunde, beniitzt werden. In letzter Beziehung mub auch die Waldwolle, ans den Blättern gewonnen, erwähnt werden, sowie die zu Bädern beniitzten ätherischen Öle der Bliitter, welche iiberaus heilkräftige Wirkung haben. Zu Heilbädern beniitzt man anch die jungen Sprosse, ja von einigen Arten wird aus diesen Sprossen sellst ein alkolıolisches Getränke, Spruce-beer, bereitet.

Die Rinde mancher Arten enthält reichlich Gerbstoff oder auch Farbstoffi, sowie sonstige offizinell gebriuchlichen Teile.

Selbst der Zapfen vird in letztgenannter Hinsicht beniitzt, da $e 1 \%$ B. anch atherische (O) le enthält; auferdem ist el ein gesuchtes Bremmaterial. Andererseits dienen die Beerenzapfen speziell ron Junisperusarten - teils zur Nahrung, teils zur Bereitunœ alkoholischer Getränke, "Genever" und dergl. Was 
nun noch den Samen betrilt't, so enthilt derselbe fette () le, Eiweif, Zucker, Kóohlenhydrate, iitherische () le etc. und dient direkt als Nahrungsmittel, wie z. B. die Samen von Arancaria inblicata, oder die Samen werelen als Delikatesice benitlyt, als Ersatz der Mandeln, als (Gewiirz, wie \%. B. diejenigen vieler Kiefern, Pinus Pinea u. s. w.

Einige Arten enthalten abor auch scharfe Alkaloide und Glycoside, sind also einerseits als scharfe Giftptlanzen zu betrichten, dienen aler andererseits medizinischen Zwecken.

Welch eminent giinstigen Einflub noch der Wald, der Lauhwald wie der Nadelwald, auf unsere klimatischen Verhailtnisse hat, daratuf nïher hier dirzmehen, wiirle zu viel Raum beanspruchen, es muth deshalb in dieser Beziehung auf die cinschliinige Literatur verwiesen werden.

\section{Die Heimat der Koniferen}

und das Verhalten fremdländischer Arten in deutschen Klimaten.

Eine Scheidung der Koniferen nach Florengebieten, wie es hei den Laubhölzern angïngig ist, kamn bei den Nadelhölzer'n nicht so leicht - hüchstens als im ganzen betrachtet - durchgefiihrt werden.

Bei der etwas näher genommenen Heinatslïnder-Bestimmung ist sofort ersichtlich, daf die Kioniferen vorzusweise die borealen Gegenden der Kiontinente mul zwar speziell die der nördlich gelegenen Kontinente hevorzugen, welchen sodann jene der gemäbigten Zone folgen. Einige Arten aus tropischen (tegenden entstammen den Höhenzïgen dieser Zonen.

Autfallend ist, daf einzelne Arten ganz riesige Distrikte entweder ganz allein oder nur mit ein bis zwei weiteren Arten vereinigt, beherrschen; ein Zusammenleben mehrerer Arten ist verhältnismäßig selten.

In der alten IVelt steigen die Nadelhölzer am weitesten nördlich und zwar in Skandinavien nahezu bis zum $700^{\circ} \mathrm{n}$. Br., speziell Pinus silvestris, um sodamn mit Picea excelsa in der Form P. exc. obovata bis zum 65. ${ }^{\circ} \mathrm{zu}$ sinken. Im Anschluß hieran folgt Abies und Larix sibirica, sowie Pinus Cembra, dem wiederum Picea exc. obovata - als bis zum 60.0 11. Br. grehend - anzufiigen wäre. (Siehe Karte am Schlut3 des Buches.)

Abies sibirica, Picea ajanensis und Larix dahurica, zum Teil auch noch Pinus silvestris und Picea excelsa mit ihren siidlichsten Grenzen führen hinüber zu der großen Anzahl von Arten der gemäßigten Zone. 
Auf rem europäischen Kontinent sind nun hier zuerst Alies pectinata, Larix europaea (besonders in Zentraleuropa), Picea excelsa, Taxus ${ }^{1}$ ), dam Pinus Pinaster, Picea Onorica, Pinns Laricio austriaca und Laricio selbst, in Spanien Abies Pinsapo, Juniperus, ostlich Abies cephalonica, Nordmanniana, cilicica, Picea orientalis, sowie auch Abies pectinata zu nemen, welchen sich sidlliche Pinus- und Cupressusarten anschliefen; ferner noch Cedrus Libani, die jenseits des mittelländischen Meeres in Nordafrika durch Cedrus atlantica ersetzt wird. Dort sind noch Abies numidica, verschiedene Pinus, Juniperus, sowie die bei uns nicht mehr winterharten Callitris zu finden.

Gegen Asien schliełen sich besonders Picea Schrenkiana, und am Himalaya verschiedene Pinus, damn Abies, sowie Cedrus Deodara an, welch letztere aber nur noch in den W eingegenden Deutschlands sich anbauwiudig zeigen. Weiter ostlich folgen C'upressus, denen sich in dem in Koniferen noch wenig bekamten China, dam aber besonders in den japanischen Gebieten eine große Artenzahl von Nadelhölzer anreihen, und zwar Pinus, Larix, Picea, Tsuga, Taxus, Pseudolarix, 'Torreya, Taxodium, Sciadopitys, Thuyopsis, Juniperus, Biota, Chamaecyparis, Abies, Cryptomeria, der in eigener Familie stehende Ginkgo, ferner in suddicheren Breitegraden $\left(20^{\circ}\right)$ Agathis, Torreya, Cuminghamia, Cephalotaxus, Podocarpus, Libocedrus, welchen sich in den Höhenziigen Siid-Australiens und der anschliefenden Inseln weitere Arten von Agathis, Podocarpus, Dacrydium, Nicrocachrys, Arthrotaxis, Phyllocladus, Saxegothaea, Fitzroya, Callitris, Araucaria und Actinostrobus anfügen.

Anderseits bietet der tropische Teil Afrikas wohl keine (?) Vertreter der Koniferen und erst auf Madagaskar und in der Capgegend ist wieder Callitris und Podocarpus anzutreffen.

Was num die Kontinente des $n$ e $u$ e $n$ Weltteiles betrift', so steigt dort Picea alba in Alaska ungefähr bis zum $68 .^{0} \mathrm{n}$. Br., um hierauf im brit. Nordanerika bis zum 50. ${ }^{0}$ wieder heral,zusinken, woselbst westlich nahezu vom $600^{\circ}$ schon Picea sitchensis, ostlich Abies balsanea sich anschliefen. Etwa vom $500^{0}$ 11. Br. an, westlich iiber demselben, östlich unter demselben, folgt nun gewissermaßen das Dorado, das Zauberland der Nadelhïlzer. Wird das mittlere Nordamerika besonders von Picea alba, nigra, rubra, Abies balsanea und Pinus Strobus besetzt, so folgen östli ch die Ausläufer genannter und eine Reihe weiterer Kiefern, ferner Tsuga, Larix, Thuya, Juniperus, Torreya, Cupressus und Taxolium, die letzteren etwa bis zum $25 .{ }^{0}$ n. Br., westlich dam wieder Reihen von Picea, Tsuga, Larix, Thuya,

1) In den Alpen steigt Pinus ( Cembra am höchsten, da:m folgt Lärche. Fichte, Kiefer. 
Psendotsuga, Pinus. Chamacyparis, Sequoia (Wellingtonia), Abies, Torreya, Taxus, Libocedrus, mu dann gesen Vittelamerika wieder mit 'Taxodium, Abies und Pinns, beim 13. ${ }^{0}$ etwa, zu endigen.

In obenwenanntem reichsten Koniferenlande, das ein Analogon bis jetzt nur im japanischen Reiche timlet, trifit man auch die gröbten Mengen an Nadelhölzer'n und die höchsten Exemplare derselben an.

Bäume von $90 \mathrm{~m}$ Höhe sind keine Seltenheitcn, ihnen folgen solche von 100, ja von $120 \mathrm{~m}$ Höhe; dabei erreichen einzelne Arten ein Dickenwachstum von 10 m Durchmesser, ja sogar (Taxodium mexicanum) über $16 \mathrm{~m}$ ! -

Solche Bäume erreichen anch ein iuberaus hohes Alter. So ist fiir ebengenannte Taxodie ein allerdings fragliches Alter voll etwa 4000 Jahre, damn ein wohl genaues Alter von 2000 Jahre fiu Sequoia gigantea - welche $120 \mathrm{~m}$ hoch wird und $10 \mathrm{~m}$ Durchmesser, also ca. $32 \mathrm{~m}$ Umfang zeigt, angegeben. Ähnliches Alter, aber entfernt nicht ähnliche Höhe, erreichen in der alten Welt Cupressus sempervirens var. fastigiata und Taxus baccata mit etwa 3000 Jahre, sowie Cedrus Libani mit iiber 2000 .Jahre, dem noch Abies pectinata mit 1200 . Jahre zur Seite steht.

Übertroffen werden diese Narlelholzbïume allerdings durch Laubbäume und zwar imAlter durch Dracaena Draco mit 6000Jahre, Adansonia digitata mit 5000 Jahre; im Dickenwachstum nur durch die eßbare Kastanie mit $20 \mathrm{~m}$ !, und im Höhenwachstum noch durch einen australischen Laubbaum, der aber verhältnismäßig geringes Dickenwachstum zeigt - durch Eucalyptus amygdalina mit 152\% $1 \mathrm{~m}$ ! (Köhner Dom $156 \mathrm{~m}$, Ulmer Miinster. 158 bezw. $160 \mathrm{~m}$ ).

Was nun noch das nördliche Sidamerika betrifft, so birgt dieses bis etwa zum $130^{\circ}$ si̊dl. Br. keine Nadelhölzer, worauf Arancaria brasiliensis im mittleren, östlichen Teil, Arancaria imbricata im westlichen Teil einsetzt, der Libocedrus, Podocarpus, Dacrydium, Saxegothaea und Fitzroya bis nach der Siidspitze des Landes, Potagonien, folgen.

Von allen genannten Länder'n liefern num fïr Deutschland

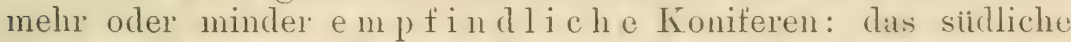
Europa, Kleinasien, Taurus, Persien, Nordafrika, Suidafrika, der untere und auch der nordwestliche Himalaya, Indien, China, Siidjapan und Australien; in Nordamerika, besonders Florida und die angrenzenden siidlichen Länder, das Kïisten-Kalifornien. dann Mexiko, sowie das ganze Siidamerika.

Um num auf das Verhalten fremuliundischer Gehölze in Deutschlands Klina, besonder's in Bezug auf ihre Winterhärte, 
näher einzugehen, mufi in dieser Hinsicht vorweg bemerkt werden, daß hieriiber noch vielfach eine recht geteilte Meinung herrscht, entsprungen aber wohl durchegs einer ungenügenden, zu kurzen Erfahrung.

Thren natuirlichen Stand haben alle Nadelhölzer in mehr oder minder geschlossenen Beständen, sich sellst gegenseitig Schatten gebend oder wenigstens am Fuße Schatten elhaltend, orler auch mit Lauhholz untermischt in ähnlichem Verhältnis stehend.

Feuchte Luft, oder wenigstens freie, kiihle Luft, ist das Bediurnis fast aller Koniferen, und selbst jene Arten, welche größere Trockenheit auszuhalten scheinen, wie z. B. Pinus und .Juniperus-Arten, dringen doch tief in das Erdreich ein, oder legen ihr Wurzelwerk möglichst unter Steinen, Felsen und sonst den Sommenbrand abhaltenden Gegenständen an. Aber auch diese Koniferen haben auf solch trockenem Standort niemals ein gutes, normales Wachstum.

Die Bläter (Nadeln) der Líniferen sind fast durchwe@ sehr gegen stärkere bezw. raschere Wasserverdunstung geschützt und zwar so, dafi die Atmungsorgane (Assimilationsorgane) besonders an der Unterseite der Blätter erzeugt werden, ferner daß diese Organe noch reduziert, versenkt und sonstwie geschiitzt werden, oder daß aufierden die Oberfläche der Nadeln durch ein korkartiges Häutchen bedeckt wird.

Sehr empfindlich øegen Trockenheit, bezw. mangelhatte Fenchtigkeit sind auch die IVurzeln der Nadelhölzer, ein Faktor, derfürdie Widerstandsfähigkeit derPfllanzen von grober Wichtigkeit ist.

Unginstig ist auch ein sehr loindiger, schwerer Boden, da er der freien Entricklung der Wurzeln oft sehr hinderlich ist. Überhampt spielt die physikalische Beschaftenheit des Borlens in den meisten Fïllen eine sehr wesentliche Rolle bei der Wiichsigkeit und Widerstundstahigkeit der Koniferen, zudem hiebei oft noch weitere I'unkte mitspielen, die entweder nicht beliant orler nicht genau beachtet werden oder werden können. Aus diesem Grunde ist as auch wohl selten von besonderem Torteil geresen, die ron fernen Laindern einzufiihrenden Koniferen nur anf solchen der Heimat @leichenden Boden und in ihnlichstem Klima etc. bei uns anzubauen.

T)af hei Stellung in IT aldhest inden diesellue eine naturgemiifie ist und deshalh fremdländische Koniferen dam hei uns in den meisten Fiallen sich den (O)tlichkeiten anpafiten und Wiichsighoit wir ohenso eute Widerstandskraft zeigten, ist bekannt.

Cimurlvershieden int aber fast stets das Terhalten fremdlindischer — oft anch einheimischer - Koniferen bei plötz- 
licher Einzelstellnug in Giirten odes Parks. Sind die Boclenverhältnisse, Luttfeuchtigkeit u. s. w. minstig, so gerleihen besonders wemn durch geregelte Banmschulbelandlung, ofteres Umptlanzen etc. die Exemplare fiir ihre spoitere Vertwendung vorbereitet wurlen, auch die isoliert stehenten Pflumen meist prichtion mol hillen jene wundervollen, oft tiefbeasteten Exemplare.

Ganz ander's aber. wenn mit dem nummehrigen nenen Standort anch die mehr oder minder ungiunstiø einwirkenden Faktoren das IV:achstum der Pflanze heeinflussen: unzutrighliche Beschaftenheit des Bodens und des Untergrundes, Lutttrockenheit, trockene und anch kalte Winde, besonder's in den Friihjahrsmonaten, heibe Somnenbestrahlung, ganz speziell Winters bei etwas gefrorenen Ptanzenteilen und gefrorenem Boden, weil durch die Somnenwiame das Leben besonders der aiberen Gewebemassen erweckt wird und Wasser rerdunstet, das aber bei gefrorenem Borden nicht ersetzt werden kamm), Einwirkmg der schwefelioen Siure rauchfiihrender Örtichkeiten, Stialte ete. - und was dergleichen Faktoren noch mehr sind, -- damn ist nicht nur mangelhafte Entwicklung des Nadelholzes die Folne, sondern oft dis Schicksal der PHanzen iberhanpt besiegelt. Gar hald stößt die Konifere eine grofe Anzahl ruerst bramrot cewordencr Bliatter und Triebe ab, was oft bis zur violligen Ruppigkeit des Exemplars fortscheiten kann; damn nimmt auch das WTachstum der Pflanze sehr rasch, oder doch von . Tahr zu Jahr ab, worauf damn plötzlich, meist aber nach einem nicht eimmal scharfkalten Winter das Ende herbeigefiihrt wird. Solche Exemplare sind jedoch, wie meist angenommen wird - nicht erforen, sondern weit eher verhungert und vertrocknet.

Etwas ganz anderes ist es mit dem wirklichen Erfrieren der Nadelhölzer.

Das Erfrieren ist individuell.

In welcher Terfassung der ganze Ban oder auch einzelne Teile einer Pftanze sich befinden, wemn die Kälte auf dieselbe einwirkt - also bei normalem Zustand sesmules ITachstum, ausgereifte Triebe etc, Nangel schällichel Einfliisse rerschiedenster drt - und rorausgesetzt, dafi die Ptlanze iiberhaupt imstande ist, die heirschende Kialte zu ertragen, in diesem Grade willersteht sie anch dem Winter. Beeinflutit irgend ein schädlicher Faktor die Konstituion der Pfanze, so wird

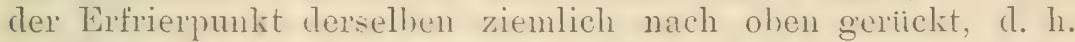
die Pflanze erfriert bei tinem geringeren Kailtegral, als sie schon ausgehalten hat. Deshalh auch oft die ITidersuriche iiber ausgehaltene Kälte.

Ein seln wefurchteter. von aufien wirkender, lats Erfrier'n einer Pthanze sthr oft voran lassender Faktor ist lie sumen- 
bestrahlung, teils daf solche in kalten Wintern eine erhöhte Tätigkeit der Saftzirkulation, Füllung der Zellen mit Wasser, erzengt, welch letztere damn in der folgenden kalten Nacht weit eher gefrieren als die wasserarmen Zellen, teils daß die Sonnenstrahlen einen gefrorenen Pflanzenkörper rasch zum Auftauen bringen, der Pflanze also nicht ermöglichen, das durch das Gefrieren in die Interzellularräume ausgetretene Wasser wieder langsam zu resorbieren. Ist das Chlorophyll getötet, so stirbt die Pflanze unbedingt al). Sehr oft wirken natiulich beide schädlichen, oben angeführten Umstände zusanmen.

Aus diesen Gründen können also auch einheimische und selbst alte, sonst widerstandsfähigere Pflanzen erfrieren, oder doch stark beschädigt werden.

Sicher ist, daß eine das Jahreswachstum gut abgeschlossene, also a usgereifte Pflanze weit eher die Unbilden eines Winters erträgt, als unfertige Pflanzen.

Ebenso sicher ist aber auch, daf keine Pflanze auch nur un einen Kältegrad mehr erträgt, als die normalen Kältegrade ihres Heimatlandes betragen.

An diesem unumstößlichen Gesetz scheitern alle sogenannten Akklimatisationsversuche.

Wo nur irgendwo von einer Anpassung gesprochen werden komnte, war das Klima glejch dem der Heimat! In allen anderen Fällen waren die Angaben falsch.

Wohl kann, da die Wurzeln gegen zu große Kältegrade sehr empfindlich sind, durch Bedecken des Wurzelstockes die Widerstandskraft um eine Kleinigkeit erhöht werden, oder es wird durch Schutzpflanzungen, Anbringung von Schutzwänden (Tamnenreis und dergl.) die direkte Sonnenbestrahlung algehalten, also auch erhöhte Lebenstätigkeit in den Winter- und ersten Friihjahrsmonaten (!) möglichst verhindert aber es ist alles umsonst, wemn zu ho he Kältegrade die Pflanzen betroffen haben.

Nicht unerwiihnt sei hier, daß einzehne Exemplare - oft unter hunderten! - eine höhere Widerstandskraft gegen Kälte zeigen und meist auch behalten, aber deren Nachkommen sollen - nach Erfahrumgen - diese Eigenschaft nicht besitzen.

Femer ist bekannt, daß biau-, grau- oder silberblätterige For'm en einer Art widerstandsfihiger als letztere sind. Ebenso sind natiolich nicht nur Formen sondern auch solcherlei Arten widerstandsfïhiger; ermöglicht durch einen wachsartigen Überzug in genannten Farben, ausgenommen jedoch daun, wemn haue orler graue etc. Arten aus warmen Gegenden stammen! Zu beachten ist sehr, daf eine große Reihe von Koniferen von einem bestimnten Alter ab, z. B. Picea orientalis vom 12. 
bis 14. Jahre ab, widerstandsfähiger gegen Kiilte werden. Alte Pflanzen sind meist alle unempfindlicher.

Werden bei anzuptlanzenden Nadelhölzern die zu deren sonstigem guten Gedeilhen nötigen Punkte möglichst heachtet, so haben wir für eine grobe Reihe von Arten, deren Ausdaner erprobt ist, die bestimmte Sicherheit, die Pflanzen zu herrlichen Exemplaren sich entwickeln zu sehen.

Erwiahnenswert ist, dath die Gesetze der 'Temperaturumkehr' oft nicht beachtet werden, wodurch die schcinbaren Widerspriiche der kïlteren Temperaturen im Tal hezw. Hügelland imnerhalb kurzer Zeit entstehen.

Nach kalten Niichten liegen frihhnorgens die tief'sten Temperaturen im tiefsten Punkte der Landschaft!; von hier aus aufwärts wird es wïrmer.

Am darautfolgenden sonnigen Tag drehen sich die Verhailtnisse um: die wïrmeren Temperaturen liegen im Tal, während es von hier a ufwärts kälter wird.

Die Pflanzen des Tales haben also die großen Temperaturwechsel stärker und lïnger auszuhalten, als jene der Höhen. Auf ebener Fläche ist es stets kïlter als in bewegtem Terrain und der kälteste Punkt ist wohl stets direkt ïber der Schneeflïche. Nach ausgeführten Messungen - die Versuche sind jedoch noch lange nicht abgeschlossen - hält sich die für unsere jungen Koniferen gefährliche Kälteschichte vom Boden bezw. der Schneefläche ca. $80 \mathrm{~cm}$ hoch.

Bei vielen Koniferen-Arten stehen uns feste Erfahrungen uiber die Winterhiirte nicht zur Seite, weshall es geboten ist, bei solchen Nadelhölzern gröfiere Vorsicht walten zu lassen.

\section{Schlüssel zu den Notizen über die Winterhärte der in Deutschland angepflanzten Nadelhölzer.}

Um besonders dem Unkundigen bei der Aupflanzung. von Nadelhölzerı ïber die Winterhärte derselben einige Anleitung zu geben, wurden in diesem Buche - wie auch schon anderwiirts, z. B. im "Handbuch der Laubholzbenennung" (von Beißner, Schelle, Zabel - bei Parey 1903) den einzelnen Arten, oft auch den Formen, Angaben iiber diesen Punkt - nebst weiteren ganz kurzen Bemerkungen iiber Standortsverhältnisse und dergl. - beigegeben, und entsprechen die römischen Ziffern I-VII nun 7 Regionen, in velche ganz Deutschland eingeteilt ist, und von welcheneinzelne Regionen einenganzen Landstrich einnehmen können, oder auch nur rein örtlich betrachtet werden mïssen.

Aufgestellt wurde diese Finteilung auf Grund gesammelter Notizen, sowie eigener, ca. 30 jähriger Erfahrung iilor jene 
Kältegrade, welche betreffende Pflanzen unter verschiedenen Verhältnissen ausgehalten hatten.

Der wegen Winterhärte einer Konifere in jeweiliger Gegend Ratsuchende muf - mach Beachtung der fiir das Gedeihen des Nadelholzes nütigen Faktoren - die normalen und anormalen Kiiltegrade des Ortes, hezw. der Gegend, in welchem er pflanzen will, genau kennen, sofern das zu pflanzende Gehölz auch ohne Schaden aushalten soll.

Region I unfaht diejenicen kältesten Gegenden Deutschlands, in welchen eine Wintertemperatur von -28 bis $30^{\circ} \mathrm{C}$ nichts Seltenes ist und in welchen in außerordentlich kalten Wintern die Kälte - 31 bis $36^{\circ} \mathrm{C}$ erreicht.

Region II verzeichnet in nornalen IVintern eine Kialte von $26,5^{\circ} \mathrm{C}$, in anormalen jedoch bis zu $30,5^{\circ} \mathrm{C}$.

Region III zeigt - $22,5^{\circ} \mathrm{C}$ in normalen und - 26,5 his $27,5^{\circ} \mathrm{C}$ in anormalen Wintern.

Region IV hat normal - 19.5 $5^{\circ} \mathrm{C}$, anormal $-23,5^{\circ} \mathrm{C}$, welche Region als der Weingegend entsprechen wiirde.

Region $\mathrm{V}$ weist normal $-16^{\circ} \mathrm{C}$, anormal $-21 \mathrm{~b}$ is $22^{\circ} \mathrm{C}$ anf.

Region VI verzeichnet normal - 13 bis $14^{\circ} \mathrm{C}$, anomal $-17^{\circ} \mathrm{C}$.

Region VI hat ebenfalls - 13 bis $14^{\prime \prime}$ C in normalen und - $17^{\circ} \mathrm{C}$ in anormalen Wintern, jedoch ist in diesen von mildem Krlima und ginstiger Witterung vorteilhaft bedachten Punkten Deutschlands die Kälte keine anhaltende, sondern dauert nur kurze Zeit, meist nur eine Nacht.

\section{ill. Körperbau der Koniferen.}

Dem Rahmen des Buches entrplechend, miissen die dusfiihrungen dieser Ahteilung auf las Notwenligste beschränkt werden, weshalb den cinzelnen Busprechungen nur wenice Zeilen œevidmet werden konnten.

Koimlinge. Dieselhen fihren 2-15 schmale, teils pfriemliche, rerschichlen lange heimlititter von meist dreiseitiger Gestalt, gezähnt oder ungezähnt. Ihnen folgen die

Erstlings- oder Primärblätter, welche entweder nur schuppentionnig oder nadelföming, einerseits flach, andererseits serwilht, seziihnt orler nicht seziihnt, spitz, anch mit Spaltöflnmen versehen num damit mehr oder minder weiflich gezeichnet

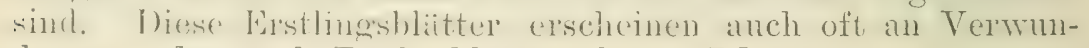
dungen oder nach Rüickschlägen älterer Pflanzen. 
Die mit Erstlingshlaitern versehenen P'llanzenteile aligerschnitten und wieder zur Bewurzelung gehracht, crgehen Pflanzen mit nur Erstlingsblaitter-Belaubung.

Verschiedene Arten hezw. Formen el'zengen auch zwischen normalen Blätter'n solche Primärblätter.

Wurzeln. Je nach der Loniferenart mul deren standort, ob in flachgriudigem, steinigem, felsigem oder sumptigem Boden stehend, sind die Wurzeh cutsprechend flachstreichend oder tief eindringend, was z. B. bei der Anpflanzung geringwurzeludej Koniferen in windigen Gegenden wesentlichen scharlen brachte. also sehr zu beachten ist.

Mit Ausnahme einiger Arten sind die Wurzeln der Nadelhölzer :iufierst ziihe und verankern den Baum so stark, dafj derselbe bei Sturm eher oherhall, der Erde abgedreht wird, ehe das Wurzelwerk zerreift. Die Verwendung der Wurzeln zu Flechtarbeiten, Förhen etc. ist also naheliegend.

Interessant sind die knieartigen, oft meterhohen Wurzelauswiichse der Sumpfzypresse, welche imen hohl sind und als luftzufiihrende Or@ane der im Sumpfic steckenden Wurzeln betrachtet werden. Anf mehr trockenem Boden werden diese Auswiichse nicht leicht gebildet.

Sehr charakteristisch, selhst fiir sehr viele Arten, ist das

Holz der Nadelbäume. Es unterscheidet sich vom Lauhholz besonders dadureh, daf dem sekmudaren Holz die den Dicotylen charakteristischen, lurzgliedrigen, die dichte, engzellige Hclzmasse durchsetzenden, sogenannten getiipfelten Gefiatie fehlen.

Das Nadelholz ist sehr harzreich und - mit Ausnahme einiger Arten - stark von Harzkaniilen durchzogen, leicht oler schwer von Gewicht, rou heller bis ganz dunkler Farhe, mit wenig Ausnahmen in Kern- und Splintholz genau unterschieden, durch seine Zellenlagerung sehr leicht bis schwierig in der Terrendbarkeit hei Kleinhehandlung, infolge Wnchsverhiblnissen nach der Verarbeitung die Form etwas indernd (sich werfend!), oder konstant hleiluend, und dergleichen Punkte mehr.

Sehr verschieden ist Bau, Stellung u. s. w. der

Äste, welche sehr häufig quirlföming oder nahezu guirlförmig, weniger zerstreut, spitz anfstrehend his rein wagrecht, ahwairts gerichtet, sanz im Bogen sich wieder anfichtend ole'r selhst kniefömig wieder nach oben strebend sind. Ähnlich in Stellung sind auch die

Zweige und T' ri e be, hei denen man Zweige erster und zweiter Ordnung (erst-und zweitwiichsige) unterscheidet, welche autierdem noch sehr verschiedene Firhung zeigen mil solche vom Austriel) bis zum Herbste indern. Dabei sind die 'Triche entweder' glatt oder mehr oder minder stark hehant, hereift, hesonder: 
beim Austrieb, auch durch die am Triebe herabgewachsenen, angehefteten Blätter rauh, l'unzelig aussehend, was auch älteren Zweigen vielfach noch eigen ist und überdies noch durch die Narben der Ansatzstelle abgefallener Blätter bezw. Narleln hervorgerufen werden kann.

\section{$\mathrm{Zu}$ unterscheiden ist ferner noch zwischen}

Langtrieben, welche die Astfortsetzung bilden und an welchen die Blätter zwar spiralig aber doch ziemlich zerstreut entstehen, sowie zwischen

Ir urztrieben, besonders seitlich stehenden oft sehr kleinen Fortsetzungen, deren Blätter, wenn auch ebenfalls spiralig; so doch ziemlich gebiischelt stehen; vielfach sind die Kurztriebe auch die Bliitenträger. Bei einzehnen Koniferen werden die Kurztriebe zu Flachsprossen umgewandelt (Phyllocladus).

Erwähnenswert ist der Wuchs der Langtriebe, welche sich nicht star'r aufrecht, sondern oft in großen Windungen nach oben dehnen (!), wie es besonders Picea zeigt. Ebenso interessant ist, daß Gipfeltriebe zuerst ïberhängen und damn erst sich autrichten, wie man es z. B. bei Chamaecyparis Lawsoniana sehr deutlich beobachten kann.

Ganz eigentiumlich ist das Verfahren der Sumpfzypressen, welche - je nach Art - ihre Kurztriebe samt den Blättern im Herbst desselben oder des nächsten Jahres abwerfen.

Durch die Stellung und Form von Stämmen, Ästen und Zweigen wird bei den Nadelhölzern zumeist ein pyramidaler

Ban erzeugt, der besonders in der Jugend der Mehrzahl der Arten eigen ist. Erst im Alter plattet sich die Krone mancher Arten ab, der Stamm "astet sich aus", reinigt sich, und es entsteht eine mehr breite bis schirmartige Krone; einzelne behalten allerdings auch die Äste bis tief herab, ja letztere machen dem Stamme oft Konkurrenz, z. B. bei Pinus Strobus und anderen.

Wenige Koniferen haben von Jugend auf buschiges Wachstum, doch ist die Zahl der Arten und ganz besonder's del Formen, welche kurz, knieartig, Hach wachsend, selbst kriechend sind, nicht gering.

Rein als Gebius ch wachsen sehr wenig Arten.

Abnormitiaten in Wuchs sind sehr vielfach vertreten, teils dath die Aste und Zweige allein vom normalen abweichen, so \%. B. olne jede Verzweigung fortwachsen oder solche mehr oder minder gering entwickeln und tergleichen mehr, oder daf die Trielse mit den Blaittern die wunderlichsten Wuchsverhältnisse bis zur vollkommensten Verwachsung, oft Verkriimmung und ähnliches mehr, zeigen. 
Interessant ist anch die

Rinde, welche nicht $n u$ verschiedenfarbig ist, sondern anch in ihrer Konstruktion vicle Abweichungen zeigt: ob ganz glatt, ob yuer-, lings-oder ungleichrissig, Hach-oder tiefrissig, ob sie bleibend ist, oder abgestolien wirl, selbst abblättermi ist, ob sic moleich grofie oder gleichmifige, of in bestimmten Formen autieißende und abgestofine Teile zeigt, u. s. w.

Ähnliche Verhiiltnisse herrschen anch bei der

Borke, welche sehr verschieden in ihrer St:ïrke bezw. Dicke sein kann, tief oder geringrissig, fast holzig hart his korkartig weich, das tiefste Schwarzhram bis zum hell milchartigen Weiß in der Färbung aufweist.

Eine Eigentimlichkeit einer sehr großen Anzahl ron Koniferenarten ist die

Harzausscheidung, kurzweg "das Harzen“, inden durch die Rinde manchmal ganz beträchtliche Quantititen Harz ausgeschieden werden, welches oft in großen Benlen oder Höckern sich ansammelt. Die Sammlung desselben, dam aber noch des durchVerwundumgen hervorgerufenen Harzes, war friiher ein förmlicher Erwerbszweig, ist jerloch in letztgenannter Bezichung, da es den Baum unbedingt schwächt oder doch das Holz entwertet, in rationell behandelten Forsten aufgegeben worden. Vervundungen aller Art versucht die Pflanze iiberhaupt durch sehr reichlich ausgeschiedenes Harz zu bedecken. Auch die Blätter scheiden Harz aus, z. B. bei Pinus excelsa.

Vielgestaltig und oft gute Merkmale bietend sind die

Knospen, verschieden in Farbe und Form, von der kugeliggedriickten Knospe bis zur auswezogenen, langen, spitzen Art, veränderlich auch im Überwinterungszustand, gegeniiber dem im Austrieb. Ferner sind noch die Schuppen der Knospen verschieden, von der einfachen glatten bis zur gezähnelten, mehr oder minder abstehenden, selbstzurüickgerollten Ḱnospenschuppe. Viele Knospen zeigen starken Harziberzug; viele wenig oder keine Verharzung. Diese Verharzung kann aber iibermäßig stark (krankhaft) werden, sodaß die Pflanze nicht austriebsfiahig ist. und der Zweig verkriippelt, wie solches a uf $u$ n pas s endem Standort bei verschiedenen Koniferenarten beobachtet werlen kamn.

Die größte Mannigfaltigkeit in Gestalt und Form zeigen jedoch die

Blätter oder Nadeln. Beginnend mit den kleinen, oft winzigen, schuppenartigen Blittern von verschiedenster Form, als Breit- oder Flachblätter oder Seiten- und Kantenbliitter, anliegend bis abstehend, dachziegelig, wirtelig, gegenständig gestellt, mit O ldr ii s e n in linglicher bis runder Form vertieft bis erhöht stehend, mit Übergangsblättern, welche an di* bei den Keimbliittern erwähnten Erstlingsblïtter erimner'n, alsı 
narlelfürmig' und mehr oder minder anliegend bezw. abstehend sind, bis zu ten linealen, flachen, schmalen bis breiten, kantigen, rimnigen, ein- oller zweiseitig-, hoch- oder geringgekielten, gewölhten, von der Rinne orler dem Kiel beiderseits nach außjen gewölbten, glatten oder gezähntrandigen, diinnen oder geradezu dicken, zweikantigen, dreikantigen, ja vierkantigen, geraden, sebosenen, gedrehten Blattern, mit ganz stumpfer bis ganz feinnadeliger Spitze, doppelgespitzt, ausgeschnittener (gekerbter) spitze. Ferner sind die Bläter in Gröbe sehr verschiedten: Tom kleinen, an den Ecken etwas abgerundeten, länglich-viereckigen Blatt bis zum feinen, echt nadelförmigen, bei $30 \mathrm{~cm}$ lameen Blatt, odter auch sich verbreiternd und die Form der dikotylen Blatter annehmend, z. B. bei $15 \mathrm{~cm}$ Länge und $5 \mathrm{~cm}$ Breite, und wenn das Blatt von Ginkgo hereingenommen wird, fïcherartig einfach bis doppelt gelappt, fast zweiteilig. Dabei ist die Form, Grülie, Spitze und Stellung der Bliitter an verschiedenen Zweigen, besonders Fruchtzweigen, ander's als an den iihrigen Teilen des Bammes. Überhaupt ist anch die Stellung' der Bliitter sehr verschicden, also ob dieselben vereinzelt, weit his dicht, den Zweig deckend, bis abstehend, an Kurztrieben doppeltreihig', mehr oder minder zrweiseitio, scheitelig stehen, alio an der 'Triebunterseite durch Anfwärtschehung der Blätter' dieselbe gewissermatien blattlos machen, und was deroleichen Andermenen mehr sind. Ferner sind die ,falschen" Blätter von Ściadopitys zu erwihnen, d. h. es sind die dort als Blätter betrachteten Organe aus zwei verwachsenen Nadeln gebildete Kurztriehe. und die e chten Blättchen stehen als Schiippchen an den Langtrieben und tragen teilweise Achselknospen, welche wieder zu Seitentrieben auswachsen. Auch der scheinbar einnadeligen Kriefern nuß hier gedacht werden, deren Eimnadeligkeit meist durch Terwachsumg von zwei und mehr Nadeln entsteht, nur Pinus monophylla zeigt anatomisch einen einheitlichen runden Körper.

In der Farbe wechseln die Blätter vom hellen lichten Griun bis zum dunkelsten, fast schwarzen Griu, oder wenn ein Wachsiiberzug sich beigesellt. vom Blaugriun bis zum silberfarbigen Weiß. Ehenso sei der gelben und weißen Blätter, in particller oder gänzlicher Verfäbung gedacht, nicht zu vergessen die Winterverfirbung, welche oft ein richtiges Fuchsrot aufweist. Auch der Harzausscheidung einzelner Koniferen an den Blättern sei gedacht. Des weiteren ist die Konsistenz der Blätter zu erwihnen, besonders ob solche weich, schlaff, bis hart und steif ist. Manche Kiefernblätter werden bei feuchter Witterung dem Triebe etwas angelegt, z. B. bei Pinus Strobus, was aber bei schneefall förmlich als Auffang dient und deshall, oft schädlich wirkt.

Von Wichtigkeit ist auch das Alter des Blattes, ob nur 
ein- bis zweijilhrig, ob es nach einer Verfarlumg in Herbst teils mit den Kurztriehen - abgeworfen, oder ob es mehrjahrig, d. h. meist vier- his f'iufjührig, doch atch bis zehnjiihrigr wird, wie bei Araucaria.

Das in den Bliittern enthaltene itherische (ol, bezw. der besonders beim Zerreiben der Bliitter bemerkhare Geruch ist fiir viele Arten bestimmend.

Von großer Wichtigkeit sind auch die

Spaltiot toungen der Blatter, welche dem Blatt meist

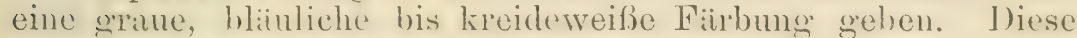
in Linien stehenden Assimilationsorerane befinden sich sehr hïutig aut der Thlattoberseite, durch vollkommene Wendung des sanzen 73lattes, aher seheinbar un te $n$ sichtbar; bei anderen Arten befinden sie wich auch beiderseits, bei drei-und vierkantigen Blittern anch auf allen S'siten angebracht, der Pflanze meist eine ganz reizende Färbung gebend.

Elwihmenswert ist noch, dati manche Narlelhölzer, aus milnten Gewenten mit i'euchter Lnit stammend, in weniger giinstiarem Flima ihre vorden langen und veichen Blätter verkiirzen und solche nun steif, starl zeigen: auch haben in ietztgenanntem Klima die Blätter nun eine meist geringere Lebensdauer.

Die Gefäßbiindel und die Harzgänge der Blätter bilden bei der Bestimmung vieler Koniferen ein gutes Merkmal. Bei Taxus z. B. fehlen die Harzgänge.

Die Form des Blattes gegen die Ansatzstelle hin ist ebenfalls verschieden, ob ein

Blattstiel vorhanden ist oder nicht, ob das Blatt direkt dem Trieb angeheftet ist, oder ob es einen mehr oder minder langen, auch verschieden geformten und gefärbten Stiel zeigt, ob derselbe an der Ansatzstelle einfach oder verbreitert, verdickt ist, ob er gerade oder gekriimmt, auch gedreht ist, ob die

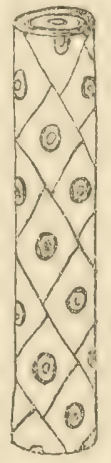

Fig. 1.

Blattansatzstellen (Abies pectinata).

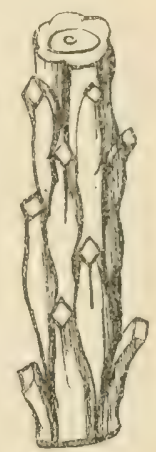

Fig. 2.

Blattansatzstellen (Picea excelsa). A ns a tz ste 11 e, das B l at tk is s e 1 , die Anheftung höckerig oder knieförmig gebog'en ist, ob am Triebe "herablaufend" ausgebildet, ob das Blatt nach dem Abfall eine Narbe zuriickläit oder nicht, und dergleichen mehr. (Fig. 1 u. 2.)

Speziell den Kiefern zukommende Bildungen sind die

Blattscheiden, häutige, verschiedenfarbige und verschieden große bezw. lange, frith oder später abfallende Gebilde, aus 
welchen die Nadeln hervorwachsen, und in welchen dieselben zu 2-5 (ja selbst 7) Stuick vereinigt sind.

Äußerst interessant ist die

Blïte der Nadelhölzer.

Die Koniferen, inkl. Ginkgo, gehören zu den „nacktsamigen“ Pflanzen, d. h. die Samenknospen (Ovula) s ind ni clit von e in e m F r chtknoten umschlossen, sondern zur Blitezeit frei (irackt) an der Fruchtblattachse oder dem schuppenförmigen Blatte, der Samenschuppe, angeheftet. Fs ist deslaalb anch keine Narbe (Stigma) vorhanden, sondern die männlichen Befruchtungszellen, die Pollenkömer (Mikrosporen) gelangen durch den IVind direkt auf den Ei- oder Knospenmund (Mikropyle), durch welchen der sich dort entwickelnde Pollenschlauch zu der weiblichen Keimzelle (Makrospore), dem Embryosack durchwächst, um hier num die weibliclien Befruchtungsorgane (Archegonien) zu befruchten.

Die Koniferenbliten, welche keine oder hiohstens hochblattartige Bliitenhiillen besitzen, sind teils einhäusig, monözisch, d. h. mämliche (ち) und weibliche (f) Bliten wachsen getrennt auf einer PHanze, oder auch zrveihäusig, diözisch, d. h. männliche und weibliche Bliiten wachsen auf zwei Pflanzen, wovon die cine nur mämnliche, die andere nur weibliche Bliiten erzeugt.

Die männlichen Blitten stehen in den Blattwinkeln. am Grund des jungen Triebes, einzeln oder zu mehreren und rlam zu einem Köpfchen veremigt, in kätzchenartigem, ährenförmigem, auch selbst doldigem (selten!) Stand.

Sie zeigen reichlich schuppenförmige Staubblätter, Staubgefiffe (stamina), an einer gemeinsamen Achse. An

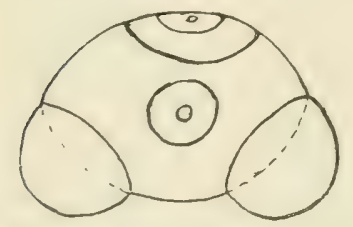

Fig. :3. Pollenkorn mit Flugblasen

(stark vergrößert). der Unterseite der Staubblätter befinden sich die zwei- bis sechs- und mehrfächerigen Staubbeutel (Antheren), mit dem gelben Blit enstanl, den Pollenkörnern, welche meistuiberausreichlich erzeugt werden. Letztere sind etwas scheibenförmig, zweilappig und sehr oft mit Flugblasen ausgestattet. (Fig. 3.) Die Fächer der Antheren springen mit einem Rund- oder einem Längsriß auf. Durch das verlängerte Mittelhand der Anthere erhält die Bluite oft ein schuppenförmiges Anhängsel oder Connectiv.

Nach der Bliitezeit fällt der männliche Blütenstand ab, am Trieh, l,ei manchen Arten eine nadelfreie Stelle (z. B. bei Kiefern) erzeugend. 
D) ie we iblichen Blit en sind teils endstandig, teils seitenstandig; sie stehen einzeln, doch auch ifter's bis zu sechsen beisammen, zu ebenfalls kitzchen-, ähren- oder zapfontörmigen, spiralig geordneten Bliitenstianden vereinigt. Die Bliitenschuppen stehen ein- bis zwei- bis mehreihig einander geweniiher, oder drei- bis vierfach quirli@, entweder zu wenigen, $4 \quad 6 \quad \tau$ - 4 , bis zu einer grofen Anzahl vereinigt. Sie können klein his grofi, sitzend oder gestielt sein, sich dachziegelartig decken: sic sind selten mit einem, meist mit 2 bis mehr a ufechten oder umgewendeten Samenknospen, Eichen, versthen. Es sind jedoch nicht alle Blitenschuppen mit Eichen besetzt, also fruch tbar.

Die Schuppen, Samenschuppen, Fruchtblatter, Fruchtschuppen (spiater Zap,fenschuppen) fiihren auferdem noch Deckschuppen, Brakteen, welche klein und versteckt sind, odes: so grob werden, daf sie iiber das Fruchtblatt hervorsehen, ja iiber dasselbe iibergebogen werden. Ihre Form ist sehr verschieden, mehr oder minder breit, gelappt, doch oben in eine Spitze auslaufend. Mit der Braktee ist die Fruchtschuppe mehr oder minder verwachsen. Letztere kamn auch zu einem Fruchtboden verwachsen sein.

Es werden die Fruchtblatter teilweise auch nur rudimentär angelegt, es entsteht also eine "nackte" Samenanlage; oder" die Blätter werden fleischig, bilden einen mehr oder minder dicken und fleischigen Samenmantel (arillus), der ring- oder becherförmig gebildet sein kann.

Durch Verschmelzung mehrerer weiblicher Bliiten entsteht auch ein beerenartiges Gebilde, ein gering oder stark Heischiger Beerenzapfen (galbulus).

Der Stand der Bliite ist zur Zeit der Befruchtung ein mehr oder minder aufrechter, mit dachziegelartig gestellten Fruchtblätter'n. Nach der Befruchtung, bezw. nach dem Eindringen des Pollenschlanches zur Samenknospe, bleibt der Bliitenstand entweder aufrecht stehen, oder er wendet sich (bei einer sehr arołen Anzahl Koniferenarten) um ein Geringes seitlich oder auch ganz abwärts. Bei den dann abwärts gerichteten Bliitenständen (den zukiinftigen Zapfen) stiilpen sich, kurz ehe die Wendung beginnt, die Fruchtblätter nach oben, sodaß nach der Drehung alle Samenanlagen genau wieder dachziegelartig gedeckt sind.

Der heranwachsende

Zapfen (conus oder strobilus), der zur Reife ein bis drei Jahre benötigt, bleibt — wie oben bei der Bliite bemerkt entwerler aufrecht stehen, neigt sich seitlich oder hängt ganz abwiirts. Seine Schuppen sind sehr verschieden in Form und Farbe: letztere wird oft während des IVachstums bis zur völligen Reife zwei- bis dreimal, ja fünfinal geändert, damit auch dem 
ganzen Zapfen die Färbung gebend. In Form sind die Zapfenschuppen hauptsächlichst fächerartig, unten spitz, gelappt, gezackt, ausgeschnitten, sainthaarig bedeckt, gewellt, gezähnt, slatt, runzelig, höckerig, gekielt, ferner: diinn bis lederartig und holzig, mit einem Schild (Aposyphe) versehen, welcher in einen

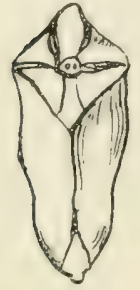

Fig. 4.

Zapfenschuppe (vord. Ansicht) von Pinus montana Mill. var. Mughus.

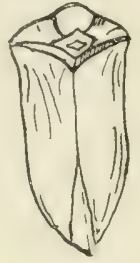

Fig. 5.

Zapfenschuppe (vord. Ansicht) von Pinus montana Mill. var. Pumilio.

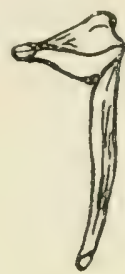

Fig. 6.

Zapfenschuppe (Seitenansicht) von Pinus montana Mill. var. uncinata.

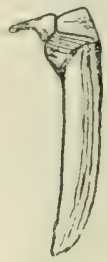

Fig. 7. Zapfenschuppe (Seitenansicht) von Pinus rigida Mill.

flachen, tiefen, oder erhöhten Nabel, oder in eine stumpfe bis feine, auch höckerige Spitze endigt (Fig. 4-9).

Die Schuppen komnen locker bis geprefit fest an der Z a p f enachse, der Zapfenspindel, stehen, odler von ihr abfallen:

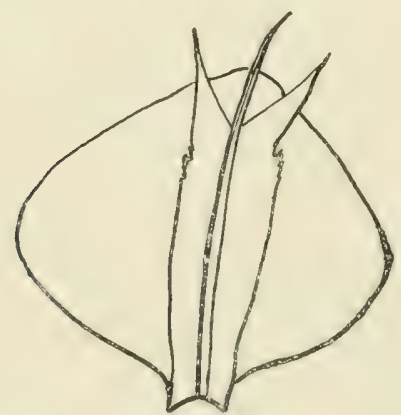

Fig. 8.

Zapfenschuppe mit hervorragender Braktee $($ Pseudotsuga Douglasii). Vergrößert.

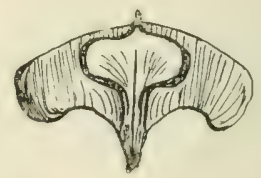

Fig. 9.

Zapfenschuppe in Fächerform und lappig, mit nur an der Spitze hervorragender Braktee (Abies Veitchii). Vergrößert.

(ler Zapfen .,zerfaillt", was bei aufrechtstehenien Zapfen oft der Fall ist, oder sie kömmen festgewachsen sein, es fällt also der canze Zapfen ab, was in selben Jahr, in nächsten oder dritten Jahr eintreten kann. 
Bei Kiefern entstehen manchmal an Zweigen eine ILenge Zapfen (bis li6 wurden erezilhlt), was als Zaptensucht bezcichnet wird, hervorgerufen dadurch, dati an stelle der männlichen Bliiten nur weibliche treten. Diese Menge weiblicher Bliiten sind aber als Zwitterbliiten zu betrachten. indem an jedem Bliitenstand der nutere Teil von den spiralig angeordneten männlich en Bliiten eingenommen wird, wählend der obere, dariiberstehende 'T'eil (der aber mindestens 3/4 der ganzen Spindellinge haben muti, wenn Befruchtung eintreten soll) von den spiralio angeordneten we ib li chen Bliiten eingenommen wird.

Je nach der Fruchtharkeit der Art birgt dsu Zapfen wenig oder viel

Samen. Derselbe steckt, wie oben schon besprochen, entweder in einer mehr oder minder Heischigen Schuppenumhiillung. ocler er ist in den meisten Fällen frei angebracht. Ton hauptsichlichst ovaler Gestalt mit verschiedener Abinderung bis zum keilfürnigen oder rundlichen, von ein paar Millimeter Gröbe

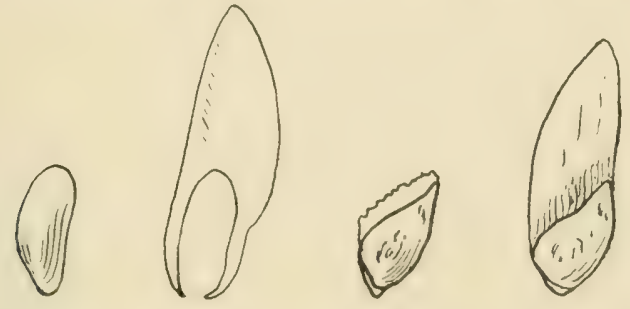

Fig. 10. Samen mit sich lösendem (zangenförmigem) und mit fest gewachsenem Flügel.

bis ca. $5 \mathrm{~cm}$ Länge, zeigt derselbe sich zumeist mit einem häntigen, oft bedeutend gröberen, verschieden sreformten, den Sanen zangenförmig unfassenden und sich damn lösenden, oder ganz mit dem Samen verwachsenen Flii ocler selbst bis zu (i derselben) versehen (Fig. 10), welcher so grof sein kann, daf er iber die Fruchtschuppe hervorsieht, aber auch bis zu einem Bunde reduziert sein, odler ganz felılen kann. Auferdem hat der zum Teil geprefte bis ganz flache Samen eine feine, weiche, diune, läutige bis steinharte, glatte bis höckerige, resp. grubig vertiefte $\mathrm{H}$ iille. Furner ist der Samen olne oder mit Harzgiangen versehen. Erwilhnenswert ist noch, daf der Samen entweder unter der Erde bei der Keimung verbleibt, oder hiebei ïber dieselbe erhoben wird. Die Keinfihing, keit dauert $1 / 2$ bis 7 Jahre. 
 \\ IV. Kultur der Nadelhölzer.}

Hier eine vollstandige Kulturanweismug der Koniferen zu sehen, ist gänzlich ausceschlossen: nur das Wissenswerteste kann hier in zusammenfassenden Zügen niedergelegt werden, zudem einzelne wichtige Punkte bei der "Beschreibung der Nadelhölzer" speziell erwähnt werden.

Pffanzzeit. Wann sollen Nidelhölzer verpflanzt werden? Diese Frage drängt sich - besonders dem Neuling - zuerst auf.

Wir haben zwei Terptlanzzeiten: Frihjahr und Spätsommer (nicht Herbst!). Unter Friihjah ist in diesem Falle die Anstriebszeit der Koniferen gemeint: etwa von der dritten Woche des April bis Mitte Mai. Wird triher geptlanzt, so können sehr oft durch die kalten, austrocknenden Winde an den Pflanzen große Beschädigungen entstehen.

Wird später als zu angegebener Zeit pepflanzt, so ist wecren der entstehenden Hitze bei den sohon triebigen Gehölzen ein Ausdören, Diirwerden zu befürhten, abgesehen ron der croben Störung des Wachstums iiberhaupt.

Im Winter empfindliche Koniferen sollten unbedingt Friihjahrs verptlanzt werden, wie andererseits in sandio-trockenen, heiben Gegenden nur Spätsommerptlanzung zu empfehlen wäre. Wird Ende August und im September die Pflanzung vorgenommen, so wächst die Konifere vor Winter noch gut an, wobei bei seltenen und teueren Exemplaren eine nicht zu kleine Bodenbedeckung des Wurzelstockes mit Moos oder Stroh sehr vorteilhaft ist! In Gegenden mit sehr kalten Wintern und sofern dort das Frialijahr nicht sehr rasch mit grober Wäme eintritt, ist ehenfalls Friihjahrspflanzung geboten. Alte Praktiker setzen Cupressineen, Juniperus, Pinus sehr ungern im Herbst. Larix muf auch im Friilıjahr möglichst zeitig geptlanzt werden, ebenso setzt man Taxineen gerne kurz vor dem Austrieb.

Was die

Bodenbeschaffenheit betriftt, so ist durchwegs anzunehnen, dafi schwerer, bindiger Boden, undurchlässiger Untergrund, schädigend fiir Nadelhölzer ist. Frischer, lockerer Boden mit guten Wasserabzugsverhältnissen ist das normale. Ausnahme in den Wasserverhältnissen ergibt sich natiirlich bei den iiberhaupt in sumptigerem 'Terrain wachsenden Arten, z. B. Taxodium. Die Beachtung des

Standortes hat fiur das gute Gedeihen der Koniferen grołen Wert. Das "Erfrieren" vieler Arten, welche auf nicht zusagendem Standort ihr kimmerliches Dasein fristen, oder doch mangelnden Wuchs reigen, ist sehr haufig anf diese Nichtbeachtung der 
Bediufnisse fraglicher Arten zurickzufiihren. Fs sind hei den meisten Arten in diesem Buche neben den Winterhairteangaben iiber Standortsverhailtnisst Bemerkungen heioefiigt, anf welche hiemit verwiesen werden muß3.

Beigefingt sei, dafi durch passende Borlenhearbeitung in gehörig grotem Fliichenraum, durch Beigabe lockernden Erdmaterials in schweren Bïden, z. B. mittelst Sand, Torfmull, Lauberde. Heidererde, Moorerde und derol. mehr, verbunden mit g'uter Entwïsserumg, der giunstigen Entwicklung hetreffender Exemplare Vorschub geleistet werten kanm.

Emptindliche Arten und Formen lieben Schutz durch in der Nithe stehende, gröbliere Nadel- oder Lanbholzpflanzen und wiire es auch nu Fermschutz gegen allzu scharfe Winde, gegen zu starke Somnenbestrahlung mol besonder's auch durch Beschattung des Erdreiches.

Empfindlichkeit gegen Rauch mol Staub. In Stailten und auch an einzelnen Orten mit größerer Rauchentivicklung leiden viele Koniferen, speziell aber die Rottannen, durch die giftigen Rauchgase besonders an sonnigen Tagen, sowie durch den Niederschlag von schwefeliger Sänre. Mancherorts ist es aus diesem Grunde absolut ummöglich, Fichten, Tamnen etc. hochzubringen. Einzelne Koniferen sind allerdings ziemlich widerstandsfihig, allein aut' die Daner doch nicht; zumeist entstehen grobe Beschädigungen. (Schwefelige Siure greift ibrigens alles an, auch Metalle, selbst Marmor.)

Pflanzung. Koniferen in IValde gezogen und dam in die Gärten verpflanzt geben wohl durchwegs schlechten Erfolg, außer junges, kleines Material. Es hat dies seine Ursache in dem immerhin mangelhaften Wurzelvermögen, soweit es besonders Neben- und Saugwurzeln anbelangt.

Un letztere reichlicher zu erzengen, findet in richtig betriebenen Baumschulen ein öfteres (meist alle zwei .Tahre) Umptlanzen der Koniferen statt. Hiedurch werden mehr seitliche Wurzehn erzeugt, während die den nichtumgepflanzten - also anch den Waldptanzen - eigenen, grofien, tiefer gehenden Pfahlwu'zelı nicht so stark ausgebildet werden. Die zur Einzelstellung (Solitiir) bestimmten Koniferen werden in Körben möglichst haltbaren Materials, Weilen, spanisches Rohr, Drahtgeflechte etc. verpflanzt, sodafi solch behandelte Exemplare der Baumschulen selbst in grohen Exemplaren olme besondere Gefahr verpflanzt. und transportiert werden können.

Beim Setzen selbst ist zu beachten, dafi das Exemplar nicht ti efer zu sitzen kommt, als es rorher stand, eher eine Idce höher. Der Boden der Pflanzwruhe wird wohl meist nach oben a e w o lht angelegt, sodaf clas Wurzelwerk möglichst gleichmaifig nach allen Seiten etwas ahwairts zu liegen kommt. Ist 
(ler Pflanzenballen ganz zertallen, so ist es ein Vorteil, die W'urzehn vor der Pflanzung in einen steifen Lehmbrei zu stecken.

Große Exemplare miissen durch Drïhte nach allen Seiten befestigt, sturmfrei gemacht werden. Werden sehr große Pflanzen versetzt. so umgräl,t man diese muter Belassting eines ziemlich grofen Erthallens ein, hesser zwei Jahre vorher, wodurch allerdings manche starkere ITurzel ahgestochen wird, dafiir aber mehrere neue Wurzeln elzeugt werden.

Dafo unter Verhiitung des Vintretens der Erde durch sutes Einschlemmen des Bodens mittelst IVasser die Wurzeln in Erde wehettet werten missen, ist selbstrerstandlich. Später ist eher auf ein iofteres Cherbrausen der PHanzen, als auf ein starkes Begiefien Acht zu gehen. Torteil ist eine Bedeckung des Borlens mit einem, die stirkste Somnenbestrahlung abhaltenden Material, wie ebenso eine solche im Winter gegen zu starke, eindringende Kiilte (!) vorzunehnen. Was mun die weitere

Pflege der aröleren Koniferen betrift, sn bedarf es allerlings eines wachsamen Auges. um (nitstandencm schaclen ahzuhelfen, entsthender Gefahr vormulumen.

Da eben vielerorts trotz aller Gefahr empfindliche, für hetreftente Geuremlen nicht passente Naldelhiber angeptlanzt werden, weil her Eigentimer cinesteils Versuche hiemit anstellen will, orler weil er elon bis zum nichsten, aufierorientlich kalten Winter sich des Anblicks hetreftender Arten erfreuen will, so ist einerseits dnch einen riemlich weitgehenden Bodenbelig mit kumem Dun!g. Mons und dergl.. sowie mit etwas Tammeneis der emptindliche Trumelstock zu schiitzen. Ferner ist die PHanze gegen Tordust, (1st und Siulost mit vorwesteckten, gegen Schneedruck und sturm kriftigen Stangen, an welchen Weiftamenreis (es ist wohl das beste anslanernde I) ekmaterial), schilf u. s. w. befestigt ist, so zu decken, dafi das Exemplar selbst nicht beriiht wird. Eine rickseitige gleiche Bedeckung kamn wohl auch ausgefiuht werden, ist aber nicht notwendig.

In der Jugend emp find lich e Arten können oder miissen in kiilteren Gegenden in $\mathrm{gleicher}$ Weise behandelt werden. Ist es jedoch den angeptlanzten Exemplaren nicht mönlich, l,is zum Herlost ihr IIolz vollstandig auszureifen, teils daf der jeweiligen Art unsere Sommer zu kurz sind, nasises ITetter oder nasse Borlenverhältnisse die Pflanze im Trieh erhalten, orler ist es auch zu trockener Standort, welcher der normalen Entwicklung linderlich war, dann werden bei eintretender scharfer lialte alle oben angegebenen Bemiihumgen, abgesthen von den schon weiter rome besprochenen Punkten, umsonst sein, di* Pflanzen zu crhalten. Am schwierigsten sinrl aber noch allo solche Anpflanzungen in luftrockenen Gegenden! 
Schiadigend wirkt auf die Natelhiblzer auch oft tine zu srofe sichneelast. Zumeist hefreit wohl ein Windstofi die Biume hieron; in manchen Fiillen ist man aher doch gezwungen, durch mit Lappen unwickelte Kritickenstangen mitclst cines ganz leichten Stobes einzugreifon. Ist aber der Schnce angefroren, damn schadet je.ler Eingrilf chrch Menschenhand weit mehr als er niitzt!

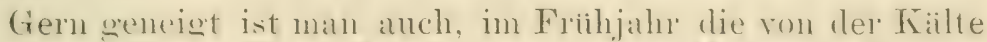
stark beschioligten Exemplare kurzweg zu cutfermen: allein es diurfe da doch ofwas Vorsicht seboten sein, dem oft sind wohl

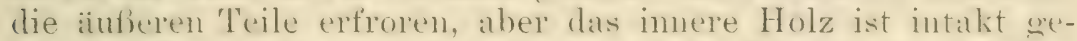
blichen. Im letzteren Fille .putzt" sich die P'Hanze medist schom im lanfenden tahr wieder zu vinem prächtigen, schn dichten Exemplar heraus.

Manche Arten rerlieren öfters den Gipfelsproti. I)ie Mehrezahl der foniteren soret num meist sofort sellost datior. dati ein nächst stehender Seitenzweir sich anfrichtet und an die fiihnende Stellung tritt. Tielfach werien aber auch melnere seitentriche erhoben, oder die PHanze treiht sofort aus Adrentiv-oder Nehenknospen eine Anzahl aufistrebender Zweige. In diesem Falle miissen alle iiberzibligen Triehe vorsichtio entfernt und wenn möglich nur ein e r als Leitzweig belassen werden.

Macht die Pflanze aber keine oder sehr mangelnde . Instalten, den Schaden ausumer\%en, so muf durch lockeres Aufbinden eines gesmulen Triehes versucht werden, dem Exemular wieder eine Fortsetzung zu gehen; manchmal sind zwei solcher Triehe nütig, da oft der ausgewählte Seitentrich durch schwachen Wuchs mit der zugedachten Bestimmmg nicht einverstanden zu sein scheint. - Ein

Schnitt der Koniferen ist bei jenen Natelhölzern, welche leicht Seitensprosse erzeugen, g'ut anzumenlen, so z. B. bei Thuya, Taxus, Cupressus, Chamaecyparis, Biota, anch Seyuoia, Crrptomeria, Juniperus u. s. w.; bei Fichten ist es in mehreren Fiallen - besonder's bei der gewöhnlichen Fichte - elentalls ganz gut angiingig, Tamnen und Kiefern liefern dagegen nu teilweise den erwiunschten Erfolg.

In übrigen ist es gut, gröfere Wunden bei Nadelhölzern zu vermeiden, oder wenn solche gemacht werden miissen und die Pflanze sorgt nicht selbst fiur rasche Verharzung oder kamm solche nicht gुut ausfiihren, die Wrunde mit etwas wamem Teer zu verschliefien, denn in Terwundungen setzen sich gerne Schäcllinge pflanzlicher und tierischer Art an.

Was num eben diese Schädlinge, bezw. den

Schutz gegen Schïdlinge der Nadelhölzer betrift', so kann und muf ein solcher möglichst vielseitig sein. Man unterscheidet: 


\section{a) Pflanzliche Schädlinge.}

Das Heer derselben ist ein großes und gehören dieselben fast durchwegs niederen Organismen, den Pilzen an. Herbeigeführt durch die Luft- bezw. Windbewegung, entstehen und rerbreiten sich dieselben an ehesten an luftfeuchten, besonders dumpfen Orten, bei enger Stellung der Bäume, an kleinen Pflanzen bei fenchter Becleckung u. dergl.; aber auch an guten Baumbeständen, an gesunden, kräftigen, einzehn stehenden Exemplaren zeigen sich plötzlich und verheerend diese Schädlinge.

Alle Teile des Baumes werden befallen, von den Blättern, Bliiten und Zapfen bis hinab zu den Wurzelspitzen.

Eine Reihe der Pilze sind auch "IVirt wechselnd", d. h. sie wachsen in ihrer ersten Generation auf anderen Pflanzen: Gräseru, Berberitzen (Sauerdorn), Birm- und Apfelbäumen usw., in der zweiten Generation dam auf Nadelhölzern, dort wie hier stark schädigend.

(Wer diese Pilze genauer kennen lernen will, muf dieselben näher untersuchen lernen und die eigens hieriber entstandene Literatur durcharbeiten.)

Eine Reihe der Schädlinge treten nur partiell auf, sich gering, oft aber auch sich plötzlich stark ausbreitend, sind aber trotzdem nicht allgemein bekannt und gefiirchtet; andere aber treten oft und stark schädigend auf als Schrecken der Forstwirte, Gärtner und Koniferenfreunde.

So ist z. B.

Agaricus melleus, der Hallimasch, ein besonders auf alten Buchenstöcken sich zeigender, dann aber auch wohl auf alle Nadelhölzer iibergehender, zwischen den Wurzeln lebender Pilz, der emimenten Schaden anrichten kann.

Anch andere Agaricus-Arten können schädigend wirken.

Lophodermium (Hysterium) Pinastri ruft die Nadelschiitte der Kiefern, d. h. das vorzeitige Abwerfen der Nadeln hervor. Einzelne Nadelhölzer zeigen noch bestimmte Pilzarten, wie z. B.

Hypoderma brachysporum speziell die gefürchtete Nadelschuitte der Weymouthskiefer erzeugt.

Dasyscypha (Peziza) Willkommii, der Lärchenkrebs, zeigt sich durch das lasche Erbleichen junger Zweige an alten Ästen an.

Trichospluaeria parasitica iiberspinnt nicht nur die Nadeln, sondern ganze Triebe der Tannen, worauf vollständige Bräunung derselben eintritt.

Pestalozzia Douglasii auf Pseudotsuga, und

Pestalozzia funerea auf Cupressineen, schnüren insonderheit die jungen Triebe ein und bringen dieselben zum Absterben. Ähnlich wirkt hesonders an jungen Koniferen: 
Pestalozzia Hartigii.

Sehr gefiuchtet ist im Saatbeet:

Fusoma parasiticum, der schähllichste Kémlingspil\%. welcher unheinlich rasch unter den heimlingen autriumt.

Tremetes Pini erzeugt an Aststellen von Kiefern, Fichten, Weifotanen, Douglastamnen und Liirchen das Kernoder Ringschälen des Holzes.

Tremetes radiciperda zersetzt das Holz ron Tammen, Fichten, Föhren. Thuyen mul Wachholder, mol erzenet die sogenamute Rotfäule, Stockfäule, K's'nfia ule.

Ähnlich - Holz zersetzend — sind verschiedene

Polyporus-Arten.

Rhizinia undulata, ein Saprophyt, bewirkt die Rincseuche an Wurzehn, ein "dichtfilziges" Durchwachsen der Wurzeln, den "Wurzelschwamm".

Gymnosporangium Sabinae schidigt einerseits dis Holz ron Juniperus, geht dann auf den Birnbaum iiber und schiidigt dort Blätter und Triebe. Öhnlich ist es bei

Grmosporangium juniperinum, der dem gewöhnlichen IV́achholder einerseits und den Apfelbäumen andererseits Verderben bringt.

A ecidium elatinum erzengt den ,Hexenbesen", d. h. ein ständiges Neubilden unzähliger, kleiner, dichtstehender Triebchen mit kleinen Blättchen.

Andere Aecidien erzengen entweder andere Arten ron Hexenbesen oder doch Deformation von Nadelholztrieben, orler zerstören die Fruchtzapfen.

Peridermium Pini, der Kienzopf der Kiefern, auch als Krebs. Riude bezeichnet, bringt Rinde, Bast und Holz der Kiefern zum Ahsterben, wohei zu unterscheiden ist zwischen Per. Pini acicola, der die Nadeln beschädigende, und Per. Pini corticola, der die Rinde etc. zerstörende Pilz oder Blasenrost.

Septoria parasitica und

Phoma (Fusicoccum) Abietina bringen beide besonders junge Triebe zum Absterben.

Cronartium ribicolum der Blasenrost der Weymonthskiefer ist in seiner ersten Generation anf' Johannis- und Stachelbeerstrinchern, in der \%weiten Generation als starker Schädling auf oben genannter Kiefer, der Strobe.

Solcher drten könnten noch eine grobe Reihe anforefïhrt werden. Achutzmittel sind nur wenige vorhanden. Am besten ist die Torbengung - soweit mighlich - der Krankheiten: 'Trockenlegung feuchter Teile des $\mathbb{V}^{\prime}$ aldes und sonstiger Sitandorte, Verhiitung ron Terletzungen am Holz usw, da sich hieran @ern die schädlinge ansetzen: Ausholzung (Durchforstung) nur bei diurem Holz (Trockeniistung). Ein Bespritzen der 
hefallenen Baime mit einer Lösung aus Kupfervitriol (2"/o) und lialk $\left(2^{\prime \prime},{ }^{\prime}\right)$ hat sich als gutes Nittel gegen die Weitela usbleitung der Schädlinge erwiesen. Reifenden Pilzen, also solchen, welche ihre Śporen - oft zu Milliarden - ausstreuen, beizukommen, ist nahezu unmöglich.

ITier missen auch jene Bakterien (Mykor'hiza) genannt werden, welche in Symbiose (gemeinschaftiches Zusammenleben) mit den Wurzelspitzen der Pflanzen leben, in diesen vegetieren, und wie es scheint die Wur\%elzellen gegen die Einwirkung schädlicher Bakterien schützen.

Diese beschiitzten Wureln hat man kurzweg als , Bakteliorhiza"hezeichnet. Bestimmt nacherviesen ist - bei Narlelund Laubbäumen, - daß Pflanzen in Erde verbracht, welche keine oder wenige dieser Mykorhizen enthielten, oder Pflanzen mit anderon Mikorrhizen als die nene Erde sie enthält, nicht oder schlecht wachsen! Es sind schon manche Hiltsmitel empfohlen worden: Einfiihrung hezw. Beiqahe winstiger Erde, Zwischenptlanzmon naheverwander Arten und dergl. mehr.

Von höher entwickelten Pflanzen seien noch Formen der Mistel (Tiscum) genannt. Welche durch Saftentrichung, besoncler's an Gipfel von 'Tammen und Fohren, ziemliche Holzheschädionng erzeugell.

\section{b) Tierische Sachäallinge.}

Auch hier ist die Zahl derselhen eine ganz eminente, anch hier erfordert das Kemnenlernen der Schiallinge ein volles Studium derselben. Leider sind es auch deresingermafen wirksamen (iegenmittel ganz wenige. Ein Abhieb befallener Bämme. hesonder's aber noch das sofortige schälen derselben. T'erhremen der Abfälle u. durgl., greift noch am giustigsten ein.

Durch gefiillte, sogenannte "Lockbiume" kïnnen unzählige Schïdlinge gefangen werden, also dafi an eigens fiu die Tiere ginstiger Stelle, besonders in Gräben, ganze Bäume den Tieren cine bestimmte Zeit lang iberlassen werden, wodurch man dann der Schädlinge leicht habhaft wird.

Daf altes Holz so rasch als moglich entrindet und entfernt werden muß, ist einleuchtend.

Ein Abklopfen verschiedener Schädlinge an kleineren Bäumen, abfangen durch allerlei Mittel, kann nur teilweise helfen. Weit besser noch hat sich das Anbringen von Leimringen erwiesen, speziell fuir a ufkriechende Schädlinge. \%. B. Motten- und Schmetterlingsraupen. Sehr rasch aber und am besten dezimiert die Natur selbst die Ŕchädlinge, indem wiederum P'ilze aufteten, - aus ircend welcher Veranlassung, z. B. nafikaltes Wetter - welche die Schädlinge befallen und sehr rasch zum Absterben bringen, wie z. B. ein bestimm- 
ter Pilz: Bacterium monachae. in kurzer Zeit enderiltig muter der gefiurchteten Nomne, liparis monacha, anfrimut. Bis solehes eintritt, muti natiolich schon vorher durch die menschliche Hand eingegriften werden.

Eine Anzahl Rauhkiafer und deren Larven, forner hestimmte

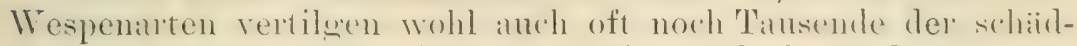
lichen Insekten, allein dies ist trotzdem unbedentend.

Es hat sich evereiget, dath hefallenes Holy dureh Borkenkiifer immer noxh hesser zum G(thrameh blich, als jenes, dessen Nadeln durch Raupen abgefressen worden waren.

Am meisten befallen werden kidhten, Tannen, Sieforn und

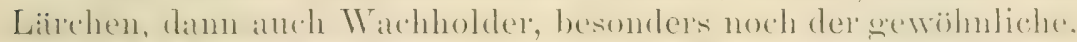

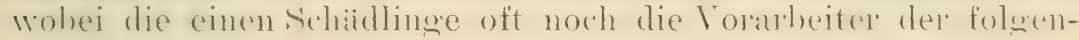
den Zerstörer sind.

Unsere Fichten werden an den Wurzeln von

Otiorrhynchus-Arten, Riisselkäfern, beschädigt. An Rinde und Bast sind besonders

Hylesinus cunicularius, der schwarze Fichten-Bastkïfer, und

Hylobius Abietis, der große braune Rüsselkäfer, als

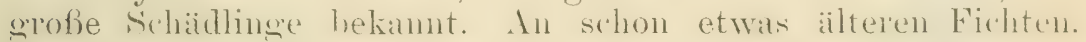
bezw. an deren jungen Trieben sind etliche Wickler:

Tortrix-Arten, oft großen Schaden bringend. Sehr gefiurchtet ist anch

Tortrix (Grapholita) tedella, der Fichten-Nestrickler, mit seinen Minierweschät. Eines der schaidlichsten Tiere ist aber die $\mathrm{N}$ o $n \mathrm{ne}$,

Liparis monacha, welche alles kahlfressend, äußerst verderblich wirkt. Dann folgen noch:

Orgyia antiqua, der Schlehenspinner, verschiedene

Tomicus, Borkenkäferarten, besonders

Tomicus typographus und T. chalcographus, welche sanz gesunde Bestiude hefallen. .Jede Alt dieser Borkenkiifer zeichnet sich durch eine bestimmte Form seiner Fratimance aus! Neben diesen schädigen im Bast hesonder's noch:

Hylesinus-Arten, speziell H. micans, der Riesenbastkäifer; ferner

Pissodes, die Harzrisselkäfer, und andere mehr. Sellsst an Zapfen und Samen schaden rerschiedene Arten. Ton Wichtipkeit ist auch die gelbe Fichtenlaus

Chermes Abietis. Überwinterte Tiere stechen im AprilMai die Kinospen - speziell der gemeinen Fichte - am unteru Teil an und legen dort Eicr ab. Durch den Stich schwellen 
die Nadeln an der Basis an, schließen sich an den Ränder'n ene aneinander, oder verwachsen auch miteinander und bilden später jene Ananas-artigen, oder zaprenartigen Gebilde, welche - da sich oft die Triebe noch umbie-

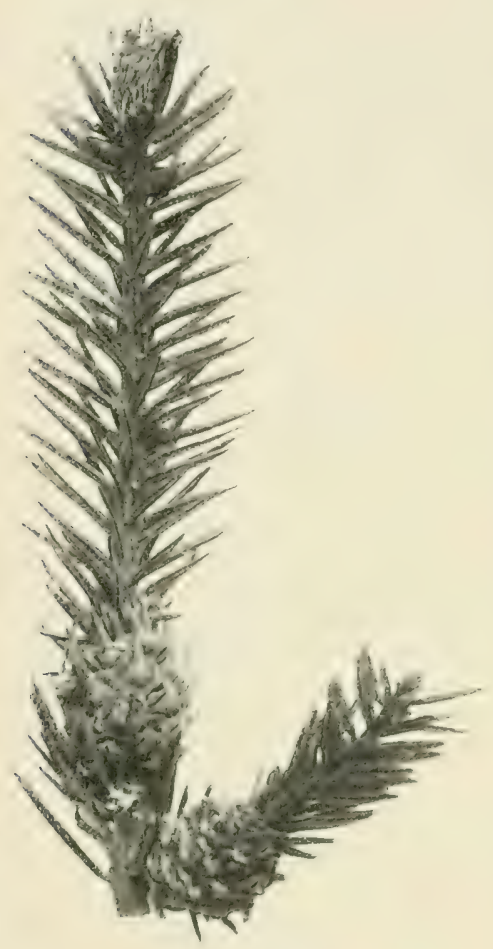

Fig. 11.

Zapfenähnliche (ananasähnliche) Gebilde an Ficea excelsa, hervorgerufen durch den Stich von Chermes Alietis, der gelben Fichtenlaus. gen, häßlich, wenn auch nicht besonder's schädlich wirken, außer' an den Fortsetzungszweigen.

Das Gebilde, in dessen Innern die jungen Låuse saugen, öffnet sich durch Aufbiegen der Schuppenrảnder im August und entläßt die geflügelten Läuse (Fig. 11).

Ähnliche Gebilde werden auch von verschiedenen anderen Chermes-Arten erzeugt.

Tannen werden besonders von Schmetterlingen und Käfern heimgesucht. So durchnagt

Pissodes Piceae, der Tannenrüsselkäfer, das Holz alter Bäume.

Tomicus curoideus, der Tamnenborkenkäfer, schädigt in gleicher Weise; dann ist wieder

Liparis monacha, die Nonne, zu nennen, ferner verschiedene

Tortrix-Arten, speziell T. nigricans, welche den Knospen und jungen Trieben Schaden bringen.

Auch Galläuse an Trieben, sowie Samenschädlinge verschiedener Herkunft, können verheerend einwirken.

Sehr stark befallen werden auch

die Föhren oder Kiefern.

An jungen Pflanzen schädigen

H ylesinus-Arten, durch Benagen von Rinde und Bast. Pissodes notadus, der braune Kiefernkultur-Riisselkifer, zïhlt zu den wefïhrlichsten Feinden der Föhrenkulturen.

Können eine Reihe kleinerer Schadlingskifer iibergangen werden, so muß wieder

Tortrix Buoliana, rer Krieferntriehwickler, durch sein Aushiohlen der Knospen und jungen Triebe - die sich damn 
meist $\because$ fömig biemen - als einer der wefihnlichsten bereichnet werden.

Tortrix turionana und 'T'. duplana schaden in ähnlicher Weise. Als Bastzerstörer wirken am verselieflene

Tomicus-Arten; dagegen ist neben der Nomne bedingt

Liparis monacha, diesen schrecklichen V'rolerber, un-

Bombyx Pini, der Kiefernspinner, zu nemnen, der, wenn ihm nicht im Friihjahr der Aufzus am Bam verhindert word, durch Frati im Friihahr und in Herbst an den Blaittern eminenten Schaden anrichtet.

Ebenso sollen noch die sogen. Prozessionsraupen, welche oft sehr g'roßen Schaden anxichten, so z. B.

Cnethorampa pinivora, der hiefern-Prozessionsspinner, genannt sein.

Auch die Kieferneule

Noctua piniperda, wie ebenso

Noctua vestigialis, die Kiefernsaateule, sowie die

Hylesinus-Arten, welche ganze Kronen zum Absterben bringen, müssen noch erwähnt werden.

Verschiedene Bockkiifer, weitere Borkenkïfer und ChermesArten wirken ebenfalls oft sehr schädlich.

Auch die Lärchen werden von tierischen Feinden stark heimg esucht.

Dasyscypha (Peziza) Willkommii, der Liarchenkrebspilz, ist meist die erste Ursache tiur die nachfolgende Schädigung durch

Tinea (Coleophora) laricella, der Lärchenminiermotte, welche die Blätter aushöhlt (solche erscheinen dann weif)!), dann in eigentimlichen, selbstbereiteten Säckchen iiberwintert und mit dem Blattaustriel, sofort wieder weiterschäiligt.

Tortrix pinicolana, der Lärchenwickler, an jungen Trieben fressend, gefährdet ganze Bestände.

Auch hier könnten noch eine größere Zahl weiterer schiidlinge angegeben werden, doch mub wie in allen anderen Fällen des gemessenen Raumes halher auf die einschlägice Literatur verwiesen werden.

Dat die Schnecken, Maulwurfsorillen, die Engerlinge, die Drahtwïrmer (Elateriden) in den Saatschulen ganz gevaltigen Schaden anrichten ${ }^{*}$ können, braucht wohl nicht speziell erwähnt zu werden. Vorsichti@e Dimgung mit Kunstdinger hilft vielfach. Sehr eifrig stellen verschiedene Vögel besonders den Drahtwiirmern nach.

Von höher stehenden Tieren schädigen der Krenzschnabel und ein parr andere Vögel durch Fraß seltener Samen: in gleicher Weise, sowie durch Verbif junger 'Triebe schadet auch das Eichkätzchen. Dann findet in Park und Wald ein Verbifi 
der' 'Triebe - vor' welchem nur' wenig Nadelhölzer, aufier' die widerlich riechenden und die stechend benadelten so ziemlich reschiitzt sind, - durch das Wild statt. Als bestes Gegrenmittel ist zur Zeit: Gleitsmanns säurefreier Baunteer(GleitsmannMinchen, Ickstattstr. 19) zu nennen, welcher dium aufgetragen, ein sehr gutes Abhaltemittel ist.

Durch das "Fegen" der Rehböcke und Hirsche werden oft serade die schönsten Bïume entschält. Ein Einbinden des Stammes ist wohl das einzige Gegenmittel. Ebenso ist ein Einziiunen oft ganzer Pflanzen im unteren Teil mit verzinktem Draht dort woselbst Hunde frei laufen, das einzige Mittel, die Pflanze vor' dem raschtötendem Urin letztgenannter 'Tiere zu schiitzen, was auf offentlichen Plätzen unbedingt, jedoch auch in zugänglichen Parks nicht unterlassen werden sollte.

\section{Vermehrung der Nadelhölzer und Pflege der jungen Pflanzen.}

Bei der Beschreibung der Koniferen ist bei vielen Arten auf obengenannte Punkte Ruicksicht genommen, sodaß hier so kurz als möglich diese Angelegenheit behandelt werden kamm. Die naturgemäßeste Vermehrung der Nadelhölzer ist jene aus

Samen. Material von normalen, gesunden Bäumen aus meist kälteren Gegenden gesammelt, als der des zukiuftigen Wuchsortes, ferner solches nur in frischer und keimfïhiger Ware zu erhalten, das ist die erste Bedingung fuir späteren guten Erfolg.

Reelle Firmen arbeiten schon seit langem dahin, nur solchrenamnten Samen, unter Garantie der Echtheit und der genamen Keimkraft-Angahe(!) zu verkaufen. Selbst wenn solche Firmen smy erheblich teurer verkanfen müßten, so wiiren diese Samen doch erheblich billiger, als der billige Samen ohne Garantie! Samen vom eigenen Forst oder Park ist wohl sehr angenehm und in vielen Fällen ein sicheres und billiges Naterial. Allein viele Beobachtungen haben es bestätigt und es lient auch schon im Wesen der Samenverbreitung, daf fremde Samen besseren Erfolg, besonders in späteren Wuchsjahren erreben, als samen in der eigenen Gegend gesammelt, abgesethen in der Keimunfïhiskeit vieler eigenen Simereien. Erwiesen ist ferner, hesonder's bei Föhren, dak Samen aus nördlichen Latgen stammend, bessere Erfolge zeitigen, als solche von siidlichen (selbst \%.B. mitteldeutschen!) Bäunen. Samen von Höhenlagen scheinen in Tieflagen keine guten Resultate zu er'seben. Mit 
Ansmahme der einheinischen und einer kleinen Anzihl cingefiihrter, iiber 100 Jahre bei uns kultivierter Arten siml wir olmehin auf fremden Samen angeviesen.

Die Ernte der Simereien ist im Herhst und Frihjahr, ehe der Ausfall berinnt und ehe Tiere den Samen holen, wobei am besten die - oft zerfallenden - Zapfen und Beeren in geschlossenem Zustand eingeheimst und in geeigneten Rïunen weiter behandelt werden.

Warme - nicht heifie - Luft (auch Ofenwiarne his zu $40^{\circ} \mathrm{C}$. mul sonne sind - wo angängin - das sicherste Mittel zum Öffnen der Zapfen. Einige Arten, z. B. Zedrrn, setzen allerelings diesen Mitteln lange Widerstand entgexen und miissen unter. Umstïnlen durch vorsichtiges Ausboh. en der Zappenspindel zum Zerfall des Zapfens gebracht werden.

Beerenzupfen list man in IVasser und trocknet dam die Samen nach.

Schnitfproben zur Pritung der Samen sind beleutumgslos: Keimproben miissen nach 5-25 Tagen die Erfolge zeicen.

Vorteil bei der Ansat ist, die Samen sobald als mömlich nich der Reife dem Boden anzuvertrauen! Solch behamdelter Samen keint sehr hald: anderer liegt leicht iiber, d. h. brancht lange Zeit, oft ein Jahr, ehe er keint. Manche Samen keimen auch nur nach und nach! Muß Samen anfbewahrt werden, so hält er sich am besten noch im Zapfen, oft eine Reihe von Jahren, andererseits ist solcher, eingeschichtet in trockene's Miaterial an einem kiihlen Ort zu bewahren, um dann etwa im Friihjahr, März-April, ausgesät zu werden. Mit Fliigel versehene Samen werden in kleinen Quantititen in Siicke erehracht mol hier vorsichtig aber grindlich gerieben, bis die Flii@el ohne Terletzung des Samens alogestoßen sind.

Sehr ginstio ist es, die Sat feinerer ofler seltener Nallelhölzer in flachen Holzkistchen orler Schalen im Herbst vorzunehmen und in mäusefreien, kalten Mistheetkästen zu ïberwintern. Solches ist auch bei den Beerenzapfen tragenden Alten auszufiihren.

Gegen Vögel, z. 'T. auch øegen Näuse, ist es vorteilhaft, den Samen mit Bleimennig zu farben, auferdem sind Wachholdernadeln ein kleines Schutzmittel regen letztrenaminte Nager. Gegen Pilze ist es gut, die Samen eine Nacht Iang in $2 \%$ oige Kupfervitriollösung zu legen!

Samen sehr stark mit Erde, Sand oder dererl. zu belecen ist meist schädlich; andererseits wirkt das Bedecken der Salat mit etwas Moos, das aber nach dem Keimen zu entfernen ist, sehr riinstig. Als Ersatz dieses Schutzes emptiehlt es sich un bedingt, in angemessener, der Luft frejen Zutritt gervihrender Entfernung rom Boden leichtere śchattenvorrichtungen 
irgend welcher Art anzublingen. Man versäume dies - wonn irgend möglich - niemals.

Große Nadelholzsämereien, z. B. von Araucaria, steckt man einzeln, mit den spitzen Teil voran, zu $2 / 3$ der Namengrörłe in die Erde. Seltene Samereien sit man iiberhaupt möglichst gleichmähig, d. h. verteilt solche, daß jeder Samen einen greniigend oroben Ramm erhält, sodaf die aufgehenden Kémbinge sich nicht dricken. Üherhaupt sïe man nicht zu eng! In engen Sarten riumen Pilze oft iberraschend schnell aut.

Daß bei wärmebedirftigen Sämereien, z. B. Araucaria, Cupressus usw. die Saat in temperierten Haus oder doch in Iiästen nuter Glas vorgenommen werden sollte, liegt nahe, doch ist kihle Saat immer' vorteilhafter als warme.

Schwer' aufgehende Sämereien in 'Töpfen miissen z. T. auch nach einiger Zeit ungesteckt werden.

Den aufgegangenen Sämlingen ist der Luttzugang soweit es nur inmer möglich ist, zu gewähren, dagegen schiitze man dieselben geren Somne! Die schönste Douglastannensaat kann durch starke Sonnembestrahlung vernichtet werden.

NB. Sonne ist notwendig, aber mit Maß!

Lockere, sandige Erde ist das beste substrat fiur alle Koniferensaaten.

Schntz g’enen Vögel, Schnecken, Mäuse, Maulwiirfe, Dialıtwirmer, Maulwurfsgrillen. Engerlinge, verschiedene Käfer muß stets ausgeubt werden.

Dumpfe, feuchte Luft ist Vorbedingung fiù schädliche Pilze! Auch die im Winter etwa nötige Schutzdecke sei möglichst trocken und liege - wenn sie aufliegen muB - möglichst leicht auf.

Im April des nächsten Jahres, kurz vor dem Austrieb, verpflanzt man die Jährlinge in Beete mit lockeres', sandiger Erde. unter grofer Bericksichtigung der gesen trocknende Luft empfindlichen WVurzeln. Pflanzen in Töpfen erzogen, werden wieder in solche verpflanzt. (in zwar lockerer, doch schon mit etwas schwerer Erde versetzter Mischung'), was sich so lang't wiederholt, bis die Pflanzen auspflanzungskiaftig genus sind. Die Töpte werden nicht eingesenkt, sondern gänzlich wenn auch micht zu tief - eingegraben, wodurch meist WVurzelbildung ii her dem Topfrand stattfindet.

Bedacht ist zu nehmen, dafs die Pflänchen in Topt wie im freien Land so viel Raun erhalten, daß sie 1-2Jahre stark "achsen können, ohne sich za leengen. Das Erolveich wird mit irond einem leichten Material - am besten kurzem Dinger ludeckt, mn sheichmäßjo bleibende Feuchtigkeit (aligesehen Anreh Begicien, wenn solches ofter's geschehen kanm), zu erzengen. Lichte, hochstehende Beschattung, ist auch jetzt noch 
ron Vorteil. Sind schiidliche Pilze zu hefiurchten, so iibersplityt man die Sämlinge mit einer Lösme von 2"/n Kupfervitriol mol $2 \%$ Kalk.

Nach 1-2 Jahren findet wiederholtes Umpflanzen statt.

Stecklinere. Von cines entiberen Anzahl Loniteren-drten

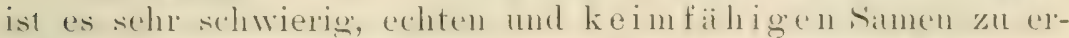
halten: fernel erechen sumen von Formen viner drt zuneist die Stanmform wioler, und eine slotie Reihe von Formen

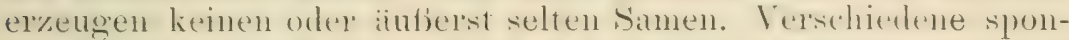
tan anferetretene Formen einer Art wurlen regetativ remehrt mol wiirden anch bei der Samenvermehrumg wohl stets nur die stammform eroeben. In solchen und anderen Fiallen ist man gezwnngen, eine Stecklingsermehrung vorzmehne'n.

Allerdings zeigen ans stecklingen erwathene P'Hanzen selten das mehr oder minler anfstrebende Warhstum der samenphtanzen. sondern bilden meist ziemlich gedrungene, buschige Exemplare. Ferner ist von spotbem Einfluti anf den Wuchs, oh

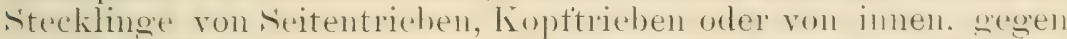
den stamm zu gewachsenen Trieben entnommen werden, da z. B. viele drten aus Seitentriehen erwachsen, allch sehr lande? ein seitliches Wachstum zeigen. öfters ïherhaupt kemen kopt-

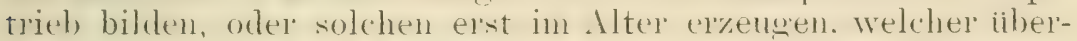
dies noch durch eine Adventivknospe entstehen kann. Man ist deshall, vielfach rezwungen, un hopftiche zu crhalten, alte PHanzen ahzuschmeiden, wolurch passendes Material meist in gröberel Anzahl nachwaichst. Man kamn darauf rechnen, dafi Stecklinge von Cupressineen fiast durchwegs gut sich bewurzehn und sut gedeihen; Ausmahmen sind allerdings vorhanden. Bei schlecht wachsenden Arten ist es zu emptehlen, möglichst jugendliche Triebe zu benitzen, also 'Triebe mehr' vom oberen 'Teil der Nutterptlanze, oder wie bereits bemerkt von solchen in der Nithe des Stammes erwachsenen, wie dies hesonders bei Cupressus, Callitris, Libocedrus etc. der Fall ist.

Sitecklinge von Anbentrieben eræeben selten ginstiges Resultat: dagegen wachsen Jugend- und Uhergungsormen ausgezeichnet. Ebenso darf man bei hangenden Formen nur Kopftriebstecklinge nehmen, da hibuencle Aubentriebe meist nnfoimliche Gestalten exzengen. Agathis, Arancaria, Cuminghamia sind nur aus Kopftrieben zu vermehren. Sciadopitys ergilut aus Stecklingen nur kleines, unwiichsiges Material.

Cellus mod Larix wachsen ebentalls panz sut aus Stecklingen, erstere aus immen stehenden Triehen, letztere aus Gipfeltrieben. Kictelecria, Tsusa aus nicht zu staken Trieben eroeben schöne PHanzen, wemn auch durch stiitzen in der ersten Zeit

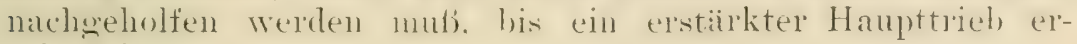
leicht ist. 
Ebenso wählt man bei Picea nur feine Triebe, doch wachsen dieserlei Stecklinge ganz gerne.

Abies wächst ebenfalls gerne aus Stecklingen, doch bilden die meisten Arten mehrköpfige Exemplare, aus denen nur bei wenigen ein Haupttrieb sich emporringt, mit Ausuahne dann, wenn reine Kopftriebe vornweg genommen wurden.

Die Größe der Stecklinge ist meist bei $10 \mathrm{~cm}$, doch nimmt man, je nach Art und Material, auch größere und kleinere Teile.

Krantige Stecklinge werden selten verwendet, z. B. von Ginkgo, meist werden etwas - wenigstens unten - ausgereifte Triebe beniitzt, welche man alle mit etwas Ansatzholz vom Muttertrieb abschneidet.

Ist für einzelne Stecklinge - die krautartigen - der Vorsommer der güustige Noment, so ist für die iibrigen der Nachsommer, vom August al, der passendste Zeitpunkt, doch sollte die Stecklingsvermehrungbis längstens MitteSeptembergeschehen sein.

Als Substrat wählt man Heideerde, Sand, Torfstreu, bezw. Inll mit Sand, orler auch nur fiir Wasser gut durchlässige, sandige Erde (Holzkohle als Beigahe ist sehr gut, besonders in Töpfen). Man drickt die Stecklinge nur so tief ein, dafi sie nicht allzuleicht unfallen. Stehen Handkïsten mit ïberdeckharen Glasscheiben, oder kalte Mistheetkästen mit Fenstern, oder Glasglocken zur Verfïgung, so beginstigt dies die Bewurzelung. sehr (dem erhöhte Wiirme ist unter allen Unständen von vorteilhafter Einwirkung), andernfalls muf man sich auch mit Glasglocken in freien Lande behelfen. Fiir empfindliche, und fiir Wrirme bediurftige Sorten ist es wohl am besten, einen gut schließenden Mistheetkasten zu wählen (wenn nicht ein Vermehrungshaus zur Verfiigung steht), was ja auch bei den Samen, wie besprochen, sich als notwendig erweist.

$\mathrm{Zu}$ vermeiden ist auch, dafi die Triebe zu dicht gesteckt werden. Dumpfe Luft und starke Bestrahlming der Somne mufi vermieden werden, ebenso zu große F'euchtigkeit; im ersten wie letzten Fall wird leicht Pilzbildung erzengt, im anderen Falle leiden die Stecklinge durch zu große Wasservertunstung. Wasser wird nach Bedarf gegeben, doch sollte dies nicht allzuoft geschehen miissen. Vermehrung im Warmhaus hat oft schlechte Erfolge; giunstig ist solche jedoch meist, wenn mit geringer Wärme begommen wird und erst später mit dem beginnenden Heizen des Hauses auch höhere Grade - etwa $2\left(0-25{ }^{\circ} \mathrm{C}\right.$ - erzeugt werden. Trotz guter Pflege wird aber das Substrat leicht sauer, was bei schwervachsenden Arten oft der Fall ist, weshalb dasselbe durch gleichartiges Material zu ersetzen ist, ehe die feinen Wiirzelchen erschienen sind.

Die in den Kästen, besonders aber jene in Freiland verbleibenden Stecklinge miissen - unter Vorkehrungen gegen 
Mäuse - bei Beginn des Winters gut gegen Kälte geschiitzt werden: auch sollte an milden Wintertagen sut beizukommen sein, um etrvaigen schiollichen Einflissen stenern, event. auch erenigende Luft heilassen zu kömnen. Nath der Bewtuzelung. welche allerdings oft cr'st nach einer Reihe ron Monaten stattsefunden hat, ist ein Umptlanzen unter gleichen Tedingungen wie bei den Saimlingen notwendig.

Im iibricen sei, wie eingangs erwihnt, in obigen und weiteren Punkten anf die jeweiligen Angaben hei den Arten in der "Beschreibung der Koniferen" hingewiesen.

Ableger oder Fenler. In Notfall, besonders wenn di: PHanzen nicht zerschnitten, d. h. zu Stecklingen verwendet werden sollen oder können, kann man bei den Gupressineen bei Thuya, Tuniperus, Larix mol Pseudolarix, Ginkgo, J'odocarpus, Scidilopitys u. s. W., damn aber auch bei Abies und besonders hei Picen, speziell in funzweigigen Arten und Jusendformen, Ableger oder Senker bilden.

Zu diesem Zwecle werden jünere Zwrige his zur Erde niechercebogen, dort woselhst sie den Boden berilhren, etwa bis

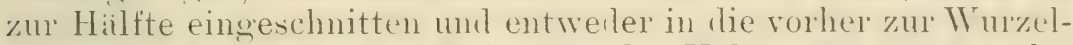
hililum locker gemachte Erde mittelst Halien etwas rersenkt, orler nur aufoelegt und mit Moos oder derol. iiberdeckt. I)ie Erite darf natiorlich an diesen Absenkmosstellen nicht meln ganztrocken werden.

Es dauert meist ziemlich lange Zeit, oft eine Reihe von Monaten, selbst ein bis zwei Jahre, bis Bewurelung stattgefunden hat, worauf der Ifutterptlanzentrieh in der Niihe des Senkers nach und 11 ach abeschnitten wird. S'chlecht hewurelte Senker geben selten gute Ptanzen: ïherhaupt erhailt man bei dieser Art der Termelnung meist Exemplare, welche nie den raschen, kraftigen Wuchs der normalen PHanzen zeigen.

Pfoplung. Auch in dieser Angelegenheit ist bei der Beschreibung der Arten, oder doch bei der der Gattumen, das Wesentlichste angegeben. Hier soll nur noch einiges allgemein Wissenswerte beriuht werden.

Wem irgend angängig, ist immer auf die Stammform zu pfropfen und nur im Notfall greife man zu möglichst nahverwandten Arten und zwar wiahle man nicht zu alte, oder gar schlecht bewurzelte Unterlagen, sondern gutwiichsige, etwa schwach bleistiftstarke Exemplare. Fern-verwandte Arten nehmen sich ausnalmsweise ebenfalls an, allein die Erfahrungen sind noch nicht so allgemein und sicher, dafi zutreffende Schliisse, besonders für spätere Jahre gtzogen werden könnten.

Als Propfinaterial rerwendet man meist ausgereifte Triebe, selten älteres Material und nu hei Pinus krautartig weiche Pfropfer. Im ersten Falle ist also etwa von Anfang Herbst 
an die günstigste Zeit; doch können verschiedene Arten (Abies, Cednus) schon Ende Sommers mit Vorteil repforoutt werlen. Über Mitte Olitober sollte die Pfroptzeit nicht verlangert werden, aufier man hat Riume zum Einschlas der veledelten PHanzen. in welchem Falle sthst in den el'sten Monaten des Tahres sepfropft werden kann. Laubahwerfende Arten pitropft man uberhaupt vor Austrieb der Pflanzen.

Gewöhnlich ptroptt man möghichst nalee dem Wrurzelhals, erhailt auch hier normale Verwachsume; doch wird auch. entsprechend den Cnstanden, oder zu Versuchen, bedentend höhex,

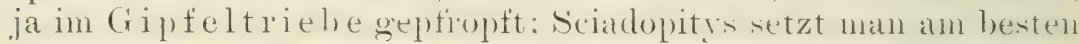
auf WVurzeln der eigenen Art.

Bei der Pfroptume auf Cnterlagen in Toipten - fast bei dele Mehrzahl der Koniferen - sollten die Unterlacen sut in den Töpfen angevachsen sein oder eben durchtreiben.

Die Art des Pfropfens ist eine etwas verschiedene. Bei den immergrinen Nadelholzern wird wohl stets das SeitenPfropten in Anwenciung gebracht, da hiechureh die Listerlage nicht vder kanm gestiont wirel: in den iblupen Fillen dagegen wird entweder das sogenamte Anplatten angewandt, indem nit dem Kopulicrschnitt - ein schräger ländicher schnitt durch den ganzen Trieb - las Pfropfreis zurecht gerichtet wird, um sodam ein diesem Schnitt entsprechendes Stiick der Cnterlage zu entnelumen, worauf' beicle Teile -- nuter yenauer Decknng: von Rinde und splint - aneinander a no gelegt - angeplattet - werden. Oder es tindet das Einspitzen oder Pforopten in den seitlichen sipalt statt, indem man das Pfropfieis von zwei seiten anschneidet, woratuf ein entspechend grotjer Ein. schnitt schrag einwarts in lie Unterlage zur Austiilnong kommt, in welchen das Pfroptieis so eingeschoben wird, diatich sich ebenfalls wieder Rinde und splint decken. Ein lockeres Verbinden mit Wollfaden ofler derol. ist matiolich sehoten, dagegen ist es wohl meist unötig, ein Verstreichen der Pfropt'stellen mit Pfroptwachs oder derol. vorzunehmen, auber hei der krautartigen Spaltpfropfung der Pinusarten.

Bei den laubabwerfenden Koniferen kann anch kopuliert werden, oder es kommt das spaltpfropfen mud Tieilpfroplen in Anvendung.

Das verwendete Messer ist stets rein zu halten!

Trem irgend möglich, werden die geptroptten PHanzen unter Glas sehracht, $u n$ in fenchtwalnes Luft rasch verwachsen zu kijnnen. Ist solches ersulitheh, so wird der Verband pelockert. Bei fassender Zeit finclet hieranf nach Ahhärtung der P'Hanzen ein - Dusplfanzen ins Freiland statt (wolnei es von Vurteil ist, wenn die Veredlung elonfalls etwas mit Erde bedeckt werden kinnm), den dann in ilen esstrenannten Fiallen - Seitenveredlung - ein 


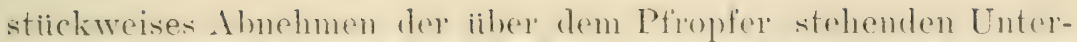
lagenteile folgt, dessen Rest im niichsten . Tahr dicht iiber der Ptropfstelle weggenommen wird.

Erwihnemswert ist noch, dafi anferepfropte. Jusend- und Whorganderomen fist in allen Fillen Wuchs und Hahitus derselben beibehalten, also selten zur normalen Form iibergehen.

Anderersoits wohen rolschiedene Zwereformen, insonderheit jene von thies, nach einigen .Jahren unbelingt in die Art zuriick, d. h. verliesen ihren 7wero-('harakter und hilden sich zu normalen PHanzen aus, so z. B. Chamaecyparis ohtusa pyomat, Abies balsamea hudsonica, Picea excelsa nana u. a. m.

\section{Grössere Nadelholzanpflanzungen in Deutschland.}

ITo wären solehe in Deutschland nicht zu finden? Deutschland hat aut seinen mehr als 54 Nillionen Hektar Land bei 1t Millinnen Hektar. Wald! Hievon fallen anf Nadelholzptlanzen efwa!) Millionen Hektar. Allerdings begreift dies fast durchweg rationellen Waldban in sich, hei dem fast alle idealen Zwecke kamm Ramm finden kïmnen; ebenso beschränkt sich dieser. Waldban in der Hauptsache auf Rotfichte mod Weiftanne, auf die gewionnliche und isterreichische Kiefer, anf Zirhel- und Bergkieter sowie aut Liachen. Neuerdings gewinnt die Douglastame iiherall und immer mehr Boden, ferner die sitkafichte, die Strobe (Pinus Strobus), Abies balsamea und sonstige.

Ton mseren Kulturptlanzen schöne Exemplare dem Walde zu crhaltun, ist das nenerdings starke Bestrehen der Forsthehiorlen und mafigehenten Winisterien, was dankend anzuerkemen ist. Hiedurch ist es dem Koniferenfreund eher möglich, des ifteren slofie, altehrwirdiøe Narlelhölzer zu hewundern, ohne dati erezwunen ist, weite Strecken zu durchreisen, wenn er urvichsiges Material sehen will, wie solches z. B. der Schwarzwalı, rie Volalpen, die Höhenziige ron Iittel- und Nordlentschland noch so reichlich hergen. Anch in Privatiositz findet man hewmulerunswiondise Bestinde und in solehem anch meist die ini 17. und $1 \Varangle$. Jahrhundert eingefuhrten, fremdlandischen Nalelhïlzer, wïhend die: Stantsforsten und derol. sich mit letyteren meist erst srit der zweiten Hälfte des rergangenen Tahrhmolerts etwas intensiver befassen.

Herrliche Fomplare hesonders nordanerikanischer, fermer japanischer und kleinasiatischer Xarlelhölzer neben unseren rin- 
heimischen Bäumen zieren die forstlichen Anlagen und Parks begreisterter Koniferenfreunde und Liebhaber.

Durch ganz Deutschland hindurch und in den vom Klima mehr begiinstigten Gegenden deutscher Gaue finden wir noch weitere Arten aus wärmeren Kilimaten, ja selbst von den Hïhenziigen tropischer Länder stammende Arten, deren meist kriiftiges Wachstum loffen liift, daß sie, sofern unsere Winterkialte nicht tiefer ist als jene ihrer Heimat, uns erhalten hleiben.

Richtig ist, daf in lufttrockenen Gegenden Deutschlands die Mehrzahi der Nadelhölzer das üppige, tiefsatte, orler so herrlich blan iiberhauchte Ansehen nicht leicht zeigen, wie jene in lufteuchten Gegenten wachsenden und auch noch gegen die Friihjahrswinde, hesonders Nordost- und Ostwinde geschiitzten Bestänle. Wenn Schutzptlanzungen. gute physikalische Beschaffenheit des Bodens u. s. w. nicht genigen. auch die empfindlichen Arten gedeihen zu lassen, so ist fü diese Gegenden doch noch eine iiberaus erotie Auswahl anderer, prachtroller. Koniferen vorhanden. welche reichen Ersatz fiir die emptindlichen Sorten hieten. Lnd selhst in museren kialtesten mul fiir feinere Narlelhölzer uns sehr ungiunstig dünkenden Ganen findet man bei richtiger Answahl noch eine solch aroße Anzahl oft der schönsten Arten oler Formen, so dafo dort nicht allzuviel ron jenen Koniferen zu vermissen ist. welche in ginstioreren Klimaten so hewundert werden. Dafo die Auswahl eine richtige und zufrierlenstellende ist. daf in unseren dentschen Bannschulen rie Koniferen unter einem allgemein gefihlten Namen erhaltbar sind, latiir hat erst die Neuzeit gesorgt mol zwar durch eine Vereinigung von Konferenziichtern und Kennern, welche die ron Gartenimspektor Beifiner-Bom aufgestellte, einheitliche Benenumg der Koniferen in ihren Baumschulen und Gïrten durchfïhrte!

Genamnte Tereinigung löste sich in der 1892 gegriundeten und gegenwartig iiher 1500 Nitglieder zählenden, in ihrer Eigenart, ihren Zwecken und Zielen einzig dastehenden Dentschen Dendrologischen Gesellschaft ${ }^{1}$ ) auf, und in ilieser Gesellschatt wird, hasierend auf wissenschaftlicher Grundlage, aber mit Ricksichtnahme ant Bestrebungen der Praktiker, genannte einheitliche Benennung - in gleicher Weise auch bei den Laubhiilzern - strengstens durchgefiihrt bezw. heihehalten. Den Bestimm-

1, Es ist Jedermann, der sich mit Tímiferen und Lauhhölzern befint, sehr zu raten, genamnter Gesellschaft - ler D. D. G., wie sie kurzweg grenamnt wird - als Mitglied beizutreten. Jahresbeitrag 5 - /l. Geschïftsfiihrer der Gesellschaft: Garteninspehtor Beitin er-Poppelsdorf bei Bonn a. Rh. Ein von der Gesellschaft allj: ihrlich herausgegebenes prachtvolles Werk ersetzt allein den Beitrag um gut das Doppelte. 
ungen dieser Gesellschaft schlietien sich neuerdings die Giehölzziichter, Kenner und Liebhaher des Auslandes immer meln an.

So treffen wir die Koniferen iiberall unter gleicher Benenu ung und nicht unter zwei- his zehntacher Bezeichnum, wie es frïher der Fall war, an.

Woselhst das Kilima mu etwas gimstion ist, dort pflanzten mon pflanzen Liehhalser je nach ihrer IVahl die Koniferen aller Laimder an, und deshall, tindet der suchende oft prachtrolle Exemplare gerale dort, woselhst er sie kaum rermutete.

In sidhlentschland ist die Insel Mainan im Bodensee wohl Gis: Dorado der feineren Koniferen. Thm schlieben sich die Geliande des Bodensees an, besonders von Lindau, Friedrichshafen, an Überlinger- bezw. Untersee, bis hinein in die Schweiz cinerseits, andererseits dem Rhein folgend, rechts und links die anliegenden Lïnder, hesonters in Baden um Freilure. Baden, Batenweiler, denen sich rechts Karlspuhe, Heidelberg. links einion Teile ron Elsaf-Lothringen und die Rheinpfalz anschlieben.

In unteren Wiuttemberg, besonders dem Neckarlaut mu seinen Haupttlissen folgend, iiber Stuttgart, Heillnom und den T'mgegenden sind herrliche Koniferen in Wrald und Parks zu finden, wïlnend in oberen Wïrtemberg, also auch gegen und um Tiibingen schon wieder scharfe Auswahl getroften werten mul, andererseits aher gegen den nahen Schwarzwald hin die staatsforstlich und privat angehanten Nadelholzbestänle Riesenexemplare in Menge zeigen. Die Masten der See-Schiffe stammten ja seinerzeit fast alle von dort her!

Bayern zeigt außer seinen urwichsigen Waldungen gegen die Alpen hin schöne sammlungen von Koniferen z. B. in Gratrat, am starnberger See u. s. w., in Klingenburg (bayer. Schwaben), in Diedorf bei Augshurg und in dessen Umgehnng, fermer gegen Landshut, Regenshurœ, hinein ins fiänkische Bayerm, dam in Berneck, bei Hof, Aschaftenburg, Wiirzure, iiherhaupt anch am Main.

Sehr reich an Koniferenschätzen ist das mittlere Deutschland, beginstigt dureh passendes Kilima, besonder's an seinen Flußläufen oder in seinen Gebirgsziigen.

Bei Luxemburg, hezw. hei Trier heginnend, bieten die ganzen Rheingegenden und Nebentialer prichtiges Material, solann in der Bonner (regend his Essen, Remscheid, Disseldorf und dessen Ungebung, z. B. Dyck bei Kilembroich. Dann folgen ron unten wieder beginnend, die heginstigte Bergstratie mit Anerbach, schinberg, Weinhein u. s. w., ferner Darmstadt, damn an Main die Nadelholzanptlanzungen besonders in Frankfurt, Wiesbaden, Cronherg: Weiter nördlich ist Kiassel, namentlich mit Wilhelmshijhe und der Au, ferner Miunden zu nennen. Giinstio 
wirkend fiur Koniferen ist auch Klima und die Bodenbeschaffenheit von fast ganz Thüringen.

In Sachsen begegnen wir grofen Sammlungen besonder's in den königlichen Gärten, speziell in Pillnitz, dann in Tillowitz, in Hermhut, um Dresten, in Tharandt, Kamenz, sodamn in Merseburg (Zöschen) u. s. w.

Das nördliche, speziell nordwestliche Deutschland, bietet z. 'T. großartige K'oniferen-Pflanzungen. Ginstig wirkt gegen die Meere hin die fenchte Luft, das weiche - nicht kalkhaltige und dadurch harte - Wasser (wie solches so vielfach hinderlich fiir feinere Nadelhölzer ist), damn aber auch, daß dort an manchen begiustigten Orten eben keine solch hohen Kaltegrade auftreten, wie im nordöstlichen Deutschland, oder in Schlesien, im siddlichen Bayer'n bis hinein wieder ins östliche Wiurtemberg. Kältegrade von 25-30 (und mehr!) Graden verbunden mit sehr kalten Winden, lassen in diesem nördlichen Teil Deutschlands ebensowenig die feineren Koniferen zur Entwicklung kommen. wie in dem zuletztgenannten, oft fälschlich als ., wärmer" bezeichneten siidlichen Deutschland.

Wundervolle Entwicklung zeigen die Nadelholzpflanzungen ron Oldenburg, Knyphausen-Liitzburg, von Bremen, Hamburg, \%. B. mit dessen herrlichem Friedhof in Ohlsclorf, in Necklenburg, Riigen, Putbus u. s. w., Hannover, IVeimar, Celle, Hameln, Biickeburg, Gadow bei Lanz, Bramschweig, Helmstedt, Destedt, dann weiter Berlin, Scharfenberg bei Tegel. Potsdan und Ungehnug: Anhalt mit dem herrlichen Wörlitz, das grobartige Muskau. Eisenberg in Böhmen u. s. w., der giunstig wirkende Har\%, hesonders mit Wernigerode.

So könnte in diesen Gegenden noch eine @roße Reihe ron Orten genannt werden, welche dem Koniferenfremule schönstes Material zeigen würden.

Auch Sichlesien bietet schöne Nadelhölzer. nur ist dort das Ḱlima nicht allzu ginstig, aber Auswalıl-Sammlungen bieten verschiedene Orte, wie z. B. Gleiwitz, WVoislowitz, Fischbach u. s. w.

Auch das nordöstliche Pommern, damn Ostpreußen iiberhaupt, versuchen dem Anbau fremdländischer Nadelhölzer fortgesetzt näher zu treten, voran besonder's die Forsten des preurischen Staates.

Giar viele Orte Dentschlands rom Siiden bis Norden und ()sten bis Westen, welche z. 'T. imposante, oder noch seltene Loniferenhestande oller Parks mit einer Reihe bewndernswerter Exemplare an Nadelhölzern aufweisen, konnten des heschrankten Ramues halber hier nicht aufgeziihlt werden. An vielen Orten haben jedtrufalls, wie so viele Beweise es bestaitigen, Koniferenlicbhaher durch Anptlanzung seltener Arten fortschrittlich länst schon werwht und so treffen wir oft unerwartet in rerschwiegen 


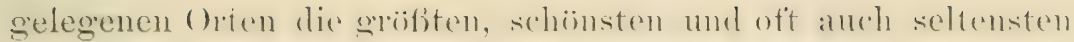
Koniferen!

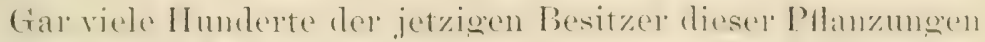
schliefien sich als Mitolieder der dentschen dembolocischen Gesellschaft an mul diest wiederum fiiht alle fahne ihre schandiirstemlen . Jitolieder in allen Teilen Deutschlands diesen herrlichen Sammlungen edler Nadelholzbäume zu.

Möchte die Liebe zu den Koniferen immer mehr deutsches Gemeingut werden!

\section{Einteilung der Koniferen.}

Die Loniteren bilden mit den Ginkgoaceen, den Guetaceen uml den ('rouleen die erste Lnterabteilumg der Phanevogamate wler Blitrinptlanzen: die (irmmospermen oder ,nacktsamigen" PHanzen. Nacktsamie deshalh, weil der Same nicht umhiillt. sonclern nackt anf ilem ansehreiteten Fruchtblatt angebracht ist.

Bis vor wenigen Jahren noch rechnete man den (rinkwo. (inkwobaum, ehenfills zn den Konteren: allein

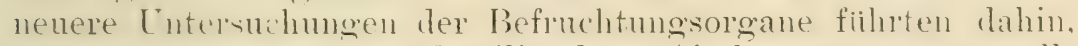

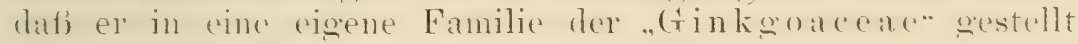
wurde.

Dieser vorangestellten Familie reihen sich sofort jene (Ter Nadelhölzer oder Koniferen an.

Es sind zwei Hauptfanilien zu unterscheiden:

I. Taxacea, Taxusartige Pflanzen, EibenGewächse.

II. Pinacene, Ki fefrertige Pflanzen.

\section{Taxaceae.}

Hier sind drei Unterfamilien festgestellt:

a) Podocarpeae, Stein-Eiben ähnliche, mit jo Genera:

1. Microcachrys Hook. fil., Kleinfrucht-Eibe. 1. ${ }^{1}$ )

2. Saxegothaea Lindl., Patogonische Eibe. 1.

3. Podocarpus L'Herit., Stein-Eibe oler Fuffrucht, 7;

(incl. Prummonitys P/il.) mit + Unterabteilungen:

I. Nageia Gaertn.

IJ. Eupodocarpus Endl.

III. Stachycarpus Endl. (incl. Pmomonitys).

IV. Dacrycarpus Endl.

1) Zahl der in diesem Werke angefuhrten A rten. 
4. Dacrydium Sol., Harz-Eibe. 1;

(incl. Pherosphacra Arch., Lepidothamnus Phil.).

5. Phyllocladus Rich. Blatt-Eibe. 4.

h) f'phalotaxeae, Kopf-Eiben ähnliche, mit einem Genus.

6. Cephalotaxus Sieb. und Zucc., Kopf-Eibe. 6.

c) Taxeae, Eiben ähnliche, mit zwvei Genera.

7. Torreya Amott., Torreye (Nuß-Eibe). 5.

8. Taxus Tournef., Echte Eibe. 1.

\section{Pinaceae.}

Hier sind vier Unterfamilien festgesetzt.

(1) Araucarieae, Schmucktannen ähnliche, mit zwei Genera.

9. Agathis Salisb). (Dammara Lamb.), Dammaratanne. ‥

10. Araucaria Juss., Schmucktanne, 7 , mit $z$ wei Untelabteilungen:

c) Columbea Salisb.

B) Eutacta Link.

e) Abietineae, Tamnen ähnliche, mit 9 Genera.

Hier werden zwei Hauptabteilungen nach Wuchsverhältnissen unterschieden:

c) Die Pflanzen füren nur Langtriebe.

11. Picea Link, Fichte, 17, mit zwei Abteilungen:

(c) Eitpicea TVillk.

ק) Omoriea Willk.

12. 'Tsuga Carr., Hemlocks- orler' Schierlingstanne, s, m it zwei Abteilungen:

a) Eutsuga Engelm.

(3) Hesperopeuce Engelm.

13. Pseudotsuga Carr., Douglastanne. 3.

14. Abies Link, Tanne. 31.

15. Keteleeria Carr., Keteleerstanne. 5.

ß) Die Pflanzen fiihren Langtriebe und Kurztriebe.

16. Larix Link, Lärche. 13.

17. Pseudolarix Gord., Goldlärche. 1.

18. Cedrus Link, Zeder. 3.

19. Pinus Limné, Kiefer, Fïhre. Forche. 66, mit + Unterabteilungen:

1. Pinaster Endl., Bin a e, zweinadelige.

2. Taeda Endl., Ternae, dreinadelige.

3. Cembra Spach. 1 Q uinae, funfnadelige.
1. Strobus Spach. 
f) Taxodieae, sumpfaypresien ahnliche, mit 6 (ienera.

20. Sciadopitys Sieb. und Zucc., Schirmtanne. 1.

21. Cunninghamia R. Braun, Cumninghamie, spiefitanne. 1.

22. Sequoia Endl. (Wellingtonia Lindl.), Sequoia- oder Mammutbaum. 2.

23. Arthrotaxis Endl., Gliederfichte. ?.

24. Cryptomeria Don, Cryptomerie. 1.

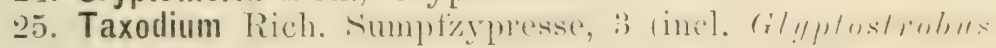
Endl.).

a) C'upressineale Zypressen ahnliche, mit 10 (ienera.

26. Actinostrobus Miq., Schuppen-Zypresse. 1.

27. Callitris Vent. Schmuck-ZYynesise, $T$ incl. Octoclinis F. von Muell., Frene la Mirirb., Widd ring ton ia Endl.).

28. Fitzroya Hook. fil., Alerce, 2 (incl. Diselma Hook.).

29. Thuyopsis Sieb, und Zncc., Hiba. 1.

30. Biota Endl., MIorgenländischer Lebensbaum. 1.

31. Libocedrus End1., Flußzeder. 6.

32. Thuya Tournef., Lebensbaum, 4, mit 2 Abteilungen:

1. Euthuya Benth. und Hook.

2. Macrotlinya Benth. und Hook.

33. Cupressus Tournef., Zypresse. 7.

:34. Chamaecyparis Spach., Lebensbaum-žypresse. 5.

35. Juniperus Linné, Wachholder, 30, mit :3 Abteilungen:

1. Sabina Endl.

2. Oxycedrus Endl.

3. Caryocedrus Endl. 


\section{Beschreibung der Koniferen incl. Ginkgo.}

\section{Ginkgoaceae.}

Wie bereits schon heim System der Nadelhölzer bemerkt, war der Vertreter dieser Familie friiher den echten Koniferen und zwar den Eiben-Gewächsen eingereiht. Nun haben aher For'schungen der letzten . Tahre ergehen, dati sich in den Pollenschläuchen des Ginkgo bewegliche Spermatozoiden (männliche, hervegliche Samen) befinden, wodurch eine nene, eigene Familie geschaffen wurde, welche sich von den Koniferen abtrennt und mehr den Cycadeen nähert.

Diözische Bäume mit reicher Verästelung, Lang- und Kurztrieben. laubartigen, keil- bis fïcherförmigen, eingeschnittenen Blättern.

Weibliche Blüte ohne Hülle (Cupula), einzeln, langgestielt. mit 2. selten 3 zur Entwicklung kommenten Samenknospen. Staubblätter zahlreich, ährenähnlich. 2 Monate nach der Bestäubung tritt in dem a h g e fall e ne n Samen erst die Befruchtung ein. Äußere Samenhiille fleischig, innere sehr hart.

Nur eine Art. Zahlreiche nahe verwandte Arten wurden rom Tertiär (also in Versteinerungen) ruickwärts lis in die Juraformation gefunden.

\section{Ginkgo Kämpfer.}

Ginkgobaum.

Ginkgo biloba L. Echter G. Heimat unhekannt. In China und Japan kultiviert. (Fig. 14.)

Syn.: Salisburia adiantifolia Simith.

Ein prächtiger, eigenartiger, iuber

I. ${ }^{1)}$

Junge Pflanzen lieben etwas Schutz. Warmer, nicht zu trockener Standort. $30 \mathrm{~m}$ hoch werdender, reich verästelter Baum, mit Kurz- und Langtrieben (F1g. 12), ahfallenden, rerschieden groben, hesonders fiicherartigen, lïngsgenervten, mehr oder minder.

1) Schlüssel hiezı siehe Seite ? 


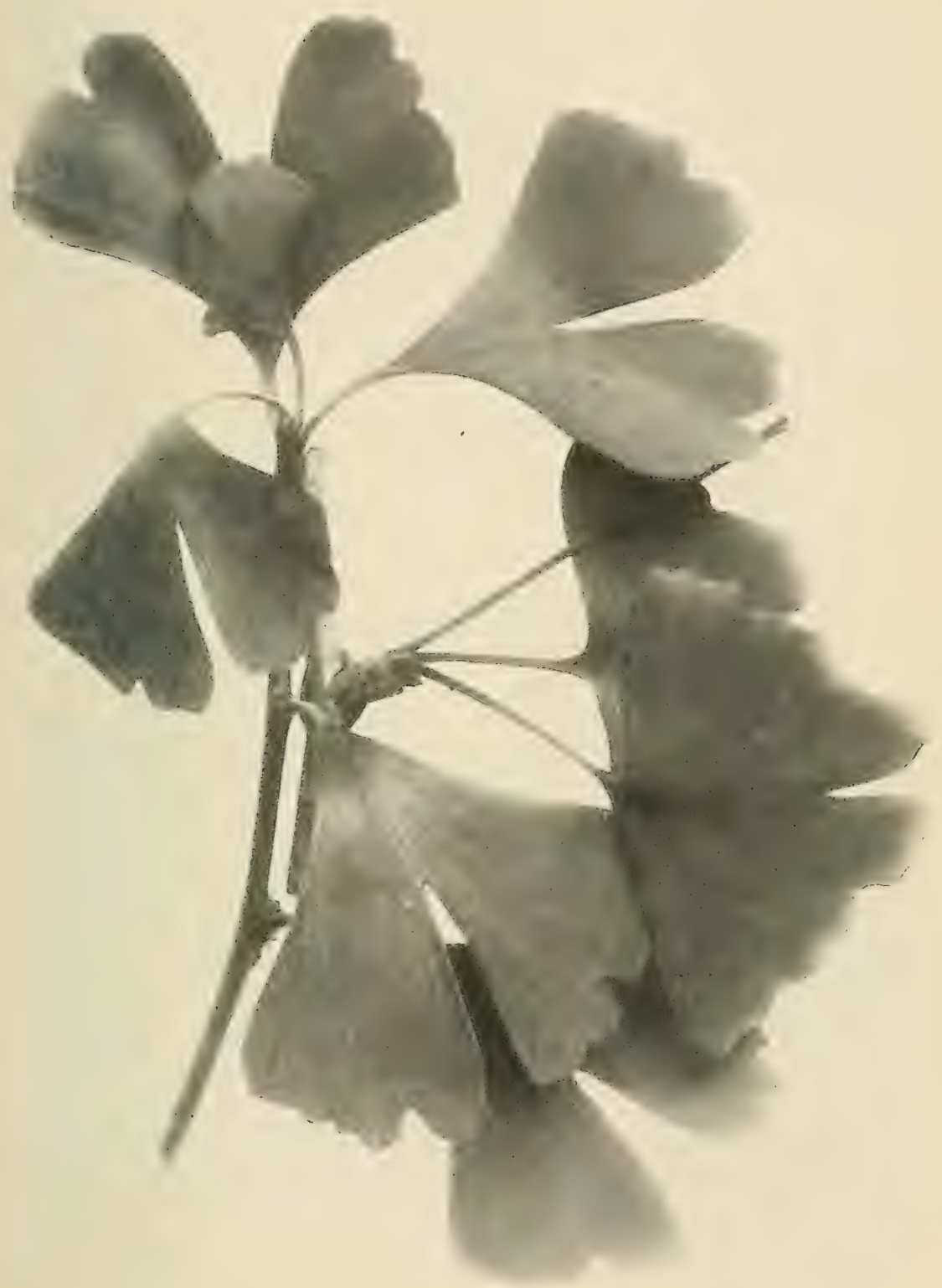

Fig. 12. Kurz- und Langtrieb von Ginkgo biloba L. (um $1 / 5$ verkleinert). 
selappten und auch geschlitzten, langgestielten Blättern, welche an den jährigen Langtrieben wechselständig, an den älteren Kurztrieben in Buischeln stehen.

Die länglichrunde, oben spitze Frucht ist zuerst griun, dann gelb, fleischig, innen nußartig. (Fig. 13.)

Da der weihliche Baun weit seltener als der mannliche ist, so pfropft man, 1 m Befruchtung zu erzeugen und Frichte zu erhalten, Triebe des männlichen Baunes auf den weiblichen.

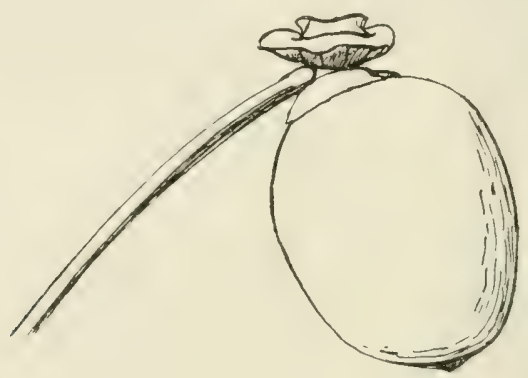

Fig. 13. Frucht des Ginkgo biloba L.

Das Holz des Baumes ist weich und wird in China und Japan gerne verarbeitet. Das Fleisch der F'rucht, welches auch offizinell beniitzt wird, enthält Buttersäure: der Same liefert ein gutes ÖL und ist in gerösteten Zustand in China und Japan als Dessert sehr beliebt.

Vermehrung durch Sumen, welcher am besten in Töpfen auf etwas erwïmte Beete gestellt, keint. Krautige Stecklinge wachsen gerne, gehen aber keine sehr schöne, hochwiichsige, somdern mehr breite Bäme. Pfropfung der Formen auf die Art, vor dem Austrieb. - Zeigt nach Abhieb einen guten Nachwuchs.

Formen sind:

Ginkgo bil. variegata Hort., gelbbunt. II.

" " laciniata Hort., geschlitztblättrig.

" " pendula Hort, etwas hängend. 


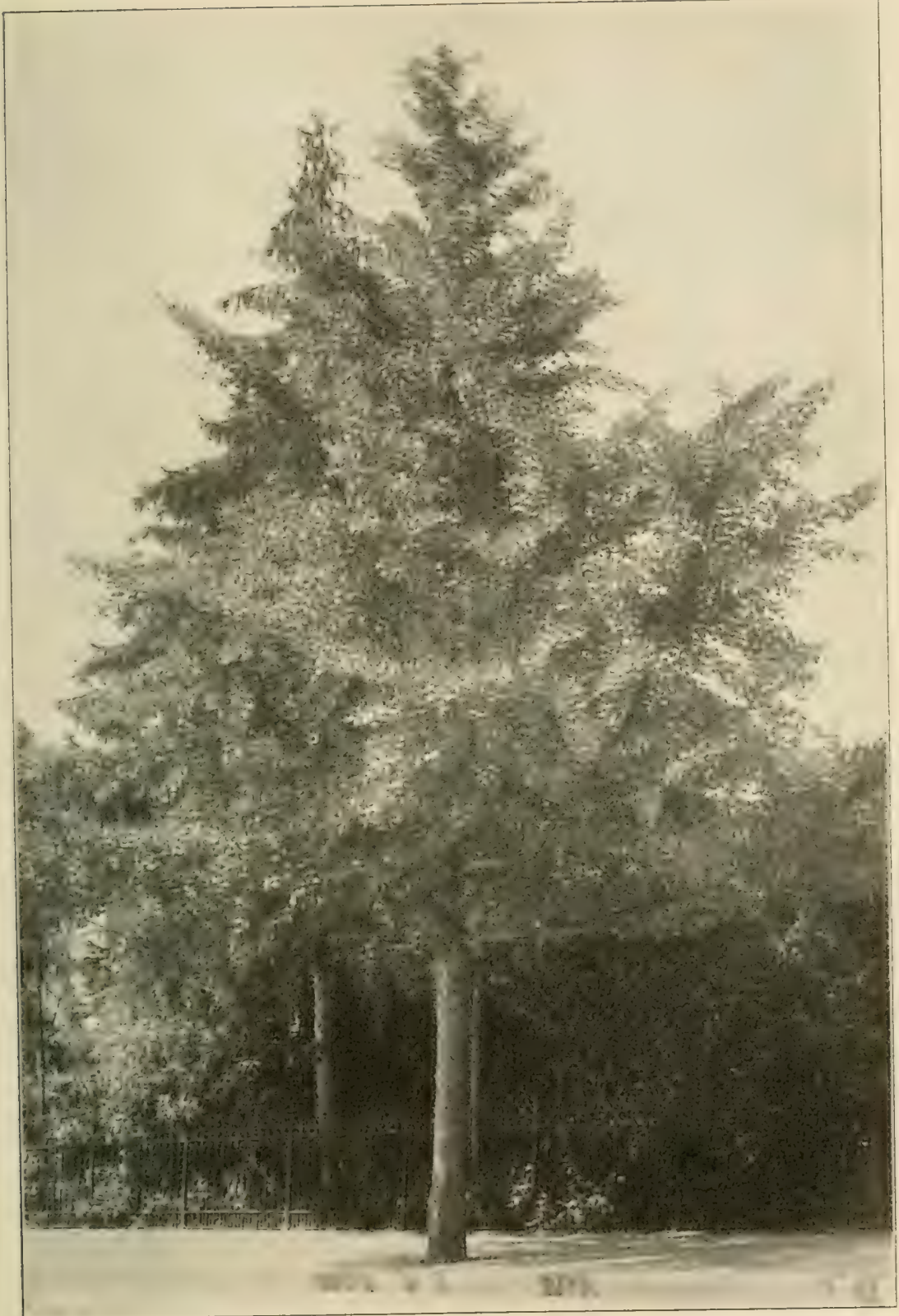

Fig. 14. Ginkgo biloba L. (etwa sojähriger Bamm). 


\section{Coniferae, Nadelhölzer. \\ I. Taxaceae,}

Taxusartige Pflanzen, Eiben-Gewächse.

\section{a) Podocarpeae,}

Stein-Eiben ähnliche Pflanzen.

Immergrüne Bäume und Sträucher mit mehr oder minder unregelmatrig gesteliten, meist ziemlich autstrebenden Ästen und Zweigen. Bliatter teils diom, schmal, borstenartig, teils lineal. teils klein und dachziegelartig sestellt, auch schuppenartig. teils lanzettlich bis laubartig und einfach oder melntach senervt. Bliiten monözisch oder diözisch, end-oder achsel-tandig: mämnliche einzeln oder zu mehreren, anch bisschelförmig, dick, länglich oder fadenförmig, mit 르 Pollensäcken: weibliche in meist kurzen, eng spiralig sestellten Ähren, mit Heischigen Schuppen, teils bracteenlos, die Fruchtschupen je eine Santenknospe tiihrend. An Stelle des Zapfens wird eine steinfrucht init fleischiger Hülle gebildet. (!)

Samen ziemlich nufartig, von harter Schale umceben. Von simtlichen Arten halten ein par im siunstigsten Fall in Region VII unter Schutz aus.

1. Microcachrys Hook, fil.

Kleinfrucht-Eibe.

Kleine Bäume, fast kriechend, mit diinnen, zypressenartigen Asten und Zweigen, schuppenförmigen, segenstïndigen Blättchen, diozischen Bliiten und länglichen, einzelstehenden. maubeerartigen Zäpfchen, aus 8-10 tleischigens schuppen. S'anen einzeln.

Microcachrys tetragona Hook. fil., Tasmanische Kle-infrucht-E. Tasmanien.

In Deutschland am hesten als Kialthauspflanze zu hehandelin.

\section{Saxegothisea Lindl.}

Patagonische Eibe oder Mahin.

Immergrine, kleine Bäune mit linealen Blättern und monözischen Bliiten. 
Saxegothaea conspicua Lindl. Auffallende patagonische Eibe. Anden Patagoniens.

VII.

Ǩleiner buschiger Baum, mit anscelneiteten In Schutz. Ästen und Zweigen, Zweireihi@ gestellten, liinglich lanzettlichen, etwas sichelförnigen, anch leicht medrehten, oben mehr hellgriinen, unten blaugriinen Blättern.

Zapfen kugelig, durch Verwathsen der Heischig wertenden Fruchtbliitter beerenartig; der Samen liegt in harter sichale. Vermehrung durch Samen unter Glas in 'Töpfen.

\section{Porlocarpus L' Herit.}

\section{(Incl. Prumnopitys Phil.) \\ Steineibe, Fuffrucht.}

Immergrine, hohe Büume, seltener Striucher, mit zerstreut, oft fast quirlartio stehenden, mehr oder minder aufstrehenden Asten und meist zahlreichen Zweigen. Bliitter wechselständi@, gegensticindi oder spiralig, lineal oder lanzettlich, fast laubartig oder wiederum schuppenartig. Blite monözisch oder diözisch, weibliche oft mit fleischigen Schuppen.

Aus der großen Zahl der Arten - ca. 40 -, welche im tropischen Amerika, tropischen östlichen Asien und den gemä̈bigten Zonen der siidlichen Halbkugel vorkommen, sind es bis jetzt nur wenige, welche in giinstigen Fiillen in Region VII im Schutz ausgehalten haben.

Sämtliche Porlocarpeen wurden in 4 Abteilungen geordnet, und zwar:

I. Nageia Gaertn. - II. Eupodocarpus Endl. - III. Stachycarpus Endl. (incl. Prumnopitys). - IV. Dacrycarpus Endl.

Podocarpus alpina R. Br. Alpen-Steineibe. (2. Abteilung.) Gebirge Neuhollands, Viktorias, Tasmaniens.

Buschiger Strauch mit abstehenden VII. Soll in IV aushalten. Ästen, sehr schmalen und $1 / 2-1^{1 / 2} \mathrm{~cm}$ langen, derben, geraden oller etwas gekrimmten, spitzen Bliittern, welche gestielt und mit einer Lüngsfurche versehen sind. Der Zapfen ist klein.

Podocarpus andina Pöpp. Andina Stein-E.; kirschfrichtige St. (3. Abteilung.) Anden Suid-Chiles.

Nittelhoher Baum mit derben, an den

VII.

Mit Schutz.

Rändern etwas eingebogrenen, kurzen, linealen, ganz kurz gestielten, dunkelgriinen Blättern und kirschenartigem Zapfen.

Podocarpus chinensis Vall. Chinesische Steineibe. (1. Abteilung.) China-Japan.

Hoher Strauch mit schmallanzettlichen,

VII.

Mit Schutz.

mittelgrofen, an den Riudern eingebogenen und mit einem

Schelle, Koniferen. 
Mittehnerr versehenen, oben hell-, unten bläulichgruinen Blättern. Zapfen länglichrund.

Podocarpus macrophylla D. Don. (nicht Wall.). Großblättrige St.-E. (2. Abteilung.) Japan.

Mittelhoher Baum, gelbrindig, dicht VII. Mit Schutz. bezweigt, mit trocken lederartigen, geraden oder kaum gekrümmten, lanzettlichen, oben glänzendgrünen, unten blaßgrünen, starkgenervten Blättern und länglichrunden, erbsengroßen Zapfen.

Podocarpus Nagi (Mayr') (Nageia R. Br.) Japanische St.-E. (1. Abteilung.) Gebirge Japans.

Ziemlich hoher Baum mit wohlriechenVII. Mit Schutz.

der Rinde. Blätter gegenständig oder wechselständig, breit lanzettlich, spitz. Zapfen rund, diunnfleischig.

Podocarpus cuspidata Endl. Eso. (1. Abteilung.) grandifolia Endl. Japan u. China. (1.Abteilung.)

Es liegt nahe, daß die Podocarpeen, deren es eine grooje Anzahl Arten gibt, in den milden Lagen teilweise aushalten. Versuche in dieser Beziehung sind aber wohl noch sehr wenige gemacht worden.

Vermehrung von Portwearpus durch Samen, durch Stecklinge im Pflanzenhaus und durch Pfropfung auf eine möglichst verwandte Art. (Die Pfropfung auf Trurus ist zu verwerfen.)

\section{Dacrydium Sol.}

(Incl. Pherosphaera Avch. und Lepidothamnus Phil.). Harz-Eibe.

Immergrine hohe Bäume, bis herab zum niederen, kriechenden Strauch; dementsprechend Bau und Stellung der Aste sowie Zweige sehr verschieden. Bliiten diözisch, selten monözisch; weibliche Blite einzeln, endständig, mit breiter, schalenförmiger, auch fast hohl gebildeter Fruchtschuppe, männliche Bliite kugelig, dichtstehend, mit 2 Pollensäcken. Blätter klein, spiralig. dicht gestellt, ganz schmal oder borstenförmig. Samen in diinner, etwas fleischiger Huille (Zapfen), länglich-rund.

Sämtliche Arten stammen aus Tasmanien, Neu-Seeland und dem malayischen Gebiet. Alle sind in Deutschland $11 \mathrm{icht}$ winterhart.

Eine Art hat in England 12-15 $\mathrm{C}$ ansgehalten, welche hier also kurz genannt sein soll.

Dacrydium Franklini Hook fil., Franklins H.-E. Tasmanien. Hoher, pyramidal wachsender Baum, mit ausgebreiteten, später iilserhängenden 
gestellten, länglich runden, liast rautenförmigen, schwach spitzen, gliazend dnnkelgrimen, sporadisch weî punktierten Blättern. Steinfrucht klein.

5. Phyllocladus Richard.

Blatt-Eibe.

Immeroriune Bäume oder Strïucher, mit aufstrelsenden, abwechsehnden oder quirlförmigen und horizontal abstehenden Asten, sowie blattartigen Kurztrieben (Pliyllodien), zur Winterszeit, wie auch im ailteren Zustand sich rötlich-griun his rötlich-braun färbend. Die echten Blätter sind schuppenförmig. Die Frucht (der Zapfen) ist steinfruchtartig, indem der mit einem knochenharten Mantel versehene Samen voll einer krugförmigen, fleischigen Huille umgeben ist. Keimling mit zwei Samenblättern.

Das wertvolle Holz ist schwerer als Wasser; die Rinde enthält reichlich Tanin und roten Farbstoff.

Es sind Pflanzen von Tasmanien, Neuseeland und Borneo; alle in Deutschland nicht winterhart.

Es wären zu nennen:

Phyllocladus trichomanoides Don. (Fig.15.) Neuseeländische Blatt-E. Baum von 30 in Höhe aus Neuseeland.

Phyllocladus rhomboidalis Rich. Rautenförmige

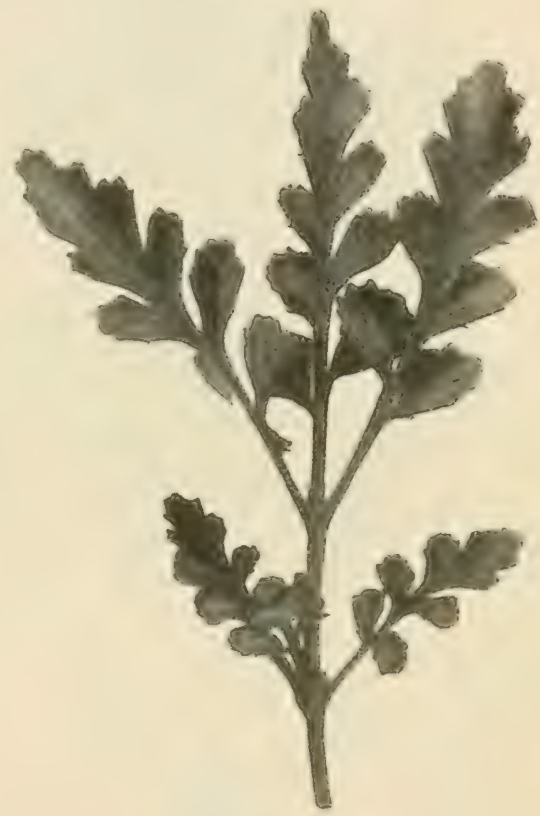

Fig. 15 .

Phyllocladus trichomanoides Don. Bl.-E.

Syn: Phyllocladus aspleniifolia Hook.

Baum von $25 \mathrm{~m}$ Höhe aus Tasmanien.

Phyllocladus alpina Hook. Alpen-Bl.-E. Kileiner Busch ron den Gebirgen Neuseelands.

Phyllocladus hypophylla Hook. Bam mittlerer (iriblie von den Gebirgen Boneos. 


\section{b) Cephalotaxeae.}

Kopf-Eiben ähnliche Pflanzen.

Immergrine, kleine Binme, nit ausbreitender Ḱrone, ebenfalls sich ansh)reitenclen, yuirlig gesteilten, wagrechten und auch iiberhängenden Isten, zweireihig, meistens gegenständig sowie wechselständig gestellten Zweigen. Blätter wechselständig,

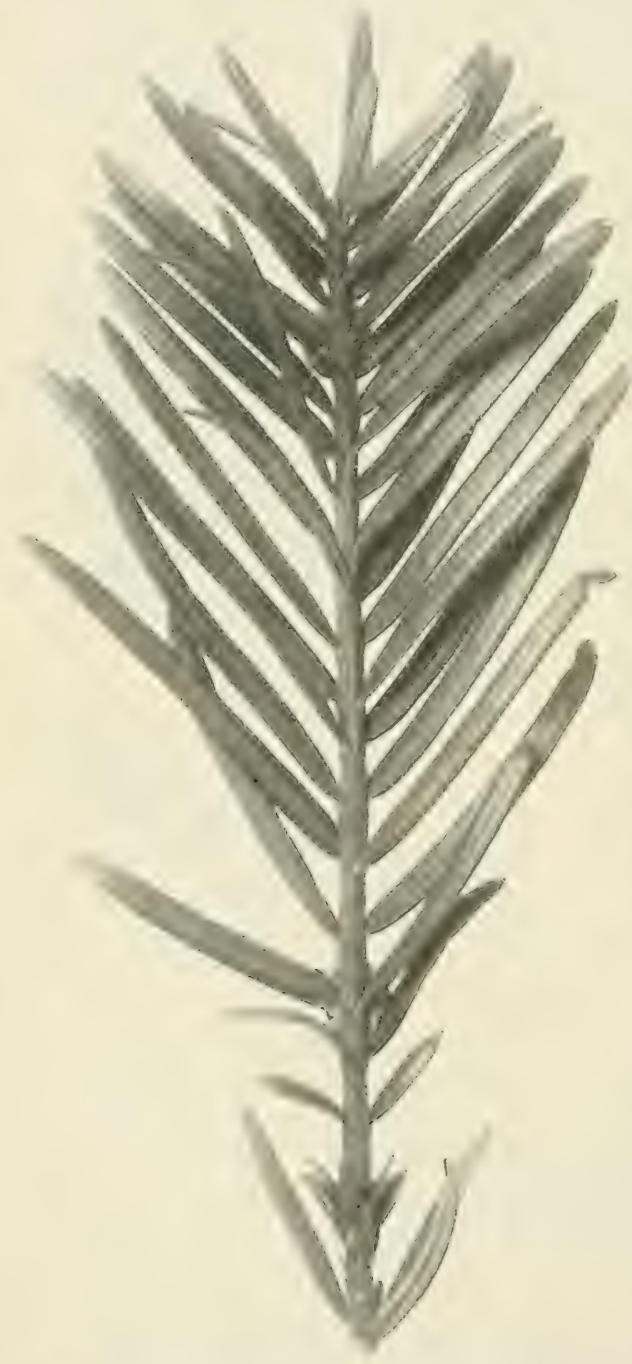

Fì. 1\%. Cephalotaxus peduneulata S, u. Z. selten gegenständig, fast zweireihig, kurz gestielt und unten am Trieb herablaufend, dabei lineal, spitz, auch fein gekrümmt, einnervig. Blüte diözisch, sehr selten mo-

nözisch; männliche seitenständig, dicht gestellt, in Köpfchen, weibliche ebentalls seitenständig, bezw. wechselständig, zu 2-3 zu einem Köpfichen vereinigt. Die zur Reifezeit verkïmmerten Fruchtblätter tragen 2 nackte Samenknospen, welche dann von einel. fleischigen, pflaumenartigen Hülle (Integument) umgeben werden. Der Samen hat einen sehr harten und einen häutigen Mantel.

\section{Cephalotaxus}

Siebold und Zuccarini. Kopf-Eibe.

\section{Cephalotaxus peduncu-} lata Sieb. und

Zucc.

Ge- Liebt Höhen-

stielte K.-E. lagen, bei ge- schütztem und Gebirge Ja- halbschattigem pans. (Fig. 16).

Syn.: Cephalotaxus Harringtonia C. Koch. T'axus Havingtonia Forbes. 
In der Heimat schöner. kleiner lbaum von fi-s m Höhe, bei uns hoher Strauch. mit breiter Krone, an cien Ästen bramer, an den Zweigen dunkelgriner Rinte, zahlreichen, puirlig stehenden, auslatenden und auch etwas iiberhiangenden Ästen und meist gegenstindio in zwei Reihen gestellten Zweigen. Blitter ebenfalls zweireihig, wechselstintie, kurz gestielt. $2-f^{1}$ : cm

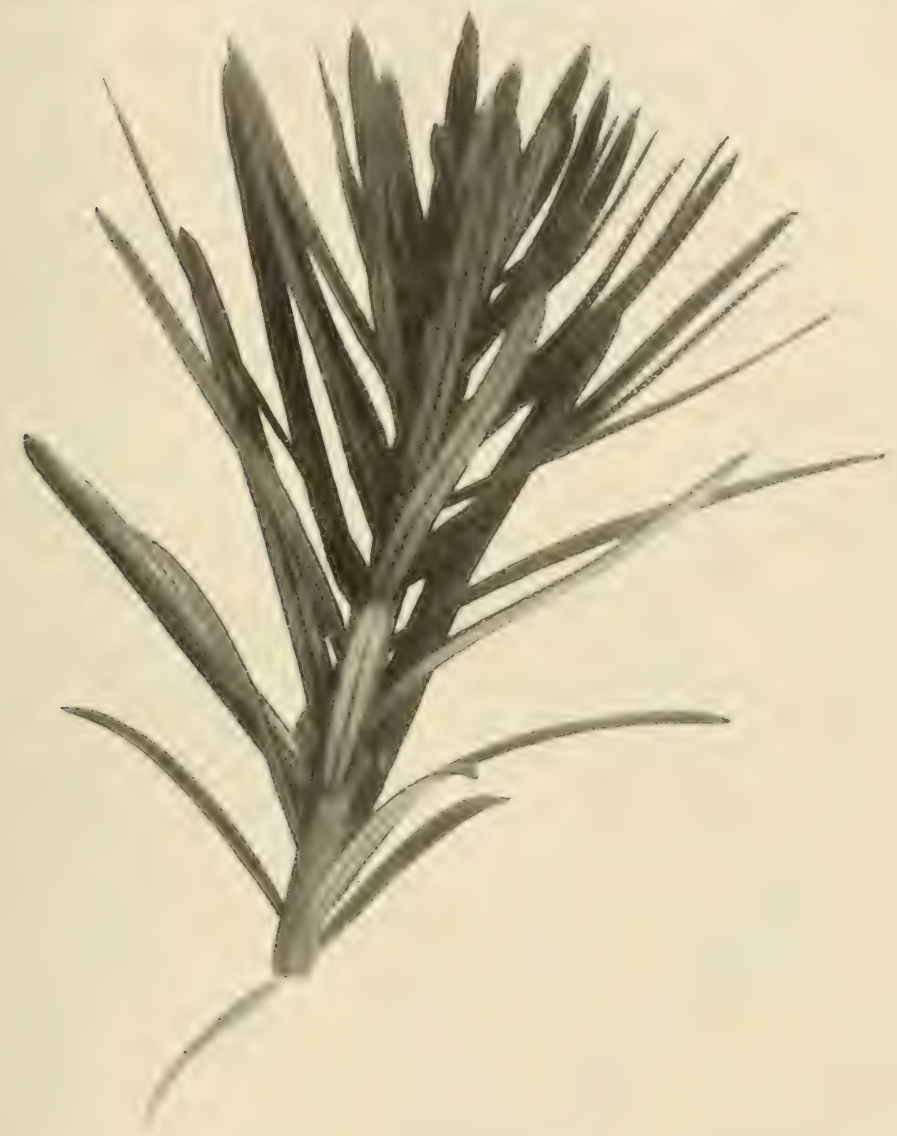

Fig. 17. Cephalotaxus pedunculata S. u. Z. fastigiata Carr.

lang, 2-3 $3^{1}, 2 \mathrm{~mm}$ breit, etwas sichelförmig, spitz, oben glinzendgriun, mit starkem Mittelnerven, unten mit zwei weibbliunlichen spaltöffnungslinien. Knospen mit Schuppen bekleidet: gellhicher Austrieb. Die einzelne (auch 2-3), brimliche Steinfrucht auf ziemlich langem stiel wird 2-3 cm lang, $1^{1 / 2} \mathrm{~cm}$ breit und ist fleischig. 
Termehrum durch Samen unter Glas in Kistchen orler Töpten, der aber baldigst nach der Reife angesät oder stratifiziert werden muß, obwohl er bis zum zweiten Jahr liegen bleibt, ehe er aufgeht. Trocken aufbewahrter Samen verliert nach einem halben Jahr schon seine Keimkraft. Stecklinge wachsen gerue, geben buschige, aber - mit Ausnahme von Cephalot. pedunculata fastigiata - selten schöne Kopfpflanzen. Pfropfung im Friihjahr oder August mittelst Kopftrieben auf die Stammform, auf Stecklingspflanzen oder auf Taxus baccata.

Formen sind:

Cephalot. peduncul. sphaeralis Mast., etwas großblätterige Form mit runden Friichten.

Cephalot. peduncul. fastigiata Carr. (Fig. 17.) Viel unstrittene, hreit säulenförmige Form, mit aufrechten, langen Ästen, sitzenden, (!) wechselstindigen, fast spiralig rings (!) um den Trieb gestellten Blättern.

Syn.: Cephalotaxus koraiana Sieb. und Zuce.

\section{Hort. drupacea fastigiata Maxim. \\ Podocarpus koraiana Sieb.}

Cephalot. peduncul. fastigiata aureo-variegata Hort., älmlich voriger', aber gelbbunt.

Cephalot. peduncul. nana compacta Hort, etwas gedrungen und buschig wachsend.

Cephalotaxus Fortunei Hook. (nicht Hort.). For- III (IV) tumes K.-E. Nord-China, Japan. (Fig. 18.) Geschützter und Schöner Barm in seiner. Heimat, von 15-20 m halbschattiger Höhe, Kunmert in Rinde quirlig und wagrecht gestellte Rince, quirlig und wagrecht gestellten, zuer'st aber unfruclitbarem aufstrebenden, spaiter etwas ïberhängenden $\ddot{A}$ sten, mul sand. hellgrinen, ebenfalls etwas hängenden, nahezu zweizeilig g'estellten Zweigen. Blaitter groß, an ïppigen Jungpflanzen bis 9 cm lang und fast 1 cm breit (an älteren Exemplaren kürzer und schmailer), scharf gespitzt, lanzettlich, leicht gekrümmt, kurz gestielt, derb, oben gliuzend dunkelgriun, hervortretender Mittelnerv, unten mit zwei weibbläulichen Spaltöffnungshinien. Knospen klein, mit langen feinen Schuppen bedeckt. Die Frucht ist reif grimlichbraun, iiber $2 \mathrm{~cm}$ lang und $1-1 \frac{1}{2} \mathrm{~cm}$ breit. Vermehrung wie bei erster Art.

Formen sind:

Cephalotaxus Fortunei masculina, die männliche Form. feminina, die weibliche Form, etwas kleinblätteriger.

Cephalot. Fortunei robusta Hort., kriaftige, etwas mehr aufsteigende Form. 


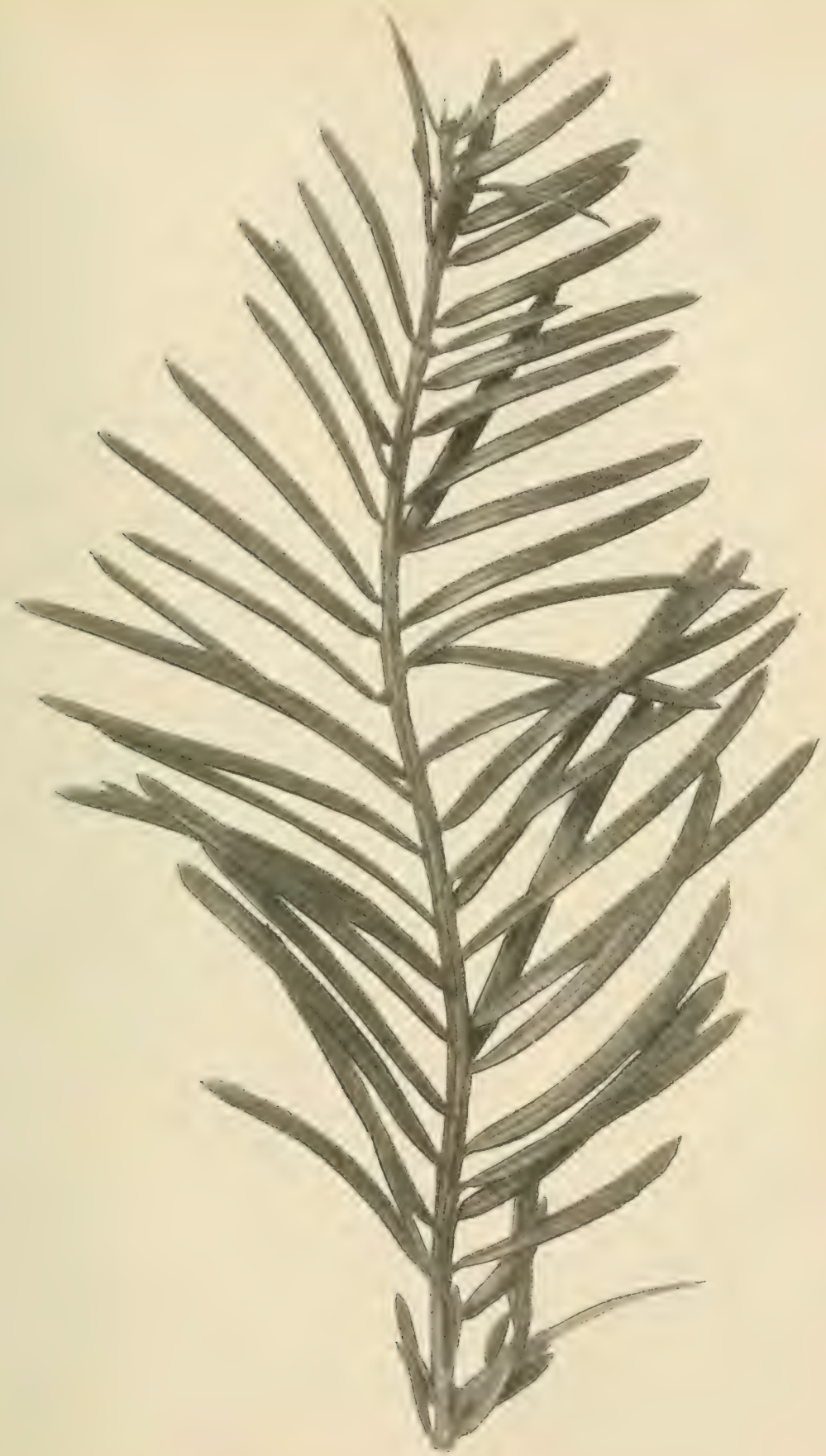

Fig. 18. Cephalotaxus Fortunei Hook. 
Cephalot. Fortunei lanceolata Beissu., starkwiichsig, langblätterig, Blattunterseite mehlweißfarbig.

Syn.: Cephalotaxus lanceolata Hort.

Cephalot. Fortunei-drupacea Hort, eine zwischen dieser und der näclistfolgenden Art stehende Form.

Cephalotaxus drupacea Sieb, und Zucc. Stein- IV (V) fríchtige K.-E. Japan. Beigeschütztem

Schöner, in der Heimat 7-10 m hoher Baum, halbschattigem mit quirlig gestellten, aufsteigenden Ästen, zahlreichen wechselständigen, nicht genau zweireihig gestellten, sonst wie die der rorigen Art in Form und Farbe gleichen, höchstens kiirzer gespitzten Blättern. Auch die Frucht gleicht der der vorigen Art.

Diese selten in Kultur befindliche Kopfeibe gehört vielleicht als Form zu Ceph. Fortunei.

Vermehrung etc. wie bei ersterer.

Formen sind:

Cephalotaxus drupacea Harringtoniana Miq. fastigiata Car's, säulenförmig.

Cephalotaxus Griffithii Hook. fil. (nicht Olivier). Griffiths K.-E. Mittleres China.

(VII ?)

Strauchförmige, dem C'ephalot. Fortunei ähnliche Art mit schmalen, etwas sichelförmigen, $6 \mathrm{~cm}$ langen und $3-4 \mathrm{~mm}$ breiten, oben glänzendgrimen, mit starkem Mittelnerv versehenen, unten auffallend mehlweißen Blättern. Frucht $3 \mathrm{~cm}$ lang, 1/2 cm breit. Sehr selten in Kultur, jedenfalls nicht in Baumschulkultur, weil nicht leicht winterhart.

Auch die folgenden Arten sind wohl nur Kalthauspflanzen.

Cephalotaxus Mannii Hook fil., von Siidwest-China.

Olivieri Mast., von Mittel-China.

Syn.: Cephalotaxus Griffithii Oliv.

\section{c) Taxeae.}

Eibenähnliche Pflanzen.

Immergriule Bïume, auch Sträucher, mit oft sehr grofien, breiten Kronen, abstehenden, teils vechselständigen, teils auch quirlständigen Ästen, hauptsächlichst riemlich zweizeilig stehenden Zweigen, sowie meist zweireihig stehenden, spiralig angehefteten, al wechselnden, kurz gestielten und linealflachen Blättern. Bliten monözisch und diözisch; männliche achselständig, in Köpfchen, weibliche meist einzeh, mit kleinen, becherartigen auch fleischig werdenden Samenschuppen, welche die einzelne Samenknospe, bezw. später den ziemlich grofen Samen, mehr oder minder umhiillen. 
7. Torreya Arnott, Torreye (Nuß-Eibe). (Caryotaxus Zuccarini).

Immergriue, in ler Heimat $10-30 \mathrm{~m}$ hohe Biiune, mit ausgebreiteten, fast schirmfömigen, zuerst pyranidalen Kóronen, quirlförnig und anch wechselständig gestellten, horizontal abstehenden Ästen, sowie ebenfalls abstehenden, ziemlich gegenstiundig, oder auch fitst zweizeilig gestellten und meist leicht überhängenden Zweigen.

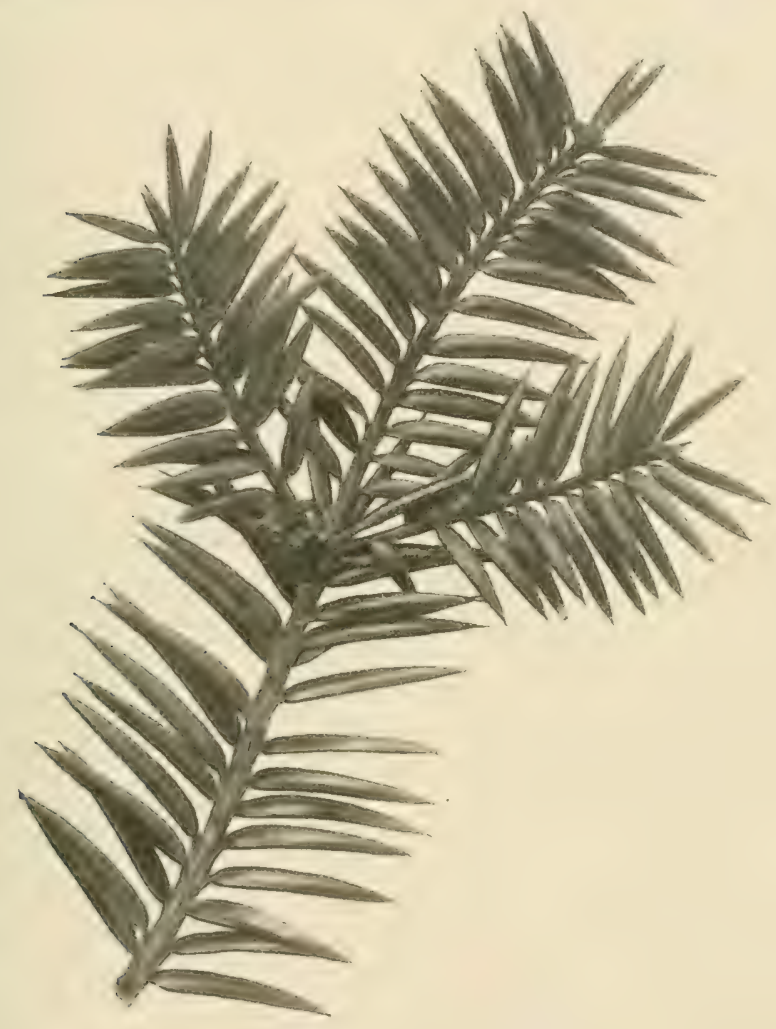

Fig. 19. Torreya grandis Fort.

Blätter eng wechselstiandig, zweizeilig, lanzettlich, zum Teil etwas sichelfürmig, $2-3 \mathrm{~cm}$ lang und $3-4 \mathrm{~mm}$ breit, mit kurzem und gedrehtem Stiel, scharfspitzig, derb, oben dunkelgriun, mit Mittelnerv versehen, unten hellg'iin oder bläulich-weifo.

Blïten diözisch; mämnliche in Kätzchen, achselstiandig: weibliche ebenfalls achselstindig, oft $2-3$ beisammen, mit fleischigen Schuppen und einer dickfleischigen Samenschuppe. 
Der nufartige Sinnen mit harter. Schale steckt in pflannenationer Unhüillung. Keimling mit 2 Samenblättern.

Torreya glrandis Fort. Grofie T. Nordchina (Fig. 19). v v (IV) Syn.: Caryotaxus grandis Hochst. Jung empfindPraichtiger Banm in der Heimat, bei uns etwas lusteuchte triandichsigel strauch, mit weit ausgebreiteter Krone, Lage, bei halberaubramer Rinde, quirlstiandigen Asten, ziemlich gleicheuchtem geerenstandigen und etwas iiberhängenden Zweigen, vorteil. sowie wechselständig zweizeilig stehenden, derben, schmallanzettlichen, rasch zugespitzten, his $3 \mathrm{~cm}$ langen und $3-t+1 n n$ breiten, kurzestielten, oben glinzendgrinen mit Mittelnerv versehenen, unten hlaforinen Bliittern. Die ca. $2^{1} / 2-3 \mathrm{~cm}$ lange und $1^{1} / 2$ bis nahezu $2 \mathrm{~cm}$ dicke, fleischige steinficucht ist oval, zugespitzt, reif gelblich.

Termehrun durch Samen unter Glas in Kistchen oder Tijpfen: sofort nach der Reife anzusäen oder zu stratifizieren, da der Samen bald die Keimkraft verliert; liegt bis zum zweiten Jahn. Stecklingsptlanzen geben wenig gute, kopftrielige Exemplare. Pfroptung anf die Stannform, anf Stecklinespflanzen, orler auf Cephalotaxus. Ptropfungen auf Taxus baccata sind nicht zu empfehlen. Alte Exemplare ertragen das TerpHanzen schlecht.

Torreya nucifera ,ieh, und Zucc. Nußtragende T. Gebirge Japans.

Syn.: Caryotaxus nucifera Zuc.c.

Ton dieser in der Heimat etwa $10 \mathrm{~m}$ hohen, baumförmigen Art besitzen wir his jetzt nur die weibliche Pflanze. Rinde luraun und ablösend, Aste ansbreitend. quirl- mul wechselstandig; Zweige ziemlich zweizeili@ gestellt. Die ebenfalls zweizeilig sestellten (bein Zerreiben -mangenehm riechenden), schmallanzettlichen. of etwas gekrimmten, kurzgestielten, $2-3 \mathrm{~cm}$ langen und $3-4 \mathrm{~mm}$ breiten Blätter sind derb, oben glänzendcriun, mit Titteherr versehen, unten bläulich-weil) gezeichnet. Erucht oral his linglich, $3_{12}^{1} \mathrm{~cm}$ lang und $1^{1 / 2} \mathrm{~cm}$ breit, fleischig, braun, übelriechend.

Der Samen liefert ein den Speisen zuzusetzendes Öl, das aber auch arlstringierend wirkt; das Holz ist wertwolles Nutzholz. Vermehrung etc. wie bei erster Art.

Torreya taxifolia Arn. Eibenbliatterige T. StinkEibe. Florida.

(VII?)

Syn.: Caryotaxus taxifolia Henk. und Hochst.

Torreya temifolia Hort. Rovelli.

In der Heinat kleiner Bamn mit quirlstindigen İsten, nahezu zweizeilicen Zweinen, chenso westellten (heim Zerreiben 
ibbeliechenten), schmalen, 2-3 cm langen, 2 mm breiten, derben, oben loblaft grinen, mit Mittelnerv versehenen, unten blanlich-

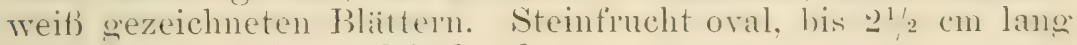
und $1^{1} / 2 \mathrm{~cm}$ breit, iibelriechend.

Vermehrung wie bei erster Art. Das Holz ist wertrolles Nutzholz.

seln selten in Kinltur. wohl in Dentschlaud anch nicht winterhart (?).

Eine noch emplindlichere, an den jungen 'Trichspitzen weibe Form ist:

Torreya taxifolia argentea Beissn.

Syn.: Torreya temifolia argenter Hor't. Rovelli.

Torreya californica Tor'r. Kalifornische oder V (IV ?) Muskat-T. Sierra Nevada Kaliforniens.

Syn.: Torveye Myristica Hook. fil. Caryotaxus Myristica Henk. und Hochst.

Feuchter, halbschattiger Standort.

Tittelhoch bis hoch werdender Baum in der Heimat, nit

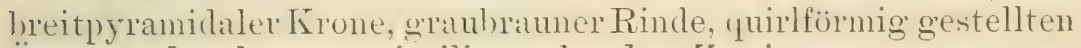
Ästen und nahezu zweizeilig stehenden 'Zweigen.

Die beim Zerreiben scharf riechenden, ziemlich zweizeilig gestellten, schmallanzettlichen, 5 cm langen und 3 mm breiten, scharfoespitzten, derben Blätter stehen ant' kurzen stielen, sind oben lehhaft griin, zeigen einen Mittelnerven und unten weibliche Fiarbung. Die Steinfrucht ist elliptisch, $t$ cm lang und 2 cm breit, scharfiechent, etwas fleischig, fast hart. Sie wird als .,kalifornische Muskatuutj" den Speisen zugesetzt.

Vermehrung etc. wie bei erster Art.

Auf Wilhelmshöhe bei Kissel entstand ein Bastard:

Torreya nucifera $q \times$ Torreya grandis $\succsim$.

Eine weitere wohl noch nicht in unseren Tulturen betindliche und jedenfalls in Deutschland auch nicht winterharte Art ist:

Torreya Fargesi Franch., aus China.

\section{Taxus Tournefort, Echte Eibe, Eibenbaum.}

Tmmeroriuse, mittelhohe Bäume oder hohe Striucher, mit breiter, dichter Krone, roter, in grauen Stiicken ablösender Rinde, abstehenden, zerstreut aufgebauten Ästen md kurzen, etwas hängenden Zweigen.

Bliitter wechselstindig und fast zweireilig, breit lineal, auch sichelförmig. zugespitzt, auf kurzen und gedrehten Stielen, mit Mittehner'v. Bliiten diözisch; männliche achselständig, in nahezu runden Kätzchen, Antheren zahlreiclı; weibliche einzeln, achselstandig', dicht mit Huilschuppen versehen, die Simen- 
schuppe eine Samenknospe umhïllend, spüter zum becherartigen, fleischigen Mantel vergrößert, welcher dam den mit harter Schale umgebenen Samen ganz odel nahezu unhiullt, ohne demselben - außer unten - angewachsen zu sein.

Keimling mit zwei Samenblättern.

Taxus baccata L. Eibe, Eibenbaum, Taxbaum. Europa, Nordafrika, Kraukasus, Armsnien, Himalaya, freistehend II Ost-Asien, China, Japan, Nord-Amerika (Fig. 20-22), Jung empfind-

Syn.: Taxus meifera Wall.

\section{Wallichiana Zucc.}

Charakteristischer, schöner, hreiter Baum oder

Strauch, mit zerstrent aufgebauten Ästen und kurzen, $\begin{gathered}\text { Winters. Liebt } \\ \text { kalkhaltigen }\end{gathered}$ etwas hängenden Zweigen. Die ohen dunkelgrinen, gegen scharfe Winde und starke Sonnenbestrahlung, miten blaßgriuen, mit einem Nitteherv versehenen, flachen, 2 bis $3 \mathrm{~cm}$ langen und $2-2^{1 / 2}$ mm breiten, dichtstehenden, wechsel-

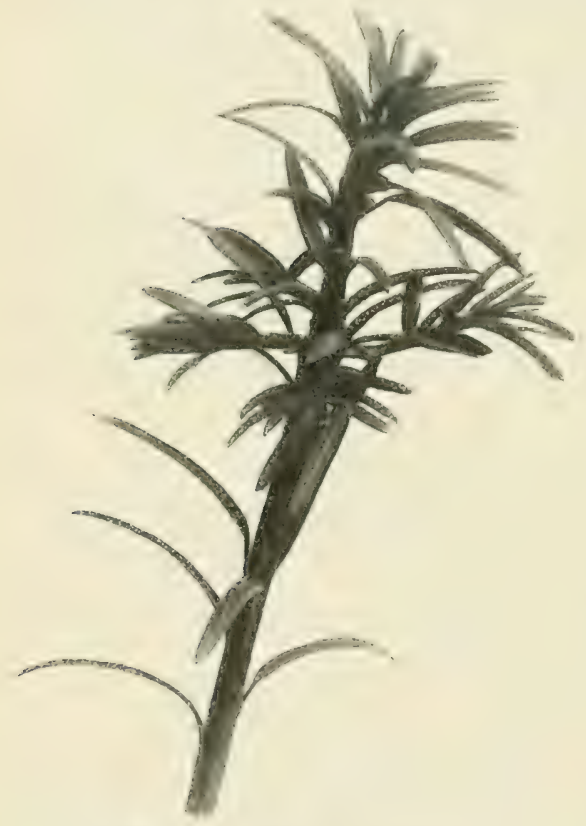

Fig. 20. Tuxus baccata L. Junger Trieb. seiti $\underline{\text { und }} z$ weiseitig gestellten Blätter haben kurzen griinlichen Stiel, sind ziemlich starr, dabei kurz und stachelspitzig. Knospen rundlich, beschuppt.

Der zuerst wie in einer Eichelschiissel sitzende, schwarzbraune Samen wird später von einer bei der Reife weichen und hochroten, becherartigen Umhiillung(Arillus) vollständig: bedeckt.

Den beiden Samenblättern des Keimlings folgen spiralig gestellte Erstlingsblätter.

Bei Abhieb treibt Taxus reichlich Schößlinge, auch ersetzt er durch Nebenzweige ziemlich rasch den abgegangenen Mitteltrieb. Daß die Eibe den Schnitt gut erträgt und durch Nachwuchs rasch die Liicke anszufiillen sucht, ist selbst dem Laien bekamnt, denn die Hecken, Wände und selbst Figuren ans Taxus spielten friiher eine grobe Rolle in den Gairten. Auch das Terpflanzen erträgt Taxus gut, doch darf er nicht aus dem Schatten in die Sonne gepflanzt werden. 
Vermelurung aus Samen, der bald gesit werden mu1, da er bei trockener Aufhewahrung nach einem lialben Jahr oft

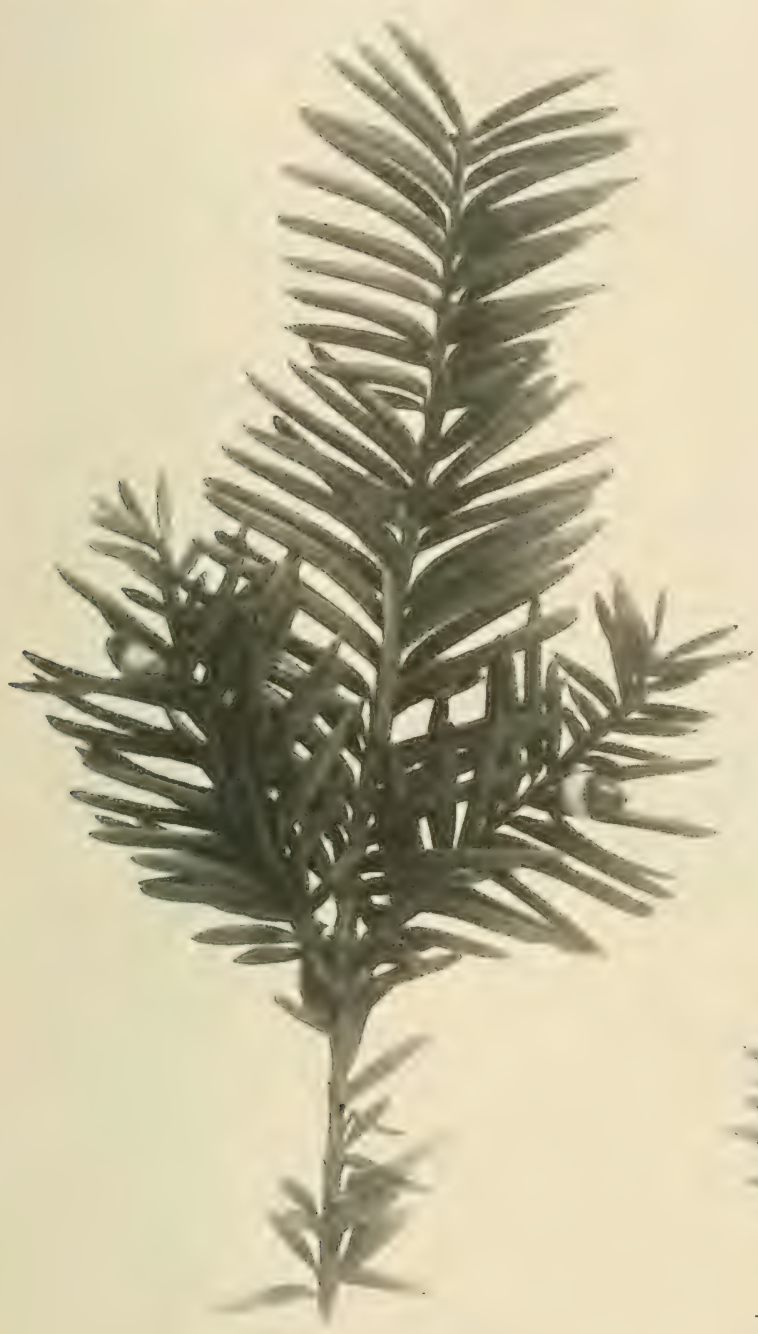

Fig. 21. Taxus baccata L. Fruchtender Trieb. schon die Keimkraft verliert; er keimt aber erst im nächstfolgenden Tahr. Stecklinge sind nul von Kopftrieben zu empfehlen, da die Seitenstecklinge meist nur breite Buische geben; ebenso sind die auf die Stammform oder Stecklingspflanzen zu setzenden Pfropfreiser' nur den Kopftrieben zu entuehmen.

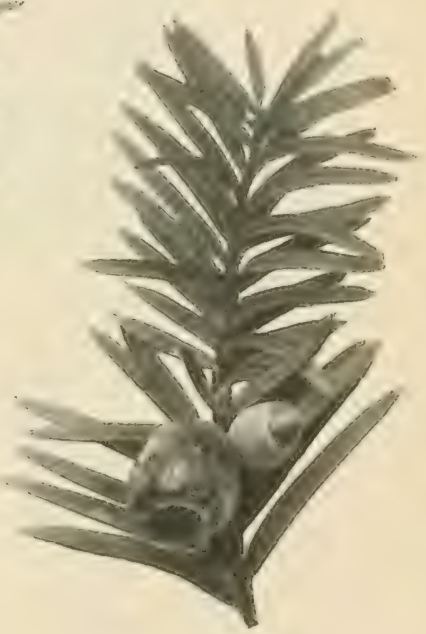

Fig. 22. Taxus baccata L. Junge und ganz reife Frucht. ('Lapfen.)

Die Eibe ist ein altes Find unserer deutschen schattigen Wälder, etwas langsam wiichsig, in verhältnismä13i@ kurzem, dickem Stamm oft ein Alter von 1000 und mehr Jahren dar- 
stellend. Der schnell produktiven Nenzeit sind diese alten Denkmäler fast alle zum Opfer gefallen.

Das iiberaus harte, schwere, zähe, außen gellhliche, imnen rotbrame Holz wird von Drechslern sehr gesucht, es findet gebeizt (neben dem des Cytisus Laburnum) als „deutsches Ebenholz" gute Verwendung.

Blätter und Samen enthalten ein scharfes Alkaloid, Taxin, hesonders die Blätter der mämnlichen Pflanze, welche auch als Abortivmittel beniitzt werden, dagegen ist der purpurrote oder auch gelbe - Arillus, die fleischige Umhiullung des Samens, nicht giftig, höchstens etwas abführend.

Taxus baccata ist in seinen Formen äußerst variabel und reichhaltig.

Taxus baccata major Hort., iippig und raschwachsend. tige Form.

microcarpa Trautv. und Maxim., kleinfrüch-

Taxus baccata macrocarpa Hort., großfruichtig.

fructu luteo Loud., gelbfriichtig.

schmalen Blättern.

linearis Carr., mit gelblich-grünen, langen,

Taxus baccata albo-variegata Hort. Späth, weißbunt. aureo-variegata Hort., gelbbunt.

elegantissima Hort., junge Triebe goldgelb.

Syn.: Tax"us bacente anreo-elergantissima IIort. III (II)

Taxus baccata Washingtoni Hort,, goldbronzen, gedrungen. wüchsig." elvastonensis aurea Hort., goldgelb, gedrungen

Taxus baccata semperaurea Ottol. und Hooftm., goldgelb, dichtzweigig.

Taxus baccata glauca Carr., dunkelblau-griune Form. pyramidalis Carr., breitpyramidal wachsend. intermedia Carr., licht gebaute Form (ein Sämling" von Taxus bacc. fastig).

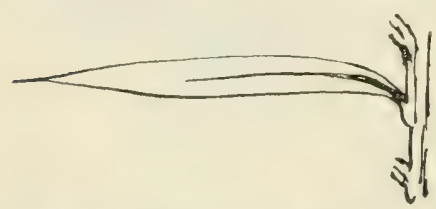

Fig. 23. Einzelnes Blatt von Tuxus baceata L. cuspidata Carr. (Vergrößjert.)

Taxus baccata horizontalis Knight., in Ästen und Blättern licht gebaute Form, die Blätter auch oft noch gekrümmt.

Taxus baccata recurvata Carr., breitgebaute, auffällige Form, mit oft iibergebogenen Ästen und riickgekriimmten Blättern.

Taxus baccata Jacksonii Gord., breitgebaute Form mit meist übergebogenen Ästen und Zweigen, sowie dichtstehenden, einwärts gekrimmten Bliittern.

Taxus baccata cuspidata (iurr. (Fig. e:3) (vielfach noch als (igene Art betrachtet), auffällige, aufwärts strehende, ziemlich 
dichtwiichsige Form, mit derben, leicht sichelförmigen, an den Rïndern etwas umgebogenen Bliittern, welche auch noch eine schwärzliche Spitze (!) zeigen; Blattstiel gelb his gelbbräumlich.

Syn.: Taxus cuspidata Sicb. und Zucc.

Taxus baccata cuspidata formosana Pilger.

Davisii Hort, aufrecht, diumadelig.

. . " Dovastoni Carr., interessante, prächtige Form, mit quir]fürmig" stehenden, überhängenden Ästen und Zweigen, welche vegetativ nur aus Kopfstecklingen vermehrt werden sollte, da sie sonst einen breiten Busch bildet.

Syn.: Cephalotaxus umbraculifera Sieb.

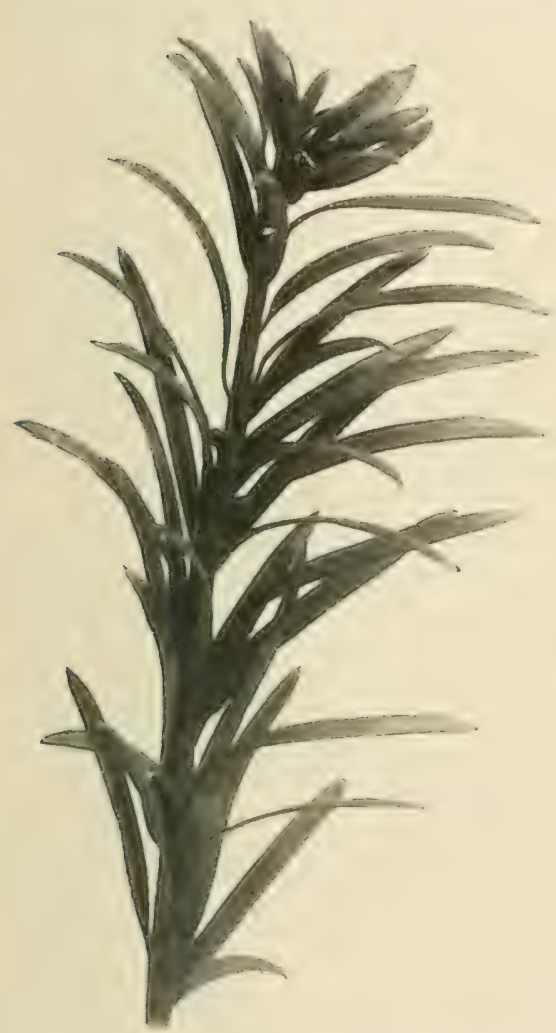

Fig. 24. Taxus baccata L. fastigiata Loud. Junger Trieb.

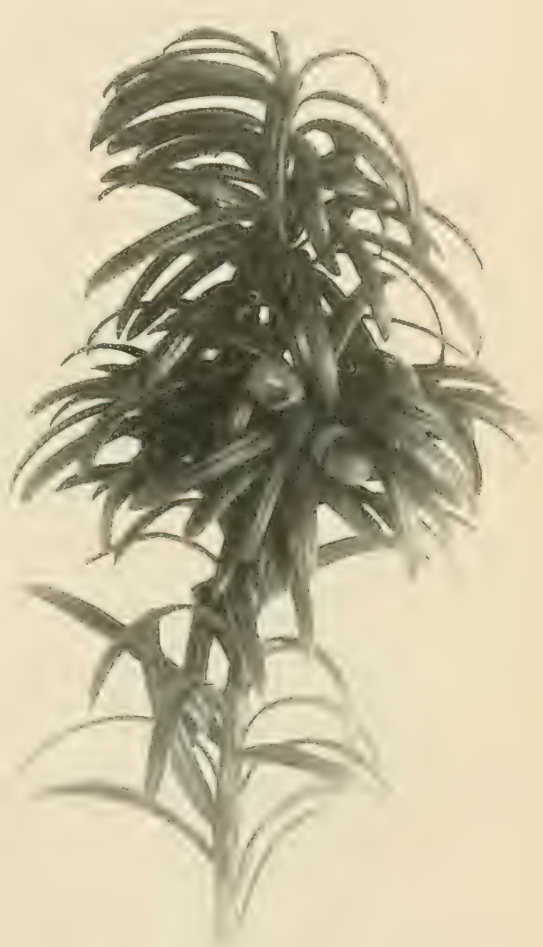

Fig. 25. Taxus baceata L. fastigiata Loud, Fruchtender Trieb.

Taxus baccata Dovastoni aureo-variegata Beissn., ithnlich voriger, goldbunt.

Syn.: Taxus baccata Dovastoni pendula variegata Hort. 
Taxus baccata gracilis pendula Hort., ïberhängend, zierlich.

Taxus baccata pendula gratiosa Orer., stürker iberlängend als vorige:

Taxus baccata pendula variegata Hort. S.-L., gellbunt. erecta Loud., aufstrebender Strauch, dichtwüchsig, schmalblätterig.

II (III)

Taxus baccata erecta glauca Hort., wie vorige, bläulichgruin. gelb-bunt. aureo-variegata Hort., wie erstere, hell-

Taxus baccata imperialis Hort., aufstrebende, schlanke Form, etwas kleine Blätter.

Taxus baccata conica Hort., schmal pyramidal wiichsig.

Nedpath Castle Hort., breit säulenförmig, langzweigig mit blaugrünen Blättern.

Taxus baccata fastigiata Louıl. Irländische Säulen-E. II (Fig. 24 u. 25).

Syn.: Taxus hibernica Macliay.

baccata libermica Hort.

Etwas langsam wiichsige, steif aufrechte, siulenförmige, ganz charakteristische Form, nit rings um den Zweig gestellten, (!) bogig gekriummten, schmalen, oben gekielten, dunkelgriinen Blättern.

Die Sämlinge dieser Form zeigen ziemliche Abweichungen und nähern sich sehr der Stammform.

Taxus baccata fastigiata nova Hort. Tollert, kräftiger als vorige, winterhart.

Taxus baccata fastigiata aurea Stand, gelbe Form, III (IV) nur noch einen griinen Streifen auf den Blättern zeigend.

Taxus baccata fastigiata aureo-variegata Hort., goldbunt.

III (IV)

Taxus baccata fastigiata aureo-variegata compacta Hort, wie vorige, doch gedrungen wüchsig.

III (IV)

Taxus baccata fastig. aureo-marginata \pm (Beifin.), mit gelbrandigen, rings um den Zweig gestellten Blättern.

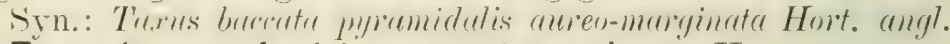

Taxus baccata fastigiata argenteo-variegata Hort., weißbunt.

Taxus baccata columnaris Carr., goldbunte, kleinblätterige, schmale Süulenform, (Simling von Tax. bacc. fastigiata).

Taxus baccata cheshuntensis Gord., blaugriune Sïulenform, mit um den Zweig gestellten Blïttern! (Ebenfalls Sämling von Tax. bacc. fastig.)

Taxus baccata Blue John Hort. angl., ähnlich voriger, die blaue Färbung aber stårker.

Taxus baccata compressa Carr., viel- und steifzweigige, schmal-kegelförmige Form, mit etwas kleinen, zerstrent stehenden Blättern. 


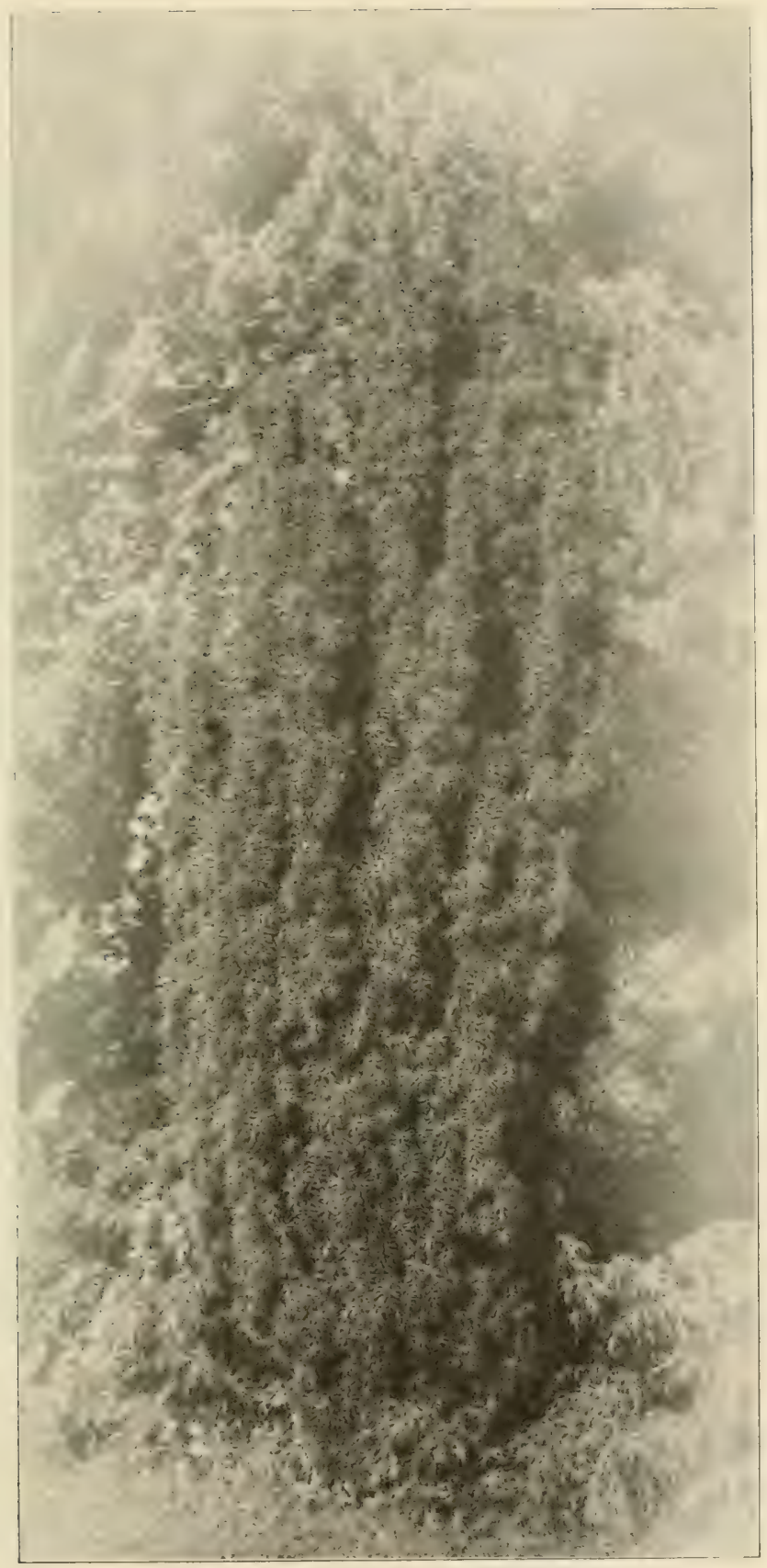

Fig. 26. Taxus baecata L. fastigiata Loud. 
Taxus baccata nana Knight, buschige Zwergform, mit sichelförmigen Blättern.

Taxus baccata epacroides Hort., schwach und gerlrungen wiichsig, sowie feinblätterig.

Taxus baccata ericoides Carr., Zwergform, mit sehr spitzen, schmalen Blättern.

Syn.: Taxus baccata microphylla Jacques.

Witchelli Hort.

Taxus baccata monstrosa Carr., monströse Zwergform mit ungleich langen Blättern.

Taxus baccata Sieboldii (Beißner) flachwachsend, etwa dreimal breiter als hoch.

Syn.: Taxus Sieboldii Hort. Musk.

Taxus baccata expansa Carr., niedere, auf dem Boden sich ausbreitende Form.

Taxus baccata adpressa Carr., in England in Kultur enstandene, viel umstrittene und friiher als Art aufgestellte Form, welche zur Zeit nur vegetativ rermehrt wird. Bildet meist etwas hreitbuschige, doch auch anfsteigende Pflanzen mit zahlreichen, dichtstehenden Ästen und Zweigen und 5-10 (12) mm langen und $3-4 \mathrm{~mm}$ breiten, kurzspitzigen Blättchen.

Syn.: Taxus adpressa Gord.

brevifolie Hort., nicht Nuttall.

adpressu Hort.

parvifolia Wender.

tardiva Lares.

Cephulotaxus adpressa Hort.

tardiva Sieb.

Taxus baccata adpressa variegata Hort.. ähnlich roriger. weißbunt.

Syn.: Taxus adpressa variegata Hort.

Taxus baccata adpressa aurea Hort., gelbblitterig.

Taxus baccata adpressa aureo-variegata Hort., goldlbunt. hiibsch.

Taxus baccata adpressa stricta Hort., sehr hiilhsche, aufstrebende, sïulenfïrmige, zierliche Form.

Syn.: Taxus adpressa stricta Hort.

$$
\Rightarrow \quad \text { " erecta Hort. }
$$

Taxus baccata canadensis, kanadische E., Kanada I bis Virginien.

Syn.: Taxus canadensis Willd.

Schneedecke günstig. 
Raschwiichsige, oft mit anderen ähnlichen Formen von Taxus baccata verwechselte, auch als eigene Art aufgestellte Form, mehr oder minder dem Boden autliegend, aber mit den İsten aufsteigend. Bliitter dichtstehend, abwechsehnd zweizeilig, ca. $11-20 \mathrm{~mm}$ lang und $1^{1 / 2}-2 \mathrm{~mm}$ breit (!), etwas sichelförmig, stachelspitzig, gelblich grin, im Vinter fuchsrot werdend! Form.

Taxus baccata canadensis aureo-variegata Hort., gelbbunte

Taxus baccata brevifolia, kurzbliitterige E. Insel Vancouver bis Kalifornien.

Syn.: Taxus brevifolia Nutt. Lindleyana Murr.
IV

Ziemlich feuchter und beschatteter Standort.

Etwas langsam wiichsiger, in ler Heimat bis $25 \mathrm{~m}$ hoch werdender Baum mit breit-kegelformiger Krone, dimnen, aufrechten Ästen, abstehenden und etwas iiberhängenden Zweigen und 10-12 mm langen, sowie $2 \mathrm{~mm}$ breiten, dicht und zweizeilig stehenden Blïttern, welche gelhlich-grim, sowie scharf gespitzt sind und anf kurzem, gelbem Stiel stehen.

\section{Pinaceae.}

Kiefernarige Pflanzen.

\section{d) Araucarieae.}

Schmucktannen ähnliche Pflanzen.

Immeroriine, interessinte mul schöne Binme von charakteristischem Habitus, mit quirlfömig cresteliten Asten, welche im Alter mehr oder minder hïngent sind, in ähnlicher Veise die ebenfalls zuerst meist wagrecht gestellten Zweige. Blitter flach oder pfriemlich, mehreihig, spiralig gestellt. Bliite meist diiizisch, minnliche in länglichen Kítzchen mit zahlreichen, vichfächerigen Stauhgefäben; weibliche endstandig, zapfenfïmig, die Samenschuppe der Braktee angewachsen, mit ciner Samenknospe. Zapfen aufrecht, nahezu kugelig, mit holzigen Fuchtschuppen. Samen mit der Fruchtschuppe rerwachsen, teils coefligelt, teils nicht gefligelt, mit lederiger his knochenharter ichile.

\section{Igathis Salisb. \\ (D a $\mathrm{m}$ m a r a Lamb.) \\ Dammara-Tannne.}

Hohe, immergriue Bäume, mit starkgegliederten Ästen mehr oder minder laubartigen, dahei derben, grofien, spitzen 
sitzenden, eirumelianglichen wler lanzettlichen Bliattern. Bliiten numözisch oder anch diüzisch. Zalpten rund mit breiten S'chupen. samen klein, einseitig oder zweiseitig und hreit wefligelt, selten olme Fliigel.

Leider alle Arten in Dentschland nicht winterhart. Inseln.

Agathis Dammara Rich. Agath-Tanne. Molukken, SundaSyn.: Dammara orientalis Lamb.

Liefert das" Dammaraharz.

$$
\text { clba Rumph. }
$$

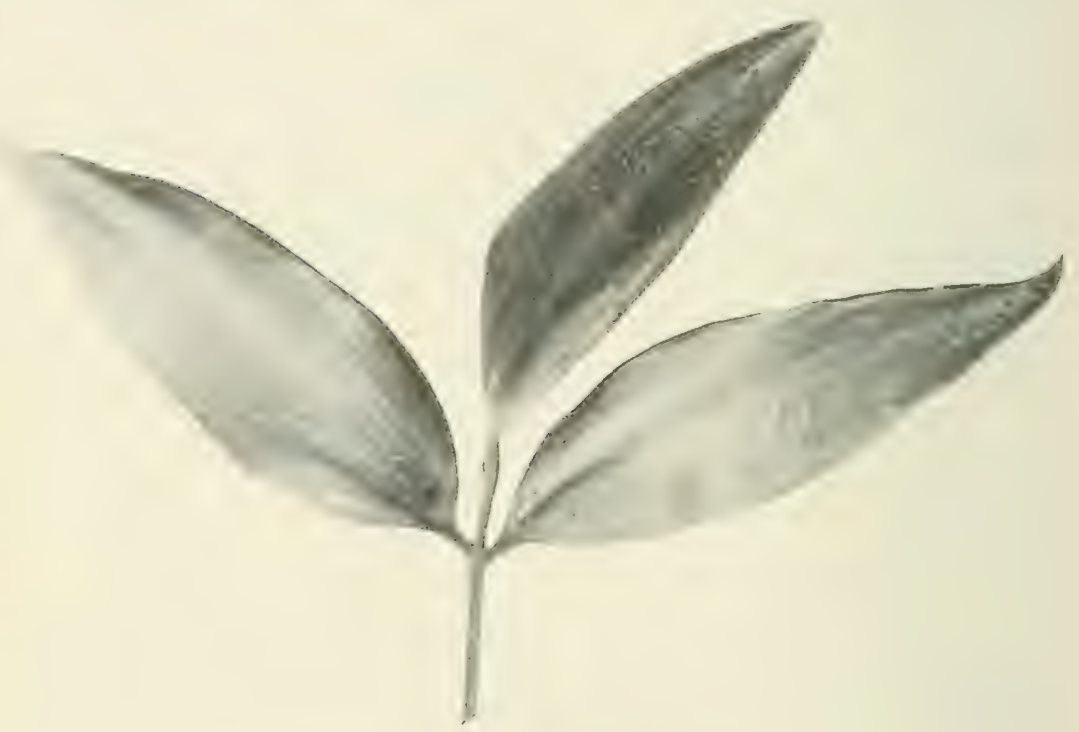

. Fig. 27. Agathis (Dammara) obtusa.

Agathis australis Salish. Kaurifichte. Neu-Seeland. Syn.: Dammara australis Lamb.

Liefert den feinen Kauri-Kopal.

Die Anführung weiterer Arten ist hier wohl nicht notwendig:. Termehrung dieser Arten durch Samen unter Glas in Töpfen.

\section{Arancaria Juss. \\ Schmucktanne.}

Hohe, immergriine Bäume mit teils breiten, lederartigen, teils pfriemlichen und sichelförmigen Blättern. Blüten diözisch, seltener monözisch. Zapfen rundlich, oft groß, im zweiten Jahr reifend. 


\section{Abteilung: Columbea Salisb.}

Blitter flach. Zapfen breit. Fruchtschuppen kaum orler nicht gefliigelt; Samen unterirdisch keimend.

Araucaria imbricata Par. Chilenische sichnt. (iebirge des siddlichen Chile. (Fig. 28 u. 29.)

Y' (VI)

Höhenlage ist

Hoch werdender Baum mit geradem Stamm, Vorteil; ebenso korkartig zerrissener Rinde, hreitpramidaler Krone, doch nicht in unten dichten, oben lichteren (juirlen stehenden, $\begin{gathered}\text { trockener } \\ \text { Boden. }\end{gathered}$ etwas aufgerichteten oder wagrecht ausgebreiteten bis hïngenden Ästen, welche (wie auch der jiungere Stamm) Riickstiincle der Bläter zeigen. Die Zweige sind meist gegenstindig und sehr

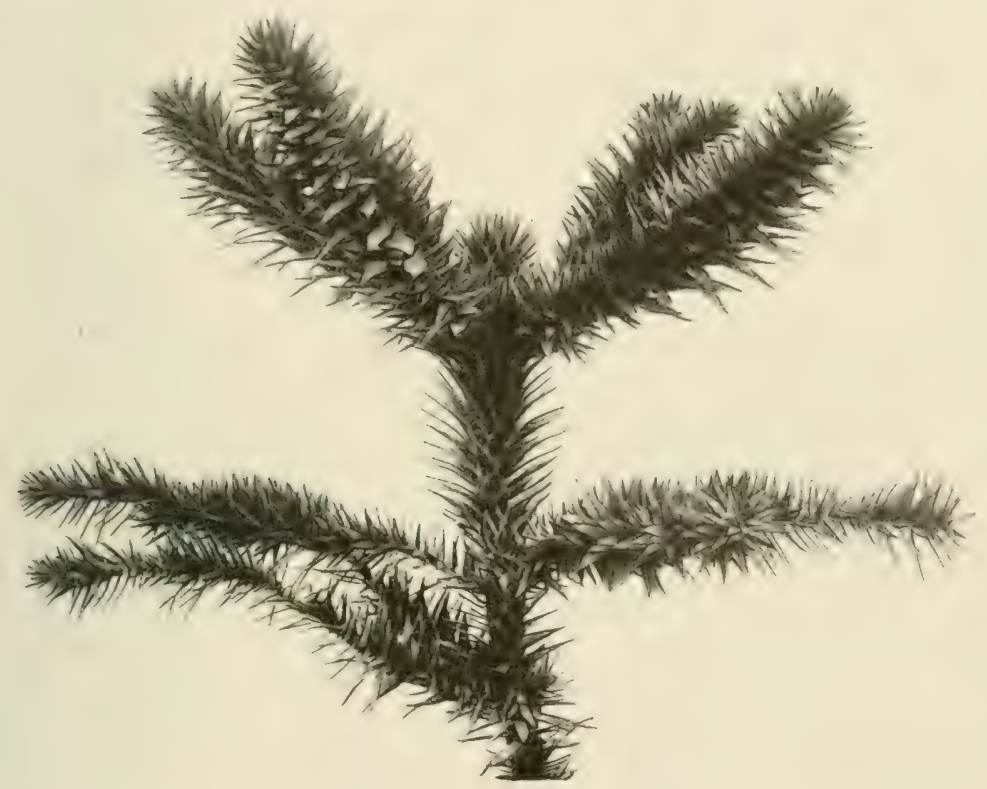

Fig. 28. Araucaria imbricata Par.

lange bedeckt ron den eiförmig-lanzettlichen, spitzen, steifen, lederartigen, $3-5 \mathrm{~cm}$ langen und bei $1-2 \mathrm{~cm}$ breiten, dunkel-, fast schwarzgrimen Blättern. Die mämmlichen Blüten bilden eine ziemlich zylindrische Gestalt und stehen sehr dicht spiralig gedrängt; die Pollenfächer sind in eigentiimliche, nach innen gebogene Gebilde verlängert; weibliche Blite dickeirund mit selı zahlreichen Schuppen, welche spiralig stehen, spitz zulaufen und je eine Samenknospe führen. Der bis etwa $20 \mathrm{~cm}$ grołe, rundliche Zapfen hat zahlreiche, feste, fast fligelartige 


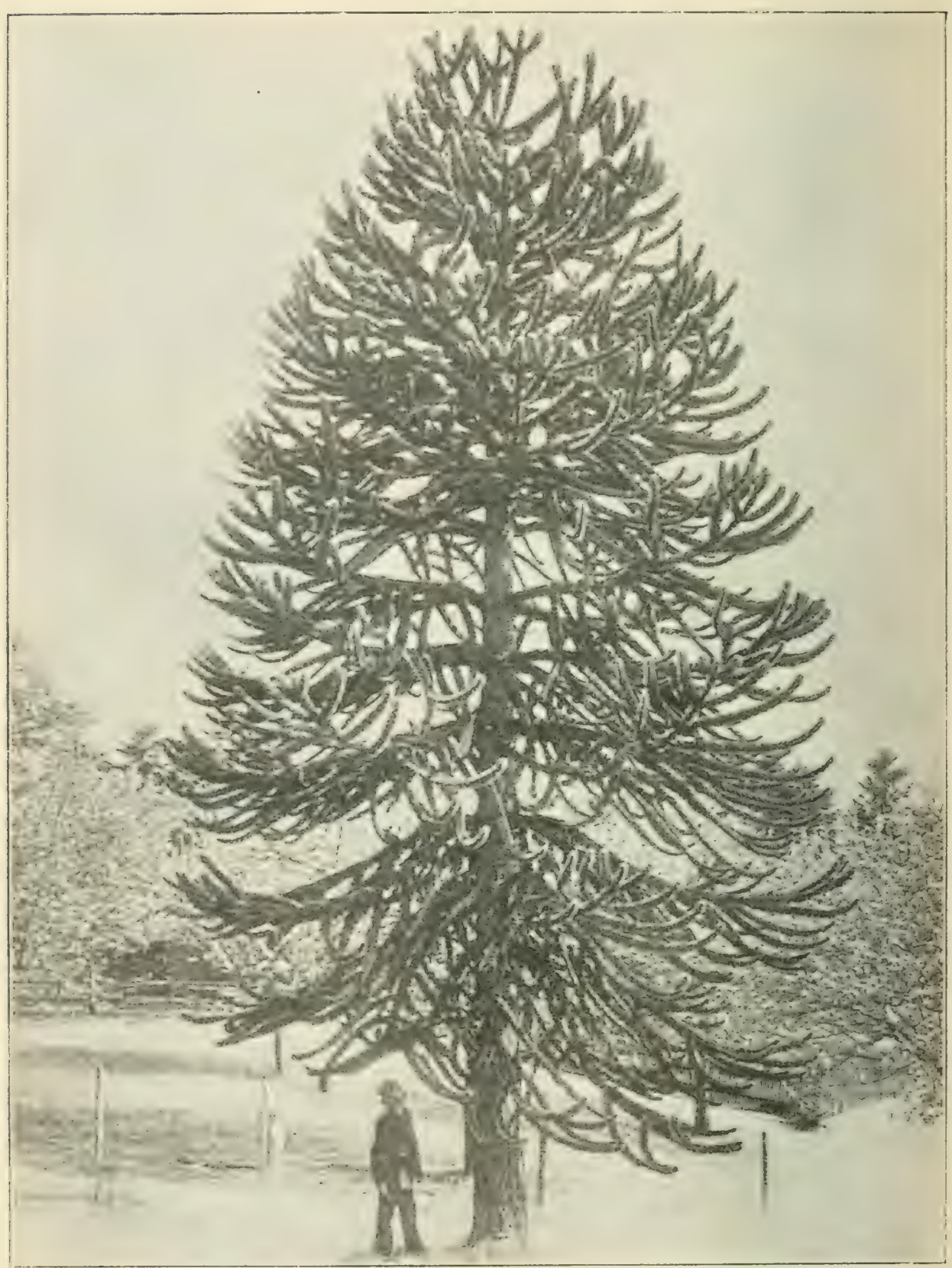

Fig. 29. Araucaria imbricata Pav., $12 \mathrm{~m}$ hoch. (Aus: Mitteilungen der deutschen dendrologischen Gesellschaft.) 
Fruchtschuppen mit je einem grofien, langen, in wethbramer, ohen etwas verhreitorter. unten spitzer. dickhintiger Schale steckenden samen. Limling mit unter der Erole sich entwickelnden Keimblättern.

Vermehrung dureh Samen, (der bald die Kromkratt resliert, unter Glas in Töpfen.

(irobtere Exemplare sind wenige in Dentschland rorhanden; in der Schweiz, in Frankeich mol England giht es Exemplare, ja ananze - wenn anch kleinere - Bestinde his mit iiher 30 m hohen Bäumen.

Das innen celle, außen hellere Holz ist din suhr cutes, zu feineren Arbeiten verwenlbares Material. J)as Harz wirl in der Heimat oftizinell gebraucht und der Samen bildet ein hochwichtiges Nahrungsmittel der Eingeborenen. Ein Zapfen hirgt meist 200-300 Sanren, ,Pinones“, welche als die genigende Tagesration eines Eingeborenen angegeben werden.

Von weiteren Arten sollen noch genannt sein:

Araucaria brasiliensis A. Rich. Brasilianische Schmt. Höhere Teile Brasiliens.

Araucaria Bidwillii Hook. Bidwills Schmt. Australien.

Araucaria Rulei Miiller. Rules Schmt. Neu-Caledonien.

2. Abteilung: Eutacta Link.

Blätter pfriemlich; Zapfen kugelıund; Fruchtschuppen breit gefliigelt; Samen uiber der Erde keimend.

Arancaria Cunninghamii Ait. Cumninghams Schmt. NenSiidwales.

Araucaria Cookii R. Br. Cooks Schnt. Neu-Caledonien.

Araucaria excelsa R. Br. Norfolk-Tanne. Norfolk-Inseln. Eine der' beliebtesten Zimmerpflanzen.

Alle - außer A. imbricata - sind Pflanzen unserer Gewiichshäuser, also in Deutschland nicht winterhart.

\section{e) Abietineae,}

Tannenähnliche Pflanzen.

a) Die Pflanzen führen nur Langtriebe.

11. Picen Link.

Fichte.

Immerg'uine, hohe Bäume, von schönem, prramidalen Wruchs, ziemlich quirlförmig gestellten, erst aufstrebenden, dam wag- 
rechten und zuletzt mehr oder minder hängenden Ästen, deren Enden sich gerne wieder aufrichten, sowie nit etwas unregelmibig bis zweiseitig stehenden, meist auch behaarten und rauhen Zweigen.

Die Blätter sind um den Zweig spiralig, teils auch ungleich zweiseitig gerichtet, meist auf hohe Blattkissen gestellt, von $n$ adeltörmiger, mehr oder minder vierkantiger Gestalt und mit Spaltöffnumgslinien auf allen vier Seiten, oder - bei einigen Arten - flach, tamnemadelnartio und dann mit Spaltöffnungen an der Oberseite versehen, welch letztere aber durch Drehung oft abwärts gerichtet ist. Dabei sind die Blätter mehr oder minder starr und spitz, beiderseits auch gekielt, dunkelgriin in der Grundfarbe, im trockenen Zustand bald abfallend, zum Gegensatz der sehr lang haftend bleibenden Nadeln der Tannen.

Die Knospen sind mit Schuppen bedeckt, z. T. auch harzig. Bliiten monözisch; männliche einzeln, achselständig, bei oft ziemlich langem, etwas aufrecht stehendem oder hängendem Bliitenstand, limglich bis zylindrisch, von schuppenartigen Brakteen dicht ungeber, Antheren dicht spiralig gestellt, gelb-rötlich, die Pollensäcke durch einen Längsspalt geöffnet, meist eine Unmenge mit Flugblasen versehene Pollenkörner entsendend, (welche vom Winde fortgefiihrt und bei Regen niedergeschlagen besonders in Pfuitzen bemerkbar, die Veranlassung zu sogenanntem "Schwefelregen" ergeben); weibliche Bliite endständig, aufrecht oder doch ziemlich aufgerichtet, bräunlichrot, eiförmig bis länglich, dicht mit Schuppen ungeben, kleine Brakteen und zwei umgewendete Samenknospen führend.

Die Zapfen sind hängend (!) oder auch bei wenigen Arten abstehend. Nach der Befruchtung wird der ganze Bliitenstand nach unten gedreht und hiebei die konvexen Schuppen in konkave Lage gebracht, umgestülpt, sodaß dieselben wie vorher die Blite, nun den reifenden Samen dachförmig bedecken. Die im ersten Jahre reifenden Zapfen haben meist längliche bis walzenförmige Gestalt, spiralig gestellte, dachziegelartig sich deckende, aber nach der Reife nicht von der spindel abfallende Schuppen und sehr kleine Brakteen.

Samen zu zweien unter der Schuppe, ohne Harzgänge, eiförmig spitz, auch etwas gepreßt, mit weicher Schale und großem, sich später ablösendem Flügel. 5-7 Jahre dauert die Keimfähigkeit der Samen; sie keimen 3-4 Wochen nach der Saat, entwickeln bis 8 (selbst 10) dreikantige, an einer Seite auch etwas gezähnte Keimblätter und vierkantige, allseitig gezähnte Erstlingsblätter.

Das Holz der Fichten, leicht und weich, ist als Standholz, Bau- und WVerkholz in vielseitigster Verwendung. Die 
Pllanzen selbst sind, da sie sich meist gut nach dem Schnitt erneuern, als schutzmittel, zu Hecken, in särtnerischer Verwertumg u. derol. mehr, stark beniitzt. ()ffizinell ist das Harz, der 'Terpentin, der Splint, die Rinde und das ïtherische Öl der Nadeln; ebenso liefern junge Sprossen Material zur Bierbereitung. Gegen die schwefeline sime, welche in stialten mit viel Rauch in starkem Matbe vorhanden ist, wie ehenso gegen starken Staub ist die Fichte meist sehr empfindlich.

Die Vermehrung geschieht in der Hauptsache durch Samen, welcher in weiter Saat grelegt wird, ferner durch Veredlung auf Samenpflanzen besonder's von Picea excelsa, dann aber auch auf P. alba, P. orientalis und P. nigra, wobei aber Material zur Veredlung von älteren Pflanzen genommen werden muf, soll nicht jeweilig die Jugendform fixiert werden, welch letzter Umstand aber auch bei der Vermehrung durch Stecklinge zu beachten ist; auch wächst als Steckling meist nur diimnes Material von feinzweigigen Sorten gut. Seitenzweige fast aller Arten bilden ganz gerne Gipfeltriebe.

\section{Abteilung: Eupicea Willkomm., echte Fichten.}

Blätter vierkantig und vierflächig, auf jerler Seite mit Spaltöffnungen versehen. Zapfen hängend.

Picea excelsa Link. Hohe Fichte, Rottanne. Nord- und Mitteleuropa bis zu den Pyrenäen, Alpen, Kümmert in Karpathen. (Fig. 30-33).

Diese durch die Kultur weit verbreitete, in Bedürrem Boden. Erträgt Rauch und Staub sehr zweigung, Nadeln und Zapfen sehr veränderliche Fichte erreicht eine Höhe bis zu $50 \mathrm{~m}$ mit prachtvollem, geradem, säulenförmigem, oben sich verjüngendem Stamm, er'st hellbrauner, glatter, später rötlicher oder grauer, sich abblätternder Rinde, g'anz spitz zulaufender, pyramidaler Krone und zuerst aufstrebenden, damn wagrecht abstehenden oder etwas gesenkten, an den Spitzen wieder aufstrebenden Ästen, sowie aufrechten bis iuberhängenden Zweigen und sehr kleinen, spitzen Knospen mit hellbraunen Schuppen, welch letztere beim Austrieb wie eine Kapuze abgehoben werden.

Die an jungen üppigen, wie auch an alten Pflanzen oft sehr verschiedenen, teils dicht rings um den Zweig oder auch etwas zweiseitig stehenden Blätter sind starr, vierkantig, gerade oder etwas gekriummt, sehr spitz, stehend, $1^{1 / 2}-2^{1 / 2} \mathrm{~cm}$ lang und $1 \mathrm{~mm}$ breit, haben allerseits glänzend griune Färbung und stehen auf kantigen, hohen, hellbraunen Blattkissen. (Fi@.30.)

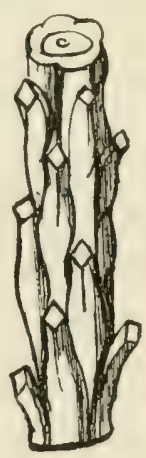

Fig. 30. Blattansatzstellen (Picea excelsa). 


\section{- it}

Niannliche Bliiten in langen Wiirstchen; die weibliche Bliite ist sehr hiibsch rot gefirbt. Alsstufungen in der Farbe der Bliiten ist stets $z u$ beobachten.

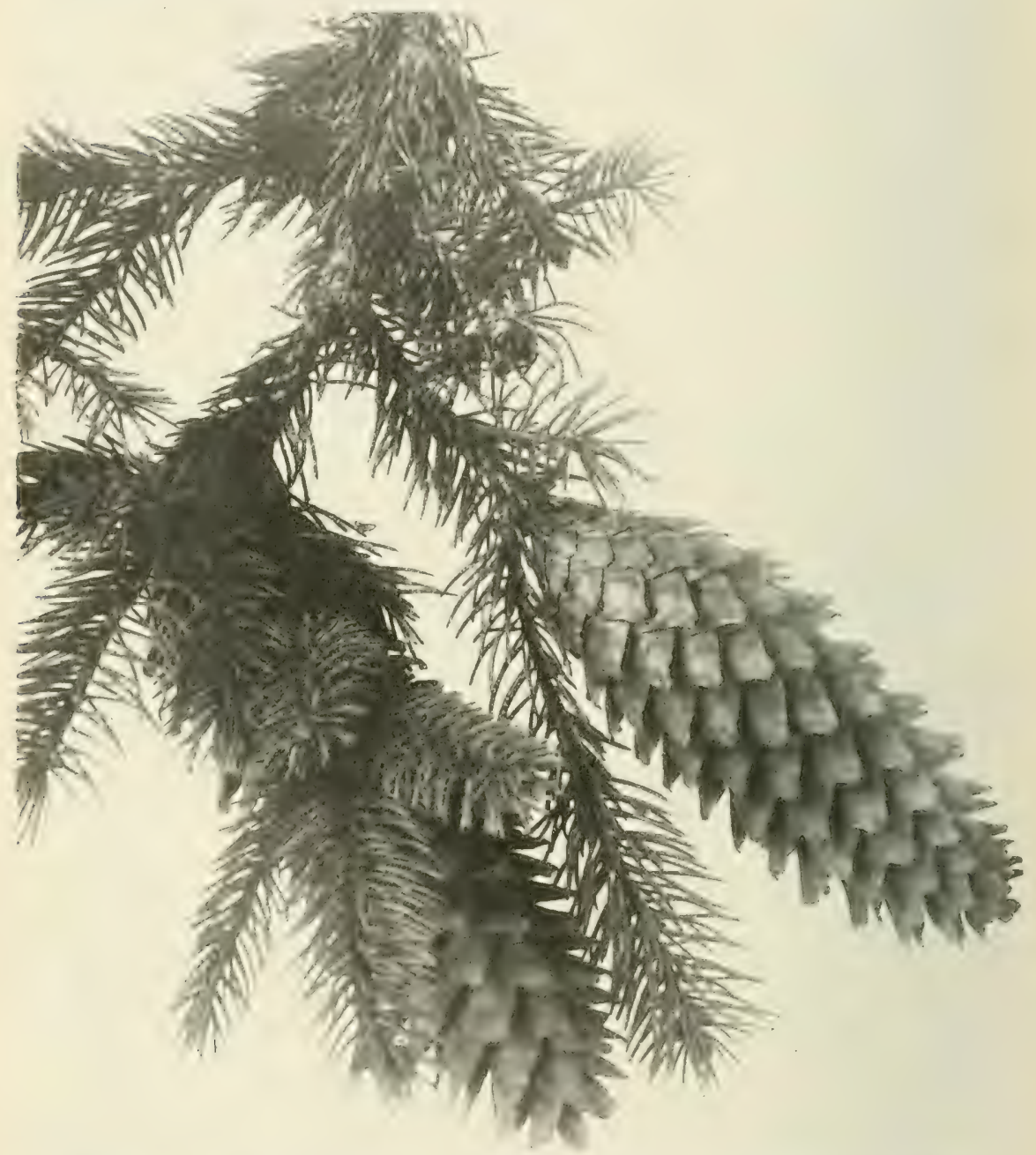

Fig. 31. Fruchtencler Zweig von Ficen excelsa Lk. mit geöffneten Zapfen kurz vor dem Abfall.

I) ie 10-16 cm langen, 3-4 cm dicken, zylindrischen, abgestmmpften, erst griunen, dann hellbramen Zapfen führen eine grofe Anzahl gewöll,ter, welligrandiger und auch ungleich gezithuter, stumpt zucespitzter, lederartiger Schuppen, sowie kleine, 


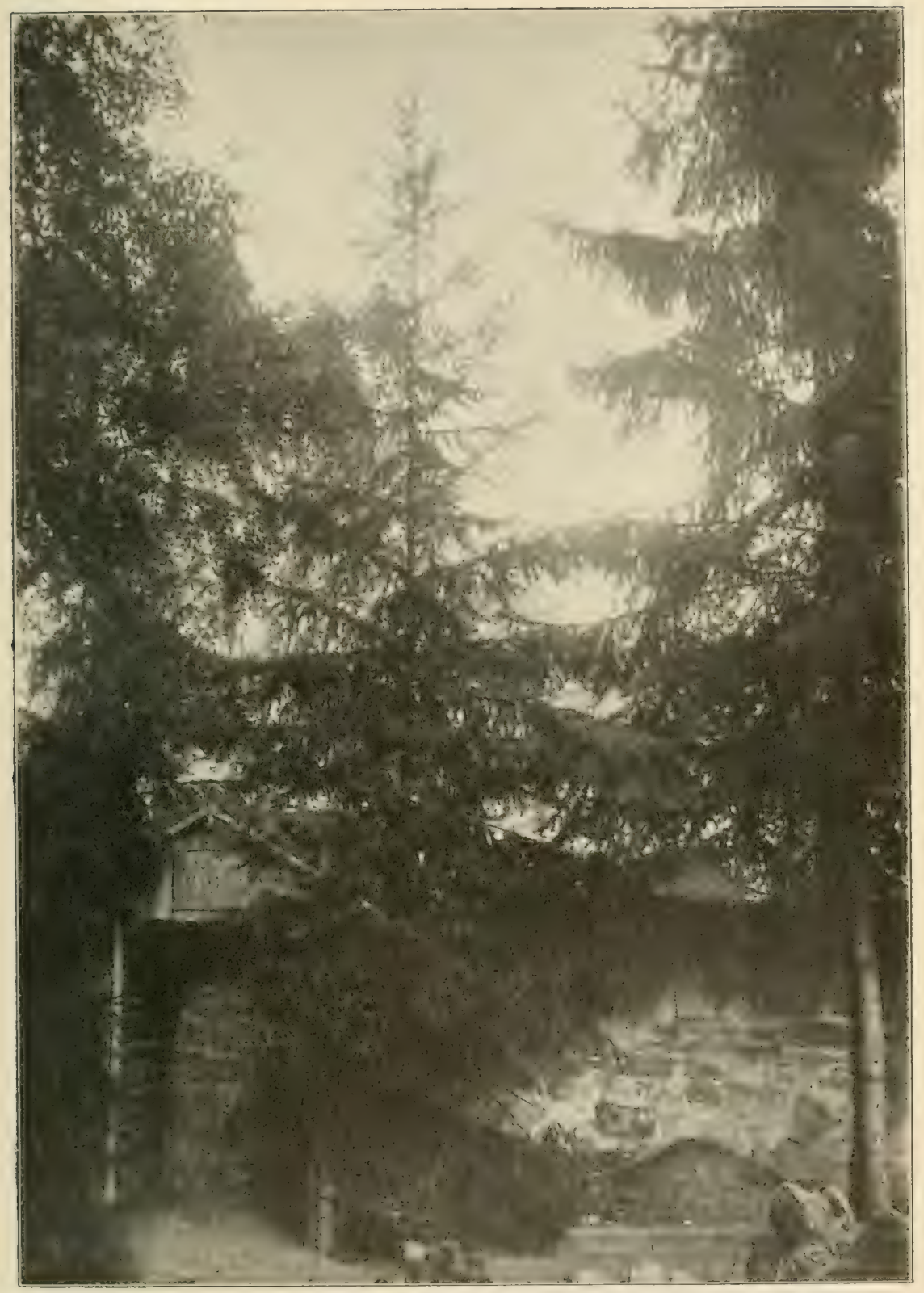

Fig. 32. Picea excelsa Lk.

(ca. 30- und 45 jährige Bäume). 
lïngliche Braliteen. werden im Oktober reif, öftuen sich aber erst im Spätwinter.

Der eiformige, spitze, dunkelbraune Samen hat dreimal so langen, rötlichgelben Flïgel, hält sich 5 (selbst 7 ) Jahre keimfähig und geht 3-4 Wochen nach der Saat auf.

Die Keimlinge zeigen meist. 8 dreikantige, einerseits etwas qezähnte Samenblätter und vierkantige, an allen Kanten gezähnte Erstlingsblätter.

Vermehrung durch Samen an besten Nitte bis Ende April ins Freie gesät (oder schon frihher in Kistchen mit Schutz gegen Spätfröste) wobei die Saat $1 \frac{1}{2}-2 \mathrm{~cm}$ tief - nicht geringer - mit Erde herleckt werden muB. Stecklinge wachsen nicht gerne, doch sollten Zwergformen am besten durch solche vermelnt werden, da bei Veredlung die Pfropfer gerne ausarten. Zur Pfropfung bedient man sich als Unterlage zwei- bis dreijähriger Sämlingspflanzen von etwa $2^{1 / 2} \mathrm{~cm}$ Stärke an der Veredlungsstelle.

Picea excelsa dient bei den meisten iibrigen Arten als Unterlage, doch wächst P. alba nicht besonders gut auf ihr (auch excelsa auf alba nicht). Senker von P. excelsa bewurzeln sich nur manchmal.

Das Holz der Rottanne ist gelblich bis gelblich-weiß, ohne genauen Unterschied zwischen Kern- und Weißholz, bildet eines der wichtigsten Holzarten unserer Forstbäume und ist, da es sich je nach Standortsverhältnissen äußerst leicht spalten läßt, vortrefflich als Bau- und Werkholz verwendbar. Auch als Material zu Musikinstrumenten, als Resonanzholz, ferner in möglichst astfreier Ware zur Cellulose-Bereitung, also besonders zur Papierfahrikation ist es sehr gesucht und wird gut bezahlt. Auch die Rinde ist als Gerbematerial im Gebrauch.

Da der Baum den Schnitt leicht verträgt, so ist die Pflanze besonders auch in gärtnerischem Betrieb stark verwendet, wie sie ja auch als Christbaum stark in Beniitzung ist (bei unsern heidnischen Vorfahren zur Zeit der Wintersonnenwende als Symbol der nie ersterbenden Natur aufgestellt). Nenerdings wird sie allerdings in dieser Beziehung besonders durch die ihre Nadeln auch in trockenem Zustand haltende Weißtanne stark verdriangt. Splint und Rinde, Harz bezw. Terpentin und das ätherische Öl sind offizinell; ebenso dienen Sprosse und Nadeh zu medizinischen Bädern.

Was die Formen betrifft, so gibt es deren eine sehr große Anzahl, wobei allerdings dic Standortsformen noch speziell in Berechnung gezogen sind. Man unterscheidet:

a) Standortsformen mit nicht erblichen Eigenschaften, hervorgerufen durch Einfluß des Klimas, der Örtlichkeit, oder durch Eingriffe von Tieren. 


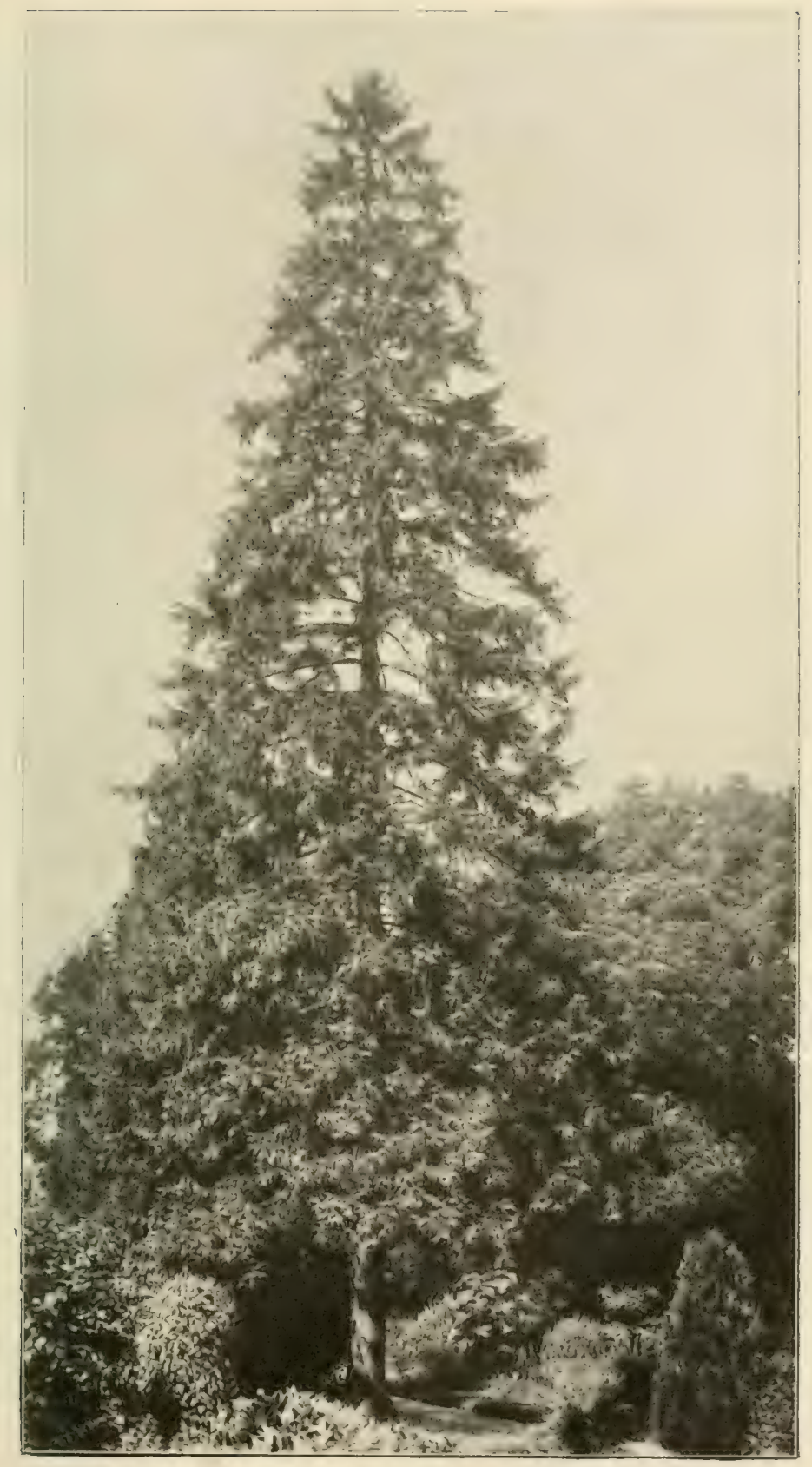

Fig. 33. Picea excelsa Lk, (ca. 100 jähriger Baum). 
Pyramidenfichte, von kegelfürmigem, aber sonst norınalem Wuchs.

Walzenfichte, aus hohen Lagen stammende, zylindrische Form mit kurzen Ästen.

Zwillingsfichte, mit zwei Stämmen, welche nahe der Basis entspringen und meist durch Abnagen eines Bäumchens durch Tiere entstanden ist.

Garbenfichte, statt zweier Stämme entstehen 3-9 Stämme aus gleichem Grund wie bei voriger.

Wetterfichte, vielgipfelige Tanne der Hochlagen, durch Schneedruck, Sturm oder Blitzstrahl entstanden.

Stelzenfichte, mit ihren oberen IVurzeln wie auf Stelzen stehende Fichte, welche durch Zufallssaat auf gestuirzte und nachher zerrottete Baumstämme - auch auf hohen Stammstöcken - entstanden ist.

Kandelaberfichte, eine Anzahl Ïste - oft bis zu 20 - richten sich zu Neu-Stämmen empor.

Schneebruchfichte, Ausläuferfichte (forma stolonifera Christ): da die Fichte nur Hachwurzelnd ist, so leidet sie unter Schneedruck und Wind sehr stark. Hiebei wurden zum Teil die unteren Äste dem Boden test angedriickt, bewrurzeln sich - besonders in fenchten Gegenden - und hilden nun neue kleine bis mittelgroße Bäume.

Mattenfichte, eine Form mit sehr kurzem stamm, aber sehr langen Ästen, welch letztere dem Boden fast aufliegend, ganze Rasen bilden.

Ziegenfichte, oikr Grotze, rerkiiiplelte Zwergform, lurch Benagen von Ziegen entstanden.

Zargen-, Hasel- oder Weissfichte, eime eigentimliche Fichte der Hochlagen, hesonders auf kalkhaltigem oder Glimmerschieferboden vorkonmend, mit einem fiur Mlusikinstrumente ganz volziiglichen und deshalb sehr gesuchten IHolz, das im Frühjahrsholz hreit und weiffarbig, im Herlostholz schmal und braun ist. Aufiallig durch manchmal bischelig gestellte Bliatter, oft ganz. helle, später gelhliche Sprosse, hellfarloige, f'eine, ziemlich glatte Rinde und auffallend spiralig gestellte Zapfenschuppen.

Unterschierlen wird ferner noch zwischen links und rechts Irehend wachsemle (willer- (gegen-) und nach- (mit-) somige) Formen, wovon letztere ein gesuchtes, gerarlspaltiges Holz führen.

b) Formen und Abarten mit erblichen Eigenschatten, inklus, einigen Standortsfichten:

Picea excelsa var. obovata ('. Toch, Altaifichte. Skandinavische Halbinsel, Norl- und Ostrufland, Sibirien bis Mandschurei, Kamtschatka, Kurilen.

Syn.: Picea obovata Ledeb. 
Bei 30 m hoch werkende Fichte ron pyramidalem, zierlichem Wuchs, mit etwas hängenden Ästen, etwas behaarten, hellbraumroten 'Trieben, von Nadeln umhiillten, kegelförmigen Knospen, dichtstehenden, diunen, vierkantigen, 12-20 cm langen, durch die allseitig sich zeigenden Spaltöffnungen bläulich-griinen, dabei scharfspitzigen Blättern.

Durch die Zapfen werden zwei Hauptformen unterschieden:

Picea excelsa var. obovata uralensis (Teplouchoff).

Syn.: Picea excelsa uralensis 'Tepl.

Mit. $6 \mathrm{~cm}$ großen, länglichen Zapfen, welche weiche, etwas flache, gestutzte oder auch auscerandete Schuppen fiihren.

Picea excelsa var. obovata altaica (Teplouchoff).

Syn.: Picea excelsa altaica T'epl.

Jit holzig harten, gewölbten, abgermuleten Schuppen.

Als Gebirgsform wird bezeichnet:

Picea excelsa var. obovata japonica Maxim., von den Hochalpen Japans. (Fig. 34.)

Syn.: Picea Maximowiczii Rgl.

Eine gedrungen wiichsige, kur\% uml dichtzweigige Zwergform, mit glatten, rotbramen Trieben, harzigen (!), kurz kegelförmigen, spitzen, hraunen Ḱnospen und 10 (17) mm langen, $1 \mathrm{~mm}$ dicken wie breiten, dicht und ringsum stehenden Bliattern, welche aber an alten, kleinen Nebenzweigen wieder der Tarietit gleichen. Die Zapfen werden nur $6 \mathrm{~cm}$ lang.

Picea excelsa var. obovata lapponica (Ber'o), mit $n u 1^{1} t^{1 / 2}$ bis $5^{1 / 2} \mathrm{~cm}$ langen und bei $2 \mathrm{~cm}$ breiten Zäpfchen.

Picea excelsa fennica Rupr., von Fimlanu, mit kleinen, abgerunterten, meist 7-9(10) cm langen Zapten. Answesprochene Uebergangsform zu var, obovata.

Picea excelsa Uwarowii Kinufm. [Tramms Fichte.

Lang und diunnistig. mit leicht hïnemenlen, verhailtnismition wenim Zweigen, kurzen, dicht und ringsum stehenden Bliattern, S-9 cm langen, etwas stumpten Zitpten, deren Schuppen kaum oder nicht eingerandet sind. Alpen.

Picea excelsa alpestris Briigger. Alpentichte. Graubiurher

Von erelpungenem Wuchs, weibgraner Rinde, steifstehenden, dicken Zweimen, 15-1s mm lanen. dicken, starrabstehen-

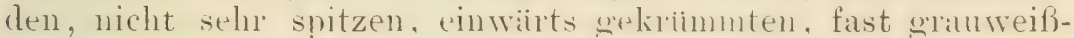
grünen Blättern und $7^{1 / 2}-12^{1 / 2} \mathrm{~cm}$ langen Zapfen.

Unter-Formen hievon wären noch zu unterscheiden:

Picea excelsa alpestris chlorocarpa (Builin.), griinzaptic. erythrocarpa (Beißn.), rotzapfig.

Das Holz" dieser "Form ist sehr gesucht als Material fiur Resonanzbödlen. 
Picea excelsa medioxima Nylander, nordische Fichte. NortSkandinavien, Finnland, Nord-Rußland.

Stranchig oder klener Bam, nit dichtstehenden, oben den Zweig dicht deckemelen, kurzgerpitzten, dicken, glïnzend

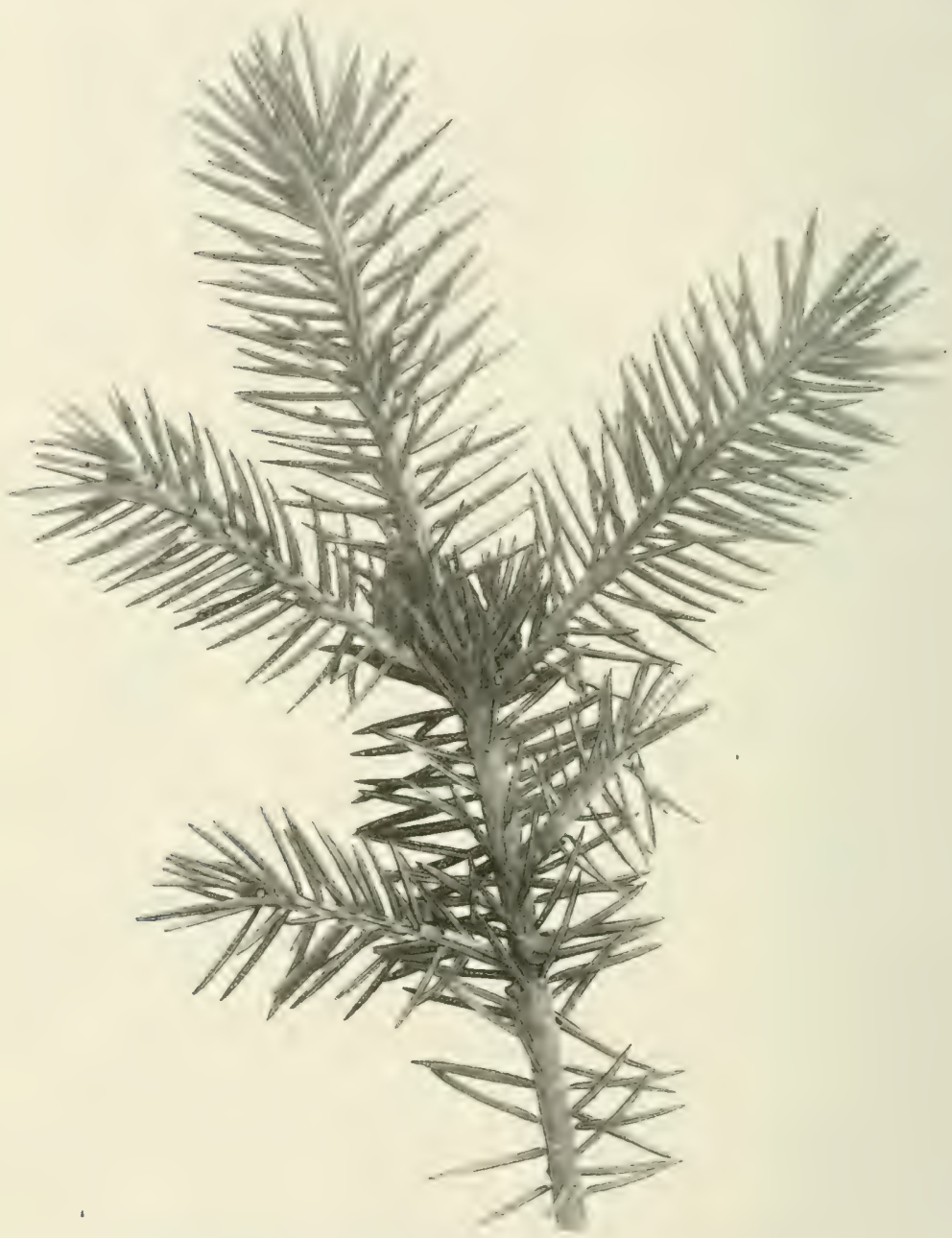

Fig. 34. Picea excelsa Lk, var. obovata japonica Maxim.

dunkelgrinen Blättern, sowie höchstens $8 \mathrm{~cm}$ langen, länglicheiförmigen, schief abw:irts (!) gerichteten Zapfen. 
Picea excelsa septentrionalis Hort, schwedische Fichte. hercynica Hort., Fichte vom Harz, eine gedrungen" wich"ige, kahlyweigige, fein und kurzhlitterige, sowie kurzzapfige Form.

Picea excelsa carpathica Loud., Karpathentichte, ehenfills sedrungenwiichsig, nit ganz l'einen, behaarten Zweigen, kurzen, diimen, dem Zweig anliescenden Blättern und kurzen Zapfen.

Picea excelsa borealis Hort., iippio wachsencle Form.

gigantea Hort, starkwiichsig, mit schlanken Zweigen und diumen Blättern.

Picea excelsa sibirica Carr., pyramidaler Strauch, mit feinen, den Zweigen anliegenden Blättern.

Picea excelsa nigra Loud., schwarze Fichte; starkwichsige, rötlich-rindige, großzapfige Form, mit langen, dabei etwas dicken Blättern.

Picea excelsa corticata Schröt., dickrindige Fichte, mit läng'srissiger, bis $9 \mathrm{~cm}$ dicker Rinde.

Picea excelsa tuberculata Schröt., Zitzenfichte, deren unterel' Stammteil höchst eigentumliche, kegelförmige Kiorkwucherungen zeigt.

Picea excelsa chlorocarpa Purk., griinlich-hraunzapfige (erst hellgrüe) Fichte mit großen, rechts spiraligen Blättern, welche auf auffällig langen, ausgezogenen Blattkissen sitzen, nit großen Kinospen, diinnem, hellgelb geflugeltem Samen und schwerem, gelblichem Holz.

Picea excelsa erythrocarpa Purk., rotzapfige - jung dunkelviolette - Fichte, mit links spiralig gestellten Blättern auf kurzen Blattkissen, und dickem, rotbraun gefligeltem Samen.

Picea excelsa acrocona Th. M. Fries, fiihrt neben normalen Zapfen an den Zweigspitzen auch noch langgestreckte, mit Nadeln durchwachsene Zapfen.

Picea excelsa integrisquamis Carr., mit ganzrandigen Zapfenschuppen.

Picea excelsa squarrosa Jacobasch, Zäpfchenfichte, eine sehr große Anzahl kleiner, 1 1/2:1 cm bis 4:2 cm große Zäpfchen (mit keimfähigen Samen!) tragend.

Picea excelsa crassifolia Hort., mit dicken, robusten Nadeln. glauca Sr., blaugrüne Benadelung.

wickelte, stahlblaue Form.

coerulea Breinig, sehr schöne, kräftig ent-

Picea excelsa finedonensis Hort, junge Triebe blaßgell, fast bronziert; nicht hervorragend.

Picea excelsa aurea Carr., hellgelbe Form, in der Sonne empfindlich.

Picea excelsa aurea magnifica Hans, roligellse, hiibsche. raschwiichsige Form. 
Picea excelsa aureo-spicata Hort. Kirrol., goldgell, in Austrieb. albo-spicata Hort, gelhlichweif austreibend.

Svn.: Picea excelsu mutubitis Hort. holl.

Picea excelsa argenteo-spicata Hort. Hesse, beim Austrieh, hiibsch weißfarbig.

Picea excelsa argentea Hort., weiłbunt, mwesentlich. variegata Carro, teilweise gelblumt, II ohne besonderen Wert.

Picea excelsa Diedorfiana Schwer., kurznadelig, der erste 'Teil rler ausgetriebenen Nadeln goldgelb, die folgenden aber grün!

Picea excelsa araucarioides Beißn., mit nu' yuirlför'mig' gestellten Ästen, ohme kleine Zwischenästchen.

Picea excelsa candelabrum Sr., Form mit ziemlich aufstrebenden, in regelmäßigen Quirlen stehenden Ästen.

Picea excelsa acutissima Hort., mit feinen, scharfgespitzten Blättern.

Picea excelsa microphylla Schwer., kurznadelige, an P. orientalis erinnernde Form.

Picea excelsa cincinnata Hesse, mit meist aufstrebenden, sonst ragrechten Ästen, jung rotbramen Trieben und eigentimlichen, kurzen, lockigartigen Verzweigungen, sowie grołen, aufiärts gebogenen Blättern.

Picea excelsa pendula Carr., Hänge- oder Trauerfichte, mit ziemlich hängenden Ästen und ganz schlaff hängenden, dicht. beblätterten Zweigen.

Picea excelsa major pendula Hort.

Syn.: Picea excelsa pendula major. Hort.

Mit iiprigen, hängenden, jung bramen Trieben und grofjen, säbelartig aufwärts gekrimmten Nadeln.

Picea excelsa inversa Hort., starkwiichsime, schöne Form, mit stark hängenden Ästen, schlaffen Zweigen und kräftigen, langen Blättern. Form.

Picea excelsa aegra myelophthora Casp., seltene, hängende

Picea excelsa columnaris Carr., Siulenfichte: eine kurz- und dichtzweigig'e, schmale Säule bildend.

Picea excelsa cupressina Thomas, prramidalwiichsig, doch al,cerundeter Giptel, im Habitus einer alten Zypresse gleichend.

Picea excelsa pyramidalis Hort. S.-L., Kinelform mit verdickten İsten in gechängten, wagrechten Quirlen; Zweige dicht, fein, chenfalls wasuecht oder aufuerichtet.

Picea excelsa pyramidalis robusta Hort.. dichtwiichsige, dickknospige Pyramide. 
Picea excelsa pyramidalis gracilis Hort., kleiner und feiner als vorige, mit rötlichen Knospen.

Picea excelsa eremita Carr., schmale I'yranide: interessant. Syn.: Picea excelsa crimitii Hort. gull.

Picea excelsa petrowskiensis Sr., pyramilalwiichsic.

Shelesnowii Hort, dichte, niedere Pyramide. intermedia Carr.

Syn.: Abies excelsa denudala Can.

Starkwithsige Form, mit langen, dimmen, ungleichmäbig westellten Asten, etwas wenigen, langen und dimnen \%weigen, sowie verschieden langen, teils dicht, teils diim restellten, teils auch anliegenden Blättern.

Picea excelsa viminalis Casp., schwedische Hängefichte, ähnlich voriger, aber mit me hr Asten und sehr langen, dimmen, schlaff herabhängenden Nebenästen.

Picea excelsa glomerulans Kihlm., Mittelform zwischen Stammform und virgata, mit kaum entwickelten, kleinen Kinäueln ähnlichen Zweigen an regelrechten Ästen.

Picea excelsa plumosa Sr., ähnlich viminalis, mit sehr dicht stehenden, hängenden Zweigen.

Picea excelsa virgata Jar., Schlangen- oder Rutenfichte; ganz wunderliche For'm, welche bei quirlförmiger Verastung meist nur an der Spitze derselben, oder an den ganz wenig entstandenen Zweigen ebenfalls nur außen weiterwichst, also lange, schlangen- oder rutenförmige Triebe bildet, welche teils aufstrebend sind, teils auch dem Boden anliegen und hier selbst Wurzel schlagen. Die verschieden langen, dicklichen Blätter sind am Nitteltrieb angedriickt, an den Seitentrieben abstehend.

Picea excelsa Cranstonii C'ar'., der vorigen ähnliche Form, mit sehr langspitzigen, seitlich geprebten Blättern.

Picea excelsa Dicksonii Hort. gall., mit voller bezweigten Asten als virgata, und iippigen, jung rötlichen Trieben.

Picea excelsa oligoclada Hort., sehr armzweigige Form. ramosa Pillichody, nur mit einigen Hauptisten - "aher ohne Stamm - und mit einer grotien Menge vom Wruzelhals der Pflanze ausgehenden, sehr diinnen Ästen und Ästchen in wagrechter Richtung (!', fächerförmig, sodaf also die Nitte leer heibt: Benadelung dium und spärlich.

Picea excelsa interrupta Beifnn, bildet alle zwei Jahre (!), l. h. abwechselud mit einem normalen Trieb, einen ganz kurzen, monströsen Trieb, mit breiten, schuppentürnig und dicht anliecrenden Blïttern: es entwickeln sich aber dicse hreiten Blätter nur im ersten Bildungsjahr. 
Picea excelsa adnata Beißn., wunderliche Form, bei der sich jählich aus der Wipfelknospe zwei gleichstarke Triehe entwickehn, die aber wieder zusammenwachsen und hiedurch eine ovale, ringförmige Figur bilden.

Picea excelsa reflexa Carr., eigentiimiche Form, mit im Bogen abwärts gerichteten Ästen und ebenfalls hängenden Hauptzweigen, sowie dichtstehenden, dichtbeblätterten Nebenzweigen.

Picea excelsa monstrosa Hort., ohne Zweige, nur mit einem langen, dicht beblätterten Haupttrieh und einigen Hauptästen; Blätter lang, kräftig.

Picea excelsa Maxwellii Hort, mit kurzen, knopf-oder bischelartigen Seitentrieben und an der Spitze gekriimmten Nadeln.

Picea excelsa monocaulis Nördl., nur mit Nitteltrieb -. selten Äste, - nur an der Spitze Blätter.

Picea excelsa Barry Hort., mit langen, dicken Haupttrieben ind sehr kurzen Nebentrieben.

Picea excelsa Ellwangeriana Hort., von breitem gedrungenem Wuchs und mit kurzen, feinen Blättchen.

Picea excelsa concinna Carr., hellrindige, autstrebende, sehı diinnästige Form, mit dichtstehenden, dünnen, kurzen, anliegenden Blättern.

Picea excelsa attenuata Carr., ïhnlich voriger, mit etwas kräftigeren, öfter's auch gebogenen Zweigen und nicht so dicht stehenden Blättern.

Picea excelsa phylicoides Carr, tine Zwergform von unregelnäßigem Bau, mit dimmen, oft gebogenen Zweigchen und kurzen, starren, scharf'spitzen Blättchen.

Picea excelsa Ohlendorfii Späth, Zwerg-Kegelform, abgestumptt, hübsch zierlich.

Syn.: Picea orientalis pygmaea Hort. compacta Th. Ohlendorf.

Picea excelsa nana Carr., breitrundliche, kräftige Zwergform, mit dichtstehenden, kurzen, an der Spitze etwas monströsen Zweigen.

Picea excelsa nana conica Kihlm., ähnlich voriger, doch mehr gedrungener Wuchs.

Picea excelsa nana variegata Carr., bunte Benadelung. aurea Carr., gelbbunt.

" pallida Hort., griingelb.

Picea excelsa compacta Hort., dichtwiichsige, rundlich breite, kurzblätterige Form.

Picea excelsa compacta pyramidalis Hort., ähnlich voriger, doch mehr aufstrebend.

Picea excelsa Remontii Hort., spitzkegelige Zwergform mit dichter Bezweigung. 
Picea excelsa elegans Hort, hiibsche kleine Kugelform, mit dichter, kurzer Benadelung.

Picea excelsa conica Carr', Kegelfichte, grelrungen wiichsig. und diunzweigig, mit gepreften, feinen, scharf spitzen, blaiulichgrüinen Blättern.

Picea excelsa compressa Schwer., kegelfömige, gedrungene, der vorigen ähnliche Form, mit dichten und aufwärts gerichteten Ästen und kurzen Nadeln.

Picea excelsa Clanbrasiliana Carr., dichte, rundliche Kegelform, dicht und kurzzweigi@, mit rötlichen Knospen und dichtstehenden, derben Blättchen.

Picea excelsa lubecensis Hort. Rose, zierliche, goldgelb austreibende Zwergform mit kurzen Nadeln.

Picea excelsa cellensis Hort. Schiebl., Zwergform mit Ericaähnlichen Zweigen, sowie kurzen, im Austrieb goldgelben Nadeln.

Picea excelsa archangelica Hort., gedrungene Kegelform, kurzzweigig und mit stechenden Blättchen.

Picea excelsa pumila Hort., ganz breitrunde, dichte Form. Benadelung. nigra Hort., wie vorige, dunkelgrüne

Picea excelsa pumila glauca Hort., mit blaugrimen Nadeln. pygmaea Carr., originelles, kegelfürmiges Biischchen, mit vielen kurzen Zweigchen an aufstrebenden Ästchen.

Picea excelsa Gregoryana Hort., von breit-kegelförmigem Wuchs, mit feiner Bezweigung, dicken Knospen und derben, spitzen Blättern.

Picea excelsa humilis Hort, sehr der vorigen ähnliche, platte Zwergform.

Picea excelsa parviformis Hort., niedere, hellgrimnadelige Zwergform.

\section{Syn.: Picea excelsa microsperma Hort.}

Picea excelsa minuta Sr., Zwergform von 40-60 cm Hiihe, aber einstämmig, feinzweigig, mit blaßgriner Benadelung.

Picea excelsa convoluta Beißn., kleine Kingelform, mit kurzen, dichtbenarlelten, tütenförmig gedrehten Zweigchen.

Picea excelsa echinoformis Hort., Tgelfichte, kurzzweigige, igelartige Kugelform. (Von diesbeziglichen Liehhabern oft hoch veredelt).

Picea excelşa Merkii Th. Ohlend, rundlich platte, dicht und kurz, fast krauszweigige Zwergform.

Picea excelsa mucronata ('arr., Zwernform mit mehr ocler' minder ausgebreiteten Zweigen und festen, scharfspitzen Blittern.

Picea excelsa capitata Croux., buschige Zwergform, deren Zweige kopfförmig gehäufte, kurze Triebe tragen.

Picea excelsa procumbens Carr., sich Hach aushreitende, klein- und vielzweigige, dicht- kurz- und feinbläterige Form. 
Picea excelsa dumosa Carr., ähnlich voriger, doch lichter gebaut und mit lichter stehender Nadeln.

Picea excelsa repens Hort., femmadelig, von flach kissenförmigem, kleinem Bau.

Picea excelsa tabuliformis Carr., niedere, feinzweigige, wagrecht wachsende, einer Tischplatte ähnliche Form.

Picea excelsa nidiformis Beifn., mit feiner, hellgrüner, kurzer, gerwissermaßen schichtweise und abgeplattet sich anordnender Bezweigung, olme Mitteltrieb, also mit nestartiger Vertiefung.

Picea Mastersii Mayr. Masters Fichte. WutaishanGebirge in China.

Wohl noch nicht in Baumschulkultur befindlicher, in der Tracht sehr an eine Tamne erinnernder Banm, mit hellgrauer Rinde, erst gelben dann gelblich-weißen Trieben, gelben, stumpfen Knospen, mit vom Zweig abstehenden und fun demselben sehr verschieden großen, $3 \mathrm{~mm}$ bis $18 \mathrm{~mm}$ langen, vierkantigen, allseitig mit weißen Spaltöffnungslinien versehenen Blättern.

Die etwa $5-6 \mathrm{~cm}$ langen und $2^{1} / 2-3 \mathrm{~cm}$ dicken, gelbbraunen Zapfen führen unten etwas gekrümmte, oben abgerundete und etwas gekerbte Schuppen.

Picea Schrenkiana Fisch. und Mey. Schrenks Fichte. Thianschan, Alataugebirge.

Bis $25 \mathrm{~m}$ hoch werdender, pyramidalwiichsiger Baum mit erst aut'strebenden, damn ausgebreiteten und auch etwas hängenden Ästen, eben solchen sowie kahlen, jung graugelben Zweigen. Blätter $2-31 / 2 \mathrm{~cm}$ lang und bis $1^{1 / 2} \mathrm{~cm}$ breit, vierkantig, spitz, stechend, durch die Spaltöffinungslinien blafgriin, nach rorne abstehend, auf hervortretenden, etwas rötlichen Blattkissen stehend.

Die zylinderischen bis walzenförmigen Zapfen werden gut 9) cm lang und $2^{1 / 2} \mathrm{~cm}$ dick, führen ahgerundete, an der Spitze etwas algestutzte, keilfürmig zulaufende, lederartige Schuppen, kleine Brakteen, sowie dunkell,riune, fast schwärzliche Samen mit langen, hellgelben Flïgeln.

Noch nicht in Kultur sind die Formen:

Picea Schrenkiana Loczyi Kanitz.

globosa Schelle. Rundlicher Bau, langzweigig, vielgipfelig, kleinwiichsig. (Fig. 35.)

Picea Morinda Link. Himalaya- oder Tränenfichte. West-Himalaya.

\section{Svnn.: Pisen Smithiane Bedford. Pimes Smithiane Wallich. Abies Khutrou Loud.}

VI

Licbt gleichmässig feuchten Boden, sowie Schutz im Winter gegen kalte scliarfe Winde und starke Sonnenbestrahlung. Leidet durch Späıfröste. 


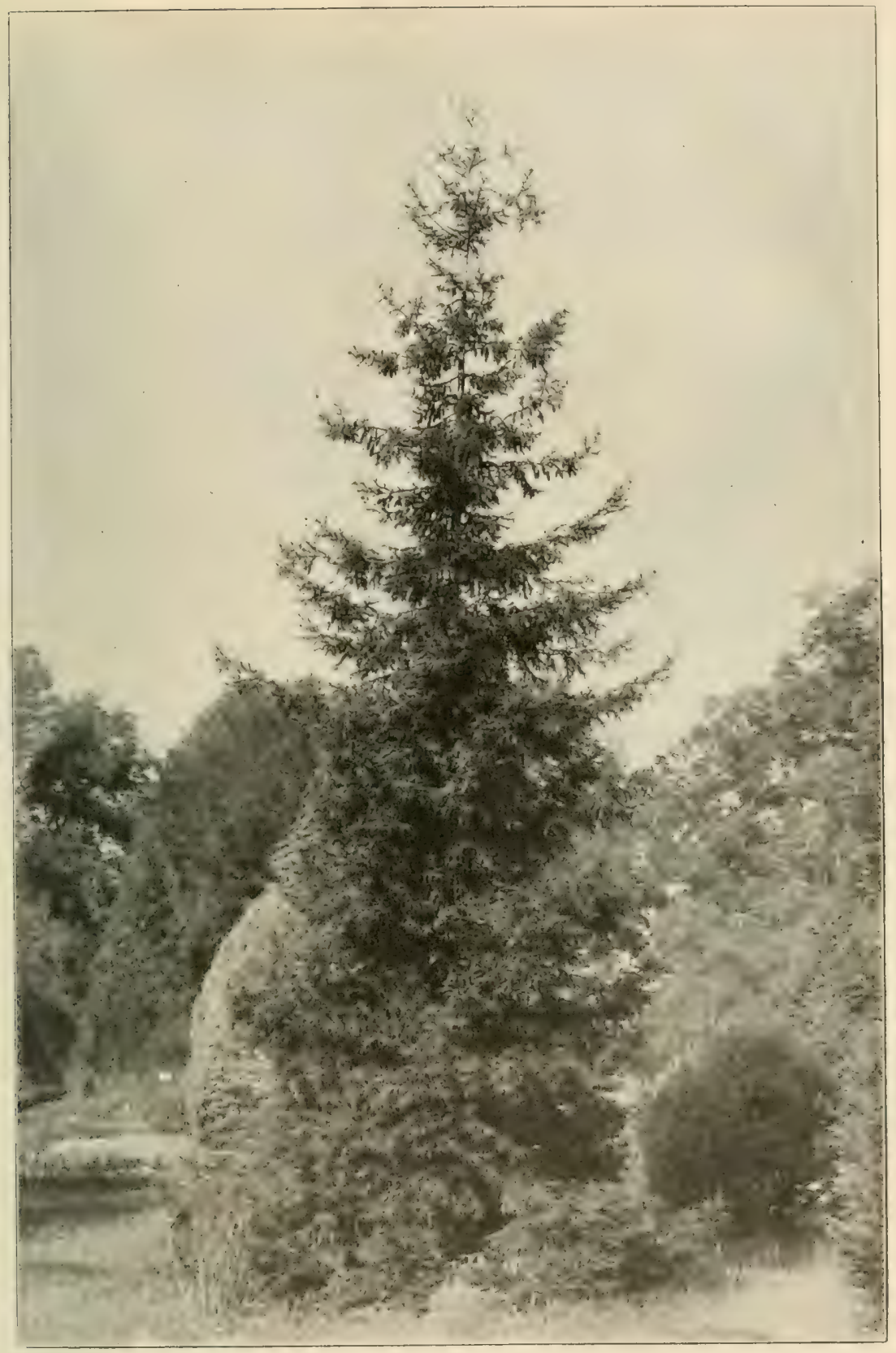

Fig. 35. Ficea orientulis Link (etwa 30 juhrip); rechts unten: Ficen Schrenkinn Fisch. u. Mey. globosa Schelle (2ăjährig). 
Prächtige, iiber $30 \mathrm{~m}$ hoch werdende, schlankvichsice, prramidale Fichte, mit graubramer, sich ablüsender Rinde, zahlileichen, besonders im Alter hängenden Ästen, ebenfalls hïngenden, gelben, kahlen Zweigen mit glänzend braunroten Knospen, sowie $2-4$ (5) cm langen und bis $1^{1} / 2 \mathrm{~mm}$ dicken, vierkantigen, dicht- und etwas abstehenden, stechenden, manchnal etwas gehogenen, lebhaft grinen Blättern, welche auf gelb-

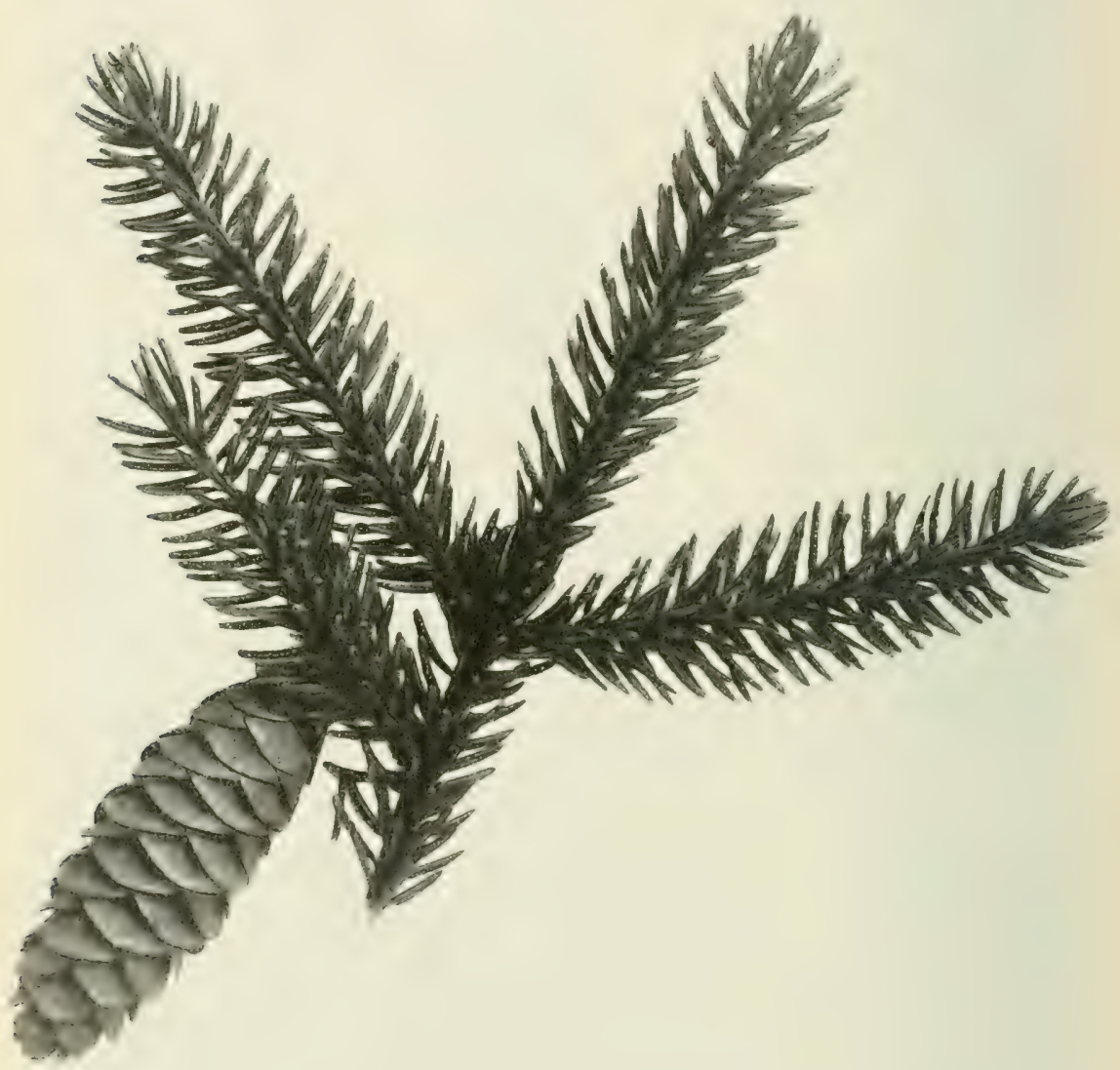

Fig. 36. Ficea orientalis Link.

branen, kantienen Blattlissen stehen. Die Pflanze scheidet helles Harz aus, welches in Tropfen zuletzt an den Blättern hängt mol deshalb zur Jezeichnmon ."Tränenfichte" Teranlassung gab.

Minnlicher Blitenstand in auffallend langen Wiirstchen. stark nit Pollenstaub versehen. Die er'st grinen, damm dunkelbranuen, lïnglich ovalen, 12-15 cm langen und $3-4 \mathrm{~cm}$ dicken 
Zapfen haben verkehrt eiförmige, hart lederartige, glinzende Schuppen, kleine Brakteen und eiförmige, dunkelbrame Samen mit dreimal lïngeren, ziemlich breitem, rotgelblichem Fligel.

In der Heimat ist das Holz als Bau- und Werkholz in Gebrauch.

Es ist bedaurrlich, daß diese schöne Fichte nicht stärkere Kältegrade bei uns aushält.

Als Form wird bezeichnet:

Picea Morinda compacta Beißn., von gedrungenem Wuchs.

Picea orientalis Link. Morgenländische Fichte. Sapindusfichte. Kaukasus, Taurus, Antitaurus. (Fig. Als jüngere 35 und 36.)

Syn.: Abies orientalis Poir.

Schöner, charakteristischer, tiefästiger, 20-25 m Pflanze in kalten Gegenden etwas empfindlich. hoch werdender Baum von pyramidalem aber langsamem Wuchs, mit ausgebreiteten, elegant getragenen, ziemlich quirlig gestellten Ästen und zahlreichen, zierlichen, jung feinbehaarten, bramen Zweigen mit ziemlich spitzen Knospen. Auch diese Fichte scheidet öfters helles Harz aus, welches, an den Blättern häugend, als "Sapindustränen" bezeichnet wird.

Dichtstehend und den Zweig deckend sind die nur 5 bis $9 \mathrm{~mm}$ langen und $1^{1} / 2 \mathrm{~mm}$ starken, breit viereckigen, zum Teil etwas gebogenen, stumpfen bis fast breitgespitzten, glänzend dunkelgrünen Blätter.

Der eiförmig-walzige, $6-8 \mathrm{~cm}$ lange und $2-2^{1} / 2 \mathrm{~cm}$ dicke Zapfen hat abgerundet dreieckige, ganzrandige, liingsgestreifte, matte aber außen glänzendgerandete, lederartige Schuppen mit kleinen, rundlichen Brakteen, sowie kleine, schwärzliche Samen mit dreimal längerem, etwas rundlichem Flügel.

Das harzreiche, dauerhafte und zähe Holz ergibt wertvolles Bau- und Werkholz.

Der Baum ist in unseren Parks besonders als Einzelpflanze cire schöne, elegante Erscheinung.

Formen sind:

Picea orientalis aurea Hesse, mit in Austrieb goldig schimmernden Blättern.

Picea orientalis aureo-spicata Hort. Spee., goldig austreibend. den Zweigen.

nutans Hort. Niem., mit elegant überhängen-

Picea orientalis gracilis Hort. bel心., zierliche und feinzweigige Zwerg-Kugelform.

Picea Glehnii Fr. Schmidt. Glehns Fichte. Amurland, Sachalin, Eso.

Tun Ban und in der Bezweigung an vorige Art erinnernde. in manchen Baumschulen gegenwaitig noch mit P. ajanensis 
und $P$. hondoënsis verwechselte, bis $40 \mathrm{~m}$ hoch werdende, schmalstämnige, ziemlich pyranidalwichsige Fichte, mit grauer, dimner, ahblätternder Rinde, wagrechten, auch etwas hängenden Ästen, kurzhehaarten rotbramen Zweigen und dimnen Knospen.

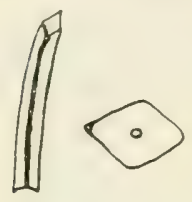

Fig. 37.

Blatt und Blattquerschnitt von ficea Glehnii

Fr. Schmidt.

(Vergrößert.)

Die einwärts gebogenen, stumpf-vierkantigen, 6-7 mm langen und $1 \frac{1}{2}-2 \mathrm{~mm}$ breiten, beiderseits gekielten Blätter haben allerseits, am stärksten aber oben sichtbare Snaltöffnumgslinien, sind außerdem dunkelgrau-grün, abgestumpft, und stehen auf auffälligen, birnförmig erhabenen, oben iibergebogenen Blattkissen.

Zapfen elst purpur- dann blaurot, von langzylinderischer Form, 4-6 cm lang, $2 \mathrm{~cm}$ breit, mit ziemlich rundlichen, endlich verschmälerten, ungleich tief gezähnelten, rotgerandeten Schuppen und kleinen, spitzen, länglich-runden Brakteen. Der kleine, verkehrt eiförmige, bräunliche Samen hat etwa zweimal längeren Flïgel.

\section{Picea Alcockiana Carr. Alcocks Ficlite.} Insel Hondo. (Fig. 38 und 39.)

Syn.: Abies bicolor Maxim.

Picea bicolor Maxim.

Picen japonica Hort. Petrop.

Abies Alcoquiana J. G. Veitch und Lindl.

Abies acicularis Hort.

Spättreibender, dicht pyramidal wachsender Bam mit graubranner, kleinschuppiger Rinde, ausladenden, reichrerzweigten Asten und etwas ibergebogenen, fast kahlen, rotbramen Zweigen.

Die stmpt-vierkantigen, gebogenen und nach vorn gerichteten, 12-18 mm langen und bis $1^{1 / 2}$ mm breiten, zienlich

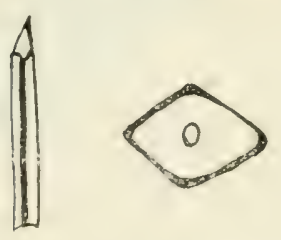

Fig. 38.

Blatt umr Biattiluer-

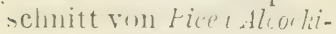
(17m! C:ill'.

(Vererioliert.) dichtstehenden Blätter sind scharfgespitzt, stechend, oben bläulich weißgriun, unten dunkelgrün, meist aber die Oberseite nach unten gedreht(!), auf etwas knotig verdicktem Blattkissen stehend.

Die erst bläulich-roten, dann braunroten, bis $8 \mathrm{~cm}$ langen und $4^{1 / 2} \mathrm{~cm}$ dicken, länglich-eiförmigen Zapfen führen rotrandige, breit-eiförmige, unten verschmailerte, gezidnelte und gestreifte, lederartige chompen, sowie canz lileine, hreitlanzettliche, gezähnelte Brakteen. Der eiförmige, kräftige, dunkelbrame Samen hat einen dreimal längeren, nicht sehr breiten Fligel. 
Tererlelume am besten auf Picea orientalis, ankerdem aut alba oder excelsa.

Das Holz wird besonders als Bauholz verwertet.

Die Alcockfichte der Höhenziige wird als

Picea Alcockiana alpina,

Syn. Picen acicularis Maxim., bezeichnet.

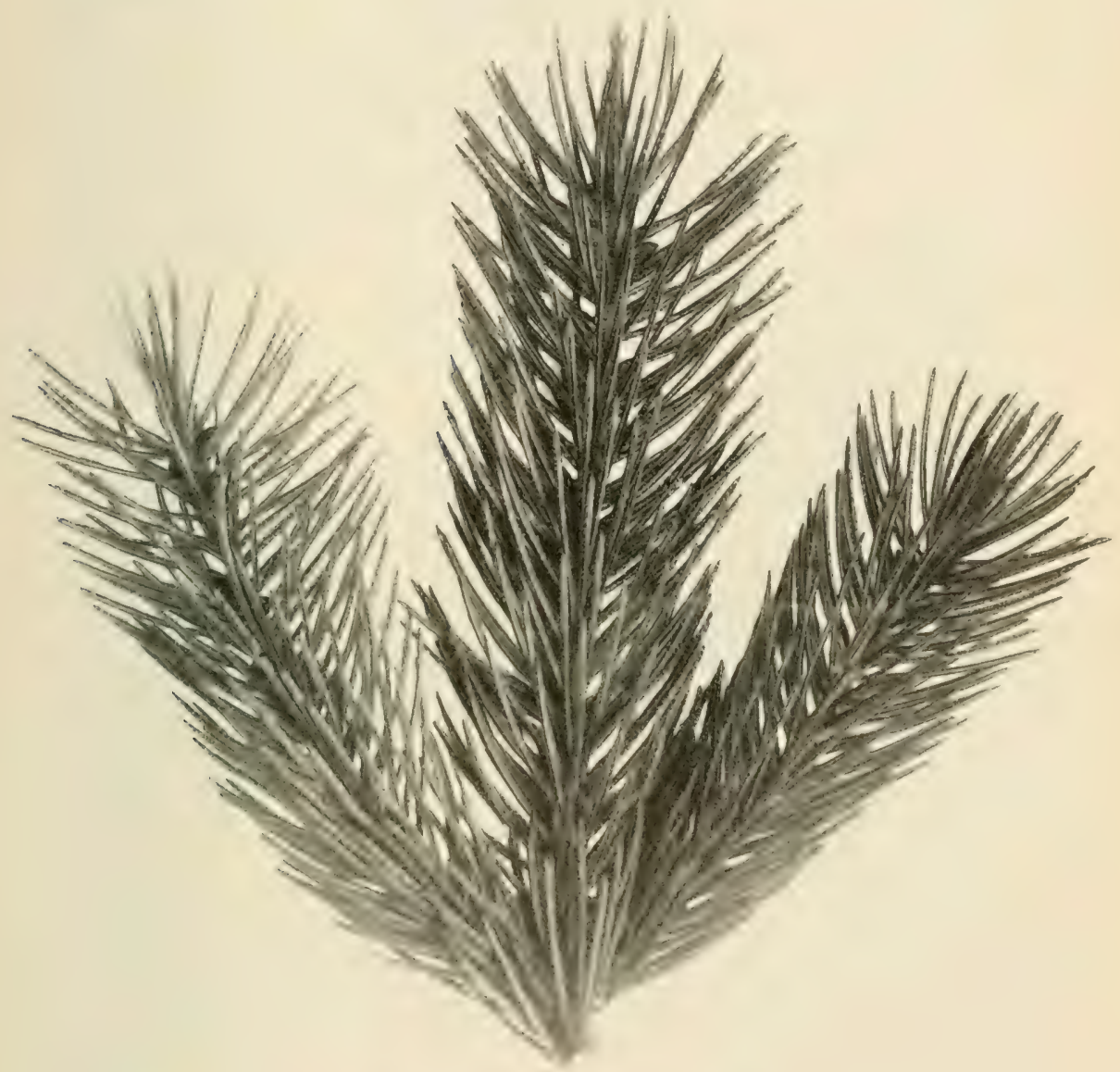

Fig. 39. Picea Aleockiana Carr.

Picea Wilsonii Mast. Wilsons Fichte. China. (?)

In unseren Bammschulkulturen wohl kaum vorhandene und anch noch nicht wanz sicher hestimmte, schione, dichtzweigige Fichte mittlerer Höhe, mit blatioranen $Z$ weigen, ziemlich rundlichen Knospen und 1 cm langen vierkantigen, gebogenen, aller- 
seits mit spaltöffimugen versehenen, spitzen, jung flaunigen Blätern auf flaschenfömigen Blattkissen stehend.

Die $4-5 \mathrm{~cm}$ langen, $3 \mathrm{~cm}$ breiten, Jänglichzylinderischen Zapfen fuihren rundliche, ganzrandize oder etwas gezähnelte. an Raude etwas aufgerollte, keilförnig zulaufende, braunrote, lederartige Schuppen und kleine, schmale Brakteen. Der verkehrt eiförmige Samen liat einen nahezu dreinal längeren Flïgel.

\section{Picea montigena Mast. Berg-Fichte. Höhenziige West-Chinas.}

Ebenfalls bei uns wohl noch in keiner Baumschule kultivierte, bis $20 \mathrm{~m}$ lohe Fichte, mit grauen Ästen, jung rötlichgellen und behaarten Zweigen, breit eiformigen Ḱnospen und vierkantigen, allseitig mit Spaltöffnungsinien verselıenen, dickstumpflichen, 10-12 $11 n$ langen und $1 \frac{1}{2}-2 \mathrm{~mm}$ breiten, genervten und gebogenen Blättern.

Die abgestumpft langzylinderischen Zapfen sind 10-12 cm lang und $+-5 \mathrm{~cm}$ dick und führen längliche, gewellte, abgestutzte, hellbraune und rötlich iiberlaufene Schuppen.

Picea polita Carr. Glattzreigige oder Torano-

Fichte. Gebirge Jord-u. Mittel-Japans. (Fig. 40.) Auf nicht zu teuchtem

Syn.: Abies polita Sieb. und Zuce.

Abies Torano Sieb.

Picea bicolor Horl. (fälschlich).

Schöner, sehr spät austreibender, bei 30 scharfe Winde und starke Sonnenbestrahlung im Winter empfindlich. Gegen Spätfrost fast unempfindlich.

bis $35 \mathrm{~m}$ hoch werdender, jum nicht rasch wachsender (erst rom 10. Jahr ab, mit weiforauer, sich in kleinen Schuppen ahlïsender Rinde versehener Baum, ron liegelförmigem Truchs. mit ausladenden, kriattigen Ästen, hängenden Zweigen, kahlen. selbhraunen, etwas dicken Trieben und grofen, krïtigen, kugeligen, hellbramen, fast roten Knospen. Eine Eigentimlichkeit der Art ist, daß die Wipfeltriebe oft kümmern.

Die dichtstehenden, ringsum gestellten. staren, derben und lehhaft oriunen, mit bliulichen spaltoffinumgsinien versehenen Bläter sind rorwäts gebogen, stmmptkantig. scharf his sehr scharf crespitzt, $13-25 \mathrm{~mm}$ lang, 1 bis fast $2 \mathrm{~mm}$ hreit und lick mol stehen auf stark hervorragenden Blattkissen. An den ailteren, hängenden Zwejgen legen sich die hier auch etwas erriberen Bliitter den Zweigen ziemlich dicht an (!).

Lïnglich-eifömige Form zeigt der erst gelloriune. dann hellhrature Zatpten. welcher $4-12^{2}$ cm lang und $3^{1}-f^{1} 2$ cm dick wirl und zilhleiche. lerlesartixe. Ireit-rundliche, etwas geziahuelte fichupen, hleine, schuale Brakteen. sowie stumptopitze.

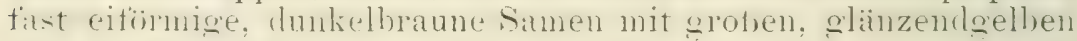
Fligeln führt. 
Das Holz ist in der Heinat zu Hochbanten mol als Werkholz in Verwendung.

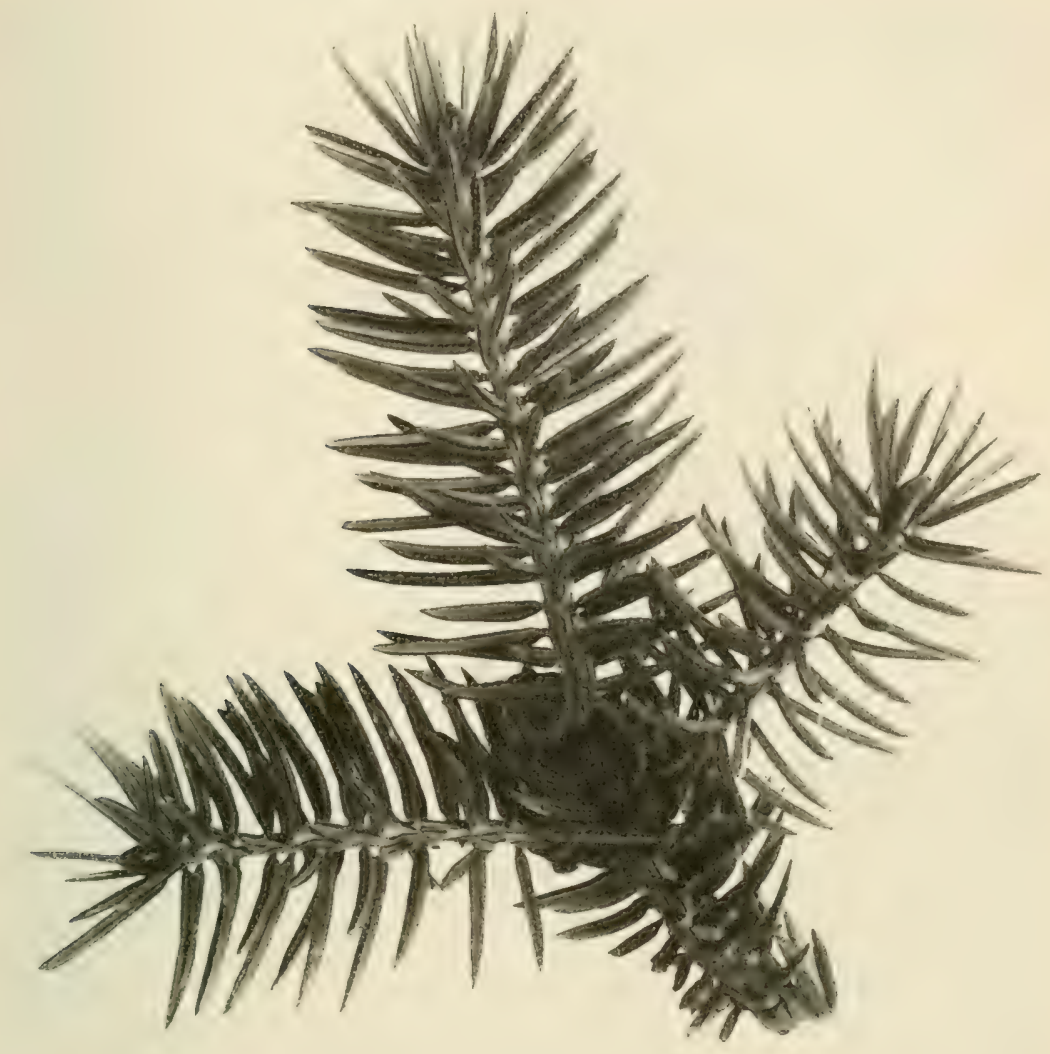

Fig. 40. Picea polita Carr.

Als Form wäre zu nemnen:

Picea polita glauca Hort. Wernig., mit kamn nenmenswerter, bläulicher Färbung.

Picea Breweriana Wats. Brewers Fichte, amerikanische Trauerfichte. Nördl. Kalifornien. Auf nicht zu feuchtem

Noch sehr selten in unsern Parks und Gärten Standort.

anzutreffende, in der Heimat $30-40 \mathrm{~m}$ hoch werdende, mit diinner, roter Rinde versehene, der Picea excelsa im Bau sehn' ähnliche Fichte, deren Ïste wagrecht stehen, aber deren jung bräunlich-filzigen Zweige lang und schlaff, peitschenschnurartip 


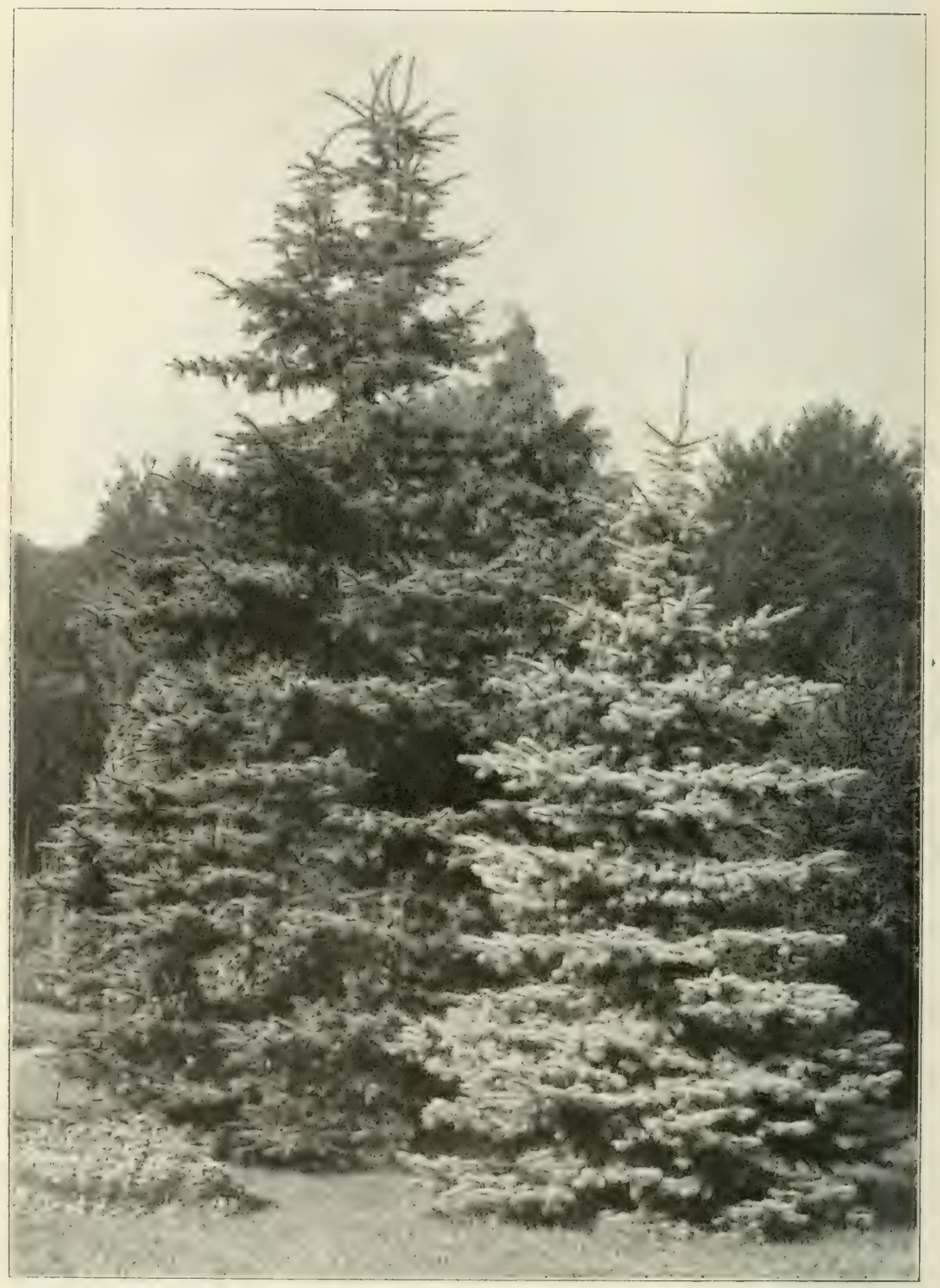

Fin. 41. Picen pungens Engelm. (links, 30 jïhrig): Picen pungens argentea Hort. (rechts vorne, etwa 25 jährig). 
herabhïngen. Knnospen hellbram mit z. T. zuridckeroilten Schuppen.

Dite lehlaft wrinen, oben mit Mittelners, muten meist mit schwachem Kiel, sowie mit weiblichen spaltittnumshinen ressehenen Blaitter werten 1s-28 mm lang und 2 mm hreit, fiilnem

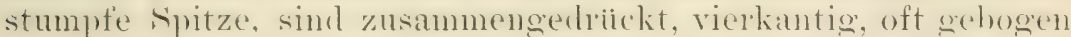
und stehen anf langen, gekriimmten Blattkisisen. C'her den wanzen Bam verteilt zeigen sich die glanzend-hrantuen, schmalzylinderischen. 4 -. 9 cm langen und his 3 cm dicken Zapfen, welche rerkehit eirunde, diime, glattrandige, unten weichlsehante Schuplen, schmale, ganz kurze Brakteen mol kleine, etwas lingliche Samen mit dremal längerem Fliigel fiihren.

Das weiße, zälie $\mathrm{Holz}$ ist wertvoll.

Picea pungens Engehm. Stechende Fichte. [Felsengebiroce Nord-Amerikas. (Fig. 41 und 42.) Liebt etwas feuchten,

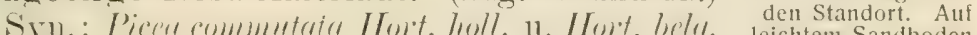
Picea Parryana Barr.

leichtem Sandboden schlecht wüchsig.

Frätig wachsende, (jun allerdings etwas gegenStanbund Rauch. langsam), his $40 \mathrm{~m}$ und mehr hoch werdende, prichtip pyramidalwiichsige, mit wrauer, rissiger Rinde ausgestattete Fichte, deren wasrecht abstehende Aste ziemlich quirlig gestellt sind. Zweige dicht und etwas nmregelmäßig gestellt, gelbbraun, kahl und mit in ihrer Art einzig dastehenden, sehr großen, dicken, bräunlichen Knospen, mit zuriickgeschlagenen, etwas eingerollten Schmpen, hiedurch schon auf einige Entfernung erkemnbar.

Die ebenfalls dicht und rings um den Zweig stehenden, etwas graugriunen, leicht gebogenen Blätter sind $1^{1} / 2-3 \mathrm{~cm}$ lang, $1^{1 / 2} \mathrm{~mm}$ breit, stunpti vierkantig, geprefst, an älteren Zweigen mehr flach und stehen auf hervortretenden Blattlissen.

Zapfen länghich-walzenförmig , 8-10 cm lang und $3 \mathrm{~cm}$ fick, hellhraun, mit welligen, ausgerandeten, dimmen Schmpen und sehr kleinen Brakteen.

Der ovale, braune Samen hat ziemlich breiten Flügel.

Forstlich selbst an nassen und bruchigen Partieen empfohlen; fast ganz frei von Wildverbiß.

Ist schon die Art sehr schön, so haben wir in einzelnen Formen wahre Schmucksticke fiur unsere Parkis und Gïrten.

Picea pungens glauca Hort., von prächtiger, blaner Färbung. pendula Koster, durch abwärts gebogene Äste und schläf hängende Zweige mit gleicher Fäbung wie vorige ausgezeichnet.

Picea pungens coerulea Hort,, mit weißblatuer Benadelung. argentea Hort. (Fig. 41 und 43),

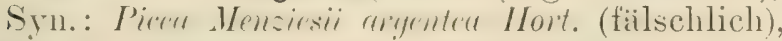
wunderoll silberweif! Ein Paralestiick fiir jeilen Garten. 
Größere Anpflanzungen ergeben einen großartigen, ganz eigenen Anllick. Leider fallen Sämlinge dieser (und der iibrigen Formen) nur zu einem geringen Prozentsatz wieder rein aus.

Besonders reinweiße Exemplare, oft auch noch durch schönen, gleichmäßigen Bau ausgezeichnet, erhalten von ein-

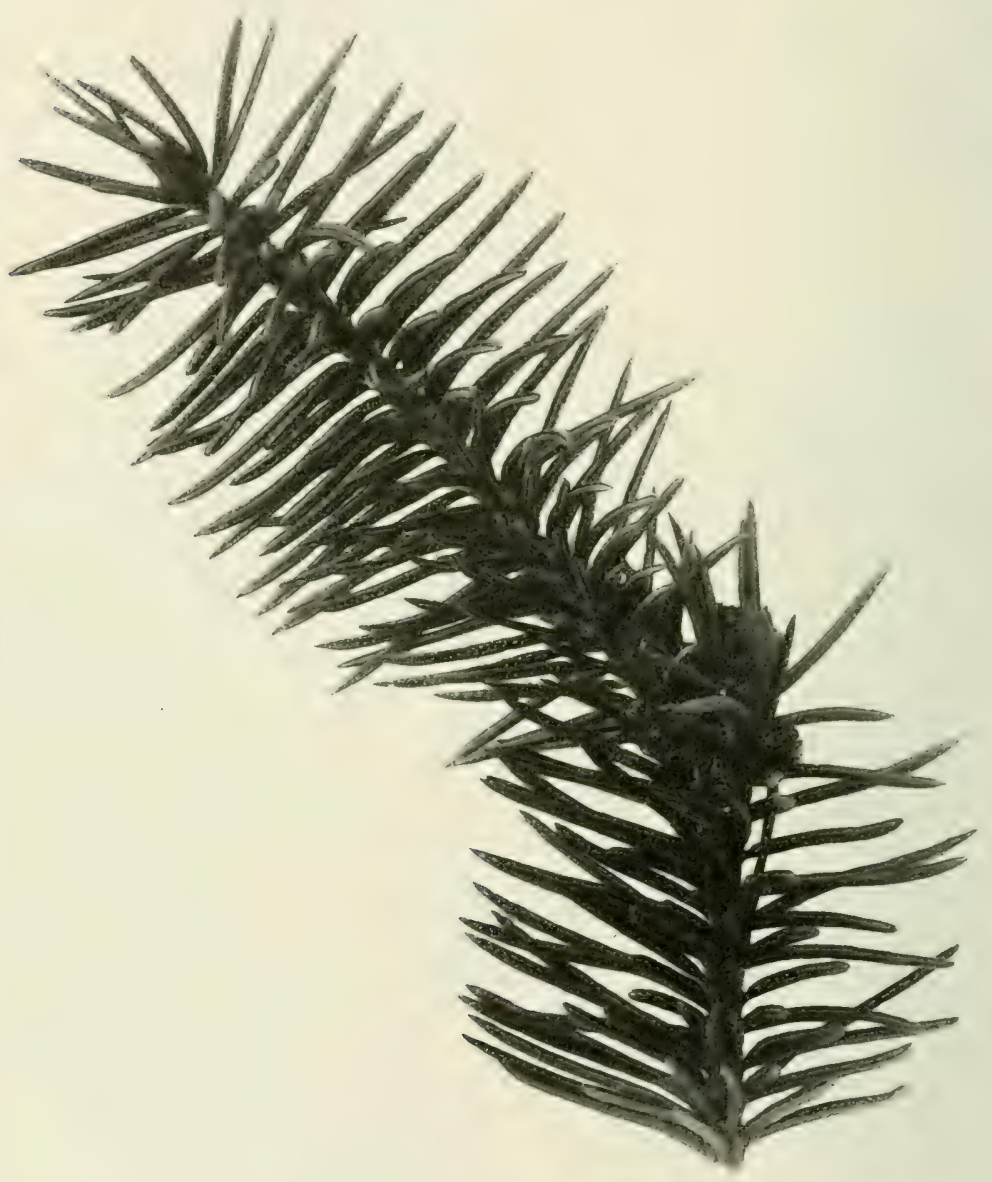

Fig. 42. Picea pungens Engelm.

zelnen Zuichtern noch besondere, meist zueignende Personemnamen, z. B. Fiirst Bismarck, König Albert.

Picea pungens Kosteri Hort. holl, prächtig blau, langnadelig. Nadeln. aurea Hort. Niem., mit schönen, goldgelben 


\section{$-97$}

Picea pungens flavescens Hort. Niem., von eigentimlicher, in der Sonne weißgelber Färbung der Nadeln.

Picea pungens columnaris, sïulenartiger Wuchs.

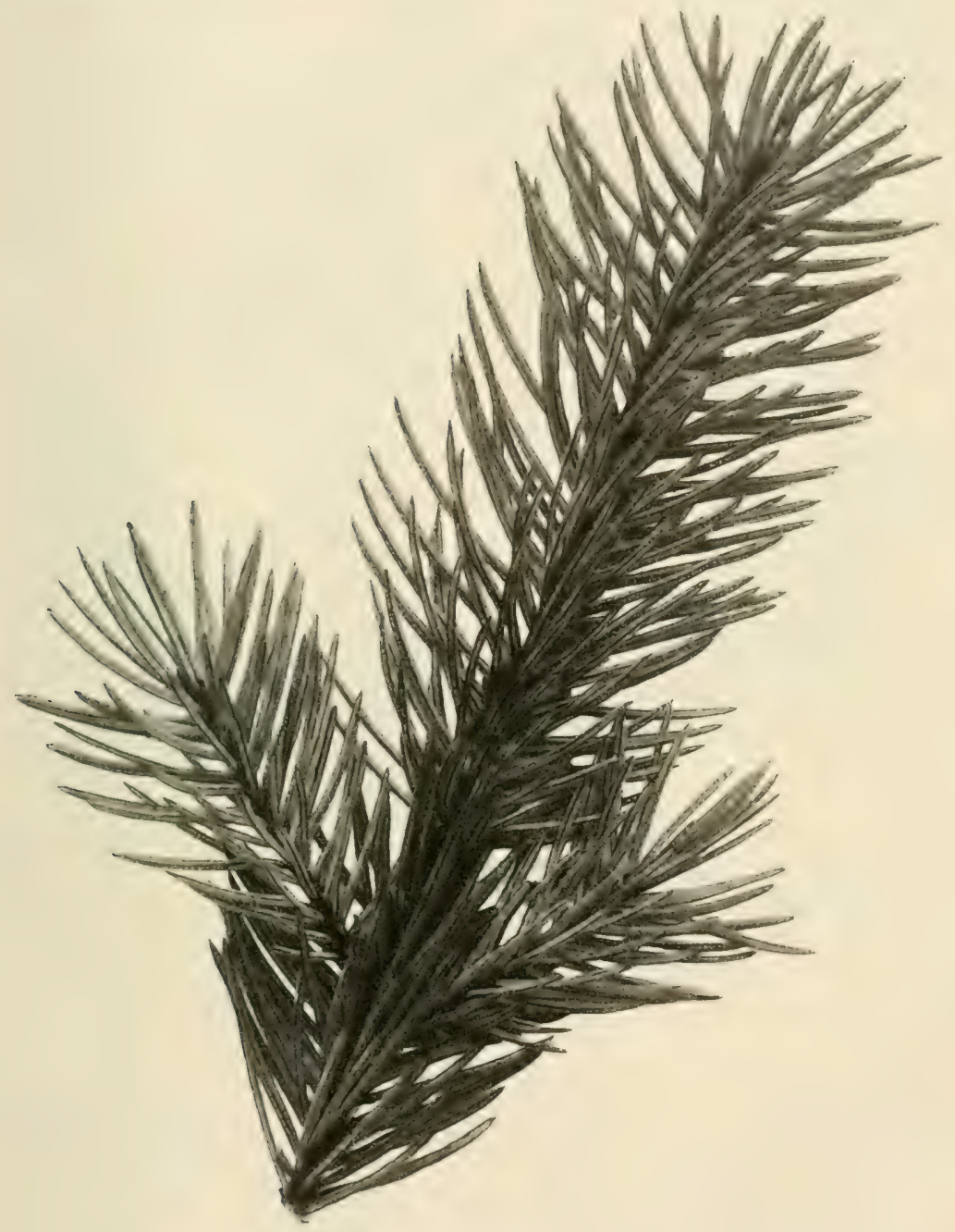

Fig. 43. Picea pungens Engelm. argentea Hort.

Picea pungens glauca prostrata Hort. Ansorg., ohne Mitteltrieb, knieholzartig, mit ausgebreiteten Ästen.

Picea pungens glauca aurea Hort. Petrop,, goldcelbnadelig. Schelle, Koniferen. 
Picea Engelmannii Engelm. Engelmamns Fichte. Felsengebirge Nordamerikas.

Syn.: Picea pseudopungens Dieck.

Leidet manchmal durch Spätfröste.

Pyramidal aber langsam wiichsige, bis uiber $40 \mathrm{~m}$ hoch werdende Fichte, mit diimner, brauner, abschuppender Rinde, wagrecht abstehenden Ästen, kurzbehaarten, rötlichgelben Trieben und gelblichen, bald austreibenden Knospen.

Die dunkelgrïnen, vierkantigen, etwas gepreßten, mit bläılichen Spaltöffnungslinien auf allen vier Seiten versehenen, nach rorne gerichteten, nicht besonders starren Blätter sind 17 bis $20 \mathrm{~mm}$ lang und $1^{1 / 2}-2 \mathrm{~mm}$ breit, etwas gebogen, dahei spitz und stechend.

Die rötlichlramen, länglich-eiförmigen Zapfen werden 4 bis $6 \mathrm{~cm}$ lang und bis $3 \mathrm{~cm}$ dick und führen verkehrt eiförmige, ungleich gezähnelte, gestreifte Schuppen, sowie ähnlich geformte, kleine Brakteen.

Der kleine, braune, ovale Samen hat dunkelbräunlichen, ziemlich doppelt so langen Flügel.

Das weiche, schöne weiße Holz ist gesucht, ebenso die zu Gerbezwecken dienende Rinde.

Formen sind:

Picea Engelmannii glauca Hort., mit sehr schöner, blaugrüner Benadelung.

Picea Engelmannii glauca pendula Beißn.: (Purp.), ebenso blaugrün, doch mit hängenden Zweigen und Ästen.

Picea Engelmannii glauca aurea, ganz gelb-blätterig. Form. argentea Hort., sehr hiibsche, silbergraue

Picea Engelmannii pendula Hort. Wernig., mit hängenden Ästen, sonst wie die Stammform.

Picea Engelmannii microphylla Hesse, kleinblätterige Ku ugelform. Columbiana,

Syn.: Picer" Colmultimun Lemm., eine in allen Teilen kleinere Gebirgsform.

Picea alba Link. Weiße Fichte. Östliches Nord-Amerika, von der Hudsonbai biș Karolina Kümmert I auf trockenem (Fig. 44 u. 45).

Syn.: Abies alba Michx.

Bis zu 20-25 m hochwerdende, duimstïmLuft. Erträgt windige (aber feuchte) Stellung, deshalb auch Dünenbaum. mige, pyramidale, nur in feuchtem Boden raschwiichsige Fichte, mit ausladenden, ziemlich quirlig gestellten Ästen und zahlreichen, erst gelblichen, dann bramen, rosa bereiften, rauhen Trichen mit hell-gelbbramen Knospen.

Die meist licht $1 \mathrm{~m}$ den Zrveig gestellten, etwas nach rome grebogenen, 10-18 mm langen und 1 mm breiten Blätter sind 
ausgesprochen rierechig, etwas stumpf zugespitzt, wrumpin. durch die Spaltofthmuren tast blangrion, heim Zerreiben stark aromatisch, etwa mach schwarzen Johamisbeeren riechend.

Reizend machen sich die rötlichen. mainnlichen Bliten.

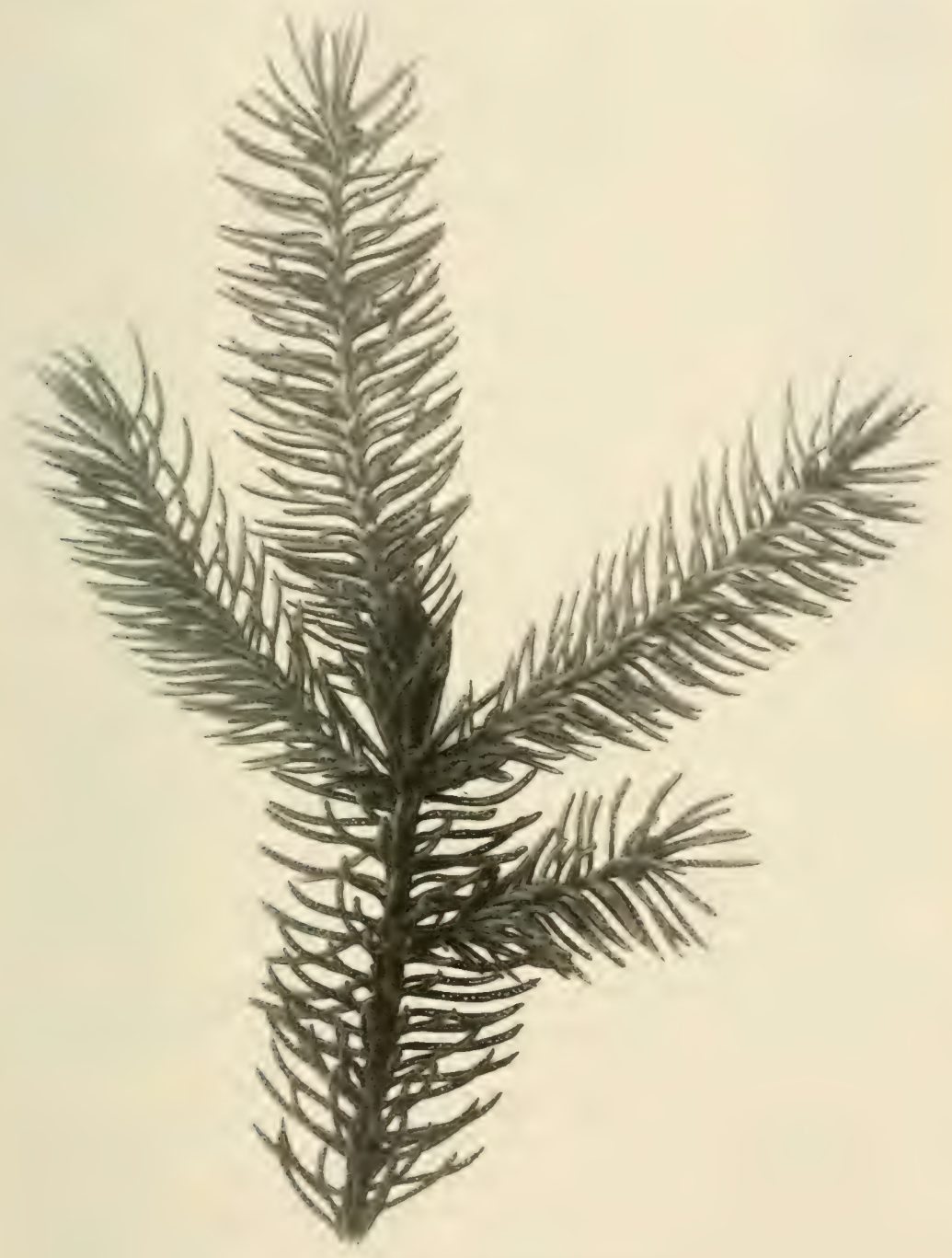

Fig. 44. Picea alba Link.

Die kleinen, 3-5 $5^{1 / 2} \mathrm{~cm}$ langen und $1^{1 / 2}-2 \mathrm{~cm}$ dicken, länglich-ralzigen, erst grum bis hellgrinen, damn hellbramen 
Zapfen führen diinne, gewölbte, gestreifte, am Rande glänzende, Treit-herzförmige, biegsame Schuppen, kleine eiförmige Brakteen und ganz kleine, dunkelbraune Samen,

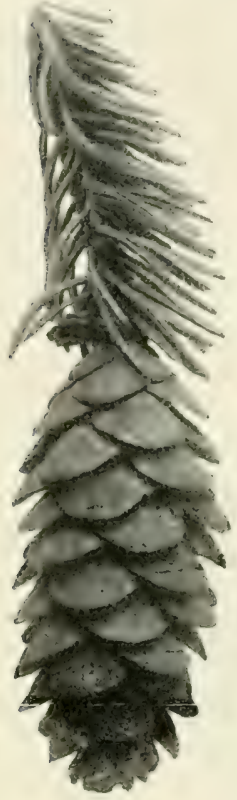

Fig. 45.

Zapfen von Picen alba Link. mit gut dreimal längerem, gelbem Flügel.

Das nicht sehr hervorragend gute $\mathrm{Holz}$ wird als Bau- und Werkholz benuitzt.

Diese Art liefert passende Unterlagen zu Pfropfungen von Picea Alcockiana, P. pungens und auch P. Engelmannii.

Formen sind:

Picea alba coerulea Hort., Schimmelfichte, schöne, blaugrüne bis weißlich-blau-grüne Form, von etwas gedrungenem Wuchs.

Syn.: Abies rubra coerulea Loud. Picea rubra coerulea Hort.

Picea alba coerulea hudsonica (Hudsonii) Hort, mit erst wagrechten, dann etwas hängenden Ästen und ganz blauen Nadeln.

Picea alba aureo-variegata Hort. amer., teils gelbe, teils goldgelbe Triebe.

Picea alba aureo-spicata Hort. Karol., gelb austreibend.

Picea alba aurea Hort., kräftige, goldgelbe Form.

Picea alba variegato-spicała Beißn., mit eigentiumlich griin und weiß gezeichneten Nadeln.

Picea alba acutissima Hort, mit diinneren und spitzeren Blättern als die Stammform.

Picea alba pendula Hort, Häuge-IVeiBfichte, hübsche, blaugraue, stark hängende Form.

Picea alba fastigiata Carr., mit aufstrebenden, etwas sparrigen Zweigen und dicken, scharfgespitzten Blättern.

Picea alba wörlitziensis Hort. Späth., gedrungen pyramidalwiichsig, mit feinen, etwas aufstrebenden Zweigen und bläulichen, etwas kurzen Nadeln.

Picea alba compacta pyramidalis P. Smith, zierliche, blaugraue, kleinblätterige Zwergpyramide.

Syn.: Picea alba compacta gracilis Breinig.

Picea alba pinsapoides Beißn., anfrechte Form, nit kurzen, fiast monströsen Zweigchen und rings un den Zweig gestellten, haugrinen, nur 5-12 mm langen, etwas spitzigen Blättchen.

Syn.: Picea pinsapoides Hort. Tottenh.

Picea alba compressa Hort., bläuliche, dichte, zierliche Kingelform. 
Picea alba nana Hort., hreite, rundliche, nicht hochwerdende Form mit weitgestellten Nadeln.

Picea alba glauca Hort, blaugrine Zwergform.

echinoformis Carr, ganz dicht- und kleinzweigige, später breit werdende, dichtbeblätterte Kugelform.

Jhr nahe stehend, vielleicht Abart (nach Rehder) ist

Picea Albertiana St. Brown. Alberta-Fichte. Camadische Provinz Alberta. - Est eingefuihrte, schmal pyramidalwichsige Fichte, mit wellhramen, unbereiften Zweigen, bliulichen, einwiirts gekrimmten, starr gespitzten Blätern, sowie eiformigem, $2^{1 / 2}-3^{1} / 2$ cm langem Zapfen mit imen zimmtbramen, autien kastanienbramen Schuppen.

Picea rubra Link. Amerikanische Rotfichte. Nordöstliches Nord-Amerika, von Neu-Schottland Liebt feuchte Luft und Nortusthiches Nom feuchten Boden; und Neu-Fundland bis zu den arktischen Regionen. kummert bei Trocken-

Ein schlanker, pyramidaler, bis $20 \mathrm{~m}$ (und mehr) hochwachsender Bamm, ofters mit Picea excelsa und P. alba verwechselt, aber durch feineren Bau und kiirzere Benadelung sich auszeichnende Fichte, mit ähnlicher Beastumg wie genamnte Arten, sowie mit kurzbehaarten, rotbramen Zweigen.

Die glänzend lebhaft grimen, ziemlich derben, starren, aber etwas gebogenen, rundlich-viereckigen, kurz gespitzten Blätter sind $1-1^{1 / 2} \mathrm{~cm}$ lang und $1^{1 / 2} \mathrm{~mm}$ breit.

Ziemlich lang hïngen hleiben die an kurzen Zweigen befestigten, erst rötlich-violetten, dam glänzend rotbraunen, harzigen Zapfen, welche $3-4 \mathrm{~cm}$ lang und $1^{1 / 2}-2 \mathrm{~cm}$ dick verden und fast herzfömige, gewolbte, etwas gezähnelte und cestreifte Schuppen, kleine, spitze Brakteen, sowie kleine, schwärzliche, oft sehr spitze Samen mit fast dreimal so langem Flügel führen.

Sehr gesucht ist das der Art ihren Namen gebende rötliche Holz.

Eine Form ist:

Picea rubra virgata Rehul die schlangenförmise Rottichte. mit sehr langen Asten ohme Nebenäste.

Picea nigra Link. Schwarzfichte. Kanada bis Nord-Farolina (Fig. 46).

Syn.: Abies nigra Michx.

Auf nicht zu trockenem. eher feuchtem Standort.

Abies Mariana Miller.

Schmal pyranidal and ziemlich langsam wachsender Baum von 20-25 $1 \mathrm{~m}$ Höhe, nit schwarzlicher Rinde, quirlförmig gestellten, erst warrecht ausladenden, dann etwas gesenkten Aesten und rauhen, gelbbraunen, feinbehaarten Zweigen und gelb- his rotbraunen Knospen. 
Die 7 -12 mm langen und bis $1^{1 / 2} \mathrm{~mm}$ breiten, dichtstehenden. ganz dunkelgrinen, mit weifblanen Linien versehenen Blätrer sind gepreßt vierkantig, zum Teil gebogen, dünn, stumpfgespitzt, beim Reiben angenehm riechend.

Nännliche Blüte aufrecht stehend!

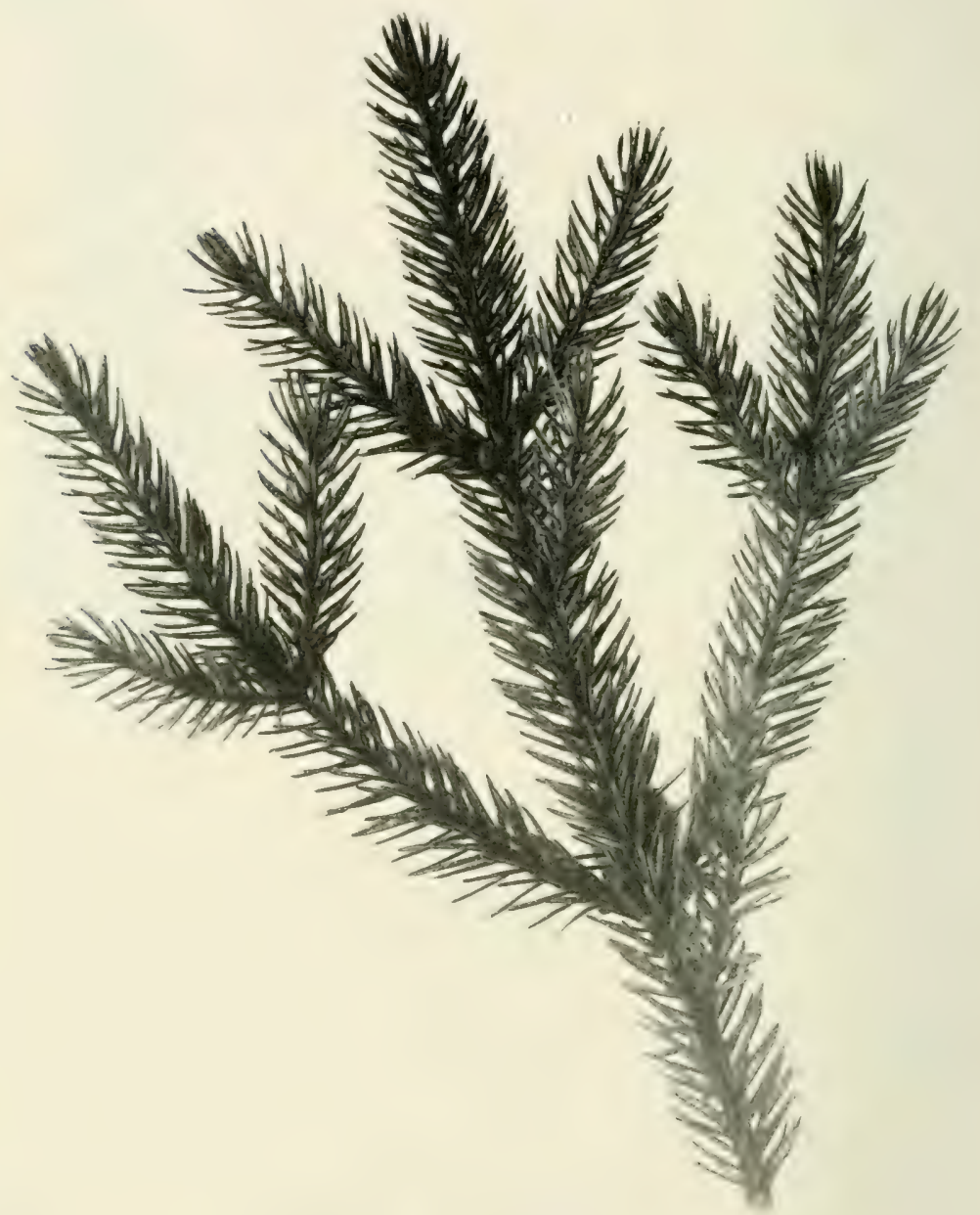

Fig. 46. Picea nigra Link.

Erst violetthraun, dann rothraun zeigen sich die kleinen, $2-3^{1}$ 2 cun langen mul $1,3-1,8 \mathrm{~cm}$ dicken, auf kleinen gebogenen Stielen und oft gehiäuft stehenden, meist lange am Bam hängen

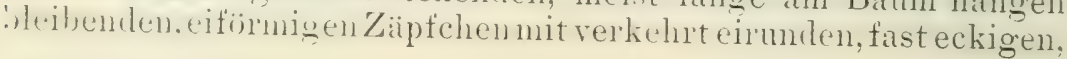


gezähnelten, etwas welligen, diumen, gestreiften Schupıen, kleinen spitzen Brakteen, sowie kleinen, dunkelbramen Samen mit dreimal längerem Flïgel.

Das zähe, weîe Holz ist weniger als Butholz, mehr aber als Werkholz in Verwendung.

Die jungen S'srossen liefern Material zur Bereitung des sogenannten Fichtenbieres, (Spruce beer).

Die aus stecklingen erzogenen Pflanzen zeigen stets einen etwas kleineren, gedrungenen Wuchs.

In der Heimat soll es auch eine rotholzige Form geben. In Kultur sind:

Picea nigra aurea Hesse, mit goldig schimmernden Nadeln. argenteo-variegata Hesse, eine weißbunte Form.

Mariana Hort., Wilhelmshöher Schwarzfichte. Im Gesamtbild wundervoller, breit kegelförmiger, niederer Baum, mit dichter Bezweigung und kurzen, schönen, blaugrimen Nadeln.

Die Mutterpflanze, ein prachtvolles Exemplar, steht frei auf dem Rasen auf Wilhelmshöhe bei Kassel.

Die Vermehrung dieser For'm geschieht durch Stecklinge und Ableger.

Picea nigra Doumettii Carl., ebenfalls prächtige, an vorige erimernde Form, nu schlanker und noch kegelförmiger aufgebaut, sowie mit fast violett-grünen Blättern.

Picea nigra pendula Schwer., mit sehr stark hängenden Zweigen. fastigiata Carr., niedere, kurzblïtterige Säulenform. nana Hort., von hiibschem, kugeligem Zwergwuchs. brevifolia Rehd.

Syn.: Picen brevifolia Peck.

Abies brevifolia Hort. amer.

Eine wohl noch nicht, oder auch ganz wenig in unseren Baumschulkulturen befindliche, aus den Mool- und Sumpfgegrenden ihrer Heimat stammende Form, von strauchiger oder kleinbaumartiger Gestalt, mit ganz kurzen, derben, stumpfen bis stachelspitzigen, blaugriuen Blättern. Die oralen Zapfen haben erst griue mit rötlichem Rande versehene, dam purpurrot werdende Schuppen, sowie kleine Samen mit doppelt so langen Flïgeln.

Picea nigra semiprostrata Rehd., wie vorige, aber strauchartig kriechend bis aufsteigend.

Picea neoveitchii Mast., von Mest-China, ist hei mis noch nicht in Baumschulkultur.

Eine mittelhoch werdende, glatt und hellbraun-zweigige Fichte, mit vierkantigen, aller'seits mit spaltüfthumgsinien velsehenen, gebogenen, $15 \mathrm{~mm}$ langen Blaittern und etwas gelirimmten, läglich-zylinderischen, zugespitzten, wellhramen 
Zapfen, welche schief länglich-runde, wellige, aber ganzrandige, schwach zugespitzte Schuppen führen.

II. Abteilung: Omorica Willkomm., Fichten mit tamenartigen Blättern.

Blätter umgedreht, zweiflächig, beiderseits stark gekielt, aber nur oberseits mit Spaltöffnungshlinien. Zapfen hängend oder abstehend.

Picea Omorica Panč. Omorika-Fichte. Höhenzïge von Bosnien, Serbien, MLontenegro, Westbulgarien Jung etwas (Fig. 47).

Jung etwas langsam wachsende, dann aber etwa vom sechsten Jahr ab sich kräftig und schmalpyramidal auswachsende Fichte, nit dünner, bramner, in Stücken sich lösender Rinde, alt etwas gedrehtem Stamine, oben fast wagrecht ausgebreiteten, unten im Bogen sich wieder aufrichtenden, schlanken Ästen und etwas hängenden, kaum behaarten, graubräunlichen Zweigen und ähnlichłarbigen Knospen. Die linealen, vierkantig-breitgedrückten, den Zweig nahezu deckenden, 8 bis $14 \mathrm{~mm}$ langen und bei $2 \mathrm{~mm}$ breiten, beiderseits gekielten, rasch in eine kurze Spitze zulaufenden Blatter stehen (umgedreht) auf abstehenden, etwas riickwärts gerichteten Blattkissen, und zeigen unterseits (weil gedreht: oberseits) eine glänzendgrüne, unten mit weißlichen Spaltöffnungslinien versehene Färbung.

Die schmal-zylinderischen, spitz zulaufenden, erst bläulichschwarzen, reif hraunen Zapfen sind liängend oder abstehend, mit rundlichen, gewölbten, welligrandigen, etwas gestreiften Schuppen, ganz kleinen Brakteen und dunkelbramen, kleinen Samen mit fiust dreinal so langem, bräunlichem Flïgel.

Die Keimlinge zeigen, wie die echten Fichten, an Samenund Erstlingsblättern etwas Bezahnung.

Das Holz wird in der Heimat zu Standbäumen und als Bauholz verwendet.

Eist neuerdings wird die typische Form von wohl allen Batumschulen verbreitet; vorher war dieselle nur in botanischen und ähnlichen Gärten und nur in zwei Handelsbaumschnlen, welche Anfang's der achtziger Jahre des vorigen Jahrhunderts vom Entcecker Sinnen erhielten - so auch der hiesige Garten echt vorhanden; andernfalls war es immer nur die vegetativ vermehrte Jugendform der Art.

Veredlung am besten auf Picea orientalis.

Picea ajanensis Fisch. Ajan-Fichte. Ost-Sibirien, Ajan bis zunn Amurgebiet, Sachalin, Kurilen, Iturup bis Eso (Fig. $48-50$ ). 


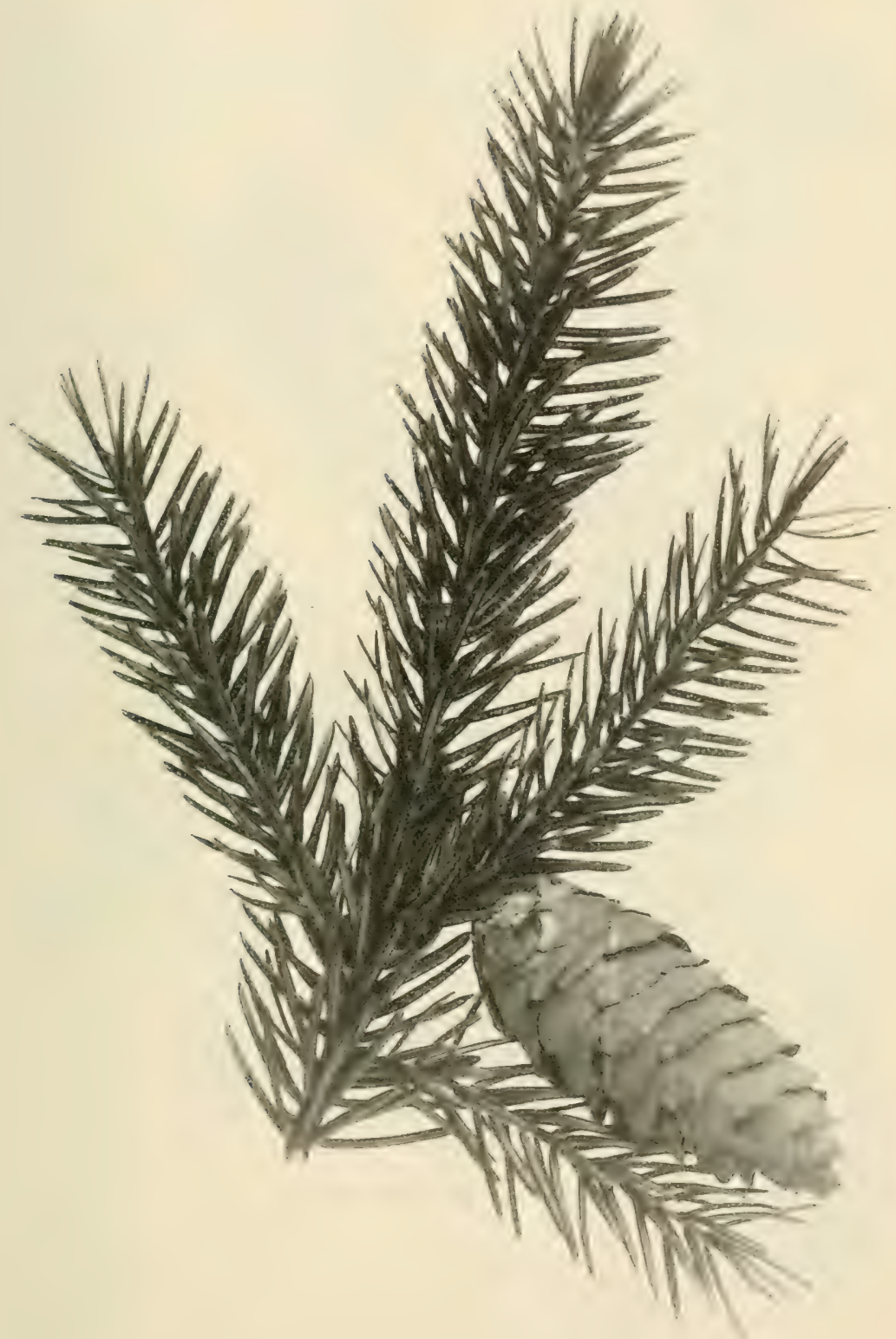

Fig. 47. Picea Omorica Panč. 
Syn.: Abies ajanensis Lindl. und Gord. Abies Alcoquiana J. G. Veitch (fälschlich).

Picen jezoënsis Carr.

Ein $30 \mathrm{~m}$, in der Heinat selbst bis $60 \mathrm{~m}$ hoch werdender Baum, mit ziemlich glatter, grauer, sich in kleinen, sechseckigen Schuppen lösender Rinde, steif wagrecht abstehenden, auch

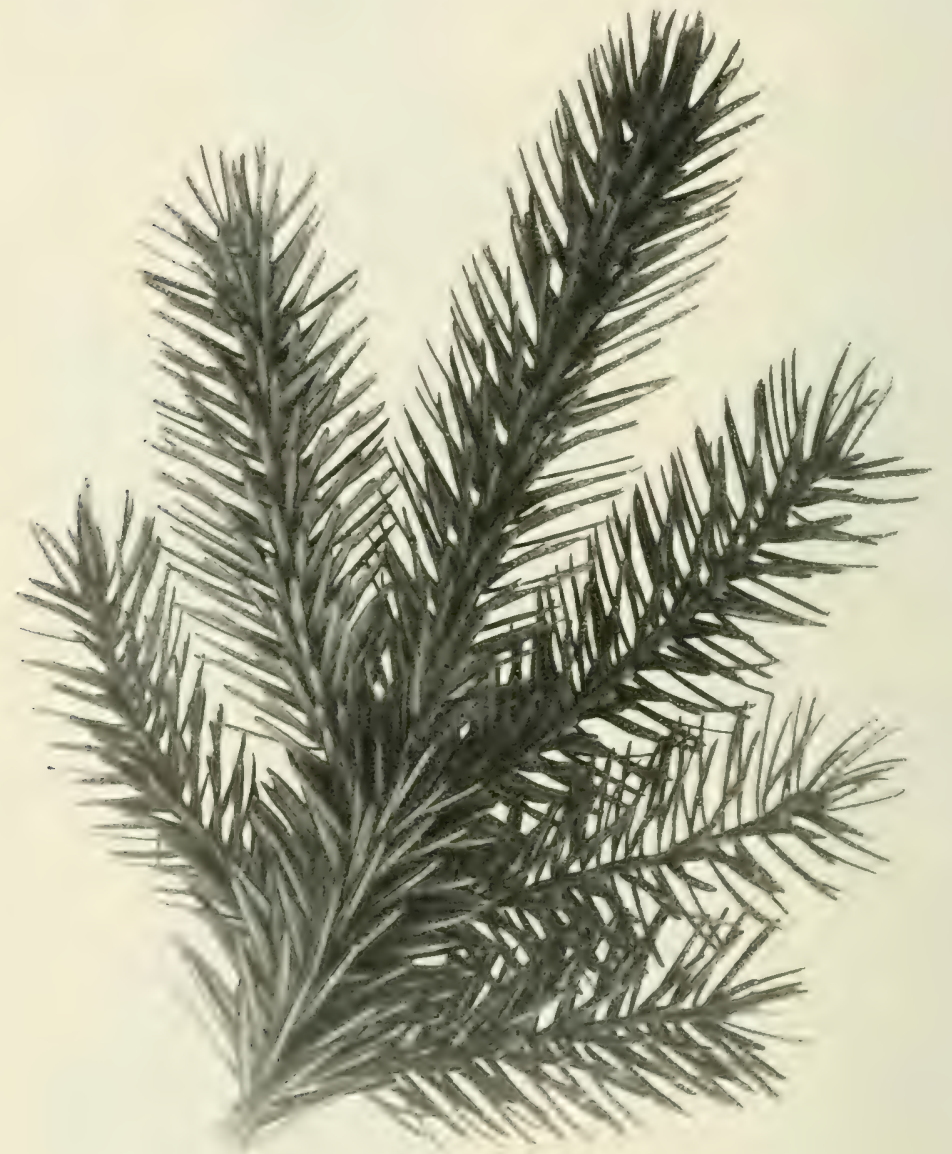

Fig. 48. Picea ajantnsis Fisch.

etwas ïherhängenden Ästen und ziemlich eben solchen, kahlen, grelblichen (!). sehr rauhen Zweigen und gelbbramen Knospen. Die spiralis, dicht und aufoerichtet stehenden, zum Teil auch \%weizeilig cestellten, etwas gebogenen, stumpfen bis gespitzten, stark cekielten Blatter werden bis 2 cm lang und 
$1^{1 / 2-2} \mathrm{~mm}$ breit, sind umgedreht - oberseits bläulich silberweiß, unterseits (also num oben) glänzend dunkelgriin und stehen auf hervortretenden Blattkissen.

Der erst purpurfarbene, dann hellbraune, abgestumpft schmal-zylinderische, $5-7 \mathrm{~cm}$ lange und bis $3 \mathrm{~cm}$ dicke Zapfen hat oval-abgestumpft eckige, diinne, gewellte, tief (!) gezähnelte Schuppen und kleine, schmale Brakteen.

Der kleine Samen führt doppelt so langen, etwas einseitigen Flügel.

Das besonder's als Werkholz gesuchte, gelblichweiße $\mathrm{Holz}$ ist leicht und weich.

\section{Eine Form ist:}

Picea ajanensis aurea P. Smith, mit besonders in Austrieb goldgelber Benadelung.

Als ein sehr interessanter Bastard wäre zu nennen:

Picea Moserii Mos. (Picea ajanensis $\times$ Picea nigra

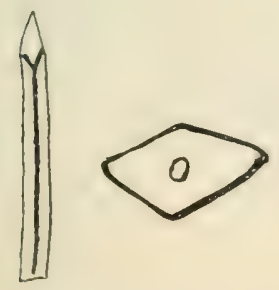

Fig. 49.

Blatt und Blattquerschnitt von ficer ajanensts Fisch.

(Vergröłert.)

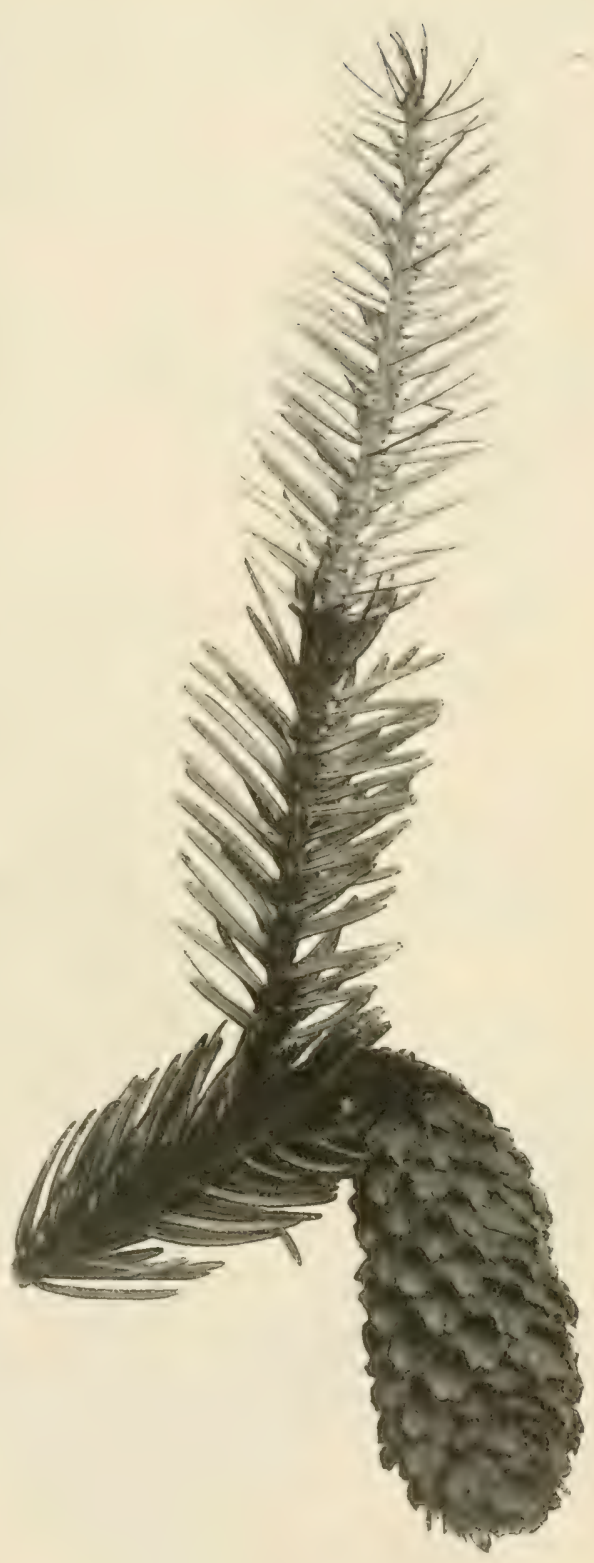

Fig. 50.

Zapfen und (rïckseitiger) Trieb von ticea ajanensis Fisch. 
Doumettii), mit brauner Rinde, geschwungenen Zweigen, sowie auf vorstehenden Blattkissen stehenden Blättern, deren obere und

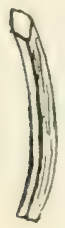

mittlere dem Zweige angedriickt sind.

Picea hondoënsis Mayr. HondoFichte. Hochgebirge der Insel Hondo. (Fig. 51.)
Syn.: Picea ajanensis var. microsperma Mast. $" \quad$ " $\quad$, japonica Maxim. " microsperma Carr.

Fig. 51.

Blatt und Blattquerschnitt von Ficen honloënsis Mayr. (Vergrößert.) d. h. Gebirgsform der vorigen Fichte betrachtet), bis $30 \mathrm{~m}$ hoch werdender, im Habitus auch dieser gleichender, nur in allen

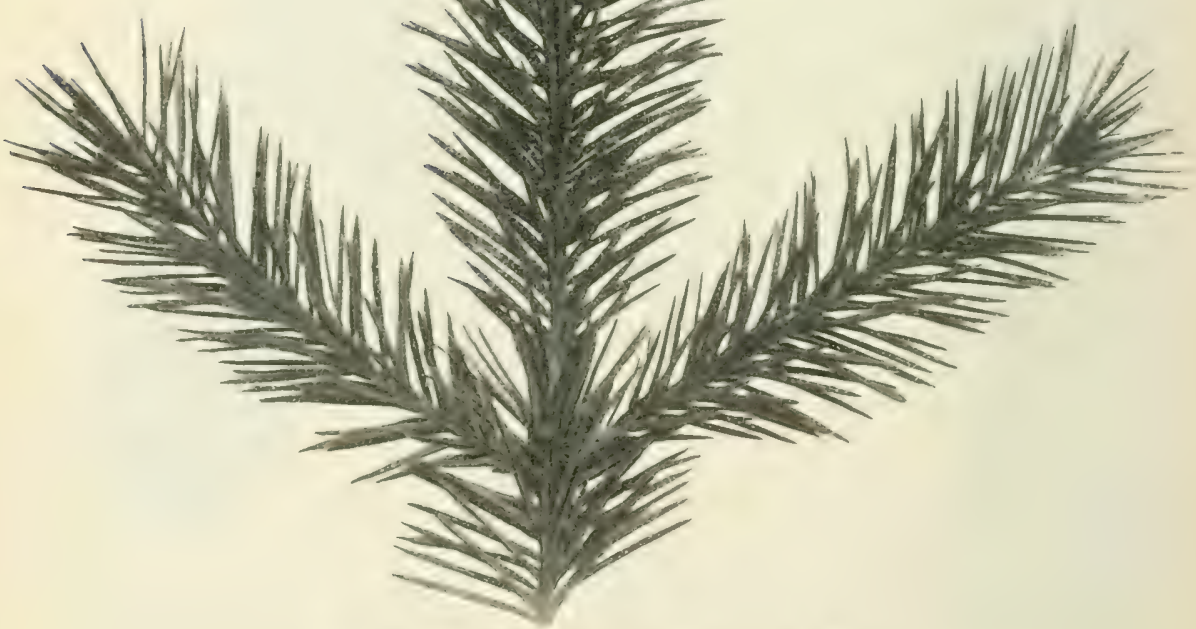

Fiщ. 52. Ficea sitchensis Trautr. u. Mey. 
Teilen kleinerer Baum, welcher sich durch mehr in rundlichen Stiicken ablösender Rinde, harzige Knospen der hell- bis rötlich-braunen Triebe, sowie kiirzere und stumpfere Nadeln, welche auf stark hervortretenden Blattkissen stehen, die zwei Rinnen zeigen, unterscheidet.

Der Zapfen ist etwas kürzer als bei voriger Art.

Das Holz fuihrt zum Gegensatz von Picea ajanensis rosafarbenes Kernholz.

Picea sitchensis (sitkaënsis) Trantv. und Mey. II Sitka-Fichte. Von Sitka und Vancouver durch Britisch- Liebt feuchte Kolumbien bis Vord-Kalifornien und Kolrado. (Fig 52 . Luft und feuchSyn.: Abies Menziesii Loud.

Raschwiichsige (besonder's vom 10. Jahr ab) bis (Kalkboden unzir 30 Kümmert in $21130 \mathrm{~m}$, In der Heimat selhst his $60 \mathrm{~m}$ hoch wer- heissen, diurren dende, im Wuchs der Pseudotsuga nahezu gleich zu $\begin{gathered}\text { oder schweren } \\ \text { Böden. Gegen }\end{gathered}$ stellende, starkstämmige Fichte, von pyramidalem Frühfröste ist Wuchs, mit diunner, rotbramer, in Schuppen aufreißen- Pie ganz junge der Rinde, quirlig, wagrecht und dichtstehenden, be- empfindlich. sonders im oberen Teil mehr aufstrebenden Ästen, sowie kahlen, dicken, fast steifen, durch die Blattkissen sehr rauhen, gelblichen Trieben mit gleichfarbigen, ovalen Knospen.

Die rings um den Zweig gestellten, teils etwas zweiseitig gerichteten, feinen, dabei aber ziemlich starren, spitzen und stechenden, 1-2 cm langen und $1 \mathrm{~mm}$ breiten, oft etwas gebogenen Blätter sind flach-vierkantig, beiderseits gekielt, gedreht und unterseits (also eigentlich oben) griun, oberseits mit weißen Spaltöffnungslinien versehen.

Der oval-zylinderische, gegen die Ansatzstelle etwas gekruimmte, sonst stumpf zugespitzte, erst gelbgriine, dann glänzend ockergelbe, $6-8$ (selbst bis 10 ) $\mathrm{cm}$ lange und $2^{1} / 2-3 \mathrm{~cm}$ dicke Zapfen hat längliche, in eine breitgestutzte Spitze zulaufende, diimne, ungleich tief gezähnelte, rimmige Schuppen und mittelgroße, lanzettförmige Brakteen.

Der kleine, rotbraune Samen zeigt stark doppelt so langen, ziemlich schmalen Fliigel.

In der Heimat sehr gesucht, bei uns in forstlicher Kultur ebenfalls schon erprobt und anerkannt ist das ausgezeichnete, leichte, weiße bis hellbräunliche Holz.

Es wird behauptet, daß diese Fichte noch unsere gewöhnliche $P$. excelsa vielerorts verdrängen werde.

Als Form wird genannt:

Picea sitchensis speciosa Beißn., eine etwas gegen scharfe Kialte empfindliche, schwachwiichsige Fichte, III mit mehr aufstrebenden Ästen, kiurzeren, steiferen, scharf ge- 
spitzten und stäker hlanweif gezeichneten Blättern ausgezeichnet.

Picea spinulosa Griff. Feinnadelige Fichte. Himalaya, bei über $3000 \mathrm{~m}$ vorkommend.

Syn.: Abies spimulosa Grift.

Picea morindoides Rehd.

Picea Alcockiana var. morindoides Wottet.

Picea microsperma Hort. Allard.

Wohl kaum in unseren Baunschulkulturen vorhandene, schlankpyramidalwichsige Fichte, nit quirlig gestellten, ausgebreiteten, Aesten und meist hängenden, diunen, glatten, erst gelblichen dam graugelblichen Zweigen, mit eiförnigen, gelbbraunen Ḱnospen.

Die flachen, linealen, geraden, dimnen, breit viereckigen, gekielten, $2^{1} / 2$ bis $3^{1 / 2} \mathrm{~cm}$ langen und bis $1,2 \mathrm{~mm}$ breiten Blätter führen oberseits (durch Drehung nun unterseits) zwei weife Spaltoffnumgshinien, haben unterseits dunkelblau griune Färbung, sind mit stechender. Spitze ausgestattet und stehen auf diunem, @elblichem Nadelkissen; auch legen sie sich dem Zweig auf der Oberseite ziemlich an.

Zapfen länglich, $8 \mathrm{~cm}$ lang und $3-4 \mathrm{~cm}$ dick, erst griun bis rötlich grïn, reif glänzend gelbbram, mit spatelförmigen verkehrt eifömigen - jung purpurgerandeten, an der Spitze abgestutzten, gezïhnelten und welligrandigen Schuppen, sowie kleinen spitzen, länglich eiförmigen Brakteen.

Samen hell graubram, verkehrt eiförnig, mit ziemlich gleichförmigem, fast dreimal so langem Flïgel.

Picea complanata Mast. Flachblätterige Fichte. Westliches China.

Nicht leicht bei uns schon in Baumschulkultur befindliche, bis zu $30 \mathrm{~m}$ hoch werdende Fichte mit gelbbraunen, glatten Zweigen, durch Drehung unten (eigentlich oben) grinen, oben mit bläulichen Spaltöffnungslinien versehenen, stark gekielten, schwach viereckigen, spitzen, 20-22 $\mathrm{mm}$ langen und $1 \mathrm{~mm}$ breiten Blättern auf hervorstehenden, schief dreiseitigen Blattkissen, sowie zugespitzt-zylinderischen, jung purpurroten, reif brannroten Zapten, mit länglichen bis rundlichen, gezähnelten, am Rande leicht umgebogenen Schuppen.

\section{2. 'Tsuga Carrière.}

Hemlockstanne, Schierlingstanne.

Immergrune, kleine bis hoch werdende, durch ihre Benarlelung, sowite durch die Zïpfchen sofort auftallende, meist licht mid elegant gebaute Biume, mit pyranidaler bis schmal- 
kegelförmiger Krone, ziemlich reichlichen, mehr oder minder breit ausladenden und an den Spitzen auch etwas iiberhängenden Ästen, - ebenso der Gipfel, - unregelmäbig gestellten, dünnen, ebenfalls etwas hängenden Zweigen.

Die tammenartigen Bliatter sind Hach, aber auch eckig, schmal lineal, spirali@ bis fast zweireihig gestellt, kurz- und gekniet-stielig, mit schwach verdicktem Blattkissen, oben ziemlich dunkelgriin, auch glïnzend, unten mit weiflichen Spaltöffnungslinien; dabei nur einen (!) Harzgang fiihrend. Knospen mit Schuppen bedeckt.

Blite monözisch; männliche achselstiundig, klein, rund bis lïnglich, spiralig gestellt, dicht beschuppt, gelblich: weibliche endstindig, einzeln, rund, griunlich, dicht beschuppt und mit doppelten Schuppen. Samenknospen umgerventet, mit der Samenschuppe zusammenhängend.

Zapfen meist klein, hängend oder nickend, rundlich bis länglich, locker gebaut, nach der Samenreife noch sehr lange an Baume hängenr, mit kleinen Brakteen.

Die Samen sind sehr klein, eiförmig bis ziemlich eckig, mit weicher Schale, mit Harzheulen und fest verwachsenem Fliigel; Keimung nach wenig Wochen. Der Keimling führt 3 (-6) Samenblätter.

Vermehrung der 'Tsuga meist aus importierten Samen, der' aber z. Z. immer noch nur in etwas mangelhaftem Zustand erhälthlich ist; durch Stecklinge von weichen Trieben der inneren Zweige, sowie durch Pfropfung auf die Stammformen, bezw. auch auf Tsuga canadensis.

\section{Abteilung: Eutsuga Engelmann, Hemlockstamen.}

Blïtter flach, ziemlich stumpf, am Rand fein gesägt, Spaltoffnumgen nur auf der Unterseite. Zapten klein, nur bis zu $2^{1 / 2} \mathrm{~cm}$ lang.

Tsuga canadensis Carr. Kanadische H. Kälteres Nordamerika, speziell von der Hudsonbay bis Nord-Karolina (Fig. 53-55).

Syn.: Abies canadensis Michx.

Eleganter, bis $30 \mathrm{~m}$ hoch werdender, ctwas langsam wiichsiger, wenn freistehend besonders In melir feuchtem als trockenem Boden; kümmert bei heibem, trockenem Standort.

Erträgt Überschirmung durch andere Bäume, liebt aber freie Lage. im Alter prachtvoller Baum, wirklicher Zierbaum, von pyramidalem, oft auch gegabeltem Wuchs, erst brauner, dam grauer Rinde, weit und fast wagrecht ausgebreiteten, aufien iiberhängenden Ästen, sowie zahlreichen, erst gellgrimen, damn brïunlichen, jung weichbehaarten Zweigen.

Die Blätter stehen fast zweireihig, werden bei $1^{1} \frac{2}{2} \mathrm{~cm}$ limg und $1,1,2-2 \mathrm{~nm}$ breit, sind flach, lineal, etwas steit, stumpef, 


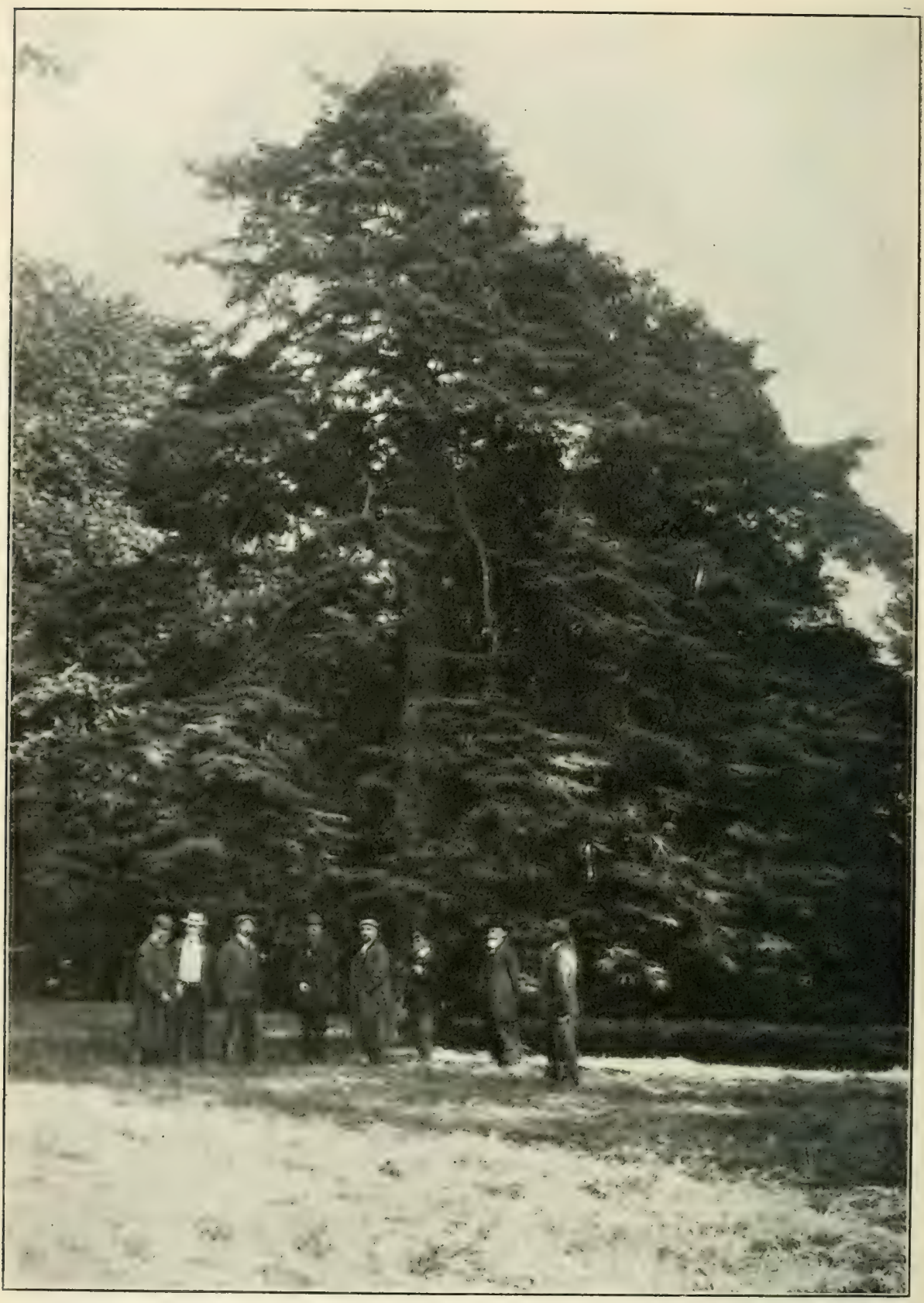

Fig. 53. Tsuga canadensis Carr., 120jähriger Baum.

(Ans: Mitteilungen der (leutschen dendrologischen Gesellschaft.) 
vorne kaum merklich gesiigt, oberseits gerimnt, glinzend griun, unterseits mit weißen Spaltölfnungslinien, dabei fein, kurz, hell-

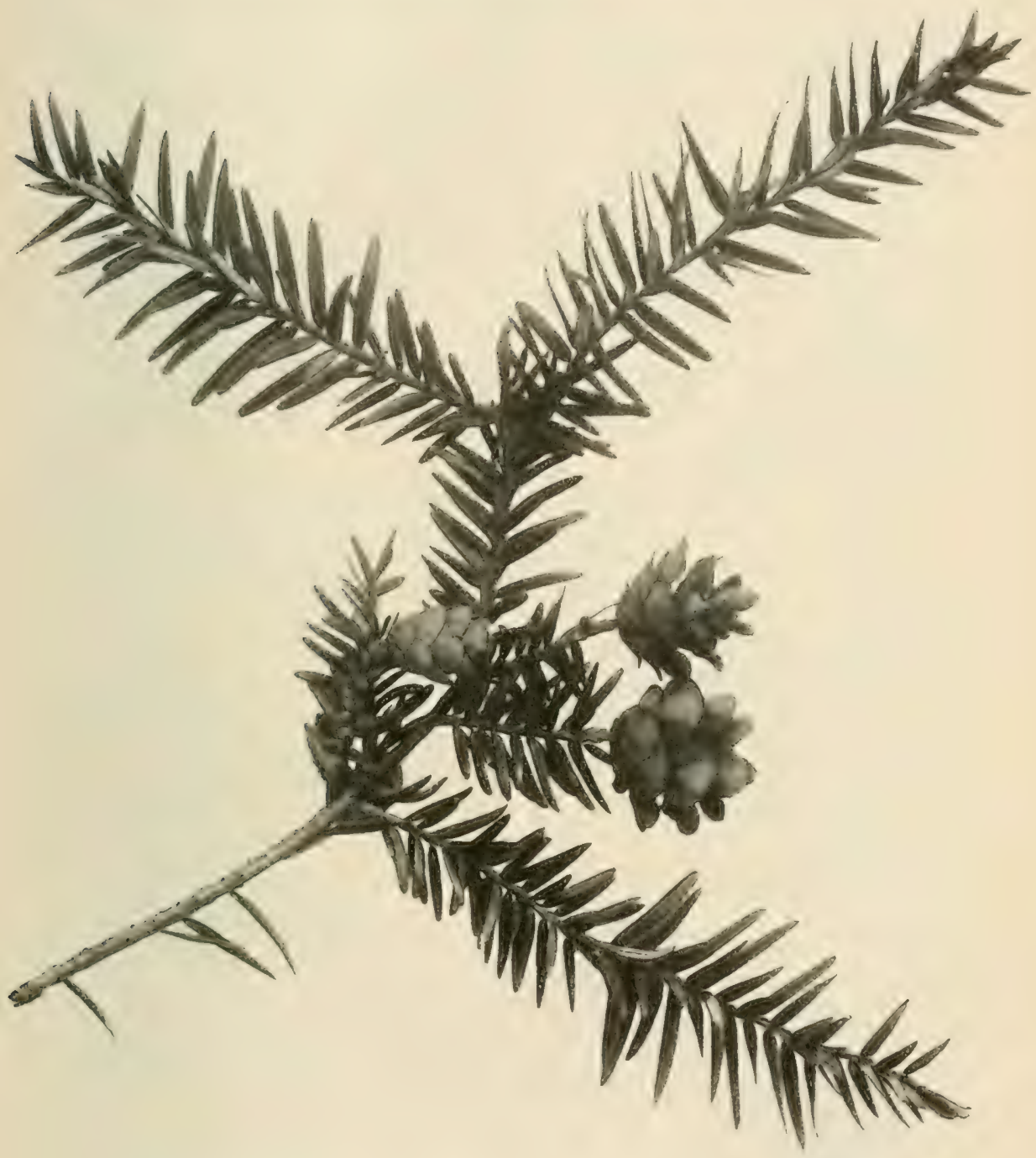

Fig. 5t. Tsuga canadensis Carr. (mit geöffneten Zäpfchen).

gelb gestielt, auf rötlichen Nadelkissen stehend. Auffallend sind die am Trieb oberseits stehenden, meist sehr kleinen Blätter. 
Die reizenden, kleinen, erst grimen dann braungelben, hängenden Zäpfchen sind $17-25 \mathrm{~mm}$ lang und $12-15 \mathrm{~mm}$ breit, eiförmig oder etwas länglicher, ziemlich locker, mit gebogenen,

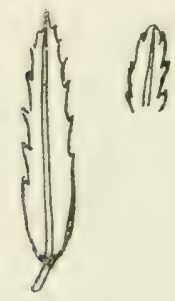

Fig. 55.

Blatt und stumpfe

Blattspitze ron

Tsuga conadensis

Carr. (Tergrößert.) feinen Schuppen und kleinen, a bgestutzten Brakteen, nicht abfallend; überhaupt bleiben die Zapfen nach dem Samenausfall auch das folgende Jahr noch hängen. Der Samen ist gelblichbraun, oval, mit einem um ${ }^{1 / 3}$ längeren Flügel.

Das harzarme, weißliche Holz wird ähnlich unserem Tannenholz verwendet. Die Rinde liefert hochgeschätztes Gerbematerial (wie alle T'sugen), sowie Terpentin und CanadaBalsam.

Die einen Bitterstoff enthaltenden jungen Sprosse werden zu einer Art Bier (Spruce beer) benützt.

Formen sind:

Tsuga canadensis aurea Hort., goldgelbe Form. albo-spica Hort., mit weißen Zweigspitzen. argentea Hesse, mit silberweißen Spitzen. argenteo-variegata Hort., silberweiß-bunte

Form.

$" \quad " \quad "$

Tsuga canadensis gracilis Hort., gedrungen wiichsig, mit kurzen Blättern und hängenden Zweigen.

Tsuga canadensis pendula Hort, eine zweimal so breit als hochwiichsige For'm, prächtig in Bögen überhängend.

Syn.: Tsuga canadensis Sargentii pendula Hort. amer.

Tsuga canadensis fastigiata Hort., mit stark aufstrebenden Zweigen.

Tsuga canadensis columnaris Bolle, eine echte Säule bildend. microphylla Hort., eine eigentuimliche, auffallende, feine Form, mit nur $1 / 2 \mathrm{~cm}$ langen und $1 \mathrm{~mm}$ breiten, unten weiß gezeichneten Blättern.

Tsuga canadensis parvifolia P. Smith, ähnlich voriger, mit nur noch etwas kleineren Blättern, ohne weiße Zeichnung.

Tsuga canadensis sparsifolia Beißn., auffällige Form, mit unregelmäßig um den Zweig gestellten Blättern.

Tsuga canadensis nana Carr., niedere, buschige Form. minima Hesse, zierliche, niedere Form. hübsch "艹berhängend. compacta Beißn., gedrungen wüchsig,

Tsuga canadensis compacta nana Hort., niedere, mehr oder minder kugelige Form. 
Tsuga canadensis globosa Itort., reizende, regelrechte Kinelform.

Tsuga Mertensiana Carr., Mertens H. Westliches Nordamerika, von Alaska bis Mittel- Liebt etwas feuchten tiches Nontanenika, von Alaska his andent und freie Lage kalifornien.

\section{Syn.: Abies Mertensiana Lindl. Albertiana Mur\%.$$
\text { 'T'suga heterophylla Sarg. }
$$

Der vorigen sehr ithuliche Art, sehr hoch

II (III) Boden und freie lagh
erträgt aber auch Ueberschirmung. Schutz gegen kalte Winde und starke Somnenbestrahlung. Jung empfindlich, aucli gegen Spätfröste. wertend, raschwichsig, mit rotbramer Rinde, pyranilalem Wuchs, wagrecht aushalenten und auken iberhïngenten Isten, sowie zahlreichen, schlanken, etwas hängenden, durch die Blattmarben rauh werdenden, erst dicht braunfilzigen 'Trieben.

Blätter 1-2 $\mathrm{cm}$ lang und $1^{1 / 2} \mathrm{~mm}$ breit, (die oberseits am Zweig stehenden oft kaum $1 / 2 \mathrm{~cm}$ groß), flach, lineal, stumpfspitzig, kaum merklich gesägt und jung mit Haarspitzen versehen, oberseits rinnig, glänzend grün, unten im jugendlichen Zustand weiblich-griun; ziemlich zweireihig gestellt, auf hellrötlichen Nadelkissen stehend (Fig. 56).

Der brïunliche Zapfen wird $2^{1}{ }_{2} \mathrm{~cm}$ grof, ist liunglich-zylinderisch und fiihrt ganz fein behaarte(!), lïngliche Schuppen und etwas ge es p itzte, kleine Brakteen.

Der hellbraune, kleine Samen hat doppelt so langen Fliigel.

Das weiße, weiche Holz findet als Bau- und Werkholz Verwendung; ebenso ist die Rinde ein gesuchtes Gerbematerial.

Formen sind:

Tsuga Mertensiana macrophylla Beißn., mit großen Blaittern und iippigem Wuchs.

Tsuga Mertensiana argenteo-variegata Beißn., mit weifjen, wie gepudert aussehenden Zweigspitzen.

Syn.: Abies Albertiana argenteo-variegata Hort. holl.

Tsuga Sieboldii Carr., Siebolds japanische H. Japan, bis zur Buchenregion.

Syn.: Abies Tsuga sieb. und Zuce.

"Araragi Loud.

Bei uns langsam wachsender, in der Heimat etwa $30 \mathrm{~m}$ hoch werdender Baum, vou Tsuga

IV

In der Jugend empfindlich. Liebt nicht zu feuchten Boden und luftige freie Lage; im

Tal Schutz gegen kaite Winde und starke

Sonnenbestrahlung. diversifolia etwas schwer unterscheidbar, mit pyramidaler Krone, ausladenden, ziemlich unregelmäriog stehenden, außen iiberhängenden Ästen und jung hellgelbbraunen, dann gelbbraunen glämzenden, glatten Zweigen. Knospen gelbbraun, rundlich. 
Die Blättel stehen fast zweizeilig auf kurzen Stielchen, sind flach, lineal, $1-1^{1 / 2} \mathrm{~cm}$ lang, $1^{1 / 2}-2^{1 / 2} \mathrm{~mm}$ breit, längs

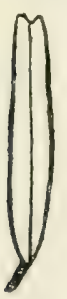

Fig. 57.

Blatt ron

T'suga Siebol.

dii Carr.

(vergrößert). gerimnt, stumpf, doch an der Spitze ausgeschnitten, ziemlich fest, oberseits dunkelgriun, glänzend, unterseits weiß gezeichnet; nit rotbraunen Nadelkissen (!). (Fig. 57).

Der hängende, glänzendbraune Zapfen ist gestielt, rundlich, $2-2^{1} / 2 \mathrm{~cm}$ lang und $1^{1} / 2 \mathrm{~cm}$ breit, spitz-zylinderisch, mit lederartigen, gestreiften Schuppen und zweizipfeligen, kleinen Brakteen.

Der Samen ist leicht gedrickt, verkehrt eiförmig, mit gleich langem Flügel. holz.

Das gelblichbrame Holz ergibt feines Werk-

Formen sind:

Tsuga Sieboldii variegata Hesse, buntblätterig. Tsuga Sieboldii nana Carr, ein breiter Zwergbusch.

Tsuga diversifolia Maxim. Verschiedenblaitterige $H$. Höhenzüge Japans.

II

Freie, luftige Lage.

Noch renig bei uns verbreitete, schöne, zierliche Art, leicht mit 'Tsuga Sieboldii zu ver'vechseln, mit schmalpyramidaler'

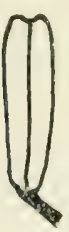

Fig. 58.

Blatt von

Tsuga diversifolia Maxim. (vergröbert).

Krone, dümnen Ästen und ebensolchen, rotbraunen, dicht behaarten Trieben.

Blätter ziemlich zweizeilig stehend, ungleich groß, $1 / 2$ bis $1^{1 / 2} \mathrm{~cm}$ lang, $2 \mathrm{~mm}$ breit, flach, lineal, kurz gestielt, die unten am Trieb stehenden Blätter oben ausgeschnitten, jene gegen die Triebspitze hin immer schmäler werdend und spitz, alle oben dunkelgriin, lackartig glänzend, unten hell bis weißlich gezeichnet (Fig. 58).

Zapfen bräunlich, kurzgestielt, nickend, 20 bis $23 \mathrm{~mm}$ lang, 10-13 mm breit, eiförınig spitz, mit gestutzten, kurzen Brakteen.

Liefert dauerhaftes Nutzholz und gerbstoffhaltige Rinde.

Tsuga caroliniana Engelm. Karolina-H. Karolina.

\section{Syn.: Abies caroliniana Chapm.}

Ebenfalls noch ganz wenig verbreiteter, seltener Baum, ron iiber $20 \mathrm{~m}$ Höhe, mit pyramidalem Wuchs und ausgebreiteten Ästen und Zweigen.

Die ziemlich zweizeilig und dicht stehenden Blätter werden $16-23 \mathrm{~mm}$ lang, $2 \mathrm{~mm}$ breit, sind oben stumpf bis eingeschnitten, mit dunkelgriner Oberseite und weißgezeichneter Unterseite (Fig. 59). 
Der lïngliche Zapfen ist 22-32 mm lang, die Schuppen sind länger als breit, bei der Reife sehr weitklaffend.

Der Samen fiiht einen doppelt so langen Fliigel.

\section{Tsuga Brunoniana (VII ?)}

Carr. Brunons H. Wiir- (III??) mere Zone des Himalaya (Fig. 60).

Syn.: T'suga dumosa Loud.

Bei uns wohl kaum aushaltende und wohl auch nicht in Baumschulkultur befindliche Art, mitausladenden Ästen, schlanken, ziemlich hängenden Zweigen und hell rötlichbraunen, behaarten Trieben. Blätter etwas aufwärts gerichtet, ziemlich zweizeilig, Hach, lineal, stumpf, 2-21/2 cm lang und $2 \%$ mm breit, gerinnt, fein gezähnt, oben lebhaft griun, unten weiß gezeichnet. Zapfen stumpf-eiförmig, braun, ungestielt, $2^{1} / 2 \mathrm{~cm}$ lang' und $1^{1} / 2 \mathrm{~cm}$ breit. Samen mit sehr langen Fliigehn. In China soll auch eine Form existieren:

\section{Tsuga Brunoniana chinensis Franch.}

Tsuga yünnanensis Mast. Yümnan-H. China, Höhenzïge von Yünnan, Sze-chuan, Hupeh.

Syn.: Abies yïmanensis Franch.

In England in Kultur, also auch wohl baldigst bei uns angepflanzte, allerdings strauchartige Hemlockstame mit ausladenden İsten. Die 18-25 mm langen, ganzrandigen, breit abgestumpften oder seicht eingekerbten, an den Rändern etwas umgerollten Blätter sind oberseits rinnig, grin, unterseits blaugrün.

Die fast kugeligen, wagrecht abstehenden, hellgelbbraunen, leicht gestreiften Zapfen werden $2^{1 / 2}-3 \mathrm{~cm}$ lang und fiihren kleine Brakteen. Samen mit nicht großem Fligei.

Welche Winterhärte diese mir unbekannte Hemlockstanne haben wird, muf erprobt werden; wahrscheinlich wird sie besten Falles noch in Region IV gedeihen.

\section{Abteilung: Hesperopence Engelmann.}

Bliitter stark konvex, oben gekielt, gespitzt, Spaltöffnungen a uf beiden Seiten. Zapfen bis $7^{1 / 2} \mathrm{~cm}$ lang. 
Tsuga Pattoniana Engelın. Pattons H. Höhenzilige des westlichen Nordamerika (Fig. 61 u. 62).

Syn.: Albies Prittonii (Pattoniana) Jeffr).

Tsuga Pattoniana glanea Hoit.

Hookeriana Carr.

Eine bei uns leider viel zu selten ange-

I (II?)

Liebt gleichmäßig feuchten Boden und Lufffeuchtigkeit bei freier Lage. Im Tal Schutz vor kalten Winden und starker Sonnenbestrahlung. pflanzte, ganz aparte, auffällige und wenn etwas größer geworden, - sie wächst leider etwas langsam bei uns - geradezu wunder-

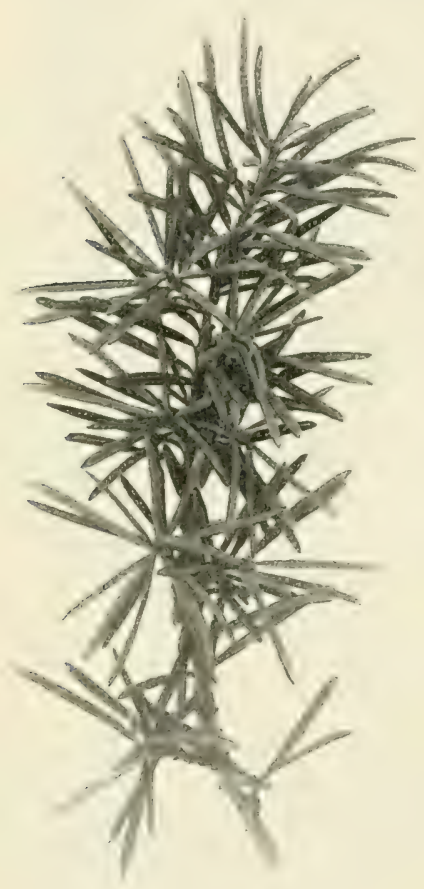

Fig. 61.

Tsuga Pattoniana Engelm. volle Art, welche in der Heimat bei $40 \mathrm{~m}$ hoch wird, einen prächtigen, rein pyramidalen Wuchs, wagrechte, fast zedernartig gestellte Äste und meist dicht gestellte, dünne, hellbräunliche, weichhaarige Zweige zeigt.

Interessant sind die dicht, fast buischelig, ziemlich rings um den Zweig gestellten, in zweiseitige Reihen ubergehenden, meist etwas gekrümmten, stumpfgespitzten Blätter, welche bei einer Länge von 14 bis $25 \mathrm{~mm}$ und einer Breite von etrva $1 \frac{1}{2} \mathrm{~mm}$ eine dreieckige, ja fast viereckige Form und dabei oben wie unten (!) weiße Spaltöffnungslinien zeigen, was bei der sonst hellgriinen Färbung der Blätter dem Baum eine graue oder weißlich-griue Färbung gibt.

Die hellbraunen

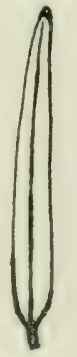

Fig. 62.

Blatt von

Tsugn Pattuniana Engelm. (vergrößert).

\section{Zapfen sind fast zylin-}

lerisch, 5-71/2 cm lang und hei $2 \mathrm{~cm}$ dick, jung reizend purpurhlan gefäbt, mit rundlichen, ohen leicht wewellten Schuppen mid anz kurzen Brakteen. Der kleine, $5 \mathrm{~mm}$ lange Samen hat beinahe doppelt so langen, oben verbreiterten Flugel.

Das Holz finctet als Bau- und Werkholz gute Verwertung, die Rinde ist als Gerbematerial sehr gesucht.

Eine sanz winterharte, prichtige, weiß- bis silberoraue Form ist:

Tsuga Pattoniana argentea Beißn.

Syn.: Abies Hoolieriana Murr. 


\section{Pseudotsuga Carrière.}

Douglastanne.

Immergriine, zum Teil grope, unseren Fichten ähnliche Bäume, mit im Alter ziemlich ausgebreiteter Krone, tiefrissiger, dicker Rinde, fast quirlig gestellten, sich ziemlich flach auslegenden Ästen, sowie etwas zerstrent stehenden, zum Teil auch leicht iiberhängenden Zweigen. Blätter flach lineal, unten zu einem kurzen Stiel verschmälert. Knospen sehr spitz, glainzend braun bis braunrot.

Blïte monözisch; männliche Kätzchen länglich, achselständi@, dicht mit Brakteen versehen, spiralig angeordnet, Antheren dicht stehend; weibliche Bliite endstaindig, einzeln, mit wiahrend der Bliitezeit schon ziemlich großen Brakteen, Samenschuppen mit je zwei umgewendeten Samenknospen.

Der Zapfen im ersten Jahre reifend, ist braun, hängend, lianglich, hat nicht abfallende Schuppen, welche mit auffallend langen, zweizipfeligen und mit langer Spitze versehenen Brakteen ausgestattet sind.

Samen lïnglich, fast dreieckio, etwas flach, ohne Harzzellen; die Schale mit dem Flidel verwachsen. Der Sämling; hat 6-12 dreikantige, anf der Oberseite mit Spaltöffnungen versehene Samenblätter.

Pseudotsuga Douglasii Carr., Douglas-Tame, Douglas-Fichte. Westliches Nordamerika, Tan- I, die Gebirgsform conver bis Real del Monte in Mexiko (Fin. 63, Colorado?). Liclitfreie, 64 und 79).

Syn.: Abies Douglasii Lindl.

Picer Douglasii Link

Pinus "Sub.

taxifolia Lamb.

Pseudotsuga Douglasii suberosa Lemmon

Tsunga Douglasii Car\%.

Lage. Jung empfindlich.

V, die Küstenform.

Kümmert in schwerem Tonboden und

Moorboden, in unfruchtbarem Sandboden und an nassen Stellen.

Spätfröste und Frühfröste, sowie starke Sonnenbestrahlung sind den ganz jungen

Wohl der wertvollste, rationellste Nadel-

Pflänzchen oft schädlich. holzbaum aller eingefiihrten, ausländischen Toniferen!

Sehr raschwiichsiger, besonders jum stark harzreicher, iiber $60 \mathrm{~m}$ hoch und unten iber 2 m stark wertenter, majestitischer, festwurzehuler, gut sturmsicherer Bamm, von erst lyratmidalem Wuchs, dann mehr breiter Krone, dicker, bramer, tiefrissiger Rinde, mregelmä13ig quirliog gestellten, sich ricmlich flach ausbreitenden Asten, etwas zerstreut stehenden, zum Teil leicht hängenden, bramen, jung ganz kur\% behaarten Zweigen. Finospen ganz spitz zulaufend (!), braun rötlich bis @linzendhraun. Blatter spiralig gestellt bis nuregehnabig zweizeilig, 18 bis 


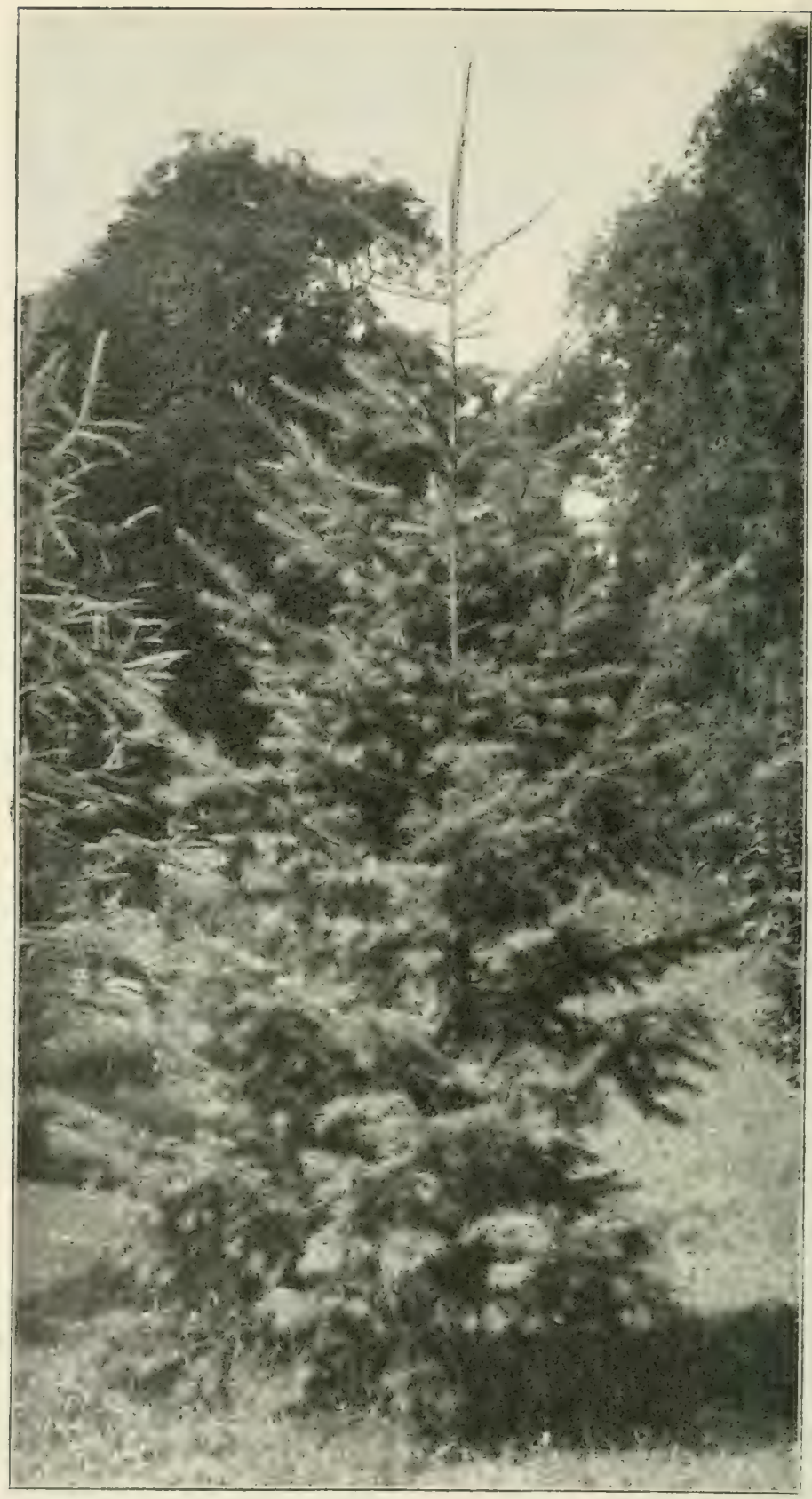

Fig. 63. Pseudotsuga Douglasii Carr. (junger Baum). 


\section{$-121-$}

$35 \mathrm{~mm}$ lang, $1-1^{1}$ - $m$ hreit. Hach, lineal, stumptospitzi@, manchmal gekrimmt, olen mit Rille und wainzenderin, nnten mit weiben Spaltüfnumslinien, nach dem Abfall Narben hinterlassend.

Der hingente, hellbraune Zapfen ist länglich, $8(10) \mathrm{cm}$ lang, $3-3^{1}$ a cm breit. mit oben gerundeten, lederartigen Schuppen

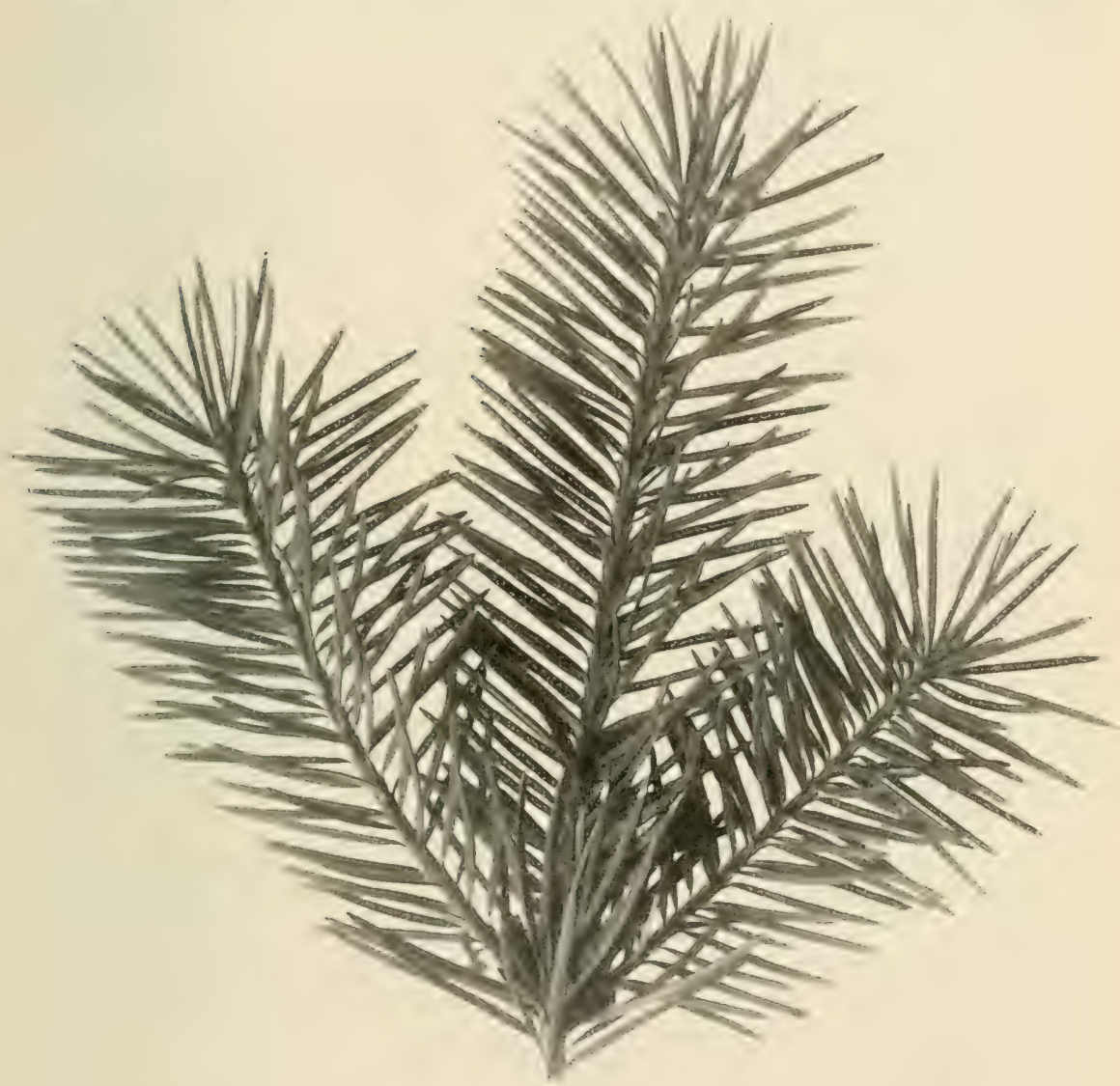

Fig. 64. Pseudotsuga Douglasii Carr. (um 1/10 verkleinert).

und anffilligen, dreispitzigen, die Schuplen trenigstens mit der mittleren Spitze lang iberragenden Brakteen. (Siehe Fig. 8, S. 18.)

Samen ziemlich breitgedriickt, länglich dreieckig, oben rötlich-braun, unten weiblich, mit dopnelt so langen, stumpfspitzen Fliigeln.

Bei dem mit Harzkanälen durchzogenen, wertvollen Holz ninterscheidet man ein vom Alter der Bäume abhängiges weifes 
Holz - Yello Fir - und ein rotes Holz - Red Fir -, das mit allen unseren einheimischen Koniferenhölzern - aufer mit Lärchenholz, welches noch harzreicher ist - nicht nur gleichen Stand hiilt, sondern dieselben auf einigermaßen gutem Boden oft weit an Zuwachs ibbertrifft. Dabei hat es die Eigentuinlichkeit, daß es (zun Gegensatz unserer sonstigen Koniferen) mit der Nenge an Substan\% und Harz gleichen Stand hält, also schwerer wird, wie breit auch die Jahresringe werden und wie rasch die Pflanze sich auch entwickeln mag! Das Wachstum ist so stark, dafi es auf gleichem Boden, z. B. mit Pinus silvestris, diese sehr'weit an Wachstum übertrifft ${ }^{1}$ ). Sehr oft werden Gipfeltriebe, Jahrestriebe von $1 \mathrm{~m} 20 \mathrm{~cm}$ beobachtet. Jedoch darf nicht angenommen werden, daf die Douglastanne einfach überall wächst! Auf mageren, trockenen, etwa noch sehr kalkreichen Böden gedeiht sie ebensowenig wie andere Koniferen.

Die Rinde des Baumes wird als Gerbematerial verwendet, wie auch die Harzbeulen vorziiglichen Balsam lieferndes Material ergeben.

Der (auch in Deutschland schon geerntete) Samen keimt innerhall 4 Wochen, doch liegt er auch manchmal uiber, d. h. er keimt erst im zweiten Jahr; die jungen Pflänzchen sind -- wie anch wohl alle unserer einheimischen Koniferen - etwas Schutz bediurtig, besonders gegen Somnenbrand, oft bis zum dritten Jahr. Suidabhänge zeigen in der Heimat der Douglastanne niemals diesen Bamm, weshall, hierauf auch hei uns speziell Rücksicht zu nehmen ist.

Vermehrumog durch Simen und durch Pfropfung auf die Stammform.

Eine Abart ist:

Pseudotsuga Douglasii var. glauca (Hort.), ron Colorado, eine schöne, hlangribe, was langwam wachsende Form, nit schräg nach when stehenten siritentriehen, welche friiher als die anbauwimdigste weil harte) Form angegehen wurde. was jedoch seine

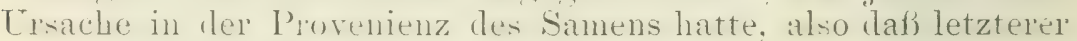
von den Höhenzügen der Heimat stammte.

Diese Abart wurde übrigens von Dr. M a y r in seinem Werke: .. Die IValdungen ron Tordamerika" als eigene Art, Psendotsuga shanca, aufecetellt, welche besonders rom britischen Territorimm his Ifexiko vorkommt und sich durch kiirzere, blau his weifigriine, dem 'Trieh mehr anliegende Nadehn, kleinere, bahl sich zeigende Zapfen mit kiirzeren Brakteen, mul durch halbhohen II uchs als Ionglasii ausweichnet und keinen zweiten Jahrestrieb (Nachtrieb) bilden soll.

¿) Siehe T'afel am Ende des Buches. 
Eine hängende Form hievon ist:

Pseudotsuga Douglasii var. glauca pendula Beißn.

Formen der Hauptart sind:

Pseudotsuga Douglasii argentea Koster, weißhlane Benadelung. weiße Nadeln.

nova (Hort. angl.) (Beißn.), ganz

Pseudotsuga Douglasii argentea pendula Beißn., hängend.

Wuchs.

" compactaHans, mitgedrungenem

Pseudotsuga Douglasii violacea Hort. holl., langnadelig, b]au. liängenden" Ästen.

Syn.: Pseudotsuga glaucescens Bailly.

Abies glanea Hort.

$"$ glaucescens Hort.

" Tlapalcatuda Roezl.

Nadeln.

Pseudotsuga Douglasii caesia Schwer., mit bläulich bereiften

Pseudotsuga Douglasii variegata Forbes, bunte, unschöne Form.

Stairii Hort., unbestïndig weißbunt; empfindlich gegen kalte IVinde und Sommenbrand im IVinter.

Pseudotsuga Douglasii taxifolia Carr., mit langen, dunkelgriinen Blättern, pyramidalem, gedrungenem IVuchs. Zapfen mit kiirzeren Brakteen als bei der Stammform.

Pseudotsuga Douglasii Standishii (Standishiana) Hort., mit großen, dunkelgrinen, unten ganz weißen Blättern.

Pseudotsuga Douglasii pendula Engelm,, mit besonders an den unteren Partien des Baumes hängenden Ästen.

Pseudotsuga Douglasii pendula glauca, stark hiingend, hlangriin.

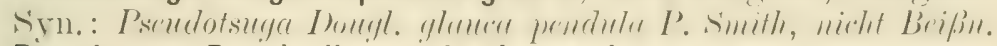

Pseudotsuga Douglasii pendula glauca elegans, wie rorige, iipui@ wachsend, reich bezweigt.

Syn.: Pseudotsuga Dougl. glenea clegans Hort. holl.

Pseudotsuga Douglasii fastigiata Carr., starkwiichsig, kecrelförmig, Äste aufstrebend.

Pseudotsuga Douglasii elegans Hort, dicht und gedrung'tu wiichsig, kleine dichtstehende Blätter.

Pseudotsuga Douglasii pumila Beißn., Buschform, nit kurzen, hellgriinen Nadeln.

Pseudotsuga Douglasii compacta Hort., dicht und gedrungen wachsend, kurze und dichtstehende Nadeln.

Pseudotsuga Douglasii compacta viridis Beibn,, dichtbezweigte Kungelform; Bliatter rings $n$ den Zweig, an der Zweigspitze rosettenförmig gestellt.

Pseudotsuga Douglasii compacta glauca Beifon., wie vorice im Wuchs, blaugriin, Blätter mehr abstehend. 
Pseudotsuga Douglasii globosa Beißn., lockerzweigige, kleine Kugelform.

Pseudotsuga Douglasii Fretsii Beifn., nierlrige, uippige Pyramide, mit kurzen, rings um den Zweig gestellten, nach der Zweigspitze zu immer kürzer werdenden Blättern.

Syn.: Pseudotsuga Fretsii Hort. holl.

Pseudotsuga Douglasii denudata Carr., mit starkwachsendem Mitteltrieb, aber kleinen Nebentrieben, dicken Knospen und ungleich langen Blättern.

Pseudotsuga Douglasii monstrosa Hort., monströse, dichte, niedere Form, mit stumpfen, dichtgestellten Blättern.

Betreffs den griun- oder graublätterigen Fornen bedarf es noch weiterer Klärung. So wird gegenwärtig die Douglastanne aus Britisch-Columbia eingeführt, welche gr ii $n$ e Nadeln führt, andererseits ist die aus Colorado importierte Douglastame mit grauer. Benadelung ausgezeichnet!

D. Japan.

Syn.: 'T'suga japonica Shirasawa.

Luftfeuchter, freier Standort; lehmiger Sandboden.

In der Heimat bis 20 m hoch werdender Baun mit kegelförmiger Krone, dunkelbrauner, langrissiger Rinde, nahezu wagrecht abstehenden Ästen, hellbraunen, glatten Trieben und länglich-spitzen, glänzendbram beschuppten Kinospen.

Narleln flach, schmal lineal, etwas gebogen, bis zu $2^{1} \frac{1}{2} \mathrm{~cm}$ lang und $2 \mathrm{~mm}$ breit, Nittelnerv nach unten hervortretend, an der Spitze eingekerbt, oberseits griu, unten mit zwei hellweißen Spaltöffnungslinien, oben an den jungen Blättchen etwas gerötet.

Der dunkelbraune bis schwärzliche Zapfen wird $4-5 \mathrm{~cm}$ lang und $2-2^{1 / 2} \mathrm{~cm}$ breit, hat starken, hakenförmigen Stiel und ist hängend. Zapfenschuppen auf der Rückseite bläulich bereift. Die dreiteiligen, iuber die Schuppen etwas hervorragenden Brakteen werden bei der Zapfenreife zuriickgeschlagen.

Der sundlich-dreieckige, oben hellbraune, unten grauweife, braunpunktierte Samen ist etwa dreimal so groß, als der von Douglasii und lang gefligelt.

Das aufen weißliche, innen hellbraune, wertvolle, leicht spaltbare Holz ist sehr gesucht.

Pseudotsuga macrocarpa Mayr. Großzapfige D. Bernardinoberge Siid-Kaliforniens.

Syn.: Pseudotsuga Douglasii macrocarpa Engelm.

VI (IV ?)

190607 u. 08 in Tübingen $-23^{\prime \prime}$ C ausgehalten; gebräunt.

Auch in der Heimat seltene Art, im Bau der 1 i c h t e n Douglastanne ähnlich, jedoch mit abstehenden Ästen, mit ganz hellgriinen, kiirzeren Blïttern an auffallend hellgelben (!) Trieben, 
und mehr kegelförnigen, glänzendbramen Knospen. Die Zapfen, von lockerem Bau, sollen bis $13 \mathrm{~cm}$ lang und $6 \mathrm{~cm}$ dick werden.

\section{Abies Link.}

T a $n$ e.

Immergriue, hole Bäume von meist pyramidalem Wuchs, ziemlich quirlformig gestellten Ästen und hauptsiichlichst zweiseitig stehenden, jung oft fein beharten Zweigen.

Bliitter rings um den Trieb gestellt, bis zweiseitig, zum Teil aufwiirts gerichtet, meist flach, auch etwas gewölbt, lineal, stumpf bis spitzig', ausgeschnitten bis zweispitzig, anf der Obelseite fast durchweg gerimnt, hell- lis dunkel-olinzendgriun oder weif, unten sehr oft gekielt und mit weißen Spaltöffnungslinien versehen, gegen die Basis hin stielartig verschmilert, auch gedreht, auf mehr oder minder erhabener Ansatzstelle stehend und hier nach dem Abfall Narben zuriicklassend.

Knospen verschieden gefornt, mit Schuppen bedeckt, harzig ocier nicht beharzt.

Bliite monözisch; männliche zahlreich, achselständig口, dicht von Brakteen ungeben, spiralig gestellte Antheren, mit grofen, gefligelten - mit Luftsäcken rersehenen - Pollenkörnern; die Pollen durch einen Querspalt sich öffnend!; dabei ein rundlicher oder länglicher Blitenstand; weibliche endstindig, aufrecht, rund bis liuglich, beschuppt, mit doppelten, dahei spiralig und mehrreihig gestellten Fruchtschuppen und selten iiber letztere hervorragenden Brakteen.

Samenknospen zwei, umgewendet.

Zapfen aufrecht (!), mehr oder minder länglich, im ersten Jahr reifend, mit dachziegelartig gestellten, von Brakteen teilweise iiberragten, mit der Samenreife von der Zapfenspindel abfallenden Schuppen.

Samen zu zweien, eiförmig bis keilig und kantig, gepreßt, mit Harzgängen, weicher Schale, bleibendem, oft grobem Fliigel. Keimdauer kurz.

Die Keimlinge zeigen nadelförmige Samenblätter, welche oberseits Spaltöffnungslinien aufweisen, sowie ebenso geformte Erstlingsblätter, welche genannte Linien unterseits führen.

Vermehrung der Tannen am besten durch Samen, der eher zu diunn als zu dicht angesät und gut mit Erde gedeckt werden muß; ferner durch Stecklinge, jedoch nur bei den Zwergformen, da im uibrigen Stecklinge schlecht oder auch gar nicht anwachsen; drittens durch Pfropfung, das am besten durch seitliches Einspitzen von Wirteltrieben - abgeküpfte Pflanzen erzeugen oft viele solcher - ziemlich tief unten an den am besten vierjährigen Sämlingen vorgenommen wird. 
Als Unterlage fuir kurznadelige Tamnen wählt man: Abies pectinata, als solche fuir la $n$ g nadelige: Abies Nordmanniana.

Ein besonders dem Laien dienendes Erkennungszeichen einiger Arten der Tamnen ist lie Farbe der Zapten vor der Reife. Man kann etwa zusammenstellen:

Zapfen griin oder gelbgriin: Abies bracteata, cephalonica, cilicica, concolor, firma, grandis, magnifica, Nordmanniana, numidica, pectinata, umbilicata.

Zapfen bla u bis purpurot: Abies amabilis, arizonica, homolepis, Fraserii, Mariesii, nobilis, religiosa, Veitchii, Webbii.

Zapfen graugrün, graublau, olivengr ü n: Abies balsamifera, sibirica, subalpina.

Abies pectinata DC: Weißtanne, Edel- und Taxtamne. Gebirge Mittel- und siideuropas bis zur den Karpathen und bis Nordwest-Kleinasien (Fig. 65 und 66).

\section{Syn.: Abies alba Mill. \\ Picea Lindl. Pinus Picen L.}

I

Bei bestimmter Luftfeuchtigkeit auf günstigem, lockerem, gleichmassig feuchtem Boden. Kümmert in sehr schwerer, trockener oder nasser Erde.

Leidet in Frostlagen oft stark, ebenso durch Spätfröste.

Einheimische, bei uns auch forstlich stark angebaute, allbekannte, 4-500 Jahre alt werdende, tiefwurzehnde, erst langsam wüchsige, 40-60 m hoch werdende Tanne, mit auffallend (sprich wörtlich ge wordenem) schlankem Stamm, schınalpyranidalem Aufbau, quirlständigen und wagrecht ausgebreiteten Aesten (in engeren Stand die unteren bald abstokend), sotvie ausgebreiteten, kurz behaarten Zweigen und gelbgriinen Trieben. Letztere stellen sich am Gipfel des Baumes förmlich nestförmig, wodurch derselbe wie abgeplattet aussieht. Am Gipfel, uiberhaupt an den Wipfeltrieben stehen auch die Blätter mehr oder minder aufgerichtet, dabei spiralig um den Zweig gestellt, während sie sonst zweireihig stehen.

Die Blätter sind flach, lineal, 2-3 $\mathrm{cm}$ lang und 2-3 $\mathrm{mm}$ breit, stumpf, ausgeschnitten, oder selbst zweispitzig, besonders an Gipfeltrieben scharf spitzig, dabei ziemlich starr, oberseits rimig und glänzend dunkelgriin, unten gekielt und mit zwei bläulichweißen Spaltöffnungslinien versehen. Knospen beschuppt, harzlos.

Die Bliite steht aufrecht und bleibt aufrecht, ebenso der in ersten Jahr reifende, erst rötlich-violette, damn brame, zylinderische, $10-18 \mathrm{~cm}$ lange und 3-5 $\mathrm{cm}$ dicke Zapfen, welcher keilförmige, selten etwas gelappte, oben ziemlich abgerundete, am Rande feinfilzige Schuppen, sowie mit einer Spitze hervorschauende und ungeschlagene Brakteen zeigt. Die Zapfen. spindel bleibt ein Jahr und noch länger stehen. 
Der gelhlichrote, weiche, fast dreikuntige, stark terpentin-

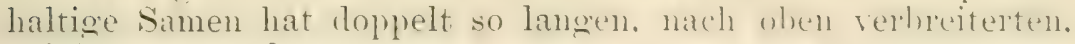
gelbbraunen (selten rötlichen) Fliigel, hält seine Keimkraft nur bis zum Friihjahr und geht drei Wochen nach der Saat auf.

Der Keimling zeigt 5-6, etwa $2-3 \mathrm{~cm}$ lange, flache, oben mit 2 Spaltöftnungslinien versehene, unten glänzend - grüne Samenblätter, mit welchen oben grime und unten weißgezeichnete, $1-1^{1 / 2} \mathrm{~cm}$ lange Erstlingsblätter abwechseln.

Das leichte, zähe, elastische, leicht spaltbare, weiße $\mathrm{Holz}$ ist höher im Wert als Fichtenholz und findet als Bauholz, Werkholz und zu Musikinstrumenten reichliche Verwertung.
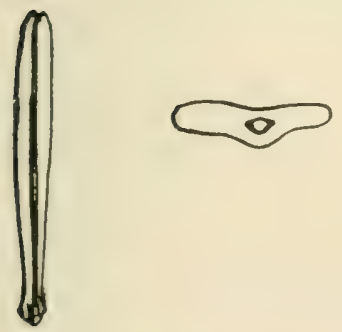

Fig. 65.

Blatt und Blattquersehnitt von Abies pectinata DC. (vergrößert).

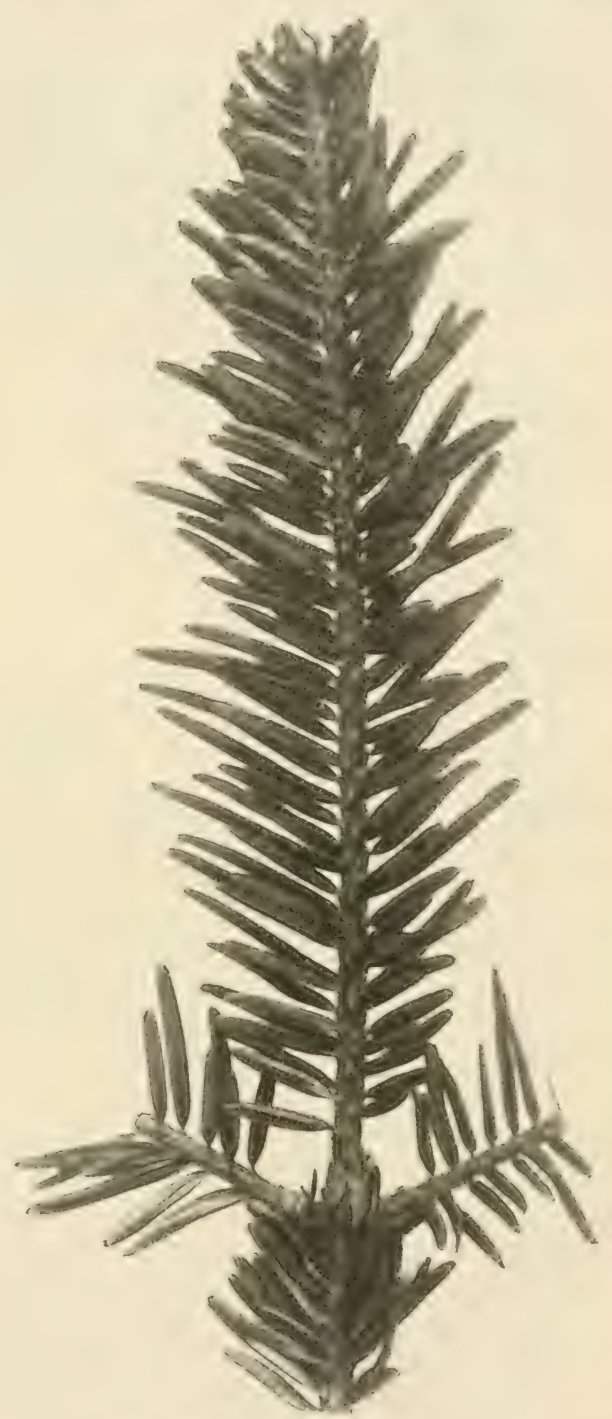

Fig. 66. Abies pectinata DC.

Die Veiftanne erträœt Überschirmung und den Schnitt, ist, weil sie auch am alten Holz noch austreiht, auch zu Hecken verwendbar und bildet selbst kräftige Stockausschliige. 
Das weiße Harz, welches der Baum schon im jugendlichen Alter ausscheidet, enthält Abietinsäure und liefert das sogenannte Straßburger Terpentin; das in den Blättern enthaltene aitherische Öl wird besonders zu Heilbädern verwendet.

Diese Art eignet sich vorziiglich als Unterlage beim Pfropfen der mehr kurznadeligen Tannen.

Von pflanzlichen Feinden ist es ein Pilz: Aecidium elatinum, der eine Triebwucherung, den sogenannten "Hexenbesen" der Tannen erzengt; ebenso schädigt die Mistel, Viscum album, durch Wucherungen mittelst ihrer Haustorien (Saugwurzeln) besonder's das Gipfelholz.

Als Formen sind zu nennen:

Abies pectinata Equi Trojani Ascher's. und Sint., eine wohl kaum in Knltur befindliche, nur botanisch wichtige For'm ans Nordwest-Kleinasien, mit meist einspitzigen Nadeln, breiten Zapfen und langen Brakteen. Form.

Abies pectin. variegata Hort., unwesentliche, weißlichblätterige

Abies pectin. aurea Hort., ebenfalls unwesentliche For'ın init einzelnen gelben Blättern.

Abies pectin. podolica Sr., Standortsform aus Westrußland, sehr widerstandsfähig gegen Kälte.

Abies pectin. tenuifolia van Geert, mit sehr feinen, dimnen Blättern.

Abies pectin. tenuiorifolia Hort., mit langen Blïttern und 25-30 cm langen Zapfen.

Abies pectin. virgata Casp., Schlangen- oder Rutentanne, eine absonderliche Form mit langen, hängenden, dicht beblätterten, aber nur an den Enden Verzweigung führenden Ästen.

Abies pectin. virgata irramosa Moreill., gar nicht oder kaum verzweigt.

Abies pectin. fastigiata (Beißner), ganz schınale Säule, Äste aufstrebend.

Syn.: Abies pectinata pyramidalis Carr.

Abies pectin. stricta Hort., gedrungen und dichtwüchsige, kurzblätterige Pyramide.

Abies pectin. columnaris Carr., kurzästige Säulenform. pendula Hort, mit hängenden, dicht anliegenden Ästen, förmlich eine Säule bildend.

Abies pectin. compacta (Beißner), breitrundliche Zwergform. Blättern. brevifolia Hort., zwergig, mit kurzen aber breiten

Abies pectin. tortuosa Booth, Zwergform mit sparrigem Wuchs und fast monströsen Zweigen und Blättern.

Syn.: Abies pectinata nana Hort. 
Abies Nordmanniana Link, Nordmamns Tanne. Gebirge vom westlichen Kaukasus bis Armenien. (Fig 67 u. 68).

Ein herrlich schöner, an unsere Weiftamne erimernder, sehr beliehter Batun, der wohl in keiner noch so kleinen Koniferenpflanzung fehlt,

II

Scliutz gegen starke Somenbestrahlung und scharfe Nordostwinde in Winter. (In gescliütztem Waldbestand aucli I.I

Auf moorigem Boden nicht grut gedeihend. $30 \mathrm{~m}$ hoch wird, in der Jugend langsam wiichsig, aber etwa vom 10. Tahr ab stark wachsend ist und granschwarze Rinde, schönen, pyramidalen Wuchs hei kräftigem Stamm, quirlig und wagrecht stehende, außen etwas anfgerichtete Äste und meist wagrechte, doch auch im Kreuz gestellte Zweige mit gelhgrinen Trieben und harzlosen Knospen führt.

Auffallend sind die im F'rihjahr etwa 10 Tage später als bei anderen Tannen erscheinenden, üppigen Nadeln, welche den Zweig deckend, dicht und mehrreihig, dabei etwas zweiseitig gestellt, doch auch aufgerichtet - besonders an alten $Z_{\text {weigen - eine }}$ Hache, lineale Gestalt zeigen. Sie werden ca. 3 cm lang und $2^{1 / 4} \mathrm{~mm}$ breit, sind stumpf, ausgeschnitten oder zweispitzig, oberseits sehr schön glänzend dunkelgrinn, unten mit oft auffallig weißen Spaltöfnungslinien versehen.

Der erst gringelbe, dann braune, dem der

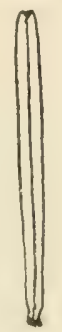

Fin. 67.

Blatt von Alies Nordmanniana Lk. (vergrößert). Weiptanne ilnuliche, harzige, auflechte, bis $15 \mathrm{~cm}$ lange und 5 cm breite Zapten lat breit keilförmige Schuppen, iblor welche die śpitzen der sonst herzförmigen Brakteen zurickgeschlagen sind.

Der eckige, längliche Samen ist breit gefligelt.

Das Holz ist ihnlich dem mserer Weiftamne benitzbar.

Diese Art ergibt eine der besten Unterlagen heim P'ropfen I an ga deliger' 'Tannen.

An Formen sind zu nemnen:

Abies Nordmann. glauca Hort., mit blaugriinen, grofien Blättern. coerulescens Hort., mit an der Unterseite auffiilicen, weifen Spaltöffnungslinien.

Abies Nordmann. aurea Hort., mit goldgelber Benadelung: aureo-spica Hesse, die Spitze der Bliitter goldgelb"

Abies Nordmann. aureo-variegata Beißn., einzelne Triebe ganz oder teilweise gelb gefärbt.

Abies Nordmann. albo-spica Hort. Gebl), mit weifen Triebspitzen.

Abies Nordmann. refracta Carr., kräftige For'm mit aufgrerichteten Blättern, wodurch die untere weiße Färbung stärker wirkt. 
Abies Nordmann. robusta Carr., robuste Form mit mehr aufsteigenden Ästen und derben Zweigen.

Abies Nordmann. erecta Hort. Pittet, auffallende Form mit stark aufstrebenden Ästen.

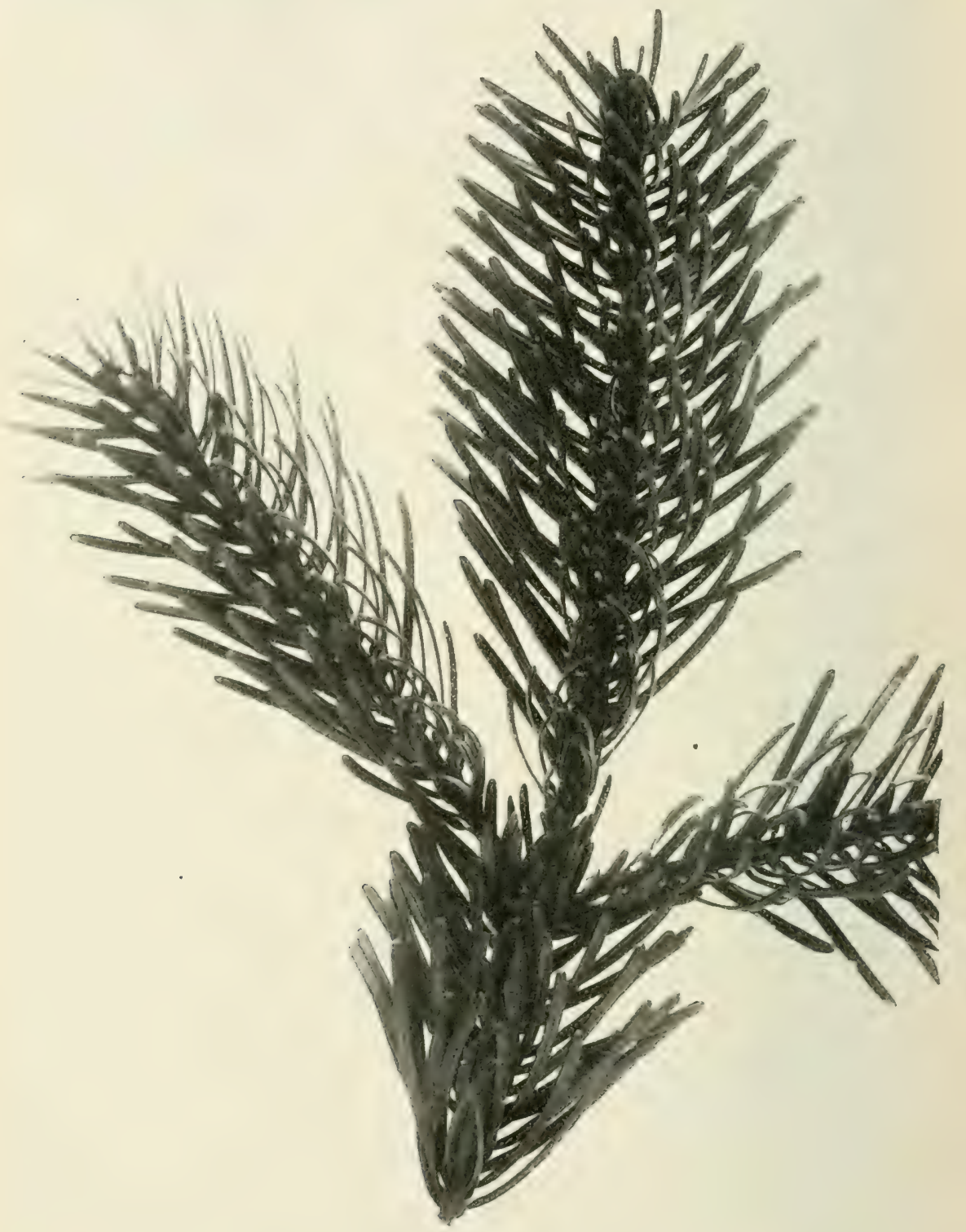

Fig. 68. Abies Nordmanniana Link. 
Abies Nordmann. pendula Hort, hängende Form. klein. brevifolia Carr., kurzblïtterig, fast monströs,

Verschiedener Orts ist ein Bastard - wohl stets Abies Nordmanniana $7>$ Abies Pinsapo - entstanden, dessen Sämlinge sich meistens durch kräftigen Wuchs auszeichnen, die verschiedensten Übergiinge zum Vater oder der Mutter zeigen und unter dem Sammelnamen

\section{Abies insignis Carr.,}

Syn.: Abies Nordmamiana speciosa Hort., vereinigt sind.

Abies cephalonica Link. Cephalonische orler griechische Tanne. (Fig. 69-70.)

Syn.: Abies panachaica Heldr.

Eine besonder's als junger Baum sehr schöne,

III (II)

Liebt gescliützte Höhenlagen. Leidet manchmal durch

Spâtifröste.

bis $25 \mathrm{~m}$ hoch werdende Tame, mit kräftigem Stamm, herrlich prramidalem Wuchs, quirlfömig und wagrecht gestellten Asten und Hachen, dicht stehenden Zweigen mit fast viereckigen, zugespitzten, etwas harzigen Knospen.

Die charakteristischen, star'x nach allen Seiten abstehenden, teilweise auch etwas zweizeiligen, linealen, flachen, 15-28 $\mathrm{mm}$ langen und $2 \mathrm{~mm}$ breiten, - die oberseits stehenden etwas kürzer sehr spitzen, scharfstechenden Blätter sind oberseits glänzend dunkelgrün, unten mit starken Rippen und bläulich-rveiben Spaltöffnungslinien versehen.

Der beharzte, erst griine damn braune, walzenförmige, oben und unten verjiungte, bis $20 \mathrm{~cm}$ lange und $3-6 \mathrm{~cm}$ dicke Zapfen hat keilförmige, oben abgerundete, sehr breite Schuppen und hervor-

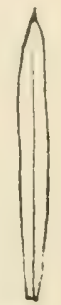

Fig. 69.

Blatt ron Alies cephalonicu Lli. (verorößert). ragende, iblergeschlagene Brakteen.

Der gelbbraune, eiformige, eckige Samen zeigt einen nach oben verbreiterten Fliigel.

Das dauerhafte Holz ist selbst in der Heimat sehr gesucht, da es dem Eichenholz kaum etwas nachgibt.

Formen sind:

Abies cephal. aurea Carr., mit goldgelben Trieben. Trieben. aureo-variegata Hort., mit einzelnen, goldbunten

Abies cephal. rubiginosa Carr., unterscheiclet sich nur dadurch, daf der Zapfen eine Zeit lang dunkel-rostfarbig ist.

Abies cephal. submutica Bailly, eine Form, deren Zapfen in der Mitte keine iibergeschlagenen Brakteen zeigen. 
Abies cephal. robusia Car'r, eigentiimliche, starkwiichsige Form, mit oben an Bamm aufstrebenden, unten etwas abwärts

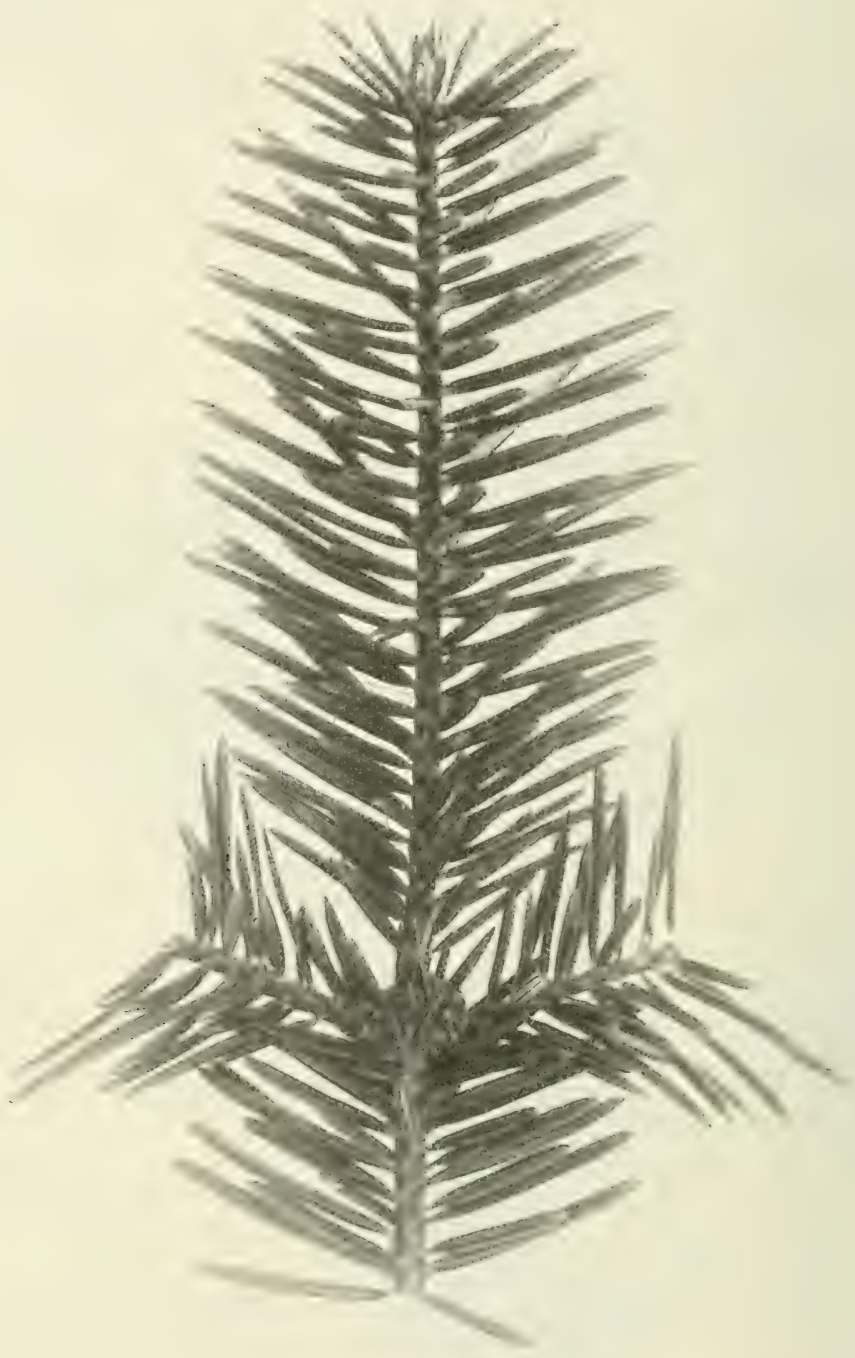

Fig. 70. Abies cephalonica Link.

cebogencm ïsten, sowic krätinen, teils stmmpfen, teils gespitzten Blättern. 


\section{Abarten sind:}

Abies cephal. var: Apollinis. Apollo-Tanne, wilde Tanne oder wilde Zeder der Griechen.

Syn.: Abies Apollinis Link.

ILit gelblichbramen 'Trieben, zweizeilig orler auch etwas nach oben gestellten Blittern, welche an jungen Zweigen stumpf, an alteren bis scharf gespitzt, auch doppelspitzig, etwas kiirzer als bei der Art sind, auf kurzem gedrehtem Stiel stehend, oberseits glïnzend griune, unten weniger weiße Färbung zeigen.

Der Zapfen ist ebenfalls etwas kuirzer, $17 \mathrm{~cm}$ lang, mit restielten Schuppen und kaum übergeschlagenen Brakteen.

Abies cephal, var. Reginae Amaliae, Könnigin Amaliens Tamne, arkarlische T., zahme T. oder III (IV?) zalime Zeder.

\section{Syn.: Abies Reginae Amaliae Heldr.} peloponnesiaca Haage.

Kiraftig wachsende, schlankwiichsige Abart, mit an jungen Bäumen kiirzeren, weichen, an ailteren auch sehr spitzen Blättern und kleinerenZapfen als bei der Art. Höchst eigentiimlich ist, daß Neuwuchs entstehen kamn, also daß neue Stämme sich am alten entwickeln, oder daf an wagrecht gestellten Ästen 6 bis $7 \mathrm{~m}$ lange Neutriebe sich bilden können.

Abies Pinsapo Boiss., Spanische Tamne. Gebirge der Provinz MIalaga, Spanien (Fig. 71).

Ganz charakteristischer, etwas langsam wïchsiger Baum von $25 \mathrm{~m}$ Höhe bei breitpyramidalem Wuchs, starkem Stamm, quirlförmig und wagrecht abstehenden Ästen und vielen quer, bezw. gekreuzt stehenden Zweigen.

Auffallend sind die spiralig und dicht gestellten, ganz starr nach allen Seiten abstehenden, derben, flachen, linealen. $5-13 \mathrm{~mm}$ langen und $1^{1 / 2}-2 \mathrm{~mm}$ breiten, stechenden, oben sewölbten, fast vierkantigen, graugr inen, auf runder Ansatzstelle hefestigten Nadeh. Knospe kugelig, etwas harzig, violett. Reizend ist die rote männliche Blute.

Der länglich-eiförmige, stumpfe, erst gellhlich-grine dann hellbraune Zapfen wird $10-15 \mathrm{~cm}$ lang und $4-5 \mathrm{~cm}$ hreit, mit oben abgerundeten, nach unten keilförmig zulaufenden Schuppen und kleinen, eiförmigen Brakteen.

Der kantige, verkehrt eifïrnige, weiche Samen ist dunkelbraun, mit ziemlich langem Fliigel.

Formen sind:

Abies Pinsapo glauca Hort., von herrlich blaugriner Färbung. nadelige "Form. 

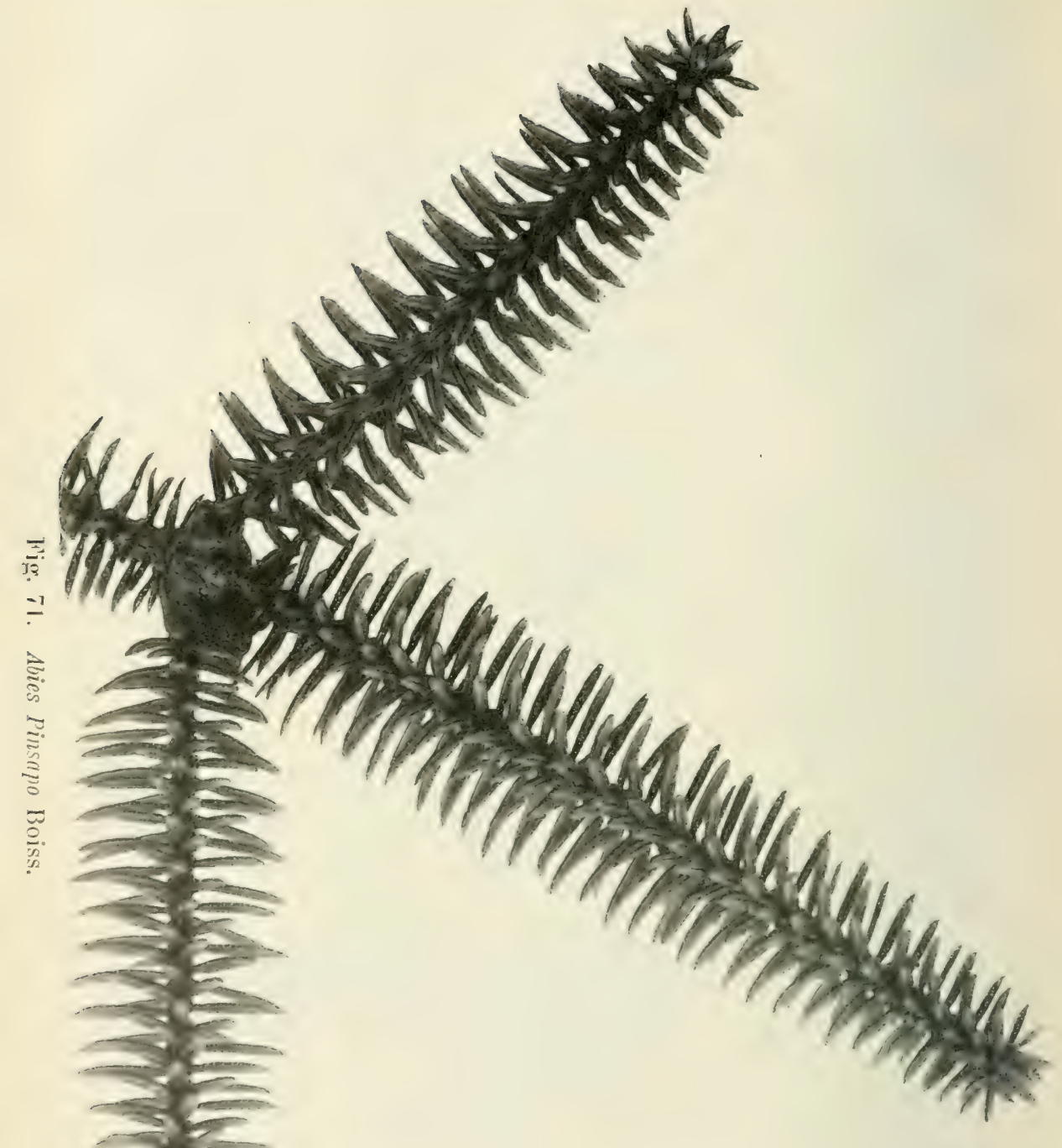
Abies Pinsapo argentea Hort., mehr oder minder silbergrau; prächtig.

Abies Pinsapo fastigiata Hort. gall., mit aufstrebenden Zweigen. pendula Hort., mit hångenden Ästen.

ausgebreiteten" Ästen.

Hammondii Veitch, kleinwiichsige Form mit weit

Ein Bastard, welcher sich verschiedenerorts schon gebildet hat, der aber wenig nemnenswerte Unterschiede zeigt, geht unter dem Namen:

Abies Vilmorinii Mast.

Syn.: Abies Pinsapo $q \times$ Abies cephalonica $す$. cephalonica $\times$ Abies Pinsapo.)

Abies numidica de Lamnoy, Numidische Tamne. Gebirge Kabyliens von Nord-Afrika.

Syn.: Abies baborionsis Latour.

Pinsapo var. baboriensis Coss.

II

Schutz gegen kalte Nordostwinde und starke Sonnenbestrahlung im Winter.

Hiihsche Art von $20 \mathrm{~m}$ Höhe, jung etwas langsam wiichsig, mit grauer, etwas gerunzelter Rinde, quirlfirmig und wasrecht gestellten Ästen bei pyramidalem Aufbau, zahlreichen, ganz kurz behaarten Zweigen und gelbgriunen Trieben. Knospen harzlos.

Die an der Basis gedrehten, fast starren, flachen, etwas spitzen oder stumpfen (an alten Pflanzen), 12-22 $\mathrm{mm}$ langen und $2^{1} / 2 \mathrm{~mm}$ breiten Blätter sind oben dunkelgrin, unten gekielt und mit bläulichen Spaltöffnungslinien versehen, dabei an der Trieb-Unterseite zweizeilig gestellt, ober'seits aber' wie bei Abies Pinsapo abstehend, oder auch - wie an den oberen Ästen — rinss um den Trieb gestellt (Fig: 72).

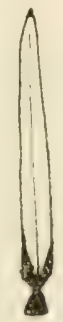

Fig. 72.

Blätter von Abies numilica de Lann. von jüngeren (links und älteren (reehts) Bämmen (vergröbert.

Die erst gelblichorinen, damn aschgranen, oft zu mehreren beisammen stehenden, $16-20 \mathrm{~cm}$ langen und $1-6 \mathrm{~cm}$ breiten Zapfen gleichen jenen der A. Pinsapo, sind aber länger und fiihren sehr breite, seitlich hakig gebogene und dabei förmlich gestielte Schuppen mit schmalen, kurzen Brakteen.

Der spitz-eiförmige Samen hat einen um die Hälfte lïng'eren, gezähnelten Flügel.

Eine Form mit ringsun stehenden Nadeln, wodurch die bläuliche Firbung der Unter'seite zur besser'en Geltung kommt, ist:

Abies numidica glauca Hort. 
Abies cilicica Carr. Zilizische Tamne. Gebirge des sidllichen Kleinasien, auf Libanon, Afghanistan.

II (III)

Geschützter Standort; gegen Spätfröste etwas empfindlich.

Eine schnellwiichsige, 20-30 m hoch werdende, schmalpyramidalkronige Tamne mit grauer, rissiger Rinde, quirlförmig gestellten, hauptsächlichst auf́strebenden Ästen und gegenständigen, glatten Zweigen und hellgelben Trieben.

Die dicht doppelt-zweizeilig, oder auch nach oben stehenden, linealen, flachen, $2^{1 / 2}-3^{1 / 2} \mathrm{~cm}$ langen und $2-2^{1 / 1} / 2 \mathrm{~mm}$ breiten, oben ausgeschnittenen Blätter sind an der Basis gedreht, oberseits lebhaft griun, unterseits bläulich-weiß gezeichnet, in der Gesamtansicht graugrün.

Der zylinderisch geformte, oben etwas vertiefte, sitzende, erst griunliche, dann braune Zapfen wird 20-25 cm lang und 4-6 cm dick und führt sehr breite, keilförmige, seitlich hakenförmige Schuppen, sowie spatelartige, gespitzte, n icht hervorragende Brakteen.

Der braumrote, eirörmige, eckige Samen hat gelbroten, schief keilförmigen Flügel.

Das Holz ist als Bar- und Werkholz wertvoll.

Abies Webbiana Lindl. Webbs Tanne. NordAfghanistan, Kafiristan, Himalaya bis Tibet und Bhutan.

Syn.: Abies spectabitis Sprech. Pinus spectabilis Lamb.

Eine der herrlichsten, aber leider fü Dentschland nur an wenigen giunstigen Punkten brauchbare, in der Heimat bis $50 \mathrm{~m}$ hohe Tanne, mit grauer, rissiger Rinde, schmaler Krone, wagrecht abstehenden, kurzen Ästen mit rothraun-glänzenden, harzigen Knospen und flachen, derben, oben ausgeschnittenen oder zweispitzigen, oberseits rimnigen, tief dmkelgrimen, unten sekielten, silberweißen Blättern, welche zweireihig oder rings un den Zweig' gestellt sind, und $3-5 \mathrm{~cm}$ lang, sowie $2 \mathrm{~mm}$ breit werden.

Charakteristisch ist der erst purpurrote, damn bläulichbrammote bis tiefblane, harzige, $17 \mathrm{~cm}$ lange und bis $6 \mathrm{~cm}$ dicke Zapfen mit erst roten, dann bramen, dichtstehenden, breitkeilförmigen Schuppen und schmalen, kleinen Brakteen.

Der eiformice, eckige Samen führt doppelt so langen Fligel.

Bei mehr trockenem als feuchtem stanclort liefert diese Tanne gutes Werkholz.

Eine Form ohne silberweife Zeichnumg der Bläter geht unter dem Namen:

Abies Webb, affinis Hort. 
Als Abart ist die von manchen Autoren als eigene Art aufgestellte

Abies Webbiana var. Pindrow Brandis zu nenuen.

Syn.: Abies Pindrow Spach.

Unterscheidet sich durch noch schmälere Krone als die der Art, mul lingere, etwa 5 cm lange, meist zweispitzige Bliitter, welche auf der Unterseite nicht auffällige weitie, sondern nur

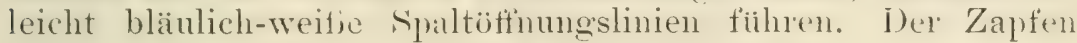
ist etwas länger und anch dicker, als jener der Art.

Abies amabilis Forl). Liebliche oder PurpurTamne. Kaskarlengebirge Oregons.

Sin.: Pimus amabilis Domrgl.

II (III)

Liebt Luftfeuchtigkcit, sowie Schutz gegen scharfe Winde und gegen starke Sonnen-

Diese an A. Noldmanniana erinnernde, in bestrahlung im Winter. unseren Gärten e cht noch recht selten angeptlanzte. sehr schöne
Tanne, für welche durch Namen- und Samenvervechshmg meist die Abies magnifica (oft auch Abies nobilis) kultiviert wurde, wird in der Heimat ein Baum von 50-60 m Höhe, mit in der Jugend dinner, weifgraner, harziger, später dicker und rotgrauer Rinde, kegelförmiorer Grone, ausgebreiteten, zum Teil abwärts gebogenen Asten, zahlreichen, kurzbehaarten, damn durch die Blattkissen rauhen Zweige, sowie hellrot-braune Triebe mit violetten, harzigen Knospen.

Die beim Reiben wohliechenden, flachen, linealen, 23-28 $\mathrm{mm}$ langen, oben ausgeschnittenen, an oberen Zwrigen spitzen Blätter stehen unregelmäßi@, sehr dicht, zweireihig, an der Zweigoberseite nach vorne gerichtet, den Zweig deckend (!) und anch noch zum Teil mit der Unterseite nach oben gedreht (!), sind oberseits glänzend-grüun und gerimnt, unterseits gekielt und mit schönen, weifjen Spaltöffnumgslinien versehen. (Fig. 73.)

Der hibsche, harzige, dunkel-purpurrote, dann reif gelhbrame Zapfen wird $11-14 \mathrm{~cm}$ lang und $5^{1 / 2}-7 \mathrm{~cm}$ breit, hat eine breit-zylinderische, oben verjuingte Form, nach unten nur wenig schmallere, gespitzte, ohen wellige Samenschuppen, sowie kleine spitze Brakteen.

Der weiche, keilförmige, kantige Samen hat einen fast doppelt so langen, ziemlich grofien Fliigel.

Abies grandis Lindl. und Gord. Grobe Lialifornische Tanne. Insel Vancourer und BritisclyKolumbien bis Nord-Kalifornien (Fin. 74-76). Syn.: Abies Grordoniana Carr.

III (II)

Liebt gleichmässig feuchiten Boden. jedoch nicht Moor.

In Waldkulturen härter, II. 


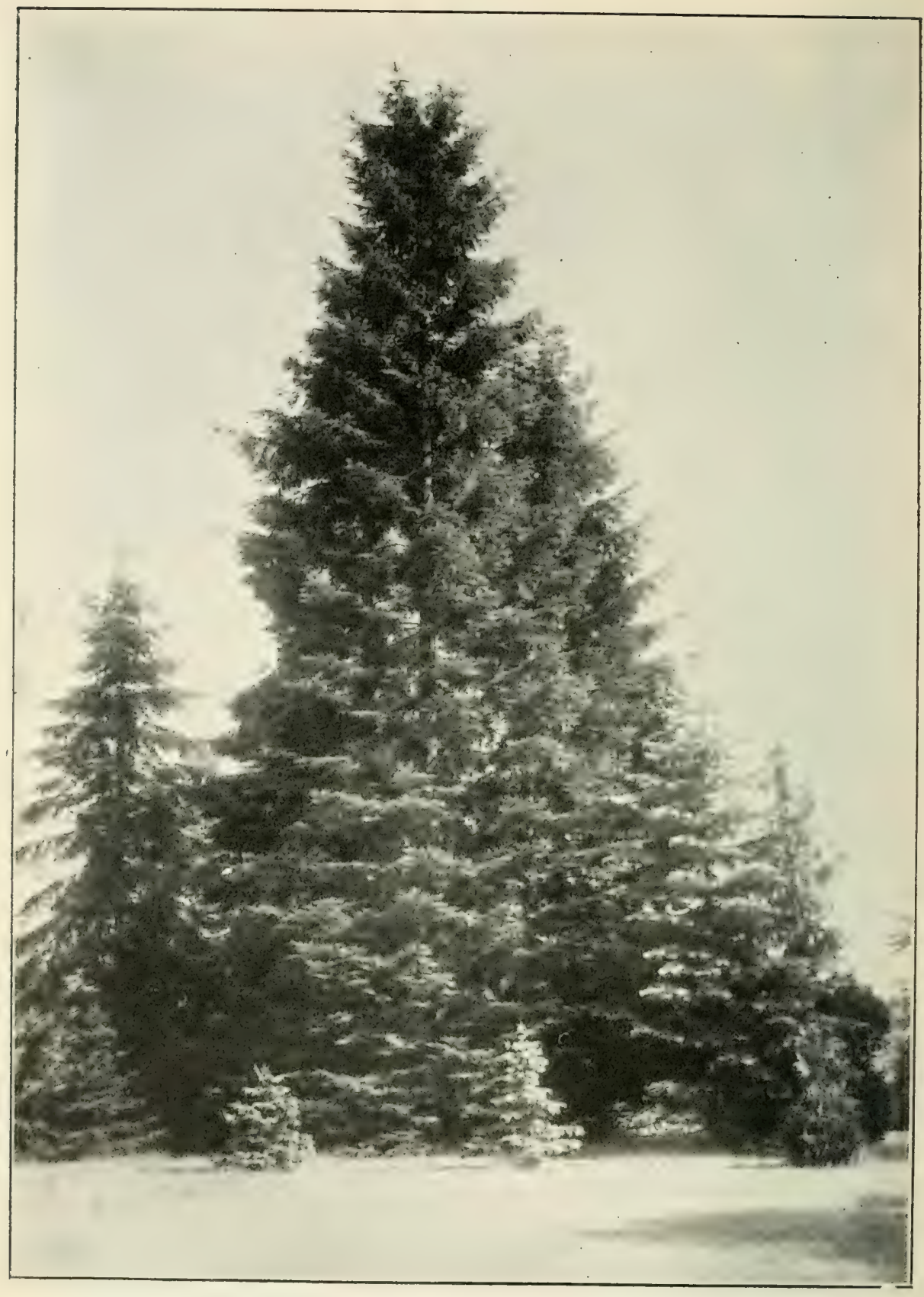

Fig. 74. Alies grandis Lindl. u. Gord. (25jährig, $26 \mathrm{~m}$ hoch); dahinter Abies Nordmanniana Link (45 jährig).

(Aus: Mitteilungen der deutsch. dendrolog. Gesellscliafı.) 
Ein in der Heimat bis $90 \mathrm{~m}$ hoch werdender, etwa vom 10. Jahr ab starkwiichsiger, schlanker, schöner Baum mit bräunlicher Rinde, pyramidaler Krone, ziemlich flach auslatenden Ästen und glatten, glïnzend gelbbraunen (!) Zweigen und violettbraunen, etwas harzigen Knospen.

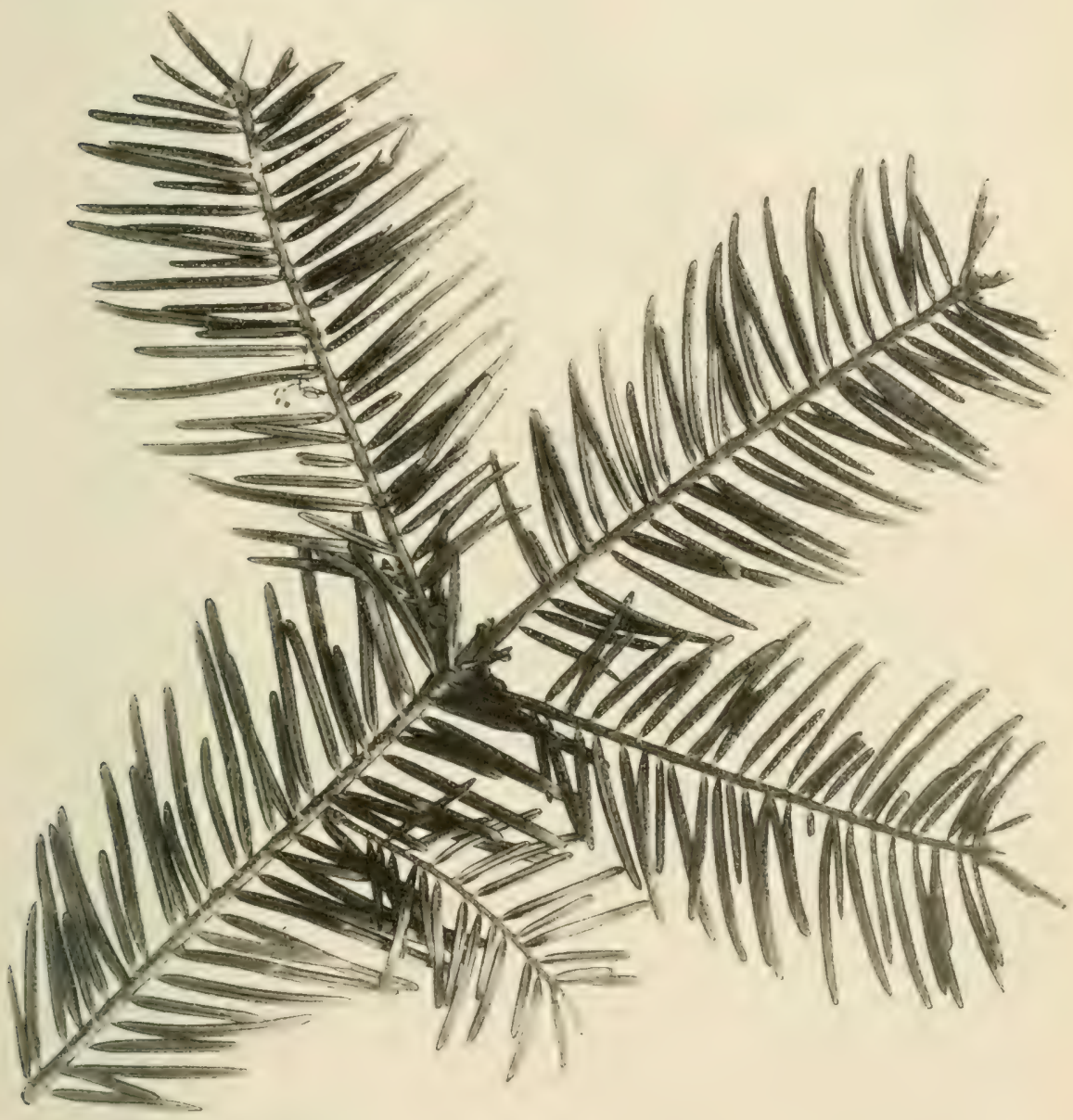

Fig. 75. Abies grandis Lindl. u. Gord.

Die genau zweizeilig gestellten, flachen, linealen, $3-4$, ja bis $5^{1 / 2} \mathrm{~cm}$ langen und $1^{1 / 2}-2 \mathrm{~mm}$ hreiten, an oberen Zweigen kleineren, dabei stumpfen oder etwas eingeschnittenen Blätter. sind oberseits glänzend dunkelgriin und etwas gerimelt, unterseits grimlichweif und stehen auf kurzen, gedrehten Stielchen. 
Charakteristisch ist das Wechseln von kurzen und langen Blättern am Trieb.

Der erst griue, dann griulichbraune, zylinderisch geformte, stumpfe Zapfen wird 8-10 (selbst 12) cm lang und 4 (-5) cm dick und führt halbmondförmige, sehr breite, unten

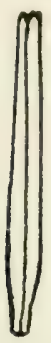

Fig. 76 .

Blatt von Abies grandis

Lindl. $\mathrm{u}$.

Gord. (vergrößert). keilförmige Schuppen und ganz kleine, eiförmige, gezähnelte und gespitzte Brakteen.

Der ebenfalls kleine, kantige Samen hat einen schief-keilförmigen Flügel.

Formen sind:

Abies grandis aurea Hesse, mit goldgelber Färbung.

Abies grandis pendula Hort. Spaeth, hängende Form.

Abies grandis compacta Hesse, sehr gedrungen wiichsig, fast zwergartig.

Abies concolor Lindl. u. Gord. Gleichfarbige Tanne. Suid-Oregon, Kalifornien bis Arizona, Utah und Suid-Colorado. (Fig. 77 und 78.)

In nicht $\mathrm{zu}$ trockener Luft und nicht zu schwerem oder trocketiem Boden. Auch auf Moor.

Der Abies grandis nahestehende, durch den Samen friher oft verwechselte, prachtvolle und ganz eigenartige, raschwüchsige, in unsem Forsten schon größere Anpflanzung' gefundene und auch forstlich schon empfohlene Tanne, welche in der Heimat eine Höhe ron 50 ja $75 \mathrm{~m}$ erreicht, zeigt hellgraue Rinde, ziemlich schmalpyramidale Krone, quirlig und wagrecht stehende Äste, sowie glänzend gellblichgraue bis violette, glatte Zweige mit rundlichen, hellbraunen, fast rosafarbigen, harzigen Knospen, welch letztere an Gipfeltrieben von Nadeln ungeben sind.

Auffallend sind die 4-7-8 cm langen -- an älteren Bäumen ziemlich kiirzeren - und $1^{3}{ }_{4} \mathrm{~mm}$ breiten, stumpfgespitzten, dahei etwas derben, fast zweizeilig gestellten, auch mehr oder minder aufgerichteten Blätter, welche eine eigentiimlich bläuliche oder graugriine Färbung, sowie schwache Rimne und Kielung zeigen.

Der harzige, hellgrine, später etwas rötliche, zylinderische, etwas stumpfe Zapfen wird bis $11 \mathrm{~cm}$ (seltener $14 \mathrm{~cm}$ ) lang und $3^{1 / 2}-5 \mathrm{~cm}$ dick und hat dichtstehende, doppelt so breite als hohe, nach unten plötzlich zugespitzte, jung Haumharige, seitlich gezähnelte Schuppen, sowie kleine, oben fast viereckige Brakteen.

Der weiche, kantige, keilfürmige Samen hat nahezu gleich langen wie breiten, etwas schiefen Fliigel. 

gleich.

Der Wert des Holzes ist etwa dem unserer gemeinen Tame

Formen sind:

Abies concolor violacea Hort., prächtige, weißhlaue Form, welche auch mit dunkelblauen Zapfen beohachtet wurle. (Fig. 78.)

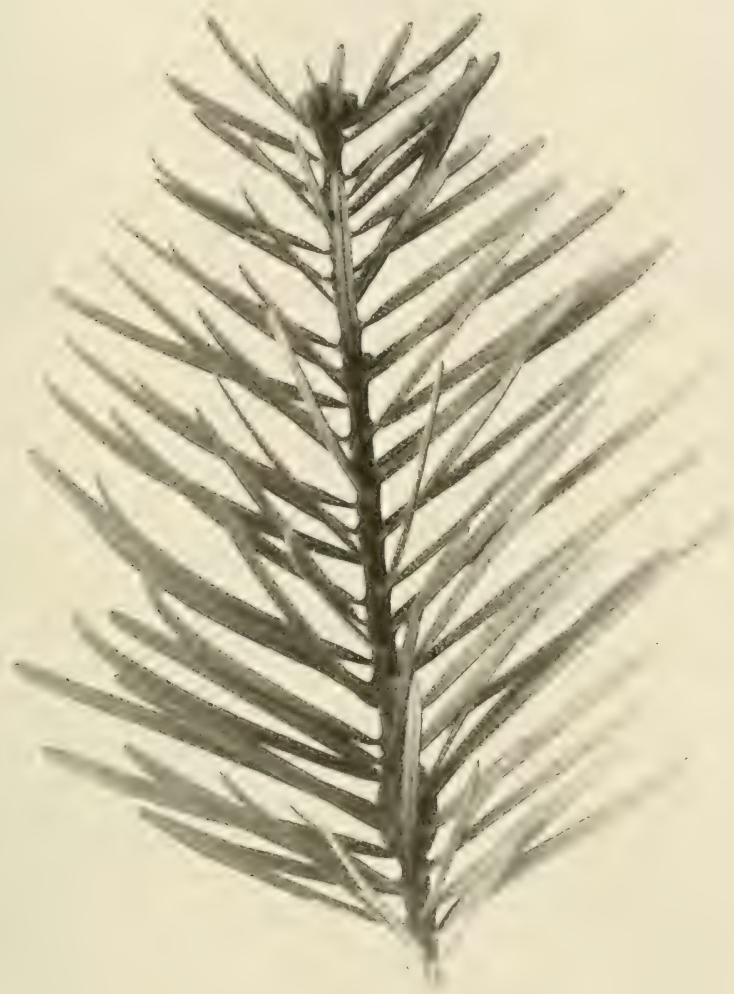

Fig. 77. Abies concolor Lindl, u. Gord.

Abies concolor violacea tenuifolia, mit feineren Blätter'n. compacta Hort., ebenso schön wie vorige, nur gedrungen wïchsig.

Abies concolor violacea compacta pyramidalis Hort. Weisse, säulenföming, mit streng aufstrebenden Isten bei kurzer Belaubung.

Durch Kreuzung von Ab. conc, violacea mit Ab. conc. arcentea sind weibblaue, schöne P'Hanzen in Kultur.

Abies concolor glauca compacta pyramidalis Hort. Sim.-T., wie vorige, aber graugrüne Färbung. 


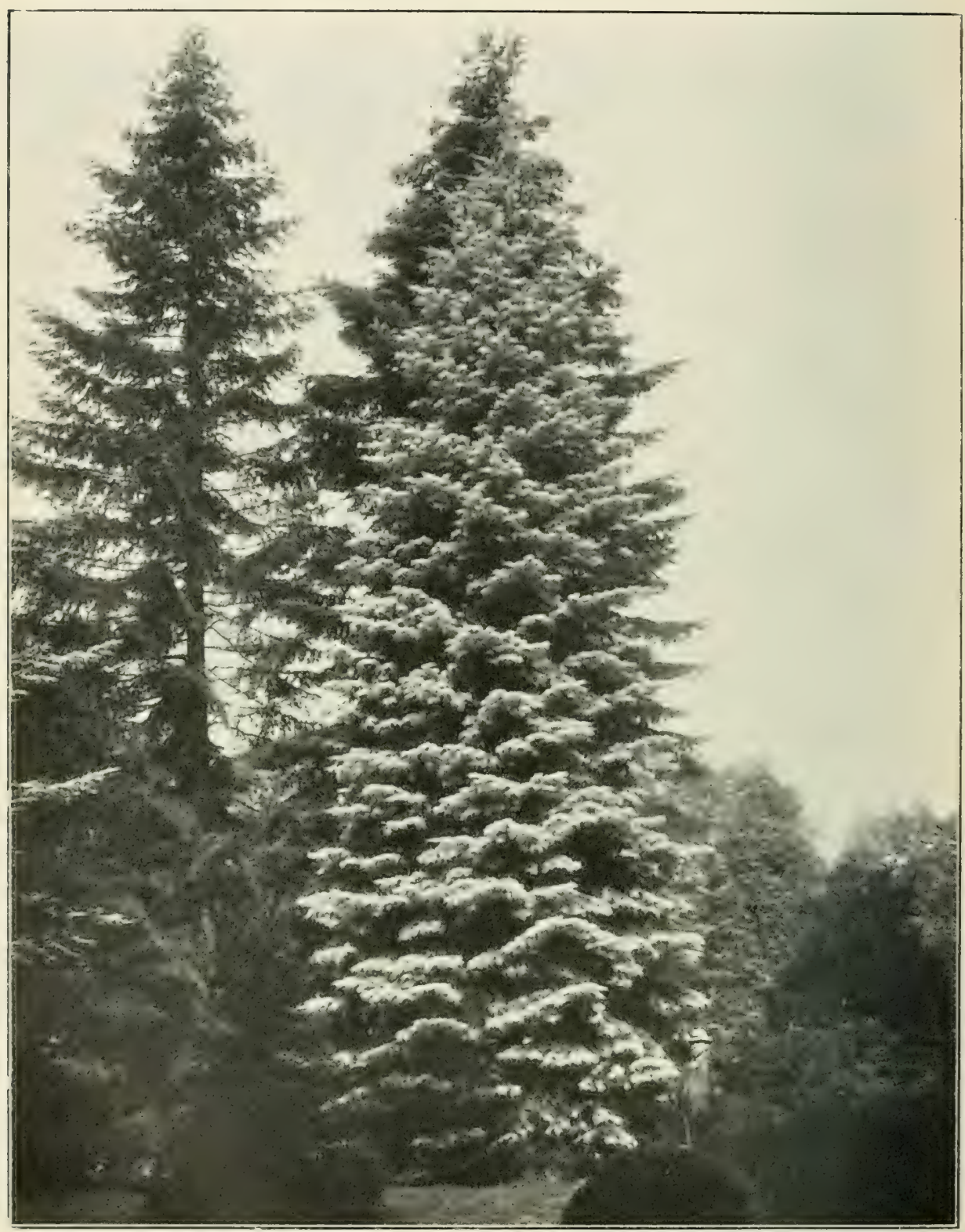

Fig. 78. Abies concolor Lindl. u. Gord. violacea Hort. (40 jähriger Baum). (Aus: Mitteilungen der deutschen dendrolog. Gesellschaft.) 
Abies concolor argentea Hort. Niemetz, sehr schöne, silherweiße Form.

Abies concolor aurea Beißn,, mit goldgelbem Austrieb, damn aber silbergrau werdend.

Abies concolor Wattezii Hort. Tottenham (Beißn.), mit mattgoldigem Austrieh, dam aber silberig weils werdend.

Abies concolor brevifolia Beißu, mit ca. $3 \mathrm{~mm}$ lreiten, sonst. aber kiirzeren Bliittern als die Art, welche ïberdies derber und stumpfspitzig sind. Nadeln.

Abies concolor falcata Hort. Niemetz, mit sichelfürmigen

Abies concolor recurva Beifn., mit kurzen, dem Trieb riickwärts zugebogenen, spitzen, bläulichen Blättern.

Abies concolor fastigiata Hort., mit aufstrelrenden $\ddot{A}$ sten. pendula Hort. Sim.-L., schmalsäulig, hängeästig. lige Zwergform.

globasa Hort. Niemetz, kurzzweigige, kuge-

Als viel umstrittene Abart ist zu nemnen:

Abies concoior var. lasiocarpa Engelm. und Sarg. Rauhschuppige Tamne. Sierra Nerala Kaliforniens. (Fig: 79.)

Syn.: Abies lasiocarpa Lindl. und Gord. Lowiana Mac Nab. grandis var. Lowiana Mast.

III

Liebt Schutz und feuchte Luft. Ist gegen kalte Winde und starke Sonnenbestrahlung im Winter sehr empfindlicls.

Friblıer "durch Samenverwechslung als Abies grandis verbreitete, durch mehr schmalprranidalen Wuchs, weniger breit ausladende und auch kiirzere Äste sich von der Art unterscheidende Tanne. Ferner sind die Blätter fast ganz zweireihig breit gestellt, allerdings auch aufwirts gekriimmt, etwas lïnger, oben bläulich-griun, unten mit deutlicheren Spaltöffuungshinien als hei der Art. Sie ist auch lichter gebaut, da sie keine nach miten wachsenden 'Triebe - wie concolor - erzeugt.

Formen dieser Abart sind:

Abies concol, var. lasioc. variegata Hort., mit blaugrau-bunten Blättern.

Abies concol. var. lasioc. pendula Hort., mit stark hängenden Zweigen.

Abies magnifica Mur's. Prächtige Tanne. Shasta und Kaskadengebirge Kaliforniens.

Syn.: Abies nobilis robusta Carr.

Durch samen fribler mit $A$. amabilis verwechselte, auch ron Abies nohilis etwas schwer

Auf Höhenlagen, doch mit etwas Schutz. Im Tal im Winter gegen kalte Winde und starke Sonnenbestrahlung schr emplindlich. 


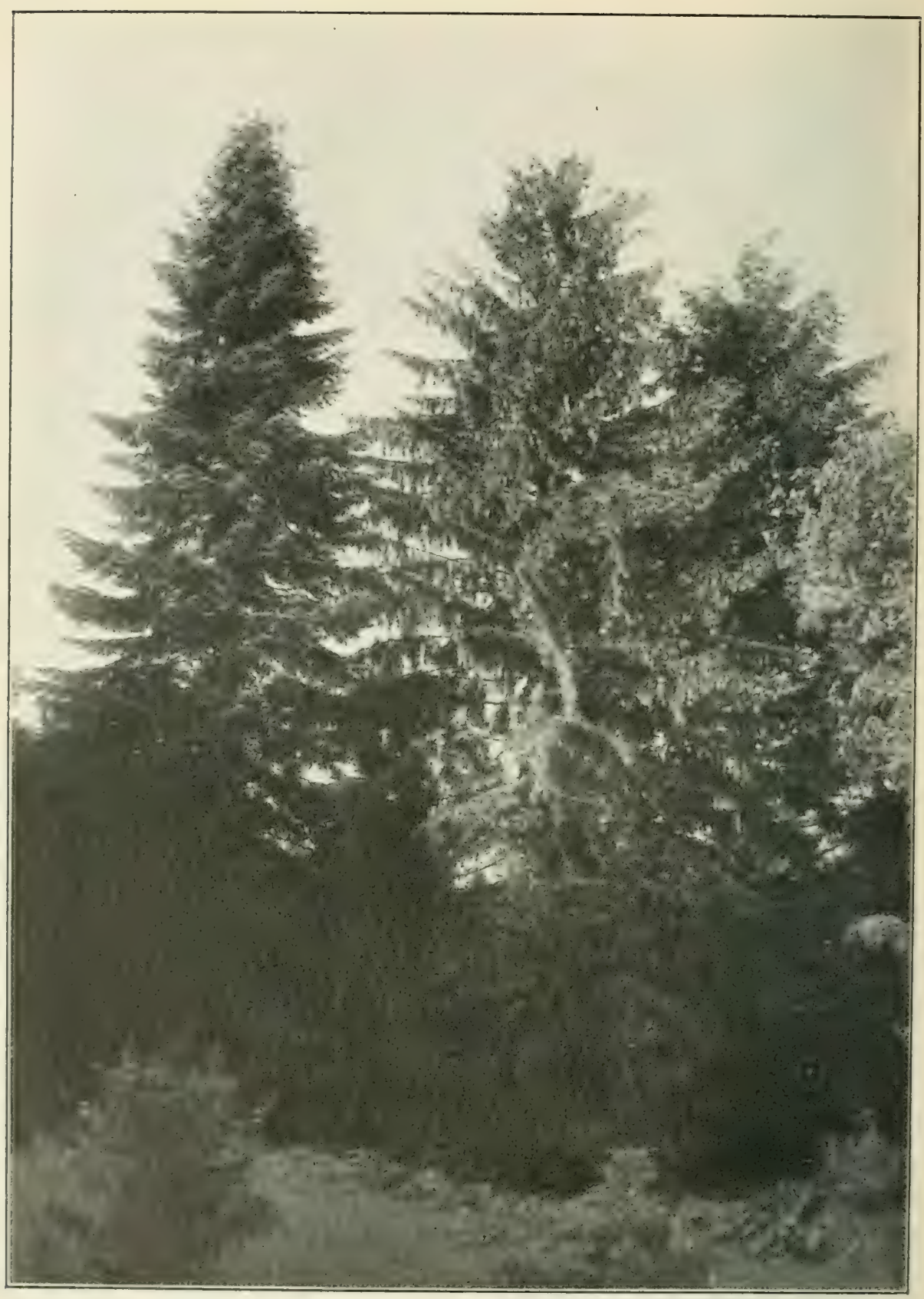

Fig. 79. Links: Abies concolor Lindl. n. Gord. var. lasiocarpa Engelm. u. Sarg. ranjührig. $27 \mathrm{~m}$ hoch). In der Mitte: Ficen excelsa Link $(80-90$ jährig, $29 \mathrm{~m}$ hochl. Re hts: Pseudotsuga Douglasii Carr. (43jährig, 25 $5^{1 / 2} \mathrm{~m}$ hoch). (Ans: Mitteilungen der deutschen dendrolog. Gesellschaft.) 
zu unterscheidende, erst trig gwichsige, ram aber hochwerdende, - $70 \mathrm{~m}$ in der Heimat - schmalpyramidale Tanne mit rotbrauner, dicker Rinde, charakteristisch regelmäßig quirlständigen und wasrecht ausgebreiteten Isten, dicht und zweizeilig stehenden, brimulichen, jung kurzheharten Zweigen und violetten, harzigen Knospen.

Die steifen, länglich drei- bis viereckigen (!), kantigen, beiderseits gekielten, oben stumptlichen, an juingeren Trieben bis $3^{1} / 2$ cm langen und $1 \frac{1}{2}$ mm breiten, hellgriinen, (an tragbaren Zweigen nur etwa $1 \frac{1}{2} \mathrm{~cm}$ langen), mehr bläulich-grinen Bliitter sind sichelförmig nach vorne gebogen, die obere Seite des Zweiges deckend.

Der auffällig große, erst griunliche, dann rötlich-braune Zapfen wird 15-22 cm lang und 7-9 cm dick, hat walzenförmige Gestalt, fuihrt dichtstehende, fïcherförmige, gestielte Schuppen und ehenfalls gestielte, nahezu viereckige, kleine Brakteen.

Der kantige, lingliche Samen hat einen sehr großen, fast dreiseitigen Fligel.

Das Holz tindet als gutes Bauholz weite Verwendung.

Die Art verliert oft den Kopftrieb und ersetzt denselben schlecht.

Formen sind:

Abies magnif. glauca Hort., mit schöner, blaugriuner Färbung. Zapfen. argentea Hort., mit mehr silberweißer Färbung. xanthocarpa Lemmon, mit kleineren, gelben

Abies magnif. shastensis (Lemmon), hat etwas feinere Blätter, schmälere Zapfen und ein wenig hervorragende Brakteen.

Syn.: Abies shastensis Lemmon.

Abies magnif. prostrata Beißn., ohne Stammbildung, ganz auf dem Boden ausgebreitete Form.

Abies nobilis Lindl., Edle oder Silber-Tanne. Höhenziige Oregons.

Syn.: Abies nobilis viridis Hort.

IV (III)

Liebt Schuiz gegen kalte Winde und starke Sonnenbestrah= lung im Winter.

Ein majestätischer, schöner, in seiner Heimat 70, ja $90 \mathrm{~m}$ hoch werdender, jung etwas langsam wachsender, von Abies magnifica und A. amabilis schwierig auf den ersten Anblick zu unterscheidender Baum, mit brauner bis grauer, imnen roter, dicker Rinde, spitz pyramidaler bis kegelförmiger Krone, quirlförmig gestellten und wagrecht ausgebreiteten, im Alter iuberhängenden Ästen und rotbramen, ganz kurzbehaarten Zweigen mit dunkelvioletten Knospen. 
Die sehr dicht stehenden, denen der A. magnifica ähnlichen, besonders an der Zweigoberseite säbelförmig aufgekriimmten und den Zweig deckenden Blätter sind derb, ziemlich dick, flach, stumpf bis spitz, $1_{12}^{1 /}-3 \mathrm{~cm}$, an jungen Bäumen selbst $4 \mathrm{~cm}$ lang und $1^{1} / 2 \mathrm{~mm}$ hreit, an der Oberseite blaugriin und schwachrimnig, an der Unterseite die weißen Spaltöffnungshinien wenig' zeigend.

Del große, jung grau- bis blauschwarze, später braune, $16-25 \mathrm{~cm}$ lange und $7-8 \mathrm{~cm}$ breite, zylinderische, stumpfe Zapfen führt echt fächerförmige, fein behaarte, an den Ecken gebogene, unten plötzlich in eine Spitze verlaufende Schuppen, und langgestielte, oben mit zwei Lappen und einer Spitze weit über die Schuppen zurückgeschlagene Brakteen.

Der lange, kleine Samen hat etwas keilförmigen, diumen Flügel. Bei Bezug der Samen ist umbedingt zu beachten, solchen von den Höhenzigen der Heimat zu erhalten, welcher dann möglichst winterharte Pflanzen ergibt.

Das Holz ist ein gutes Bauholz.

Formen sind:

Abies nobilis robusta Hort., mit längeren, kräftig'en Blätternn. $" \quad$ "glauca Hort., mit sehr schöner, dunkel-blaugrüner Benadelung.

Abies nobilis argentea Hort., mit prachtvollen, blauweißen Nadeln. (Fig. 80.)

III

III

Abies bracteata Hook. und Arn. GrannenTanne. Santa Lucia-Gebirge Sülkaliforniens.

Syn.: Abies remustu C. Kóch. Pinus vemusta Douglas.

Schlank pyramidalwiichsige, braunrindige, in der Heimat 50-60 $\mathrm{m}$ hoch werdende Tanne, mit breit- und dichtstehenden, im Alter etwas uberhängenden Ästen, sowie rotgriunen bis fuchsroten, kahlen Zweigen. Auffällig sind die mit großen Schuppen bedeckten, bis $14 \mathrm{~mm}$ langen, kegeligen, förmlich gestielten, gelben Knospen.

Charakteristisch sind auch die dicht stehenden, vielfach leicht gebogenen, flachen, lang und spitz auslaufenden, großen, $3-5 \mathrm{~cm}$ langen und $2-3^{1 / 2} \mathrm{~mm}$ breiten, oberseits glänzend lebhaft-grinen, unterseits stark gekielten und besonders an jungen Blättern mit silberweißen Spaltöffnungslinien versehenen Nadeln.

Originell ist der walzenförmige bis breitzylinderische, 10 bis 14 cin lange und $4-5$ cm breite, erst griunliche, damn helllraune Zapfen, welcher ganz nierenförmige, unten gespitzte 
Schuppen und schmale Brakteen, deren Nittelrippe zu viner bis $4 \mathrm{~cm}$ langen, geschwungenen Gramne answebildet ist, zeirt. Der längliche, kantige Samen hat einen nahezu alowerundeten

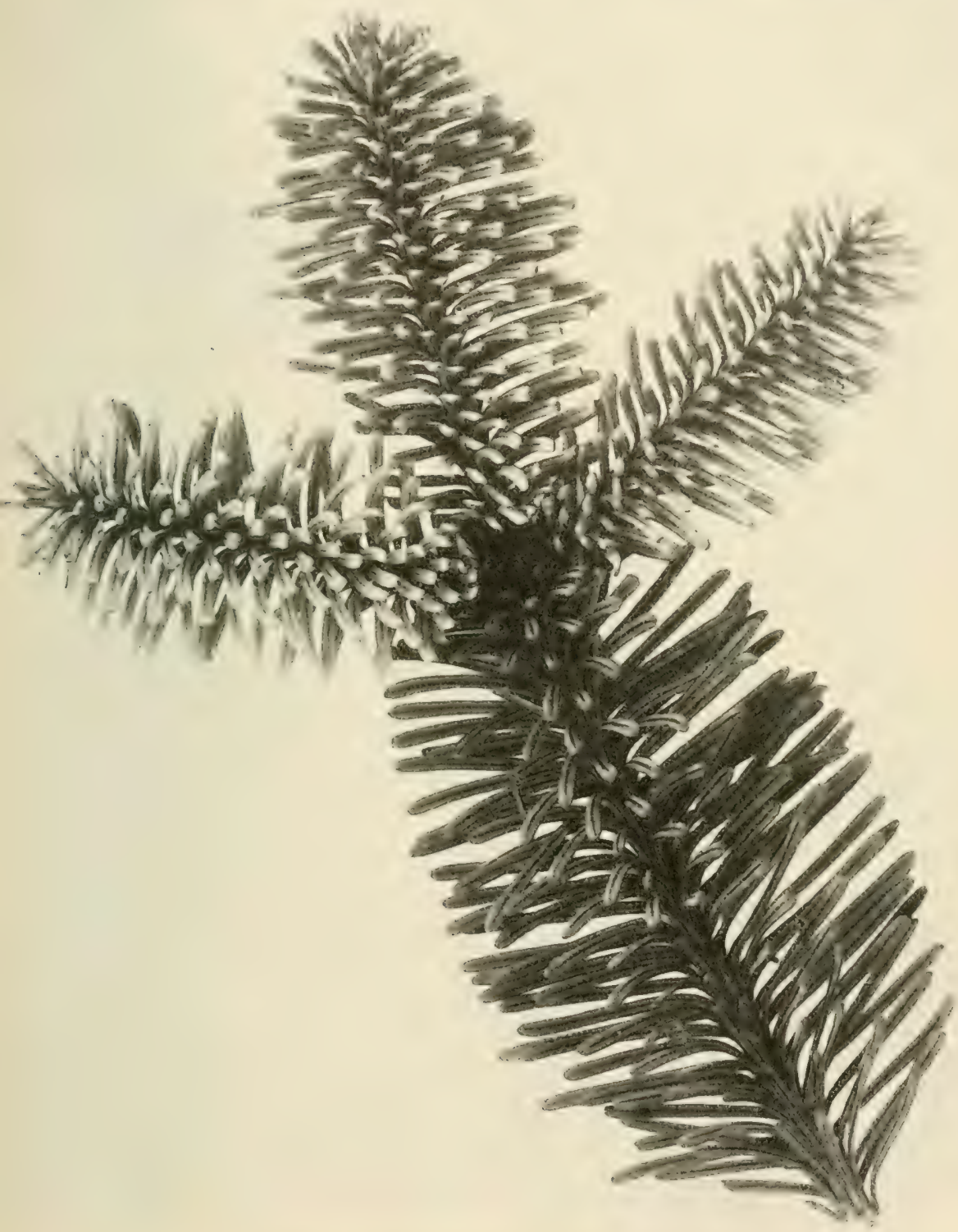

Fig. 80. Abies nobilis Lindl, argentea Hort 
Flicel. Bei Bezug der Samen sollte nur solcher von Höhenla@en stammend rerlangt werden. PHanzungen in Tialern leiden gerne durch Spätfröste. Das Holz ist sehr schwer.

Abies religiosa Lindl., die heilige Tanne von den Gebirgen Mexikos und Guatemalas, ein hei $30-40$ m hoch werdender, schmalprramidaler Bam, mit oben lebhaft grimen, unten mehr

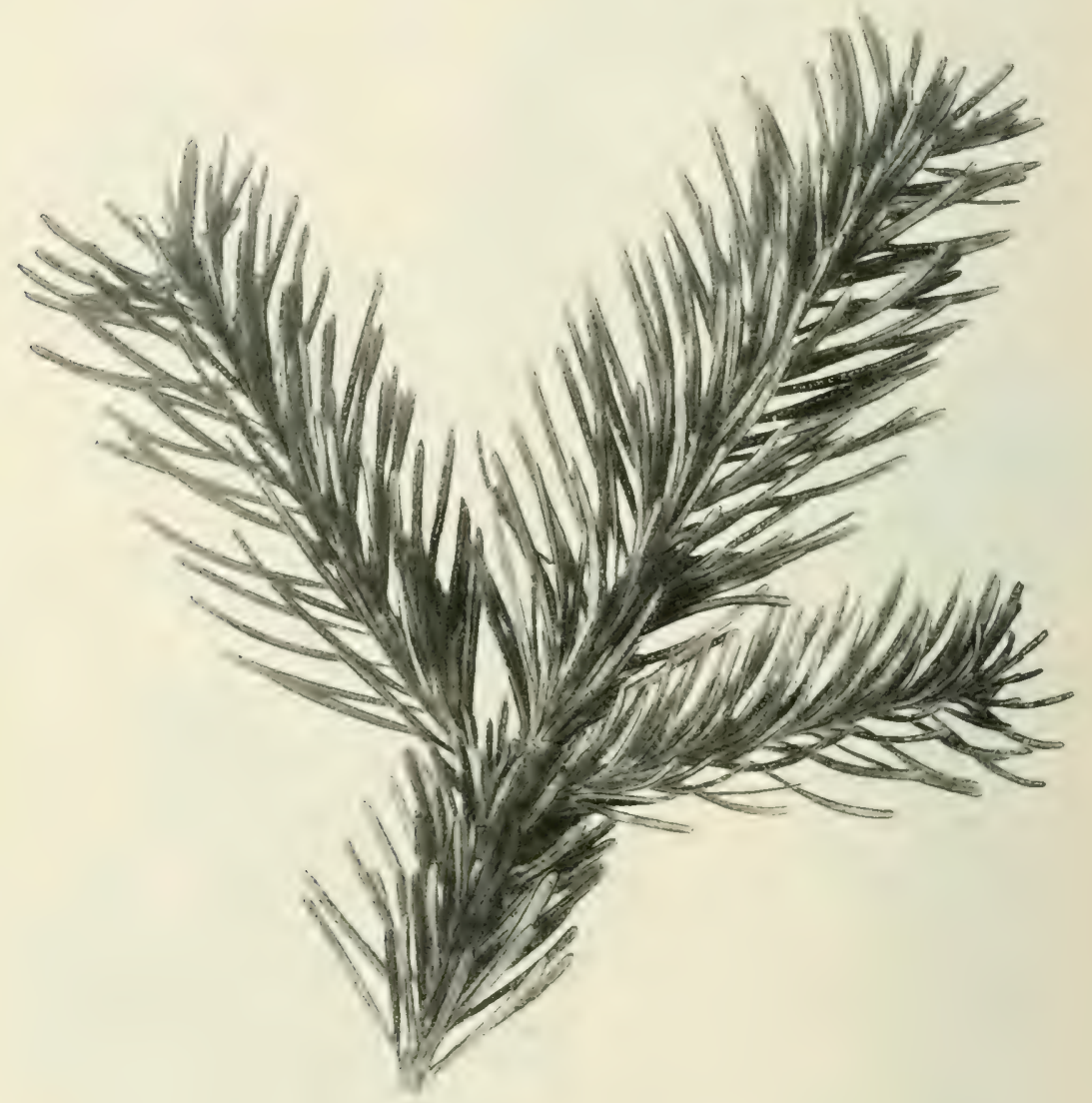

Fig. 81. Abies subalpina Engelm.

bläulich-griinen, langen, gekielten Blättern und bläulich-braunem, ziemlich dickem Zapfen, mit über die Schuppen zurüickgeschlagenen und gekrimmten Brakteen, ist in Deutschland, soweit bis jetzt die Erfahrungen lauten, nicht winterhart.

Abies subalpina Engelm. IVestamerikanische Tanne. 


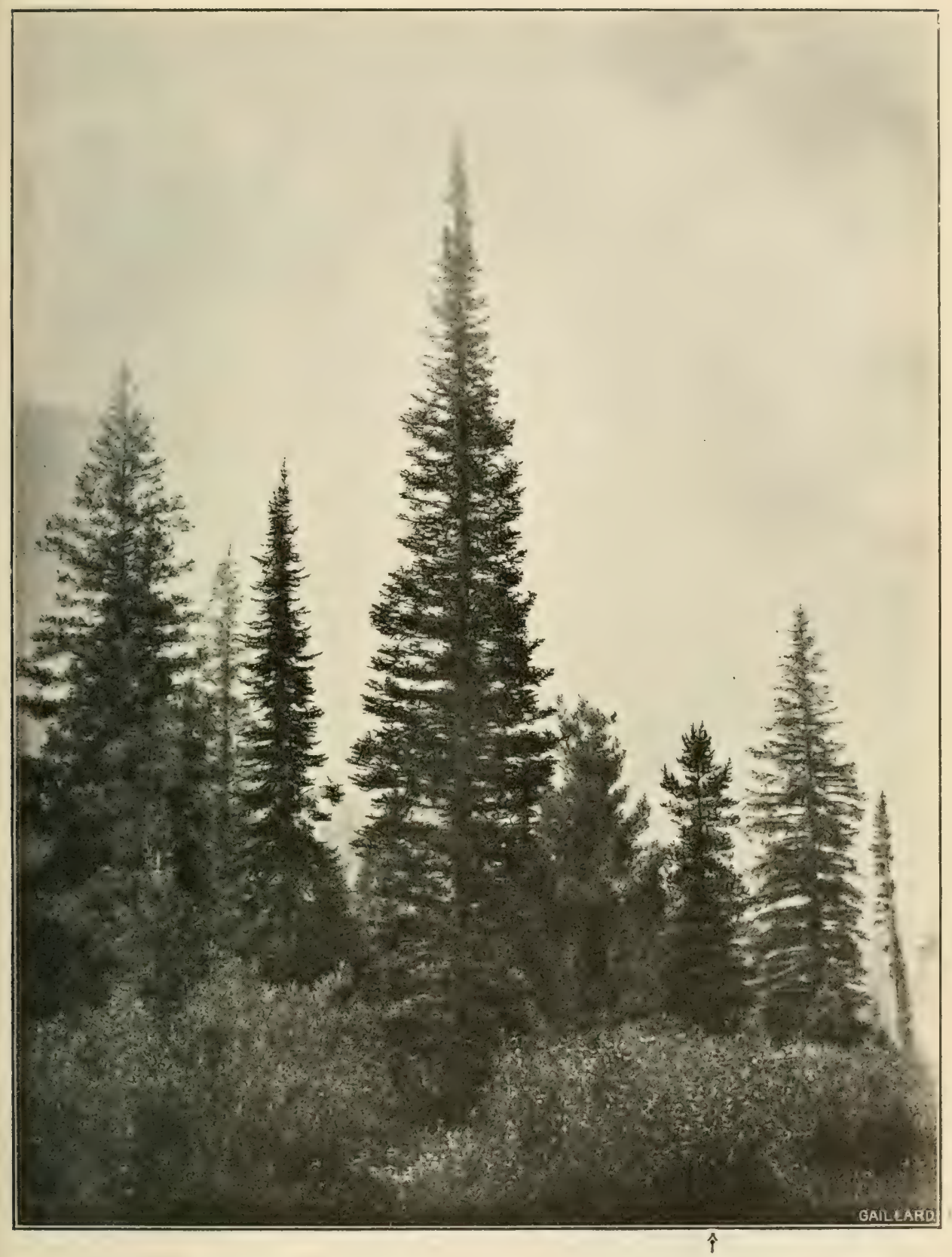

Fig. 82. Abies subalpina Engelm. (Mitte); rechts $\hat{\imath}$ : Pinus albicaulis Engelm. (Aus: Mitteilungen der deutschen dendrolog. Gesellschaft.) 
Alaska bis $60^{\circ}$ nördlicher Breite, bis Oregon, Utah und Colorado. (Fig. 81 u. 82.)

Syn.: Abies lasiocarpa Nutt.1. Mook. nicht Lindl. und nicht Hort. bifolia Hur.

Bildet einen bis $30 \mathrm{~m}$ hoch werdenden, pyramidalwiichsigen Baum, mit breit ausliegenden Ästen und ganz fein behaarten, hell-graubraunen Zweigen, sowie stumpfen, harzigen Knospen.

Die an der' Unterseite der Triebe gescheitelt, oben mehrreihig und sich deckend stehenden, $1^{1} / 2-2^{1} / 2 \mathrm{~cm}$ langen und 1 bis $1 \frac{1}{2} \mathrm{~mm}$ breiten (die oberseits stehenden sind etwas kürzer), flachen, linealen Blätter sind in ihrem oberen Teil ein wenig breiter, dabei stumpf oder etwas ausgeschnitten, - doch jene der zapfentragenden T'riebe sind scharf gespitzt, - rimnig, fast bläulich-grün, unterseits leicht gekielt und mit zwei weißlichen Spaltöffnungslinien versehen.

Der erst oliven-, dann graugriune Zapfen ist länglich eifürmig, oben und unten verjünt und etwas abgestumpft, mit ebenfalls abgestumpften, rundlichen, unten ganz zugespitzten Schuppen mi rundlichen, gestielten, kleinen Brakteen, sowie länglichen, kantigen Samen, nit rundlichem, diunnem Fligel.

Das Holz ist nur von mittelmäßigem Wert.

An Formen sind zu nennen:

Abies subalpina coerulescens Froebel, mit starker, bläulicher Benadelung.

Abies subalpina glauca Hort, weißlichblaue For'm. compacta Beißn., blaugrüne Kugelform.

Beissneriana Hesse, höchst eigentimliche, mit sichelförmig, bezw. lockig gebogenen, der Triebspitze zu gerichteten, blaufarbigen Blättern versehene Form.

Es ist auch ein Bastard in Kultur:

Abies subalpina \ Abies amabilis (nach Sargent.). Syn.: Abies lasiocarpa Hook $\times$ Abies amabilis Forb.

Abies arizonica Merriam, Arizona-Tanne. San Franzisko- und Hendrickgebirge Arizonas.

Wunderbare und eigenartige, der vorigen Art sehr nahestehende Tanne, in der Heimat $20 \mathrm{~m}$

II Nicht zu trockener Standort. Leidet manchmal durch Spätfröste. hochwerdend, mit fast schirmförmig abstehenden, auch etwas iiberhängenden Ästen und Zweigen und grünlichen, harzigen Knospen. Die hei Koniferen einzig dastehende Rinde erimnert an die Korkrinde; sie ist elastisch, an der Oberfläche samtartig und von grauer bis rahmweißer Färbung!

Die dichtstehenden, flachen, stumpfen oder etwas eingeschnittenen, $2^{1} / 2-3 \mathrm{~cm}$ langen (an zapfentragenden Zweigen 
etwa $2 \mathrm{~cm}$ langen, dickeren und scharf zugespitzten) Blätter sind blaugriin bis wundervoll silberweiß und nach vorne gerichtet.

Der dunkel- bis blïulich-purpurfarbige Zapfen wird $5 \mathrm{~cm}$ lang und $2 \mathrm{~cm}$ dick, hat mehr breite als lange, dabei seitlich konvexe, beiderseits purpurfarbene Schuppen, sowie breite, nicht hervorschauende Brakteen.

Der längliche, kantige Samen fiihrt einen ziemlich gleich breiten wie langen Flügel.

Das Holz ist nicht besonder's fest, mehr weich, ähnlich dem Pappelholz.

An Formen wurden bis jetzt bezeichnet:

Abies arizon. argentea Hort., mit blauweißen Nadeln. alpina, wohl nur die Stammform, aber von den höchsten Lagen stammend und dementsprechend kleinwiichsiger.

Syn.: Abies arizon. pygmaea Hort.

Abies arizon. pendula Hort., mit hängenden Zweigen.

Abies Fraserii Lindl. Frasers Tanne. Alleghanygebirge von Karolina und Tennessee.

III

Diese auch heute noch seh" vielfach mit Abies balsamifera (besonders olne Zapfen) verwechselte und deshalb auch fälschlich als vollständig winterhart bezeichnete Tanne, mit in der Jugend brauner, dam grauer Rinde, hat flache Äste und ebensolche, sowie etwas kuxz zottighaarige Zweige.

Die Blätter sind lineal, flach, dicht rings um die Zweige gestellt, aufwärts gekrimmint (!), $1-2^{1 / 2} \mathrm{~cm}$ lang und $1^{1 / 2} \mathrm{~mm}$ breit, oben ausgeschnitten, von dunkelgriuner Färbung mit ziemlich stark weißlichen Spaltöffnungslinien.

Die erst fast bläulich-schwarzen, dann grauen, zu mehreren beisammen stehenden Zapfen sind kürzer als jene von Abies balsamea, nur $3-5 \mathrm{~cm}$ lang und $2 \mathrm{~cm}$ breit, eiförmig, mit oben rundlichen, sonst breit fächerförmigen, keilartig zulaufenden Schuppen und großen, in eine weit zuriickgeschlagene Spitze auslaufenden, die Schuppen stark verdeckenden Brakteen.

Der hellbraune, punktierte Samen hat längliche, gestreifte Flïgel.

Abies balsamea Mill. Balsam-Tanne. Syn.: Abies Fraserii Hort.

Nördliche Staaten Nordamerikas, vom

in hohen Lagen;

II

im Tal. atlantischen bis stillen Ozean. (Fig. 83.)

Vielverbreiteter, schnellwiichsiger, bis $25 \mathrm{~m}$ hoch werdender, pyramidalwiichsiger Baum, mit schwärzlich-grauer Rinde, welche viele Harzbeulen aufweist, quirlförmig gestellten, aus- 
ladenden Ästen und ungleichmäßig stehenden, etwas behaarten Zweigen, sowie stumpfen, stark harzigen, rötlichen Knospen.

Die rings um den $Z_{w e i g}$ lis fast zweizeilig gestellten Bliitter sind zum Teil etwas gekriimmt, $13-28 \mathrm{~mm}$ lang, $1^{1} / 2 \mathrm{~mm}$ breit, dabei lineal, oben etwas eingeschnitten, gegen die rund-

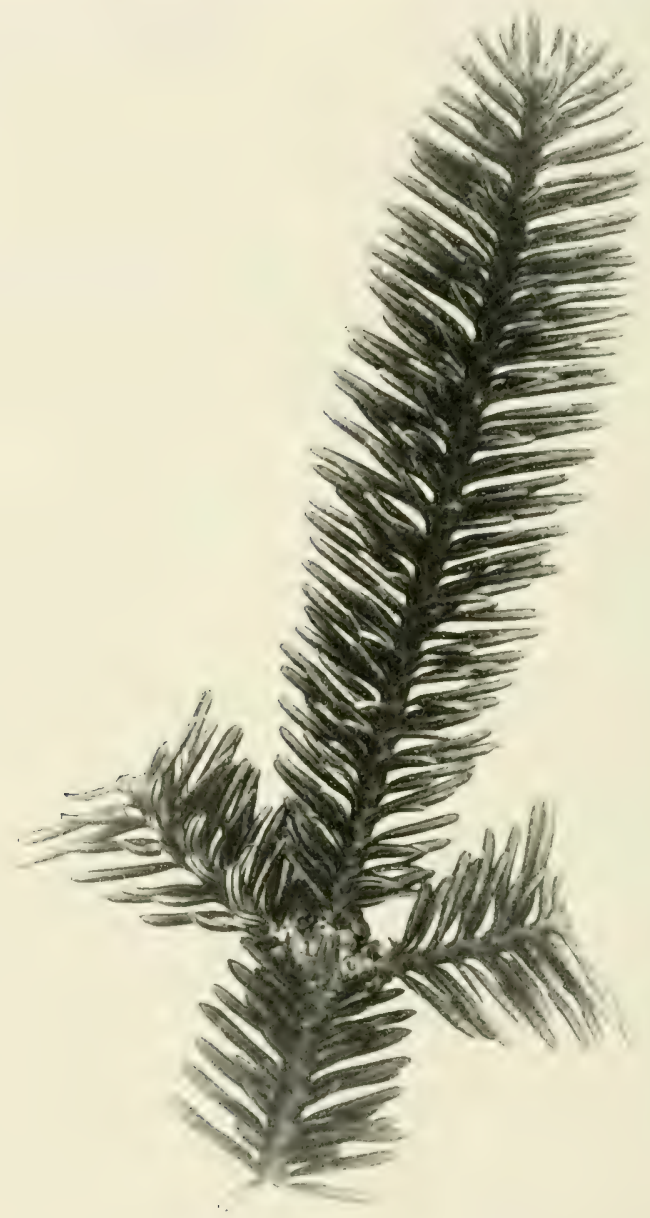

Fig. 83, Abies balsamea Mill.

liche Ansatzstelle hin etwas gedreht, oberseits glänzend dunkelgrün, rimnig, unterseits gekielt und mit weißen Spaltöfnung'slinien versehen; beim Zerreiben entwickeln sie einen stark aromatischen Geruch. 
Der erst graubliaulich-griine, damn graulraune, walzenförmige, $6-10 \mathrm{~cm}$ lange und $2^{1}{ }^{2} \mathrm{~cm}$ dicke, abgestumpfte Zapfen fiihrt feinbehaarte, fächerförmige, unten ganz spitze Schuplen, und runde, geziihnelte, meist nicht oder nur nit den spitzen sichtbare Brakteen.

Der kantige, lingliche, weiche, hraune simen hat doppelt so langen und dabei breiten Flügel.

Nicht besonders hervorragend ist das Holz; dagegen liefert das Harz einen vortreftlichen Terpentin und sogenannten KanadaBalsam; die Wurzel wird offizinell (gegen syphilis) beniitzt.

An Folmen sind zu nemnen:

Abies balsamea variegata Hort., Sammelname fur mehr oder minder gelbbunte Formen.

Abies balsamea marginata Schröd, mit an jungen Trieben gelbgerandeten Blättern.

Abies balsamea lutescens Schwer., mit gelbweißen Nadeln.

$" \quad$ " argentea Hort., weiß gespitzt.

$" \quad$ glauca Hort., robuste, auch an der Oberseite der Blätter etwas weißgezeichnete, sonst bläulich-griine Form.

Abies balsamea Iongifolia Endl., kräftiø wachsend, mit längeren aber schmäleren Blättern als die Stammform.

Abies balsamea brachylepis Willk., mit etwas kleineren Zapfen, kleineren Brakteen und roten Samenflïgeln.

Abies balsamea pyramidalis Hort., von schlankem, aufstrebendem Wuchs.

Abies balsamea columnaris Hort., eine Form mit kurzen, außen aufgebogenen Asten und etwa $1 / 2$ cin langen Nadeln.

Abies balsamea coerulea Carr., niederwiichsig, mit zweizeilig. gestellten, dunkel-blaugrünen, unten silber'weißen Blättern.

Abies balsamea nana Hort., dichtwiichsige Zivergform, mit dunkelgriinen, unten blauveißen Nadeln.

Abies balsamea globosa Hort., kugelige Zwergform.

hudsonica Sarg. u. Eng'elm., ebenfalls dichtwiichsige, fast ausgebreitet wachsende Zwer'kugelform, mit auffallend dunkelgriinen, unten blaugriinen Blïttern; muh durch Pfropfung vermehrt werden.

Syn.: Abies hudsonica Bosc.

Abies balsamea prostrata Hort., Zwergform mit weit ausgebreiteten Ästen.

Abies balsamea denudata Carr', ganz paradoxe For'm: ein Nitteltrieb mit ganz wenig Verzweig'ungen.

Abies balsamea nudicaulis Carr., ähnlich voriger, doch ohme alle Verzweigung, mit dicken, anliegenden Blättern. 
Ein Bastard ist:

\section{Abies balsamea $\times$ Abies sibirica.}

Syn.: Abies sibirica parvula Schröd.

K'leiner gebaut in allen Teilen als die Eltern; bei Pflanzen der Abies balsamea of sind die Knospen rot, bei jenen der Abies sibirica $\propto$ dagegen $\mathrm{g}$ e l b.

Abies sibirica Ledeb., Sibirische Tanne. Nordund Ost-Rußland bis Mongolei, Amurgebiet und Kamtschatka.

$$
\text { Syn.: Abies Pichta Forl. }
$$

\section{Semenowii Fedtsch.}

Auf Höhenlagen, bei feuchter Luft und nicht zu trockenem Standort. Tallagen ungünstig! Treibt früh aus.

Eine Tanne der kalten Gegenden, erst etwas langsamwiichsig (wenn ca. $1 \mathrm{~m}$ hoch dam rascher), eine Höhe von 40 Tleter erreichend, mit schmalpyramidaler Krone, glatter, schwärzlich graner Rinde, quirlförmig gestellten, wagrecht ausladenden, iiberhängenden Ästen und vielen gelblich-granen, meist glatten Zweigen mit grünlichen, stumpfen, harzigen Knospen. Die dichtstehenden, ungleichmäßig zwveireihig gestellten, flachen, linealen, $1-3 \mathrm{~cm}$ langen und kaum mehr als $1^{1 / 4} \mathrm{~mm}$ breiten, teils nach oben gekriinmten, spitzen, sonst aber - besonders an fruchtbaren Trieben - etwas ausgeschnittenen und kürzeren Blätter haben weiche Beschaffenheit, oben glänzend dunkelgriine Färbung und unten mehr oder minder weiße Spaltöffnungs. linien.

Der harzige, länglich walzenförmige, abgestumpfte, jung purpurfarbige, reif hellbraune Zapfen wird $6-8 \mathrm{~cm}$ lang und $3 \mathrm{~cm}$ dick und führt fächerförmig-keilartige, zugespitzte, gezähnelte Schuppen, sowie runde, kurzgespitzte, kleine Brakteen. Der eiförmige, kantige Samen hat purpurfarbigen Flügel.

Formen sind:

Abies sibirica alba Fisch., mit langen, stark weiß gezeichneten Blättern. Trieben.

Abies sibirica variegata Schröd,, mit einzelnen, gelblich-weißen

Abies sibirica glauca Schröd., Form mit nach oben gedrehten Blättern, von bläulicher Färbung.

Syn.: Abies balsamea? $\times$ Abies sibirica.

Abies sibirica candelabrum Schröd., die unteren Äste erzeugen aufrechte Nebenstämme.

Abies sibirica elegans Hort., zeigt ganz genau quirlförmig und wagrecht stehende Äste, bei gedrungenem Wuchs und dicken, kurzen Bliittern mit silberartig schimmernden Rändern.

Abies sibirica pyramidalis Hort., mit aufrechten Ästen. pendula Schröd., mit stark hängenden Ästen. 
Abies sibirica pumila Schröd., niedriger Zwerghbch mit gering entwickeltem Stamm.

Syn.: Abies sibirica nana Schröd.

Abies sibirica compacta glauca Hort., dichter Zwergkegel, mit bläulichen, derben, kurzen Nadeln.

Abies sibirica monstrosa schröd., monströse, kurzhuischelige Form.

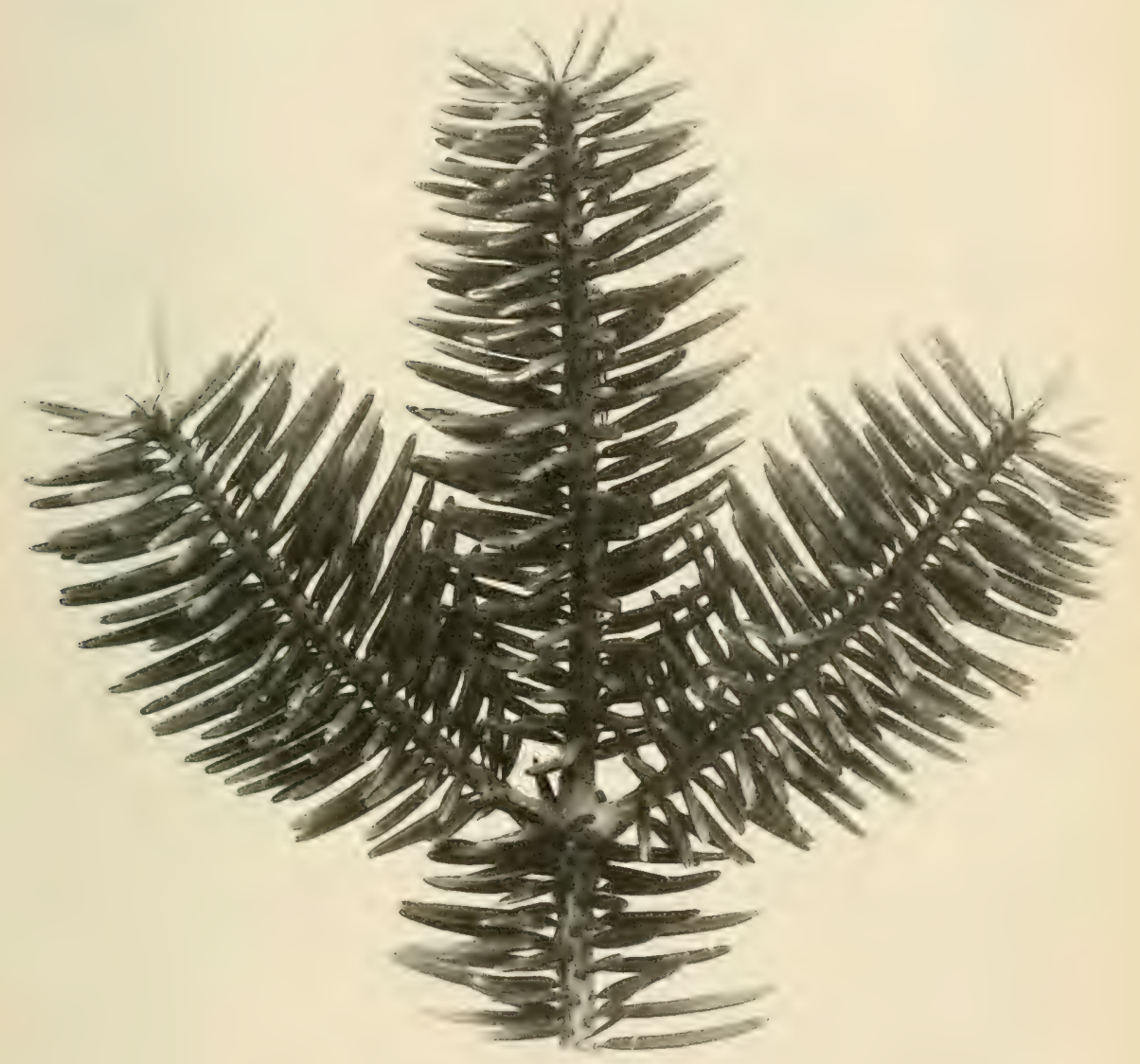

Fig. 84. Abies Veitchii Carr.

Abies Veitchii Carr., Veitchs' Tanne. Auf Kuimmert auf Shikoku und Hondo. (Fig. 84 u. 85.) trockenem Boden.

Syn.: Abies Eichlerii Lauche.

Prächtige, gegen verschiedenste Unbilden widerstandsfähige Tamne von 30-40 $\mathrm{m}$ Höhe, mit quirlförmig gestellten und wagrecht abstehenden Ästen, bräunlich-gelben, rauhen, meist gegen- 
seitig stehenden Zweigen, sowie roten, runden, kleinen, etwas harzigen Knospen.

Die ziemlich zweiseitig, dicht stehenden, an den Trieben oben aufwiits gerichteten und den Zweig deckenden, zum Teil
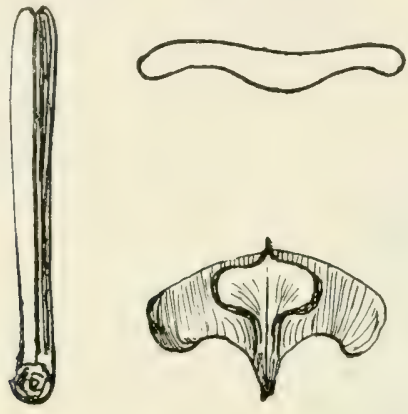

Fig. 85.

Zapfenschuppe mit Braktee, Blatt und Blattquerschnitt von Abies Veitchii Carr. (vergrößert). etwas gekrummten, $1^{1 / 2}-2^{1 / 2} \mathrm{~cm}$ langen und bis $2 \mathrm{~mm}$ breiten Blätter sind stumpf gespitzt orler kaum ausgeschnitten, oberseits glänzend grün und rimnig, unterseits gekielt und silberweiß.

Der kaum gestielte, nahezu zylinderische, abgestumpfte Zapfen von erst braun-bläulicher, dann dunkelbrauner Färbung wird $6-7 \mathrm{~cm}$ lang und $2^{1} / 2-3 \mathrm{~cm}$ dick und führt engstehende, seh1 breit nierenförmige, seitlich etwas lappige, zugespitzte Schuppen, und zweilappige, ganz kurz gespitzte und mit der Spitze öfter's etwas hervorsehende Brakteen.

Der gelbliche, kantige, keilförmige Samen hat kurzen, nach einer Seite etwas verbreiterten Flügel.

In Kultur ist noch eine mehr weißgraue Form, eine solche mit ganz hellen Zapfen, u. a. m.

Abies Delavayi Franch, Delavays Tanne, vom Gipfel des Tsang-Chan und Onei (3500-4000 m) in Yünnan (China), ist wohl noch nicht in Baumschulkultur.

Es soll ein niederer Baum sein, 7-17 m, mit flachen, an den Spitzen Pinsel bildenden Zweigen und mit $1^{1 / 2}-2^{1 / 2} \mathrm{~cm}$ langen und $1^{1 / 2}$ mm breiten, oben etwas eingeschnittenen, an den Rändern eingerollten Blättern und dunkelblïulichem, lang-zylinderischem, abgestutztem, 6-7 cm langem und $3 \mathrm{~cm}$ breitem Zapfen, welcher keilförmige, an der Spitze zurückgebogene, zur Reifezeit abstehende Schuppen und spatelförmige, mit einem kurzen Spitzchen iiber die Schuppen hervorschauende Brakteen zeigt.

Samen eirund, breit gefligelt.

Abies sachalinensis Mast., Sachalin-Tanne. Sachalin, Kurilen, Eso.

Syn.: Abies Veitchiivar. sachatinensis Fr. Schmidt.

Liebt frischen, sandigen

Von verschiedenen Autoren als Abart der Ab. Veitchii betrachtete, bis 40 in hohe Tanne, mit glatter, hellgrauer Rinde, pyramidalem Bau, wagrecht ausladenden Aesten und rauhen, 
bräunlich-gelben, ganz jung ef was behanten Zweigen, sowie besonder's an jungen PHanzen rötlichen bis violettbraunen Knospen.

Die an den Zweigen ringsum gestellten, hauptsïchlichst nach oben gerichteten, nur bei iippigen Trieben mehr zweizeilig

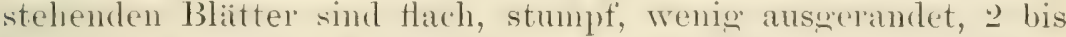
$3 \mathrm{~cm}$ lang und $1-2 \mathrm{~mm}$ breit, an der 'Trieboberseite etwas kiirzer, dunkelgrin und rinnig, unten grekielt nnd besonders an jungen Zweigen weif gezeichnet. Gegen die Ansatzstelle hin dreht sich das Blatt etwas; erstere ist rautenförmig und rauh.

Der dunkel-olivengriune Zapfen ist stumpf-zylinderisch, 6 bis $8 \mathrm{~cm}$ lang. $2^{1} / 2-3 \mathrm{~cm}$ breit und zeigt fein beharte, ganz breit nierenartige, seitlich gezihnelte, gespitzte Schuppen.

Der kantige, längliche Samen hat ziemỉich breiten, dunkelgrauen Fliigel.

An Formen werden unterschieden:

Abies sachal. typica Mayr, mit oben abstehenden und zuriickgeschlagenen, gelappten, hellgelbgrimen Brakteen bei dunkelolivengrỉnen Zapfen.

Abies sachal. nemorensis Mayr, mit nicht her'vorsehenden Brakteen, sowie erst griunen, damn braum behaarten jungen Trieben.

Abies holophylla Maxim. Ganzblätterige Tamne.

Siidost-Mandschurei.

Wohl noch nicht bei uns in Baumschulenkultur befindliche, im Wuchs unserer Weifhanne gleichende Tamme mit flachen, kräftigen, oben lebhaft grinen, unten gekielten und weif gezeichneten, besonder's an den oberen Zweigen scharf spitzen, auf etwas erhabenen Blattkissen stehenden Blättern.

Der längliche, abgestumpfte Zapfen hat oben abgerundete, seitlich gelappte und plötzlich spitz auslaufende Schuppen, sowie nicht hervorstehende Brakteen. Der gelbliche, keilförmige Samen hat kurzen, fast viereckigen Flügel.

Abies nephrolepis Maxim. Nierenschuppige Tanne. Russische Mandschurei.

Liebt mehr trockenen Syn.: Abies Teitchii mandschurica Maxim. als feuchten Boden.

\section{$" \quad$ " nikkoënsis Mayr. \\ " sibirica nephrolepis Trautv.}

In unseren Baumschulen wohl ebenfalls noch nicht in Kultur befindliche, der Abies Veitchii ähnliche, schlanke Tanne, nit dichtästiger Krone, rauhen Zweigen, heller Rinde und derben, den Zweig deckenden, flachen, ausgeschnitten bis gespitzten, auf runder Ansatzstelle stehenden, dunkelgrimen, unten gekielten und hellweißen Blättern.

Der kleine, länglich-eiförmige, er'st rötliche, damn schwärzlich-blaue, aufrechte Zapfen hat oben abgerundete, nieren- 
förmige, unten zugespitzte Schuppen und nicht hervorsehende Brakteen.

Der längliche, kantige Samen hat nahezu viereckige Fliigel. Folm ist:

Abies nephrolepis elegans Hort., gedrungenwüchsige Form mit hellrandigen Nadeln.

Eine jedenfalls hierher zu stellende, wohl auch noch nicht in Baumschulkultur befindliche Tanne ist:

Abies gracilis Komar, Elegante Tanne. Kamtschatka, Gouvernement Jussu.

Es soll eine feingebaute Tanne sein, mit glänzender, glatter, weißlicher Rinde, zierlichen, dimnen Zweigen und flachen, linealen, oben ausgeschnittenen, bis $2 \mathrm{~cm}$ langen und $1^{1 / 2} \mathrm{~mm}$ breiten, lebhaft grünen, unten blaßgrünen Blättern.

Der' zylinderische, bis $5 \mathrm{~cm}$ lange Zapfen fiihrt nierenförmige, ganz dicht und kurz, rötlich-gelb behaarte Schuppen, sowie langgespitzte, nicht hervorragende Brakteen, sowie länglichen Samen mit an der Spitze abgestutztem Fliigel.

Abies firma Sieb. u. Zucc. Japanische oder Momi-Tanne. Japan, besonder's nördliches Japan. (Fig. 86-88.)

Syn.: Abies Momi Siebold.

Mit Abies homolepis fast ständig ver-

Jung empfindlich; auch gegen kalte Winde und starke Sonnenbestrablung im Winter. Leidet manchmal durch Spätfröste. wechselte und deshalb als ziemlich winterhart (II oder III) bezeichmete, schöne, in der Jugend langsam wiichsige, bis 40, ja

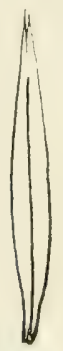

Fig. 86.

Blatt der unfruchtbaren Zweige von Abies firma S. u. Z. (vergrößert).

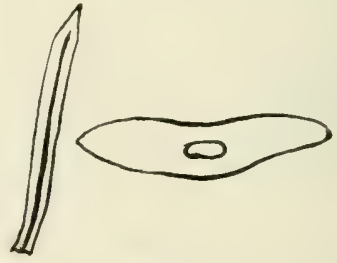

Fig. 87.

Blatt und Blattquerschnitt an fruchtbaren Zweigen von Abies firma S. u. Z. (vergrößert).

$50 \mathrm{~m}$ hoch. werdende Tanne, von pyramidalem Wuchs, grauer mid rauher, später kleinschuppiger Rinde, wagrecht abstehenden, bräunlichen Aesten und graubräunlichen Zweigen. 
Die linealen, flachen, oben ausgeschnittenen bis scharf zweispitzen (an unfruchtbaren Zweigen), lederartig steifen, dicht und ziemlich zweizeilig gestellten, 2- $-3 \frac{1}{2} \mathrm{~cm}$ langen und bis zu gut $3 \mathrm{~mm}$ breiten, an der Zweigoberseite kiirzeren - zum Teil auch etwas gekriimmten - Blätter sind oberseits rinnig. glinzend-dunkelgriu, unten gekielt und mit bliulich-weifien Spaltöffnungslinien versehen.

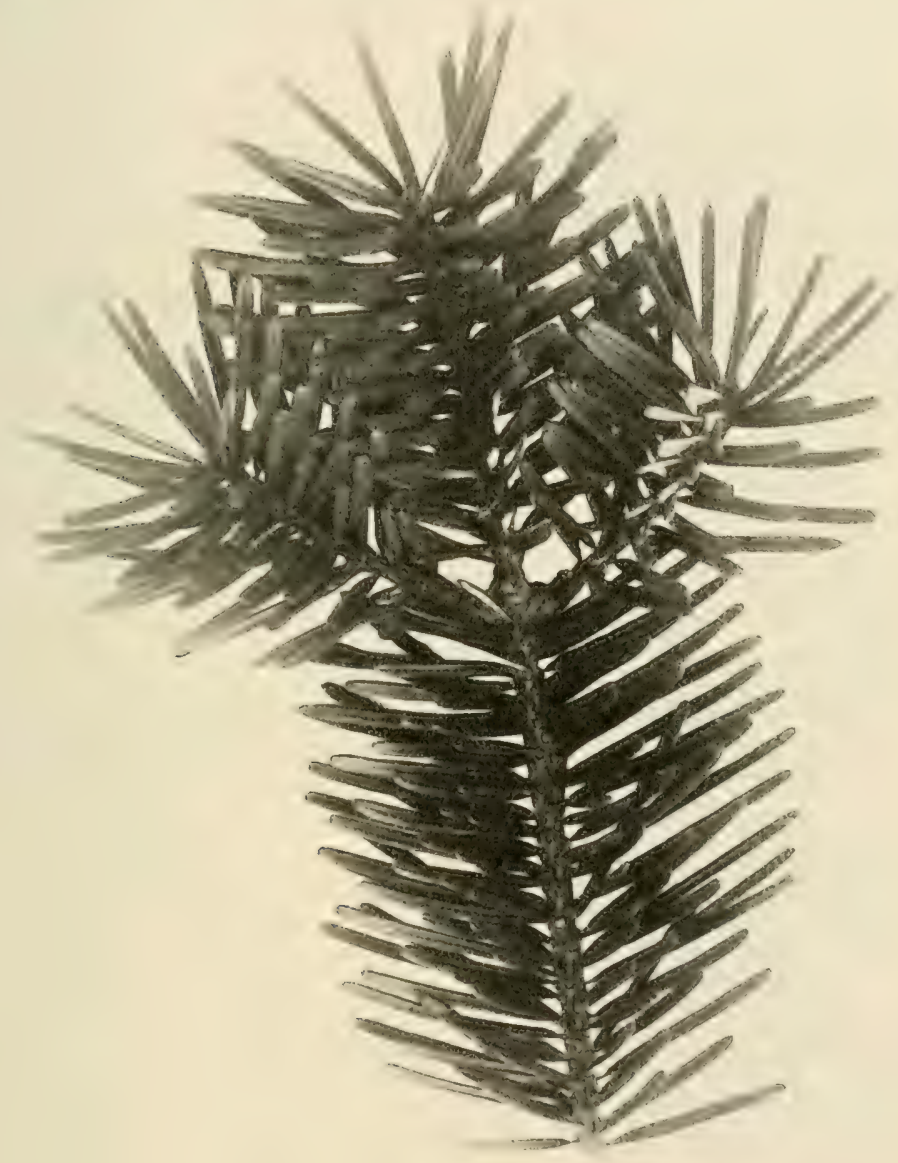

Fig. 88. Abies firma S. u. Z.

Der erst griine, dann dunkelbraune, dicke, zylinderische, etwas abgestumpfte Zapfen wird $8-15 \mathrm{~cm}$ lang (!) und $3^{1 / 2}$ bis $5 \mathrm{~cm}$ dick: er führt oben rundliche und gezähnelte, sonst breit keilförmige Schuppen und verhältnismäßig schmale, gespitzte, die Schuppen iiberragende Brakteen. 
Der eiförmige, kantige, brämnliche und fleckige Samen lıat långlich-viereckige, große Flïgel.

Diese Art benitzen die .Tapaner gerne zur Anzucht ihrer Zwergbäume in Töpfen.

Abies umbilicata Mayr. Genabelte Tanne,

Mitzumine-Tanne. Japan. (Fig. 89 u. 90.)

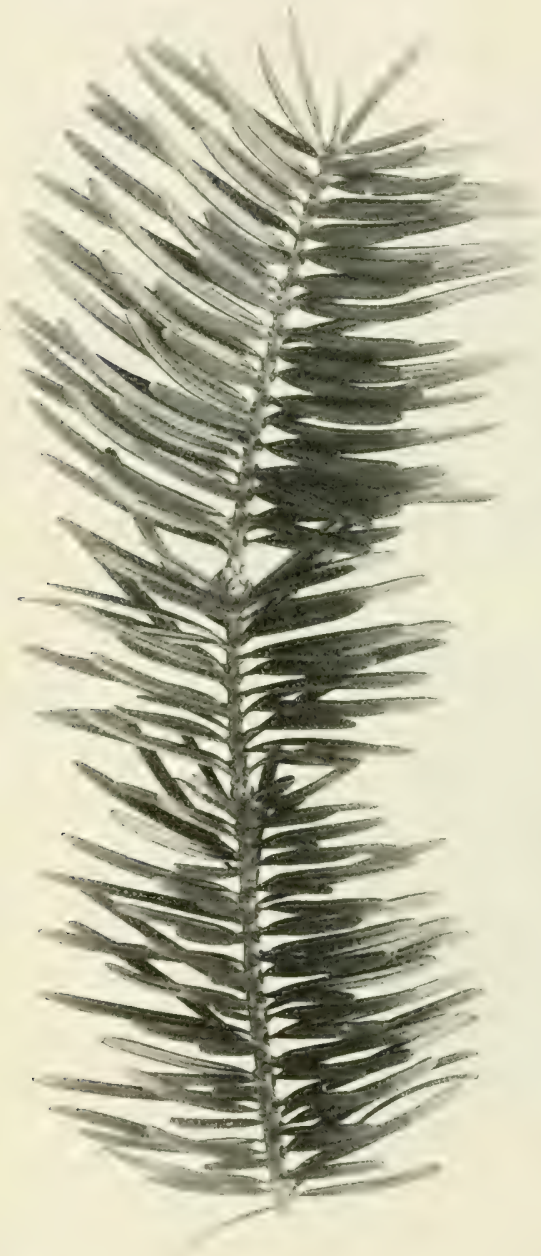

Fig. 89. Abies umbilicata Mayr.

Syn. : Abies umbellata Mayi. Im jugendlichen Zustand kaum von Abies homolepis zu unterscheidende, schöne, bei $40 \mathrm{~m}$ hoch werdende Tanne, mit erst glänzendgruiner, dann gelbgrüner, kahler, später graubrauner, schuppiger Rinde, quirlig gestellten, im Alter wagrecht abstehendenÄsten sowie ziemlich gegenständigen Zweigen und kugeligen, spitzen, harzigen Knospen.

Blätter lineal, flach, ca. $1^{1 / 2}$ bis über $2^{1 / 2} \mathrm{~cm}$ lang und $2-2^{1} / 2 \mathrm{~mm}$ breit, rings um den Zweig gestellt, aber ziemlich aufwärts gerichtet, zweiseitig stehend, oberseits gerinnt, lebhaft

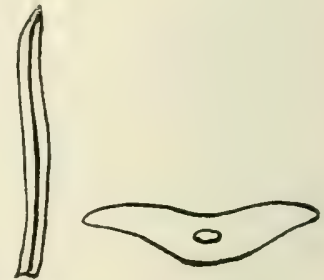

Fig. 90.

Blatt und Blattquerschnitt von Abies umbilicata Mayr, (vergrößert).

griin, meist zrveispitzig, unten mit ¿zwei weißlichen, breiten Spaltöfnungslinien, an der Ansatzstelle etwas verdickt. Ein 
zwar etwas trigerisches Erkennungszeichen ist die zweiseitige Stellung der Blätter, welche eine ziemlich unuterbrochene Linie (an jungen Bäumen) von der Spitze bis nahezu an den Stamm bildet.

Der 8-10 cm lange, 4 cm dicke, griulich-gelbe, walzenförmige, oben in eine nabelförmige (umbilicata) Spitze auslaufende Zapfen hat enganliegende, fiicherfürnige, unten etwas gelappte, mit breiter, ca. ${ }^{2 / 3}$ so langer Braktee versehene Schuppen und $1 \mathrm{~cm}$ lange Samen mit doppelt so langem, besondlers oben breitem, bräunlichem Flìgel.

Abies homolepis Sieb. u. Zucc. Kurzblatterige oder spattreibend. Nikko-Tamne. Hölıenziige von Shikoku, Hondlo, (Fig.91.) $\begin{gathered}\text { Spättreibend. } \\ \text { kimmert auf }\end{gathered}$

syn.: Abirs brachypleylla Iraxim.

\section{"Tschonostiana Rigl.}

trockenem

Prächtige, his $40 \mathrm{~m}$ hoch werdende, etwa rom 5. Jahr al, gut wiichsige Tamne mit graubrauner, kleinschuppiger Rinde, quirlig gestellten und wagrecht abstehenden Ästen und gegenständigen, glänzend hellgelben Zweigen.

Die dicht rings um den Zweig gestellten, linealen, flachen, $1^{1 / 2}-3^{1 / 2} \mathrm{~cm}$ langen und bis $1^{1} 2 \mathrm{~mm}$ breiten, an älteren Zweigen und an der Zweigoberseite kiirzeren, oben ausgeschnittenen bis

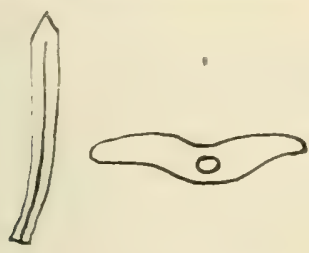

Fig: 91.

Blatt und Blattquerschnitt von Abies brachyphylla Maxim. (vergrößert).

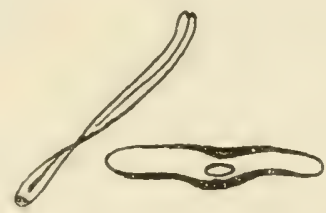

Fig. 92.

Blatt und Blattquerschnitt von Ahies Mariesii Nast.

(vergrößert).

zweispitzigen Blaitter sind gerimnt, hellgrim, unten gekielt und mit ziemlich hellweifen Spaltöfnumgshinien versehen und stehen auf rautenförmigen Blattkissen.

Der rot-his bläulich-braune Zap fen ist zxlinderisch geformt, abgestumptt, s-9 cm lang und 3 cm dick, mit engstehenden, breit nierenfömigen, seitlich gelappten und gezïhnten, ganz spitz auslaufenden Schuppen, sovie unten schmalen, oben rundlichen, nicht hervorschauenden Brakteen.

Der eifiomige, kantige und schwärzliche Samen hat nahezu viereckigen Flïgel.

Abies Mariesii Masters, Maries Tanne. Jalpan, vom 36. ${ }^{n}$ nördl. Breite bis zur Nordspitze von Hondo. (Fig. 9.2.) 
Bis zu $25 \mathrm{~m}$ hoch werdender, pyranidalwiichsiger Baum, mit kleinschuppiger Rinde, wagrecht abstehenden, auch etwas hïngenden Ästen, deren Enden sich meist wieder aufrichten, sowie rotbraunen, kurzbehaarten Zweigen.

Eigenartig sind die Blätter gestellt, welche an den Haupttrieben ringsum, an den Zweigen durch Drehung fast zweiseitig, und an frischen Trieben fast vierreihig stehen, dabei dem Zweige ziemlich anliegen und auf der Oberseite des Zweiges kiirzer sind. Die Blätter selbst sind flach, $3-5 \mathrm{~cm}$ lang, gegen die Blattspitze zu breiter als unten, oben ausgeschnitten, an der Oberseite tief gerinnt und gelblich-grim, unten gekielt und nit blauweißen Spaltöffnumgrinien versehen, welche sich an den älteren Blättern mehr verlieren.

Der dick-zylinderische, oben abgestumpfte, erst bläulichpurpurrote, dann rotbraune Zapfen wird $9-15 \mathrm{~cm}$ lang und $4-5^{1 / 2} \mathrm{~cm}$ dick und führt breite, nierenförmige, keilförmig zulaufende, seitlich mit Haken versehene Schuppen, sowie dreilappige, nicht hervorsehende Brakteen.

Der eiförmige Samen hat breite, große Flügrel.

Von weiteren wohl noch nicht in Baumschulkultur befindlichen Arten sind zu nennen:

Abies Fargesii Franch. Farges Tanme, von Zentral- und West-China (von 2000-3800 m) mit gewöhnlich $2 \mathrm{~cm}$ langen und $2 \mathrm{~mm}$ breiten, - an Fruchtzweigen $1-1^{1 / 2} \mathrm{~cm}$, an den Enden nur $1 / 2 \mathrm{~cm}$ langen - flachen, selten etwas an den Rändern gerollten, an der Spitze eingeschnittenen, unten ganz weißen Blättern, sowie purpurroten, tonnenförmigen, $8 \mathrm{~cm}$ langen und $4 \mathrm{~cm}$ dicken Zapfen mit nicht hervorstehenden Brakteen.

Eine Form ist:

\section{Abies Fargesii sutchuensis Franch.}

Abies squamata Master's, Schuppenrindige Tanne, von WestChina $(4000-4600 \mathrm{~m})$ mit sich in papierartigen Streifen lösender, rotgelber Rinde, spiralig stehenden, $1 \frac{1}{2}-2 \mathrm{~cm}$ langen und $2 \mathrm{~mm}$ breiten, etwas gebogenen, stumpfen bis spitzen, gerimten und gekielten Blättern, sowie violetten, ] än@lich-eiförmigen, bis $6 \mathrm{~cm}$ langen und $3 \frac{1}{2} \mathrm{~cm}$ dicken Zapfen, ïber deren breiten, gewölbten Schuppen die Spitzen der Brakteen hervorsehen.

\section{Keteleeria Carrière. \\ Keteleers 'Tanne.}

Immergrime, unseren Tamen ähnliche, große Bäume, mit rissiger bis korkiger Rinde, mehr oder minder schirnförmig ausgehreiteter Krone, meist wagrecht ahstehenden Ästen, etwas 
steifen, manchmal auch leicht iiberhängenden, quirlig gestellten Zweigen.

Blätter zweizeilig his zerstrent und abstehend, fein gespitzt bis stumpf, flach, lineal, iiber dem Grunde etwas gedreht, genervt, glïnzend griin, unten auch mit Spaltöftumgslinien.

Bliiten mon̈̈zisch; mïmuliche klein, gestielt, ganz ïhnlich der von Pseudolarix, Bliitenstand mit 9-10 je ca. $1 \mathrm{~cm}$ langen Bliten; weibliche Bliite ähnlich jener der Tammen, anfrecht.

Zapfen erst rot, dann braun, aufrecht, eiförmig bis länglich, nicht fest, mit lederartig verholzten, nicht abfallenden Schuppen; Brakteen klein und eingeschlossen. Samen ziemlich groß, verbreitert-länglich, mit großem Fliigel. Das Holz ist braun in Farbe. Keimling mit 2 (immer?) Kotyledonen.

Es existiert eine Reihe von Arten, oder doch Formen von Keteleerien, aber in Deutschland ist wohl nirgends eine Art in Baumschulkultur, selbst die Topfkultur ist eine sehr beschräkte, ja wir haben zur Zeit nicht einmal eine genaue Kenntnis über schon eingefuihrte Arten, geschweige dem iber noch fremde Arten.

Es können deshalb auch nur ein paar Arten etwas näher beschrieben werden.

Keteleeria Fortunei Carr. Siidöstliches China.

VI (V)? ?

Syn.: Abies Fortunei Mur\%.

jezoënsis Lindl. (nicht Sieb.u. Zuce. und nicht Maxim.)

Picea Fortunei Murr.

Pseudotsuga je:oënsis Bertrand.

Pinus Fortunei Parl.

Schöner, hoher Baum, mit hellbraumer, rissiger, korkiger Rinde, quirlig gestellten und wagrecht wie bei den Zedern abstehenden, grauen, mit Blattnarben gezeichneten Ästen, ähnlich stehenden, wohl auch etwas hängenden, rostfarbenen Zweigen mit filzigen, gelben Trieben und kurzen, kegelförnigen Knospen.

Blätter entfernt und zerstreut stehend bis zweizeilig, sitzend, doch unten gedreht, flach, steif, zum Teil gekrimint, hervortretend lïngsgenervt, die Blätter der unteren Zweige scharf gespitzt, die der oberen abgerundet, $3(-4)$ cm lang und $2 \frac{1}{2}$ bis $3^{1 / 2} \mathrm{~mm}$ brest, alle oben glänzend griu, unten blaßgriin.

Zapfen erst purpurrot-bläulich, damm braunrot, dick-eiförmig $(8-10 \mathrm{~cm}$ grob, 5-6 cm breit), auf kurzem Stiel aufrecht stehend, lederartig verholzt, bleibend, mit grohen, kreissunden Schuppen. Samen bräunlich, länglich bis eiförmin, mit großem Fliigel, der bei geöffnetem Zapfen etwas iiber die sichuppen hervorragt.

Vermehrung aus Samen (leider zeigt sich aber das bis jetzt eingefiihrte Material als schlecht keimend), ferner durch Stecklinge und Ableger, sowie durch Pfropfung auf Abies pec- 
tinata, da weitere etwa passende Unterlagen noch nicht geprüt wurden.

Keteleeria Davidiana Beißn. Nörtliches C'hina.

Syn.: Abies (Tsuga) Davidiana Franch.

Pseudotsuga Davidiana Bertr.

Hoher Baum mit glänzend-griinen, stumpfen, $3-4^{1} / 2 \mathrm{~cm}$ langen und $2-3 \mathrm{~mm}$ breiten, unterseits mit etwas vorstehendem Mittelnerv versehenen und gegen die Basis zu einem Stiel verschmälerten, an den Rändern etwas gebogenen Blättern. Zapfen zylinderisch-lang, braun.

Keteleeria sacra Beißn. China.

Syn.: Abies sacra Franch.

Vielleicht Form von voriger Art.

Keteleeria Fabrii Mast., China, mit bramen Zweigen, stumpfen und gekerbten, 2 cm langen, nur unten genervten Bliittern und etwas länglichen Zapfen.

Keteleeria Evelyniana Mast., China, mit gelbbramen Zweigen, 4 cm langen, gebogenen, kurz aber feingespitzten und hervortretend genervten Blättern und zylinderischen, bramroten Zapfen.

j) Die Pflanzenf ii hen Langtriebe und Kurztriebe.

16. Larix Link.

L ä r c h e.

Laubabwerfende, ziemlich hoch werdende Bäume, von meist ausgeprägt pyramidalem Aufbau, zerstreut stehenden, teils aufstrebenden, teils wagrechten, teils auch hängenden Ästen, zweierlei Zweigen, d. h. verlingerten Trieben = Langtriebe, und seitlich stehenden, fast knospenartigen Trieben = Kurztriebe. Erstere führen zum 'Teil Blätter' (Narleln)mit Blattachselknospen, welch letztere sich zu Kurztrieben entwickeln. Diese Kurztriebe können sich anch zu Langtrieben ausbilden, andernfalls verlängern und verstärken sie sich zu kurzen Sprossen. Die Kurztriebe entstehen mit dem Ergrimen im Frihjahr, wïhrend die Lanotriebe sich im -Juni aus den Kurztrieben entwickeln. Die Endknospen der Kurztriehe sind kugelig und haben abgerundete Knospenschuppen.

Die Nadeln sind im Herbst abfallend, diun, weich, pfriemlich, lineal, unten gegliedert, spiralig stehend, jedoch an den Kumztrieben so eng gestellt, dak sie wie gebiischelt aussehen, - eine nur Larix, Pseudolarix und Cedrus zukommende, charakteristische Eigenschaft - von Färbung lebhaft griin, im Herbst gelb. Knospen von häutigen Deckschuppen besetzt.

I)ie Bliten sind monözisch, auf demselhen Zweig entstehend; die männlichen Kiitzchen entwickeln sich kurz vor oder mit 
der Blätterentwicklumg auf nadellosen Kurztrieben, sind von Schuppen eingehullt, kurz gestielt, gelb; die weiblichen Kiitzchen sind rundlich bis linglich, erscheinen an der spitze bebliatterter Kurztriebe, sind purpurrot gefirbt (auch hellgriin), die Samenschuppe nahezu rund, mit langer, spitz anslaufender, ens angeschlossener Briktee (Deckschuppe) und mit 2 abwirts gerichteten Samenknospen.

Zapfen rumdlich bis länglich, locker, weich, im ersten Jahr reifend, nach dem Samenausfall bleibend, nicht zerfallend.

Samen unregehnäbig linglich, fast dreieckig, dimne Schale, bleibender, langer Flïgel. Keimling mit 5--7 Kotyledonen.

Die Lärchen sind Bäume der ki hhleren Regionen mul lieben tieforindigen Boden, sowie lichte Stellung. Der schlimmste Feind der Liirchen ist der Liarchenkrebs Dasyscypha(Peziza) Willkommii.

Larix europaea DC. Gemeine Lürrche. Alpen Nordeuropas (Fig. 93 und 94).

Syn.: Lavix decidua Mill.

I

Lichtbedürftig. Luftige Hochlagen. Kalkboden bevorzugt.

Prichtiger, pyramidaler Baum, mit grau- bis rotbramer Rinde, quirlig gestellten, wagrechten bis iiberhïngenden und an den Spitzen wieder aufsteigenden Ästen, sowie oft lang hängenden, erst griunlich-gelben Zweigen oder Langtrieben und kurzen, rundlichen, dicht mit Blättern (30-60 Stiick) besetzten Kurztrieben.

Blätter $1^{1} / 2-3 \mathrm{~cm}$ lang und $1 / 2-3 / 4 \mathrm{~mm}$ breit, lebhaft hellgriun, im Herbst goldiggelb, weich, unterseits mit Mittelnerr. Knospen braun.

Zapfen Ende Herbst reifend, aber erst im Friilujahr sich offnend, erst purpurbräunlich dam bram, $3-4 \mathrm{~cm}$ lang, die Brakteen etwas hervorsehend, bei Feuchtigkeit sich schließend und bei Trockenheit sich offnend und Jahre lang bleibend. Interessant ist, daß öfter's der Zapfen vom Trieb durchwachsen wird. Samen fast dreieckig, dunkel bis glänzend braun, 4 bis $5 \mathrm{~mm}$ lang, gefliigelt, nur 30(-39) \% keinfähig, doch 3-4. Tahre haltbar und bereits nach $3-t$ Wochen keimend. Feinling mit dreieckigen Kotyledonen.

Das außen gelbe, im Kern rotbraune Holz ist eines der allerbesten Werkhölzer, äußerst harzreich, fest, dauthaft, widerstandsfähig, gut spaltbar. Das Holz der Läirchen von den Alpen — Jochlärche und Steinlärche - liefert das beste Material fiur Schiffsbau, Wasser- und Erdbauten, während das Holz aus dem Tiefland - Graslärche - ihm an Giite nachsteht. Außerdem liefert das Holz den feinen, oftizinell und technisch gebranchten venetianischen Terpentin, sowie einen Bestandteil des sogen. Orenbitrer Gummis. Die Rinde ist gerlostoffreich und enthält Larixinsäure. 
Landschaftlich ein hochwichtiger Baum, einzeln oder in Gemeinschaft stehend eine prächtige Zierde.

Bei dumpf-luftigem Standort wird die Lärche gern ron Krankheiten heimgesucht. Das vorzeitige Abwerfen der Blätter,

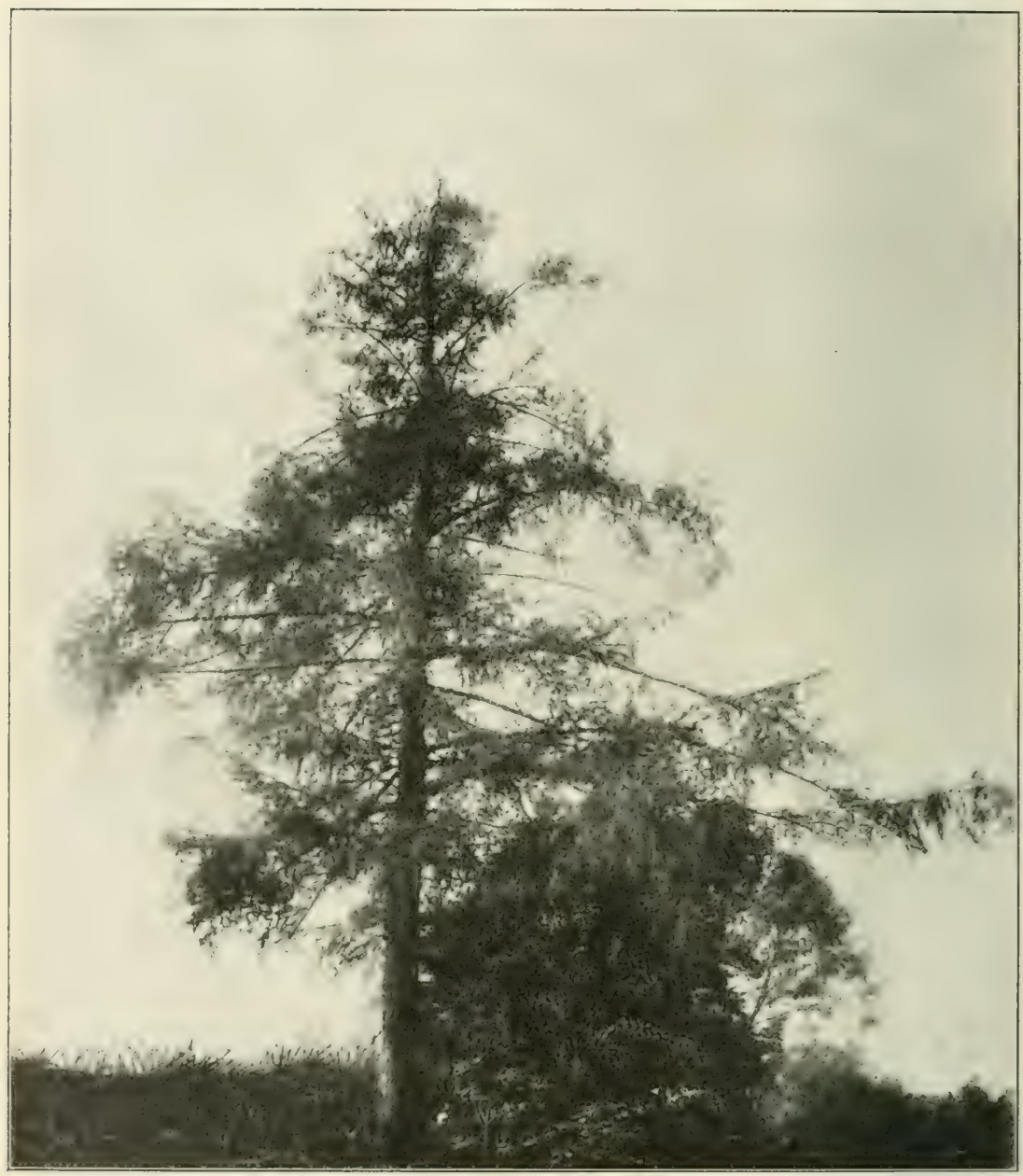

Fig. 93. Larix europaea DC. (ca. 90 jährig).

.. rie Schuitte", wird durch einen Filz "Sphaerella laricina" hervorgeruf'en, während ein zweiter, Dasyscypha (Peziza) Willkommii, ein Becherpilz, den so sehr gefiurchteten Lärchenkrebs erzeugt. Zu allem tritt auch noch oft eine das Immere der Blätter ausfressende 


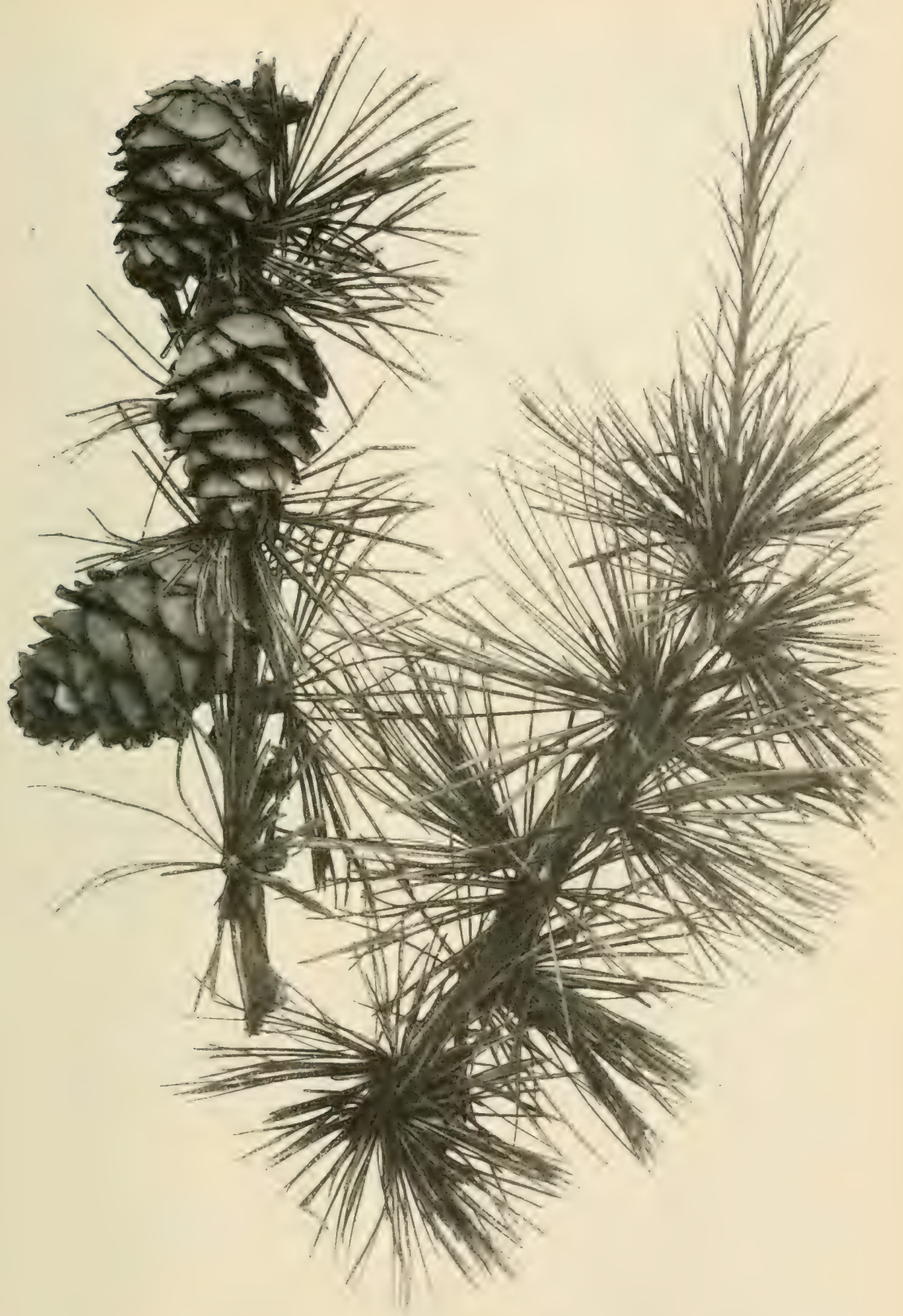

Fig. 94. Larix europaea DC. 
Niniermotte (Lärchenschabe), Coleophora laricinella, so stark hinzu, daß die Bäume ganz damit iiberzogen sind, weif aussehen. An Larix europaea und L. sibirica komnt, nebenbei benerkt, auch der offizinelle Lärchenschwamm, Polyporus officinalis (besonders gegen Nachtschweiß benuitzt) vor.

Vermehrung durch Samen von älteren Bäumen aus den Alpen (Samen von den als "Sudetenlärchen" bezeichneten und empfohlenen Bäunen, also schlesischer Provenienz, ist nicht mehr, oder äußerst selten im Ilandel). Dichte Saat und nicht zu geringe Erddeckung ist empfehlenswert. - Stecklinge aus nahezu ausgereiften Kopftrieben, sowie Ableger bringen keine kraftvollen Bäume zur Entwicklung; nicht viel besser ist es mit gepfropften Pflanzen. Pfropfung vor dem Austrieb.

In den Alpenländern unterscheidet man, ähnlich wie bei Picea excelsa, neben Wetterlärchen, Kandelaberlärchen, Garbenlärchen u. s. w, besonders zwei Formen des Holzwertes, also ebenfalls Standortsformen, und zwar:

1. Graslirchen, im Tiefland, in fetten Grasböden gewachsene Exemplare mit weichem, weiflichem, nur innen rotem $\mathrm{Hol}$, welches nur dem Föhrenholz gleich geschätzt wird.

2. Jochlär(h'n ('teinlärchen), in steinigem oder sonst festem Boden gewachsene Exemplare, welche ab dem 20. oder 30. Jahr' weniger an Länge zuwachsen, sich verdicken und besonders bei mehr sonnigem Stand ein sehr hartes und dauerhaftes, dunkelrotes $\mathrm{Holz}$ zeigen.

An systematischen Formen sind zu nennen:

Larix europ. microcarpa Beißn., Form mit kleineren, und macrocarpa Beißn., Form mit gröferen Zapfen als bei "der Stammform.

Larix europ. multicaulis Schröl, viel verzweigte Form. purpurrötlich." alba Hort., weibliche Bliite griunlich-weif statt

Syn.: Larix europ. flore albo Hort.

Larix europ. pendulina Beibn., gabelig wachsende Form mit abwärts gerichteten Ästen.

Larix europ. pendula Laws., eine schöne, mit feinen, mehr oder minder stark al)wärts hängenden Ästen ausgestattete Form, deren Gipfel ebenfalls oft iiberhingend, dann aber wieder aufsteigend ist.

\section{Syn.: Larix americana pendula Loud.}

Larix europ. glauca Hort., blaugrime Form, mit in der Jugend fast schirmartig ausgebreiteten Ästen und iblorhängenden Zweigspitzen, später mit aufstrebenden Ästen.

Syn.: Lavix europ. glanca pendula Hort.

Larix europ. fastigiata Hort., Säulenlärche, mit schlank säuleṇförmigem Wuchs. 
Larix europ. vi!gata Hemp. und Wilh., sehr seltene, äuferst trägwiichsige, aber interessante Form, mit schlangenförmig g’ewumdenen, kaum verzweigten Ästen, sowie den Zweigen fest anliegenden Blättern.

Larix europ.compacta Hort., dichte, gedrungene Pyramidenform.

Kellermannii Hort., Zivergform, dichthliitterig.

cervicornis Beiłn., geveih-ästige Kriippelform.

Es soll" auch eine Kreuzung:

Larix europaea $\times$ Larix leptolepis existieren.

Larix sibirica Ledeb. Sibirische Lärche. Sibirien.

Syn.: Larix enropaen $\beta$ sibirica Loud.

$$
" \quad \text { decidua ß rossica Henl. u. Iochst. }
$$

Der vorigen Art sehr ähnliche, doch starkwiichsigere (verschiedenerorts langsan wiichsige), gradschäftige Lärche, mit rundlicher Krone und mehr aufsteigenden Ästen, hellgelben, jungen Zweigen und schwarzg'rundigen Knospen. Blätter länger und auch dichter gebiischelt, sowie ca. 8 'Tage frither (aufer' L. kurilensis) austreibend und ca. 8 Tage friiher das Laub werfend, als sonstige Lärchen. Junge Pflanzen durch geraden Wuchs und schwache Ästchen auffallend.

Weibliche Bliite bräunlich bis gelbgriun, selten weißlich. Zapfen gröber als bei der vorigen Art. Leidet gern durch die Lärchenschütte (Sphaerella laricina).

Die Formen dieser Art sind bei uns wenig oder noch gar nicht in Kultur. Es sind dies z. B.:

Larix sibirica viridis Sr., weibliche Bliiten sowie Zapfen griuulich-wéiß.

Syn.: Larix europaea $\beta$ rossica Beißn.

$"$ decidua $\beta$ rossica Rigl.

archangelica Laws.

Larix sibirica Tittelbachii Schröd., sehr seltene Ortsform mit in der Jugend weißen Zapfen.

Larix sibirica Iongifolia, langblätterig.

robusta, kräftig wachsend.

glauca, blaugriin.

fastigiata, gipfelständig. pendula, hängend.

Larix americana Michx., Amerikanische, schwarze

L. Virginien bis Kanada.

Syn.: Larix microcarpa Bedf.

In der Heimat bis $30 \mathrm{~m}$ hoch werdender Baum mit dunkler graubrauner Rinde, heller Borke, breiter Krone, zerstreut stehen- 
den, langen, diumen und ganz hängenden Ästen, sowie überhängenden, gelbroten Langtrieben, kleinen runden Kurztrieben und rotbraunen Knospen. Die 2-3, $3^{1 / 2}$ langen und nur $1 / 2 \mathrm{~mm}$ breiten Blätter stehen dicht, sind stumpf und dunkelgrün. Zapfen auffällig klein, nur etwa zehnschuppig, fast rund, gelbbraun.

Vermehrung wie bei erster Art.

Liefert auf mehr trockenem als feuchtem Boden ein schweres, sehr dauerhaftes Holz.

Eine blaunadelige Form ist:

Larix americana glauca Hort.

Larix dahurica Turcz., Dahurische L. Amur- $\quad$ Liebt Lufteuchtigkeit. gebiet, Dahurien, Sachalin.

Noch vielfach, hesonders mit L. sibirica verwechselte, eine der in den nördlichen Regionen am höchsten gehenden Lärchen, in der Heimat normal bis $20 \mathrm{~m}$ hoch werdend, mit erst mehr wagrechten dam aufstrebenden, sparrigen Ästen, iuberhängenden, sowie in der Jugend kahlen, rosa bereiften Zweigen und dunkelbraunroten Knospen. Kurztriebe länglich oder eiförmig (!), nur etwa $6 \mathrm{~mm}$ lang. Blätter lineal, $2-3^{1 / 2} \mathrm{~cm}$ lang und $1 / 2-3^{3} / 4 \mathrm{~mm}$ hreit, z. T. sichelförmig gekrimmt. Zapfen mit etwa 20 Schuppen, rundlich, glänzend, hellbraun, bei der Reife weitklaffend.

Vermehrung wie bei erster Art. - Liefert grutes WVerkholz. Formen sind:

Larix dahur. chlorocarpa Schrö̈l, Form nit vor der Reife hellgrünen Zapfen.

Larix dahur. prostrata Rgl., Zwergform des höchsten Norclens, orler auch aus sumpfigen Niedermgen stammend. sibirien.

Larix dahur. alpina Schröd. (montana), Ortsform aus Ost-

Höchst wahrscheinlich als Bastard anzusehen ist:

Larix hybrida Schröder, mit hellbraunen Zapfen.

Syn.: Larix americana $\times$ dahuricu.

Larix leptolepis Murr. Japanische, dünnschuppige L. Hondo.

Syn.: Larix japonica Carr.

I

Gedeiht besonders in kühlen, hohen Lagen.

Die schönste unserer Lärchen! Herrlicher Baum mit breiter, ziemlich ovaler Krone, nahezu wagrecht ausgelegten und etwas iiberhängenten Ästen, sowie gelblich-grauen, bis bram-rötlichen Längstrieben. Kurztriebe rundlich und dick. Die weichen, meist grofjen, sternförnig stehenden Bliatter sind $1^{1}{ }_{2}-3^{1 / 2}$ cn lang und ${ }^{1 / 2}-1 \mathrm{~mm}$ breit, lebhatt grim, auf der Unterseite mit zwei bialich-weißen Spaltöffnungslinien, im Herbst seh" schön goldgelh und oft lang an Baume bleibend. 
Der Zapfen ist $1^{1 / 2}-3^{1 / 2} \mathrm{~cm}$ lang, sehr diimnschuppig, erst gelbgruin, dann hellbraun. Samen dunkelbraun.

Vermehrung wie bei erster Art. Liefert ganz vorzügliches Nutzholz. Forstlich schon stark angebaut, aber in Alter nicht mehr wiichsig. - Ist bei dumpfluftigem oder felchtem Stand leider eben so sehr den Krankheiten und Feinden ansgesetzt wie Larix europaea, sonst aber gut widerstandsfähig gegen die Lärchenmotte und den Krebs.

Formen sind:

Larix leptol. Murrayana Maxim., eine etwas kleinnadelige und kleinzaptige Ortsform Japans. Von dieser Form und der Stammform ziichten Japaner und Chinesen zwergige Topfbäume.

Larix leptol. aureo-variegata Hort. Dirk, mit ganz gelben, oder gelb gestreiften Nadeln.

Larix leptol. pendula Hort., mit stark liängenden Ästen. form. dumosa Beißn,, starktriebige, rundliche Busch-

Larix leptol. Ganghoferii Beißn., pyramidal bis kegelförmine Form, mit dichtstehenden, fast senkrecht anf'strehenden Ästen. Himalaya.

Larix Griffithii Hook, fil. und Thoms. Griffiths L.

Kaum echt in Kultur befindliche, in Dentschland wohl nur in Region VII aushaltende Art, welche vielfach mit Larix leptolepis verwechselt wurde - deshalb auch die falschen Angahen iiber Winterhärte —, von dieser aber durch die Nadeln, hesonders aher durch die Zapfen stark unterschiedene Lärche. Ein schlank aufwachsender Baum nit wagrecht abstehenden Ästen, erst. gelblich- dann dunkelbramen, iiberhängenden Zweigen, sowie in dichten Biischehn - bis 50) Stiick - stehenden, lebhaft griunen, 2-3 $3^{1 / 2} \mathrm{~cm}$ langen und $1 \mathrm{~mm}$ breiten, im Herbst braun gefärbten Blättern, auf auffallend langen Blattkissen.

Der brame, oft mit Harz bedeckte, $7-10 \mathrm{~cm}$ lange Zapfen hat eine ganz zylinderische Form und weit inher die Schuppen zuriickgeschlagene Brakteen.

Liefert gutes, weißes Werkholz.

Larix Lyallii Parl, Lyalls Lärche. Kaskadengebirge des Washing ton-Territoriums.

(II?)

Auf Höhenlagen.

Sehr selten echt in Kultur befindliche, auf ihre Winterhärte noch genau zu priffende Art, welche in der Heimat einen bis $12 \mathrm{~m}$ hoch werdenden, prramidalwachsenden Baum ergibt, mit nahezu wagrecht stehenden Ästen, gelbwollig hehaarten jungen Zweigen, ebenso behaarten Knospen, und länglich-runden Kurztrieben. 
Blätter dicht und büschelig stehend, weich, bis $23 \mathrm{~mm}$ lang, etwas gekriimmt, rinnig.

Zapfen länglich, $+\mathrm{cm}$ lang, $2 \mathrm{~cm}$ hreit, reichschuppig, mit seschlitzten Zapfenschuppen und roten, langgespitzten Brakteen.

Larix kurilensis Mayr. Kurilen L. Insel Shikotan Gegen Spätund Iturupp; Kamtschatka?

Syn,: Larix dahurica Turez. var. japonica Maxim. fröste ziemlich

In der Heimat bis $25 \mathrm{~m}$ hoch werdender, starkwiichsiger, dichter, erst pyramidal, dann fast schirnföming aufgebauter Baum, mit kleinschuppiger Rinde, fast ganz rechtwinkelig abstehenden Ästen, dunkelblauroten, bezw. violetten, etwas bereiften und braunrot behaarten Zweigen, sowie dicken und starken Kurztriehen. Knospen rotbraun, beim Austrieb hellrot.

Blätter an den Langtrieben $31 / 2-4^{1 / 2} \mathrm{~cm}$ lang und $2 \mathrm{~mm}$ breit, an den Kurztrieben $1^{1}{ }_{2}-3 \mathrm{~cm}$ lang und 1-2 mm breit, ziemlich steif, sichelförmig gekriinmt, bläulich-griin; treiben sehr bald aus. Zapten $1^{1 / 2}-2^{1 / 2} \mathrm{~cm}$ lang und $1^{1 / 2} \mathrm{~cm}$ hreit, jung purpurrot. Kernholz rotbraun.

Larix occidentalis Nutt. Westamerikanische L. Britisch-Columbien bis $50^{\circ}$ nördl. Breite.

Herrlicher, bis 80 m hoch werdender, sclilankwiichsiger Baum, mit nahezu wagrecht ausgebreiteten, aber kurzen Asten und kahlen, glänzend-bräunlichen Zweigen mit braunen Knospen. Die schwiirzlichen Kurztriebe sind ziemlich rund und fiihren licht gestellte - bis zu 20 - Blättchen. Letztere sind $20-27 \mathrm{~mm}$ lang, steif, lineal, spitzig, gerinnt.

Die braunen Zapfen werden 2-3 $\mathrm{cm}$ lang und $2 \mathrm{~cm}$ breit und zeigen in eine lange Spitze verlängerte Brakteen. Samen weißlich, lang geflügelt.

Liefert ganz vorzügliches, braunrotes Bauholz.

Folgende, noch ganz wenig verbreitete Lärchen bediurfen noch der Priffung iiber Winterhärte, Brauchbarkeit in Deutschland, u. s. w.

Larix chinensis Beißn. Chinesische L. China. (IV. V. ??)

Baum mit kegelförmiger Lrone, aschgraurindig, horizontal gestellten Ästen, gelblichen bis hellbraunen Längstrieben und kleinen, rundlich-länglichen, dichtblatterigen Kurztrieben. Knospen hellbraun, glänzend.

Platter schmallineal, $2-3 \mathrm{~cm}$ lang, unten mit zwei bläulichweifen Spaltöffnumgsinien. Zapfen eifürmig bis länglich, $2^{1 / 2}$ bis 5 cm lang, hellbraun, jung filzig behaart, die anliegenden, diun und spitz auslaufenden Brakteen ragen weit iiber die schuppen hinweg. Der Samen ist dunkelbram. 
Larix Potaninii Batalin, Potaninis L. West-China. ?

Syn.: Lavix thibetice Franch.

Ein der Larix Griffithii ähnlicher, in der Heimat 7-20 m hochwerdender Baum, jung mit gelber, etwas behaarter, später schwärzlichgrauer Rinde und linealen, spitzen, mit Mittelrippe versehenen, $2-2^{1}$ a $\mathrm{cm}$ langen und $1 / 2 \mathrm{~cm}$ breiten Bïittern, sowie $3-5 \mathrm{~cm}$ langen und $2^{1 / 2}-3 \mathrm{~cm}$ breiten, sitzenden, stumpfeiförmigen, graubräunlichen Zapfen, deren Brakteen etwas iiber die Zapfenblätter hervorragen.

Soll gutes Bauholz liefern.

Larix Cajanderii Mayr. Cajanders L. Ostsibirien I:

Im Bau an Larix dahurica erimernde, in mseren Kulturen noch ganz wenig verbreitete Lärche. Auffallend sind die einem dichten, gelblichen Haarbischel entspringenden, 4-5 cm langen Blätter, an erst gelbbramen, später grauen Trieben.

Die kleinen Zapfen tragen bei 20, an oberen Rande ausgebuchtete (!) Schuppen.

\section{Larix Principis Ruprechtii Mayr. Prinz Ruprechts L.}

Nordchina.

In unseren Baumschulkulturen wohl noch nicht (?) vorhandene, in Habitus, Rinde, Borke an unsere gewöhnliche Lärche sehr erimmernde, gradschaftige Art mit graugrimen, an den herablaufenden Nadelansätzen gelben Trieben, sowie rotbraumen, hellgelbbehaarten Knospen.

Narleln teils sichelförmig gebogen, bis $3^{1 / 2} \mathrm{~cm}$ lang, teils nur $1^{1} / t-2^{1} / 4 \mathrm{~cm}$ (an Kurztrieben) lang. Der geöffinet $4 \mathrm{~cm}$ lange und $3 \mathrm{~cm}$ dicke Zapfen hat Hache, feingezihnte Schuppen und steht auf $2 \mathrm{~cm}$ langem, aufwärts gebogenem Stiel.

\section{Pseudolarix Gordon.}

Goldlärche.

Laubabwerfender, großer Baum, pyramiclalwiichsig, mit ziemlich quirlförmig gestellten und hauptsichlichst wagrecht abstehenden Ästen, diinnen Langtrieben, ziemlich langwerdenden Kurztrieben, sowie weichen, flachen, sitzenden Blïtern.

Blïte monizisch; männliche $2 \mathrm{~cm}$ lange Kätzchen in dichten Dolden an kurzen, blattlosen Trieben bildend, gelblichgriin; die weiblichen eirunden Kiitzchen ebenfalls an kurzen, aber beblätterten Trieben, gestielt, hïngend, einzeln, mit dicken, spitzen, lockerstehenden Schuppen; Brakteen der Basis angewachsen. Fruchtschuppen mit 2 Samenknospen. Der ehenfalls lockergestellte, zerfallende (!) Zapfen fuihrt unter den Fruchtschuppen zwei verkehrt-eiförmige, länglich gefligelte Samen. 
Pseudolarix Kaempferii Gord. Chinesische sonniger, freier Goldlärche. Provinz Tsche-Kiang in Ost-China. Standort, gleichmäbig

Syll. Lariar Kuemperii Fort.

Pseudolarix Fortunei Mayr. ungünstigem standort oft die Gipfelknospe verlierend.

Die goldene Tanne der Chinesen! Ein bis $40 \mathrm{~m}$ hoch werdender Baum von pyramidalem Wuchs, mit fast quirlförmig sestellten, ziemlich wagrecht abstehenden, graurindigen Ästen. Endknospen der Kurztriebe mit pfriemlich zugespitzten Schuppen.

Die Blätter sind weich, lineallanzettlich, manchmal gekriimmt, gespitzt, ziemlich lang, gefurcht, die Ränder etwas ungebogen, ohen lebhaft griin, unten bläulichgriin, im Herbst prächtig goldgelb, deshalb die obengenannte Benennung. An den Langtrieben stehen die Blätter zerstreut, abstehend, an den Kurztrieben bindelständig, schirmförmig ausgebreitet, nicht sehr dicht, etwa 15-20 Stiick.

Zapfen hängend (!), verkehrt eiförmig bis länglich, $6-7 \mathrm{~cm}$ lang und $4-5 \mathrm{~cm}$ breit, jung b]äulich heduftet, alt braunrot, mit lederartig-holzigen, kaum angehefteten abfallenden (!), länglich herzförmigen Schuppen, hinter welchen die kleinen Brakteen äu $\mathrm{Berlich}$ nicht sichtbar sind. Samen oval, $7-8 \mathrm{~mm}$ lang, 4-5 $\mathrm{mm}$ breit, mit sehr langem Flügel.

Liefert grobes Werkholz. - Bei uns meist trägwiichsig.

Vermehrung aus Samen normal- und hochwiichsiger Bäume, wodurch auch bei uns kräftiger wachsende Exemplare erzeugt werden. Stecklinge aus nahezu ausgereiften Trieben wachsen wohl ziemlich gut, wie ebenso Ableger, geben aber auch keine hochwiichsige, sondern mehr buschige Exemplare. Pfropfung auf die Stammform; hingegen ist das oft iibliche Pfropfen aut Larix europaea unbedingt zu verwerfen, weil es krippelhafte Pflanzen ergibt.

Ausführung der Pfropfung vor dem Austrieb.

Eine Form ist:

Pseudolarix Kaempferii nana Hort, eine Zwergform, welche. wie die Stammform, von Japanern und Chinesen zu ihren TopfZwergbäumen gerne benitzt wird.

\section{Cedrus Link.}

\section{Zed er.}

Immergrime, hoch und sehr alt - bis 3000 Jahre werdende Bäume, mit meist sehr starken Stämmen, rissigrer Rinde, breiter, aber doch pyramidaler Krone, atushreitenden, in der Jugend mehr aufsteigenden, dann sich aber anslegenden und auch hänenden, starken Ästen, zahlreichen, doch meist kurzen, diinnen Langtriehen und kleinen, dicken, schuppigen Kurztrieben, welche sich zum Teil zu Langtrieben entwickehn. 
Blätter an den Langtrielsen einzeln, spiralig und weitstehend, an den Kurztrieben zusammengedrängt, biundeli心, im iibrigen sind diesellen nadelförmig, fast vierkantig, steif, stechend, sitzend, unten gexliedert. Knospen heschuppt.

Bliiten mon̈̈zisch: männliche Kätzchen endstiindi心, ron Schuppen umgeben, länglich bis zylinderisch. rötlich, mit zahlreichen Antheren, auf benadelten Kurtriel, in Bliitenstinden von $3-5^{1 / 2}$ cm Länge sitzend; weibliche Blite einzeln, auf kurzen, benadelten Trieben sitzend, aufrechtstehend, oval, mit. großen Samenschuppen, welche je zwei umgedrehte Samenknospen fïhren, mit kleiner, enc verwachsener Braktee.

Zapfen in 2-3 Jahren reifend, eiförnigrund, sehr hart, mit eng anliegenden Schuppen, nach dem Samenausfall abfallend. Der Samen ist breitgedrickt, länglich dreieckion, mit dimner Schale, sehr groß gefligelt und reich harzhaltig.

Keimling mit 8-10 dreikantigen Samenlappen.

Die drei existierenden Arten werden von manchen Autoren als zu einel Art gehörend hetrachtet; jedenfalls ist Cedrus atlantica und Cedrus Libani sehr nahe verwandt.

Eine der herrlichsten Zierbäume bei uns, welche aber leider nur im wärmeren Weinklima wirklich schöne Exemplare bilden.

Jiungere Bäume lassen sich schon von einiger Entfermung aus lurch ihren Habitus gut unterscheiden: Cedrus atlantica hat hauptsächlichst aufstrebende Äste, Cedrus Libani mehr waœrechte und Cedrus Deodara iiberhängende Beastung.

Cedius atlantica Manetti, Atlas-Zeder. Gebirge Nord-Afrikas.

IV (III)

Geschützter Standort,

Prichtiger, schön pyranidal wachsender und gut durchlassender Baum, mit kurzen, ausgebreiteten, in der Jugend Jung empfindich. sich aufrichtenden, spiiter wagrechten Ästen und ebenfalls ausgebreiteten Zweigen, sowie a ufrechtem Wipfel.

Blätter steif, scharf spitzig, etwa $1 \frac{1}{2}-2^{1 / 2} \mathrm{~cm} \operatorname{lang}, 1 \mathrm{~mm}$ dick, ziemlich vierkantig, hell bis dunkelblangriin, am Langtrieb weit und einzeln stehend, am Kurztrieb in Bundeln von 30 bis 40 Stuick. Knospen kugelig.

Zapfen erst grüu, zur Reife glänzend hellbraun, eirund, 5-6 cm lang, $4 \mathrm{~cm}$ dick, am Scheitel eingedriickt.

Vermehrung durch Samen unter Glas in Töpfen odes' Kistchen; das später folgende Verpflanzen fordert Vorsicht und Schonmo der jungen Pflanzen. Der sehr harte Zapfen wird durch Ausbohren der Spindel zum Zerfall webracht.

Im Frühherbst gemachte Stecklinge von diunnen, innen mehr am Holz stehenden Trieben wachsen gut; die zur gleichen 
Zeit vorzunehmende Pfropfung wird auf die Stammform ausgefülırt.

Formen sind:

Cedrus atlant. glauca Hort, blaugriine bis silbergraue Form, welche am meisten Kältegrade erträgt, d. h. noch in Region IIJ

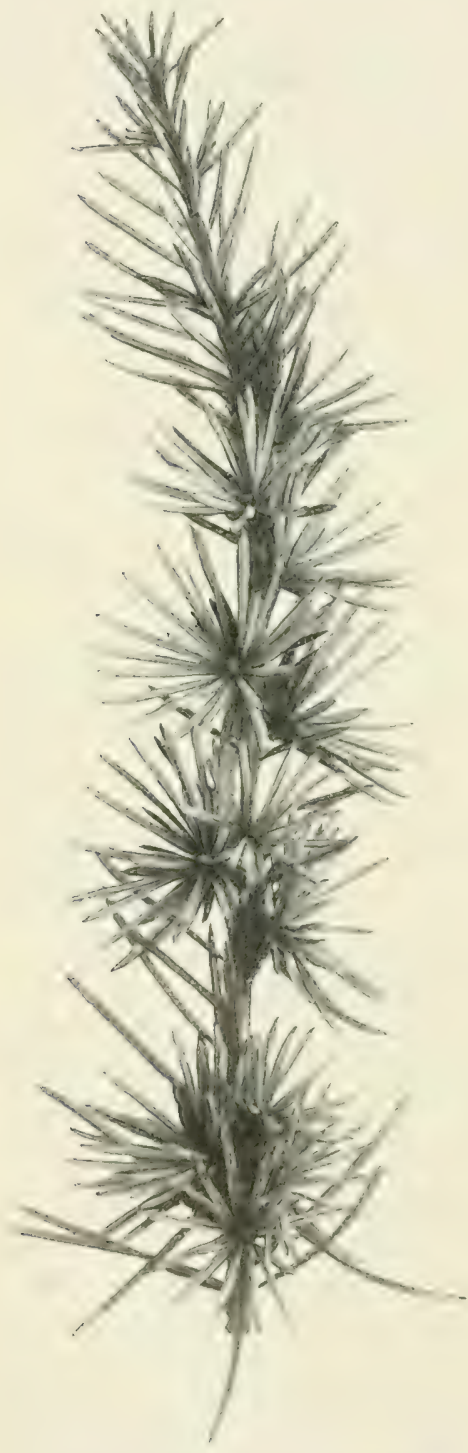

Fig. 95. Cedrus atlantica Man. mit Erfolg angepflanzt werden kann.

Cedrus atlant. aurea Beißn., mit goldgelber Färbung.

Cedrus atlant. variegata Hort., besonders an jungen Trieben weißbunt.

Cedrus atlant. brevifolia Hort., kleinblätterig.

Cedrus atlant. pyramidalis Paillet, schmal-säulenförmig!

Cedrus atlant. columnaris Otin, ähnlich voriger Form, doch mit längeren Ästen.

Cedrus atlant. fastigiata Carr., von schlank pyramidalem Wuchs und aufstrebenden Zweigen.

Cedrus atlant. pendula Beißn., schöne, hängende, blaugrüne Form.

Syn.: Cedrus atlant. glauca pendula Hort. gall.

Cedrus Libani Barr., V (IV) Libanon-Zeder. Suid- tem Standort, Anatolien, Taurus und in gleichmäBig feuchtem und Antitaurus, Libanon, durchlassenCypern, Algier (Pic $\begin{gathered}\text { Jung } \\ \text { empfindlich. }\end{gathered}$ von Tongour).

Imposanter, in der Heimat bis $40 \mathrm{~m}$ hoch werdender Baum, mit iiberaus dickem Stamm, schwarzgrauer, rissiger Rinde, breiter, im Alter schirmförmiger Krone, in der Jugend besonders in den oberen Teilen aufstrebenden, dann wagrecht ausgebreiteten, starken Ästen und dicht stehenden, kurzen Zweigen, sowie iiberhängendem Wipfel! Knospen rund. 


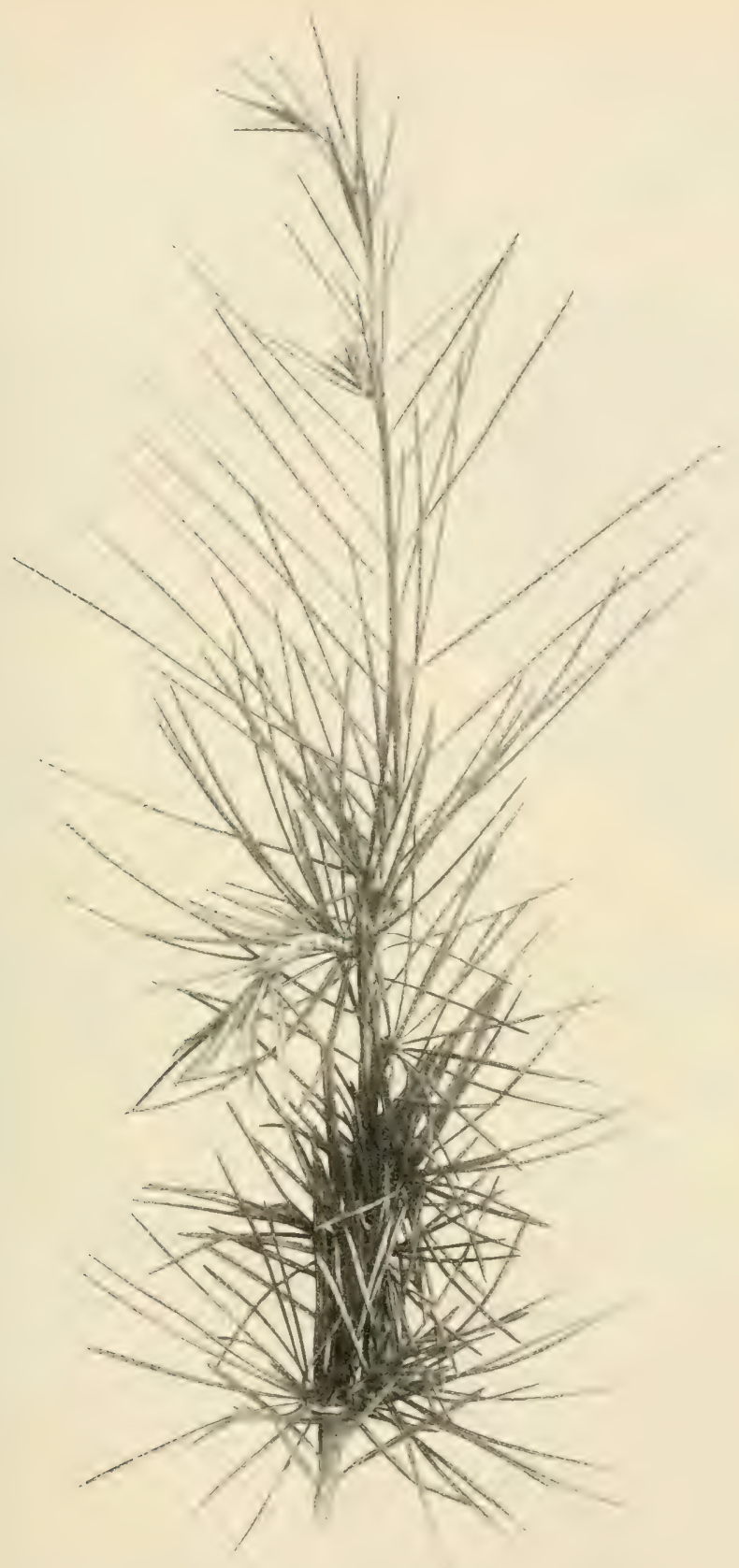

Fig. 96. Cedrus Libani Barr. (um 1/10 verkleinert). 
Blätter starr, zum 'Teil auch etwas gekrimmt, spitz, fast rierkantig, $1^{1 / 2}-3^{1 / 2} \mathrm{~cm}$ lang und $1 \mathrm{~mm}$ stark, dunkelgriin, am Langtrieb einzeln und entfernt stehend, an Lurztrieb in Buscheln von $30-40$ Stiick.

Der aufrechte, einzeln stehende, dick-eiförmige, $8-10 \mathrm{~cm}$ große und 5-7 cm breite Zapfen ist gestielt, braun, am scheitel

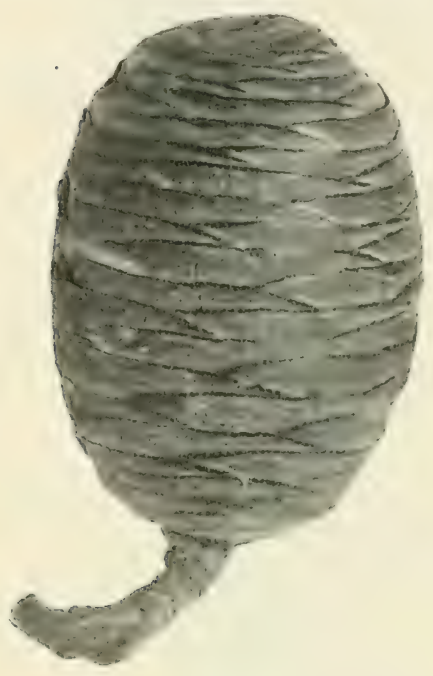

Fig. 97. vertieft, oft mit Harz bedeckt; seine Schuppen sind fein behaart. Samen länglichrund, fast eckig, sehr großgeflügelt. (Fig. 97.)

Vermehrung wie bei voriger Art; Pfropfung außerdem auf Cedrus atlantica.

Die Libanonzeder ist wenigstens dem Namen nach jedermann bekannt, da nicht nur die Schriftsteller des Altertums schon vom "Zedernholz" Mitteilung machen, obwohl es noch unbestimmt ist, ob wirkliches Zedernholz, oder solches von Taxus und besonders von Juniperus gemeint ist, sondern auch die Bibel spricht von Zedernholz, das zum Tempel Jehovas verwendet wurde.

Das außen gelbliche, innen Zapfen von Cedrus Libani Barr. bräunliche, sehr harzreiche $\mathrm{Holz}$ (verkleinert). ist allerdings ganz vortrefflich und wenn die Urkunden echt, nach 2000 Jahren noch gut erhalten. - Es enthält ein zum Einbalsamieren beniitztes Harz, sowie ein besonders zu Räucherzwecken verwendetes, ätherisches Öl. Harz und Samen dienen auch als Diureticum (harntreibendes Mittel).

Formen, welche aber zum Teil selten sind, wären:

Cedrus Libani glauca Carr., herrliche, blaugriine bis silbergraue Form.

Cedrus Libani brevifolia J. D. Hook., kleinblätterige und kleinzapfige, seltene Form.

Cedrus Libani viridis Carr., ziemlich winterharte, starkwiichsige, lebhaft glänzendgrủne Form.

Cedrus Libani denudata Carr., licht und umegelmärig gebaut, dunkelgriin.

Cedrus Libani stricta Carr., grau bis silberorau benadelt, anfierst dichtwiichsig, aufstrebend und kurzästig.

Cedrus Libani pendula Knight., mit iiberhingenden Ästen und hängenden Zweigen. 
Cedrus Libani nana Loud.; Zwergform, dicht bezteigt, huschig.

form, mit aufstrebenden Zweigen.

Cedrus Libani decidua ('arr., eine buschige, selten in Kultur befindliche, ganz, wunderliche Form, da sie im Wrinter ilre Blitter fallen läßt.

Es existiert zwischen dieser und der vorigen Art auch ein Bastard:

\section{Cedrus atlantica $\times$ Cedrus Libani. \\ Syn.: Cedrus Libani hybrida Hort.}

Cedrus Deodara Loud, Gütterbaum, Deodaroder Himalaryat-Zeder. Gebirge von Beludschistan, If

Von vorigen Zedern gut zu unterscheidende Art. Sehr schöner, in der Heimat bis zu $.50 \mathrm{~m}$

V (IV)

Geschiitzter Standort, gleichmäbig feuchter, gut durchlassender Boden.

Jung empfindlich. hochwerdender, in der. Juend bei uns etwas langsam wachsender Baum mit dunkelgrauer Rinde, von prramidalem Wuchs, erst iiberhängenden, im Alter aber etwas wagrecht stehenden Ästen, dagegen mit hängenden Zweigen. Der Wipfel ist stets hängend.

Blätter $3{ }^{1}, 2-5$ cm (!) lang, 1 mm breit, nicht sehr starr, iiherhïngend, fast viereckig, glänzend, dunkel- bis hellgrim, an den Langtriehen einzeln stehend, an Kurztrieben biischelig, bis 30 Stiick.

Der aufrechtstehende Zapfen ist erst @riun, bläulich bereift, dann reif rötlichbraun; er wird $8-12 \mathrm{~cm}$ lang, iiber $6 \mathrm{~cm}$ breit, ist dick-eiförmig, am Scheitel nicht rertieft, dichtschuppi@ und mit unbeharten Schuppen. Der rerkehrt eirunde Samen ist weißlich, großgeflïgelt.

Das Holz ist autien reißlich, immen hellbraun: nur das Kernholz ist als dauerhaftes Material verwendbar.

Vermehrung wie bei erster Art angegeben.

Formen sind:

Cedrus Deodara glauca Hort, blaugrỉne bis silbergraue Art, relche im Handel meist als die Stammform bezeichnet wird.

Cedrus Deodara argentea Hort., graugrime his silbergraue Benadelung, bei atlantica-artigem Wuchs.

Cedrus Deodara albo-spica Anesley, treibt griin aus und färbt sich mit der Reife der Triebe weiß.

Cedrus Deodara nivea Anesley, hellweif-blätteri@.

liche Form. aurea Hort., goldgelbblätterig.

" " variegata Hort., buntblätterige, unwesent-

Cedrus Deodara viridis Kinight, glänzendgriine, sehr' diinne Benadelung. 


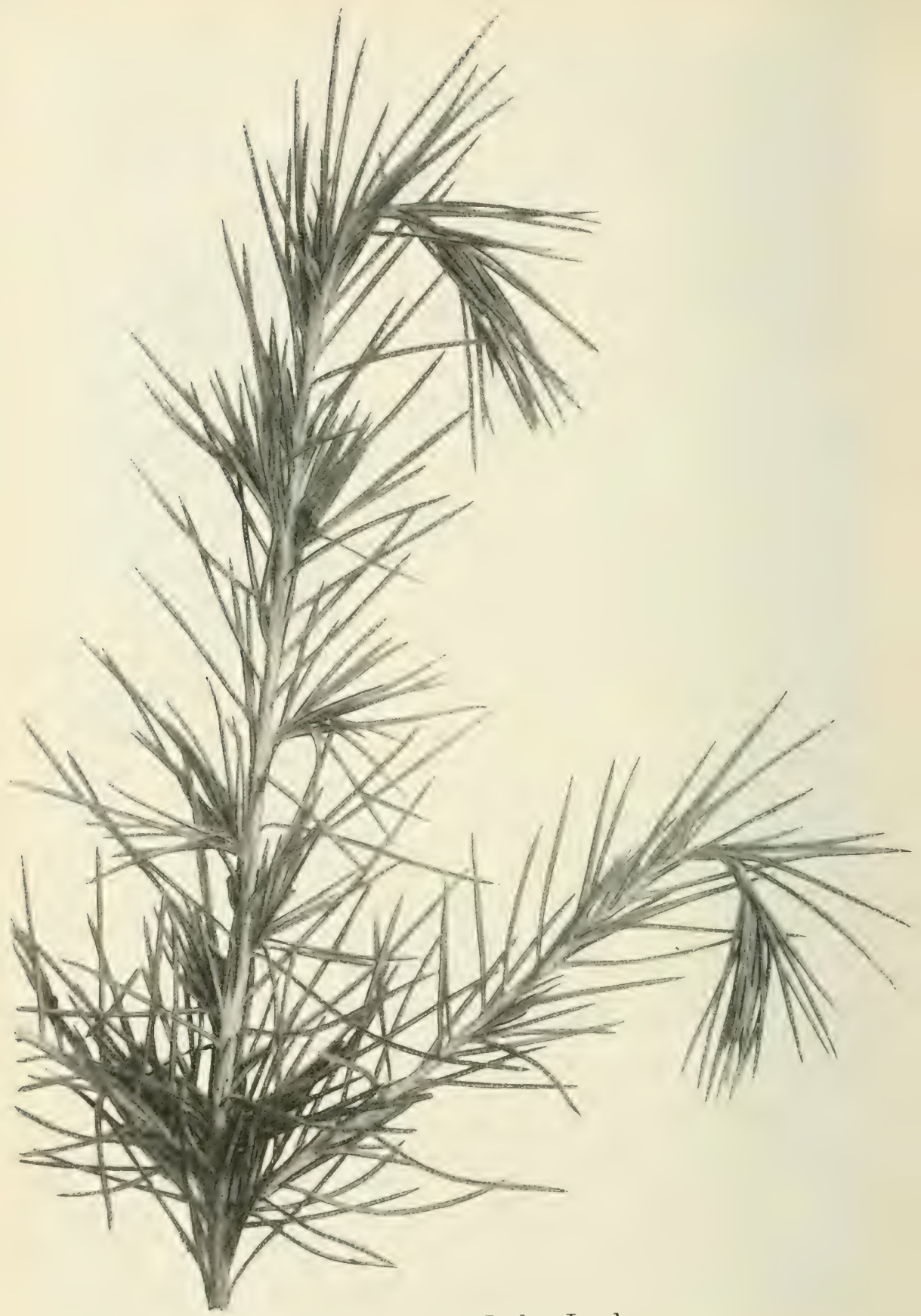

Fig. 98. Cedrus Deodara Loud. 
Cedrus Deodara robusta Hort., iippig wachend, starkistig, mit oft bedentend lingeren Nadeln als die Stammform.

Cedrus Deodara uncinata Hort., mbestindige Form, mit etwas gekriimmten Nadeln.

Cedrus Deodara verticillata Hort, mit quirlförmig gestellten Ästen, grimblätterig.

Cedrus Deodara verticillata glauca Hort., wie vorige, nur mit blaugriinen Blättern.

Cedrus Deodara crassifolia Hort., licht anfgebante Form. mit aufstrebenden, kurzen Asten und Zweigen, schwachwiichsig: weitgestellte, kurze, dicke Blätter.

Cedrus Deodara compacta Hort., dicht mul geclrungenwiichsig, eine rumdliche Pyramide bildend, mit hïngenden Ästen.

Cedrus Deodara pendula (Hort. gall.), mit weit ausgehreitet(1n, stark hängenden Ästen, ziemlich nieder bleibend.

Cedrus Deodara pendula columnaris, mit dicht am Stamm hängenden Ästen, hiedurch eine Art Säule bildend.

\section{P'inus, Linné.}

Kiefer, Föhre, Forche.

Immergrine, teils sehr hoch werdende, teils kleine Bïume, seltener strauch- orler ,knieholz"-artig, mit meist quirlförmig gestellten Ästen und "twas mrexchmäßiळ, sehn oft zweiseitio" stehenden Zweigen und stets endstiandigen (!), verschierlen gestalteten, oft von Harz iiberzogenen Knospen.

Blitter in zweierlei Gestalt vorhanden: erstens kleine, schuppenförmige Erstlingsblätter, aus deren Achseln sogenannte Kinztriebe sich entwickeln, welche dann zweitens die großen, nadelförmigen, langen, kantigen oder auch dabei hallurunden, am Rande meist feingesigten Hauptnadeln tragen, die zu zweien, zu dreien, zu fünfen, selten einzehn oder $6-7$ in einer mehr oder minder langen, mehr oder minder bald abfallenden, häutigen, den Kiterern speziell eigenen, charakteristischen s'cheide stecken.

Blïte monözisch; männliche gehäuft am Grumd der jungen Triebe, etwas beschupt, mit vielen gelben, kurzsticligen, zweifïcherigen Antheren, welche ein eigentimliches, fast halnen. kammartiges Anhänsel zeigen, sowie mit Lufthlasen verselıene, reichlich rorhandene Pollenkörner fiihren; an jener mit männlichen Bliitenstiinden besetzten Stelle bleibt der" Zweig fiur alle Zeit blattlos; weibliche Bliiten gipfelständig, oder an iler Mitte der Langtriebe, aufrecht, länglich bis rund, rot, mit spiralig gestellten Fruchtschupen, welche zwei nach unten serichtete Samenknospen (Eichen) bergen. 
Einzelne Pflanzen zeigen eine gewisse Neigung zum Diözischen, d. h. sie erzeugen vorherrschend männliche, oder weibliche Bliten.

Zapfen innerhalh zwei, selten dreier Jahre reifend und oft lang am Baum hängen bleibend, nicht zerfallend, entweder aufrecht, abstehend, bis mehr oder minder hängend, einzeln oder zu mehreren, oft bischelig stehend, von eifürmiger, kegelförmiger bis länglicher Gestalt, mit dachziegelartig gestellten, holzigen, oben verdickten Schuppen, deren Enden rhombische Felder oder Schilder (Apophysen) init erhöhtem, oft in eine lange Spitze verlängertem Nabel zeigen. Deckschuppen verkiummert.

Die gepreft-eiförmigen, meist mit krustiger, selten mit harter Schale versehenen, oder auch nackten Samen führen zum Teil bandartige, meist aber lange, den Samen oft zangenförmig: umfassende Flügel.

Die Ansaat geschieht im späten Frühjahr, (Pin. Cembra im Herbst), bei einer Weite von 10-15 mm Raum pro Korn.

Die Keimlinge entwickeln drei (und mehr) dreikantige Keimblätter und zweikantige, gesägte Erstlingsblätter.

Eine Vermehrung der Kiefern geht am besten durch Samen; Stecklinge bewurzeln sich selten gut, außer die unwesentlichen Jugendformen, eher ist Pfropfung durch Einspitzen oder Anplatten zu empfehlen, was bei einzelnen Arten fast geboten elscheint, sofern rascher, guter Wuchs erzeugt werden will, oder besonders da, wo die Art wurzelecht eben den Boden, z. P. kieselhaltigen, nicht ertragen kann.

Bei Pinus ist auch das Pfropten im kr a utatigen Zustand des Triebes (sonst wird ja ziemlich ausgereiftes Material beniitzt), im Juni und Juli in Verwendung, besonders auch bei Pfropfungen auf höhere Unterlagen. Man pfropft in diesem Falle bei abgeschnittener Unterlage in den Spalt, verbindet, verklebt mit Baumwachs die Veredlung und schiitzt letztere meist mit einer Papierhiille, oder bindet auch nux, wenn angängig, die Nadeln der Unterlage iiber der Veredlung zusammen. Oefteres genaues Nachsehen und pünktliches Lösen ist hier sehr geboten.

Als Unterlage bei Pinus wählt man mit Vorteil solche Arten, welche mit der Nadelzahl in der Scheide gegenseitig. ïbereinstimmen.

So eignet sich für die $z$ weinadeligen besonder's Pinus silvestris, für die dreinadeligen Pinus rigida, ponderosa, Jeffreyii, oder auch noch P. Laricio austriaca, sowie für die fünfnadeligen Pinus Strobus oder P. Cembra, je nach ihrer Verwandtschaft, auch $P$. excelsa ist $z u$ empfehlen.

Gut ist es auch, silber(weif)nadelige Arten auf gleichartige Unterlagen zu setzen. 
Am besten bedient man sich 2-3jähriger Pfanzen von 20-30 $\mathrm{mm}$ Stärke am IVurzelhals.

Die Kiefern sind furstlich meist hochwichtige Bäume, indem sie - oft auf sehr minderwertigem Boden - je nach Art ein vielseitig verwendbares, sehr harzreiches Holz erzengen. Ehenso bieten sie sehr viel und gutes z. T. eßbares Harz, ferner feinen Terpentin, Pech, Teer, das sogenamnte Krummholzöl u. s. w. Verschierlene Teile sind offizinell gebriuchlich, wie z. B. die Blätter ein Material - Waldwolleextrakt - für Heilbäder liefern; die gerbstoffreiche Rinde ist adstringierend.

Hochwichtig sind auch die eßbaren, sehr beliebten Samen: „Piniolen" genannt, von denen jene der "Zirbelnuisse" wohl die bekanntesten sind.

Auf den Wert als Holz liefernde Bäume in den verschiedensten Vervendungsarten braucht nicht speziell noch hingewiesen zu werden, denn dies ist wohl altbekannt und darf z. B. nur auf eine Verwendungsart, als sogenannte „Riemen" bei Bodenbelegung aufmerksam gemacht zu werden, um eine der stairksten Verbrauchsarten zu bezeichnen.

Gärtnerisch finden die verschiedensten Kiefernarten, ja selbst eine Reihe hervorragend schöner Formen, lange nicht jene Verwendung, welche ihnen eigentlich zu teil werden sollte, demn bei richtiger Verwertung werden ausgezeichnete Farben- und Figurenkontraste hervorgerufen. Richtig ist, daß die gebräuchlichsten Kiefern erstens einen sehr feuchten standort und daß alte Exemplare das Terpflanzen nicht gut ertragen, was manche Praktiker fuirchten. Ferner ist es, weil die Kiefern sehr lichtbediurftig sind, nicht gut, dieselben eng zu pflanzen, weil sie sonst bald ausasten; selbst enge Stellung mit sonstigen Gehölzen bewirkt dies. Sie verlangen mehr einzelnen Stand und entwickeln hier eine tiefe, schöne Beastung, meist pyramidale Krone, welche erst im Alter mehr ausgebreitet ist, oder selbst schirmförmig wird. Ein etwaiger Schnitt der Kiefern ist vor dem Austrieb vorzunehmen.

Was noch die Einteilung der Kiefern betrifft, so sind in wissenschaftlicher Hinsicht erstens die For'm und Gestaltung der Fruchtschuppen die beiden Haupt-Einteilungsfaktoren, zweitens damn noch die Lage der Harzgänge für die weitere Anordnung der Arten. Fiir den Praktiker jedoch, der wohl selten mit dem Vergrößerungsglas untersuchen wird, ist die altbewährte, rasch dienende Einteilung nach der Zahl der Nadeln, ob zu zweien, zu dreien, zu fünfen in einer Scheide steckend, die beste. Allerdings sind hier damn verschiedene Übergänge vorhanden, aber in diesen Fällen dienen weitere treffenden Nerkmale zur genaueren Bestimmung. 
1. Abteilung: Pinaster Endlicher.

Bina e: Zwei Nadeln — selten drei - in einer gemeinschaftlichen Blattscheide.

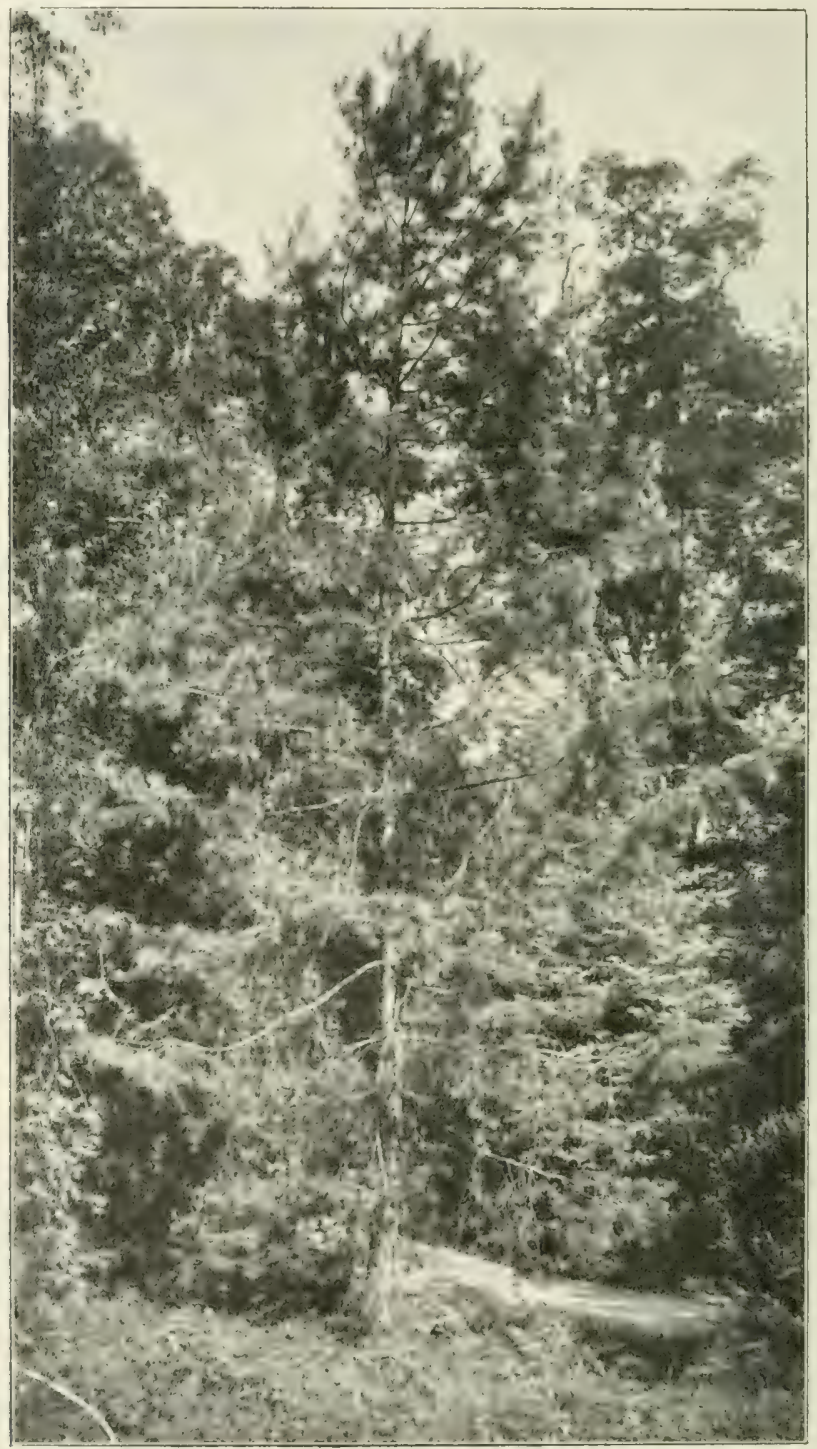

Fig. 99. Pinus silvestris L. (Junger Baum.) 
Zapfen rundlich oder kegelförmig, mit nach oben verdicktem, stumpf genabeltem oder mit hakig gekrimmtem Fortsatz versehenen Zapfenschuppen und geflügelten Samen.

Pinus silvestris L. Gemeine Kiefer, Fïhre, Forche, I Fohre, Kiene oder Kienbaum (letztere besonders in Bayern). In Norddeutschland fälschlich oft "E'ichte“, selhst "Tanne" genannt.

Von Europa und K leinasien bis zum Amurgebiet. (Fig.99 u. 100.)

Einen riesigen Verbreitungsbezirk besitzende, an weitesten nürdlich gehende, iutuerst niitzliche Kiefer von raschem Wuchs, 25 selbst to m Höhe erreichend, mit in der Jugend gelb-rötlicher, in lïnglichen, unregehmäfigen Streifen sich lösender, im Alter grauer, rissiger, mehr in Stiicken abspringender Rinde, bei langschaftigem, oft auch gedrehtem Stamm und mehr oder minder schirmförmigem Kronenbau.

Standort, Boden und klimatische Verhältnisse wirken auf die Wuchsverhältnisse dieser Art (wie anch auf andere Arten) sehr wesentlich ein.

Von den quirlförmig stehenden, ausladenden Ästen werden die unteren bald abgestoßen - der Baum astet sich aus -; die Zweige sind rauh, erst gelbrindig dann grau, und führen lange, eiförmige, gespitzte, harzfreie Knospen mit z. T. abstehenden Schuppen.

Blätter ziemlich dicht stehend, 4-7 cm lang, gedreht, spitz, fein gesägt, von besonders innen hlaugriner bis silbergrauer Färbung. Die Lebensdauter der Bliitter ist in Kiustengegenten am kiirzesten, im Gebirge am laingsten, aher doch meist nur vier Jahre dauernd.

Nicht sehr selten findet sich auf Pinus (ähnlich wie auf Fichten) der sogen. Hexenbesen, eine wahrscheinlich durch einen Pilz (Aecidium) hervorgerufene, stindige Neubildung unzähliger kleiner Zweigchen und Blittchen (siehe Seite 25), wodurch teils ein kugeliges (Fig. 101) oder ein nestartiges Gebilde bis über $1 \mathrm{~m}$ im Durchmesser erzeugt wird.

Bis Herbst des zweiten Jahres reifen die er'st rötlichbraunen. dam graubramen, ziemlich langestielten Zapfen von $3-1-7 \mathrm{~cm}$ Länge und $2^{1 / 2}-3 \mathrm{~cm}$ Dicke, von spitz kegelförmiger Gestalt, in geöffnetem, weitspreizendem Zustand linglich-rund. 
labei hängend, mit länglichen, oben länglich viereckigen, nicht länzenden Schuppenschildern, welche eine schwache (querleiste, sowie stumpfen, ahgestutzten, granen Nabel fülnen.

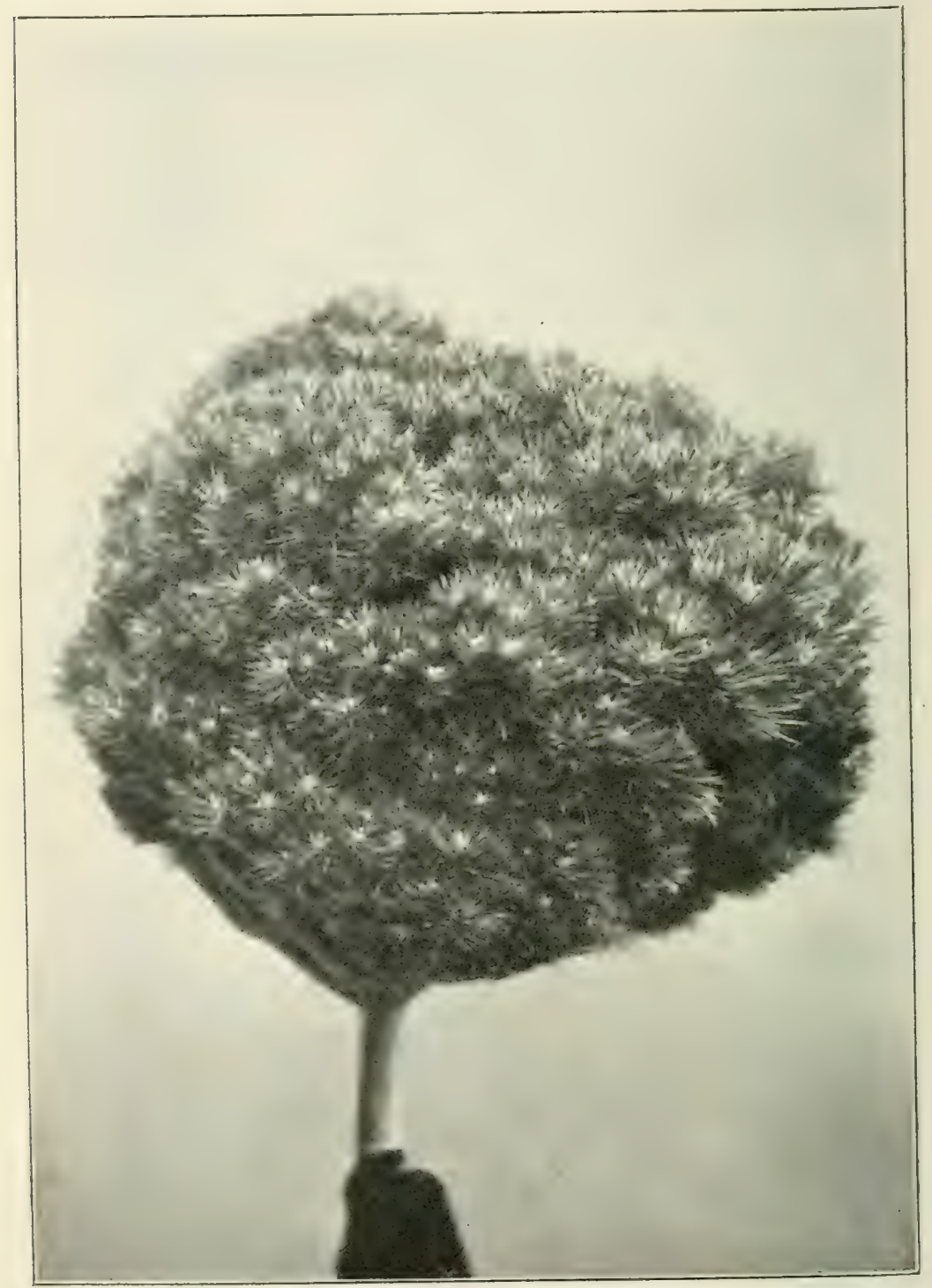

Fio. 101. Hexenbesen auf Pinus silvestris.

(.1us: Mitteilungen der deutschen dendrolog. Gesellschaft.) 
Die Zapfensucht (siehe auch. .19 ) wird ifters beobachtet, und hat selbst zur Formenbestimmung (conis argregatis) Veranlassung gegeben.

Der kleine. lingliche, eiförmige, srauschwärzliche samen hat wut dreimal so langen. den Samen zancenförmig umfissenden, hräunlichen Fliigel. Er hält sich bei drei Jahue keimfähig, geht etwa vier Wochen nach der Saat auf und zeigt 5-7 Keimbliitter, welche im ersten Jahre noch vertrocknen, denen damn gezähnelte Erstlingsblätter folgen.

Betreff' Samenprovenienz zeigt die Erfahrung, daf aus einheimischen Samen gezogenes Material noch immer das beste ist.

Pinus silvestris ist eine völlig winterharte Kiefer, die höchstens bei geschwichtem Wachstum manchmal Schaden erleidet; sie ist sehr lichtbediurftig, aber anspruchslos an den Boden, wenn sie auch natiulich in gutem Boden hochschaftige Bäume erzeugt, andererseits aber z. B. in kümmerlichem Boden nur noch von Pinus rigida, damn aber besonder's von Pseudotsuga Douglasii im Wachstum iihertroften wird. Auf nassem oder moorigem Boden ron schlechtem Wuchs, zeigt sie sich wegen geringer Tiefwurzelung auch gegen Schneedruck empfindlich, d. h. sie ist schneebrüchig.

Das harzreiche, im Fern brame, außen gelbliche Holz ist als Bau- und Werkholz selhr gesucht, hält sich anch besser als Fichtenholz, gibt wertrolles Bremnholz und ist in seinen harzreicheren Teilen als Anfeuerungsholz, Kienholz - neben den gleich brauchbaren Zapfen (Kienäpfel) - sehr heliebt, dabei auch den sogen. Kienruf liefernd. Aufjerdem liefert der Baum Harz, welches Abietinsäure enthält, sowie Kolophonium, Terpentin, Teer, damn durch die Bliitter officinelles Öl, fermer sogenamnte Waldwolle, Streu etc; die Knospen bezw. jungen Triebe werden zu Heilbädern bentitzt, die Rinde ist adstringierend, die Pollenkörner werden dem Lycopodiumpulver (Streupulver') heigemischt, die langen Wurzeln geben grobes Binde- und Flechtmaterial.

Pinus silvestris ergibt die Pfropfun tro la fur alle zweinadeligen Pinusarten!

Was die Formen betrifft, so werden meist auch Standortsformen unterschieden, wie z. B.:

Strandkiefer an den Neeresküsten,

Inorkiefer auf moorigen Böden,

Mastbaumkiefer mit prächtigen Stämmen, und dergl. Bezeichnungen mehr.

An systematischen Formen unterscheidet man:

Pinus silvestris erythranthera Sanio. schottische Kiefer, mit bräunlichroter mämnlicher Bliite, oft auch roten Knnospen, kurzen Nadehn, langschaftigem Stamm mit rotbramer Borke. 
Pinus silvestris erythranthera rubra, mit weifłlichen männlichen Bluiten und dunklerem, rotem Kernholz.

Syn.: Picea rubra Will.

Pinus silvestris genuina Heer, Weif- oder Grau-Kiefer, Kief'er von Hagenau.

\section{Syn.: Pinus haguenensis Loud. hengenationsis.}

Mit gramer bis graubramer Rinde, rijtich-grauen Knospen, grimlich-roter, weiblicher Bliite, langgestielten, spitzen Zapten mit flachen oder konvexen Schuppenschildern.

Pinus silvestris uralensis Fisch., Ural-Kiefer.

Vielleicht Form der rorigen; mit kiirzeren, steiferen Blättern als jene; mittelgrofier, dichter, ryranidenförmiger Baum.

Syn.: Pimes altaica Led.

Pinus silvestris reflexa Heer, meist kleiner Baum der Hochmoore der schweiz, speziell Bern, mit zienlich langen (6 cm) Blaittern und langen $\left(6^{1 / 2}\right.$ cm $)$, dabei schmalen Zapfen, deren rotbrame, flache Schuppenschilder einen ${ }^{1 / 2} \mathrm{~cm}$ langen Haken zeigen.

Pinus silvestris engadinensis Heer, in den Engadinel Alpen und in Lappland, im nördlichen Skandinavien und in Ford-Finnland vorkommender kleiner Bamm, von erst pyramidalem, tiefästigem Bau, dam etwas schimartiger Krone, mit rötlicher Rinde, derben, ganz kurzen (3 (cm), graugrimen Blättern und schief ab)viirts gerichteten, reif graugriinen, kleinen, spitzen Zapfen, welche glänzende Schuppenschilder mit grofem, stumpfem, nicht liakenförmigem, oft gerunzeltem Nabel füilnen.

Diese Form wird als etwas widerstandsfahiger als die Stammform gegen die Schiitte bezeichnet!

Syn.: Pines silvestris is lapponica Fr. und Schot.

. Lapponica Mayr.

.. Septentrionalis Mayi.

"silvestris $\times$ Pinus montana uncinata.

Pinus silvestris rigensis Desf. Riga-Kiefer.

Syn.: Pims silvestris septentrionalis Schott.

Hoher Wuchs, sonst ähnlich roriger: Schildhöcker nehr oder minder buckelig bis flach.

Pinus silvestris hamata Ster., rom Kaukasus, mit langen Zapfen, desien Schildhöcker in einen nach riickwärts gekrüimmten Dor'n verlängert sind.

Pinus silvestris argentea Ster., Silher-Kiefer, ebenfalls rom Kankasus. mit rotgrauer Rinde, silberglänzenden (bläulich hereiften) Bliittern; die Schuppenschilder mit riickwärts gebogener Fortsetzung.

Pinus silvestris nevadensis Christ., von der Sierra Nevada Siirlspaniens, mit schönen, purpurroten, weiblichen Bliten, kurzen, 
breiten, oben weifien Bliittern und schief abstehenden, rötlichgranen Zapfen, deren belichtetes Schuppenschild erhaben ist.

Pinus silvestris persica Hort., mit langen, hreiten, graugrünen Nadeln.

Syn.: Pimes caucasicu Fisch.

Pinus silvestris pontica C. Koch, bläuliche Benadelung, der. Form argentea sehr ähnlich.

Pinus silvestris glauca Hort., kleinerer Wuchs, mit blaugriunen Nadeln.

Pinus silvestris macrocarpa Schröd., mit bis dreimal größeren Zapfen als die Stammform.

Pinus silvestris gibberosa Kihlm., zeigt am Stamm eigentiimliche Knollen.

Pinus silvestris monophylla Hort. (Hodgins), scheinbar einblätterige For'm, deren beide kurzen Blätter eng aneinander haften und erst bei starkem Wuchs sich trennen.

Pinus silvestris Beißneriana Schwer., eine starkwiichsige, grimlich austreibende Form, welche dann aber eine bleibende, goldgelbe Färbung annimmt.

Pinus silvestris aurea Kihlm., gedrungen wïchsig, elst goldgelb, dann aber grün werdend.

Pinus silvestris variegata Hort., schwachwiichsige, unwesentliche Form, mit gelblich-weißen und ganz grimen Blättern.

Pinus silvestris argenteo-compacta Ordnung, pyramidalwiichsige, silbergraublätterige Form.

Pinus silvestris nivea Schwer., weiß austreibend, später schmutzig weißgriin. (Zur Zeit wohl nirgends in Baumschulkultur.)

Pinus silvestris crispata Schwer,, starkwïchsig, mit langen, sichelförmigen, gewissermaßen wirr durcheinander stehenden Nadeln.

Pinus silvestris anguina Hort., mit hin- und hergebogenem Stamm und eben solchen Ästen, bläulich-grïnen Nadeln, sowie $4 \mathrm{~cm}$ langen Zapfen mit ganz flachen Schuppenschildern.

Pinus silvestris tortuosa Bittner (Beißner), Drehkiefer, eine sehr seltene Form, deren Stamm und Äste von rechts nach links gedreht, bezw. gewunden sind.

Pinus silvestris virgata Casp., Schlangen- oder Rutenkiefer; äußerst selten, - z. Z. nur drei Stammpflanzen bekannt -, mit ungleich quirlig gestellten Hauptästen, langen, schlangenartig gewundenen Zweigen, von welchen nur die äußersten mit Blättern besetzt sind.

Pinus silvestris fastigiata Carr., Säulenkiefer, d. h. von breitpyramidalem Wuchs, mit steif aufstrebenden, starken Ästen, silbergrauer Benadelung und kleinen, ovalen Zapfen. 
Pinus silvestris fastigiata Watererii, von voriger kaum verschieden.

Syn.: Pinus silvestris Watereriana Hort.

Pinus silvestris compressa Carr., echte Säulenkiefer, mit ganz steifen, dem Stamm oft anliegenden Ästen.

Pinus silvestris columnaris compacta Croux, niedere, dicht bezweigte Säule, mit glänzend-dunkelgruinen Blättern.

Pinus silvestris pendula Hort., mit stark hängenden Ästen. microphylla Schwer., zwergige Form mit nur $1 / 2-1^{1 / 2} \mathrm{~cm}$ langen, dünnen, scharfspitzen Blättern.

Syn.: Pimus silvestris brachyphylla Wittr.

Pinus silvestris pyramidalis glauca Hort. holl., dichtzweigige, blaugrïn-nadelige Kegelform.

Pinus silvestris pumila Hort., blaugrime Zwergform. genevensis Hort. Sim.-L., bläuliche Zwergkegelfor'm mit" jung braunen Trieben, rötlichen Knospen und kleinen, bläulichen Nadeln.

Pinus silvestris beuvronnensis Hort., Zwerg-Kungelform, mit rötlichen Kinospen und kurzen, blaugrünen Nadeln.

Pinus silvestris globosa Hort, blaugrime Kugelform. viridlis Hort, grỉne Kugelform.

Wachstum.

umbraculifera Hort., mit breit kugelförmigem

Pinus silvestris pygmaea Hort., ganz dichte Zwerg-Kugelform.

Mit Pinus montana entstanden eine Reihe von Bastarden mit allen Übergängen, welche zusammengefaßt wurden in dem Namen:

Pinus rhaetica Briigger.

Pinus montana $X P$. silvestris (Briëgg.), wovon in engerer Einteilung genannt sein sollen:

Pinus rhaetica Heerii Brigg., vom Oberengadin.

Pinus montane uncimutu XY. silvestris engadinensis (Brö̈g\%.). " silvestris hybrida Heer.

" humitis $\times P$. silvestris (Christ.).

In Habitus und mit den jungen, aufrechten Zäpfchen der Pinus silvestris engadinensis gleichend, mit den älteren, langen Zapfen mehr oder minder an Pinus (montana) uncinata erinnernd, sodaß selbst Formen wie:

Pinus rhaetica Heerii subuncinata und

Pinus rhaetica pyramidalis Brigge.

superuncinata gebildet wurden.

Pinus humilis Link $\times P$. silvestris forma submontana.

Sehr seltene, an Pinus silvestris im Aufban erinnernde, hreitpyranidale, mit den unteren gebogenen Asten dem Boden 
ziemlich aufliegende Form, dagegen in den Blïttern und den wagrecht abstehenden, srinlich-violettbraunen Zapten mit ihren etwas hakigen schmpenschildern der Pinus montana wleichend.

Pinus rhaetica Cliristii Brüg'g.

Pinus humilis Link $\times P$. silvestris (Christ.).

Teils durch strauchigen Wuchs und blänliche Bliitter zu Pinus montana uncin. rotundata neigend, dabei aber mit den Zapfen an Pinus silvestris erimernd, oder aber mehr Pinus silvestris weichend, jedoch durch die rerschieden gestellten Zapten mit gellorauen Achupenschildern sich wieder ersterer nähernd.

Von sonstigen Bastarden wären noch zu nemnen:

Pinus digena Beck, nicht Wetstein, mit starken Tererbungen der Eltern.

Pimes silvestris $\times P$. uliginosa Neum.

Pinus Neilreichiana Reichardt (mit männlichen Bliiten von $P$. silvestris).

Pims nigra Arnold $\times$ Pinus silvestris.

Pinus permixta Beck.

Pinus silvestris $\times$ Pinus nigra Arn.

Pinus montana Mill. Bergkiefer, Kŕrummholzkiefer. I Gebirge Mitteleuropas bis Pyrenaien, Abruzzen, Karpathen (Fig. 102 und 103).

In den Gebirgen bis 2700 m hoch steigende, gleichmäßig wenn auch langsam wachsende und bei $18-25 \mathrm{~m}$ hoch werdende Kiefer, in den Höhenlagen strauchig, auch mit niederliegenden, oder knieförmig gekriinmten und damn aufisteigenden Ästen und in diesem Falle an steilen Abhängen, besonders in Gebirge gegen Lawinen und Steinschlag von größtem Wert. Bei glänzender, ziemlich glatter, dunkel- bis schwarzbrauner Rinde, pyramidaler bis spitz kegelfömiger Krone bei normalem IVuchse, zeigt sie im Bogen aufwirts gerichtete Äste und ebensolche, gelbrindige Zweige, mit an Haupttrieben zu mehreren stehenden, h a zi gen, länglich-eiförmigen Ḱnospen.

Es kömen drei Haupt-Wuchsformen der Pinus montana unterschieden werden:

1. hochstämmige Formen;

2. kurzstimmige Formen (buschis, jedoch immer mit Hauptstamm);

3. stammlose, niederliegende Formen.

Die derben, etwas steifen, dichtstehenden, geraden oder sichelfürmig gebogenen, selbst bis zu zehn Jahre alt werdenden Blätter sind 2-5 cm lang, stumpt gespitzt, oben und unten glänzend bis dunkelgriin.

Sehr hiubsch ist die gelbe oder rote männliche Blüte. 
Zapfen an hochstämmigen Formen mehr symmetrisch, an niederen W uchsformen mehr unsymmetrisch gebaut, kurz g'estielt oder sitzend, einzeln oder bis zu vieren beisammen stehend, erst

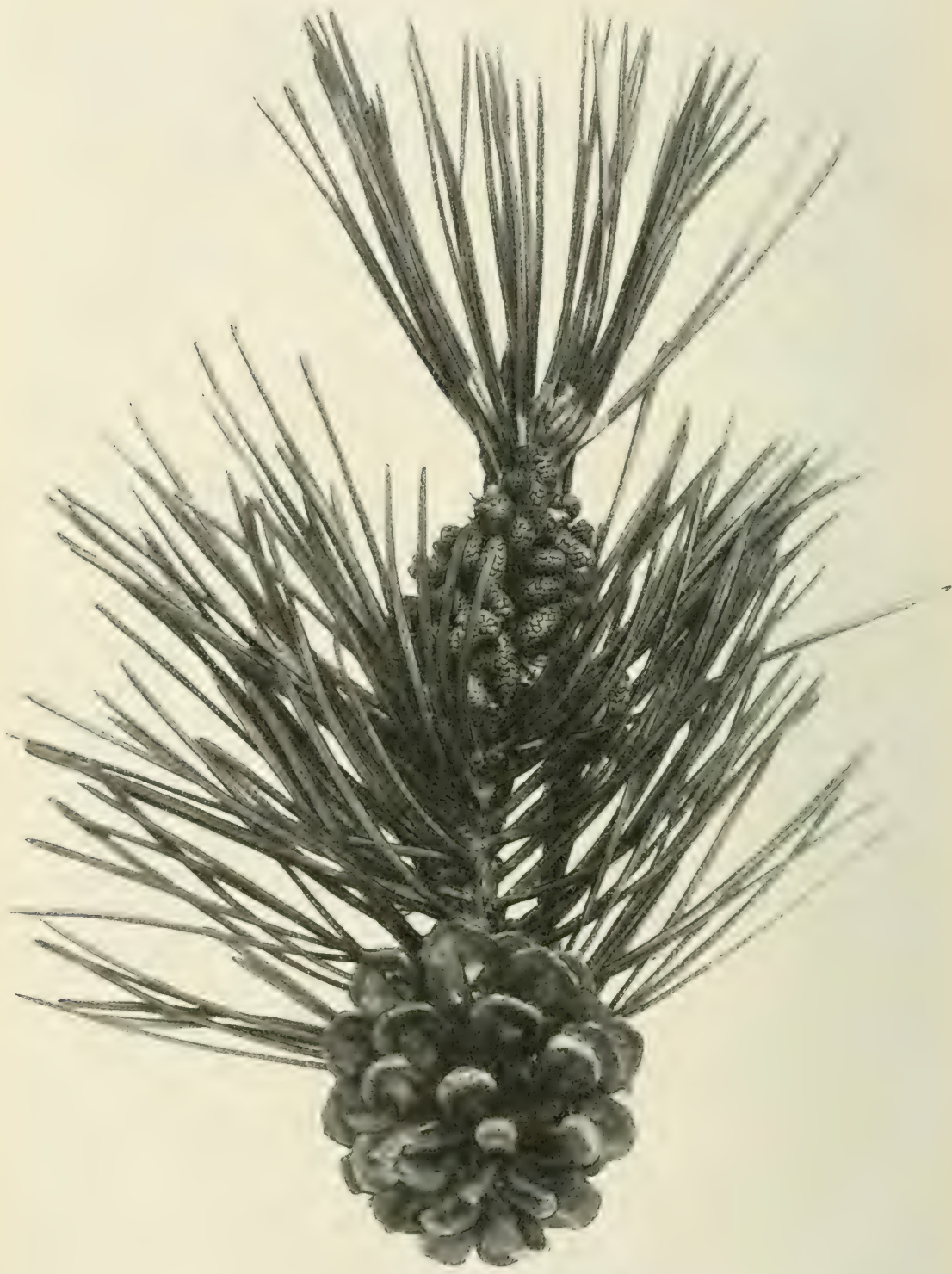

Fig. 102. Pinlis montana Mill.

Trieb mit männlichen Blütenständen, offener Zapfen von vorne. 
anfrecht, damn erst in zweiten Jahr schief ahwiirts gerichtet, bei drei Jahre am Baume haftend, 2 bis $5^{1 / 2} \mathrm{~cm}$ lang, ei- oder kegelförmig rund, abgestumpft, mit entweder flachen oder konkaven, glänz e n d e n Schuppenschildern, welche einen bramen bis grauen, großen, mehr oder minder hakigen Nabel mit schwärzlichem Ringe zeigen.

Höchst eigenartig ist die manchmal entstehende sog. "Zapfensucht", indem statt der üblichen 2-3 Zapfen deren ca. 20 bis iiber 60 von etwa $2^{1 / 2}$ cm Größe entstehen (siehe Seite 19), welches Vorkommnis aber auch bei anderen Pinusarten zu beobachten ist.

Der auf magerem Boden harzreiche, graubraune, auf Moorboden

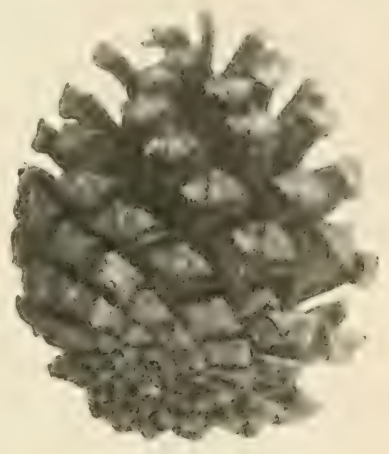

Fig. 103.

Pinus montana Mill.

Zapfen von unten (hinten). harzarme, rötliche, meist lïnglich-eirunde Samen hat dreimal längeren, bräunlichen Flügel und hält sich 2-3 Jahre keimfähig.

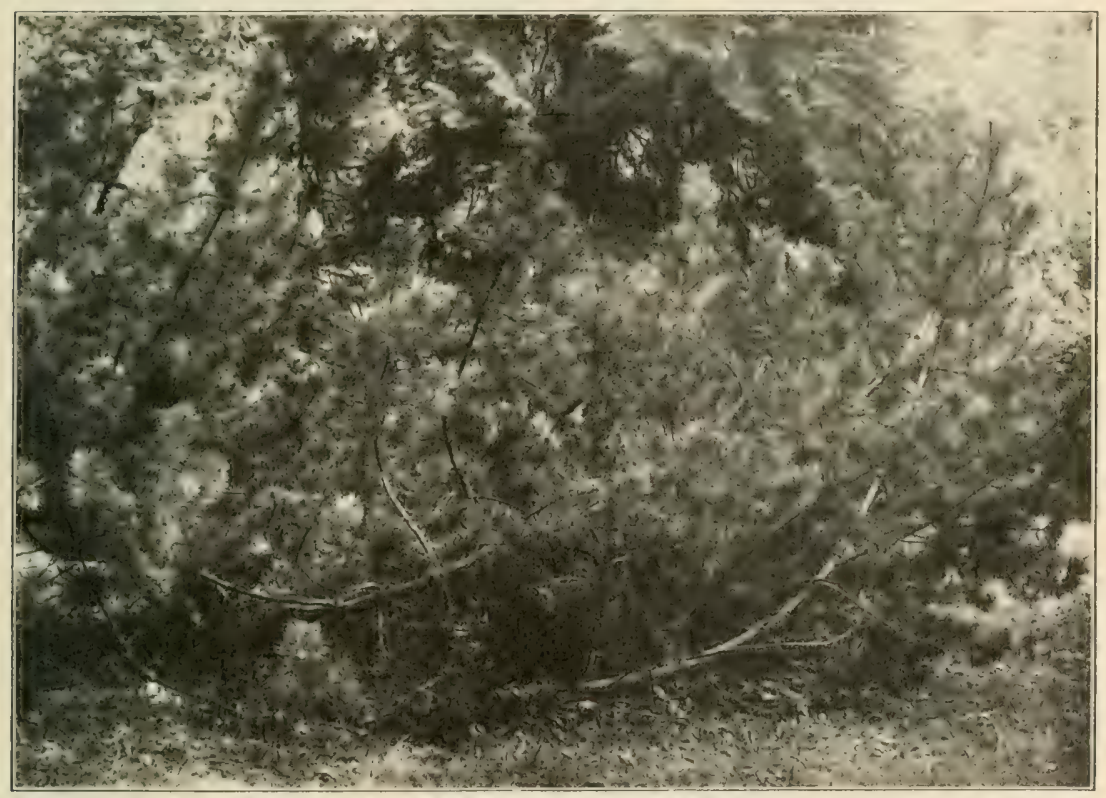

Fig. 104. Pinus montana Mill. uncinata (Willk.) (25 jährige Pflanze). Schelle, Koniferen. 
Die Keimlinge entwickeln 4-7 Keimblätter und zweiseitig gesägte Erstlingsblätter.

Das stark beniitzte Holz ist innen dunkelbraun, außen bei breitem Splint gelb. In Holz und Nadeln liefert der Baum noch Harz, Terpentin, Templin oder Kirummholzöl, Waldwolle etc.

In ihren Formen, besonders als sogenannte Latsche im Gebirge von großem Werte, ist sie auch andererseits zur Befestigung der Dïnen, ferner auf Mooren, bei feuchtem Erdbelag, (Kuscheln), ebenso in Steingeröll, da sie mit den Wurzeln langflachstreichend ist, ein sehr wertvoller Baum.

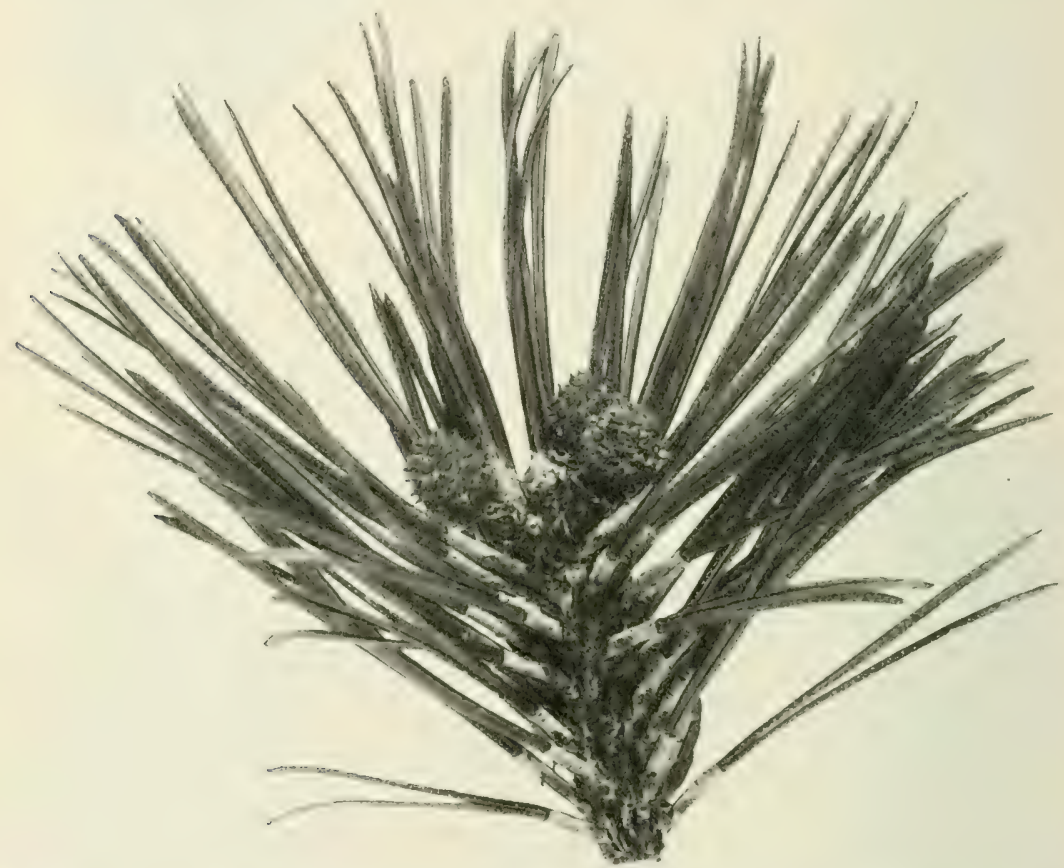

Fig. 105. Pinus montana Mill. uncinata (Willk.). Junger Trieb mit weiblichen Blütenständen.

Durch den Standort bedingt, ändert diese Art einerseits ihren Wuchs stark ab, andererseits ist sie in der Zapfenbildung sehr variabel.

Man unterscheidet nach der Zapfenbildung drei Haupttypen mit zum Teil verschiedenen Formen und Unterformen:

1. Typus: uncinata.

Pinus montana uncinata (Willk.). Hakenkiefer. (Fig. 104-106.) Syn.: Pinus uncinata Ramd. 
Der Zapfen ist ungleichseitig und unten schief gewachsen! Die Schuppenschilder sind nach dem Lichte zu aufgebogen und hakig zurückgekrümmt. Keimlinge mit 7 Keimblättern. Baumartiger bis knieholzartiger Wuchs.

Hauptformen sind:

a) Pinus (montana uncinata) rostrata Ant. Schnabelkiefer.

Syn.: Pimus uncinata rostrata Ant.

Mit kegel- bis eiförmigen, schief abwärts gerichteten bis hängenden Zapfen, deren dem Lichte zugerichteten Schuppenschilder breitgedriickt viereckig, etwas schnabelförmig und dabei hakig rïckgekriumt sind. Haken höher als breit.

Unterformen dieser Hauptform sind:

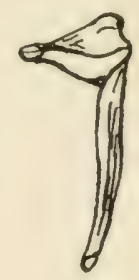

Fig. 106.

Zapfenschuppe (Seitenausicht) von Pinus montana Mill. uncinata (Willk.).

\section{Pinus (montana uncinata?) aureo-variegata}

Schwer., an einigen unteren Ästen zeigen sich einzelne goldgelbe Nadeln.

Pinus (montana uncinata?) gracilis Schwer., von langsamem, kugelförmigem Wuchs, mit $2^{1} / 2-3$ cm langen Nadeln.

Pinus (montana uncinata) rostrata macrocarpa Willk., von den Pyrenäen, eine der an höchsten werdenden Formen mit rötlichen Kinospen und großen, $5^{1} / 2-6 \frac{1}{2}$ cm langen, grïnlichhellbraunen, wagrecht stehenden oder hängenden Zapfen, deren Schuppenschilder stumpfen $\mathrm{Nabel}$ zeigen.

Pinus (montana uncinata) rostrata pendula Hart. Mscr., Höhenzuige in Spanien, der Schweiz, bis zu den Vogesen; ebentalls baumförmig, aber auch strauchig, mit nahezu hängenden, eiförmigen, braunroten bis griingrauen Zapfen, deren Schuppenschilder stachelspitzig bewehrten Nabel haben.

Pinus (montana uncinata) rostrata castanea Hart. Mscr., Alpen.

Pyranidalwiichsiger Strauch, mit glänzend dunkel- bis rotbraunen, eiförmigen bis rundlichen, $4^{1} / 2 \mathrm{~cm}$ langen, wagrecht abstehenden oder etwas abwiirts gerichteten Zapfen, deren dem Lichte zugekehrten Schuppenschilder nur am unteren Zapfenteil verlängert und im Querfeld konvex gebildet sind.

Pinus (montana uncinata) rostrata versicolor Willk., Alpen bis Schwarzwald, Böhmerwald, Erzgebirge.

Vom mittelgroßen Baum bis herab zum pyramidalen Strauch und Kniestrauch, mit $4^{1} / 2 \mathrm{~cm}$ langen, kegelfömmigen Zapfen, deren Oberfeld der Schuppenschilder ebenfalls konvex, (oft auch konkav,) gebildet ist, und welche schwarzen Nabelring und gelbliche bis grüngelbliche Färbung zeigen. 
b) Pinus (montana uncinata) rotundata Ant. u. Endl., Buckelkiefer.

Syn.: Pinus uncinate rotundata Ant.

\author{
" uliginosa Noum. \\ " silvestris is montan Wahlbg. \\ humilis Link.
}

Ton den Alpen bis zu den Togesen, Schwarzwald, Erzgebirge, Fichtelgebirge, Böhmerwald.

Spirke, Latsche, Zunder, (Teufern, Krummholz, Legföhre, Zwergföhre, Rotfuhre, Sumplfforche oder Sumpthiefer, Moosföhre, Kienfichte).

Die verbreitetste Buckelkiefer, mit wagrecht abstehenden, oder etwas abwärts gerichteten, neist kegelförmigen Zapfen, deren Schuppenschilder besonders des unteren Zapfenteiles viereckig und gekriummt ausgezogen sind, oder deren oberer Teil dick und dabei spitz zulaufend rückgekrimmnt ist. Haken breiter als hoch.

Es sind hiebei c) drei Haupt-Wuchsformen zu unterscheiden:

Spirke, leicht hezweigt, lange Nebenzweige, $4-5 \mathrm{~cm}$ lange, derbe Blätter. Reife Zapfenschuppen außen glänzend braun, grau benabelt mit schwärzlichem Ring; innen schwarz mit rotgelber Zapfenachse.

Dabei ist die Form einstämmig!

Zunder, dicht bezweigt, $2^{1 / 2}-6 \mathrm{~cm}$ lange, derbe Nadeln. Zapfen glïnzend dunkelbraun mit grauem Nabel der Zapfenschuppen. bildend.

Wuchs strauch- bis knieholzartig, teilweise anch Stämme

Latsche, mit 3-4 cm langen Blättern und a uffallend kleinen, braunschuppigen und grau-nabeligen Zapfen.

Wuchs baumartig.

ß) Systematische Unterformen sind: Böhmerwald.

Pinus (montana uncinata) rotundata pyramidata Hart. Mscr.,

Iit strauchförmigem Wuchs, glänzend hellbraunen, $4^{1} \frac{1}{2} \mathrm{~cm}$ langen Zapfen, deren Schuppenschilder an der Lichtseite viereckig verlängert und flach genabelt sind.

Pinus (montana uncinata) rotundata gibba Willk. Verbreitung. ähnlich der Hauptform.

Mittelgroßer Baum bis pyramidaler Strauch und Knieholzstrauch, mit $2^{1}, 2^{1}-4^{1} 2 \mathrm{~cm}$ langen Zapfen, deren obere Teile der Schuppenschilder dick und spitz zulaufend und oft iiber den unteren Teil etwas ausgezogen sind; Nahel konvex, ziemlich eingedrückt, stumpf bis spitzig.

Pinus (montana uncinata) rotundata mughoides Willk. Bayer. Alpen bis Schwarzwald, Siidböhmen, Fichtelgebirge. 
Kleiner Banm bis Knicholz, mit arellen bis briimlichen Zapfen, deren obere 'Teile der Schuppenfelder kaum buckelig' erhaben sind und eingedrickt - spitzen Nabel fiihren.

Pinus (montana uncinata) rotundata gallica (Rafn.)

Syn.: Pims montana gallica Rafn.

Einstämmiger Wuchs. (Ob hierher gehörend?)

Zwischen Pinus (montana uncinata) rotundata und Pinus montana Pumilio existieren noch einzelne Bastarde.

c) Pinus (montana uncinata) Pseudopumilio Willk., Oherbayern, Siidböhmen, Erzgebirge.

Knieholzstrauch, mit abwiirts gerichteten, kleinen, bis $2^{1} / 2$ cm langen, eifömigen, meist bramen Zäpfchen, deren oberer Schuppenschildteil etwas buckelig erhaben ist, bei flachem oder eingedriicktem, stumpfem bis spitzem Nabel.

\section{Typus: Pumilio.}

Pinus montana Pumilio (Hänke) Zwergkiefer. (Fig. 107.) Syn.: Pinus Pumilio Hänke.

Zwergkiefer, Legföhre, Knieholz, Latsche, Zunder, Lackholz, (Filzkoppe), Kremsen, (siehe auch Pinus (montana uncinata) rotundata).

Meist strauchig oder Knieholz, selten baumartig, mit gleichmïbig gebauten, eiförmigen bis rundlichen, vor der Reife ziemlich aufrechten, nach der Reife wagrecht oder abwärts stehenden, erst violetten, dann braunen bis gelben, $3-4 \mathrm{~cm}$ langen und $2 \mathrm{~cm}$ dicken Zapfen, deren Schuppenschilder gleichartig gebildet sind, im oberen Feld konvex, im unteren konkav, bei meist eingedrücktem und etwas (unter die Mitte des Schildes) verschobenem Nabel. Samen graubraun, mit höchstens zweimal längerem Flïgel. Keimling mit 3-4 Keimblättern.

Unterformen sind:

Pinus montana Pumilio variegata Hort.,

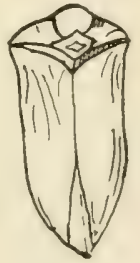

Fig. 107 .

Zapfenschuppe (vord. Ansicht) von Pinus montana Mill.

Pumilio (Hänke). gelbbunt.

Pinus montana Pumilio gibba IVillk.

In den Alpen, Abruzzen, Schwarzwald und Bayerischer Wald bis Böhmerwald, Fichtelgebirge, Riesengebirge, Karpathen.

Iit im reifen Zustand wagrecht abstehenden, oder abwäts gerichteten Zapfen, an deren unteren Schuppenschildern das obere Feld bucklig spitz und oft abwiirts gekrimmt ist, mit eingedruicktem Nabel.

Pinus montana Pumilio applanata Willk. Vorkommen der Form und Bildung des Zapfens wie bei voriger; Schuppenschild im 
oberen Felde dachförmig flach und gekielt, mit flachem oder erhabenem Nabel.

Pinus montana Pumilio echinata Willk. Kärnten.

Absonderliche Form, mit iiber 2 cm großen, gestielten, a ufrecht abstehenden, hellbraunen Zäpfchen, deren oberes Feld der Schuppenschilder gebogen und zurückgekrümmt ist; außerdem sind die Schilder gekielt und haben scharfgespitzen, kegelförmigen Nabel.

\section{Typus: Mughus.}

Pinus montana Mughhus (Scop.) Mugokiefer, Krumpholz, Krümpen (Fig. 108).

Syn.: Pinus Mughus Scop.

Krainer-, Kärntner-, sürtiroler und italienische Alpen.

Knieholzwiichsig, selten etwas baumartig, mit in zweiten Jahr anfspringenden, gleichseitig gebauten, meist kegel-

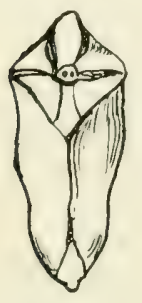

Fig. 108.

Zapfenschuppe (vord. Ansicht) von Pinus montana Mill. Mughus (Scop.). förmigen, wagrecht abstehenden oder abwärts gerichteten, hell- bis dunkelbraumen Zapfen, deren scharfgekielte Schuppenschilder des unteren Zapfenteiles flach sind und einen init Stachel versehenen Nabel führen. Letzterer steht in der Mitte des Schildes.

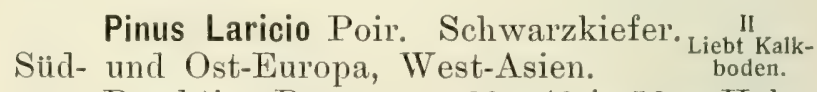
Prächtige Bäume von $20-40$ ja $50 \mathrm{~m}$ Höhe, mit schlankem Stamm, erst dünner, glatter, griinlich-brauner, dann dunkelgrauer, tiefrissiger Rinde, pyramidaler, später schirmförmiger Krone, regelmäßig quirlförmig stehenden Ästen und griingelb-rindigen Zweigen, sowie harzigen, eiförmigen, spitzen, braunroten Knospen mit silbergrauen Schuppen.

Die zu zweien - selten zu dreien - in der braunen Scheide sitzenden, kräftigen, 8-15 cm langen, oft gedrehten, oben rinnigen Blätter sind dunkel- bis hellergriun, am Rande fein gesägt und an der Spitze etwas gelblich und stechend.

$\mathrm{Zu} 2-4$ beisammen und wagrecht bis etwas abwärts stehen die hellbraunen bis gelblichen, glänzenden Zapfen von kegelförmig-rundlicher Gestalt, 4-8-10 cm lang und $3 \mathrm{~cm}$ breit, welche länglich-viereckige, oft stark gestreifte, mit Querleiste versehene Schuppenschilder mit eingedricktem, stumpfem, oft mit einem Dorn versehenen Nabel tragen.

Der dunkelgraue, fast schwärzliche, länglich-eiförmige Samen hat vier- bis fünfmal längeren, gestreiften, einerseits geschweiften Flügel und hält sich 2-3 Jahre keimfähig. Keim- 
ling mit 5-10 dreikantigen Keimblätern und zweiseitig gesighten Erstlingsblättern.

Ein wertvoller Baum mit seinen Formen, außerst harzreich und deshalb eigens vielfach beniitzt, mit außen gelbem, immen rötlichem, dauerhaftem, elastischem Holz; zu Bauten, besonders Wasserbauten, wie auch zu Werkholz sehr resucht. Wohl das terpentinhaltigste $\mathrm{Holz}$ aller Nadellölzer. Es liefert den kretischen, bezw. griechischen Terpentin und werden besonders die Formen austriaca und Pallasiana in gleicher Weise velvendet wie Pinus silvestris.

Formen, deren Fixierung oft schwierig ist, da stets Ủbergänge vorhanden, sind:

Pinus Laricio austriaca Endl. Österreichische Schwarzkiefer, Schwarzföhre. Hauptsächlichst Nicht sehr empfindin Österreich vorkommend. (Fig. 109-111.) lich gegen Rauch und Syn.: Pinus nigra Arnold. Link.

$" \quad$ maritima C. Koch.
$" \quad$ nigricans Host.
$" \quad$ Laricio $\gamma$ nigricans Parl.
$" \quad$ austriaca Höss.

Auf giinstigem Boden prächtige, riesige Bäume erzeugend, auf mehr sterilem Standort auch mehr strauchartig wachsend. In Deutschland durch forstliche Kultur stark verbreitet. Von üppigem Wuchs, meist breiter Krone, dunkelgrauer Rinde, quirliggestellten, wagrecht abstehenden Asten, schmutziggelben bis graubraunen Zweigen, und weißschuppigen Trieben mit weißlichen, ausgefranst-schuppigen Ḱnospen. - Blätter dunkelgriin, derber als bei der Stammform.

Pinus Laricio austriaca falcata Baenitz, eine unbedeutende Form mit etwas mehr sichelförmig gebogenen Blättern.

Pinus Laricio austriaca aurea (foliis aureis) Hort., mit im Soinmer teilweise goldgelben Nadeln. Form.

Pinus Laricio austriaca variegata Hort., weißbuntblätterige

Pinus Laricio monspeliensis Hort., Pyrenaien-Schwarzkiefer, Sevennen, Pyrenäen, Catalonien.

Syn.: Pinus Laricio leptophylla Christ.

" " B pyrenaica Gien. u. Godr. nicht Lap.

"Salzmannii Dunal.

Schlanker, schöner Baum mit etwas f'eineren Ästen, gelbroten oder rötlichen jungen Trieben, schmalen, dïmen und etwas weichen, dicht, fast pinselartig gestellten Blättern von $10-15 \mathrm{~cm}$ Länge, sowie 4-5 cm langen Zapfen mit graubraunen Samen. 


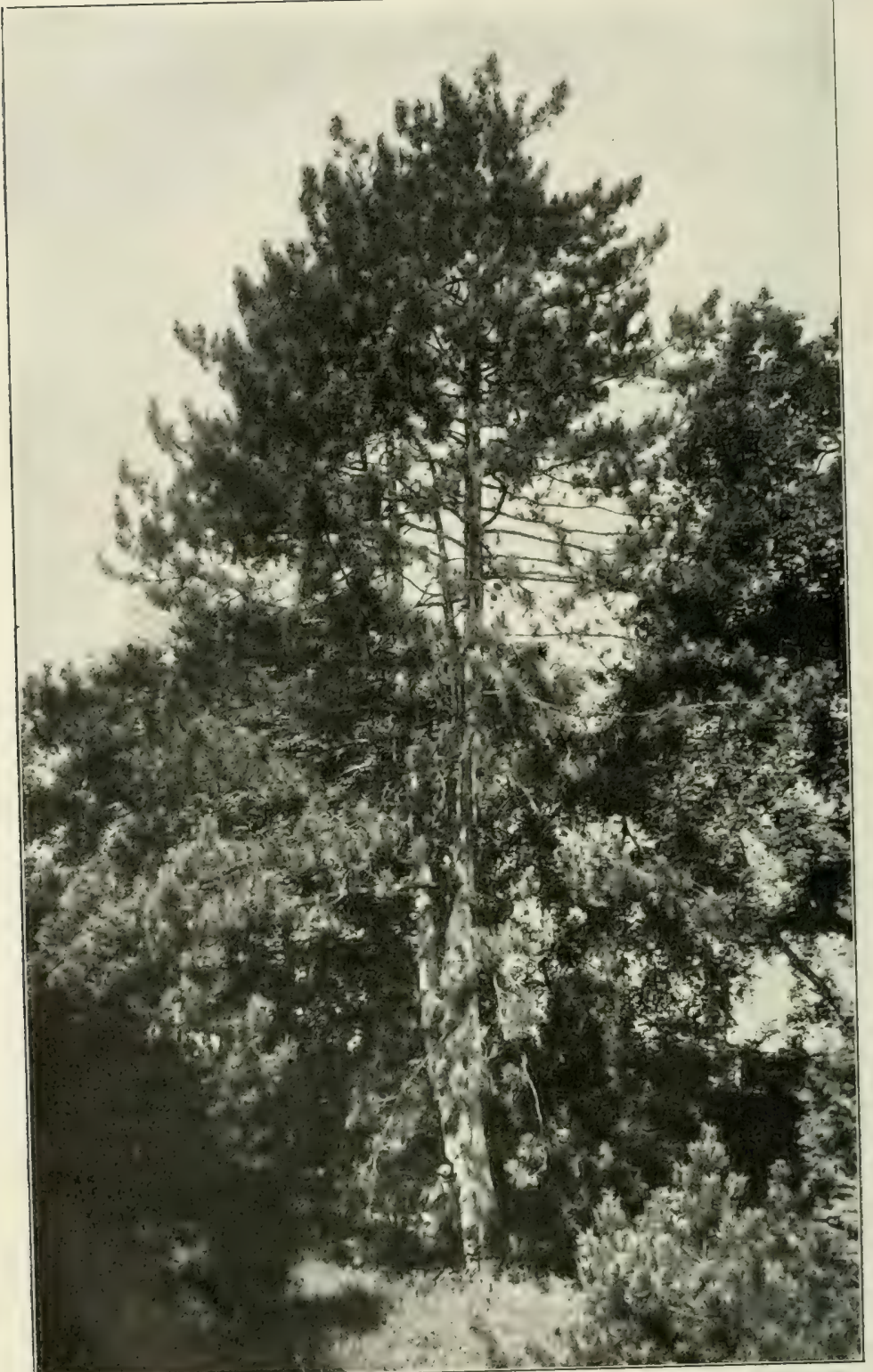

Fig. 109. Pinus Laricio Poir. austriaca Endl. Etwa 80 jähriger Baum. 
Pinus Laricio calabrica Delam. Kinlabrische Schwarzkiefer. Italien, Sizilien, besonder's Kalabrien.

Srn.: Pinns (Laricio) Poiretiana Antoine.

corsicana Hort.

italica Hort.

Üppig wachsend", hochwerdende mol gradschaftige, schönc Fichte, mit anfstrebenden meln kurzen Ästen und hellbramen

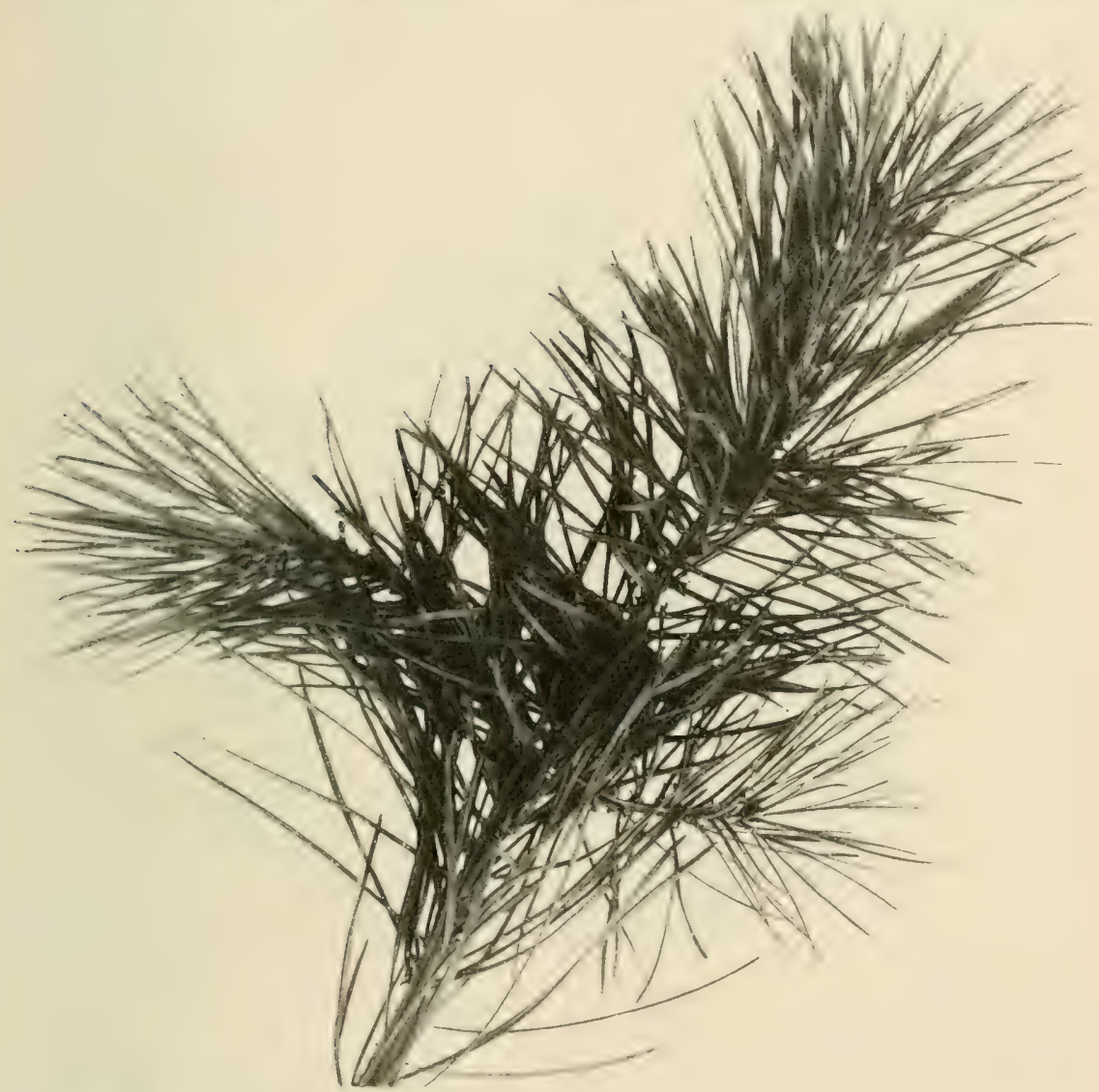

Fig. 110. Pinus Laricio Poir. austriaca Endl. (etwa $1 / 3$ der natïr. Größe).

Zweigen, dunkelgrinen, oft auch gedrehten Blättern, sowie ziemlich kleinen, länglichrunden, bramen Zapfen.

Pinus Laricio Pallasiana Endl. Taurische Schwarzkiefer. Syn.: Pimus (Laricio) tanrica Hort.

" pontice C. Koch.

"Pallasiana Hort. 
Krräftig wachsende, hochwerdende, stark ïstige (!) Form, mit gelb- bis braungranen Zweigen, kräftigen, staren, besonders aufwärts stehenden, langen, glänzend dunkelgrinen Blättern und eiförmigen, ca. 10 cm langen, hellbraunen Zapfen, deren Schuppenschilder eine Querleiste zeigen.

Pinus Laricio pindica (Beißner\%

Syn.: Pinus pindicu Formánerl.

Mit stumpf-liegelfömiger Krone, aufgedunsen verdickter, grauer Rinde, aufstrebenden bis wagrechten, selten hängenden Ästen und glänzend hellgrimen, steifen, limnigen (!), etwas gezähnelten Blättern.

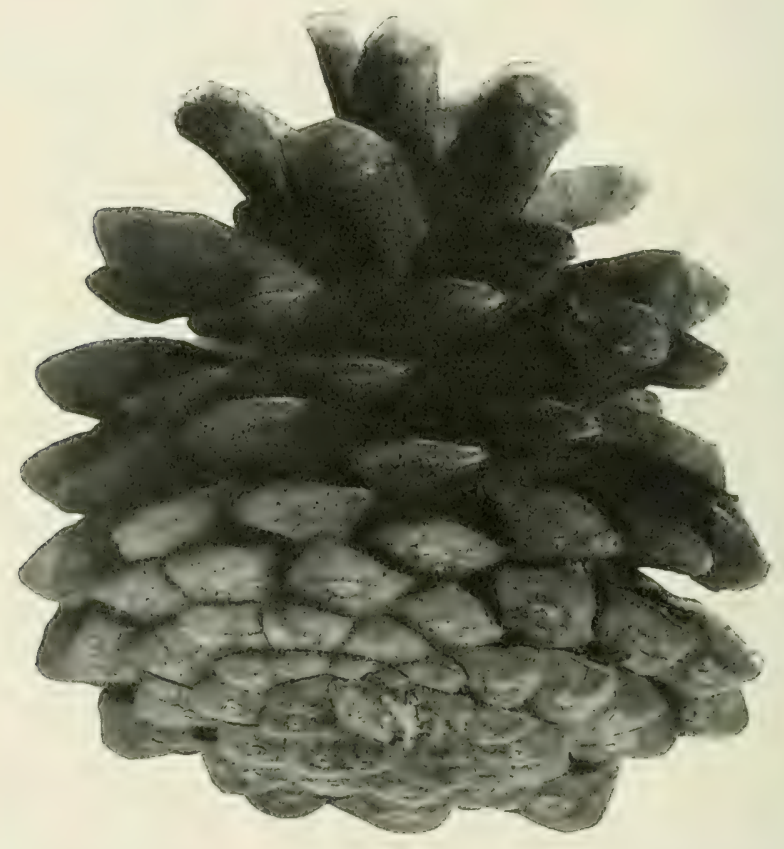

Fig. 111. Untere (hintere) Ansicht des Zapfens von Pinus Laricio Poir. austriaca Endl.

Zapfen erst gelblich, dann gelbbraun, oval kegelförmig, reif unten flach gerundet, $8-10 \mathrm{~cm}$ lang und an der Basis $5 \mathrm{~cm}$ breit, mit rundlich-dreieckigen, gefurchten, glänzenden Schuppenschildern, die etwas erhabenen, grauen Nabel führen.

Pinus Laricio Heldreichii (Master's) Gebirgsform.

Syn.: Pinus Heldreichii Christ.

Von dichtem Wuchs, in Bogen abstehenden Ästen, 7 bis $8^{1 / 2} \mathrm{~cm}$ langen und $1^{1 / 2} \mathrm{~mm}$ breiten Blättern, sowie wagrecht 
abstehenden, spitz-kegelförmigen, 7 cm langen und :3 cm breiten, rötlichbraunen Zapfen, mit gerillten und quergekielten, sowie mit rertieftem Nabel sant hakigem Höcker' versehenen '/apfenschuppen.

$\mathrm{Ob}$ hierher gehörend?

Ferner sind zu nennen:

Pinus Laricio variegata Hort., unwesentliche, weirbuntblätterige Form.

Pinus Laricio colummaris Schwer., noch seltene Siiulenform, mit kurzen, aufwärts gekrümmten Ästen.

Pinus Laricio pendula Hort., mit stark hängenden Ästen.

Moserii (Moser). Üppig wachsende, fast kugelförmige "Busch form mit im Win ter goldgelb werdenden Nadeln!

Pinus Laricio pygmaea Rauch.

Syn.: Pinus Laricio nana Hort.

Dicht- und kurzzweigige, besonders an den Zweigspitzen dichtblätterige, kugelige Form.

Pinus Laricio pumila aurea Hort., gelbnadelige, gedrungenwüchsige Zwergform.

Pinus Laricio Bujotii Hort., ganz kurz- und dichtzweigige, sowie dicht- und gedrehtblätterige Kugelform.

Pinus Laricio monstrosa Hort., monströse Folm, mit dichtstehenden, kurzen, oft verbreiterten $Z$ weigen und dichtstehenden Nadeln.

Pinus Laricio prostrata Beißn., auf dem Boden sich ausbreitende Form mit knieförmiger Beastung.

Auch von dieser Art existieren Bastarde, von welchen nur genannt sein soll:

Pinus Wettsteinii Fritsch, eine Kreuzung von Pinus Laricio anstriaca mit $P$. montana.

Pinus leucodermis Antoine. Weißrindige Kiefer. Von Dalmatien und Montenegro bis Serbien.

An Pinus Laricio erimnernde, in ihrer Heimat starkwiichsige (bei uns nicht so sehr), zu den Höhenziigen aufsteigende, bis 20, ja $30 \mathrm{~m}$ hoch werdende Art mit bräunlichweißer, in großen eckigen Stiicken aufspringender Rinde, außen weißgrauer, nach inmen rotbrauner Borke, ziemlich pyramiclaler oder auch breiter Krone, quirlig gestellten Ästen, rötlichbraunen, weißspitzen Knospen, spitzen, starren, gegen die Zweigenden dichtstehenden, außen konvexen, bei $5-6 \mathrm{~cm}$ langen und $1-1,3 \mathrm{~mm}$ dicken, dunkelgrinen Blättern. Die nicht glänzenden, gelblichen bis bräunlichen, eiförmigen, $7-9 \mathrm{~cm}$ langen, unten flachen Zapfen haben mehr oder minder stark erhabene, mit 
Querleiste rersehene Schuppenschilder und bräunlichen, mit rückwärts gekrimmter Spitze versehenen Nabel.

Der graubraune lingliche Samen hat einen gut viermal längeren Fligel. Das harzreiche, imnen rotbraune, außen gelbe Holz ist wertvoll. Orient.

Pinus pyrenaica Lap., Pyrenäenkiefer. Siideuropa, V

\section{Syn.: Pinus Paroliniuna Web. caroliniana Hort.}

Immer noch seltene, schöne, bei uns leider sehr empfindliche, sonst schnellwiichsige, bis $15 \mathrm{~m}$ hochwerdende Kiefer, mit dicht und wagrecht abstehenden, quirlig gestellten Ästen, gelblichen, ziemlich feinen Zweigen, spitzen, harzigen Kinospen und besonder's an den Zweigenden dichtstehenden, stachelspitzen, feinen, bis $15 \mathrm{~cm}$ langen und $1^{1} / 4 \mathrm{~mm}$ dicken, gefurchten, glänzendgrünen, engstehenden Blättern. Die fast stets zu mehreren beisammen und nahezu wagrecht abstehenden, dick-kegelrunden, $5-10 \mathrm{~cm}$ langen und $4-6 \mathrm{~cm}$ breiten, glänzend gelb bis rötlichbraumen Zapfen haben fast rundliche, mit Querleisten versehene, runzelige Schuppenschilder, mit ziemlich gedricktem, grauem Nabel und dunkelgrauem Samen, welch letzterer mit braunem, schmalem, dreimal längerem Flügel versehen ist.

Das Holz ist gut, wenn auch wenig harzreich.

Als Form gilt:

Pinus pyrenaica brutia (Ten,).

Syn.: Pinus brutia 'Ten., auch als Bastard:

$"$ Laricio $\times P$. halepensis betrachtet.

Pinus resinosa Soland. Harzkiefer, Rotkiefer. Nordanerika, besonders Kanada und Neuschottland. sandigen Boden.

Schöne wertvolle, schlankstïmmige Kiefer, 20-30 m Höhe erreichend, mit hell-graugelber, in diumen Scheiben sich lösender Rinde, von pyramidalem Wuchs mit kräftigen, abstehenden Ästen, auffallig hellrot-rindigen Zweigen und sehr langen, spitzeiförmigen, rotbraunen, harzigen Knospen. Etwas steif, 12 bis 16 cm lang, kurz gespitzt, an Rande feingesägt sind die fast dunkelgriinen, an den Zweigenden gebiischelt stehenden Bliitter.

Die wagrecht abstehenden, rundlich kegelförmigen, abgestumpften Zapfen sind hell-rötlichbraun, $t^{-5} \mathrm{~cm}$ lang und $3^{1 / 2}$ cm hreit, mit kaum erhabenen, rhombischen, mit Querleiste und niederem, ganz stumpfem Nabel versehenen Schuppenschildern.

Der kleine, längliche Samen hat dreimal läng'eren Fliigel.

Das äuferst reichharzige, kurzzellige,schwere, dauerhafte, rote Holz ist zu Wasserbauten, besonders auch zum Schiffsbau sehr gesucht. 
Pinus Pinaster Sol. Strand-Kiefer, Igelfölne. Mittelmeerländer.

Syn.: Pinus maritima Poir.

I'I (V?)

Auf sandigem Boden. Kalk und schwerer Lehm ist unvorteilhaft.

Schöner, in der Heimat wertvoller, je nach Standort im Habitus, in den Blaittern, oder im Zapten abiindernder baum, äufjerst

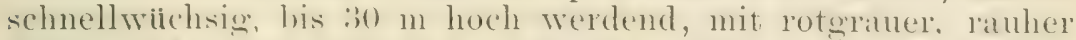
Rinde, erst pyramidenförmiger, dann kegelförmiger bis rundlicher Frone, dicht und quirlio stehenden, ansladenden, spaiter etwas gehogenen Ästen und krätigen, hläulich bereiften, etwas anffallend roten Zweigen, sowie linglichen, grofien, brannen, dabei weißgewimpert-schuppigen Knospen.

Die zu zweien - manchmal zu dreien - an den Zweigenden dichtstehenden, krätigen, stachelspitzigen, steifen, helleriinen Blitter werden bis zu $20 \mathrm{~cm}$ lang und bis zu $2 \mathrm{~mm}$ breit, sind halbrundlich, am Rande gezälmelt, oft auch gedreht.

Die hibschen, meist zu mehreren beisammenstehenden, gestielten, schief nach unten gerichteten, dick-kegelförmigen, spitz. zulaufenden, bis 12-19 cm langen und 5-8 cm dicken, glänzend gelbbraunen Zapfen zeigen kegelartig erhabene, mit scharfer Querleiste und hervorstehendem, spitzem und hakigem, meist gekriimmtem Nabel versehene Schuppenschilder.

Der große, schwarzgraue Samen hat etwa viermal lïngeren Fliigel. Das zwar nicht dauerhafte, aber harzreiche, schwere Holz liefert vortreffliches Brennholz; der Baum wird zur Harzgewinnung vorteilhaft beniitzt, liefert französischen Terpentin und wird auch sonst wie unsere einheimische Kiefer verwendet.

Thre Formen sind bei uns selten in Kiultur, es sind dies:

Pinus Pinaster Hamiltonii Parl.

Syn.: Pinus Hamiltonii Teu.

Corteana Hort.

Eine starke Form, mit derben, kräftigen, 18-25 $\mathrm{cm}$ langen Blättern und meist einzeln (!) stehenden, länglich-kegelförmigen, bis $20 \mathrm{~cm}$ langen Zapfen. Sie soll etwas mehr IVinterkälte aushalten als die Stammform, was aber wohl nicht zutrifft.

\section{Pinus Pinaster Lemoniana Endl.}

Auffallende, sich in der Krone ausbreitende, starkästige und starkzweigige Form, mit derben, langen, steifen, oft gedrehten, dunkelgrinen Blättern, einzelstehenden (!), glänzend rötlichbraunen, bis $11 \mathrm{~cm}$ langen und $t \mathrm{~cm}$ dicken Zapfen, deren Schuppenschilder eine scharfe Querleiste und grauen, stumpfen Nabel zeigen.

Pinus Pinaster minor Loisel.

Syn.: Pims Escarena Endl.

Von kleinem Bau, kleineren - als die Stammform - blaugrunen Blättern, sowie zu mehreren beisammenstehenden, $4-5 \mathrm{~cm}$ 
langen und $3-3 \frac{1}{2}$ cm dicken Zapfen. Hievon gibt es auch eine goldgelbnadelige Unterform, welche aber wohl kaum in unseren Kulturen vorhanden ist.

Pinus halepensis (aleppensis) Mill. Aleppokiefer. Nittelmeerländer und Ostkuiste des In sandigem Boden. schwarzen Meeres.

In Bodenbeschaffenheit nicht allzu wählerische, starkwiichsige, sehr schöne, aber bei uns kaum in den paar bevorzugten Teilen Deutschlands noch aushaltende, bis $16 \mathrm{~m}$ hoch werdende Kiefer, mit in Alter breiter Krone, erst grauer, dann braunroter, rissiger Rinde, aufstrebenden Ästen und vielen erst griun-, dann bräunlichgrau-rindigen Zweigen und runảlichen, harzigen, rotbraunen Knospen.

Die zu zweien - selten zu dreien - in silberigfarbiger Scheide stehenden und gegen die Zweigspitze büschelig gestellten, feinen, 7-9 cm (an jungen Pflanzen bis $15 \mathrm{~cm}$ ) langen Blätter sind hell bis bläulichgrün, wie gestreift, stumpf-stachelspitzig.

Die hängenden, im dritten Jahre reifenden, reichlich erscheinenden, schmal-kegelförmigen, glänzend rotbraunen Zapfen werden 8-10 cm lang und $4 \mathrm{~cm}$ breit, und zeigen an glatten Schuppenschildern eine Querleiste, sowie graubräunlichen, stumpten Nabel.

Samen braungrau mit langem, bräunlichem Flügel.

Das innen rotbrame, außen gelbe, harzreiche Holz ist zum Schiffsbau etc., sowie als Werkholz sehr gesucht; die Borke gibt Gerbematerial; außerdem liefert die Pflanze (offizinelles) Harz, (venetianischen) Terpentin, Holzteer u. s. w.

Eine Form, der etwas mehr Winterhärte zugeschrieben wird, ist:

Pinus halepensis Pithyusa Stev., vom westlichen Kaukasus, (Cypern?).

\section{Syn.: Pinus Pithyusa Strangu.} maritima Lamb.

Ein buschiger Baum, mit dünnen, gedrehten, bei $12 \mathrm{~cm}$ langen Blättern und kleinen, etwas gebogenen Zäpfchen.

Als Bastard: Pinus halepensis $\times$ P. Pinaster ist zu nemmen: Pinus halepensi-Pinaster $G$. de Saport.

Pinus Eldarica Medw. Eldar-Kiefer. Inneres von T'ranskaukasien.

Wohl noch nicht in unseren Baumschulkulturen befindliche, $15 \mathrm{~m}$ hoch werdende, aufrechte oder gekrimmte Kiefer, mit langabstehenden Ästen bei ausgebreiteter Krone, dem Zweige fest angedrückten, kurzen, spitzen, steifen, an Rande gezähnelten Blättern, sowie meist einzelnen, aufrecht abstehenden (!), reif 

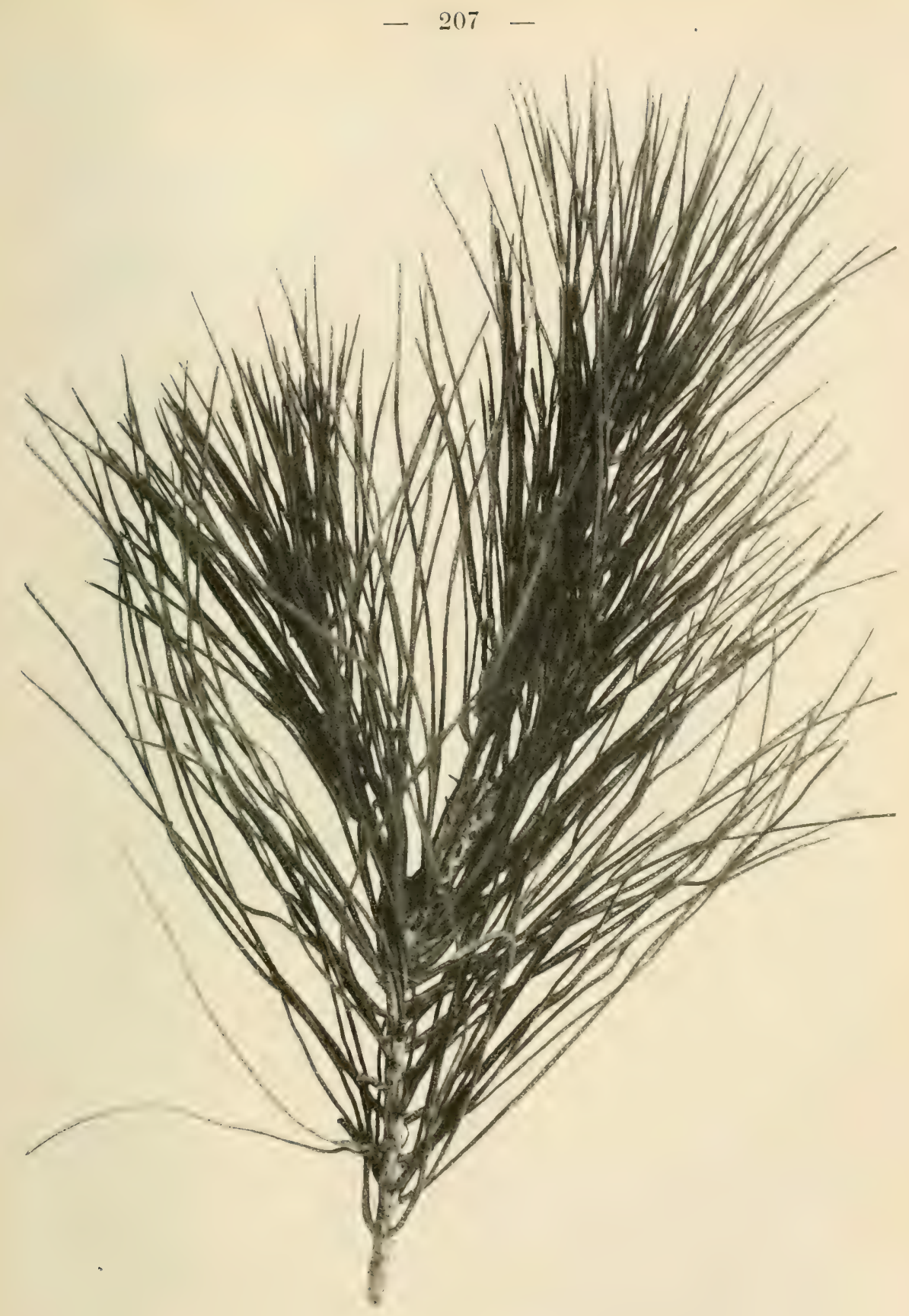

Fig. 112. Pinus Pinen L. 
eifürmig-länglichen, kleinen Zapfen mit am oberen Teile konvexen, schief erhaben gekielten schuppenschildern. In Deutschland wohl nicht winterhart.

Pinus Pinea L., Pinie, Nußkiefer, Schirmföhre, ital. Steinkiefer. Mittelmeerlinder. Kleinasien. (Fig. 112 und 113.)

In Deutschland nicht winterharte Art, die hier nur kurz besprochen werden soll. weil der Baum nicht nur vielseitig in der Literatur genannt wird, sonder'n weil anch jedermann, der Italien, Spanien etc. bereist, diese Art besonder's auffiillt, da sie der Gegend einen bestimmten Charakter verleiht.

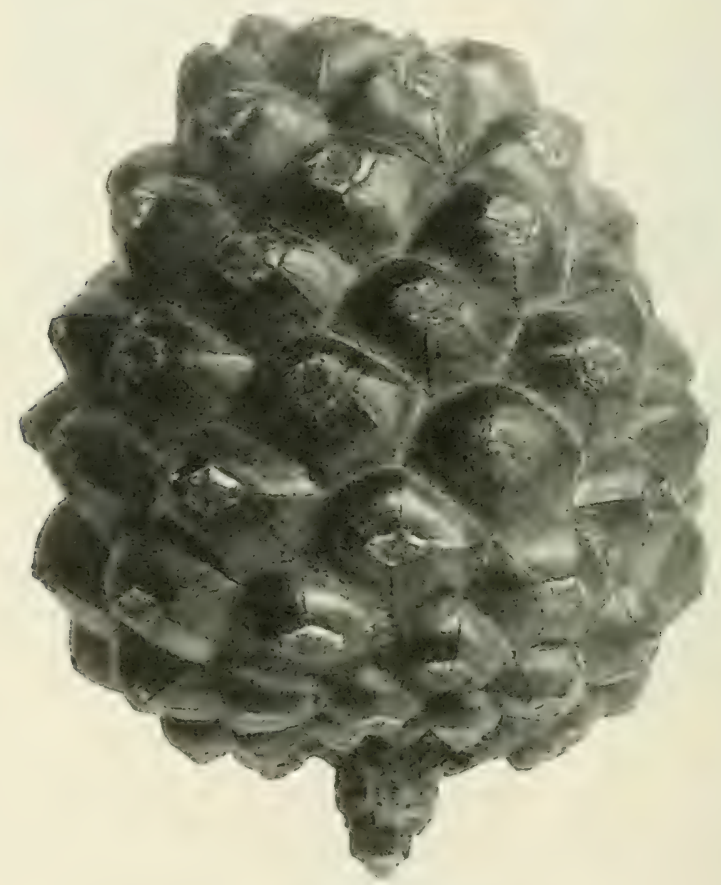

Fig. 113. Zapfen von Finus Pinea L.

In der Jugend buschig, astet sich die Pflanze bald aus, und hildet auffallend schirmförmige Kronen bei einer Höhe bis über 15 m, mit graurötlicher, später rissiger, sich lösender Rinde.

Die besonders an kultivierten Exemplaren oft zu dreien in der Scheide stehenden, an den langen, diimnen Zweigen der Jugendpflanzen blaugrinen, bis $20 \mathrm{~cm}$ langen und $1_{2}^{1}-2 \mathrm{~mm}$ breiten, an älteren Pflanzen kürzeren Blätter sind halbrund, etwas steif und spitzig. 
Der drei Jahre bis zur Reife benötigende Zapfen ist erst bräunlich, dann griin mit sranem Nabel und im dritten Jahr glänzend hellbraun, hübsch gebaut, dick eiförmig, 10-13-16 cm lang, 5-7 cm dick (Zapfen wildwachsender Pinien sind kleiner), mit gewölbten Schuppenschildern, welche flachen Nabel und 5-6 Leisten zeigen.

Die bei $2 \mathrm{~cm}$ langen und bis $1 \mathrm{~cm}$ breiten, dickschaligen Samen: „Pinien(niisse), Pignolen, Piniolen“, zum direkten Genuß und ähnlich den Mandeln zum Gebäck beliebt, haben kurzen, den Samen zangenförmig umfassenden Fliigel.

Das weiße Holz gibt gutes Werkholz, die Zapfen sind gesuchtes Anziindematerial, außerdem findet das Harz Verwendung; die taninhaltige Rinde ist offizinell.

Von den Formen soll nur genannt sein:

Pinus Pinea fragilis Loisel., mit diinner Samenschale.

Pinus densiflora Sieb. u. Zucc., Dichtblïtige oder japanische Rotkiefer. Japan bis Eso.

Unserer gewöhnlichen Föhre ähnliche,

III In lockerem, sandigem, mehr trockenem als feuchtem Boden. schlankwiichsige, 20 - 30 m hoch werdende Kiefer, mit erst gelbroter, dann graubrauner Rinde, ausladenden Ästen und dimnen, bräunlichgelben, schwachbereiften Zweigen, mit spitzen, eiförmigen, rotbraunen Knospen, deren gefranste (!) Schuppen zurückgerollt sind.

Blüten sehr dichtährig, daher der Name.

Die an den Zweigenden dicht, fast pinselartig stehenden, 6-11 cm langen, dimmen Blätter sind fein gespitzt, oben konvex, am Rande schwach gesägt, von grau- bis bläulichgriuner Färbung. Der graubraune, $5 \mathrm{~cm}$ lange und $3 \mathrm{~cm}$ dicke, kegelförmige, oben abgestumptte, etwas abwiirts gerichtete Zapfen hat flache, stumpt-rautenförmige, mit Querleisten und mit kurz und dickgespitztein Nabel versehene Schuppenschilder, sowie eiförmige, graubrame Samen mit dreimal längerem Flïgel.

Diese Art wird leider von der Schiutte ziemlich heimgesucht, speziell junge Pflanzen.

In der Heimat ist das Holz zu gewöhnlichen, wie besonders zu Schiffsbauten sehr gesucht.

Ebenso wird diese Art ron den Japanern auch zu ihren Topf-Zwergbäumen verwendet.

Von den in Kultur befindlichen (sonst in der Heimat zahlreichen) Formen sollen nur genannt sein:

Pinus densiflora variegata Beißner, mit teilweise gelbgeringelten Blättern.

Pinus densifiora aurea Hort., mit goldgelben Blättern.

"

Schelle, Koniferen. pumila Hort., von niederem Wuchs. 
Pinus Thunbergii Parl. Thunbergs Kiefer, Auf sandigem, mehr japanische Schwarz-Kiefer. Küsten Japans. Aut sandigem, men.

Syn.: Pinus Massoniana Sieb. u. Zuce., nicht Lamb.!

Eine Lieblingskiefer der Japaner. Bis zu 35 in Höhe erreichend, von schlankem Wuchs, geradem . Stamm, glatter, schwärzlichgrauer Rinde, langen, ausladenden Ästen, erst grünen, dann glänzend grau- bis griulichbraunen Zweigen mit weißen (!), seidenhaarigen, großen, eiförmigen, spitzen Knospen.

Die lebhaft grimen, $10-14 \mathrm{~cm}$ langen, oben konvexen Blätter sind kurz gespitzt, stechend, etwas gedreht und ain Rande fein gezähnt.

Reichlich erscheinen die gekrủmmten, stumpf und rundlich kegelförmigen, braunen bis graubraunen, 5-6 cm langen und 3-4 cm dicken Zapfen, mit dicken, schief rautenförmigen, kaum erhabenen, mit Querleiste und niederem, stumpfem, schwach gespitztem Nabel versehenen Schuppenschilder.

Der braune, fast eckige, sehr kleine Samen hat gestreiften, glänzend braunen, gut dreimal längeren Fluigel

Das wohlriechende, feste, harzige $\mathrm{Holz}$ wird zu Bauzwecken viel verwendet und gibt gutes Brenn- und Kohlenholz. Der Ruß der verbrannten WVurzeln gibt einen Bestandteil der chinesischen Tusche. Das Harz ist offizinell.

Der Japaner pflanzt diese Art mit Vorliebe an seine Häuser, Tempel etc., wie er Art und Formen überhaupt als Schmuckbaum, wie ebenso zu seinen Zwerg-Topfbäumen verwendet. Japanische Koniferen-Abbildungen zeigen besonders diese Kiefer.

Formen sind:

Pinus Thunbergii variegata Hort., mit teilweise gelbbunten Blättern.

Pinus Thunbergii monophylla Hort, durch Verwachsung der beiden Blätter scheinbar einblätterig.

Pinus Thunbergii tortuosa Hort., mit originell korkzieherartig gedrehten, derben, stechenden Nadehn und rötlichen (!) Knospen.

Pinus Thunbergii tabuliformis Hort., eine reich und dichtästige, sich fast tischartig ausbreitende Form mit gelblicher Rinde und $10 \mathrm{~cm}$ langen Blättern.

Als Bastard wird genannt:

Pinus Thunbergii $Y$ Pinus densiflora, nach Mayr.

Pinus Massoniana Lamb. (nicht Sieb. u. Znce.!), (VII ?) Massons Kiefer. Vom südlichen China, Formosa.

(IV ??)

Syn.: Pinus sinensis Lamb.

Mit voriger Art oft verwechselte Kiefer von hohem Wuchs, ausladenden $\ddot{A}$ sten und hellgelben Zweigen, silberhaarigen, 
langen Ḱnospen, dichtstehenden und ganz dïnnen, 1+(-18) cm langen, oben konvexen, kurzgespitzten, feingesïgten Blïttern, sowie ziemlich hängenden, lïnglich-eifürmigen, bis $7 \mathrm{~cm}$ langen und 3 cm dicken, braunen Zapfen, welche der vorigen Art ähnliche Schuppenschilder führen.

Der rotbrame, eiförmige Samen hat brïunlichen, dreimal längeren Flïgel.

Eine Form mit flacherem Kronenbau ist:

Pinus Massoniana planiceps A. Murray.

Pinus inops Soland. Jersey-Kiefer. Vom Hudsonfluß bis Krarolina.

Syn.: Pinus virginiana Mill.

Interessante und wertvolle, selten hoch werdende $(8-12 \mathrm{~m})$, meist buschig bei uns wachsende, aber sonst guttriebige Kiefer, mit breiter Krone, braunroter, rissiger Rinde, ungleichmäßig stehenden, zum Teil gedrehten Ästen und feinen, weiß bis weißblau bereiften (!) Trieben.

Die dunkelgrinen, zu zweien, selten zu dreien in auffälliger, weißer, braungeringelter Scheide stehenden Blätter sind nur 4-5 cm lang, halb gerundet, steif, etwas gedreht, stachelspitzig.

Die meist abwäits gerichteten, länglich-kegelförmigen, manchmal etwas gebogenen, bläulichroten (!) Zapfen werden $4-7 \mathrm{~cm}$ lang und $2^{1 / 2}-3^{1 / 2}$ cm dick und haben kaum erhabene, rhombisch geformte, leicht gekerbte (!) Schuppenschilder, mit zu einem diunen, feinen, aufgekrimmten Dorn verlängerten Nabel. Der kleine Samen hat einen schmalen, dreimal längeren Flïgel. An den Boden nahezu anspruchslose Art, nit wohlriechendem Harz, das besonders bei Wärme am Stamm stark ausgeschieden wird.

Eine Abart, vielleicht aber doch als eigene Art zu betrachten, ist die in der Heimat mehr sidllich gehende, bei uns nicht mehr winterharte

Pinus inops var. clausa Chapm.

Syn.: Pimus clausa Vasey,

welche sich durch ziemlich doppelt so hohen Wuchs, jung griine Triebe, hellbraune Knospen mit schmäleren Bliittern, und sich lange nicht öffnenden, großen Zapfen von der stammform unterscheidet.

Pinus mitis Michx. Fichten-Kiefer', gelbe Kiefer. Neu-Jersey bis Missouri, Florida und Auf sandigem, mehr Texas.

Syn.: Pinus echinata Mill.

Schöne, aber nur noch in Weingegenden gut gedeihende, des öfteren besonder's nit Pinus rigida verwechselte, im Habitu: 
aber an unsere Rottanne erinnernde, pyramidal wachsende, 15 bis $30 \mathrm{~m}$ hoch werdende Kiefer, die gute Stämme bildet, welch letztere rissige, dunkelgraue, mit Harzbeulen versehene Rinde zeigen. Äste besonders unten ausladend, mit weißlich bereiften Zweigen und harzigen, länglichen Knospen.

Die an jungen Pflanzen oft zu dreien erscheinenden, 7-10 cm langen, hell- bis fast gelblichgriinen Blätter sind zugespitzt, innen gefurcht, manchmal gedreht.

Der braune, etwas hängende, länglich-eiförmige Zapfen wird $4^{1 / 2}-6 \mathrm{~cm}$ lang, bei $3 \mathrm{~cm}$ dick und hat leicht breitgedritickte und etwas erhabene, mit Querleiste versehene Schuppenschilder, deren Nabel gebogen und dornig ist, sowie kleinen Samen, mit breitem, dreimal längerem Flügel.

Eine den Rückschnitt gut ertragende, vortreffliches Nutzholz liefernde Art.

Pinus Banksiana Lamb. Bankskiefer, Strauchkiefer. Von Neu-Schottland, Nord-Michigan, Liebt sandigen Boden, Wisconsin bis zum $68^{\circ}$ nördl. Breite.

An die Bodenbeschaffenheit wenig Annicht sehr durch Schütte. sprüche stellende, forstlich sehr empfohlene, auch auf armem, sandigem Boden, selbst Flugsand noch als dankbar wiichsig bezeichnete, zierliche, ziemlich schnellwiichsige, jedoch nur bis 15, selten $20 \mathrm{~m}$ hoch werdende Kiefer, mit dunkelgrauer Rinde, vielen aufstrebenden, ausladenden und auch uibergebogenen Ästen und erst grünen, dann braumen Zweigen mit länglichen, harzigen, gelben Knospen.

Die leicht gebogenen, dichtstehenden und etwas steifen, fast hellgrimen Blätter werden bis $6 \mathrm{~cm}$ lang, sie sind stachelspitzig, unten konvex.

Reichlich zeigen sich die im reifen Zustand graubraunen, meist nach innen gekrimmten, länglich kegelförmigen, spitzen, $5 \mathrm{~cm}$ langen und $3 \mathrm{~cm}$ dicken, abstehenden, oder selbst etwas aufgerichteten Zapfen, welche ungleich viereckige, mit schwacher Querleiste und kleinem, in der Jugend dornigem Nabel versehene Schuppenschilder, sowie kleinen, grauschwarzen, kurzgeflügelten Samen führen. Samenansatz findet oft schon vom achten Jahr ab statt.

Das braune, leichte und dabei doch zähe Holz mittlerer Guite ist in der Heimat sehr gesucht.

Pinus contorta Dougl. Dreh-Kiefer. Westliches Nordamerika.

Schöne, dicht und pyramidalwïchsige Kiefer,

II

Auf nicht zu schwerem, mehr feuchtem als trockenem Boden.

mit dünner, glatter Rinde, quirlig gestellten Ästen, harzigen Knospen, 3-8 cm langen und 1-2 mm breiten, lebhaft glänzend- 
grïnen, stark gedrehten, stumpf gespitzten Bliittern, am Rande fein gesägt.

Reichlich erscheinen die ovalen, ganz schiefen, $3-5 \mathrm{~cm}$ langen und 2-3 cm dicken Zapfen; dieselben haben erhabene Schuppenschilder mit schwarzem, dornig nach vorne verlängertem Nabel, sowie schwarze Samen mit dreimal längerem, spitzem F'lügel. Das schwere Holz ist wertvoll.

Form ist :

Pinus contorta Bolanderii Parlat., Alaska, Kíalifornien. Bis $8 \mathrm{~m}$ hoch werdend, mit 3-4 cm langen, kräftigen Blättern und sehr schiefen, lange geschlossen bleibenden Zapfen.

\section{Pinus Murrayana Balf. Murrays Kiefer. Auf feuchtem Boden,} Kalifornien bis Oregona, Utah und Kolorado. feuchtem Sandboden.

\section{Syn.: Pinus contorta var. Murrayana Engelm.}

In der Heimat bis $40 \mathrm{~m}$ hoch werdend, (auch bei uns starkwiichsig), starkästig bei kegelförmigem Wuchs, mit duinner, graubrauner, schuppiger Rinde, sowie 3-5 (-8) cm langen und $2 \mathrm{~mm}$ breiten, dunkelgrïnen, sehr dicht stehenden Blättern. Der Zapfen ist dem der P. contorta sehr ähnlich, doch nicht so schief gebaut und bald abfallend.

Das Holz ist sehr schwer und wertvoll.

Als noch ungeniigend bekannt, ob Abart, ob eigene Art, ist

Pinus Murrayana var. Sargentii Mayr zu bezeichnen.

Pinus muricata Don., Bischofs-Kiefer. Kalifornien.

Seltene, leicler starkwuichsige, bis $10 \mathrm{~m}$ - in der Heimat bis $30 \mathrm{~m}$-- hoch werdende Kiefer, mit rötlichbrauner Rinde, ausladenden, unregehmäßig stehenden Ästen und rotbraunen Zweigen, sowie sehr spitzen, bläulichen, oben rötlichen Ḱnospen.

Die zu zweien - selten zu dreien - beisammenstehenden, dunkelgriuen, 10-16 cm langen und ziemlich breiten, steifen Blätter sind scharf-spitzig, etwas gedreht und an Rande fein gesägt.

In Buischel abstehend, sehr schief und auch oft rückgebogen zeigensich die lange Jahre sich nicht öffnenden, eiförmigen, braunen Zapfen, welche 6-9 cm lang und $4-7$ cm dick werden und Schuppenschilder führen, die stark gekielt, im unteren Zapfenteil lang ausgezogen und dornig, weiter oben aber mehr nieder gebaut sind.

Der schwarze, rauhe Samen hat dreimal längeren Flüırel. 
Pinus pungens Michx. Stechende Kiefer. II (?) Pennsylvanien und Naryland his Karolina.

An unsere gemeine Kiefer erinnernde, bis

Auf mehr trockenem (kiesigem), als feuchtem Boden.

$18 \mathrm{~m}$ hoch werdende Art, mit rotbramer. in Stiicken lösenderRinde, starkästigen Stamm, ansgel)reiteten, unregelmäbig gestellten Ästen und bramen (jung bereiften) Zweigen mit harzigen Knospen.

Die zu zweien, selten zu dreien beisammenstehenden, dunkelgriunen, bis s cm langen, dabei derben, steifen, etwas gedrehten Blätter sind scharf'spitzio, halbrund und an Rande fein gesägt.

Zu mehreren stehen die viele Jahre an Baume hängen bleibenden, abwiarts serichteten, charakteristisch rundlichen, 6-8 cm langen und 5-6 cm ricken, gelbbraunen Zapfen, mit erhabenen, dicken Schuppenschildern, welche kriftige Querleiste und verlängerten Nabel mit auffälig gekrimmtem, dickem, stechendem Dorn führen.

Der kleine, fast rundliche, schwarzloraune Samen hat einen viermal längeren, schmalen Flügel.

Der Holzwert dieser Art ist kein hervorragender.

Zwei weitere, in unseren Kulturen aber wohl noch vicht vorhandene Kiefern sind:

Pinus funebris Komarow. Zierende Kiefer. Amurgebiet. (?)

Zu Pinus silvestris gerechnete, an diese auch sehr erimnernde, doch kleinere, dabei kräftigästige Kiefer, mit grauer Rinde und jung braunen Zweigen. Die steifen, halbgerundeten, fein gesägten, zugespitzten Blätter sind $4-8^{1 / 2} \mathrm{~cm}$ lang und bläulich-, fast grau-griin.

Die ca. 3-5 cm großen und fast ebenso dicken, grauen Zapten haben rhombisch gefelderte Schuppen (!), deren Felder etwas gepreßt sind.

Pinus glabra Walt., Glatte Kriefer, von den Siidstaaten Ostamerikas, eine meist zweinadelige Art. Ist wohl in Deutschland nicht winterhart.

\section{Abteilung: Taeda Endlicher.}

Ternae: Drei Nadeln in einer gemeinschaftlichen Blattscheide. Zapfer: rundlich oder kegelförmig, mit pyramidal erhabenem Schuppenschild, dessen Nabel bewehrt ist. Samen geflügelt.

Pinus rigida Mill. Pechkiefer, steife Kiefer. Von Maine bis $38^{\circ}$ nördl. Br. in den Alleghanies. Auf giinstigem Boden bis $25 \mathrm{~m}$ hoch werdende, etwa vom 6. Jahre ab starkwüchsige Kiefer mit schwarzgraner, dicker, tiefrissiger

I

Auf sandigem, mehr trockenem Boden; aber auch auf Mloor noch brauchbar. Bei ïppigem Boden reift die Pflanze schlecht aus. Lichtbedürftig! 
Rinde, weit herah stehenden, ziemlich wasrecht gestellten, eine dichte, fast schimfömige Krone bildenden Ästen, glatten, erst rötlich-damn gelhhramen, obiazenden '/weigen, sowie bramen, spitzen, harzigen Kuospen.

Die sehr steifen, derhen, abstrehenden, meist gedrehten, scharf spitzen Blitter sind $6-12 \mathrm{~cm}$ lang, his 2 mm breit, helleriul.

Zu mehreren an den (puirlen geren die Ditte der Zweige zu stehen die erst etwas abwiirts, dam wagrecht werichteten, lange am Baume bleibenden, bramgelblichen, länglichovalen Zapfen, mit breit viereckigen Schuppenschildern, welche Querleiste und spitzen, etwas gebogenen, später abfallenden Nabeldorn zeigen. (Fin. 11t). Der bramschwarze, eckine, etwal $1 / 2$ cul lange Samen hat gut dreimal lingeren, brïunlichen Fliigel.

Die starkwüchsigen Keimlinge bilden hiibsche, blaugriine Erstlingsblitter.

Nach Riickhieh des Bammes treibt diese Art ziemlich stark Stockausschläge.

Das trocken aufoerachsene, innen braune, harzreiche Holz ist als (falsches) "Pitch-Pine"

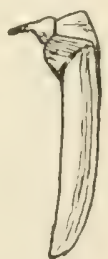

Fig. 114.

Zapfenschuppe (Seitenansicht) ron Pinus rigida Mill. - Pechkieferholz - in Handel, ersetzt jedoch das echte niemals (siehe naichste Art), da es im WVert nur etwa dem unserer gemeinen Kiefer gleichkommt, dagegen ergibt es gutes Bau-, Brenn- und Kohlenholz. Daneben liefert diese Kiefer auch Harz, Terpentin, Pech und Teer. Das auf feuchtem oder nassem Boden gewachsene Holz ist sehr splintreich, weich, leicht und gering'wertig.

Als Form geht:

Pinus rigida aurea Beißn., mit iippigen, goldgelben Trieben; dagegen ist als Abart zu nennen:

Pinus rigida var. serotina Engelm., Spait-, Morast- oder auch fälschlich Fuchsschwanzkiefer.

Syn.: Pinus serotina Michx.

In Dentschland wohl kaum winterharte, auch siidlicher als die Art, in Siidkarolina, Geor'gia, Florida und dort auf sumptigen Böden vorkommende Kiefer, mit gelblich-brauner Rinde, weit ausladenden Ästen, hellbramen, harzigen Knospen und diunen, starren, scharfspitzen, glïnzend hellgriinen, bis $18 \mathrm{~cm}$ langen Blättern, sowie rund- his linglich-eiförmigen, dunkelbraunen Zapfen, mit viereckigen Schuppenschildern, deren feine Haken bald abfallen. Der Samen fällt erst in 3-t Jahren aus. Holzwert gering.

Pinus palustris Mill. Sumpfkiefer, Besenkiefer. Ton Ḱarolina bis Florida.

Syn.: Pinus australis Michx. 
Hält in Deutschland nicht aus! Als Hauptlieferantin des echten "Pitch-Pine" (siehe vorige Art) sehr wertvolle Kiefer ron etwa 25 m Höhe, mit f'ein abblätternder Rinde, hoch hinauf dickwüchsigem Stamm, der wenig Splint bildet, und dabei äuferst harzreich ist. Hat lange (bis iiber $30 \mathrm{~cm}$ ), hellgrüne Nadeln, braune Zapfen mit großen Schuppen, deren Schilder rückgekrummte Haken fuilıren. Die Zweige der jungen Pflanzen werden zu Besen verwendet.

Pinus Taeda L. Weihrauch-Kiefer. Georgia, Liebt feuchten Boden, Arkansas, Küsten von Delaware bis Ost-Texas, besonders Sandboden.

Bei uns kaum noch die Winter aushaltende, oft mit $\mathrm{P}$. rigida verwechselte, in der Heimat auf sumpfigen Böden vorkommende, $20-30 \mathrm{~m}$ hoch werdende Kiefer, bald hoch sich ausastend, mit erst glatter, dann tiefrissiger, grauer Rinde, weit ausladenden, rauhen, gelbrötlichen Ästen und Zweigen und langgespitzten, gelbbraunen, leicht harzigen Knospen.

Die hellgriinen, etwas steifen und abstehenden, kurzgespitzten Blätter sind imnen gekielt, außen fein gesägt, 16-20 (selbst 25) $\mathrm{cm}$ lang und fast $2 \mathrm{~mm}$ breit.

Abstehend oder nach unten gerichtet sind die stumpfeiförmigen, 8-10 cm langen und 3-5 cm dicken, hellbraunen Zapfen, deren rautenförmige, wenig erhabene Schuppenschilder deutliche Querleiste und kurz- aber scharfdornigen Nabel zeigen. Der große, rotbraune Samen hat gleichfarbigen, viermal längeren Fliugel.

Das breitsplintige, aber harzreiche Holz liefert gutes Bauholz, sowie Terpentin.

Pinus ponderosa Dougl. Gelb-Kiefer, schwere

Kiefer. Kalifornien bis Oregona. (Fig. 115.) In der Jugend empfindSyn.: Pinus Benthamianr Harter.

Ziemlich ippig wachsender, in der Heimat eminent hoch werdender, 60 ja $90 \mathrm{in}$ Höhe erreichender, etwa ab 8.-10. Jahr rasch wiichsiger, schöner,

(II ?) III lich; ebenso gegen starke kalte Winde im Winter. Lichtbedürftig. Leidet durch die Schuitte ziemlich stark. sehr starkstämmiger Baum, mit rotbrauner, dicker, rissiger, in großen Stiicken sich lösender Rinde, quirlig gestellten, wagrecht abstehenden, etwas hängenden und an den Spitzen wieder aufstrebenden Ästen, kräiftigen Zweigen und bräunlich-grünen, harzigen Trieben mit länglichen, plötzlich zugespitzten, harzigen, brïunlichen Knospen. 1520 , auch $25 \mathrm{~cm}$ lang und $1^{1 / 2}-2 \mathrm{~mm}$ breit werden die kräftigen, derben, ziemlich steifen, unten gekielten, gerlrehten, scharf spitzen, am Rand fein gesägten Blätter von dunkelgrỉner Farbe.

Die zu mehreren beisammen wachsenden, abstehenden oder etwas riickgebogenen, abgestumpft breit kegelförmigen, 


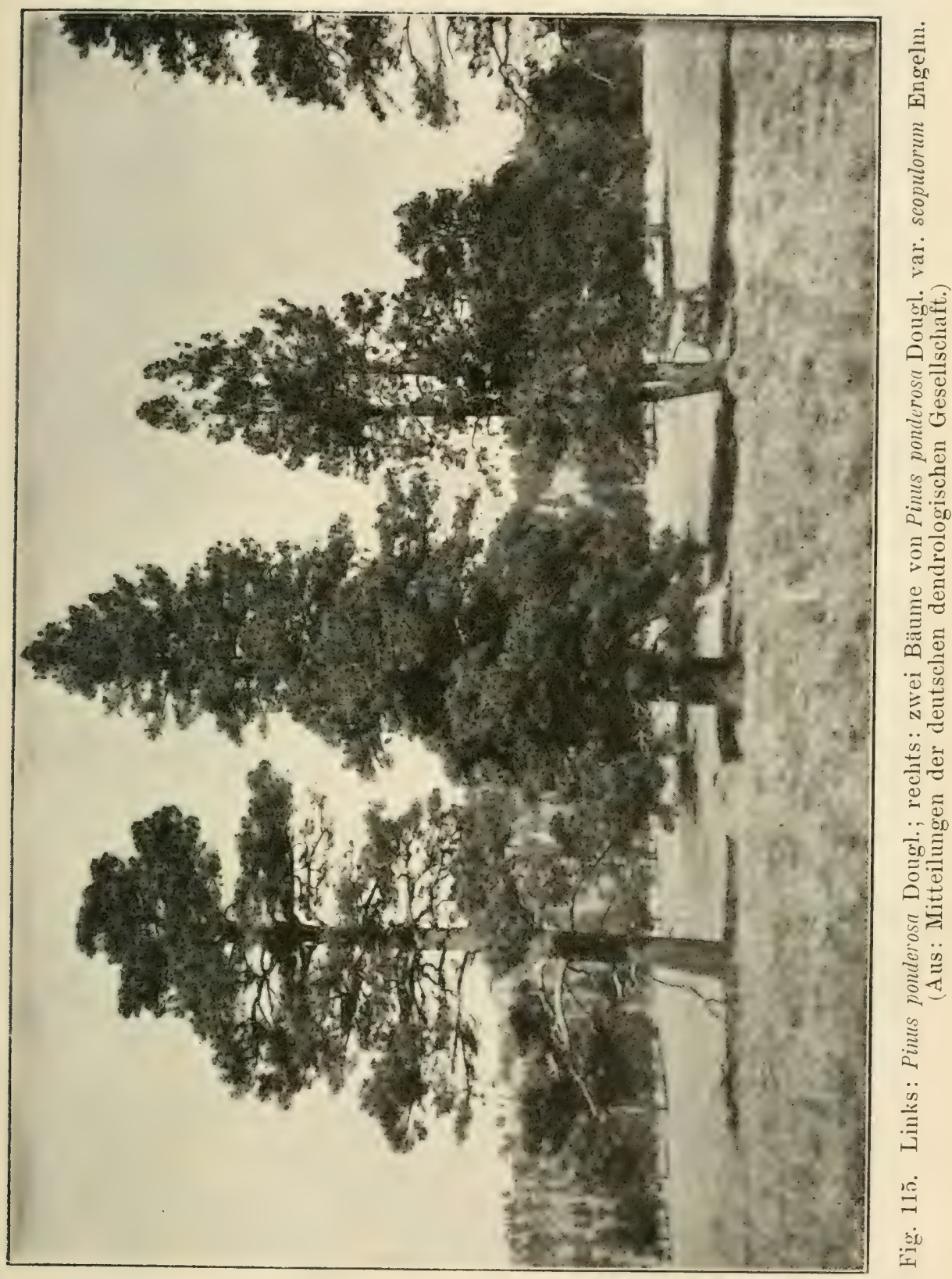


bramen Zapfen werden $7-11 \mathrm{~cm}$ lang, $3^{1 / 2}-5 \mathrm{~cm}$ dick und haben ungleich vierseitige, zieinlich erhahene, mit Querleiste und Linien, sowie mit stark einwiirts gekrümmtem, festem Dorn auscestattetem Nabel versehene Schuppenschilder. Der bis $1 \mathrm{~cm}$ arobe, dunkelbraune Samen hat dreimal längeren und iuber 1/2 cm breiten,den Samen zangenförmig ungebenden Flügel.

Als Formen gehen:

Pinus ponderosa Malletii Hort., schön und iippig wachsend, mit rötlicher, gefurchter Rinde. Ästen.

Pinus ponderosa pendula Hort. amer., mit stark hängenden

Eine Abart ist:

Pinus ponderosa var. scopulorum Engelm., vom Felsengebirge Nordamerikas. (Fig. 115.)

Syn.: Pinus scopulorum Lemm., welche nur bis $30 \mathrm{~m}$ hoch wird, aber widerstandsfähiger gegen Kälte ist.

Knospen braun, weißberandet, harzig, von Blättern etwas ceschiitzt. Blätter oft zu zweien stehend, diinner als bei der Art, z. T. gebuischelt, $8-16 \mathrm{~cm}$ lang.

Zapfen $5^{1} / 2-8(-10) \mathrm{cm}$ lang, granbraun, mit stark dornigem Schuppenschild, sowie halb so grołem Samen wie bei der Art, und $2^{1} / 2 \mathrm{~cm}$ großem Flügel.

Pinus deflexa Torrey. Gekrimmt-schuppige Kiefer. Kordilleren Kaliforniens.

Wohl kaum in Kultur befindliche, gradschaftige, glattrindige Kiefer, mit bis zu $18 \mathrm{~cm}$ langen Blättern und spitz-eiförmigen Zapfen, welche iibergebogene (deflexa) Schuppenschilder mit stark gekrümmtem, breitem, großem Nabel führen.

Pinus Jeffreyi Murr. Jeffreys Kiefer. Kalifornien bis Oregona.

II

Sehr schöner, ziemlich raschwüchsiger, an

Lockerer und feuchter, sandiger Boden.

den Boden wenig Anspruch stellender, in der Heimat bis $60 \mathrm{~m}$ hoher Baum mit fester, im Alter etwas rissiger, graubrauner Rinde, breiter Krone, weit auslegenden, starken Ästen, gelblichroten Zweigen und weißblau bereiften, wohlriechenden, jungen Trieben mit kräftigen, kurzen, hellrotbramen Knospen.

In langen Scheiden sitzen die charakteristischen, 10-15 (-20) cm langen, scharfgespitzten, feingesiagten, blau- bezw. graugruinen Blätter.

I)ie langen, biischelig stehenden Bliiten sind sehx auffällig.

Zu melneren beisammen und abwärts gerichtet zeigen sich die rund-kegelformigen, $12-18 \mathrm{~cm}$ langen und $7-10 \mathrm{~cm}$ dicken, hellbraunen Zapfen, welche stark erhabene Schuppenschilder 
mit langem, hakigem, riickwiirts gekrimmtem Nabeldorn fiihren. Samen $1 \mathrm{~cm}$ bis fast $1 \frac{1}{2}$ cm elof, dunkelbraun, mit zweimal lïngerem, den Samen zangenförmig umfassenden Fligel.

Das rosafarbige, mit breitem, gelblichem Splint versehene Holz gilt als gutes Bau- und Werkholz.

\section{fornien.}

Pinus Coulterii Don. Coulters Kiefer. Kali-

Imposanter, stark und pyramidalwiichsiger
IV

Bei gescliuitztem Standort, in lehmigem Boden.

Bamı, mit dicker, rauher, schwiirzlicher Rinde, wagrecht weit ausgebreiteten, quirlig gestellten Ästen, krïtigen, sehr rauhen, etwas steifen, graugriu-violetten Zweigen und lïnglichen, ฏroßen, lans und fein zugespitzten, harzigen, bramen Knospen.

Die zu dreien (selten zu 4-5) in langen, bramen scheiden steckenden, an den Zweigenden pinselartig zusammengedrängten, etwas spärlich vorhandenen, starr aufwärts gerichteten, gepreßten, stachelspitzen, feingesägten, meergriinen Blätter sind gefurcht und 20-25 (-30) cm lang, sowie $1-1 \frac{1}{2} \mathrm{~mm}$ breit.

Der gelbhraune, sehr harzige, länglich-kegelförmige, lange am Baum hängen bleibende Zapfen wird 25-30 (-38 cm in der Heimat) lang und 10-12 cm dick, hat keilfömige, kantige Zapfenschuppen und verdickte, hoch erhabene Schuppenschilder, mit stark gekriummtem und scharfgespitztem Dorn. Der efbare, braune, doppelt so lange als breite Samen hat kurzen, den Samen zangig umfassenden Flügel.

Pinus Sabiniana Dougl. Sabin's Kiefer, Nußkiefer, TVeißkiefer. Nordwest-Amerika, spez. $\begin{gathered}\text { Junge Pflanzen } \\ \text { empfindlich. Melr }\end{gathered}$ Kalifornien.

Prächtige, charakteristische, gerad- aber trockenen als feuchten Standort, doch feuchte Luft. oft doppeltschaftige und tiefheastete, pyramidalwiichsige Kiefer mit tiefrissiger, rothrauner Rinde, starken, aber licht gestellten Ästen und bläulich-grünen Zweigen, sowie kegelförmigen, kleinen, lang zugespitzten, harzigen Knospen. Austrieb griubereift.

Die zu dreien - selten zu vieren - in brauner, zuriickgerollter Scheide steckenden, bliulich- bis graugrinen, diinnen, meist etwas schlaffen, teilweise gedrehten, kantigen, feingesïgten Bliitter sind scharf gespitzt, 22-30 $\mathrm{cm}$ lang und $11 \%$ mm breit.

Zapfen prächtio, braun, harzig, lang restielt und hängend, von rundlich-eiförmiger Gestalt, $15-25 \mathrm{~cm}$ lang und $10-15 \mathrm{~cm}$ dick; derselbe führt hoch erhabene Schuppenschilder mit sehr starkem, gebogenem, kantigem, langem und scharfem Stachel. Der längliche, braune, eßbare, bis 3 cm grobe Samen hat kaum halb so lang'en Flügel.

Pinus Mayriana Sudworth. Mayr's Kiefer. Siid-Arizona. 
In unseren Kulturen wohl noch nicht vorhandene, (vor etwa zwanzig Jahren aufgefundene), bei $20 \mathrm{~m}$ hoch werdende Kiefer, mit dunkelbrauner, dicker, tiefrissiger Rinde und festen, gedrehten Ästen. Die Schuppen der Knospen sind zurückgerollt. gestellt.

Blätter $30-40 \mathrm{~cm}$ lang, an den Zweigspitzen pinselartig

Der braune, 8-14 cm lange, eiförmige Zapfen hat nach außen gekrümmte Schuppenschilder mit starkem, kegelförmigem, kurzdornigem Nabel. Der Samen zeigt breiten und $2 \mathrm{~cm}$ langen, hellbraunen Flügel.

Leider noch ungenügend bekannte Art.

Pinus Engelmannii Carr. Engelmanus Kiefer.

\section{N.-Hexiko.}

Ebenfalls wohl kaum in unseren Baumschulkulturen befindliche, auch kaum ausdauernde, 20-25 m hoch werdende Kiefer, mit 3 (-5) ziemlich hlaugriunen, feingezähnten, $30-40 \mathrm{~cm}$ langen, an den Zweigspitzen dicht stehenden Blaittern und $14 \mathrm{~cm}$ langen Zapfen, deren kegelförmige Schuppenschilder kräftige, stark zurückgebogene Dornen zeigen.

Pinus Torreyana Parry. Torrey's Kiefer.

Suid-Kalifornien.

Bei geschütztem Stand, in sandigem Lehmboden.

In Deutschland kaum oder nicht winterharte, bis $10 \mathrm{~m}$ hoch werdende Kiefer, mit erst glatter, dann schuppiger, grauer Rinde, reicher Beastung, weißlich bereiften, langknospigen Trieben und sehr kriftigen, gepreßten, am Rande fein gesägten, stachelspitzigen, dunkelgrinen Blättern, welche eine Linge von 20-30 $\mathrm{cm}$, eine Breite von $2 \mathrm{~mm}$ erreichen, und gegen die Zweigenden dichter in den bis zu $4 \mathrm{~cm}$ langen Scheiden stecken. Junge Pflanzen führen drei, ältere jedoch fünf Blätter in einer Scheide.

Der langgestielte, abstehende oder ziemlich hängende Zapfen wird $10-13 \mathrm{~cm}$ lang, $9 \mathrm{~cm}$ dick, ist stumpf zugespitzt, glänzend braun und hat pyramidal-erhabene, etwas seitlich gepreßte Schuppenschilder mit festem, einwärts gebogenem Nabelfortsatz. Der $2-2^{1} / 2 \mathrm{~cm}$ grofje, bräunliche, efbare Samen zeigt einen ganz kurzen, den Samen umschließenden Fliigel.

Pinus arizonica Engelm. Arizona-Kiefer. SiidArizona, Nord-Mexiko.

Wohl in unseren Baumschulkulturen noch nicht befindliche, kaum ausdanterude, 30 m hoch werdende, dunkelgrau-rindige, ziemlich starkästige Kiefer, mit jung hell-blauweiß bereiften Zweigen, hellbraunen, schmalen Knospen, sowie 5(!) (sie ist also 
Übergangsform zur nichsten Abteilung') bei 10-17 cm langen und $1 \mathrm{~mm}$ breiten, dunkelgriunen Blättern.

Der kleine, dunkelviolette, stumpf kegelige, $6 \mathrm{~cm}$ lange und $3^{1 / 2}$ (offen 5) ('m dicke Zapten hat feinrissige Schuppenschilder mit dornigem Nabel.

Pinus Chilıuahuana Engelm. Chilıuahua-Kiefer. Arizona, Neu-Mexiko, Nord-Mexiko.

Schon seit ca. 60Jahren bekannte, aber in unseren Baumschulen nicht (oder kaum) vorhandene, weil kaum winterhart, der Pinus inops ähnliche, in der Heimat $25 \mathrm{~m}$ hoch werdende, reichästige Kiefer, mit dunkelgrauer Rinde, oft knieförmig aufgebogenen Ästen, glattrindigen, glïnzend gelblichen Zweigen und braunen, spitzen Knospen.

Die zu drejen, selten zu vieren beisammenstehenden, sehr diunnen, aber etwas starren, an Rande fein gesägten, hellgrinen, innen mehr grauen, zugespitzten Blätter werden 10-12 cm lang und stecken in bald abfallender Scheide.

Der eiförmige, zugespitzte, $5-6{ }^{1} / 2 \mathrm{~cm}$ lange und unten $3^{1 / 2} \mathrm{~cm}$ dicke, gelbliche Zapfen hat etwas weißlich-gelbe, nur im jungen Zustande bedornte Schuppenschilder. Der eiförmige Samen führt dreimal längeren Flügel.

kalifornien.

Pinus insignis Dougl. Monterey-Kiefer. Suid-

\section{Syn.: Pinus radiata Don.}

\section{" tuberculate Don., nicht Gord.}

VI

Jung empfindlich.

Schutz gegen kalte

Winde. Boden- und

Luftfeuchtigkeit ist vorteilhaft.

Noch sehr selten in Kultur befindliche, schöne, gutwiichsige, reichästige und pyramidalförmig wachsende, in der Heimat bis 30 m hoch werdende Kiefer, mit rissiger, dicker, grauer Rinde, unregelmäßig gestellten Ästen, glatt und braunrindigen, dicht stehenden $\mathrm{Z}$ weigen mit langen, braunen Línospen.

Die zu dreien, selten zu vieren beisammenstehenden, dicht gestellten, lebhaft grimen, z. T. gedrehten, am Rande fein gesägten, kantigen, spitzen Blätter werden $10-14(-16) \mathrm{cm}$ lang und $1 \mathrm{~mm}$ breit.

Zu mehreren beisammen hängen die lange am Baume bleibenden, eiförmigen, zugespitzten, auffallend schiefen, braunen Zapfen, welche $8-15 \mathrm{~cm}$ lang, $5^{1 / 2}-8 \mathrm{~cm}$ dick werden und an der gekrümmten Außenseite erhabene, dicke, länglich, viereckige, kurzbedornte Schuppenschilder fiihren, welche auf der ZapfenInnenseite flach gebildet sind. Der schwärzliche, etwas rauhe Samen hat dreimal längeren Flügel.

Das Holz ist als Bau- und Werkholz gesucht.

Als Abart mit nur zwei Nadeln in der Scheide wird genannt: 
Pinus insignis var. binata Palmer, von Guadeloup stammend, welche als etwas winterhiirter (IV?) bezeichnet wird.

\section{Pinus tuberculata Gord. Höcker- oder Warzen-} kiefer. Kalifornien.

Zur Zeit wohl kaum in unseren Baumschulkulturen vorhandene, langsam wiichsige, bis 6 , höchstens $10 \mathrm{~m}$ hoch werdende, kegelförmig wachsende Kiefer, mit diunner, gelbbrauner Rinde, bräunlichen, langen, spitzen, kaun beharzten Knospen und dumkelgrimen, starren, am Rande fein gesïgten, kantigen, 10 bis $20 \mathrm{~cm}$ langen und $1-1^{1 / 2} \mathrm{~mm}$ breiten Blättern.

Reichlich erscheinen die lange am Baume hängenden, stark gekruimmten, länglich-kegelförmigen und zugespitzten, harzigen, gelbbramen, ins Graue ibergehenden Zapfen, welche $8-14 \mathrm{~cm}$ lang, 5-6 cm dick werden und an der gekriummten Seite erhabene, höckerige (kantige), imen aber flache, mit kurzen, spitzen Dornen ausgestattete Schuppenschilder zeigen, sowie kleine, schwärzliche, mit schwach dreimal liangerem Fliigel ausgestattete Samen führen.

Das rote Holz findet reichliche Verwendung.

Pinus Gerardiana Wail. Gerards Kiefer. NordAfghanistan, Kafiristan, Nordwest-Himalaya.

Fiir unser deutsches Klima nicht, oder kaum in Betracht kommende, 10-20 in hoch werdende, etwas langsam wiichsige Kiefer, mit sich ablösender, silbergraner Rinde, oben aufstrebenden, wnten mehr flachstehenden, kurzen Ästen und hellbraumen, bereiften Zweigen, sowie spitzen, kegelfömigen, harzigen, bramen Knospen.

Die starren, kantigen, am Rande f'ein gesägten, spitzen Blätter sind blaugriin und werden $6-9(-10) \mathrm{cm}$ lang.

Der rotbraune, harzige, länglich-eiförmige Zapfen wird 12 bis $20 \mathrm{~cm}$ lang und $7-11 \mathrm{~cm}$ dick und fiihrt ganz dicke Schuppen mit stark zuriickgebogenen Schildern, welche Querleiste und stachelspitzen, eckigen Höcker zeigen. Der wohlschmeckende, ef3bare, Öl liefernde Samen wird $2 \frac{1}{2} \mathrm{~cm}$ lang und hat kurzen, abfallenden Fliigel.

Diese Art liefert aufierdem Harz, feinen Terpentin, sowie ein gut verwendbares Holz.

Pinus Bungeana Zucc. Bunges Kiefer. Chinesische Silberkiefer. Nord-China.

IV (III?)

Syn.: Pinus excorticata Hort.

Bei uns inmer noch selten anzutreffende, wenn auch schon seit iiber 60 . Jhren bekannte, 20-25 m hoch werdende Kiefer, unit glatter, sich lösender und abstofender, grauer, unten weißer 
Rinde, langen, dimnen Isten, grau-bis gelbgriinen Zweigen und großen, rötlich-braunen Knospen.

Die in kurzen Scheiden steckenden, dicken, starren Blätter' sind kantig, spitz, hellgriu, 7--9 $\mathrm{cm}$ lang.

Der eiformige, 5--6 cm lange und $3{ }^{1}$ an dicke, hraune Zapfen hat oben verbreiterte Schuppen, deren flach-vierseitige Schilder eine kantige ( uerleiste, sowie einen kleinen, nach riickwäts hakenförmig gebogenen Dorn fïhren. Samen ełhar, $1 \mathrm{~cm}$ groß, mit ganz kurzem Flügel.

Das harzreiche Holz findet gute Verwendung.

Pinus Parryana Engelm. Parry's Kiefer. Siul-Kalifornien, Nieder-Kalifornien.

V

Mehr trockenen als feuchten Standort.

Syn.: Pinus quadrifolia Sudw.

Selten in Kultur betindliche, langsam wiichsige, kleine, nur 6-9 m hoch werdend, oder strauchig wachsende, reichästige Kiefer, mit quirlig gestellten, ziemlich wagrecht abstehenden Ästen und Zweigen, starren aber zarten, dreikantigen, scharf gespitzten und gesägten, dunkelgrinen Blättern von nur $3-4 \mathrm{~cm}$ Länge, zu dreien, vieren, selten zu fünfen in schwärzlicher, kurzer Scheide steckend.

Der hängende, glänzendgelbe, länglich-kugelige Zapfen wird $4-5^{1}$. $\mathrm{cm}$ lang bei $4 \mathrm{~cm}$ dick und führt rhombische, hocherhabene, sowie riickwïrts gebogene Schuppenschilder mit kurzer, gerader Spitze. Der eßbare, hellbraune Samen wird bis $2 \mathrm{~cm}$ groß und zeigt kurzen, graubraunen Fluigel.

Pinus edulis Engelm. Nußkiefer. Arizona, Neu-Mexiko, Colorado.

(V1?)

Trockener Standort, dabei sonnig, kalkhaltig.

In Deutschland nicht besonders winterharte, 3-6 m hoch werdende, langsam wiichsige, breitkronige Kiefer, mit grangrimen Zweigen, derben, steifen, scharfgespitzten, unterseits oriuen, oberseits blaugrünen, $3^{1} / 2(-4) \mathrm{cm}$ langen und bis $1^{1}, 2$ mm breiten Blättern, welche zu dreien (oder zu zweien) in ganz kurzer Scheide sitzen.

Del glïnzendgelbe, rundliche, $4 \mathrm{~cm}$ lange und $3_{1,2}^{1 /} \mathrm{cm}$ dicke Zapten hat vierkantige, dicke, oben gestutzte und riickgebogene Schuppenschilder mit Querleiste und niedergedriicktem Nabel.

Der efbare, längliche, gebogene, braune, ungefligelte Samen, ..Pinon" genamnt, ist $10-11 \mathrm{~mm}$ lang und $7-8 \mathrm{~mm}$ dick, und in der Heimat als wichtiges, besonder's in gerösteten Zustand angenehm schneckendes Nahrungsmittel sehr geschiitzt. Ebenso ist das harzieiche Holz in starker Verwendung. 
Pinus osteosperma Engelm. Stein-Kiefer. Arizona, Mexiko.

VI

Trockener Standort.

Syn.: Pinus cembroides Gord. nicht Zucc.

\section{Llaveana Schicde und Deppe.}

Sehr selten in unseren Baumschulkulturen befindliche, 8 bis $10 \mathrm{~m}$ hoch werdende Kiefer, mit ziemlich glatter, grauer Rinde, quirlig und dicht gestellten, weit ausladenden Ästen und steifen, etwas gedrehten, scharfgespitzten, dreikantigen, lebhaft grïnen bis bläulich-grimen, $3-4 \mathrm{~cm}$ langen und bei $1 \mathrm{~mm}$ dicken Blättern, welche manchmal auch nur zu zweien in einer Scheide stecken.

Der glänzendbraune, breit-eiförmige, $3-5 \mathrm{~cm}$ lange und $3-4 \mathrm{~cm}$ dicke Zapfen hat rautenförmige, erhabene Schuppenschilder mit kräftiger Querleiste und breitem, gedrücktem, stumpfem Nabel, sowie schwärzlichen, eiförmigen, in harter Schale steckenden, eßbaren Samen, welcher $1^{1 /}, 2 \mathrm{~cm}$ lang, 8 bis $9 \mathrm{~mm}$ breit wird und flügellos ist.

Pinus monophylla Torr. u. Frem. Einblätterige Kiefer. Kalifornien, Nevada, Süd-Utah, Arizona.

Syn.: Pinus Fremontiana Endl.

V (IV ?)

Jung empfindlich. Auf sonnigem, trockenem, kalkhaltigem, sandigem Boden.

Ebenfalls selten in unseren Baumschulkulturen zu findende, bei $6-8$ m hoch werdende, langsam wiichsige Kiefer, mit jung glatter, alt gesprengter, grauer Rinde, dicht stehenden Ästen und Zweigen, sowie dünnen Knospen.

Blätter einzeln stehend, (die einzige Kiefer, deren Blätter anatomisch einen einheit lichen, runden Körper zeigen, da bei den iibrigen Arten innere Verwachsungen nachzuweisen sind', selten zu zweien oder dreien in der Scheide, steif, glatt, blaugrün, von $4-7 \mathrm{~cm}$ Länge.

Die zahlreich erscheinenden, glänzend braunen, rundlichen, 4-7 cm langen und ziemlich gleichbreiten Zapfen haben dicke Fruchtschuppen und ebenfalls dicke, erhabene, nach riickwärts gebogene Schuppenschilder mit Querleiste und abgestutztem Nabel. Der in der Heimat als Nahrungsmittel, "Pinon", hochgeschätzte, dickschalige, ovale, gelbbraune Samen wird $1^{1 / 2}$ bis fast $2^{1} / 2 \mathrm{~cm}$ lang und ist ungefligelt. Das sehr harzreiche Holz ist gesucht.

Zwei weitere, im Samenhandel öfters angebotene, in unserem Klima absolut nicht winterharte Kiefern sind:

Pinus canariensis Chr. Smith, Kanaren-Kiefer. Eine auf den Kanarischen Inseln vorkommende, prächtige Kiefer, mit glänzend blaßgriinen, 20-27 cm langen, diinnen, hin und her gebogenen Blättern, sowie $17 \mathrm{~cm}$ langen, hängenden, höckerigen, glänzend-braunen Zapfen. 
Das harzreiche, danerhafte $\mathrm{Holz}$ soll von Insekten nicht angegriffen werden.

Pinus Iongifolia Roxb. Langnadelige oder Emodi-Kiefer.

Vom Himalaya stammende, prachtvolle Kiefer, mit tiefrissiger, bramer Rinde, weit und wagrecht stehenden Ästen, $15-25 \mathrm{~cm}$ langen, glänzend hellgriuen, dimmen Blättern und 12-18 cm langen, kegelförmigen, braunen, harzigen Zapfen mit harten, hakigen Fruchtschuppen und eßbaren Samen.

Neben einem besonders bei 'Trockenbau verwendbaren, harzreichen Holz liefert diese Kiefer reichlich Terpentin und Teer.

Weitere zu dieser Abteilung gehörende, zum Teil als zum Anbau versuchswiurdig bezeichnete Kiefern, wie z. B.

Pinus yünnanensis Franchet und

Pinus luchuënsis Mayr, beide aus China; ferner

Pinus Nelsonii Shaw aus Nordost-Mexiko, sind wohl alle fïr dentsches Klima nahezu unbrauchbar.

\section{Abteilung: Cembra Spach.}

Quin a : Blätter zu fiinf in einer gemeinschaftlichen Scheide. Zapfen eiförmig oder verkiurzt zylinderisch, a u f r e cht oder doch abstehend!, mit holzig-korkigen, nach der Nitte zu leicht verdickten Schuppen und dreieckigem, unbewehrtem Nahel. Samen meist ungefligelt.

Pinus Cembra L. Zirbel (Zürbel), Zirbelkiefer, Zirme, Arve. Alpen, Karpathen, Nord- In Höhenlagen und bei Rußland, Nord-Sibirien, Ural, Altai.

Eine schïne, an die Strobe ering zum Boden beastete, $10-20 \mathrm{~m}$ hoch werdende, meist langsam wachsende Kiefer, mit erst glatter, grangriner, später warziger und graubrauner Rinde und dicker, ebenfalls graubramer, rissiger Borke, mehr oder minder eiförniger Krone, starken, quirlig gestellten Ästen, charakteristisch mit rostfarbigem Filz (!) bedeckten Zweigen, deren Knospen rundlich, doch lang zugespitzt sind und bramrote, oben gedrehte Schuppen fiihren. Blätter zu fiunfen, selten zu vieren oder dreien, kantig, fein gesägt und gespitzt, 5-8 cm lang, lebhaft griu, anf der Innenseite weißlich. (Fig. 116 und 117.)

Ebenfalls charakteristisch ist der anfrecht stehende, erst violette, dann hellbrame, dick-eiförmige Zapfen von $6-8 \mathrm{~cm}$ Länge (oft noch länger) und $5 \mathrm{~cm}$ Dicke, mit länglich viereckigen, dicken, leicht runzeligen, an Rande etwas rïckebogenen und mit leicht abstehendem Nabel versehenen Schuppen- 
schildern. In harter, bräunlicher Schale stecken die flügellosen, nur mit schmalem Hautstreifen ausgestatteten, kantig-eiförmigen,

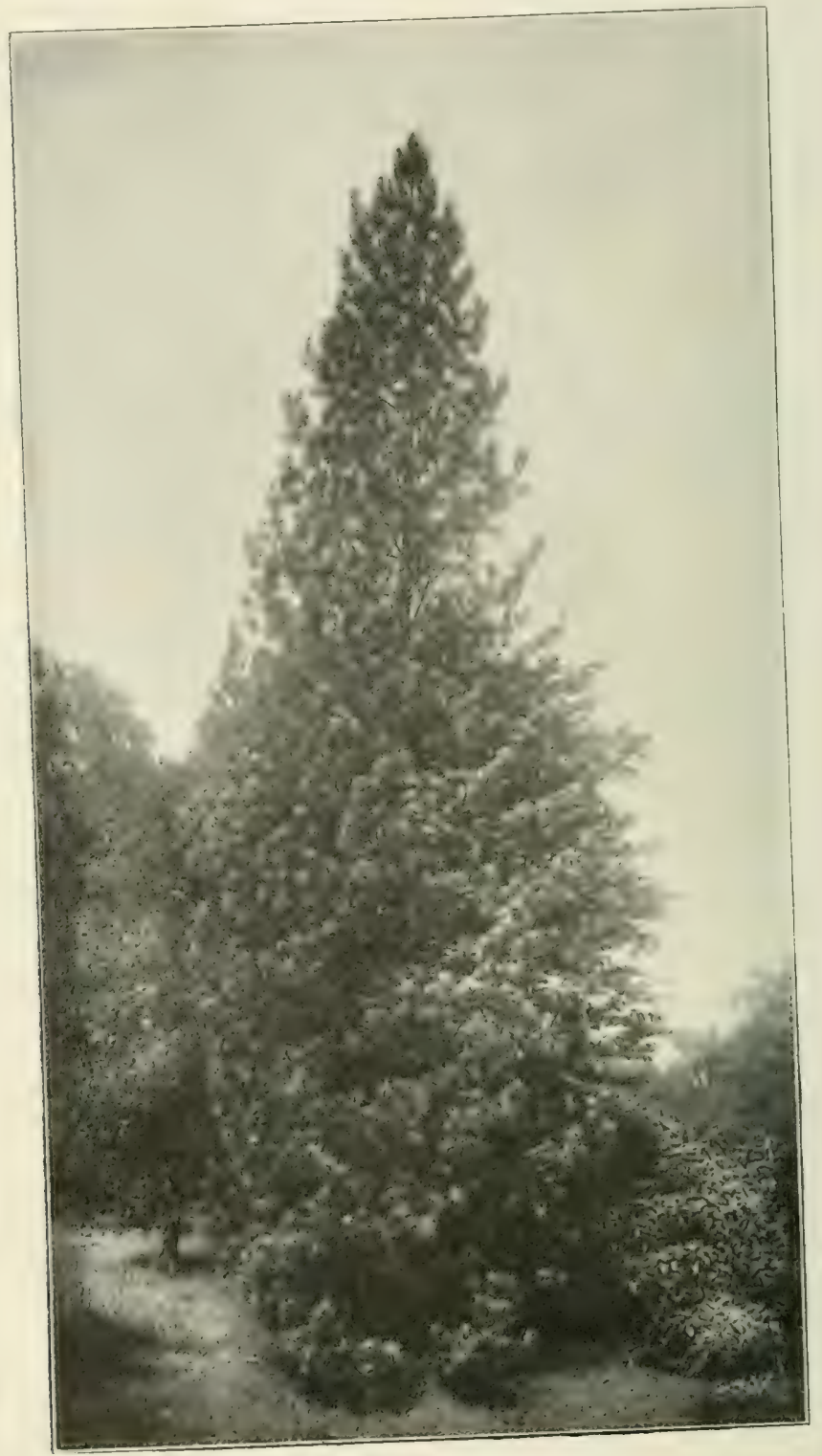

Fig. 116. Pinus Cembra L. (Etwa 40jähriger Baum.) 


\section{$-227-$}

$12 \mathrm{~mm}$ langen und $6-7 \mathrm{~mm}$ breiten, ełbaren, wohlschmeckenden Samen, Zirbelniisse, Piniolen genannt. (Dieselhen enthalten bis $56 \%$ fettes 0 l [das offizinell ist gegen Lungenkrankheiten und

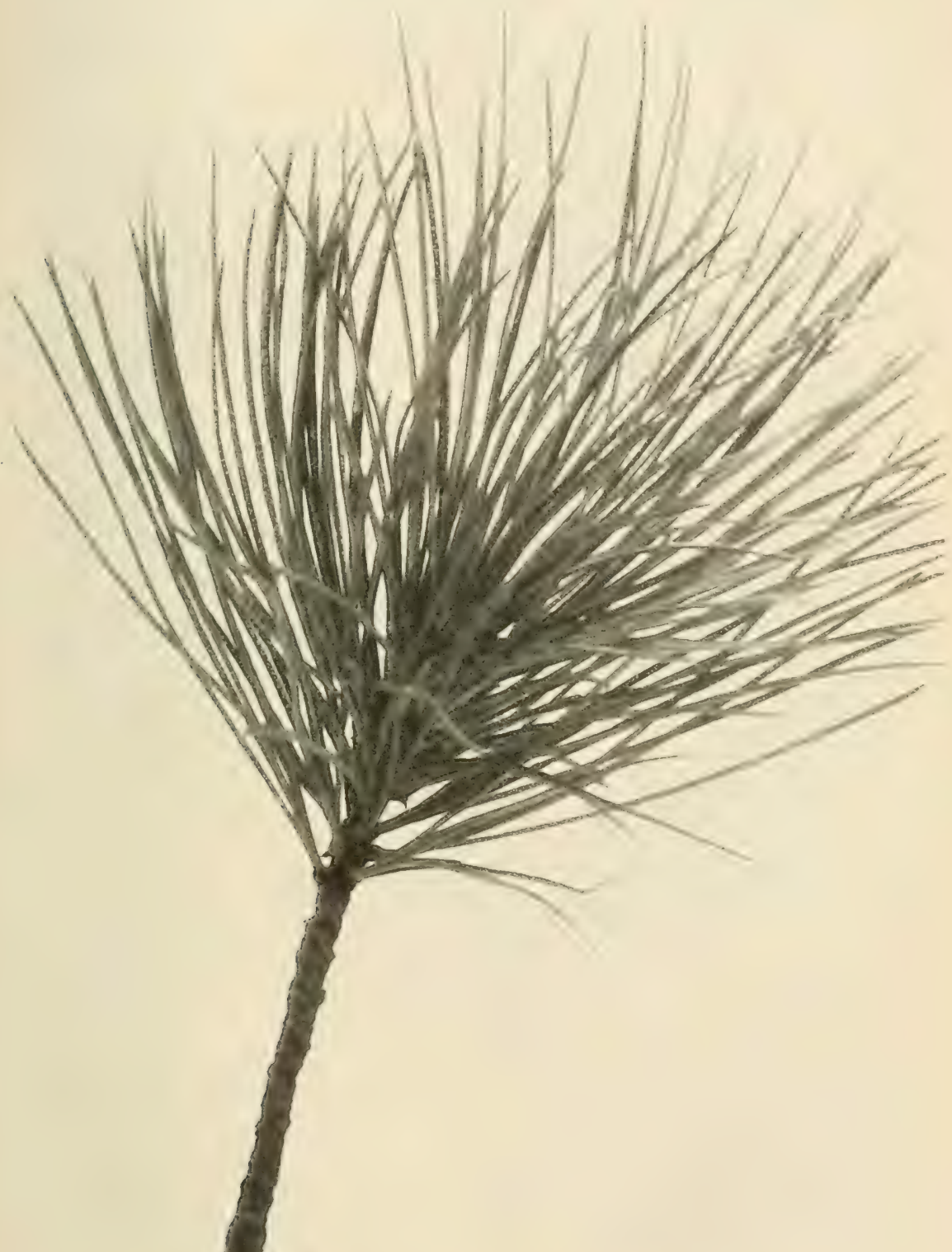

Fig. 117. Trieb von Pinus Cembra L. 
Skorbut], 4,3"0 Zucker, Amylon und 6\% Albuninsubstanzen.) Frischer Samen keimt sofort, d. h. einige Wochen nach der. Saat, älterer nach einem Jahr. Auffallend sind auch die mit 5 cm langen, dreieckigen, gesägten Keimblättern, sowie zweiseiti@gesägten Erstlingsblätternausgestatteten, jungen Pfänzchen.

Das auben gelbe, innen rotbraune, zu Schnitzereien, Möbel u. s. w. vorziiglich geeignete Holz ist harzlos und wohlriechend.

Prächtig sind die Zirbeln der Alpenländer, welche, oft vom Sturm des ersten Gipfels beraubt, nun inehrere Gipfel bei breiter Krone zeigen.

Formen sind:

Pinus Cembra monophylla Car'r, die einblätterige Zirbel, welche Form als zwergiger Strauch und bei langsamem Wuchs ein "Terwachsen" der fiinf Blätter" zu einem Blatte zeigt, aber" bei stärkerem Wuchs wieder fünfblätterig wird.

Pinus Cembra chlorocarpa, grủnzapfig.

variegata Hort. Forst., mit teils gelb gestreiften, teils ganz gelben Nadeln.

Pinus Cembra sibirica Hort, sibirische Zirbel, von Sibirien, mit kräftigerem Wuchs, etwas kiirzeren Blättern, dagegen länglichem, mehr walzenförmigem Zapfen als bei der Stammform, sowie größerem Samen. Ob Varietät?

\section{Syn.: Pimus sibivice Mreyr.}

Pinus Cembra forma nova Sr., volt zylinderischem Wuchs, mit bläulichen, un die Endknospen geneigten Nadeln, sowie konischen Zapfen.

Pinus Cembra columnaris Beißn. Säulenzirbel.

Syn.: Pinus Cembra compacta pyramidalis Hort. Hellem.

Schöne, dichtzweigige Säulenform mit senkrecht aufstrebenden Ästen.

Pinus koraiënsis Sieb. u. Zucc, Korea-Kiefer. Mandschurei, Kíorea, Mittel-Japan. (Fig. 118.) Liebt Seitenschutz und

Syn.: Pinus mandschurica Rupr. $\iota$. Regl.

Prächtige bis $40 \mathrm{~m}$ hoch werdende Kiefer Idas hiesige Tüibinger, etwa 35jährige Exemplar ist iiber $8 \mathrm{~m}$ hoch, ohne je gefruchtet zu lockeren Boden. Ist besonders in der Jugend gegen kalte Winde und starke Sonnenbestrahlung empfindlich.

hahen!), mit ziemlich slatter, schwarzbraner, dann schuppiger Rinde, dicht und quirlig gestellten, erst aufstrebenden, damn wagrecht auslegenden Ästen, sowie aufstrebenden, brämlichgriinen Zweigen und griunlich-rothranen, weichhaarigen Trieben, mit langen, cerwissermatien lockeren, hellbrannen Knospen.

Die dreikantigen, stumpfgespitzten, auben feingesägten, sminen, innen bläulichweifen, etwas wirr stehenden Blätter werden $8-9 \mathrm{~cm}$ lang bei $1 \mathrm{~mm}$ Breite. 
Wohl nur an ziemlich älteren Pflanzen zeigen sich die ganz charakteristischen, stumpt-zylinderisch geformten, locker gehauten, $10-15 \mathrm{~cm}$ langen und $5-T$ cm dicken, gelhbramen Zapfen mit keilförmigen Schuppen, welche stark wellige, rick-

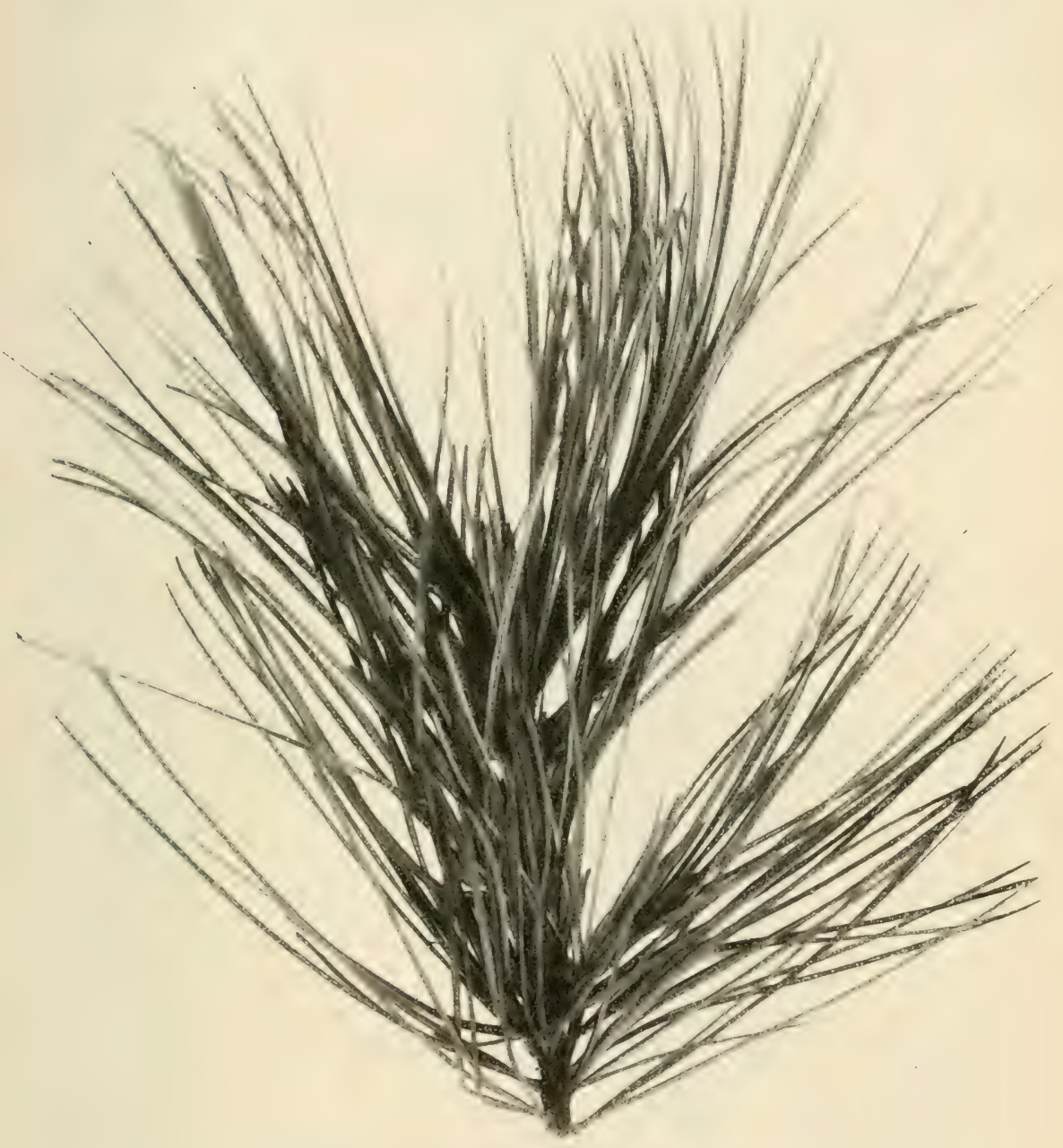

Fig. 118. Finus koraiënsis Sieb. u. Zucc.

sebogene (!), rhombische, gestreifte und runzelige Schiller zeigen, deren Enden breit ansgezonen sind. Der zienlich eiförmige, statt des Flügels eine scharfe Fiante tiihrente, eßbare Samen ist graubraun gefärbt. 
In Japan eine beliebte Zierkiefer, von der es auch - bei uns wohl noch nicht in Baumschulkultur befindliche - Formen gibt, z. B.:

Pinus koraiënsis variegata, mit gelbbunten Nadeln. $" \quad$ tortuosa, mit gedrehten Blättern.

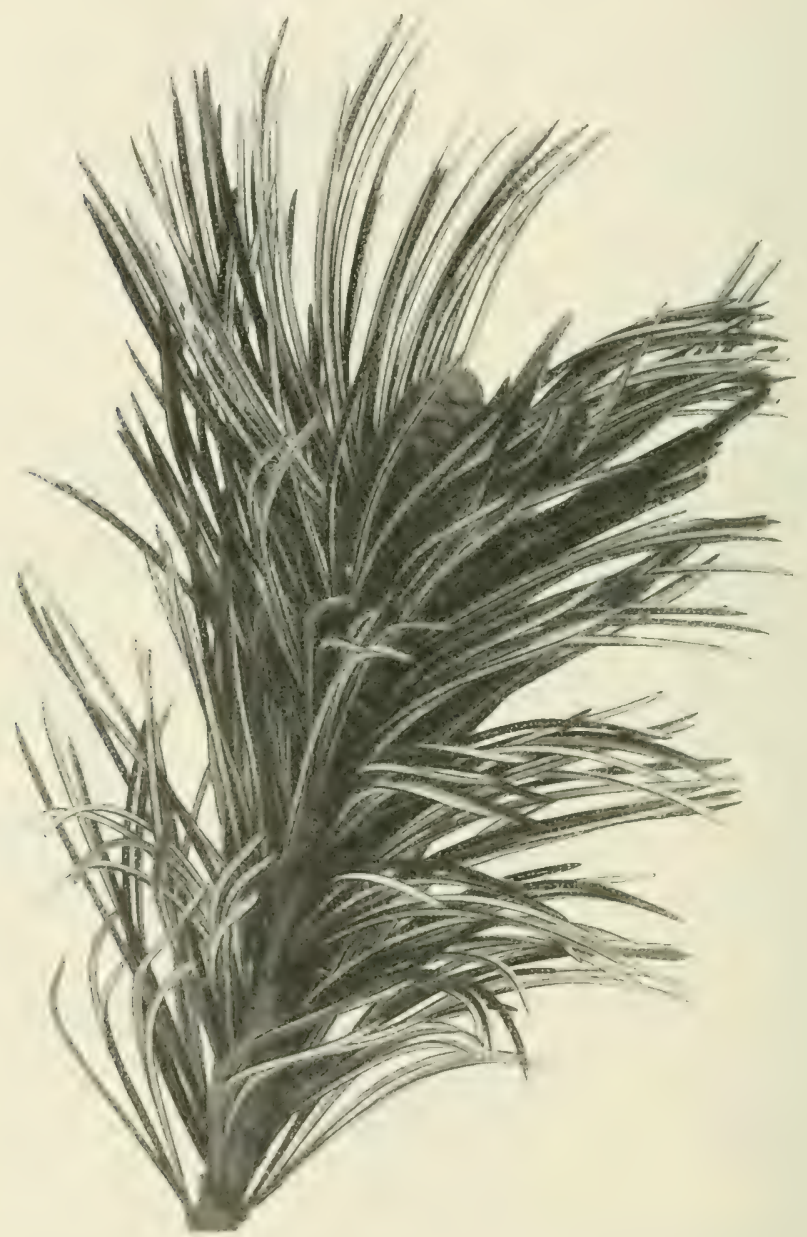

Fig. 119. Pinus parciflora Sieb. u. Zucc. (mit Zapfenansatz)

Pinus parviflora Sieb. u. Zucc. Kleinbliitige oder Miidchen-Kiefer, Nördliches Japan (Fig. 119). Auf melır trockenem

Noch selten in unseren Baumschulkulturen (Lehm-)Boden.

zu findende, bei $30 \mathrm{~m}$ hoch werdende, nicht sehr raschwiichsige, glatt und dunkelgrau-rindige Kiefer, mit wagrecht 
ausliegenden, dimen Ästen, helleranen Zwoigen mol nriinlichhräunlichen, kurzbehaaten, jungen Trieben, sowie längliehen, hellbräunlichen Knospen.

Die dichtstehenden, diinnen, dreikantigen, trils wehogenen und gedrehten Bläter sind spit\%, an Rande gesiigt, 2-5 cm lang und $1 \mathrm{~mm}$ breit, oben griun, unten weißlichblau.

Der nicht anfrechte, sondern ziemlich abstehende, bramrote, $4-7 \mathrm{~cm}$ lange und $3-4 \mathrm{~cm}$ dicke, länglich-eifömige Zapfen hat dicke, grobe, breit-krilformige Schuppen mit am Fnde cinwiirts (!) gekrimmten, wellig gerandeten schildern. Jer hartschalige, efbare, schwärzliche, lingliche, bis über 1 cm grofie Samen ist kaum geflügelt.

In der Heimat ist diese Art als Zierm und Alleenbaum, damn aber auch als 'T'opf-Zwergbaum sehr beliebt.

Formen sind:

Pinus parviflora variegata, gelbbunthlitterig. brevifolia, mit feinen, halb so langen Nadeln. tortuosa, mit stark gedrehten Nadeln.

Pinus pumila Mayr, Zwerg-Kiefer. NordostNibirien, Kamtschatka, Kurilen, Sachalin bis mittleres I (?) Japan.

Syn.: Pinus Cembra var. pumila Pull.

Nur bis $4 \mathrm{~m}$ hoch werdende, strauchartige Kiefer, mit langen. dem Boden aufliegenden Ästen, deren Spitzen sich wieder erheben, sowie erst griunen, damn rothrannen Zweigen und dreikantigen, etwas gedrehten, ziemlich dem 'T'riebe anliegenden, feingesägten, spitzen, $5-6(-7)$ cm langen, griun und weiblichen, ziemlich dichtstehenden Nadeln.

Der länglichrunde, $3^{1} / 2-4^{1} / 2 \mathrm{~cm}$ lange und $2^{1 / 2} \mathrm{~cm}$ dicke, griugraue Zapfen hat scharfrandige sehuppen mit rötlichgranen Schildern, deren Nabel stark und spitzig ist, sowie efibare, his $1 \mathrm{~cm}$ lange und $7 \mathrm{~mm}$ breite, nur mit einem Flügelrand versehene Samen.

Eine Form ist:

Pinus pumila brevifolia, mit ziemlich kiirzeren Nadeln.

Pinus flexilis James. Biegsame Kiefer. Kalifornien bis Montana und Neu-Mexiko.

Etwas langsamwichsige, bei $15 \mathrm{~m}$ hoch werdende, graumul furchigrindige Kiefer, mit rundlicher Krone, starken, etwas gredrehten und anch ïberhängenden Ästen, sovie sehr biegsamen Zweigen.

Die etwas steifen, stumpferespitzten, dreikantigen, auch gekrimmten Blätter sind $4-6 \mathrm{~cm}$ lang, lebhaft grün. 
Der leicht hängende (!), liinglichovale, $8-14 \mathrm{~cm}$ lange und bei 5-T cm dicke, glänzend-hellbraune, harzige Zapfen hat keilförmige, dicke, harte Schuppen, mit dicken, erhabene'n, quergekielten, zum Teil etwas riickwärtsgekrimmten, kur\%-, breitund gebogennabeligen Schildern. Der eßbare, bis $1 \frac{1}{2} \mathrm{~cm}$ lange Samen zeigt einen winzigen, an der Schuppe bleibenden Fligel.

Das weiße, schwere Holz ist besonders bei Tiefluanten von großem Wert.

Pinus albicaulis Engelmann, Weißstämmige Kiefer. Sierra Nevada Kaliforniens, Britisch Kolumbien, Montana (Fig. 82).

Noch sehr selten in Kultur befindliche, in der Heimat 12-15 m hoch werdende, jung, diinn- und weiBlich-, alt schuppig-rindige Kiefer, mit steifen, dreikantigen, teils gebogenen, stumpfgespitzten, $4-5^{1 / 2} \mathrm{~cm}$ langen und bei $1 \mathrm{~mm}$ dicken Blättern.

Zapfen rot- bis purpurbraun, länglichrund, $4-8 \mathrm{~cm}$ lang und 4-6 cm dick, mit ganz dicken, keilförmigen Schuppen und zugespitztem Schildnabel. Der eßbare Samen ist fligellos.

Pinus reflexa Engelm. Haken-Kiefer. Südliches Neu-Mexiko, Arizona.

Noch nicht genau bekannte, in ihrer Heimat bis notwendig.

$30 \mathrm{~m}$ hoch werdende Art, mit ziemlich wagrechten Ästen, bis etwa $7 \mathrm{~cm}$ langen, graugrinen Blättern und $11-20 \mathrm{~cm}$ langen, $4^{1 / 2}-8 \mathrm{~cm}$ dicken, gelben Zapfen, welche breite, nach riickwärts hakenförmig ausgezogene Schilde und ovalen, ungefligelten Samen fiihren.

Die folgenden beiden Arten sind in deutschem Klina wohl nicht anbauwürdig:

Pinus strobiformis Engelm. Strobeïhnliche Kiefer. Gebirge Nord-Mexikos.

Schöne, bis $40 \mathrm{~m}$ hoch werdende, der Pinus Strobus sehr ähnliche Kiefer, mit wagrecht ausladenden Ästen, 5-7 cm langen, dreieckigen, graugrïnen, fein gesägten Blättern und lïngenden, lang zylinderischen, bei $20 \mathrm{~cm}$ langen, lockerschuppigen und stark harzigen Zapfen, mit riickgebogenen Schuppen, deren schilder mit kleinem, stumpfem Nabel versehen sind.

Ehenso kommt die mit Pinus koraiënsis nahe verwandte

Pinus Armandii Franch., Armands-Kiefer, aus China, fiir unser deutsches Klima nicht mehr in Betracht.

Pinus Balfouriana Jeffrey, Balfour's Kiefer, Fuchsschwanz-Kiefer. Kalifornien. 
Interessante, in der Heimat bis 15 m hoch werdente, starkstimmige, bei uns leider etwas trïguichsige Kiefer, mit erst pyramidaler, dann mehr breiter Krone, glatter, rotbrauner, spaiter respaltener Rinde, sowie ansgebreiteten, im Alter hïngenden Aesten und schlanken Zweigen.

Die sich bei zehn Tahre am Bamme haltenden, in der Scheide zu fiufen, doch auch zu vieren und dreien vorhandenen, daheidichtstehenden, einwärts gekrimmten, dem Zweige anliegenden und ihm ein an einen Fuchsschwanz (Fox-tail Pine) erimerndes Aussehen gebenden Blätter sind harzig (!) und $3-3 \frac{1}{2}$ cm lang.

Der hiangende (!), 9-11 (-14) cm lange und bei $4 \mathrm{~cm}$ dicke, länglich-kegelförmige, purpurbrame, harzige Zapfen hat dicke, Hache Schuppenschilder, mit etwas verdicktem, in einen bald abfallenden, kurzen Dorn anslaufenden Nabel. Der punktierte, hei \& $\mathrm{mm}$ grobe Samen hat 13 -2.2 mm langen Fligel.

Das rote, schwere, harte und zïhe Holz ist sehr gesucht.

Eine Abalt ist:

Pinus Balfouriana var. aristata Engelm., Grannenkiefer, vielfach ebenfalls Fuchsschwanz-Kief'er genannt, von Kalifornien, Nevada, Siid-Utah, Nord-Arizona.

Syn.: Pinus aristata Engelm.

Mit silbergrauer, rissiger Rinde, weit ausgebreiteten, oft bis zum Boden hängenden Ästen und Zweigen, stark harzigen (!), :3 cm langen, dem Zweig dicht anliegenden (Fox-tail Pine) Blättern und eiförmigem Zapfen, dessen diinne Schuppen aut den Schildern einen dimmen, oder auch grannenartigen Dorn tragen. Der Samen ist etwas kleiner als bei der Hauptart und trägt einen ebenso kurzen, oder auch bis $11 \mathrm{~mm}$ langen Fliigel. Das sehr astreiche Holz ist ebenso vorziiglich, wie das der Stammform.

\section{Abteilung: Strobus Spach.}

Quinae: Ebenfalls - wie bei voriger Abteilung - fünf Nadeln in gemeinschaftlicher Scheide, dagegen der Zapfen verlängert-zylinderisch (!) und hïngend (!), mit diunngerandetem Schuppenschild und ebenfalls unbewehrtem Nabel, dagegen geflügeltem Samen.

Pinus Strobus L. Strobe, Weymouthskiefer (nach Lord Weymouth benamnt). Von Kanada $\begin{gathered}\text { Liebt feuchten Boden, } \\ \text { olne jedoch hieran }\end{gathered}$ bis zu den Alleghanies. (Fig. 120 und 121.) gebunden zu sein.

Prïchtige und zierende, raschwiichsige und forstlich wertvolle, 40-50 m hoch werdende, starkstämmige, aber auch meist stark- und tiefbeastete Kiefer, mit erst glänzend-grimgraver, lange Zeit glatter, später dunkler, rissiger, runzeliger Rinde, 


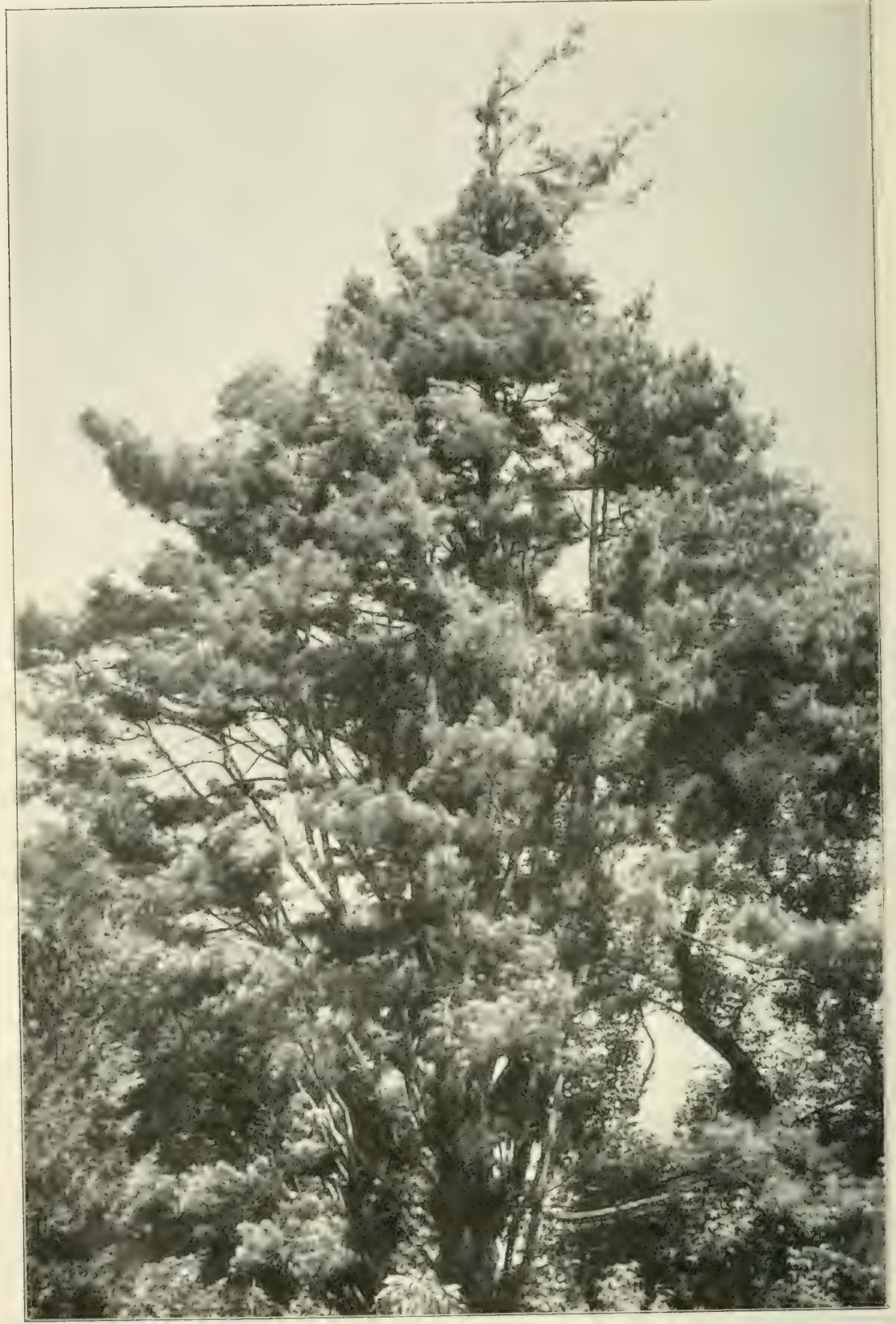

Fig. 120. Pinus Strojus L. (Etwa 90 jähriger Baum.) 


\section{$-235$}

erst pyramidaler, dam mehr breiter Krone, manchmal mehrgipfelig, mit quirlig gestellten, teils aufstrebenden, oft auch wagrecht abstehenden, biegsamen Ästen und erst griinlichen, dann grau-grimen, glimzenden Zweigen mit harzigen, rotgelben, spitz-eiförmigen Knospen.

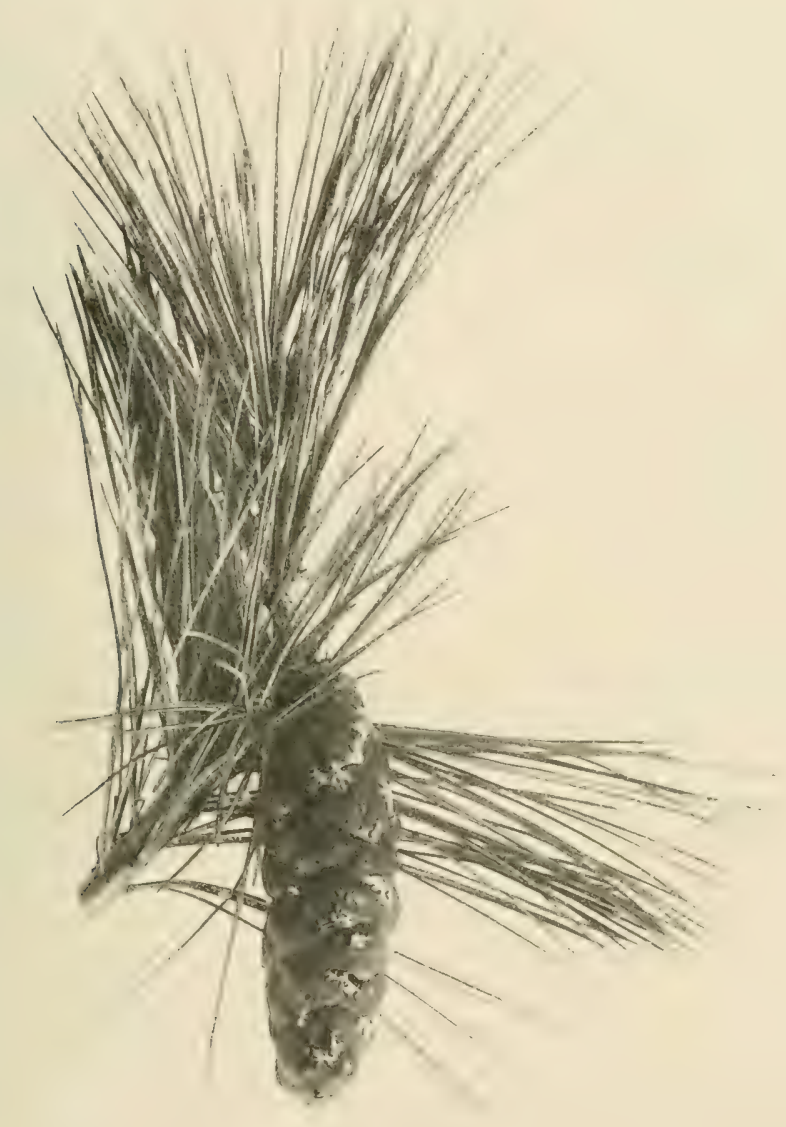

Fig. 121. Trieb und junger Zapfen von Pinus Strohus L. ('2 natïrl. Gröfe).

Die etwas schlaffen, in Winter und bei Regen sich mehr oder minder aneinanderlegenden, diunen, dreikantigen, feingesïgten und stumpf gespitzten Blätter sind 6-10 $\mathrm{cm}$ lang, $3 / 4 \mathrm{~mm}$ breit, außen gruin, innen blauweißlich.

Die er'st aufrechten, grünen, dann violetten, später hängenden, gestielten, lang- und spitz-zylinderischen, harzigen, 
etwas gekrimmten Zapfen werden $10-15 \mathrm{~cm}$ lang, $4 \mathrm{~cm}$ breit, und zeigen keilförmige Schuppen mit gelbgrauen, flachen, gefurchten, stumpfnabeligen Schuppenschildern.

Der im September des zweiten Jahres ausfliegende, kleine, spitz-eiformige, marmorierte, dunkelgraue Samen hat einseitig geschweiften, drei bis viermal längeren, braunen, gestreiften Flügel.

3-4 Wochen nach der Frihjahrssaat entwickelt sich der Keimling mit 8-11 Stiick bei $2^{1 / 2} \mathrm{~cm}$ langen, dreikantigen, grinen, imnen leicht behaarten Keimblättern und gleichfarbigen, sresägten, zweikantigen Erstlingsblättern.

Diese durch ihre feste Wurzelverankerung sehr sturmfeste Kiefer ist bei uns nicht nur als Schmuckbaun, sondern, wie schon oben erwähnt, als Forstbaun von Wichtigkeit, da dieselben einen raschen Wuchs zeigt und nicht mit der" "Schuitte" behaftet ist, wenn sie auch von schädlichen Wurzelpilzen oft heimgesucht wird. Sie liefert ein besonder's in der Trockenheit vorzügliches. leichtes, gelblichweißes, sich, „nicht werfendes", äußer'st harzreiches Holz, das im Wasser schwarz und zähe wird, und welches teils zu Schiffsmasten, besonder's aber als Bau- und Möbelholz reichste Verwendung findet; außerdem liefert diese Art noch guten (,amerikanischen“) Terpentin.

Die Fällung des Baumes geschieht am besten zur Winterszeit, da bei Sommerfällung das Holz durch Pilze leidet. Auf den Blasenrost der Weymouthskiefer, (siehe Seite 25) möge hier nochmals aufmerksam gemacht sein.

Formen sind:

Pinus Strobus glauca Hort. Veill., mit schöner, blauer Nadelfärbung:

Pinus Strobus aurea Hort.; besonders die jungen Blätter sind goldgelb.

Pinus Strobus variegata Hort, gelbbunte, unbeständige Form. zebrina Zocher, mit gelb-geringelten Blättern. feinen B̈lättern. gracilis viridis Hort., mit hellgrünen, dünnen,

Pinus Strobus viridis Hort, etwas kurzästige, ganz hellgrünblätterige Form.

Pinus Strobus brevifolia Hort., kurznadelige Form. monophylla (Tub.).

Syn.: P. Strob. forma nova monoph. Tubeuf, an alten Zweigen normale, an jungen durch Verwachsung der fiunf Bliitter nun einblätterige Form; oft in die nächste Form ibergehend.

Pinus Strobus monophylla tortuosa (Tub.).

Syn.: P. Strob. forma monoph. tortuosa I'ubeuf, 
eigentiumliche Form, welche eine Drehung, Windung, Krimmung oder Verkrippelung der verwachsenen Nadeln zeigt.

Pinus Strobus fastigiata Hort., loreit-säulenförmige bis spitypyramidale Form mit aufstrebenden Ästen.

Pinus Strobus nivea Hort.

Syn.: Pimus Strobus alba Hort., niedrige Form, mit ungleichwichsigen, teils auslatenden, teils iibergebogenen Ästen und ziemlich blanweił-griinen, oft gedrehten Blättern.

Pinus Strobus pendula IVesen., kleinwiichsig, mit im Bogen iiberhängenden Ästen.

Pinus Strobus nana Hort., Zwer'g-Weyınouthskiefer, reizende, dichtzweigige, rundbuschige Form mit etwas kleineren Blättern.

Pinus Strobus umbraculifera Hort.

Syn.: Pinus Strob. tabuliformis Hort., buschiger Strauch, dessen dichtstehende Zweige sich seitlich ausbreiten und dadurch eine flache Wuchsform zeigen.

Pinus Strobus pumila Hort., silbergrau-blätterige Kugelform. " $"$ prostrafa (Beißn.), mit niederliegenden, fast kriechenden Zweigen.

Pinus excelsa Wall., Tränen-Kiefer. Himalaya. (Fig. 122 und 123.)

III

Bei geschiitztem Standort. Jung em-

Wundervolle, rasch und wemn jung schön pfindlich. (Einzelne pyramidalwiichsige, in der Heimat bis $50 \mathrm{~m}$ hoch widerstandsfähiger werdende Kiefer, mit weißgrauer, erst glatter, gezeigt). dann im Alter sich in dimmen Stiicken lösender Rinde, quirlig gestellten, wagrechtstehenden und auch aufwärtsgebogenen Aesten und griinlichen, glänzenden Zweigen mit kurzen, keulenartigen, ganz feinbeschuppten Knospen.

Die an den Spitzen der Zweige pinselartig gestellten, schlaffen (!), dreikantigen, diinnen, feingesägten, stachelspitzen Blätter werden $12-15(-18) \mathrm{cm}$ lang, $1 \mathrm{~mm}$ breit und sind außen grün, imen stark blauweiß-silberartig gefärbt.

Die erst aufrechten, im zweiten Jahr hängenden, gestielten, griunlichbraunen, dann etwas gekrümmten, wurstartigen, in ganz reifen Zustande hellbraunen, stark mit schönen, hellen Harztropfen ("Tränen") bedeckten Zapfen werden 15-27 cm lang, $4(-7)$ cm dick und zeinen keilfömige, breite Schuppen, mit konvexen, runzeligen, gestreiften, stumpf und duskelbraungenabelten Schuppenschilern. Der gepreßt-eiförmige, schwarzmul graupunktierte Samen hat geschwungenen, zweimal längeren Fliigel.

Das weiche, reichharzige, aufien weißliche, innen rötlichbraune Holz ist als Bau-, Werk- und Schnitzholz in starker 
Terwendung; auferdem liefert die Pflanze reichlich feinen Terpentin.

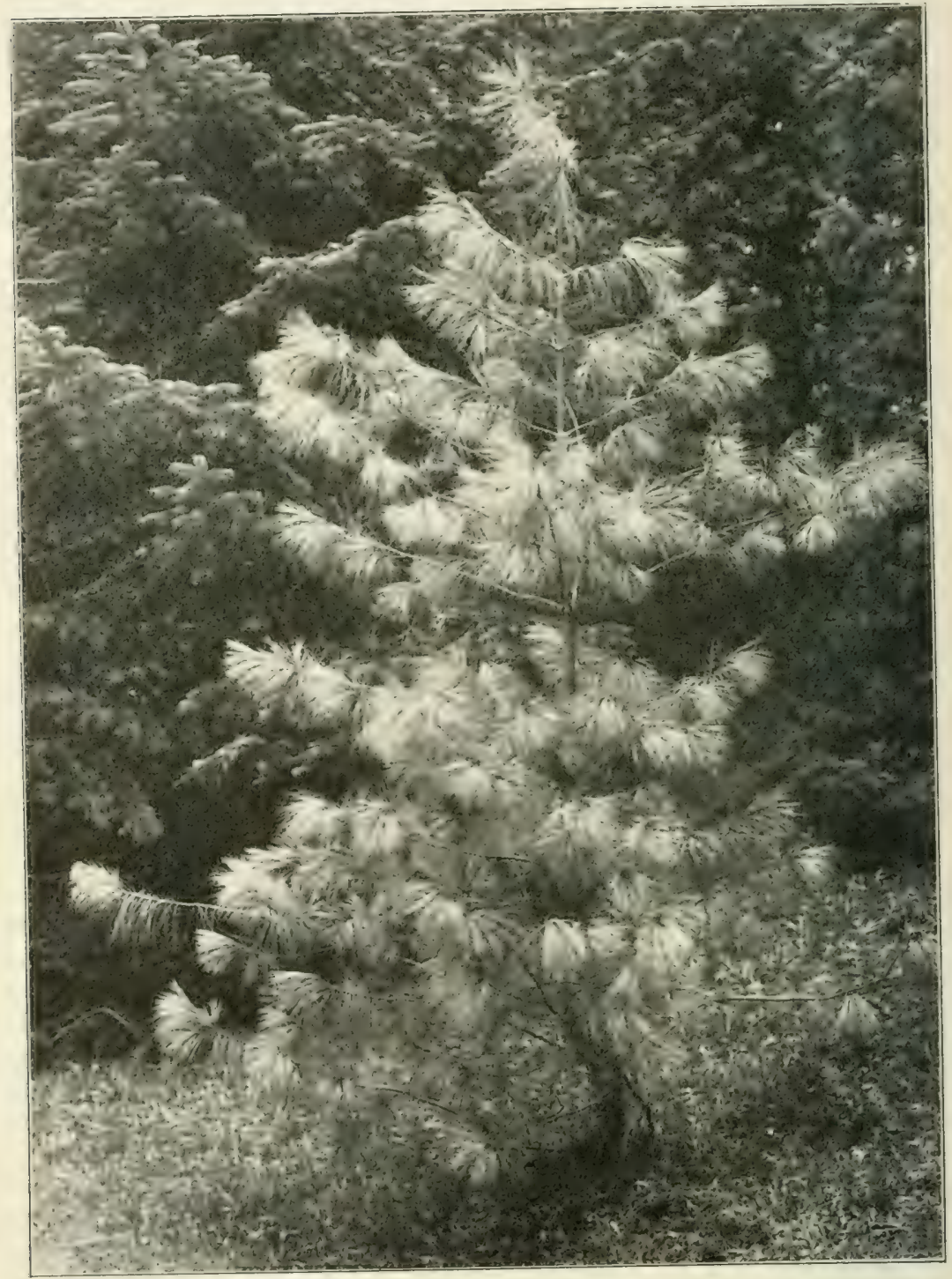

Fị. 122. Pinus excelsa Wall. (Jüngerer Baum.) 


\section{- $239-$}

Formen sind:

Pinus excelsa zebrina Croux., mit meist in der Niahe der Blattspitze weił-greringelten Bliittern, von eigentiunlichem Ansehen.

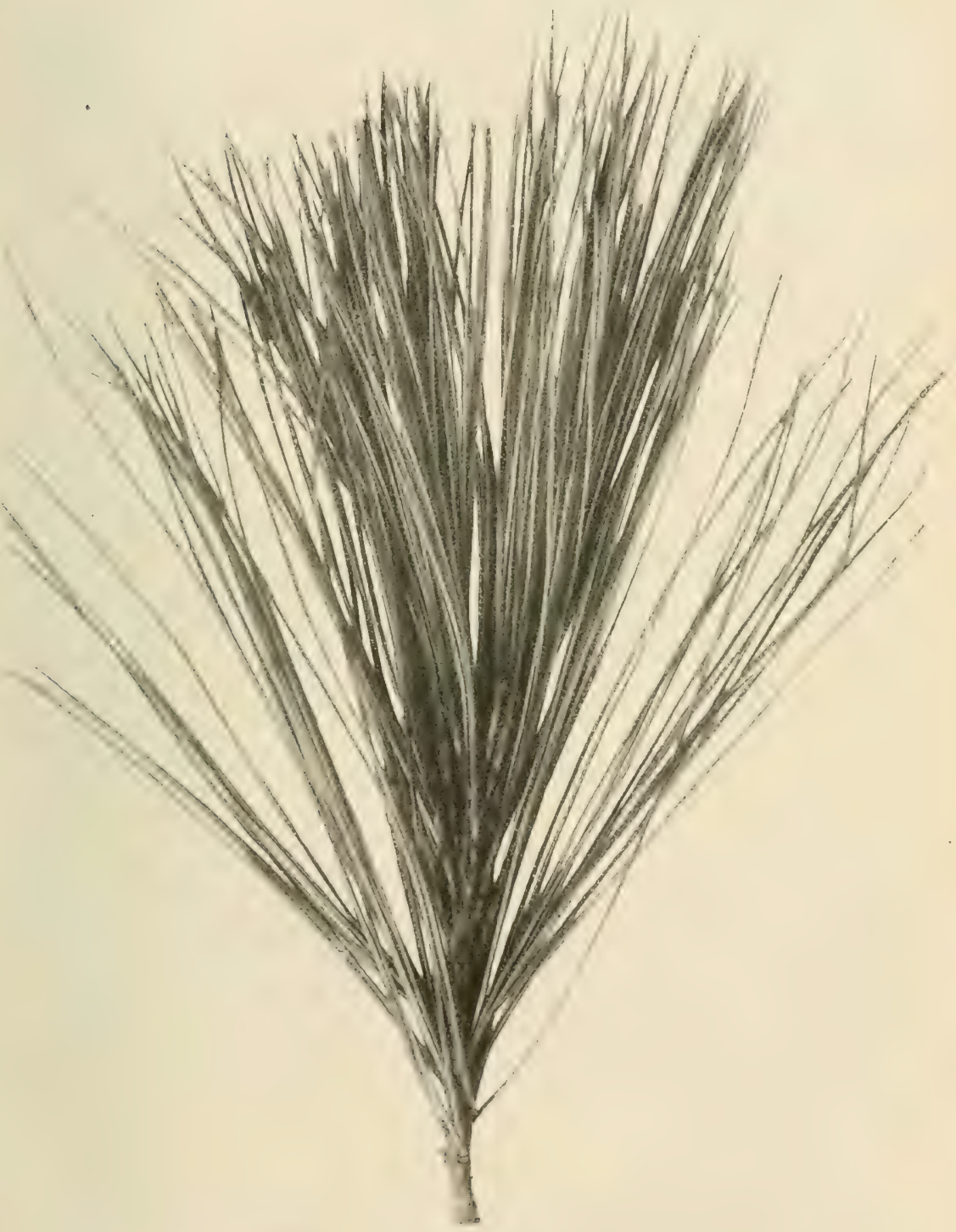

Fig. 123, Pinus excelsa Wall. 
Pinus excelsa monophylla Carr., durch enges Aneinanderkleben der Blätter scheinbar einblätterige Form.

Pinus Peuce Griseb., Rumelische

(Weymouths) Kiefer.

Syn.: Pimes excelsu ver. Peuce Griseb.

Ziemlich hart gegen Wurzelkrebs.

Montenegro, Balkan, Macedonien.

Eine der Pinus Cembra gleichende, $10-14 \mathrm{~m}$ hoch werdende. langsam und gedrungen, sowie pyramidal wiichsige, dichtästige Kiefer, mit etwas runzeliger, brïmlichgrauer Rinde, dichtbeblätterten, ziemlich aufstrebenden Zweigen, nit runden, plötzlich spitzen, weißgrauen Knospen.

Blätter aufrecht, starr, kurz gespitzt, gedreht, dreikantig, scharf gekielt, hellgriun, $7-8 \mathrm{~cm}$ lang und $1 \mathrm{~mm}$ breit. Der sich schon an jungen Pflanzen zeigende, längliche, oben verschmälerte Zapfen wird $8-13 \mathrm{~cm}$ lang und $3-4 \mathrm{~cm}$ dick.

Eine auch gärtnerisch wertvolle Art, welche einerseits schnellwiichsiger als die ihr ähnliche Pinus Cembra, andererseits winterhärter als diese ist.

Pinus Lambertiana Dougl., Zucker- oder riesige Kiefer. Vom Kolumbiafluf bis Mexiko $\begin{gathered}\text { Liebt lelmigen Sand- } \\ \text { boden und feuchte }\end{gathered}$ und bis zum Felsengebirge Nordamerikas.

Besonders in der Heimat äuferst imposante, bis 90, ja 100 m hoch werdende, aher etwas langsan wachsende, mächtigen Stamm und rundliche Kirone bildende Kiefer, mit ziemlich glatter, graugriner, sich damn in kleinen Stiicken lösender Rinde, quirlig gestellten, wagrecht abstehenden und etwas iiberhängenden Aesten und schokoladebraunen bis braungranen Zweigen, mit keulenförmigen, hellbraunen Knospen.

Die zienlich steifen, kräftigen, dreikantigen, scharfgespitzten und feingesägten, außen grünen, innen bläulichweißen Blätter werden $7-9(-11) \mathrm{cm}$ lang und $1 \mathrm{~mm}$ breit.

Ganz absonderlich sind die mächtigen, in der Heimat 30 bis $50 \mathrm{~cm}$ langen, $8-11 \mathrm{~cm}$ dicken, langstieligen, walzenförmigen, spitz auslaufenden, gelloroten Zapfen, welche braune, keilförmige, lockergestellte Schuppen, mit unten konvexen, scharfrandigen, breit- und stumpfnadeligen Schildern führen.

Der bis $1^{1} / 2 \mathrm{~cm}$ lange und $1 \mathrm{~cm}$ breite, länglich eiförmige, efibare, siifie Samen hat doppelt so langen, dunkelbraunen Flügel.

Jas weiche, weire Holz findet reiche Verwendung, ebenso findet das siifie Harz, .,Pinit", vielseitige, auch offizinelle Ver'wertung.

Es scheint vorteilhaft zu sein, _ des besseren Wuchses halber - diese Art auf Pinus Strobus zu pfropfen.

Pinus monticola Dougl. Westamerikanische (Teymonths) Kiefer. Sierra Nevada Kaliforniens bis Britisch Kolumbien. 
Der geröhnlichen Strobe ähnliche, bei 205 m - und höher werdende Kiefer, mit hellbramen, in viereckigen Stïcken sich lïsender Rinde, quirlig gestellten, wagrecht abstehenden und an den Spitzen Weder aufstrebenden Ästen, sowie braungriurindigen und brann-beharten Trieben mit granen Knospen.

Die dreikintigen, stumpforespitzten und feingesägten, riemlich steifen, aufen griunen, imnen blauweifen Blätter werden $5^{1 / 2}-7(-10) \mathrm{cm}$ lang und $1 \mathrm{~mm}$ dick.

Der stark harzige, kurzstielige, gelblichbraune, zylinlerischlange, leicht gekrimmte Zapfen wird $14-20 \mathrm{~cm}$ lang, 3-5 cm dick und fiihnt keilförmige, zum Teil stark rïckgebogene Schuppen mit konvexen, scharfrandigen, gekielten, breitgedrickt aber spitznabeligen schildern und bräunlichen, eiförmigen Samen mit nahezu viermal längerem Flïgel.

Das weiße, zähe, aber weiche Holz findet reiche Verwertung.

Pinus pentaphylla Mayr. Japanische WeymouthsKiefer. Zentrale Hochgebirge Japans.

Als jugendliche Pflanze sehr an P. parviflora erinnernde, 15-20 $\mathrm{m}$ hoch wer(ende, starkstämmige, weißrötlich und dickschuppig berindete $A r t$, mit dunkelgrinen, kräiftigen, dreieckigen, innen blauweiß gezeichneten, kurzen Nadeln.

Der 6-9 ('m lange und :3 cm dicke, zylinderische, erst blanschwarze, dann griune, reif gelbbraune Zapfen hat längliche Schuppen, mit Hachen, in der Iitte ganz leicht vertieften Schildern. Samen hell bis dunkelbraun, braungefligelt.

Holz dem der Strobe gleichwertig.

In der Heimat sollen viele Formen kultiviert werden.

Pinus Ayacahuite Ehrenl. Ayacahuite-Kiiefer (einheim. Name). Nord-Nexiko.

( $\mathrm{V}$ ??)

Fïr unser dentsches Kilima wohl kaum (trotz obiger Angabe V) noch in Betracht kommende, der Pinus excelsa ähnliche, auch mit Pinus parviflora leicht in jungem Zustand zu verwechselnde, gliuzendgrau-rindige Kiefer, mit diunen, ausladenden Ästen, dimnen Zweigen und langen Knospen, sowie ebenfalls diinen, etwas steifen, çekielten, bläulich-graugrinen Blättern.

Zapfen harzig, sehr lang, griulichbraun, mit rumzeligen, länglich-rhombischen, gekrimmten, spitzen Schildern und bräunlichen, gefligelten Samen. Das $\mathrm{Hol}_{z}$ soll nicht wertvoll sein.

Zwei weitere Arten:

Pinus leiophylla Schiede und Deppe, aus Mexiko, und

Pinus scipioniformis Mast, aus Mittelchina (Hupeh), kommen für unser deutsches Kilima wohl nicht mehr in Betracht. 


\section{f) Taxodieae.}

Suin p f z y ressen-ähnliche Pflanzen.

Meist große bis riesige, immergrine oder auch laubabwerfende Biume, mit spiralig angeordneten, nach zwei oder auch mehr. Seiten gerichteten, teils pfriemenförmigen, teils auch schuppenartigen und flachen Blättern. Bliiten monözisch; männliche Bliiten in meist zylinderischen Ständen, mit je 2-5 ja 8 Pollensiicken; weibliche Bliten mit spiralig gestellten Schuppen, welch letztere 2-9 Samenknospen fiihren. Samenschuppe der Braktee fast stets angewachsen,

\section{Sciadopitys Sieb. und Zucc.}

Schirmtanne.

Wunderbarer, immergriner, durch seine Kurztriebe (Doppelnadeln) charakterisierter Baum.

Blïte monözisch. Nännliche zu mehreren, in lïnglichen IBischeln, gipfelständig, mit kurzgestielten, spiralig gestellten Antheren; weibliche Bliite rundlich bis länglich, mit zahlreichen, dicht spiralig gestellten Schuppen, welche $7-9$ abwärts gerichtete Samenkmospen führen.

Zapfen aufrecht stehend, mit holzigen Schuppen und länglichbreiten, geflügelten Samen.

Sciadopitys verticillata Sieb. u. Zuce. Japanische Sch. Siidöstliche Gebirge Nippons. (Fig.124)

Einzigartiger Baum von pyramidalem Wuchs bei geradem Stamm, mit g'raubrauner, rissiger

III

Höhenlage Vorzug, bei geschütztem, nicht zu sonnigem Standort. Lockerer, frischer Boden.

und sich ablösender Rinde, sowie quirlförmig gestellten, nahezu wagrecht ausgebreiteten Ästen.

Interessant ist die Belaubung. Erstens sind es kleine, echte Schuppenblättchen, die spiralig an Längstrieben des Baumes gestellt sind, zweitens kann man als solche sogenannte lange Doppelnadeln nemnen, welche jedoch als Kurztriebe anzusprechen sind. Diese aus zwei verwachsenen Blättern bestehenden Doppelnatelı stehen an der Spitze der kurzen Jahrestriebe, 20-40 Stiick sich nach allen Seiten fast schirmförmig ausbreitend, haben 8-15 cm Länge und 4-7 mm Breite, sind oben glänzendgriin, in der Mitte tief gefurcht, unten mit einer weißlichen Linie versehen.

Der in zweiten Jahre reifende, aufrechte, graubraune, 6 bis $9(-10)$ cm lange und 4--5 cm breite, stumpf-eiförmige Zapfen wird durch zahlreiche, oben breitgedrickte und mit hervortretenden, unregelmäßigen Rändern versehene Schuppen gebildet, welche je 6-8 flache, brame, mit lederartiger Samenhaut versehene, gefligelte Samen führen. 


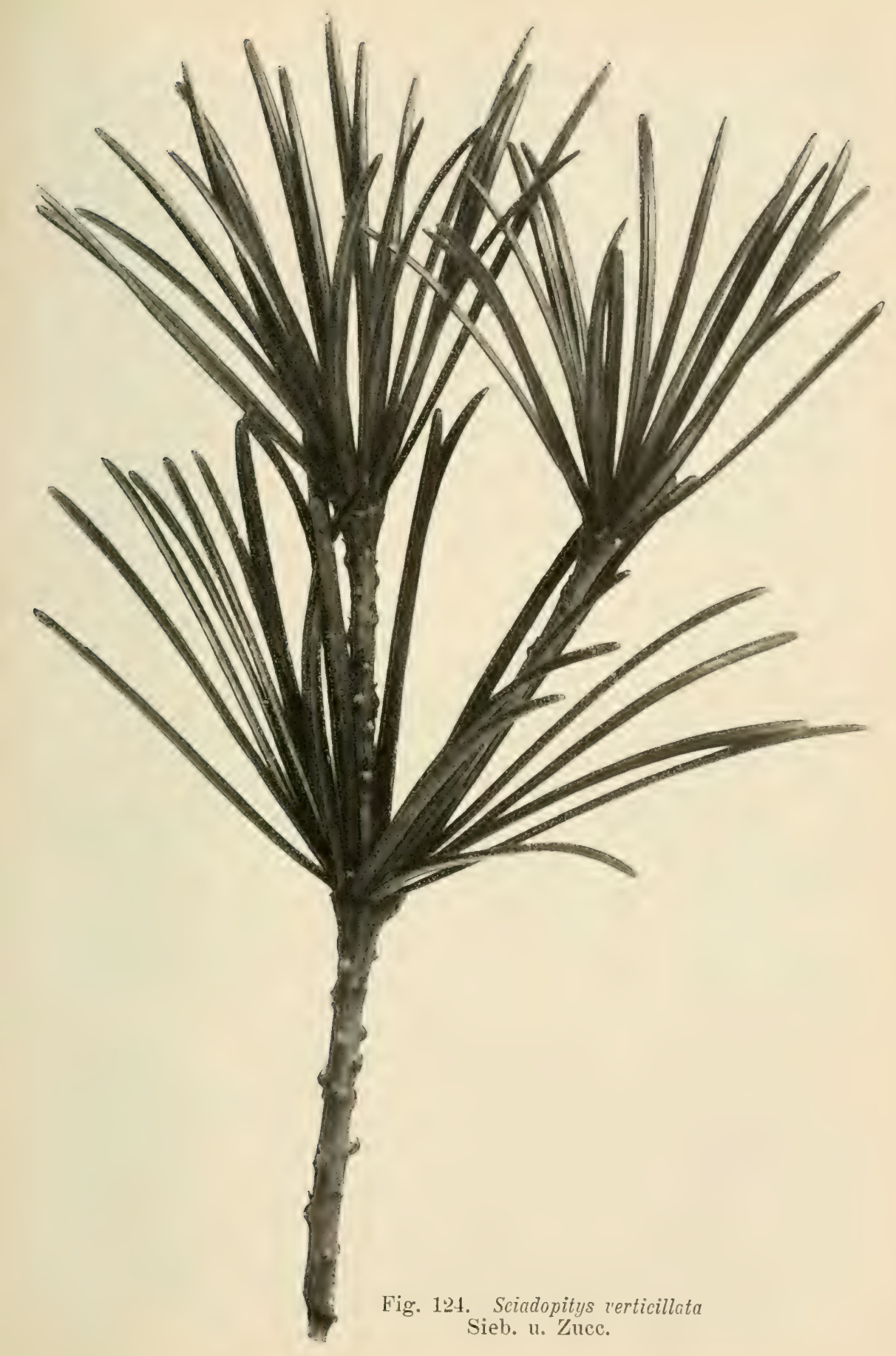


Termehrung besonders durch eingeführten Samen, welcher friiher leider von japanischen Kulturpflanzen stammte und infolgedessen bei uns kiimmerliche Exemplare ergab. Pfropfungen am besten im Februar und März auf Wurzelstiicke, welche dann in den Warmkasten oder ins Warmhans gestellt werden. Stecklinge sind nicht lohnend. Kultur zuerst in Töpfen in sandiger (auch Heide-)Erde, unter Glas, dann bis zur Auspflanzung, was möglichst bald zu geschehen hat, an geschiitzter Stelle im Freien stehend. Der Keimling bildet zwei große, grime Samenblätter und auch einige Erstlingsblätter.

Die junge Pflanze hat nicht nur bei uns, sondern auch in der Heimat ein träges Wachstum. Das schöne, weife, kernfreie Holz dient in der Heimat zu Hoch- und Wasserbauten, wie ehenso zu Schiffsbauten. (Japanische Malereien von Koniferen haben sehr oft diese Art als Motiv.)

Wo es die Unstände erlauben - Klima, Boden etc. sollte dieses auffallenile Nadelholz in keinem Garten fehlen.

Es ist von der Schirmtame auch eine Form mit hellgelben Doppelnadeln in Kultur:

\section{Sciadop. vertic. variegata Gord.}

\section{Cumninghamia R. Braun.}

Cunninghamie, Spießtanne.

Schöne, immergrine Bäume, mit quirlartig gestellten Ästen, an Araucaria erimnernden, zweizeilig gestellten Zweigen, sowie zweiseitig gerichteten, langen Blättern.

Bliite monözisch; männliche in endständigen, zylinderischen Kätzchen, mit zahlreichen Staubgefäßen; weibliche eiförmig, sitzend, endständig, mit vielen spiralig gestellten Schuppen, welche je drei Samenknospen fiihren.

Zapfen ziemlich eiförmi@, aus vielen lederartigen, an der Spitze locker abstehenden, spitz zulaufenden Schuppen gebildet, welche je drei eifurmige, mit einem samenmantel versehene, flache, gefligelte Samen enthalten.

Cunninghamia sinensis $\mathrm{R}$. Br., chinesische C. Suidl. China und Cochinchina.

Kleinerer Baum, dessen Äste in Quirlen stehend unten wagrecht abstehen, oben mehr

VI (VII)

Bei geschütztẹm, nicht zu sonnigem Standor, in gleichmässig
feuchtem, lehnige n Sandboden. aufwärts gerichtet sind, sowie mit zweizeilig gestellten Zweigen.

Die ebenfalls zweizeilig abstehenten, aber wechselstandig gestellten. 3-7 cm langen wnd 5-7 mm breiten, ziemlich schmallanzettlichen bis fist sichelförmigen, dabei etwas abwärts gerichteten Bbatter sind an der Basis herablaufend angewachsen, scharf zugespitzt, an Rand fein gesïgt, oberseits gerimelt, bei 
lebhaft glinzendgriner Fïrbung, unten mit zwei bliulich-weißen Spaltöffnungsbändern versehen.

Die meist zu mehreren beisammen stehenden, im ersten Tahre reifenden Zapten werden 3-4 en lang und fast ebenso breit und fiuhren ovale, oben scharf spitz zulaufende, an den Rändern diune, feingrezihnelte Fruchtschuppen, mit, je drei braungelben, ovalen hezw. eiförmigen, gefligelten samen.

Der Zapfen zeigt ofters das hei Koniferen (z. B. hei Larix) sonst seltene Proliferieren (Durchwachsen) eines Triebes.

Der Keimling entwickelt zwei Samenlappen.

Zurickgeschlagene oder auch zuriickgetrorene Bäume was in Deutschland sehr oft der Fall ist - entwickehn ziemlich starken Stockausschlag.

Vermehrung durch eingefiihrten Samen, möglichst bald nach der Reife, da er in kurzer Zeit die Keimkraft verliert, unter Glas in 'Tüpfen oder Kistchen. Stecklinge wachsen wohl ziemlich leicht, ergeben aber kopflose, wenn auch buschige Pflanzen.

Das Holz ist in der Heimat zu besseren Holzarbeiten sehr' gesucht.

Eine Form ist:

Cunningh. sinensis glauca Hort., blaugrinn, mit prächtiger, weißer Färbung der Blattunterseite.

\section{Sequoia Endlicher.}

Se qu o i e (Wellingtonia Lindley).

Eminent hohe, majestiitische, immeroriune Bäume, mit reicher Beastung und Bezweigung und spiralig gestellten, entweder lineal-pfriemlichen, bei abstehender, feiner Spitze schuppenartigr anliegenden, oder zweiseitig gerichteten, lanzettlichen Blättern.

Blïten monözisch; männliche seiten- oder gipfelständig, ährenförmig, dachziegelig dichtschuppig, von Form lïnglichrund, mit 2-4 Antheren; weibliche endständig, länglich-rund, spiralig, dicht- und dickschuppig, mit his zu 5 Samenknospen.

Zapfen verhältnismäßiœ klein, länglich-rund, mit oben längs gedrückten, unregelmäßig rhombisch geformten Fruchtschuppen, sowie kleinen, gefligelten Samen.

Sequoia gigantea Torren, (nicht Sequoia gigantea Endlicher). Riesige Sequoie, IVellingtonie, Mammutbaum. Sierra Nevada Kaliforniens bis zu $2000 \mathrm{~m}$ Höhe aufsteigend. (Fig. 125-127.)

Wundervoller und wunderbarer Baum! Wohl die am ältesten - ein par tausend Jahre - und an höchsten werdende Kionifere! Sie erreicht eine Höhe von iiber $120 \mathrm{~m}$, bei einem unteren Durchmesser von 16-20 m, also ca. 51

III (II ?)

In der Jugend Schutz, besonders auch des Wurzelstockes. Liebt lockeren, frischen, sandigen Lehmboden mit durchlassendem Untergrund. Kümmert in trockenem Boden. Höhenlage Vorteil. Im Tal Schutz gegen kalte Winde und Sonnenbrand. 


\section{$-\quad 246$}

his $63 \mathrm{~m}$ Umfang! Übertroffen wird Sequoia an Höhe nur noch ron Eucalyptus, einem schlanken Laubbaum Australiens.

Der seit 1853 bei uns eingefiihrte Baum, welcher in anormalen WVinter'n zwar vielfich erfroren ist, sonst aber nur stark

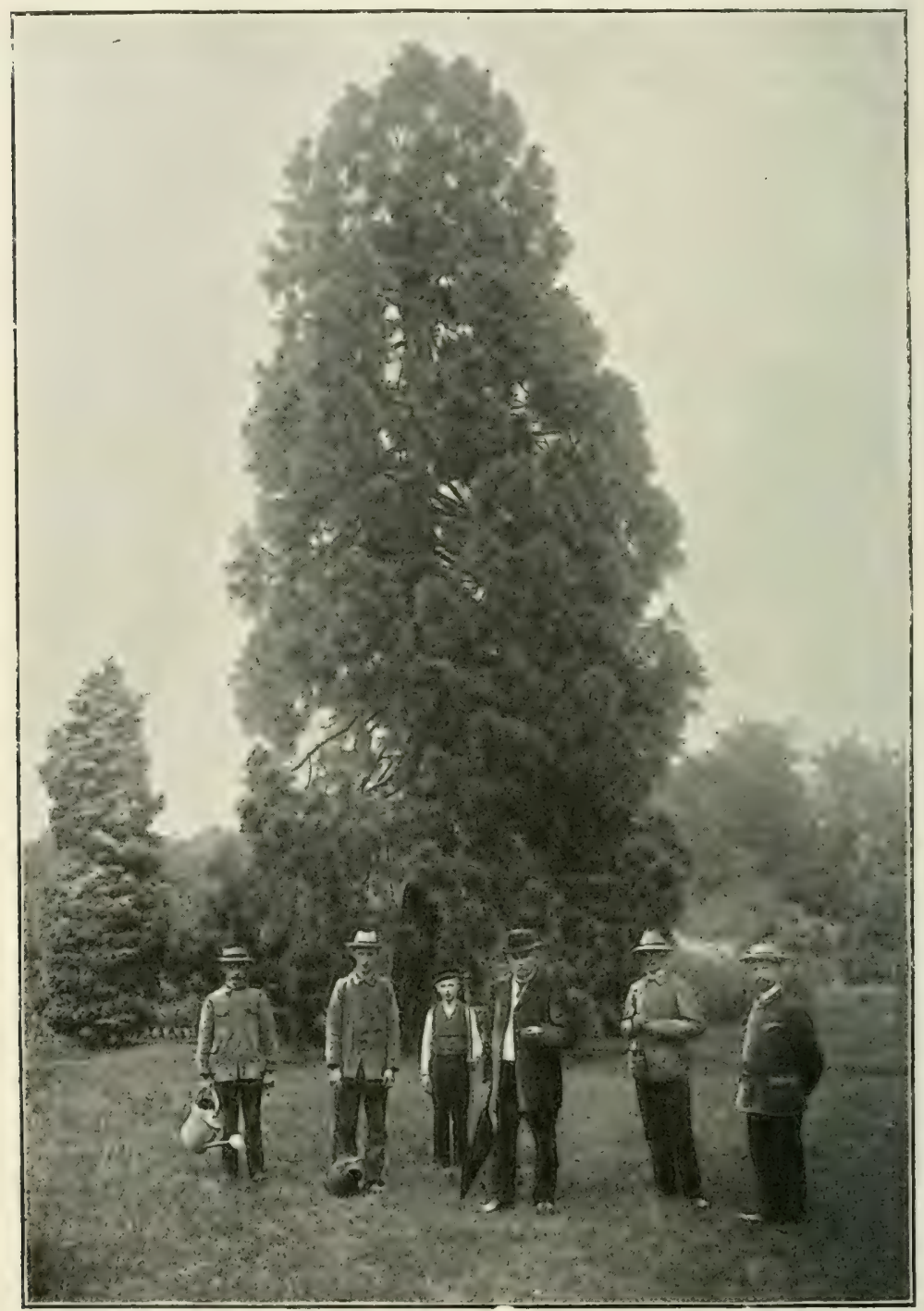

Fig. 125. Sequoia gignntea Torr. (54 jähriger Baum). (Aus: Mitteilungen der deutschen dendrolog. Gesellschaft.) 
heschädigt wurde, sich, jedoch bald wieler reinigt, d. h. in der Bezweigung erneut, ist in einigermafien ginstigen Standortsverhältnissen hei uns schon in sehr grofen Exemplaren vertreten. Er führt einen geraden Stamm mit rötlich-brauner, rissiger, sehr dicker, sich ablösender Rinde, pyramidaler Krone, unregelmäßig gestellte, sich nahezu horizontal ausbreitende Äste und zweireihig gestellte, runde Zweige.

Blätter an jungen Trieben etwas weitstehend, pfriemlich, ziemlich anliegend, oben etwas abstehend, hinten konvex gekielt, an älteren Trieben dicht spiralig gestellt, unten am 'Trieb herablaufend angewachsen, gegen das Ende der Zweige etwas kiurzer werdend, blaugriun gefärbt; sie sollen etwas giftig sein.

Der 5-7 $\mathrm{cm}$ lange und bis zu $4^{1} / 2 \mathrm{~cm}$ breite Zapfen fuilurt iiber 20 Fruchtschuppen, von oben unregelmäßig höckeriger, breitrhombischer Gestalt, breit genabelt, mit borstiger Spitze, spiralig gestellt. Jede Schuppe zeigt bis zu 5 gelbe bis bräunliche, breitgepreßte, etwas längIiche, geflügelte Samen. (Letztere, in Deutschland geerntet haben sich bis jetzt leider alle als taub erwiesen.) Der Keimling zeigt 3-5 Samenblätter.

Vermehrung durch Samen unter Glas in Töpfen oder Kistchen und möglichst baldiger Auspflanzung, sowie die Pflanzen genügend erstarkt sind. Formen pfropft man auf die Stammform.

Das Holz des Baumes entlält Farbstoff und ist dauerhaft; das breite Kernholz ist rotbraun, das duinne Splintholz gelblich, die Rinde und Borke selır dick.

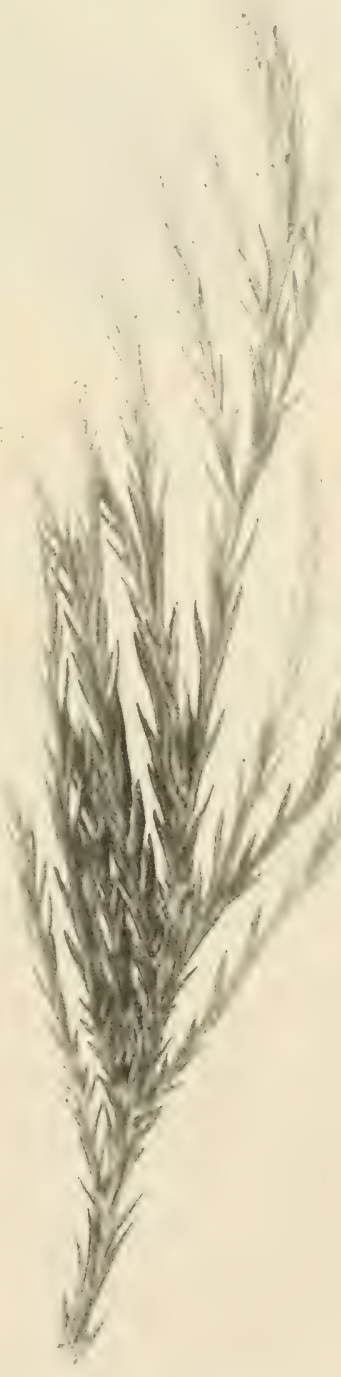

Fig. 126.

Trieh, von Sequoia gigantea Torr. 
Älere Exemplare ertragen das Verpflanzen nicht gut; dagegen treibt die Pflanze nach dem Schnitt wieder vielseitig aus.

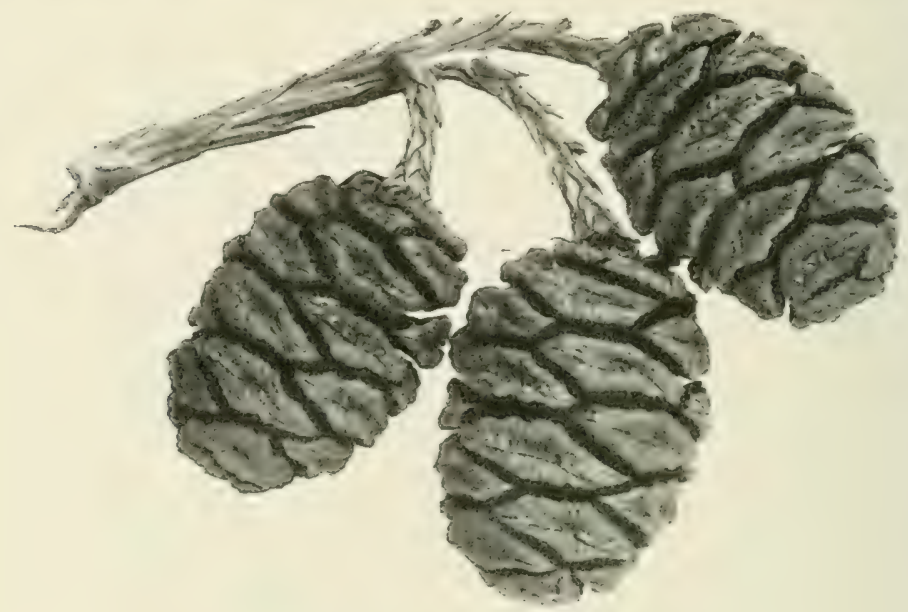

Fig. 127. Zapfen von Sequoia gigantea Torr.

Die Formen sind in Deutschland noch ziemlich selten anzutreffen, es sind dies:

Sequoia gigantea argentea Hort., weißschimmernde Form. variegata Hort., gelblich-weiß; mißfarbig. " aurea Hort., gelbe Form.

Syn.: Sequoia giguntea lutea Hort.

Sequoia gigantea glauca Hort., blaugrün. grüu, dichtwüchsig, schmalpyramidal.

pyramidalis compacta Hort., bläulich-

Sequoia gigantea columnaris Hort. (Beißn.), säulenförmig. Syn.: Sequoia gigantea pyramidalis Hort. gall.

Sequoia gigantea Holmsii P. Shmith, steif aufrechter, dabei aber gedrungener Wuchs.

Sequoia gigantea pendula Hort., sehr interessante, fast. spindelartige Form, mit stark hängenden, fest anliegenden Ästen.

Sequoia gigantea pygmaea Hort., Zwergform, buschig.

Sequoia sempervirens Endl. Immergriune S. Coast Range (Kalifornien). VI (V ?)

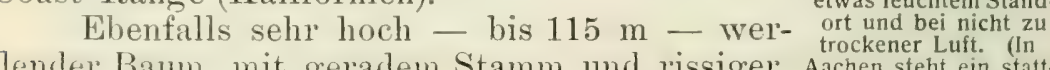
Auf lockerem, sandigem, etwas feuchtem Standdender Baum, mit geradem Stamm und rissiger, Aachen steht ein stattroter his rotbranner Rinde, pyramidaler Krone, licher Baum.) ziemlich unregelnäßßig gesteliten, breit ausladenden Ästen, sowie zahlreichen, zweizeilig gestellten Zweigen. Blätter nahezu 
zweiseitio gerichtet, lanzettlich, etwas sichelfömi@ mit konvexem Riicken, 1-2 cm lang und 2-21/2 mu breit, unten herablaufend am Trieb angewachen, oben plötzlich spitz, von derber Konsistenz, auf der ()berseite glanzendgrin, unten nit zwei weißen Spaltöffnungslinien.

Die erst granten, damn dunkelbramen Zapfen sind kleinel als jene der vorigen Art, $1^{1 / 2}-2^{1} / 2 \mathrm{~cm}$ lang und $1^{1 / 2} \mathrm{~cm}$ breit, mit $16-20$ oben breiteredrickt-viereckigen, in der Mitte mit versenkter Rinne und einer horstienen Sitze versehenen Fruchtschuppen. welche je 3-5 hramliche, breit-eiformige, wepredite, gefligelte Samen fiihren.

Termehrung durch Samen; durch Stecklinge nicht sonderlich zu empfehlen; duxch Pfropfung auf die Stammform.

Das sehr gesuchte Holz, sogen. Rotholz, ist weich und sehr danerhaft. Die Pflanze hildet beim Abhiel, starken Stockausschlae, sowie an flachliegenden Wruzeln neue schöblinge.

Von den bei uns noch seltenen Formen sollen genannt sein:

Sequoia sempervirens variegata C'arr, dichtzweigig, oft ganz kurzblätterig, dabei buntfarbig, auch ganz gelblich.

Sequoia sempervirens adpressa Carr., kurz- und dichthläterig, gelblich-тveiß im Austrieb; kleinwüchsig.

Syn.: Sequoia semperv. albo-spicn Hort.

Sequoia sempervirens taxifolia Hort., mit inehr breiten, taxusartigen Blättern.

Sequoia sempervirens pendula Rovelli, mit prachtvoll lang herabhängenden Ziveigen.

Sequoia sempervirens filifera elegans Rovelli, mit wagrecht abstehenden Ästen und langen, fadenförmigen, iiberhïngenden Zweigen, deren Blätter gregen die Zweigspitze kleiner bis schuppenförmig werden. gattung:

Ton der folgenden, aus Tasmanien stammenden Nadelholz-

\section{Arthrotaxis Endlicher,}

Gliederfichte,

immergrünen, kleinen Bäumen, mit etwas ausladenden Ästen und mehr dimmen Zweigen, ovalen, bezw. oval-lanzettlichen Blättchen, monozischer Bliite und rundlichen Zapfen, ist wohl in I)eutschland kaum eine Art mit Erfolg in freien Lande kultiviert worden, zudem sie auch nur fuir Region VII, mit Schutz, in Betracht kommen. In Frankreich und England wurlen jedoch erfoloreichere Versuche damit auswefiiht.

Es soll nur eine Art kurz beschrieben werden:

Arthrotaxis selaginoides Don., Selaginellen-ïhnliche G. 
Iit ziemlich ausbreitenden Ästen und Zweigen, oval-lanzettlichen, einwärts gekrimmten. spiralig und dachziegelartig gestellten, kleinen, grimen Blättern. Zapfen etwa nufirof, nahezu rund, mit holzigen, schildförmigen Schuppen und 2-3 braunen, gefligelten Samen.

Vermehrung durch Samen.

Weitere Arten aus Tasmanien sind:

Arthrotaxis cupressoides Don., Zypressen-ähnliche G.. und laxifolia Hook., lockerblätterige $\mathrm{G}$.

Syn.: Arthotaxis Doniana Maule.

\section{Cryptomeria Don.}

Cryptomerie.

Hohe, immergrine Bïume, mit rundlicher Krone, aufstrebenlen, zahlreichen Asten und mehrseitig stehenden, pfriemlichen Blättern. Bliite monozisch; die mämnliche in Ähren, spiraligund dichtstehend; weibliche rumdlich, einzeln, sitzend, mit spiralig gestellten Schuppenblättern, welche je t-j Samenknospen fiuhren. Samen länglich, eckig, die derbe Samenschale schwach gefliigelt.

Cryptomeria japonica Don, Japanische Cr. Gebirge des siidlichen Japans, China. (Fig. 128 und 129.)

Prachtvoller, gradschaftiger Baum, ron im Alter l'undlichem bis länglich-rundem Wuchs, bis iiber $60 \mathrm{~m}$ hoch werdend, mit geradem Stamm, briunlich-roter, lang'rissiger Rinde, dicht stehenden Asten und pfriemlichen, wach innen sichel-

IV (III) Jung empfindlich. Liebt lichtfreien Standort ohne Sonnenbrand, mehr lockeren, etwas feuchten, als trockenen und schweren Boden, bei Luft-

feuclitigkeit. Kümmert in trockener Luft; rauhe Ostwinde sehr schädlich. fömigen, beiderseits gekielten, spiralig dichtstehenden, an den Zweigspitzen kiirzer werdenden Blättern, von hellgriiner bis fein bläulich-grüner Färbung, den Winter iiber meist violett-grüu.

Zapfen rundlich, erst weich, dam härter, braun, bis $2 \mathrm{~cm}$ groß, lange hängen bleibend, mit zahlreichen - bis 18 - mehrfach gezackten Fruchtblittern, welche reichlich dunkelbraune, gering geflügelte Samen führen.

Letzterer läuft sehr bald auf (keimt), bildet einen Keimling mit zwei bis drei Keimblaittern, denen erst grune, zweibis vierzühlige und sodamn dreizählige, bläulich-griine Blattquirle folgen.

Vermehrung durch eingeführten Samen. Stecklinge, besonders von jungen Pflanzen geben dichtzweigige, doch etwas langsam wachende Exemplare. Pfropfung der Formen auf die Art. Abgeschnittene Pflanzen bilden gerne und viele Schößlinge. 


\section{$-251$}

Das Holz (ohne Haryginge) ist dauerhaft, weich mol leicht zu verarbeiten; die sehr dauerhafte Rinde findet in der Heimat des Baumes gute Verwertung.

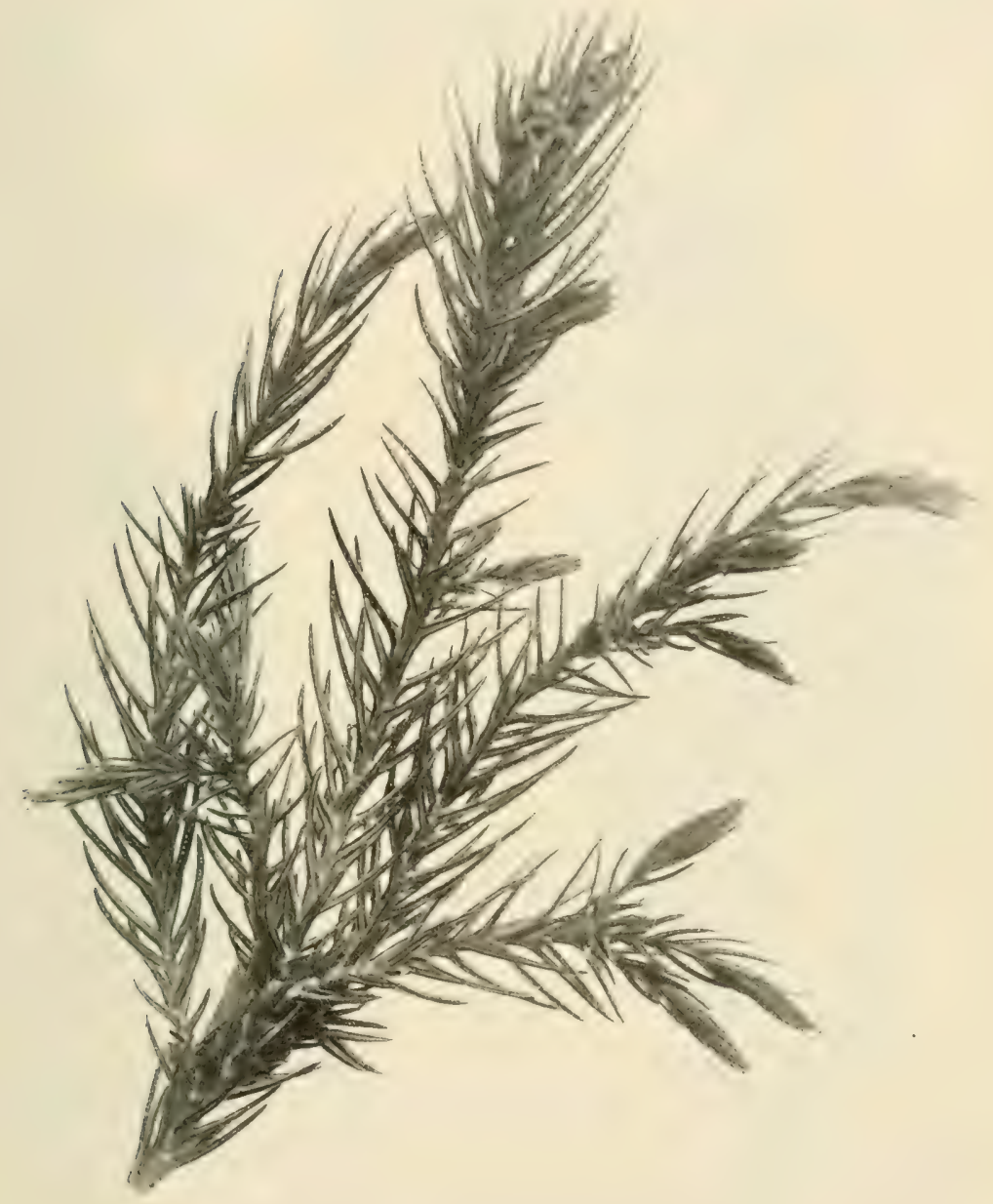

Fig. 128. Cryptomeria japonica Don.

Formen sind:

Cryptomeria japon. elegans Hort, eine JugendIII form, welche sich durch weiche, fast schlaffe, etwas weiter auseinanderstehende und auch etwas längere Blätter auszeichnet. Im Winter bräunlich grefïrbt. Junge Pflanzen hübsch, ältere sparrig. Fruktifiziert bald. 
Cryptomeria japon. elegans nana Hort., ahnlich voriger, niederwüchsig. spitzen.

Cryptomeria japon. albo-variegata Hort., mit weißen Zweig-

Cryptomeria japon. argenteo-spica Beifn., silberweißspitzig, besonder's im Austrieb schön.
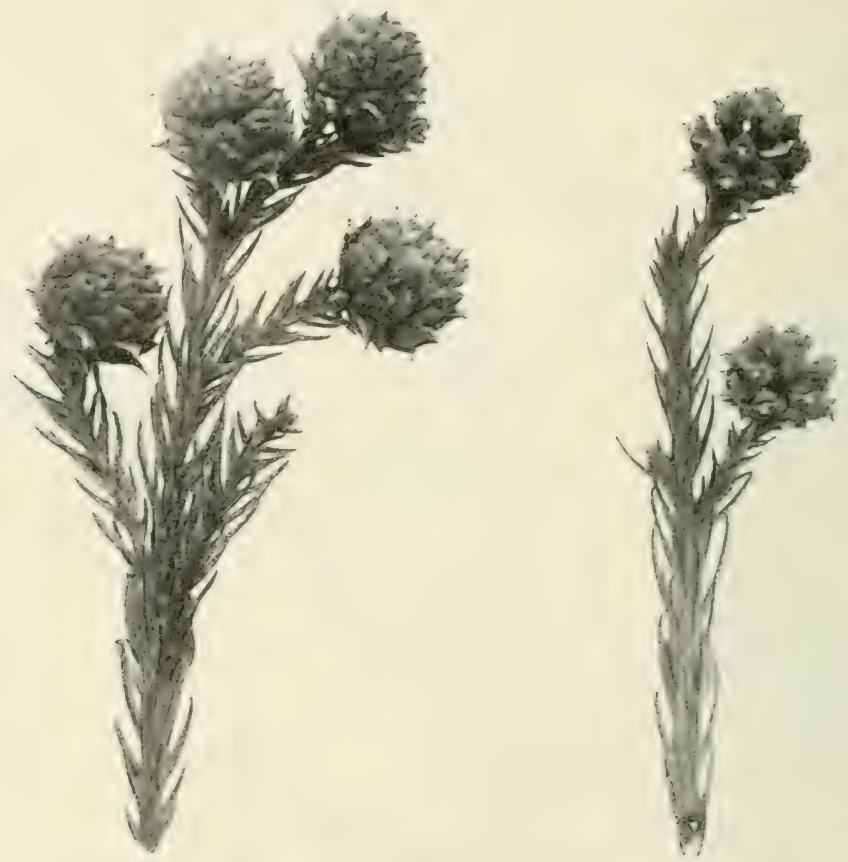

Fig. 12. Geschlossene und offene Zapten ron Cryptomeriu japcnica Don.

Cryptomeria japon. aurea Hort., goldgelb. gigantea Hort., starkwüchsig. (Fig. 130.) derbe Blätter; blaugrủn. pungens Hort., steif abstehende, stechende,

Cryptomeria japon. Lobbii Hort., rein griin, gedrungenwiichsig.

Crypłomeria japon. viridis Hort., lebhaft glänzend-griun. araucarioides Hort., mit dicken, stark gebowenen. an Araucaria excelsa erimernden Blättern.

Cryptomeria japon. dacrydioides Hort, leichtzweigig, mit kurzen, bräunlichen Blättern.

Cryptomeria japon. spiraliter falcata Hort., mit anliegenden, dicht spiralig gestellten Blättern. 
Cryptomeria japon. selaginoides Hort., Zwergform, nieder, rundlich-kegelförmig.

Cryptomeria japon. Iycopodiiformis Hort., dichtwiichsige Zwereform, mit Lycopodium-artigen Blättern.

Cryptomeria japon. III compacta Hort, gedrungen wiichsig:

Cryptomeria japon. III compacta nana Hort., Zwergform, dichtwüichsig:.

Cryptomeria japon. nana Knight, nieder, breit, monströse Bezweigung.

Cryptomeria japon. nana albo-spica Hort., wie volige, weißspitzig. Cryptomeria japon. cristata Beißn., Zwergform, mit hahnenkammförmiger Bezweigung.

Cryptomeria japon. monstrosa Hort, monströse Form.

In Japan werden noch weitere Formen kultiviert.

\section{Taxodium Rich.} (incl. Glyptostrobus Endl.). Sumpf-Zypresse.

Noch ungenügend erforschte, Laub und selbst Zweigchen abwerfende, ziemlich hohe, eigenartige und charakteristische Bäume mit starkem Stamm. braunroter Rinde, breit ausladenden Ästen, feinen,

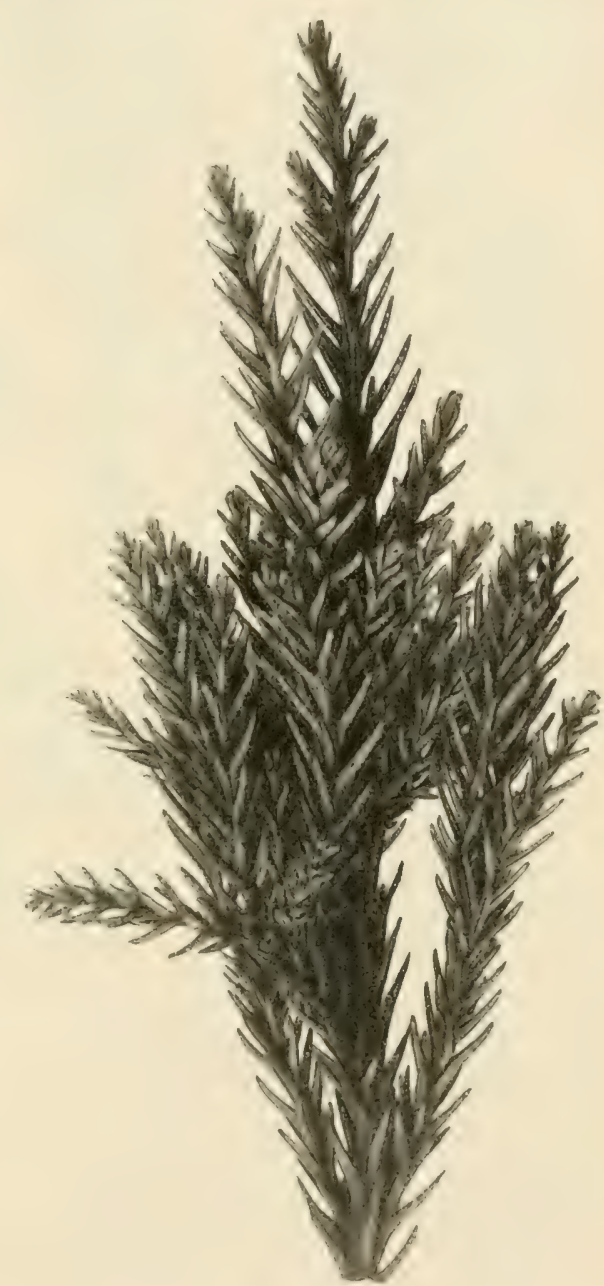

Fig. 130.

Cryptomeria japonica Don gigantea Hort. fast wagrecht abstehenden Zweigen, Lïngs- und Kurztrieben, (letztere abfallend), sowie mit schmalen, feinen, ebenfalls nadel- bis schuppenförmigen, spiralig gestellten, orler nach zwei Seiten gerichteten Bliittern. 
Bliite monözisch; männliche zahlreich, in dicken Ähren, spiralig, etwas gestielt; weibliche rundlich, auf diesjährigen, kurzen Zweigchen, mit dicken, spiralig und dicht gestellten Schuppenblättern, welche je zwei Samenknospen fïhren. Zapfen lïnglich-rund, mit nahezu viereckigen, auch meist etwas gehöckerten, sowie mit einer gehogenen Spitze versehenen Fruchtschuppen. Die eckigen, eigentiunlich getormten, ziemlich großen Samen haben eine lederartig dicke Samenschale.

Taxodium distichum Rich. Sumpl-oder NacktI (?) 7. Simp Jung empfindlich. amerika, etwa bis zum 40. Breitegrad. (Fig. 131.)

Ziemlich hoher, prachtvoller und ganz eigenartiger Baum, mit geradem, unten ziemlich verdicktem Stamm, rissiger, rotbramer Rinde und nahezu flach ausgebreiteten Ästen und Z weigen. Die feinen, breitlinealen, ${ }^{1} / 3-1^{1} / 2 \mathrm{~cm}$ langen und bis $1 / 4 \mathrm{~mm}$ breiten, besonders bei den Formen auch narlel- bis schuppenförmigen, lebhaft griinen Blaitter sind in Spiralen angeheftet und hauptsächlichst bei der Stammform nach zwei Seiten ausgebreitet, werden auch meist gegen die Spitze des zarten Triebchens hin kirzer; sie fallen alljährlich mit letzterem ab.

Der länglich-runde, $2(-3) \mathrm{cm}$ große, weichlıolzige, erst griine, dam dunkelbraune Zapfen führt 10-12 spiralig gestellte, oben ziemlich schildförnige, mit Höckerung und krummer Stachelspitze versehenen Fruchtschuppen, welch letztere 2 (oder 1) braun glänzende, eckige, fast gefliigelte, mit derber Samenschale versehene Samen zeigen.

Der Keimling mit sechs dreikantigen Samenlappen, entwickelt zuerst spiralig gestellte Nadelbliitter, ehe die normalen, breiten folgen.

Vermehrung durch Samen bei feuchtem Standort, durch Stecklinge, welche jedoch in nicht zu jungem Stadium benuitzt werten diirfen, sowie durch Pfropfung der Formen auf die Stammform, jedoch vor dem Austrieb!

Das als Nutzholz gesuchte Holz ist fest und dauerhaft, außen weiß-gelblich, innen rot, enthält viel Harz, sowie ätherisches Ö1; liefert feinen Terpentin.

Dieser schöne Baum zeigt bei feuchtem, ja nassem Standort ein rasches Wachstum, sodaß er bei giinstigen Untergrundsverhältnissen selbst als Straßenbaum (wie z. B. in Holland) Verwendung findet.

Eine Zierde jeder Aupflanzung, ist er auch noch dadurch interessant, daf er bei nassem Standorteigentimliche ,knieartige, hohle Auswiichse in verschiedener Entfernung rom Stamm bildet, welche dazu bestimmt sind, den im W asserbefindlichen WVurzeln Luft 
zuzufïhren: bei trockenem Standort werden diese Answiichse

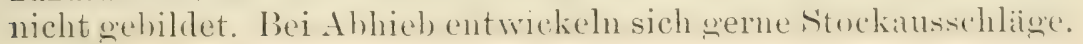

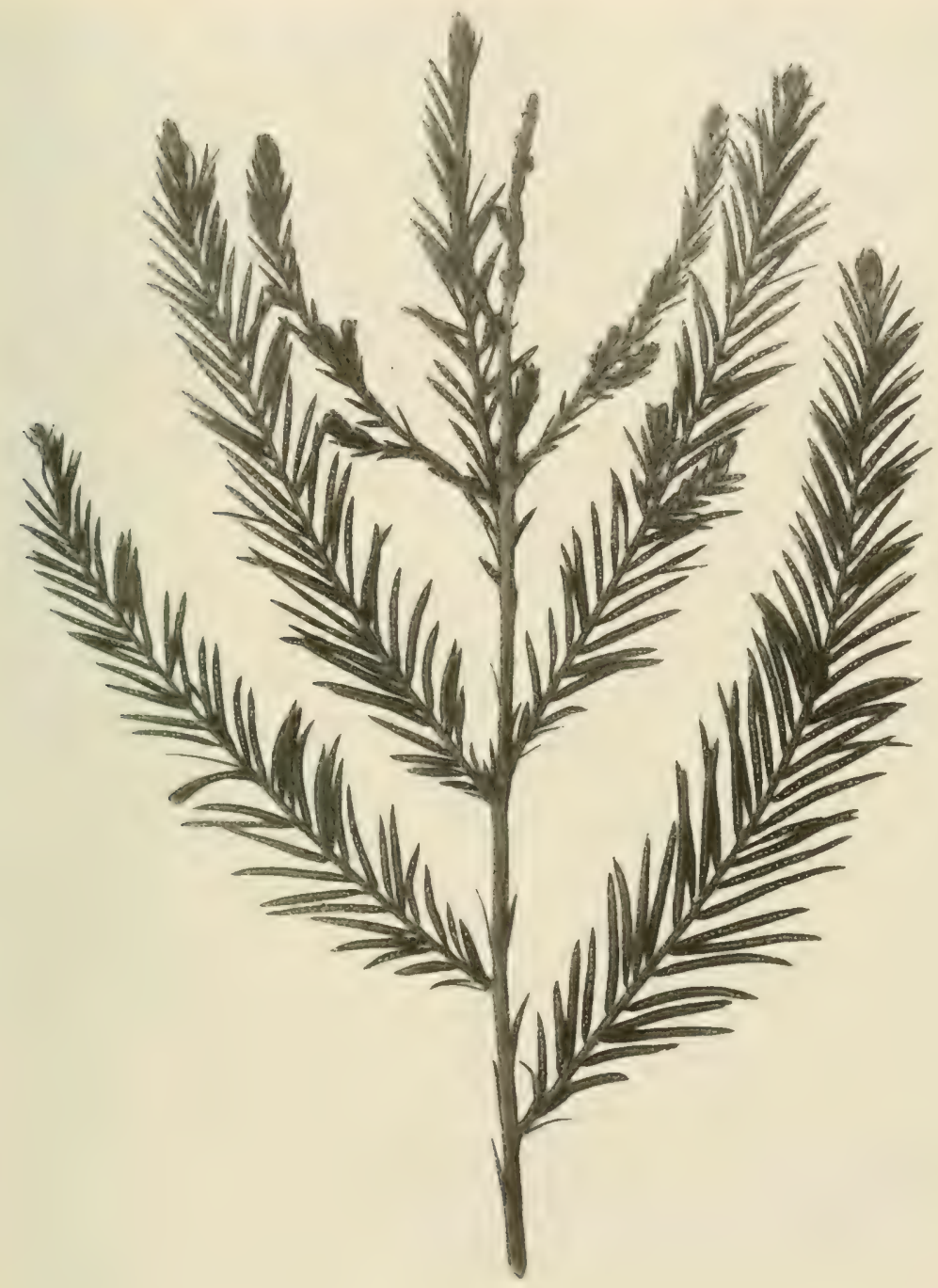

Fig. 131. Taxodium distichum Rich.

Die bei uns immerhin noch seltenen Formen sind:

Taxod. distichum pendulum Carr., nicht so hoch wie die Art, hängend, mit dicht gedrängten und verlängerten Zweigen und 
kiirzeren, auch an den Zweigspitzen angedriickten, ja schuppenförmigen, spiralig gestellten Blättern.

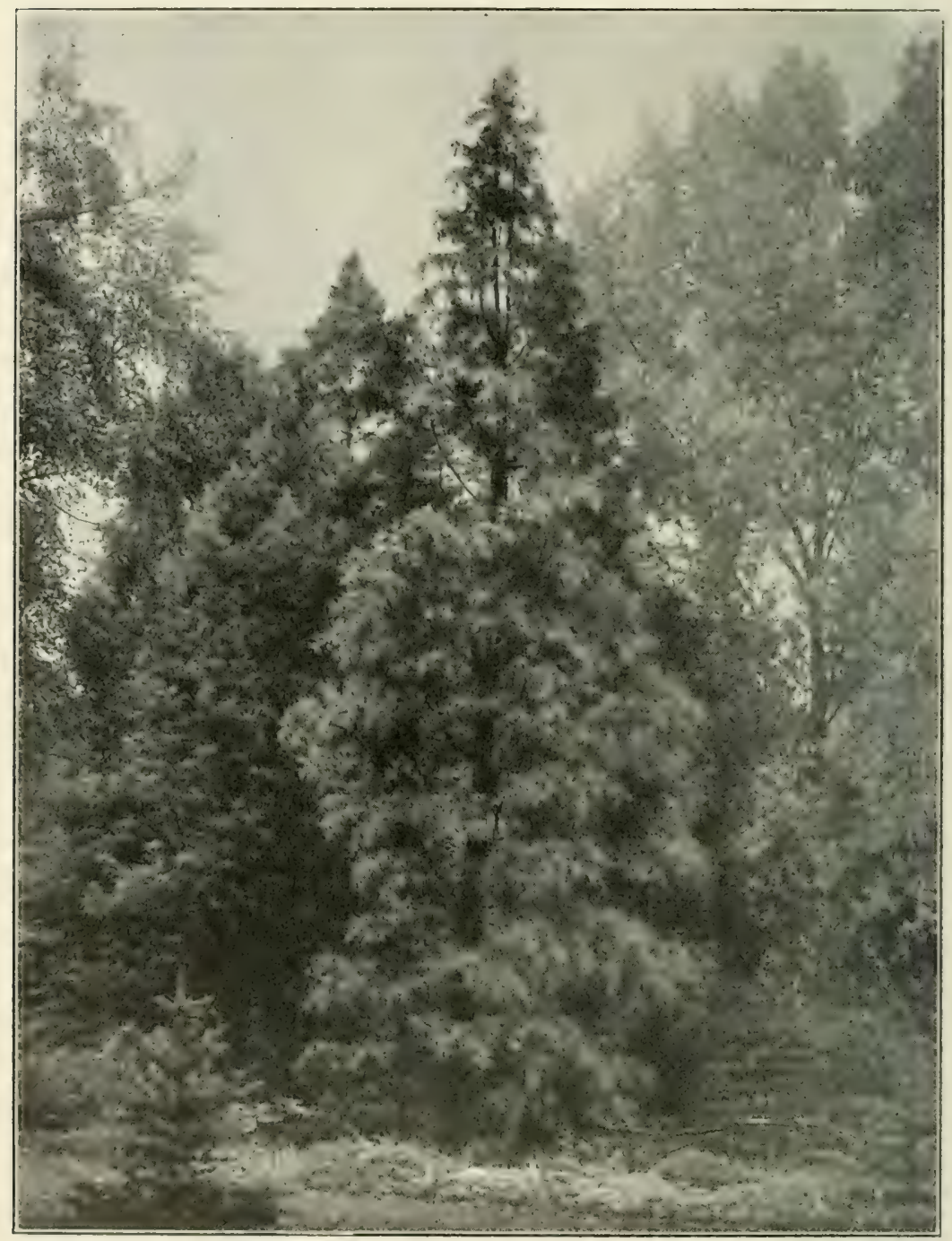

Fig. 132. Taxodium distichum pendulum Carr.

(Aus: Mitteilungen der deutschen dendrolog. Gesellschaft.)

Eine eigentiumliche Form, deren Zugehörigkeit zu Taxod. distich. noch angezweifelt wird. (Fig. 132 und 133.) 
Syn.: Taxodium distichum sinense pendulum Hort. Glyptostrobus pendulus Endl. (fälschlich).

Taxod. distichum pendulum elegans Hort., :ihnlich roriger, feinere Zweige.

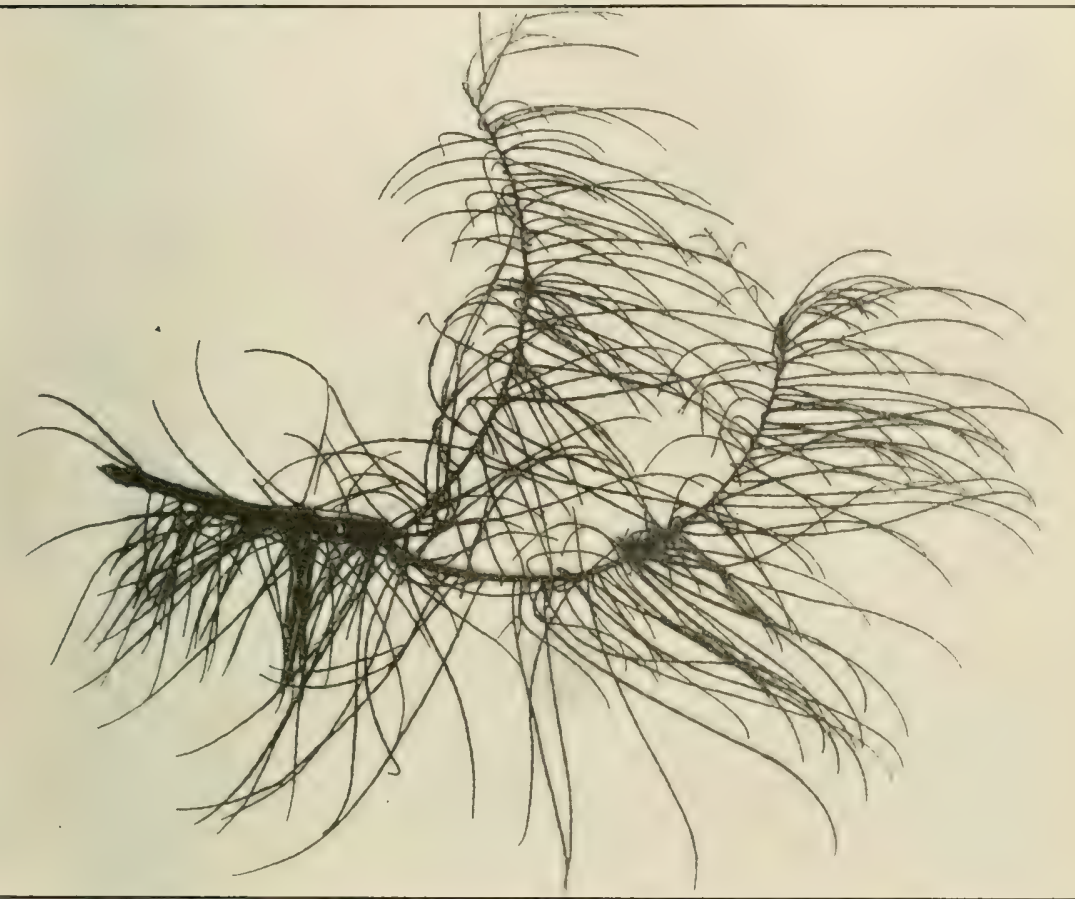

Fig. 133. Ast und Zweige von Taxodium distichum pendulum Carr. (Aus: Mitteilungen der deutschen dendrolog. Gesellschaft.)

... Taxod. distichum pendulum novum P. Smith, mit iiberhängenden Ästen und zweizeilig gestellten Blättern.

Taxod. distichum nutans Ait., licht gehaut, iibergebogene Äste, Bezweigung und Belaubung blïulich-griin, bereift.

Taxod. distichum denudatum Carr., iblergebogene Ïste, doch ungleichmäßig aufgebaut, mit kurzen, oft anliegenden Blittern. 
Taxod. distichum pyramidatum Carr., kegelförmiger Wuchs, dichtzweigig, Blätter zweizeilig.

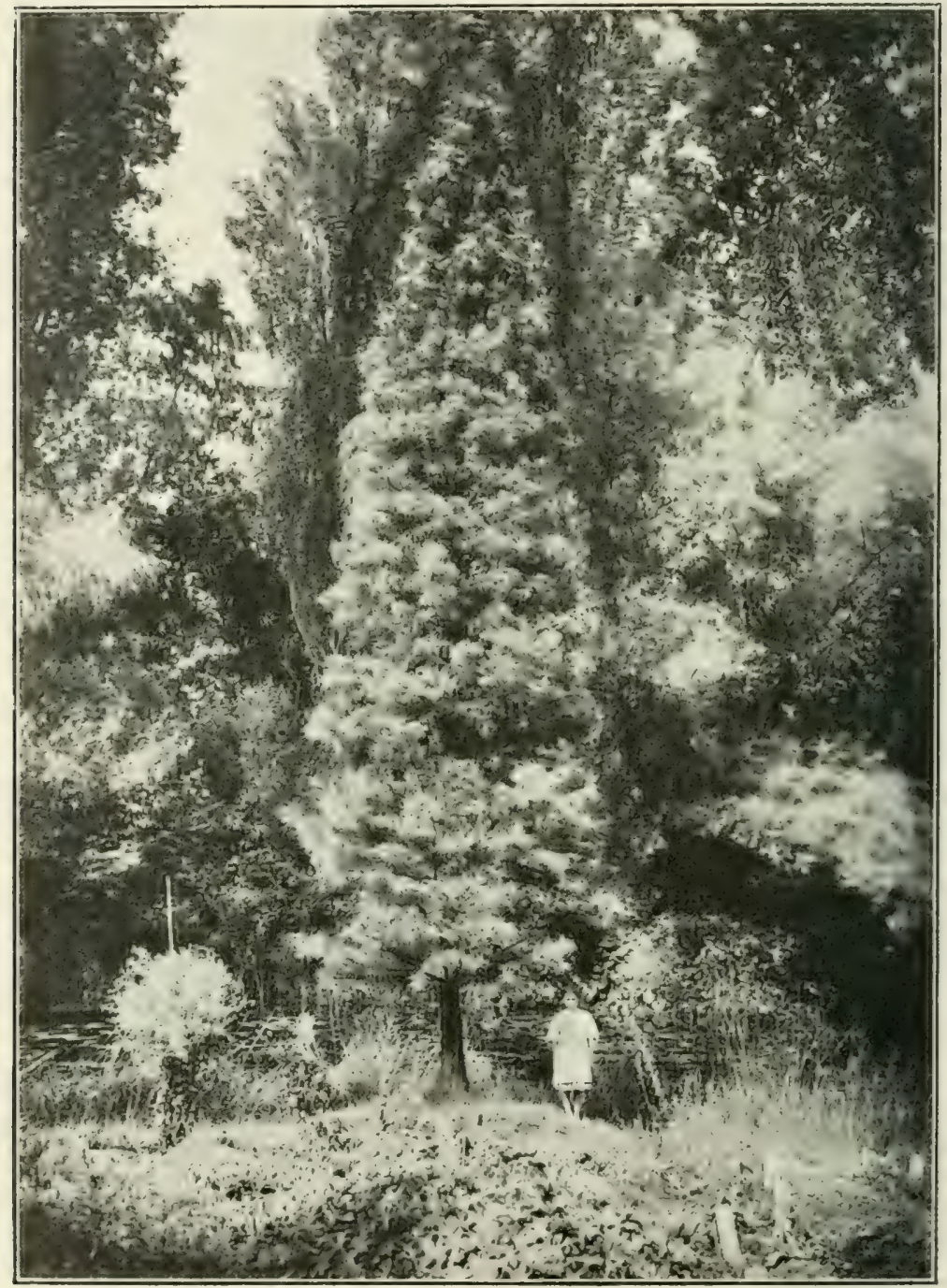

Fig. 134. Taxodium distichum erectifrons Schelle.

(Aus: Mitteilungen der deutschen dendrolog. Gesellschaft.)

Taxod. distichum microphyllum Carr., mit zweizeiligen, dam aber gegen die Zweigspitze kürzer werdenden, zuletzt 
schuppenartig deckenden Blättern. Wird anch als eigene Art betrachtet.

\section{Syn.: Taxodium microphyllum Brongn.}

Taxod. distichum intermedium Carr., eigenartige, lang hiangende Form mit schuppenartig gestellten Blättern.

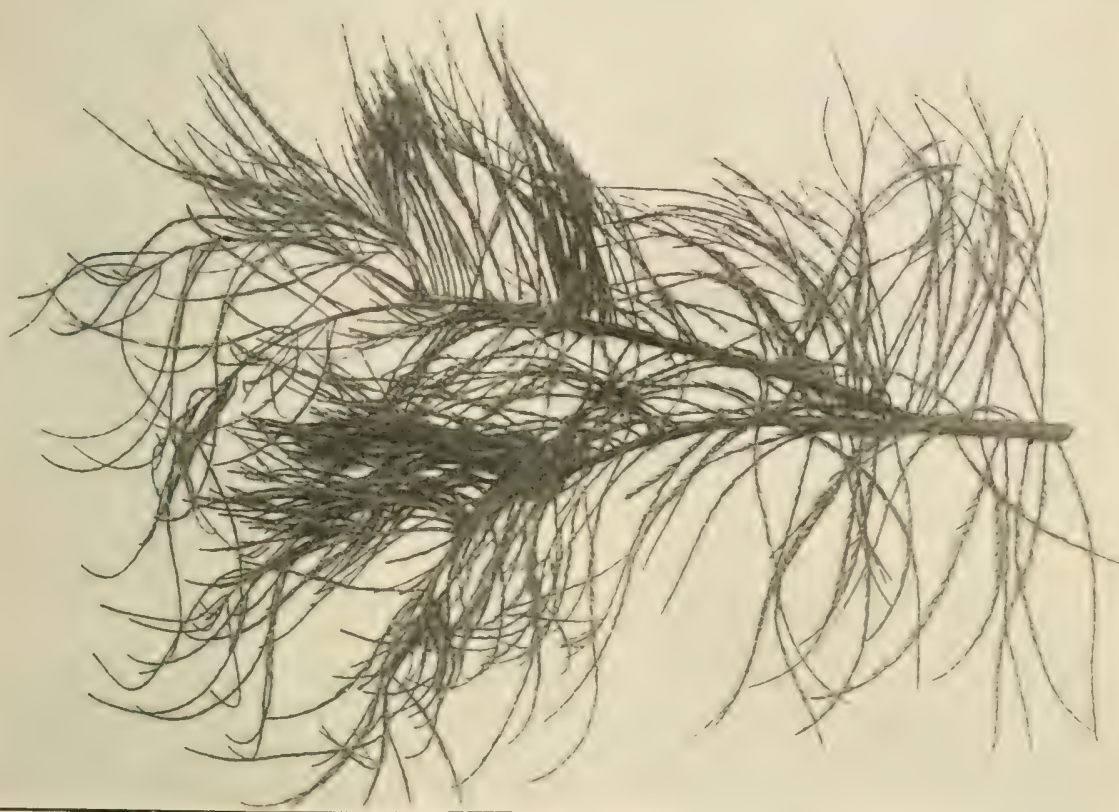

Fį̣. 135. Ast und Zweige von Taxodium distichum erectifrons Schelle. (Aus: Mitteilungen der deutschen dendrolog. Gesellschaft.)

Taxod. distichum Knightii Carr., mit licht und umregelmäßig. aufgebauten Ästen, aber dichtstehenden Zweigen und zweizeilig gestellten Blättern.

Taxod. distichum fastigiatum Knigth, mit aufstrebenden, ganz dimmen Ästen und zweizeilig gestellten Blättern.

Taxod. distichum erectifrons Schelle, höchst eigentimliche, sehr schöne Form, bei welcher die krautartigen, jährigen Zweige straff a ufw äts gerichtet sind. Blätter spiralig gestellt, lineal, schmal.

Als Solitäpflanze ihrer ganz wunderbaren Zweigstellung halber sehr empfehlenswert. (Fig. 134 und 135.) 
Taxod. distichum nanum Carr., buschig, dabei aber hochstrauchig; mit zweireihig gestellten Blättern.

Taxod. distichum nigrum Carr', breit gebaut, oft auch gebogene Äste.

Taxod. distichum compactum Hesse, gedrungener Wuchs.

Taxodium heterophyllum Brongn. Chinesische Sumpfzypresse, Wasserfichte. China.

VII (?)

Auf nassem oder gut feuchtem Standort.

Syn.: Taxodium mucronatum Hort. Glyptostrobus heterophyllus Endl.

In Deutschland nicht leicht winterharte Konifere ron wenigen Metern Höhe, durch Habitus und Belaubung an Cryptomeria erimmernd. Äste etwas aufstrebend bis wagrecht, Zweige zum Teil iiberhängend, jührige Triebe lang hängend, mit spiralig. gestellten, schmalen, fast pfriemlichen Blättern, gegen die Triebspitze gerichtet und geren diese kleiner werdend. Zapfen verkehrt eiförmig, mit länglichen umgebogenen, gezähnten Schuppen. Samen mit zwei schmalen Fligelrändern.

Diese Art wird auch als eine Form von Taxodiun distichum betrachtet.

Taxodium imbricarium (Nutt.) Harp. Nordost-Georgia, NordKarolina.

Syn.: Taxodium distichum imbricarium Sarg.

Noch ganz ungeniigend erforschte Art, - auch als Form ron Taxod. distichum betrachtet - bei uns nicht leicht winterhart.

Taxodium mexicanum Carr., Mexikanische S. Mexiko.

In Deutschland absolut nicht winterhart; in der Heimat ein Baum von ca, 45 m Höhe, bei einem Stammdurchnesser von nahezu $17 \mathrm{~m}$.

Diese Art ist hier nur deshalb erwähnt, weil diese Bäume ein - allerding's nicht ganz genau bestimmtes - Alter von etwa 4000 Jahren erreichen. und weil sie ihre Blätter und Kurztriebe erst im Spätwinter, also gewissermafen nur alle zwei Jahre abwerfen.

\section{g) Cupressineae.}

\section{Zypressenähnliche Pflanzen.}

Reichverzveigte, immergrine Bäume und baunartige Sträucher, oder auch richtige Sträucher, mit meist schuppen- 
förmiger Belaubung; nur die Erstlingsblitter der Keimpflanzen sind nadelförmig. Es zeigen sich aber letztgenannte Bliatter auch spontan an iilteren PHanzen, hesonders an unfuchtbaren Zweigen, nehen den schuppenformigen Blätern. Durch Fixierung dieser nadelförmigen Triebe, durch Stecklinge, also vegetative Vermehrung, welches Verfahren zuerst die Japaner angewandt haben, sind eigene Formen erzogen worden, die sogar, ehe man deren niihere Herkunft erkannte, als eigene Arten unter dem Namen .Retinispora” aufoestellt wurden. (Garteninspektor L. B e i $13 n \mathrm{e} \mathrm{r}^{\prime}$, friher in Garatshausen am Starnberger See, jetzt in Bom a. Rh., erforschte zuerst die Abstammung der Retinisporen und veröffentlichte seine Beobachtungen in Regels Gartenflora 1879, Seite 109. In obengenamnter Fachschrift veriffentlichte auch Garteninspektor. IV. Hochstetter, Tiibingen, 1880 Seite 362, seine sleichartigen diesheziiglichen Erfahrungen und Beobachtungen.)

Bliiten mon̈̈zisch und diözisch. Antheren mit 3-5 (selten 2) Pollensäcken. Wreibliche Bliiten mit mehrreilıig gegeniiberstehenden oder 3-4fach quirlständigen Schuppen. Samenknospen selten eine, meist zwei (und mehr) unter den fruchtbaren schuppen. Samenschuppe der Braktee angerachsen. Zapfenschuppen später offen bleibend, außer bei Juniperus.

\section{Actinostrobus Miq.}

\section{Schuppen-Zypresse.}

Krleiner Strauch mit runden Ästen, aufstrebenden und auch ziemlich wagrecht abstehenden, dreiseitigen Zweigen, sehrkleinen, schuppenförmigen, oval-dreieckigen bis län@lichen, sehr spitzen, steifen, dunkelgriinen Blättern. Monözische Bliiten. Zitpfen liinglich-rund, holzartig, im ersten Jahr reifend, mit 6 Fruchtschuppen. Samen dreiflügelig.

Actinostrobus pyramidalis Miq. Sevan-River Sch.-Z. Siidwestliches Australien.

In Deutschland nicht winterhart.

\section{Callitris Vent.}

(incl. Octoclinis F. von Muller; Frenela Mirb.; Widdring-

tonia Endlicher).

Schmuck-Zypresse.

Bäume orler Sträucher mit teils aufstrebenden. teils wagrechten Ästen, sowie mit zahlreichen, mehr oder mincler aufstrebenden, auch hiingenden, oft dimnen, oder zusammengedrickten Ziveigen. 
Blätter meist schmal, entweder nadelförmig oder schuppenartig, in 2-3-4zähligen Quirlen stehend, zum Teil mit Drisen rersehen. Erstlingsblätter nadelförmig. Blïten monözisch oder diözisch. Zapfen in ersten, oder im zweiten Jahre reifend, kugelig bis ovalrund, mit 4-6 Fruchtschuppen. Samen geflügelt.

Pflanzen von Afrika, Madagaskar, Australien und NeuKaledonien. Alle in Deutschland nicht winterhart!

Es sollen genannt sein:

Callitris australis R. Br. Östliches Neu-Holland. Syn.: Frenela australis Mirb.

Callitris fruticosa R. Br. Östliches Neu-Holland. Syn.: Frenela fruticosa Endl.

Callitris rhomboidea R. Br. Östliches Neu-Holland. Syn.: Frencla rhomboidea Endl.

Callitris robusta R. Br. Westliches Neu-Holland. Syn.: Frenela robusta Cunningh.

Callitris verrucosa R. Br. Ostliches Neu-Holland. Syn.: Frenela verrucosa Cumingh.

Callitris cupressoides Schrad. Kap der guten Hoffnung. Widdringtonia cupressoides Endl.

Callitris quadrivalvis Tent. Sandarak-Sch.-Z. Gebirge des nordwestlichen Afrika.

Liefert das offizinelle, sowie zu Firnis und Räucherung verwendete Sandarak-Harz.

28. Fitzroya Hooker fil.

(incl. Diselma Hook. fil.).

Alerce (d. i. Lärche).

Hoher Baum, oder auch nur Strauch mit dünen, ausgebreiteten, auch hängenden Ästen, vielen kurzen, dicht stehenden Z weigen, sowie teils lanzettlichen, abstehenden, teils schuppenartigen Blättern. Bliite diözisch. Zapfen rund, klein. Samen geflügelt.

Fitzroya patagonica Hook. fil. Patagonische Unter Schutz! Alerce. Siidliches Chile. Liebt feuchten Standort.

Baum bis $30 \mathrm{~m}$ hoch werdend, mit ausgebreiteten, dimnen und auch hängenden Ästen, kurzen, fast hiischelartig stehenden, ebenfalls etwas iiberhängenden Zweigen und liinglich-ovalen, bezw. lanzettlichen, abstehenden, stumpfgespitzten, dachziegelartig gestellten, kleinen, oben tiefgruinen, unten nit zwei weiklichen Spaltöffnungslinien versehenen Blättern.

Männliche Blüten in Kätzchen, weibliche Bliten rund, endstiundig, einzeln. Zapfen rund, sehr klein, mit sechs Frucht- 
schuppen, welche oben einen spitzen Fortsatz zeigen und je 2 bis 3 fast runde, zweiseitig gefliigelte, Hache Samen fïhren.

Vermehrung durch Samen unter Glas in Töpfen.

Das imen schöne, rote Holz ist sehr wertvoll, weil äufierst damerhaft und weil es sehr leicht verarbeitet werden kann, auch sonst zu allen möglichen Zwecken Verwendung findet. I lie iaßere Borke ist faserig, so dauerhaft etwa wie Cocos; sie findet als Bindematerial, als Werg etc. starke Verwertmg.

Fitzroya Archerii Bentls. Archers Alerce. Strauch ron Tasmanien. Bei uns nicht winterhart.

Syn.: Diselma Aicherii Hook. fil.

\section{Thuyopsis Siebold und Zuccarini. \\ $\mathrm{H}$ ib a.}

Immergrine, breit ausladende, prïichtige, in der Heimat bis iiber $30 \mathrm{~m}$ hoch werdende Bäume, mit breitschuppigen Blättern und monözischen Blüten. Ton letzteren sind die weiblichen endständig, mit gekreuzt gegenüberstehenden. 6-10 dicken Schuppen, von welchen jedoch nur die mittleren ca. 5 zweiseitig gefliigelte, schmale Samen tragen. Minnnliche Blite ebenfalls endständig an Seitenzweigchen, länglich vou Form. Der rundliche Zapfen lat 6-10 gestreifte Fruchtschuppen.

Thuyopsis dolabrata Sieb. und Zucc. Beil- Liebt halbschattigen, b)iitterige H. Hochgebirge Japans. (Fig. 136.) $\begin{gathered}\text { Liebt halbschattigen, } \\ \text { külten, etwas feuchten }\end{gathered}$ Auffillicer, sanz charakteristischer, ziem- Standort, doch ist lich breit werdender, in der Jugend trägwüich- Muträglich. siger Baum, dessen Habitus sich mit seinen etwas iiberhängenden Zweigen und besonders den hreiten Blättern jedermann bleibend einprägt. Die festen, breiten, schuppenartigen Bliitter zeigen ein hellglänzendes, gell,liches Grün, eine schmale Druise, sowie unten hellweitse Bänder; die etwas gröberen Randblätter sind kahnförmig.

Die braunen, auffallend dicken, alt fastholzigen Zapfen sitzen an kurzen Zweigen und fiihren 6-10 oben leicht hakige Schuppen, mit 4-5 schmalgefliigelten, lïnglich-runden, flachen Samen, welche Harzhöckerchen tragen; leider keint der Samen schlecht.

Der mit 2 Samenlappen versehene Keimling entwickelt zuerst gegenständige, dann quirlig stehende Nadelblätter.

Vermehrung am besten aus Samen; Stecklinge, besonder's von Seitentrieben, wachsen gut, erzeugen aber wohl stets mehr breit als hoch werdende Pflanzen mit mehreren Haupttrieben, so daß man gezwungen ist, einen Trieb längere Zeit hoch zu 
binden und die anderen zu unterdricken. Pfropfungen auf Biota; solche anf Thuya kimmern bald und sterben oft rasch ab.

Das hellgelhe, sehr stark und angenehm riechende, dauerhafte Hol's dient in der Heimat des Baumes zu Hoch- und Tiefbauten, sowie zu Wasserbauten etc.

Formen sind:

Thuyopsis dolabr. variegata Hort., mit einzelnen weißbunten Zweigen.

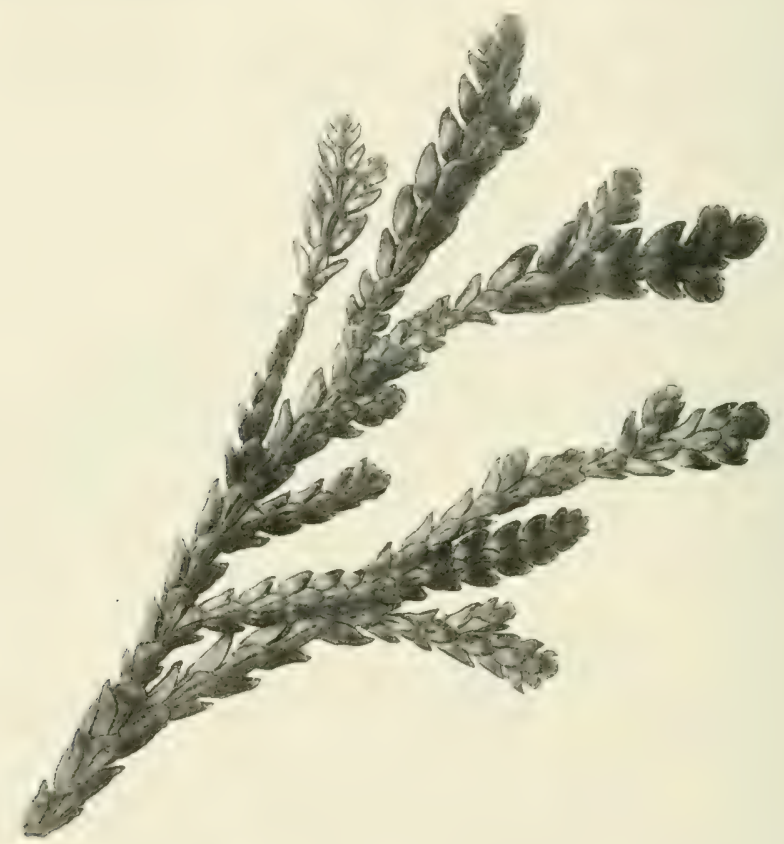

Fig. 136. Thuyopsis dolabrata Sieb. u. Zucc.

Thuyopsis dolabr. robusta Hort., stark und hoch wachsend. decumbens Hort., überhängend.

nana Sieb. und Zucc., niederliegend, nest-

artig, dünnzweigig".

Syn.: Thuyopsis laetevirens Lindl.

Thuyopsis dolabr. cristata Hort. Ansorg., gedrungen-kegelförmig, mit hreit fiicherförnigen, hahnenkammartig gekräuselten Zweigen.

Thuyopsis dolabr. plicata Hort. Ansorg, ähnlich voriger, uippiger, etwas gefaltetere Bezweigung.

Thuyopsis dolabr. altissima Hort. Ansorg., starkwuichsige, fast säulenförmige, kurzzweigige Form. 


\section{Biota Endlicher.}

Morgenländischer Lebensbaum.

Immergriune, mittelhohe, pyranidal wachsende Biiume mit aufsteigenden Asten, zweiztiliщ stehenden, steifen, senkrecht gerichteten, feineren Zweigen und schuppenförmigen, hellgrinen Blättern.

Bliten monözisch; weibliche Blite einzeln, an den Spitzen seitlicher Zweigchen, mit $6-8$ aufrecht abstehenden schuppen. Mimnliche Bliiten mehr rundlich, ebenfalls endstindig. Zapfen rundlich, mit ungefligelten Samen in ziemlich harter Schale.

Biota orientalis Endl. Morgenländischer L. China, Japan. (Fig. 137.)

Syn.: Thuya orientalis $L$.

Dieser mittelhohe, selhst hoch-strauchartige Baum, der noch vielfach unter seinem Synonym in Gärten geht, zeigt sich lösende Rinde, auf-

III (IV)

Liebt geschützten, windfreien, nicht $z ı$ sonnigen Standort bei nicht zu schwerem Boden. Empfindlich gegen Sonnenbrand und starke Ostwinde. steigende Aeste und ficherförmig sich auslegende, lotrechtstehende, zusammengedriickte Zweige.

Blätter beid e rs e its meist hellgrin, im Winter leider sich bräunlich färbend, schuppenförmig, die Flachblätter linglichrund, die Kantenblätter kahnförmiø, beide mit länglichen, vertieften Drisen. Entwickeh beim Zerreiben nur wenig Geruch!

Die an kurzen Zweigen stehenden, griinen, bläulich bereiften, länglich-runden Zapten sind ungleich grob, fïhren 6-8 an der Spitze gebogen-hakige Schuppen, von welchen die obersten unfruchtbar sind. In Alter werden die Zapfen braun, zeigen aber doch leichten Reifiiberzug. Die nußartigen Samen sind braun, dickschalig und ungefligelt.

Die Keimlinge sind an ihren beiden sehr langen, oben bläulich-, unten hellgrünen Samenlappen kenntlich; sie entwickeln zuerst nadelför'mige Blätter.

Vermehrumg am vorteilhaftesten durch Samen, der am besten noch im Herbst ansgesät wird; die der Formen jedoch durch Stecklinge, welche allerdings nicht besonder's gut wachsen, aufier jenen der Jugendformen. Pfropfung auf die Art und auf die Form pyranidalis, welche ziemlich winterhart ist, im Notfalle auch auf Chamaecyparis Lawsoniana.

Das rötliche, danerhafte Holz findet in der Heimat des Baumes reiche Verwendung.

Formen sind:

Biota orient. argenteo-variegata Hort, weißbunt. 
Biota orient. elegantissima Gord., schlank-pyramidal, im frischen Trieb goldgelb. (Fig. 138 und 158.)

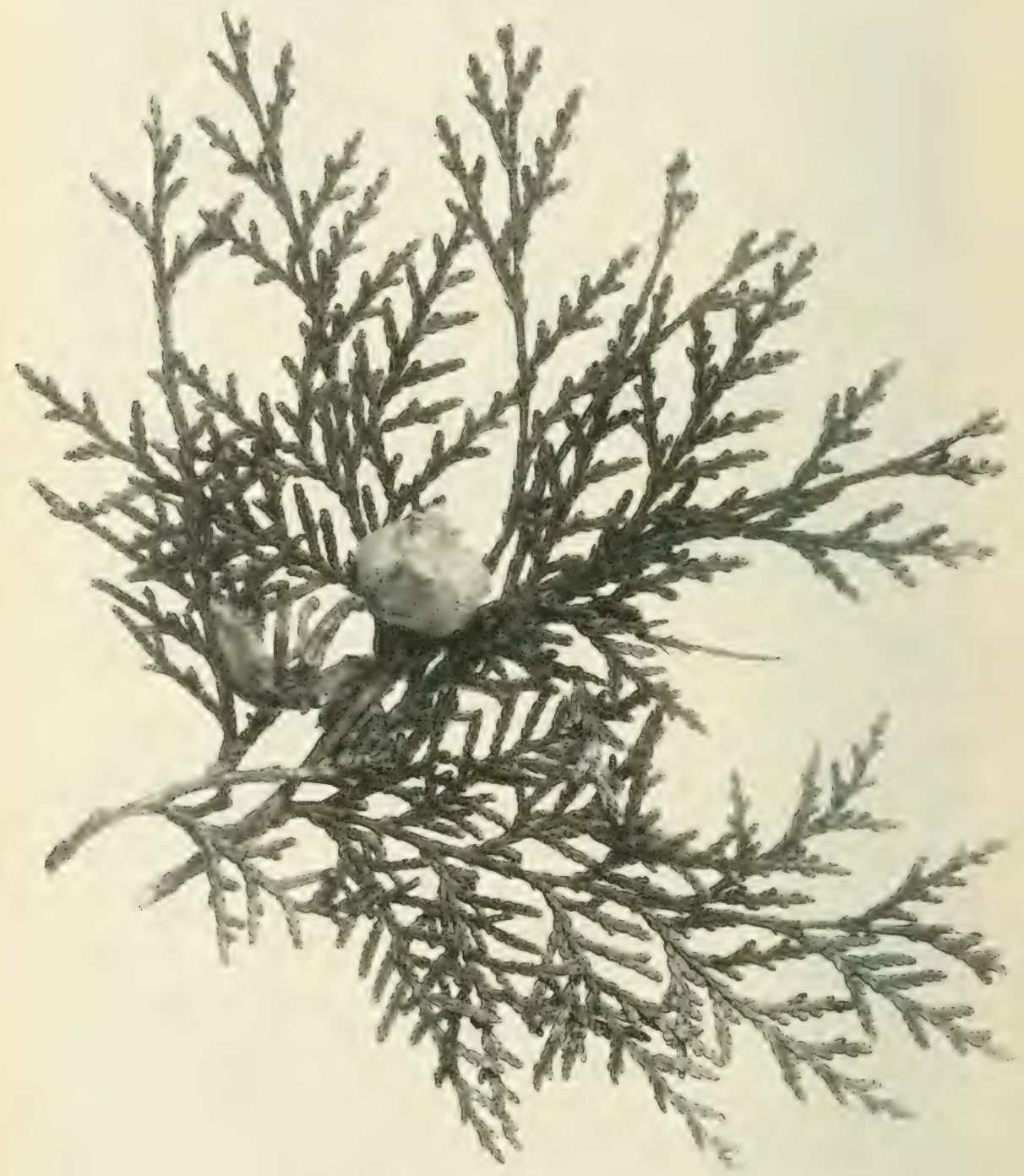

Fig. 127. Biota orientalis EndI.

Biota orient, elegantissima picta Hort., teilweise gelb. pyramidal, goldgelb.

$$
\text { semperaurescens Hort., gedrungen III (II) }
$$




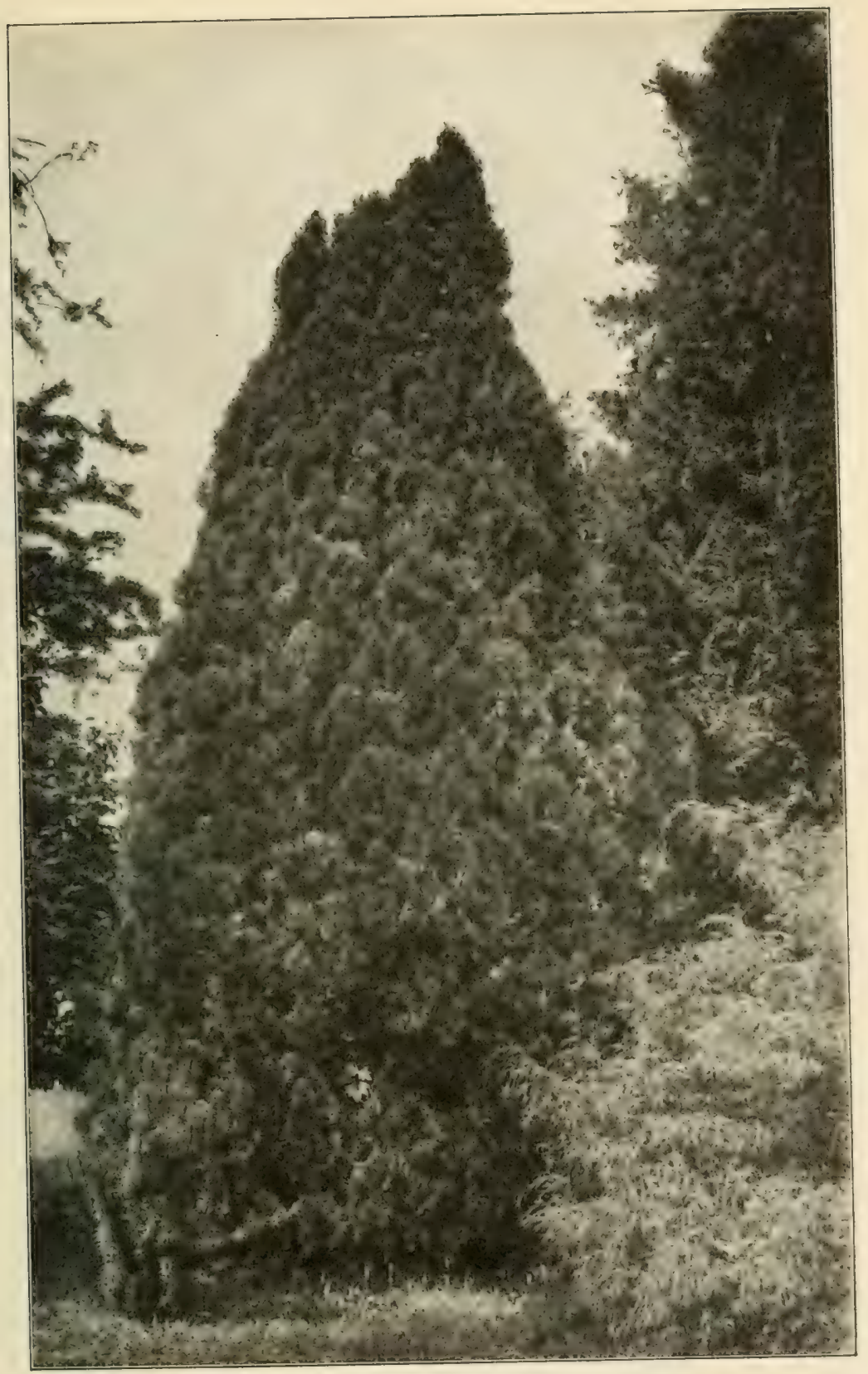

Fig. 138. Biota orientalis Endl. elegantissima Gord.

Vorne links: Cephalotaxus pelunculata S. u. Z. fastigiata Carr.; rechts: Chamaecyparis pisifera S. u. Z. filifera Hort. 
Biota orient. laxenburgensis Hort., gelhgriin, schlankpyrainidal.

Biota orient. falcata Veitch, starkwiichsig, pyramidal, II (III) die Zapfenschuppen mit rückgekrümmten Dornen.

Biota orient. gracilis Hort., feine, lebhat grime Zweige. lebhaft griun. pyramidalis Endl., pyramidal-aufsteigend,

Biota orient. Weimerii Hort., kugelig-pyramidal. Verschaffeltii Hort, gelbspitzig. densa glauca Hort.,blaugriin, dichtgebaut. III (II) hängend, blaugriine Zapfen. glauca Carr., graugrỉn, breit, uiberIII (II)

Biota orient. dumosa Carr., gedrungen, pyramidal, derbe Blätter.

Biota orient. aurea Hort., kugelig-pyramidal, gelbgriin, schön, liebt Halbschatten.

Biota orient. filiformis Henk. u. Hochst, prachtroll, fadenförmige Zweige, lang điberhängend.

Syn.: Thuya fumalis Hort.

Biota orient. filiformis stricta Hort., mit mehr aufstrebenden Zweigen und etwas abstehenden Blättern.

Syn.: Biota japonica Hort. filiformis japonica Hort.

Thuya japonica Hort. filiformis japonica Hort.

Biota orient. filiformis tetragona Hort., ähnlich voriger. intermedia Carr., starkwiichsige, rundliche Form. mit iiberhängenden Z̈weigen und schuppenIII (II) förmigen, abstehenden Blättern.

Biota orient. funiculata Hort., ähnlich voriger. III

" monstrosa Carr., verdickt-zweigig.

Syn.: Biota orient. dacrydioidis Hort.

\section{" Defiesneana Hort.}

Thuya occidentalis arthrotaxoides Hort.

$$
\text { Defresneana Hort. }
$$

Biota orient. decussata Beiß3n. und Hochst.

Syn.: Retinispora juniperoides Hort.

Fixierte Jugendform, (es findet hier das gleiche Verfahren statt, wie solches auf Seite 261 des näheren schon erwähnt wurde), mit narlelförmigen, unterseits weiß-rinnigen (Erstlings-) Blättern; im Winter dunkel-bläulichgrim.

Biota orient. meldensis Hort., Übergangsform, nadelförmige und schuppenförmige Blätter; blaugrim. 
Syn.: Retinispora meldensis Hort.

Biota meldensis Hort. (nicht Laus.).

Thuya meldensis Hort.

Biota orient. compacta Hort., r'undlicher, gedrungener

Bau. Liebt Halbschatten.

Syn.: Biota orientalis Sieboldii Endl.

Biota orient. compacta Ungerii Beißn., mit weißen spitzen an den jungen Trieben.

Syn.: Chamaecyparis pisifera Ungerii Hort. Boehm. zierlich.

Biota orient. articulata Hort., kugelförmig, feinz weigig,

Biota orient. minima compacta Hort., klein, gedl'ungen. III (II)

glauca Hort., wie vorige, graugriun.

" " sphaeroidea glauca S.-L. Kugelform, mit allen Übergängen der Beblätterumg von der Schuppenform zur Nadelform.

31. Libocedrus Endlicher.

Flu $\mathrm{Bz}$ e d e r.

Immergriune, stark veristelte Bäume. Zweige flach; der Leittrieb aufrecht. Blätter teils flach, teils kantig, die Schuppennadeln mit langer Basis an Zweig herablaufend. Weibliche Bliiten endstïndig, einzeln stehend und länglich-rund, 4-6schuppig; männliche Bliiten ebenfalls endständig, mit kreuzständig stehenden Staubbeuteln. Samen ungleich gefligelt.

Libocedrus decurrens Torr. Kalifornische Flußzeder. Kalifornien, Oregon, (Fig. 139.)

Syn.: Thuyge gigantede ('arr. I nicht Nuttall.

Hëyderin iecurrens C. Korh.

Noch mancherorts unter der ganz falschen

Höhenlage Vorteil. Liebt besonders im Winter Schutz vor Winden und starker Sonnenbestrahlung. Nicht zu trockener Boden! Jung etwas empfindlich.

Bezeichnung 'Thuya gigantea gefiihrter, prächtiger', besonders vom 5. Jahre etwa starkwüchsiger, $50 \mathrm{~m}$ hoch werdender Baum, von nahezu säulenförmigem Wuchse, fist gabelartiger V'erzweigung, tiefrissiger, abbliitternder, rothramer Rinde und glianzend griinen, gekielten, schuppenförmig anliegenden, scharf spitz auslaufenden, kreuzweise gegeniiberstehenden Blittern, welche beim Zerreiben einen eigentimlichen, scharfen Gerıch ergeben.

Die bei $3 \mathrm{~cm}$ grofen, länglich-eirunden Zapten sind braun und führen 4 grobe und 2 kleine, in eine Spitze auslaufende Schuppen, von welchen zwei fruchtbare bei der Samenreife zuriickklaffen.

Die selten zur Reife gelangenden Samen sind ungleich gefluigelt. 
Das stark riechende, hellgelbe, imen rotbraune, geaderte Holz gibt gutes Bauholz, auch scheidet die Pflanze ein offizinell gebräuchliches Harz: "Manna" aus.

Vermehrung durch Samen; Stecklinge wachsen meist schlecht. Pfropfungen werden auf die Art ausgeführt, oder im Notfall dicht an Boden auf Sämlinge von C'hamaecyparis Lawsoniana oder auch auf Thuya occidentalis.

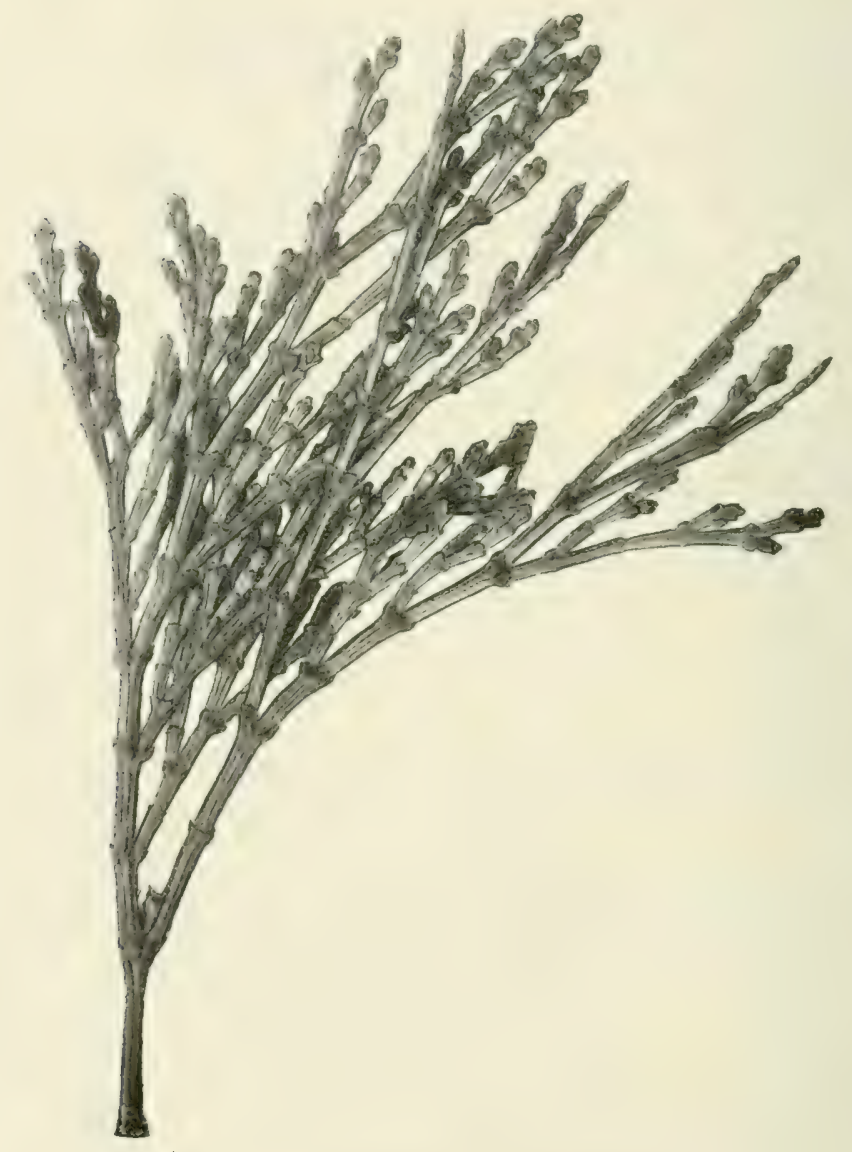

Fig. 139. Libocedrus decurrens Torr.

Formen sind:

Libocedrus decurrens aureo-variegata Hort., mit einzelnen, goldgelben $\mathrm{Z}_{\text {weigen. }}$

Libocedrus decurr. glauca Hort., mit mehr blaugriinen Blättern. satz der Böcklinzypresse. 
Libocedrus decurr. compacta Hort, nieder, nedrungen.

Libocedrus chilensis Endl. Chilenische Flufizeder, vir? von den siidlichen Anden Chilis stammend, eine schöne, Mit Schutz. spitz-pyramidale drt, mit schuppenfömigen Bliittern. Häit wohl mit Schutz ziemlich gut nicht zu scharfe Winter in Region VII aus.

Dagegen dürften

Libocedrus papuana F. v. Mr., von den Höhen Neu-Guineas, dam tetragona Endl., von den Gebirgen des nördlichen Chiles, f'erner

Libocedrus macrolepis Benth. und Hook., von China stammend, und

Libocedrus Doniana Endl., von den Gebirgen des nordöstlichen Neuseeland, welche 4 Arten zwar da und dort noch fiur dis Freiland empfohlen werden, jedoch nur noch fiir Kalthäuser passend sein, mit Ausnahme etwa von der im Wuchs einer Thuyopsis dolabrata gleichenten Libocedrus macrolepis.

\section{Thuya Tournefort.}

Lebens bäume.

Immergrine, schöne und hohe Biume, von meist pyramidalem Wuchs, oft dicken Unterstimmen, ausgehreiteten, zahlreichen Ästen, abwechselnd gestellten, flachen Zweigen, zweizeilig stehenden Zweigchen und schuppenartigen, mit Öldrisen versehenen, z. T. mit hellgrauer Linie gezeichneten Blättern. Leitzweige steif. Bliiten monözisch; männliche Bliiten einzeln, endstiandig, rundlich, mit 2-4 Pollenbenteln; weibliche Bliite rundlich oder länglich, einzeln stehend, mit gegenständigen Schuppen. Die fruchtbaren Schuppen führen je 2 Samenknospen.

Zapfen rund oder länglich, meist bald trocken und hart werdend, doch nicht verholzend, dabei lange hängen bleibend. Samen ringsum mehr oder minder breit geflugelt.

\section{Abteilung: Euthuya Benth. und Hook.}

Echte Lebensbäume.

Reife Zapfen iibergebogen lianglich-r'und, mit wenig rerdickten Schuppen, wovon jedoch nur zwei fruchtbar sind; unter jeder Schuppe zwei Samen, letzterer breit, fast gleichmäßig zweiflügelig.

Thuya occidentalis L. Abendländischer L. Östliches Nordanerika. (Fig. 140 u. 141.)

In seiner Heimat weitverbreiteter und auch bei uns sehr stark beniitzter, schon im 16. Jahr-

Kümmert auf recht sandigem, trockenem Boden. Gegen Staub und Rauch nicht sehr empfindlich. hundert eingefiihrter Baum, der seiner Anspruchslosigkeit halber nahezu sprichwörtlich geworden ist. Glänzendgriin, im Winter 


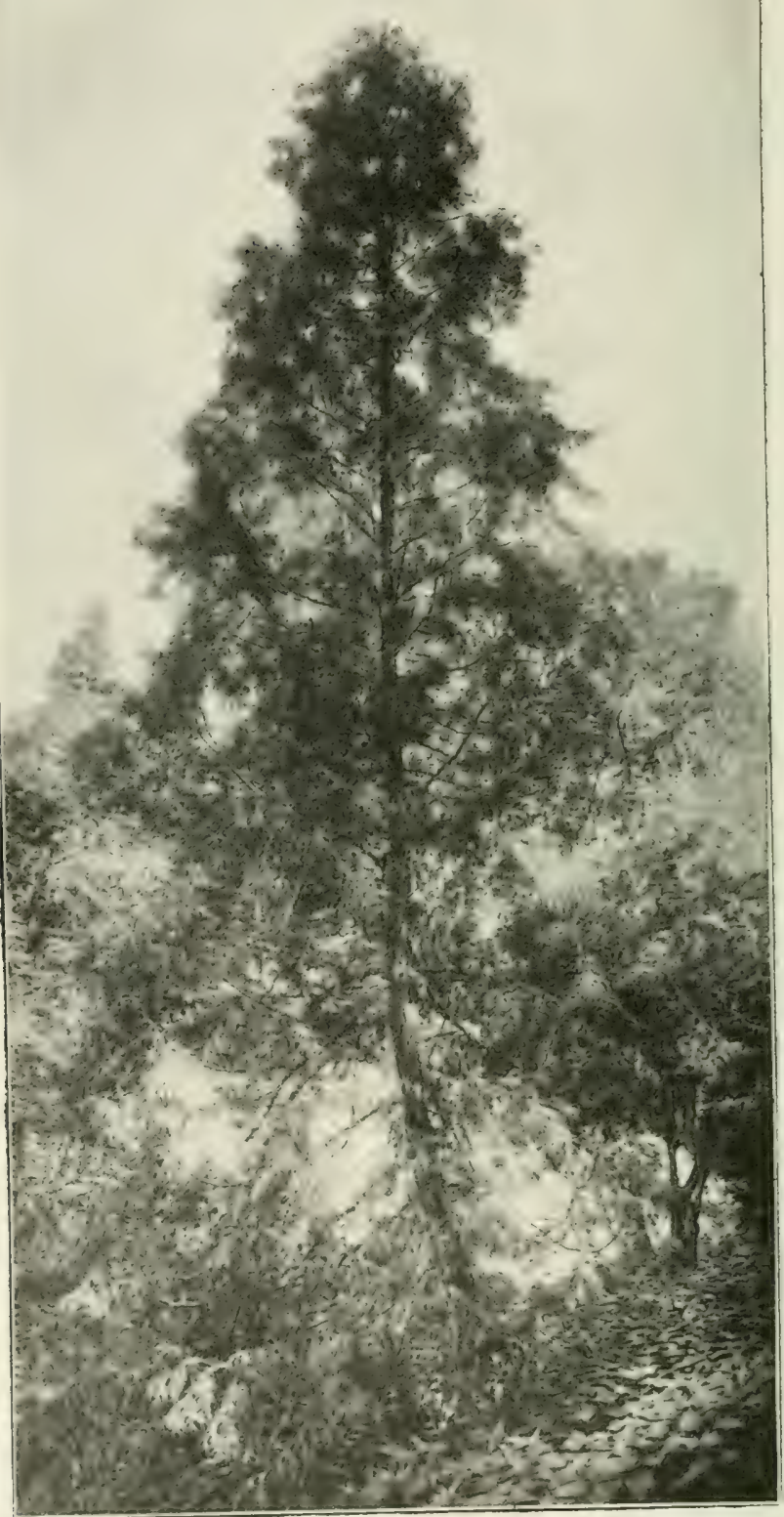

Fig. 140. Thuya occidentalis L. (Wildwuchs, 20 jährig.) 


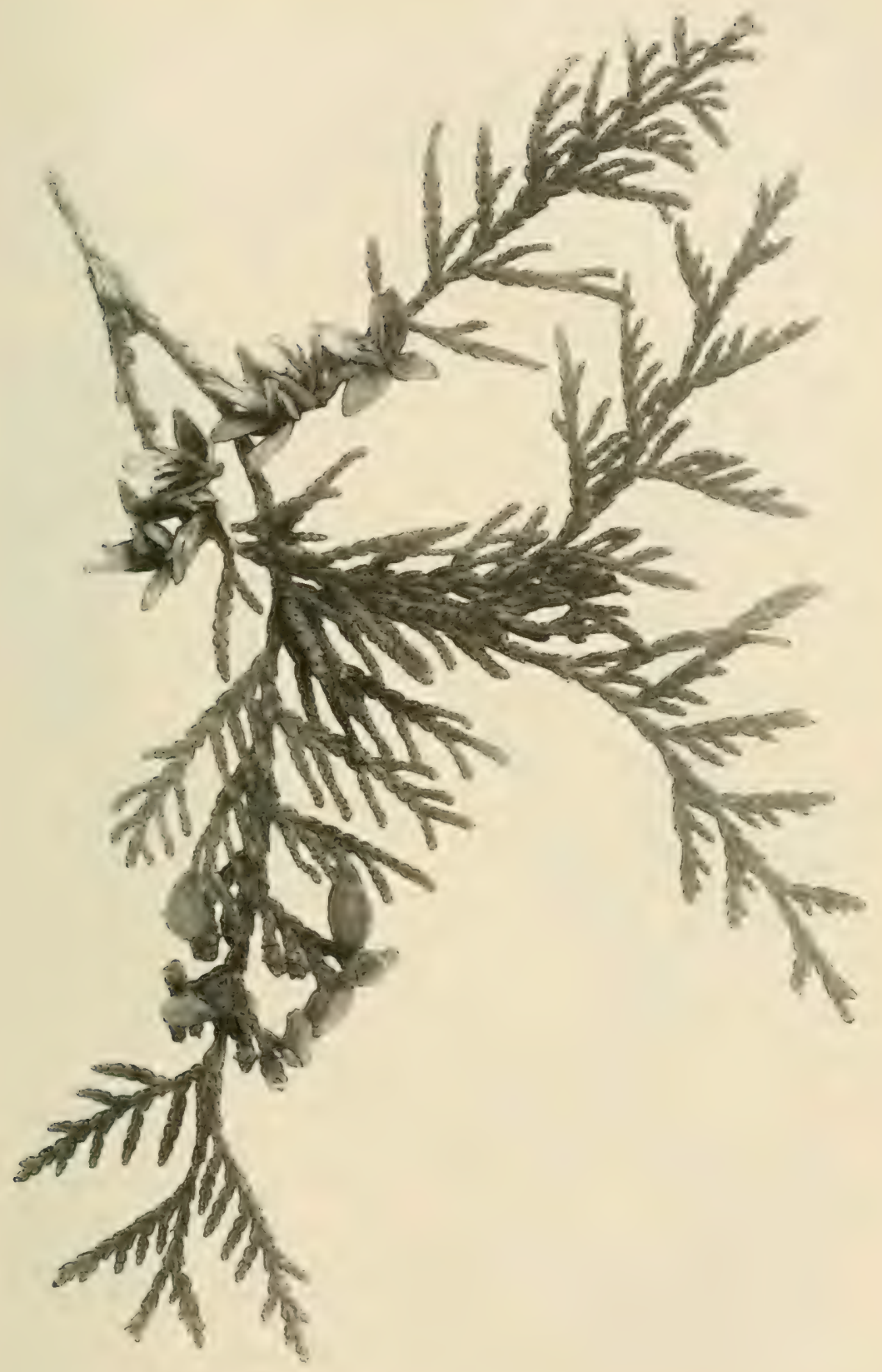

Fig. 141. Thuya occidentalis L. 
schmutzig griin, mit breitgedrickten, zweizeiligen Trieben, schuppenfömigen Blättern, die Flächenblätter mit einer kngeligen Öldriise, die Randblätter kahnfömig; Erstlingsblätter (welche besonder's auch an unfruchtbaren Zweigen wieder erscheinen) ringsum gestellt und nadelförmig.

Zapfen erst weich, bald vertrocknend, zahlreich, länglich oval, mit 6-8 gegenständigen, oben schmalen, menten hreiten schuppen, von welchen aber nur 2 fruchtbar sind. Same mit schmalen, feineu, gelblichen Fliigeln versehen. Keimling mit zwei Samenlappen. Vermehrung durch Samen und Stecklinge. Pfropfungen auf die Art.

Thuya occidentalis, - alliberall, besonder's aber auch an sumpfigen Plätzen verwendbar, oder herab bis zur leicht mit ler Scheere in jede beliebige Form zu bringenden Hecke, liefert ein äußerst dauerhaftes, wenn auch leichtes, doch besonders fiur Erd- und auch Wasserhauten (hauptsächlichst Pfahlholz) verwendbares, rötliches Holz. Das itherische ()I - ein Glycosid - und das ïhnliche Thuyin wird besonders in Nordamerika, damn aber auch bei uns in der Homöopathie sehr stark verwendet.

Die wie die Stammform in gärtnerischer Hinsicht vielseitigr verwendeten Formen sind sehr zahlreich. Von denselben soll die friiher als eigene Art unter ., Retinispora" aufgefiilute zuerst genannt sein:

Thuya occidentalis ericoides Hort. (Fig. 142.)

Syn.: Retinispora ericoides Hort.

Thuya evicoides Hort.

Diese "Form" wurde (wie bereits Seite 261 bemerkt zuerst von (len Japanern) dadurch gevomnen, dati besonders von der Sämlingspflanze, die na delförmige Blätter fiihrt, Stecklinge entnommenwurden, welche Blaitterart die nene Pfanze nun beibehielt. Doch erreichen diese Pflanzen nur ein geringes Alter, werden iiherhaupt neist schon nach 15-20 Jahren ruppig und unschön.

Obiges Verfahren wrude und wird noch bei einer weiteren Anzahl von Nartelhölzern, besonders aber hei den Cupressineen, ausgefuihrt. Es schließen sich dieser Form direkt an:

Thuya occident. Ellwangeriana Hort. (Fig. 143.)

Syn.: Retinispora Ellwangeriana Hort.

Thuya Ellwangeriana Hort.

Thuya occident. Ellwangeriana aurea Hort. Spaeth, golligbunt, kugelig.

Syn.: Thuyg occid. Ellwang. pygmaca aurea Hort. angl.

Thuya occident. Ellwangeriana, Rheingold" Hort. Vollert., präichtig, oranergelb, viele Nadelblïtter, rundliche, buschige Zwergform.

Diese drei Formen sind sogenannte Übe rgang gormen, indem rlieselben Zweige mit nadelförmigen Blättern und solche mit schuppenförmigen erzeugen. 


\section{$-275$}

Thuya occident. Spaethii P. Smith, ebenfalls beiderlei Blattformen zeigend, dabei mit monströsen und fadenförmigen Zweigen.

Syn.: Thue occident. Ohlendorfii Hort.

Thuya occident. aurea Hort., dunkelgelb, breitwiichsig. II (1)

Syn.: Thuy plicata amea Hort.

Thuya occident. aurescens Hort., gelbbiitterig. „Cloth of Gold" Arb. Arn., hellgelb, zierlich, leicht ge"bogene" Zweige.

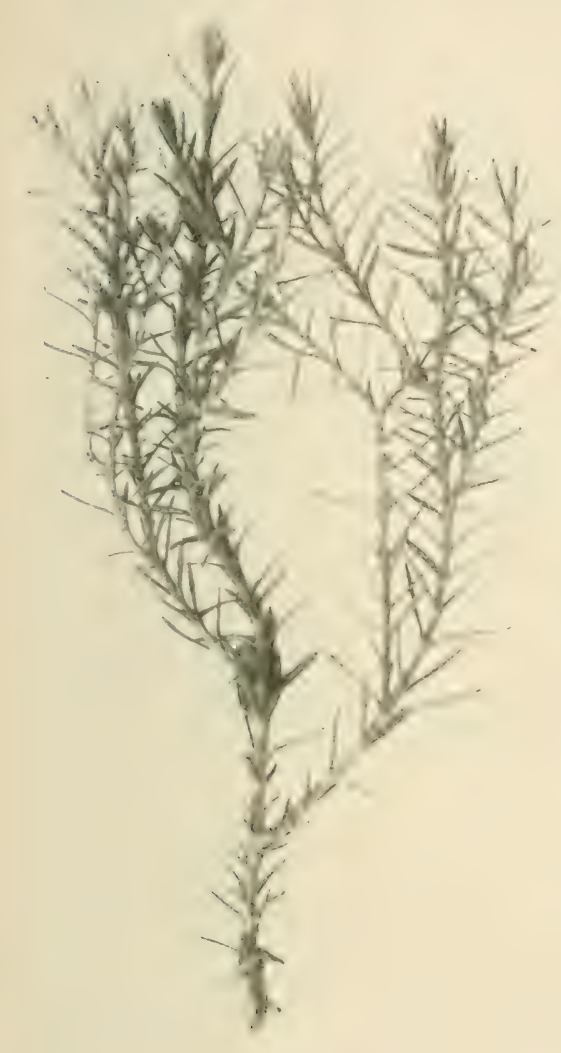

Eig. 142.

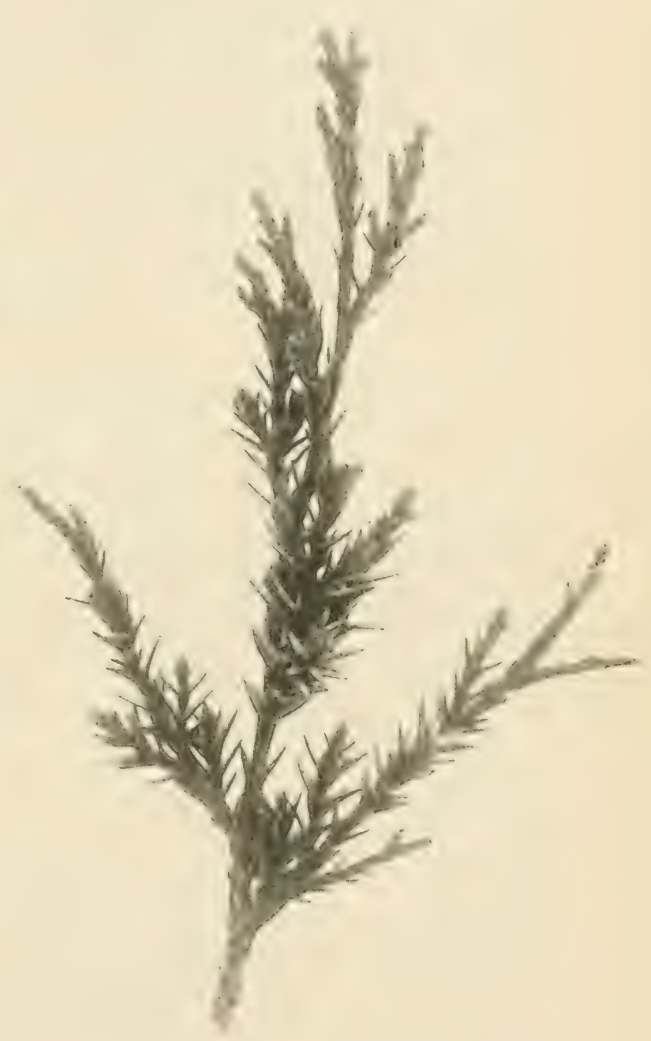

Fig. 143.

Thuyu occidentalis L. Ellwangeriana Hort.

Thuyu occidentalis L. ericoides Hort.

II (1)

Thuya occident. Iutea Hort., hellg'elb. " nana Hort., hellgelb, nieder. Trieben "gelbspitzig: aureo-spica Hort., an juingeren II (I) 
Syn.: fälschlich Thuya gigantea Nutt. aurescens Hort.

$$
\begin{gathered}
\text { Thuma occidentalis Dicksonii Hort. angl. } \\
\text { " aurea Hort. }
\end{gathered}
$$

Thuya occident. albo-variegata Hort., weifbunt.

albo-spica Hort., jung weißspitzig.

argenteo-variegata Hort., silberweiß, bunt.

„Silver Queen“ Hort., silberweiß, bunt.

Buchononii Arb. Arnold., schöne, zierliche, grangrüne, feinzweigige Form.

Thuya occident. Vervaeneana Hort, gelbbunt, breit-pyranidal. aber @rïnblätterig.

viridis, gleich gebaut wie vorige,

Thuya occident. Wareana Hort., gedrumgen-pyramidal.

Syn.: Thuya plicata Wareana Hort.

Thuya occident. Wareana aureo-variegata Hort, gellbbunt. lutescens Hort. Hesse, gelblich.

globosa Hort, dichte Kugelform. viridis Hort, dicht pyramidal, hellgrün. theodonensis Hort, pyramidal, dickzweigig. tatarica Hort., pyramidal, nicht sehr schön.

lich-grüun. Riversii Hort,, dicht, hochpyramidal, gelb-

Thuya occident. Wiegneriana Hort. (Reuter'), dicht, hochpyramiclal.

Thuja occident. recurvata Hort., pyramidal, feinzweigig, die Spitzen oft etwas gedreht, auch ubergebogen.

Thuya occident. recurvata argenteo-variegata Hort., II (I) weißbunt.

Thuya occident. recurva nana Hort., wie rorige, aber Kugelform. Zweige.

Thuya occident. aspleniifolia Hort., pyramidal, farnähnliche

Thuya occident. filicoides Hort.. farnähnliche Zweige.

Douglasii pyramidalis Hort., ähnlich voriger. cristata Hort., nieder-pyramidal, monströse

Zweige.

Thuya occident. cristata aurea Hort., gelbbunt, monströs. denudata Hort., lockerer Bau, dicke Zweige. zweigig. thuyopsoides Schneid., ähnlich voriger, breit-

Thuya occident. pendula Hort., hängend.

glauca Hort., hängend, graugrün. reflexa Hort., uiberhängend. 
Thuya occident. filiformis Beibn, häugend, lang fadentö̈rmig, zeigt hellfarbige Öldrïsen.

Syn.: Thuyge occidentalis Douglesii Hort. amer.

Thuya occident. Bodmerii Hort., etwas uiberhiangend, monströ.. erecta Hesse, aufstrebender Wuchs. stricta Hort., steif aufstrebender Wuchs. fastigiata Hort., säulenförmig. nova Hort, säulenförmig.

I'Haveana Hort., siiulenförmig, et was Luxer Bau. Rosenthalii Ohlendorff, säulenförmig.

förmig.

Columna Hort. Spaeth, ausgeprägt säulen-

Thuya occident. Columbia Hort., sïulenförmig, besonder's im Winter weiß-spitzig und bestäubt.

Thuya occident. pyramidalis compacła Hort. gall.. süulenförmig.

Wagneriana Froebel, säulenförmig.

Syn.: Thuy occidentalis columnaris (Reuter).

Versmamii Cordes. erecta vinidis Hort.

Thuya occident. hollandica Beißn., dunkelgriine Kugelform. umbraculifera Beißn., Kugelform.

pygmaea Hort., nieder.

globosa Hort, niedrig, kugelig.

Boothii Hort, unregehmäfig kugelig wachsend. Hoveyi Hort., nieder, länglich-rund.

gezeichnet. aureo-variegata Hort. Beter., soldhunt

Thuya occident. pumila Hort, nieder, breit.

"Little gem" Hort., nieder, breit.

förmig, "klein, frìsch grün. compacta Hort, mehr oder minder kugel-

Syn.: Thuya occidentalis globularis Lamb. u. Reit. Spihlmannii P. Smith.

Froebelii Hort.

Hoersholmiensis Lange.

globosa compacta Hort.

globosa viridis Hort.

Thuya plicata Don. Gefalteter L. Westliches Nord- I amerika. (Fig. 144.)

Syn.: Thuya occidentalis plicata Loud.

Niederer, im Winter griun bleibender, 1 . h. sich nicht verfärbender Baum, von langsamem Wachstum, charakterisiert schon im Habitus durch stumpt-pyramidale Form, bei ziveizeilig grestellten, an den Knoten verdickten, gepreßten, breiten Triehen von unten bläulich-griner Färbung. Die schuppigen, an den 
Spitzen freien, hinten gekielten Flächenblätter zeigen starke Driisen, die Randblätter haben eine länglich-runde, zugespitzte Form. Färbung an der Unterseite bläulich-grün, oben glänzend. Beim Zerreiben entwickeln die Blätter einen ziemlich strengen Geruch. In lufttrockenen Gegenden werden während des Sommers besonders die immeren Zweigchen und Zweigteile leicht rot und sterben ab.

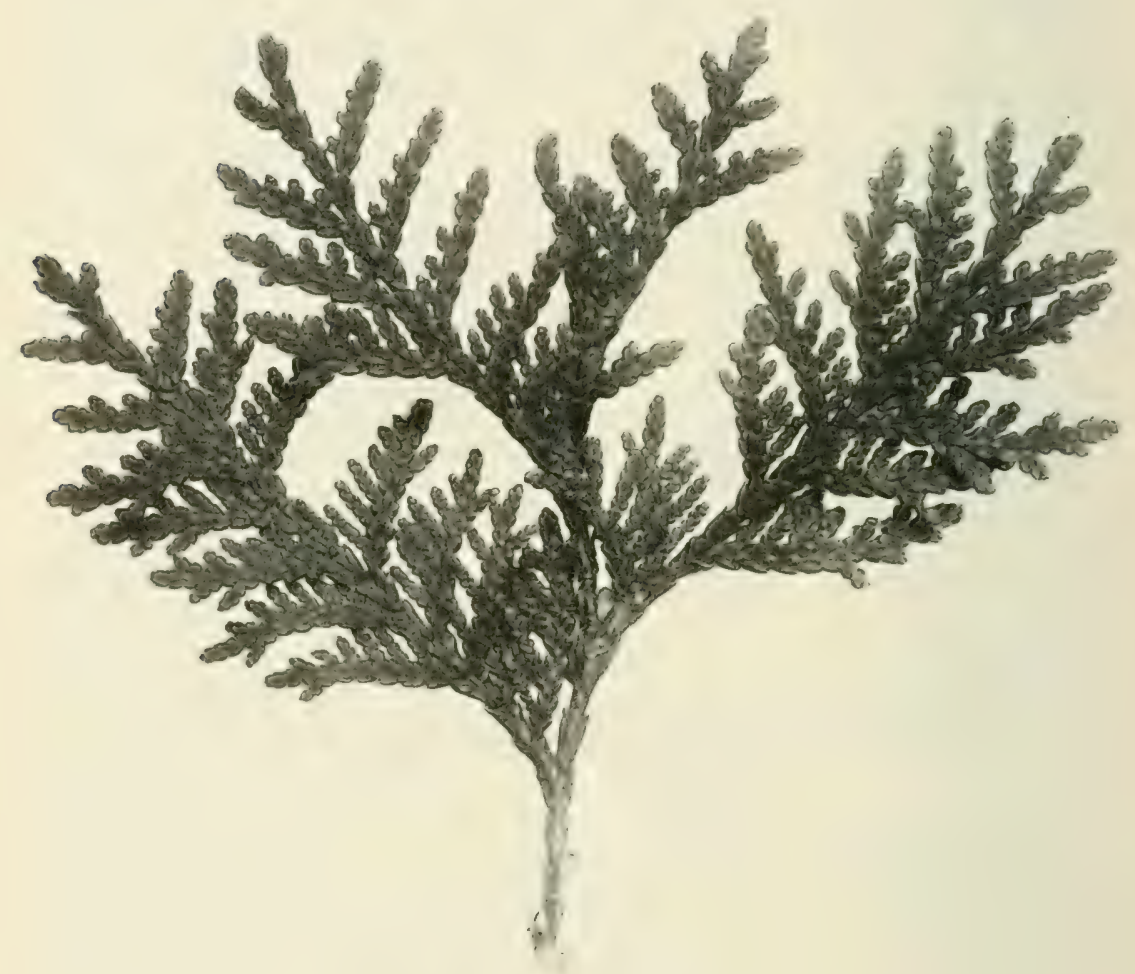

Fig. 144. Thuya plicata Don.

Die Bildung der hängenden, ovalen, sechsschuppigen Zapfen und jene des Samens ist in Deutschland als Seltenheit zu bezeichnen.

Bei uns sind fast iiberall Pflanzen aus Stecklingen gewonnen in Kultur, welche alle den eingangs elwähnten niederen Habitus aufweisen. Samenpflanzen streben etwas mehr aufwärts.

Pfropfung auf die Art und auf Thuya occidentalis. 
Formen sind:

Thuya plicata argenteo-variegata Hort., weißbunt. aureo-variegata Hort., gelbbunt. compacta Hort., gedrungenwiichsig.

Syn.: Thuya occidentulis compacta Hort., (fälschlich).

Thuya plicata dumosa Hort., sehr nieder, buschig. " " pygmaea Hort, Zwergform, dichtzweigig.

2. Abteilung: Macrothuya Benth. und Hook.

Riesen-Lebensbäume.

Zweige und Blätter mit weißer Zeichnung an der Unterseite; Fruchtschuppen 4-6 fruchtbar; der Samenfligel schmal.

Thuya gigantea Nutt. Riesiger L. (Gelbe Zypresse, Tello-Cypress der Amerikaner.) Westliches Nordamerika. (Fig. 145-147.)

Syn.: Thuya Lobbii Veitch. Menziesii Dougl.

Ein imposanter, pyramidal wachsender, etwa

II (I)

Jung etwas empfindlich, besonders in
kalten Böden. Liebt elier feuchten als - trockenen Boden.

Empfindlich gegen starke Sonnenbestrahlung im Winter.

rom 8. Jahr ab starkwichsiger Baum, mit auffallend starkem Stamm, besonders am Fuße desselben, sowie weit auslegenden Ästen und wechselständigen, mit langen Seitentrieben ausgestatteten Zweigen. Die sich gegenüberstehenden, schuppenförmigen, stets griun bleibenden Blätter zeigen an den Flächenblättern eine längliche Öldrỉse, die Randblätter sind länglichrund und gespitzt, Blattspitzen anliegend. Färbung der Blätter oben glänzend griin, miten mit weißlicher Zeichnung. Geruch der Blätter und Zweig'e beim Zerreiben kräftig, aber angenehm.

Ziemlich zahlreich mud bald erscheinen die eiförmig-länglichen, bräunlichen Zapfen, mit 8-10 stachelspitzigen, unten mehr breiten, oben schmalen Schuppen, deren untere fruchtbar sind und 4-6 Samen bergen, welche flach und beiderseits feingefliugelt sind, sowie Harzhöckerchen zeigen.

Die Keimlinge hringen nach den beiden Samenlappen zuerst Nadelblätter hervor.

Forstlich empfohlen, doch nie auf zu trockenem Boden, da die Pflanze hier von einem Pilz, Pestalozzia funerea, schwer beschädigt wird.

Der Baum liefert ein besonders fuir Tiefbauten ausgezeichnetes, wemn auch nicht schweres Holz von gelblicher Farbe. Vermehrung durch Samen, während Stecklinge sehr schwer wachsen, am ehesten wachsen noch jene der niedersten Formen. Pfropfungen werden auf' die Art, oder auf Thuya occidentalis vorgenommen. 
- $280 \quad-$

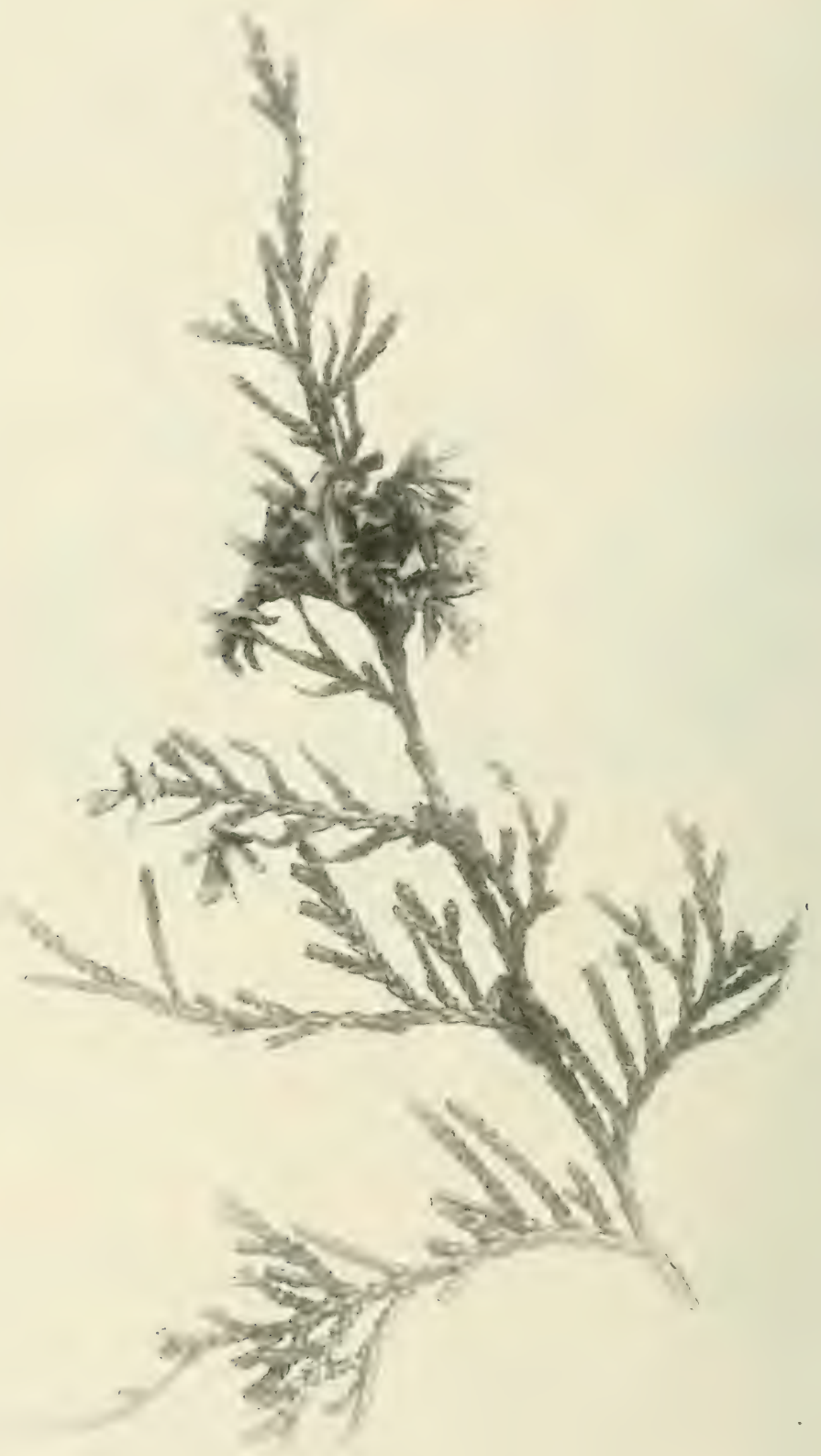

Fig. 145. Thuya gigantea Nutt. 


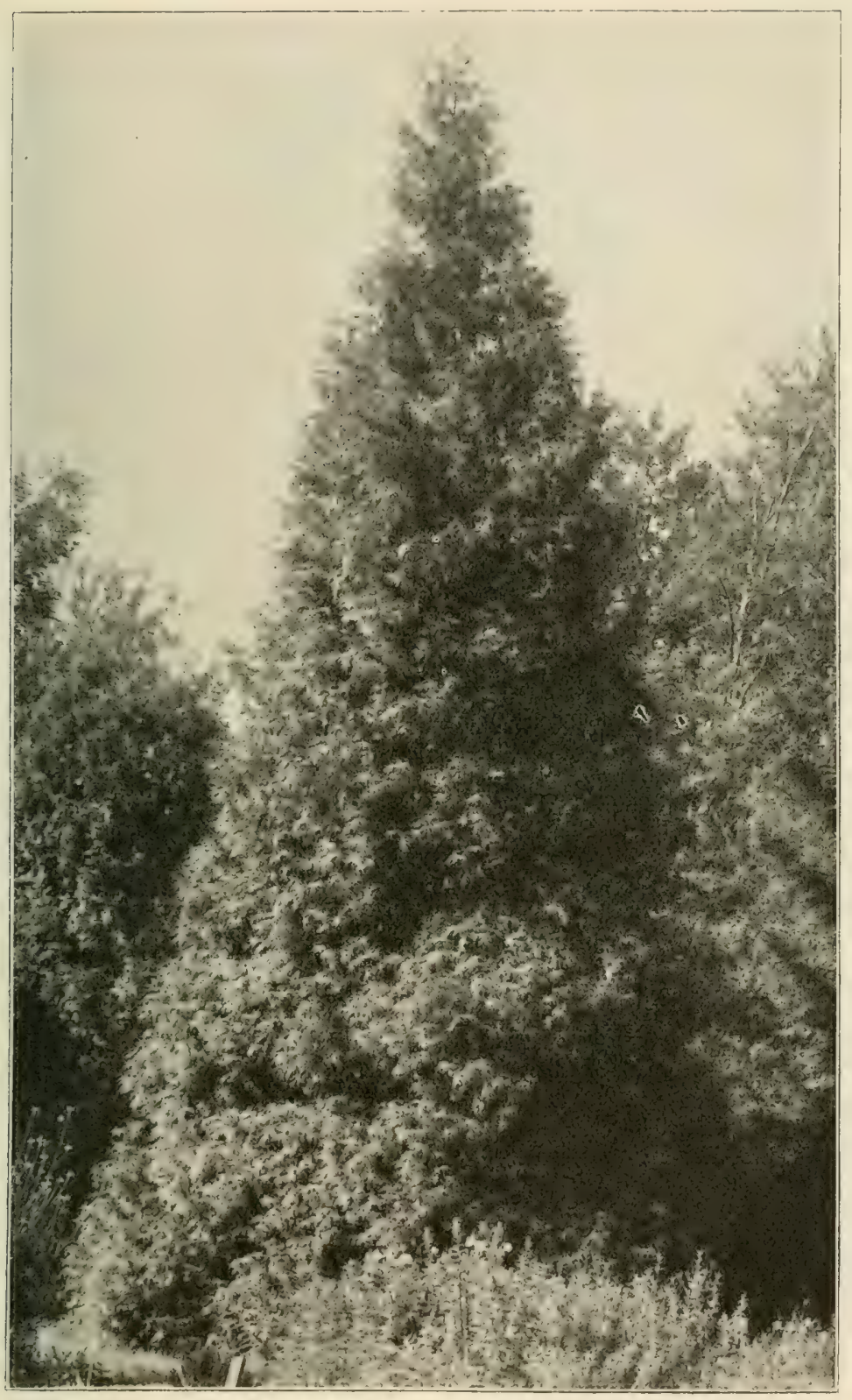

Fig. 146. Thuya gigantea Nutt. (25̃ jährig, bei Einzelstand.) 


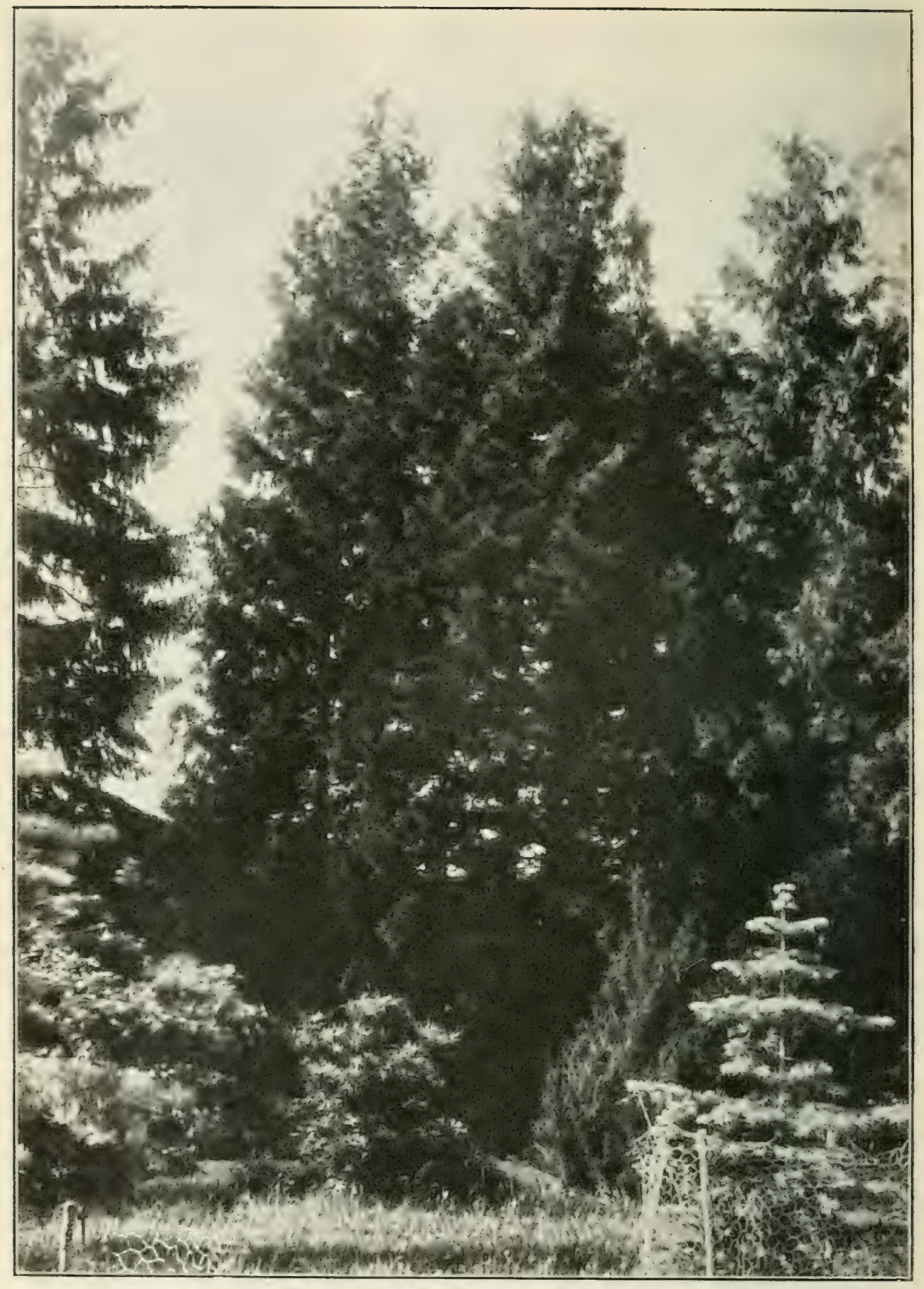

Fig. 147. Gruppe von Thuya gigantea Nutt. (30 jährig).

(Aus: Mitteilungen der dentschen dendrologischen Gesellschaft.) 
pflanzen.

Große Pflanzen lassen sich nur schwierig mit Erfolg ver-

Formen sind:

Thuya gigant. atıovirens Hort., glänzend dunkelgriun. albo-maculata Hort., weißjefleckt.

$" \quad " \quad "$

Zweigchen. aurea Hort. Späth, goldgelbfarbig. aureo-variegata Hort., gelb, buntfarbig: incurva Beißn., mit einwärts gekrimmten

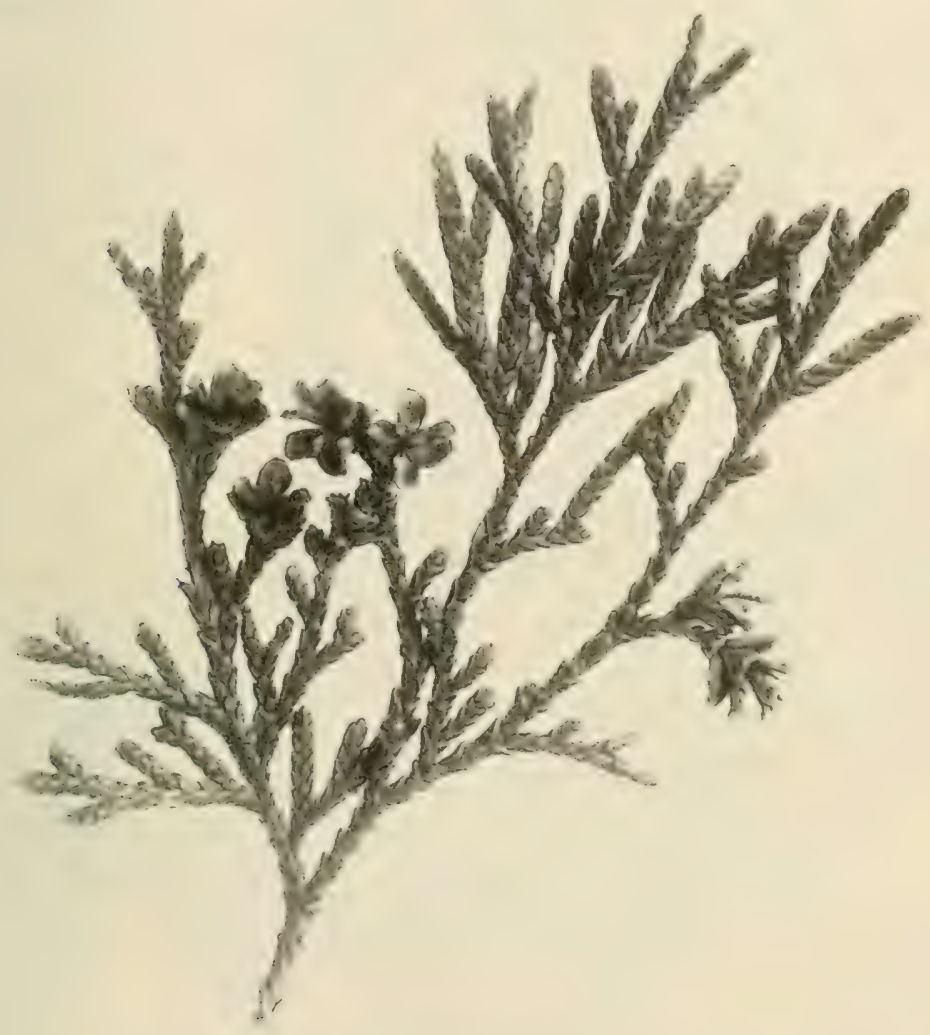

Fig. 148. Thuya Standishii Carr.

Thuya gigant. gracilis Hort., hiibsche, feinzweigige Form. " " fastigiata Hort., säulenförmige, winterharte Form. . . pendula Hort. Lieb., hängend.

Thuya Standishii Carr. Standish' japan. L. Liebt schattigen StandGebirge Japans. (Fig. 148.) feuchten Boden. 


\title{
Syn.: Thuya japonice Maxim. \\ Thuyopsis Standishii Gord.
}

Bei uns nicht allzurasch wachsender, doch jung schon fruktifizierender Baum, mit starkem, gleichmäfigen Stamm, teils wagrecht ausladenden, teils aufstrebenden Ästen und dicken, auch etwas ïberhängenden Zweigen. Blätter schuppig, fest, Spitzen abstehend mit rundlicher Drüse, oben hellgriun, fast gelbgriin, unten gran gezeichnet. Geruch der zerriebenen Blätter nicht sehr stark, aber eigentiimlich tichtenharzähnlich. Die Zapfen zeigen Ähnlichkeit mit jenen der vorigen Art, nur sind sie etwas kleiner; ebenso ist der Samen ähnlich. Die Keimlinge entwickehn nach den beiden Samenlappen ebenfalls zuerst gegenständige Nadelblätter.

Vermehrung am besten aus Samen; Stecklinge ergehen langsam wachsende Pflanzen. Pfropfung auf die Art oder auf Biota orientalis; solche auf Thuya occilentalis wachsen nicht gut.

Das sehr wertvolle dunkle Holz wird in der Heimat vielseitigst verwendet.

\section{Cupressus Tournefort.}

\author{
Z y p l'es s e.
}

Inmergriue, hochstrebende, prïchtige Bäume, mit zahlreichen, aufstrebenden, oder auch horizontal abstehenden Ästen, wie ebenso ziemlich abstehenden und auch iberhängenden Zweigen. Blätter gleichartig, schuppenfömnig, vierfach gegenständig. Bliite monözisch, auf verschiedenen Ziveigen wachsend. Mämnliche an den Zweigspitzen, weibliche seitlich stehend, einzeln bis biischelig. Samenknospen zu mehreren, selbst zahlreich an den fruchtbaren Schuppen. Zapfen 8-luschuppen fiihrend, kugelig, holzig, im 2. Jahre reifend. Samen liinglich, meist flach und fast stets etwas geflicgelt. Der Keimling zeigt 2 (seiten mehr) Samenlappen und dann zuerst Nadelblätter.

Termehrung am besten durch Samen, der aber unter Glas restellt werden inuf, iiberhaupt stets etwas "wärmer" gehalten werden sollte, als die unemptindlicheren Koniferen. Stecklinge wachsen nur von jungen Pflanzen einigermaßen gut. Zum Pfropfen bedient man sich der Samenpflanzen von Cupressis sempervirens und im Notfall der von Chamaecyparis Lawsoniana.

Cupressus sempervirens I. Echte Z. Kreta; verhreitet in Persien, Kleinasien und bis zum Himalaya. Der heilige Baum der Zend-Religion.

Sein dauerhattes, rotes $\mathrm{Holz}$ ist als Bauwie Handwerksholz iberaus gesucht, ebenso zu musikalischen Instrumenten. Rinde und Holz wird aukerdem offizinell gebraucht.
VII (VI?)

Liebt Winterschutz, besonders solchen des Wurzelstockes. Jung sehr empfindich. 


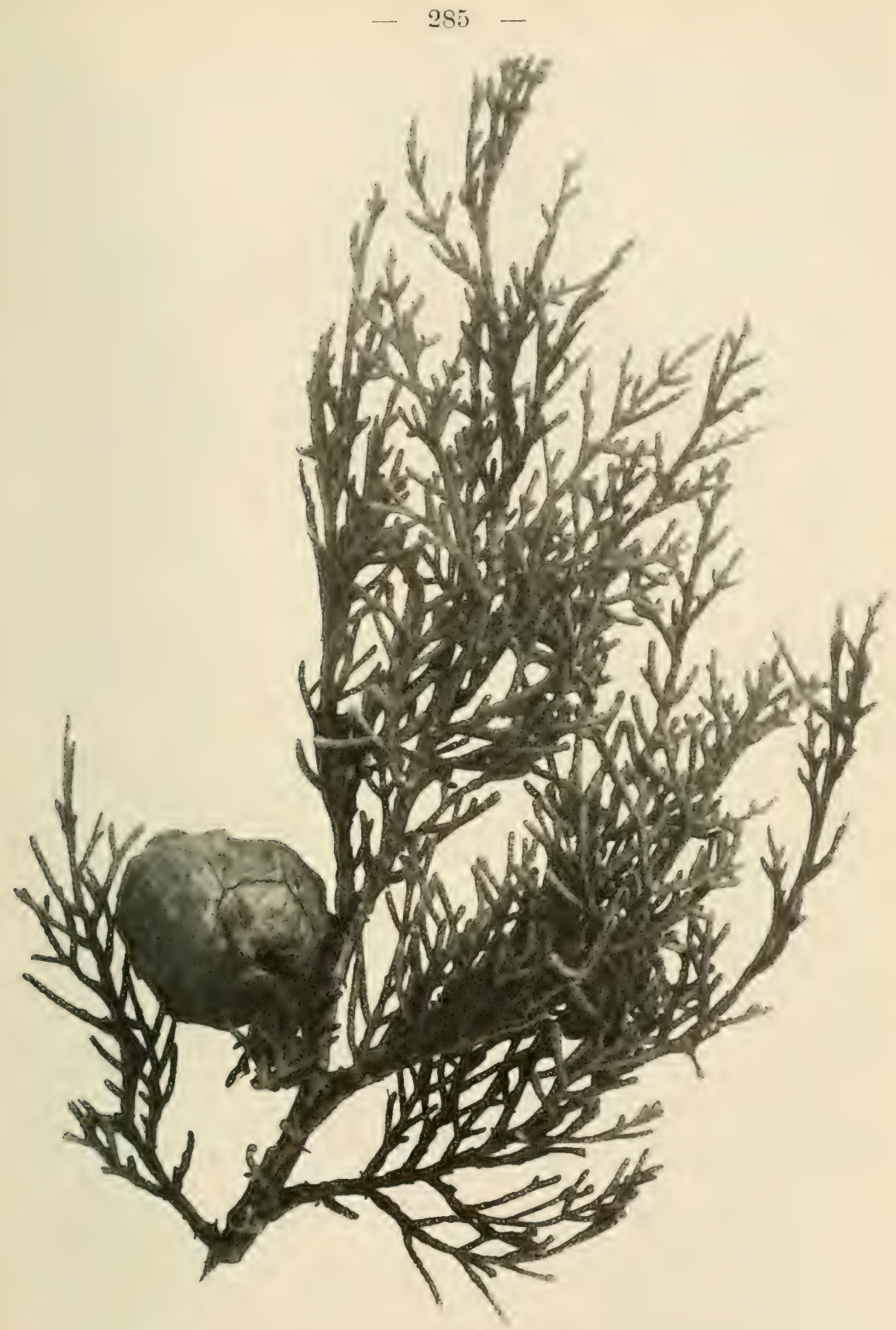

Fig. 149. Cupressus sempervirens L. var. fastigiata (DC.). 
Man unterscheidet zwei samenbeständige Abarten: (Fig. 149.)

Cupressus sempervirens var. fastigiata (DC.). Säulenförmige Z.

Syn.: Cupressus fastigiata $D C$.

$"$ pyramidalis Targ. Tozz.

Tiefgriuner, streng säulenförmiger (nicht pyramidaler) Baum, mit fast anliegenden Ästen und abstehenden, vierkantigen Zweigen, sowie dunkelgrimen, schuppenförmigen, oben ganz leicht abstehenden, hinten konvexen, mit einer etwas eingesenkten Driise versehenen Blättern, welche beim Reiben einen angenehmen Geruch entwickeln.

Die hellbraunen, oft schon an jüngeren Pflanzen sich zeigenden, nußgroßen Zapfen, fïhren 8-14 schildförmige, mit leicht gekrimmter Spitze versehene Schuppen und ziemlich viele rund- aber schmalgefligelte Samen.

Der Tranerbaum der Sidländer! Die Böcklin-Zeder, wie sie zu benennen wäre, da dieser beriihmte Maler sie so meisterhaft gezeichnet hat.

Bei uns nur zu ersetzen durch Juniperus virginiana pyramidalis, Libocedrus decurrens columnaris, ('hamaecyparis Lawsoniana conica, oder Chamaecyp. sphaeroidea fastigiata glauca.

Cupressus sempervirens var. horizontalis (Mill.).

Syn.: Cupressus horizontalis Miller.

Von voriger Abart durch ganz abstehende und außen auch leicht ïberhängende $\ddot{A}$ ste, sowie derbere Zweige abweichend.

Cupressus Mac Nabiana Murray, Mac Nabs Z. Shastagebirge (Kalifornien).

Syn.: Cupressus glandulosa Hook.

VI (VII)

Jung empfindlich. Schutz der Wurzeln im Winter.

Charak teristischer, blaugriiner, pyramidal wachsender Strauch, mit aufstrebenden Ästen, ausgebreiteten, ziemlich vierkantigen Zweigchen, sowie schuppenförmigen, oben etwas abstehenden und hier leicht verdickten Bliittern, welche am Riicken konvex sind und zwei graublane Bainder nebst rundlicher Drise zeigen. Beim Reiben entwickeln sie einen angenehmen Geruch.

Die kugeligen, nußgroßen, braunen Zapfen führen 6 schildförmige, genabelte Schuppen mit je 5 kleinen, fast rundlichen, etwas getlügelten Samen.

Cupressus macrocarpa Hartw. Großfrichtige Z. Kalifornien.

Pyramidal wachsender, mittelhoher Baum,

VI? (VII) Jung empfindlich. Schutz des Wurzelstockes im Winter.

nit zieinlich spitzwinklig abstehenden Ästen, ebensolchen, sowie etwas iiberhängenden Zweigen und schuppenförmigen, hinten konkaven, etwas rekielten, nit lïnglich-punder. Drise versehenen 
Blättern an den jiingeren Zweigen, während jene der iilteren Zweige ebentalls griin wie vorige, stumpt wespitzt, oben nicht angedriickt mel mit schmaler (O)driise ausgestattet sind. Beim Reiben der Zweige entwickelt sich ein angenehner Geruch. Die bramen, kugeligen Zapfen führen 8-12 schildfümige, eckige Schuppen mit vielen kleinen, länglich und schmal geefliigelten Samen.

Formen sind:

Cupressus macrocarpa lutea Hort., gelbblïtterig.

filiformis Hort,, fein hänge-zweigig. sulphurea Hort. Lebret., hellgelb, wohl

nur fiirs Kalthaus.

Syn.: Cupressus Lambertiana luter Hort.

Auf der Insel Mainau - ob sonst wo noch in Deutschland? - steht eine

Cupressus funebris Endl. Chinesische Trauer-Z. China. Dieses Mainaner Exemplar hat schon gut keimen-

VII den Samen erzeugt.

Es ist dies sonst ein herrlicher Baum unserer Kalthäuser, von hellen Grin, mit ausgebreiteten Ästen und Zweigen, welche später zierlich iiberhängen.

Ebenso steht auf Mainau eine

Cupressus torulosa Don., die Nepal-Z., Nepal, vir oder sonst ebenfalls ein schöner Baum unserer Kalthiuser, mit aufstrebenlen Ästen und zylinderischen, oft etwas gewundenen Zweigen, sowie sehr kleinen, hellgrinen, dachziegelig gestellten Blättern.

Es existieren auch verschiedene Formen hievon, z. B.

Cupressus torulosa cashmeriana aus Tibet, mit abstehenden, nadelspitzen Blättern.

(Syn.: Cupresus coshmeriumu Royle.)

Cupressus torulosa „Hills of Indiae“, ron zierlichem Bau und mit nadelspitzen, abstehenden, hlansriuen Blïtern.

(Syn.: Cupressus spec. Hills of Indiae.)

Seit einigen Jahren ist durch einen sehr tätigen Pflanzensammler (C. A. Purpus) eine nene, wundervolle Cupressus-Art eingeführt, nämlich

Cupressus arizonica Greene, von Arizona, welche die cinzige, wenigstens noch in W einerenden Deutsch(IV?? ?) lands olne Schaden ausilanernde Zypresse sein soll, bezw. wäre. (Fig. 150.)

Auf Sandstein und Kalk, bei et was feuchtem Standort bildet. sie in der Heimat prachtvolle, 15-20 1 hohe, pyramidale Biiume 


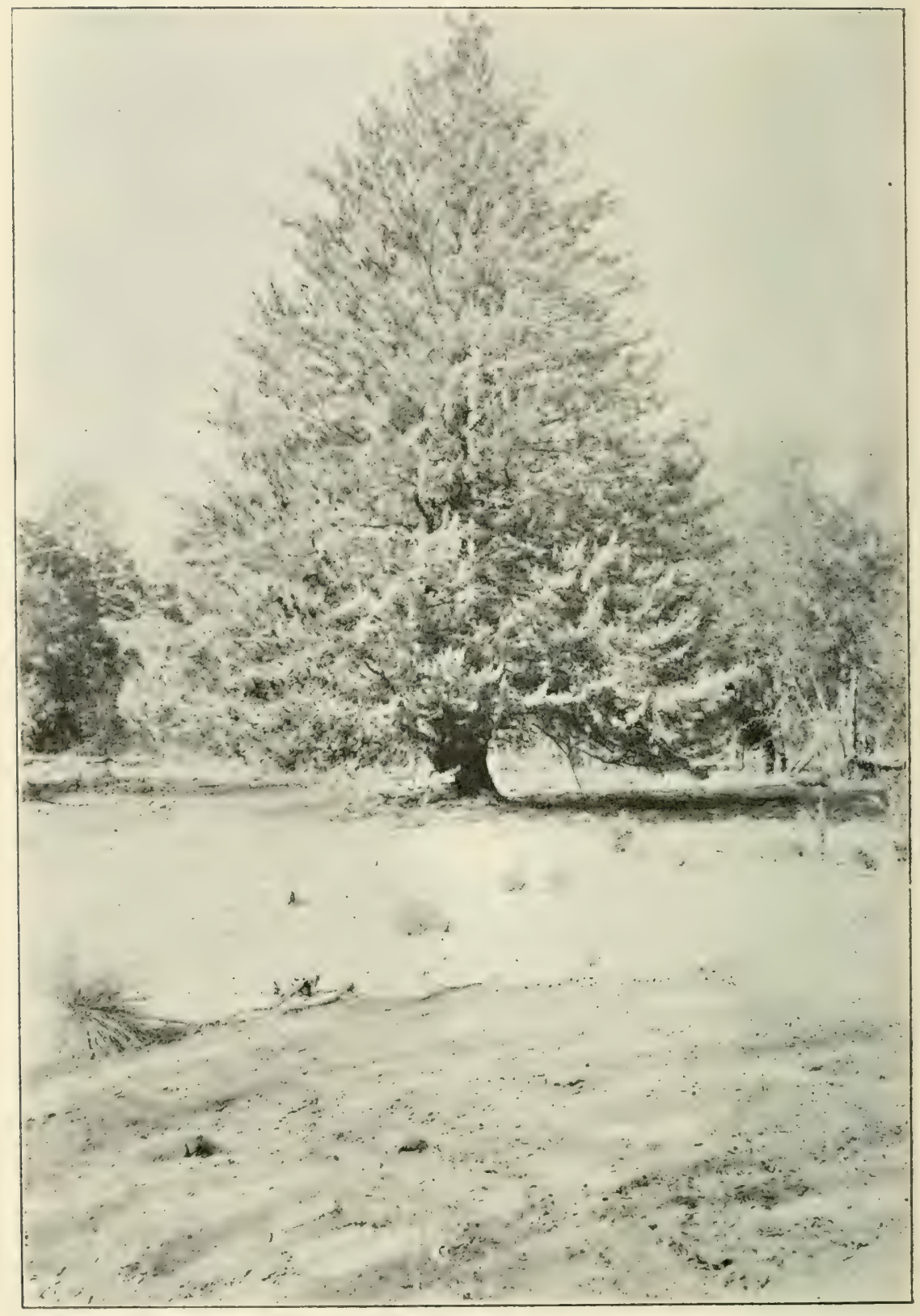

Fig. 150. Cupressus arizonica Greene.

(Aus: Mitteilungen der deutschen dendrolog. Gesellschaft.) 
mit grimer, errublauer bis silherweißer Benaclelmon! Letztere wechselt je nach Alter der Pflanze. Wuchs rasch und gut, hesonder's in mohr trockenem als feuchtem Boden, spezicll in lehmigem Sandboden (mit Kalk?), und auf somnigem standort.

Vermehrung aus Stecklingen sehr gut.

Möchte dieser Baun die Ervartungen erfiillen, die man von ihm erhofft!

\section{Cupressus Goveniana Gord. Govens Z. Meeres-} kiuste Kaliforniens.

Kleiner Baum mit schlanken, hängenden Ästen, etwas g’edrehten, dichtstehenden 'Zweigen und hellgrinen, schuppig' gestellten und rierreihig stehenden, zugespitzten Blättern. Zapfen rehiuft stehend, rundlich, mit 8-10 fast viereckigen, etwas spitz zulaufenden Fruchtschuppen und vielen kleinen, dunkelbraumen Samen.

\section{Chamaecyparis Spach. \\ L e b e n s baum-Zy press e.}

Sehr schöne, immergriue, meist hohe Bäune, mit aufiechten, abstehenden und ausgebreiteten, z. T. auch iiberhängenden Ästen, mehr oder minder flachen, selbst zusammengedrückten Zweigen und schuppenförmigen Blïttern. Leitzweige zuerst nickend. Blüte monözisch; männliche Bliite länglich-rund, endständig, weibliche Bliite ebenfalls endständig an kurzen Zweigchen, fast kugelig, sechs- bis achtschuppig, mit je 2 Samenknospen. Zapfen rundlich, klein, erst etwas Heischig, hell-bläulichgrin, dam holzig und oben hakig; 4-6 Schuppen fruchtbar. Die im ersten Jahr reifenden Samen sind länglich-rund, gepreßt, mehr oder minder breit gefluigelt.

Chamaecyparis Lawsoniana Parl. Lawsons L.-Z. (Fig. 151 und 15\%.)

Syn.: Cupressus Lan'sonituna Murray.

Dieser wundervolle Baum, vor etwa 50 Jahren eingefuhrt, hat -- mit Ausnahme sehr kalter Gegenden - den abendländischen Lebensbaum Thuya occidentalis nahezu vollstindig ver-

I,

jedoch nur in geschlossenen Beständen und bei warmem, dabei etwas feuchtem Standort. Jung empfindlich! II bei mehr isoliertem Standort. Auf Moor niclit gut, wird gern rotfaul. Lichtbedürftig. drängt, sowohl als höchst zierender Solitärbaum, bis herab zur Heckenpflanze, und besonders auch als Unterlage bei Pfropfungen passender Nadelhölzer. Als For'stbaum auf frischen Boden sehr empfohlen; sein Harz schiitzt gegen Wildverbif und Insekten.

Hoch aufstrebender, dekorativer, im Winter ebenfalls frisch griner, in der Heimat bis iiber $50 \mathrm{~m}$ hoch werdender Baum, mit mehr oder minder wagrecht abstehenden Ästen und etwas hängenden Zweigen, sowie eben solchem Gipfel! Die 
schuppenfïrmigen, doppelt gegenüberstehenden Blätter sind an jingeren Pfanzen ziemlich spitz, auch etwas abstehend, an älteren Pflanzen länglich-rund. mehr anliegend, mit einer runrlichen Driise und einer weißbläulichen Linie in Form eines $y$ oder versehen. Weibliche Blite stahlblau orler bliulich-griun, die männliche Blite herrlich rot, sehr zierend.

Ziemlich zahlreich und bald erscheinen die verhältnismäßi心 kleinen, runden, hellgriuen Zapfen, welche später hraun werden;

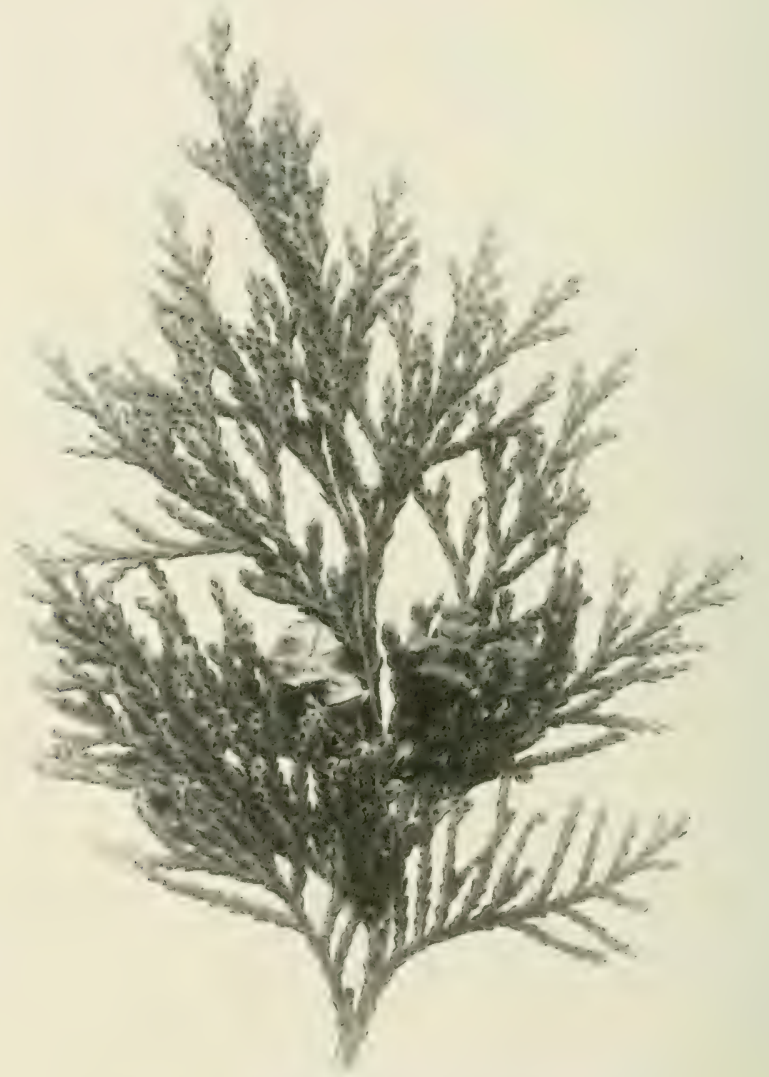

Fig. 151. Chamaecyparis Lawsoniana Parl.

die 8 Schuppen der Zapfen zeigen an den Spitzen eine bläulichgrüne Fïbung. Samen 1 5, glänzend hraun, gepreßt, rundlich geflügelt und mit Harzdruisen versehen.

Des vorziglichen, dauerhaften, auch bei Wasserbauten wertvollen und gegen Insektenfraß geschiitzten, außen gelblichen, innen: rötlichen Holzes wegen, welchem ein feiner Geruch eigen 


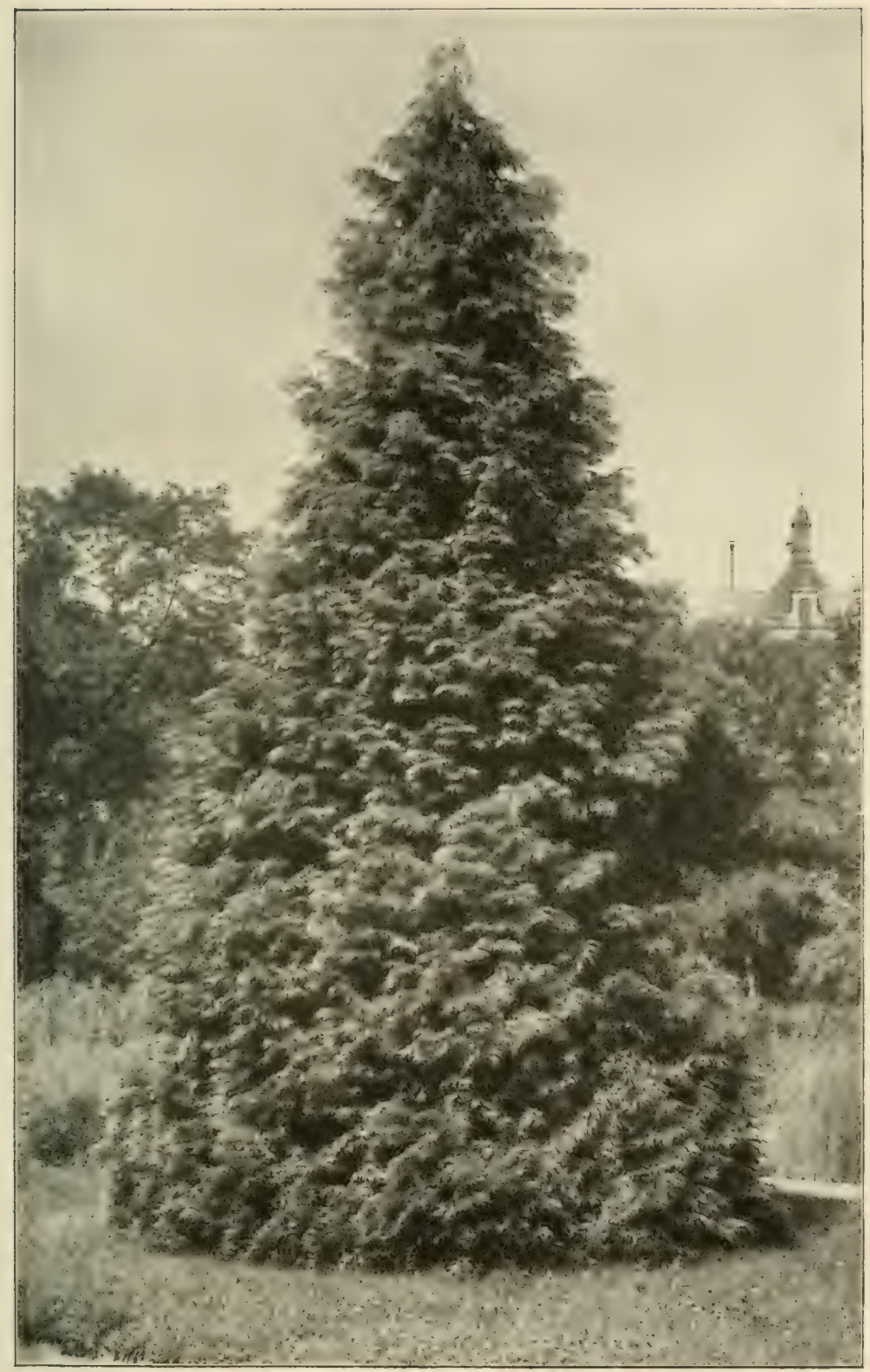

Fig. 1õ2. Chamcecyparis Lcwsoniana Parl. (30 jährig). 
ist, wird der Baum nicht nur in der Heimat hochgeschätzt, somdern nenerdings auch bei uns forstmäßig angebaut.

Termehrung aus Samen; Stechlinge wachsen, mit Ausnahme der Zwergformen, nicht besonders gut, besonders nicht solche von somng gestellten Exemplaren: es dauert auch oft längere Zeit, bis sie sich zu gleichmäßigen Pflanzen ausbilden. Pfroptung auf die Stammform.

Agaricus melleus, der Hallimasch (Wurzelkrebs), richtet oft an dieser Art großen Schaden an.

Der Formenreichtum ist ein iberaus großer und wird derselbe ständig größer, sodaß es bald selbst einem Kenner schwer sein wird, genanere Unterscheidungen bei einer Reihe der Formen zul treffen!

Chamaec. Laws. atrovirens Hort., tiefgriine Form. patula Hort., ganz dunkelgrủn, feinzweigig. laxa Hort., sparrig, dickgliederig. tortuosa Hort., pyramidal, dicke Zweige. glauca Hort., stahlblaue Form.

Wuchs. elegans Hort., wie vorige, zierlicher

Chamaec. Laws. glauca Veitchii Hort., wie vorige, üppiger TVuchs, blau.

Chamaec. Laws. argentea Hort., silbergrau, feinzweigig. I (II) nova Hort, hell-silbergrau.

Beißneriana P. Smith, graublau. nivea $P$. Smith, weißgrau.

„Silver Queen"Hort., glänzend weißgrau. I (II) lutea Hort., gelbe, schlanke, dichte Form. sulphurea Hort., mit gelbem Schimmer.

Somnenbrand ziemlich hart.

lutescens Hort., goldgelb, gegen

Chamaec. Laws, aurea Hort, helles Gelb, gedrungen. II nova Hort. Tott, lebhaft gelb.

feinzweig"ig. Westermannii Hort., glänzend, goldgelb,

Chamaec. Laws. Westermannii aureo-variegata Hort, nur teilweise gelb gefleckt.

Chamaec. Laws. darlyensis Hort., goldhunt, fein iiberhängend. Depkenii Beißn., von matt-gelblichweißer Färbung, im Winter in Griin ibergehend.

Chamaec. Laws. versicolor J. Connink, gold-und silherschimmernd, liebt Schutz gegen starke Sonnenbestrahlung und gegen kalten Wind.

Chamaec. Laws. aureo-variegata Hort, goldbunt. 
Chamaec. Laws. magnifica aurea Hort., blaugriin, mit gellsen Zweigspitzen.

Chamaec. Laws. pulcherrima Hort., weißliche Benadelung. Form. argenteo-variegata Hort., weißbunte II voriger:

Chamaec. Laws. argenteo-variegata nova Hort., ähnlich

Chamaec. Laws. Overeynderii Hort., weifsspitzig.

III pulverulenta Hort. Lieb., üppig wachsende, bläuliche, goldbunt bestiiubte Form, somnenhart.

Chamaec. Laws. erecta viridis (Waterer) Hort., schlankwiichsig, autrecht. lebhaft gr'in; in Winter gegen SomenIII bestrahlung und Wind empfindlich. (Fig. 158.)

Chamaec. Laws. erecta virid. argentea Hort., wie vorige, weiflich. grüne Form.

argenteo-variegata Hort., weißbunt.

" " alba Kees, schlank, silberig.

" " " coerulea glauca Hort., schöne, blau-

Chamaec. Laws. erecta glauca Hort., blaugriun, pyra- It midal-eiförmiger Wuchs.

Syn.: Chumaec. Lats. monumentalis nova Hort.

Chamaec. Laws. pyramidalis P. Smith, schlanke, hoch aufstrebende Form.

Chamaec. Laws. pyramidalis alba Hort., wie vorige, weißspitzig.

Chamaec. Laws. pyramidalis glauca Hort, wie erstere, blaugruin.

zierlicher" Wuchs".

luiea Hort., wie erstere, gelb. II

Chamaec. Laws. epacroides Hort. Ordnming, schlank-pyramidal, aufrechte Zweige.

Chamaec. Laws. plumosa Hort. Lieb), dunkelgriun, pyramidal wiichsig, etwas ïberhiängend, federartig gekräuselte Blätter.

Chamaec. Laws. Rosenthalii I. Sunith, siiulenförmig, zierlieh. steifïstig. Worleii P. Smith, ziemlich säulenförmig, form.

Chamaec. Laws. Alumii Hort, prachtvolle, blaugrüne Sïulen-

Chamaec. Laws. moaumentalis glauca Hort., säulenförmig, blau.

II

Chamaec. Laws. „Triomf van Boskoop" Hort. holl., wohl die schönste blave Form.

Durch Kreuzung dieser Form mit Chamaec. Laws. aurea sind blau- und goldfarbige Pflanzen in Kínltur. 
Chamaec. Laws. Fraserii Hort., säulenförmig, blau, II dichtzweigig.

Chamaec. Laws. conica Hort., säulenförmig, aufrechte, anliegende Zweige, kurze Belaubung. Guter Ersatz für die Böcklin-Zeder.

Syn.: Chamaec. Laus. Wisselii Hort.

Chamaec. Laws. stricta Hort, aufstrebend. vvüchsig. excelsa Hort., wie vorige, doch stärker

Chamaec. Laws. coerulea Hort., aufrechter Wuchs, schön bläulich.

Chamaec. Laws. coerulea erecta Hort., wie vorige, steifer. schongariensis Hort., niederer Wuchs, buschig. elegantissima Hort., feinzweigiger

und zierlicher im Bau als die Stammform.

II

Chamaec. Laws. Olbrichii Hort. Froeb), blaugriune, II (III) dichte Säule.

Chamaec. Laws. robusla Hort., dunkelgriun, säulenförnig. II (1) aurea Hort., pyramidal, gelb. II glauca Hort., pyramidal, blaugrün.

graublau. argentea Hort., ähnlich voriger, II

Chamaes. Laws. Youngii Ifort, dunkelgrime, dicktriebigre, etwas uiberhängende Form.

Chamaec. Laws. Bowlerii pendula Hort., etwas hängend. ïberhängend. pendula Hort., mehr oder minder lang

Chamaec. Laws. pendula alba Hort. hängend, weißspitzi心. Syn.: Chancies. Laus, alba pendula Hort.

Chamaec. Laws. pendula aurea Schelle, eine schöne Säule liklend, mit tief'hängenden Zweigen, und besonders an den Triebspitzen erst griingelben, dam goldgelben Blättern. hängend.

Chamaec. Laws. pendula vera Hort. Hesse, sehr schön, ]ang

Chamaec. Laws. pendula nova Hort., lang-hängend. iiberhängend. filiformis Hort., lang fadenförmig

Syn.: Chamaec. Laus. filiformis pendula Hort.

Chamaec. Laws. filiformis erecta Hort., ähnlich voriger. glauca Hort. Wezel, ähnlich ersterer', graugrin.

Chamaec. Laws. filiformis compacta Hort, nicht so hoher Wuchs als vorige, glänzende Belaubung.

Chamaec. Laws. intertexta Hort., interessante, weitzweigige, überhängende Form. 
Chamaec. Laws. intertexta atrovirens Hort., wie vorige, dunkelgrïn.

Chamaec. Laws. gracilis Wat., rundliche, leicht tiberhängende Form.

Cliamaec. Laws. gracilis nana Hort., wie vorige, nieder. aurea Hort, wie erstere, gelb.

nur feiner.

". gracillima Hort., ïhnlich gracilis, II

Chamaec. Laws. fragrans Hort. am., gedrungenwüchsig. argentea Hort., gedxungen, weißlich. conica Beifnn, kegelförming, farnwedel- und hahnenkammartig, monströs.

Chamaec. Laws. crispa J. Connink., monströse Bezweigung. casuarinifolia Hort., mehr oder minder gedrehte und monströse Zweige.

Chamaec. Laws. casuarinifolia aureo-variegata Hort. Ord., ähnlich voriger, gelbbunt.

Chamaec. Laws. falcata Hort. Ord., sichelförmig umgebogene Zweige, monströse Nebenzweige.

Chamaec. Laws. compacta nova Hort., kegelförmig. gedreht.

lycopodioides Hort., zwergig, monströs,

Chamaec. Laws. Iycopodioides aurea Hort., wie vorige, goldgell. Shawii Hort., kugelig.

Wuchs.

globosa Hort., von gedrungenem, kugeligem

Chamaec. Laws. nana Hort., nieder, kugelig. weifjbunt. albo-variegata Hort., wie vorige, II

Chamaec. Laws. nana albo-spica Hort., weißspitzig.

$"$ " $"$ argentea Hort., weißfarbig.

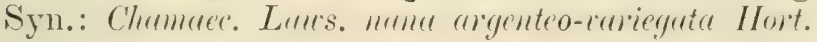

Chamaec. Laws. nana glauca Hort., blaugriun.

compacta Hort., blaugruin, gedrungen.

Raievskyana Hort. Lieb., hellgrau-silberig schimmernd, fein iiberhängend, nieder.

Chamaec. Laws. Weißeiana Hort., schirmförmig, klein; liebt Schutz im Winter gegen starke Some und scharfen Wind.

Chamaec. Laws. Kramerii Hort., dicht, breit, nieder. minima glauca Hort., ganz kleine, dichte, blaue, kugelige Zwergform. II

Chamaec. Laws. minima argenteo-variegata Hort., wie vorige, weißbunt.

Chamaec. Laws. pygmaea argentea Hort., sehr klein. III 
Chamaec. Laws. prostrata glauca Hort., niederliegend, graugruin.

Chamaec. Laws. nidiformis Hort., breite, nestförmige Zwergform.

Syn.: fälschlich Chremurcyp. nutlerënsis nidiformis Hort. non.

Chamaec. Laws. Forstekiana Hort., graugrüne, igelförmige, monströs-zweigige Kugel; Hexenbesenartig:

Chamaec. Laws. Forstekiana variegata Hort., wie vorige, gelbbunt.

Chamaecyparis pisifera Sieb. und Zucc. Liebt mehr feuchten Erbsenfriichtige L.-Z. Japan. (Fig. 153.) als trockenen Boden

Syn.: Retimisposa pisifcra Sieb. und Zuce. Tümmert in luftCupressus pisifera C. Koch. und bei trockenem

Interessanter, pyramidal

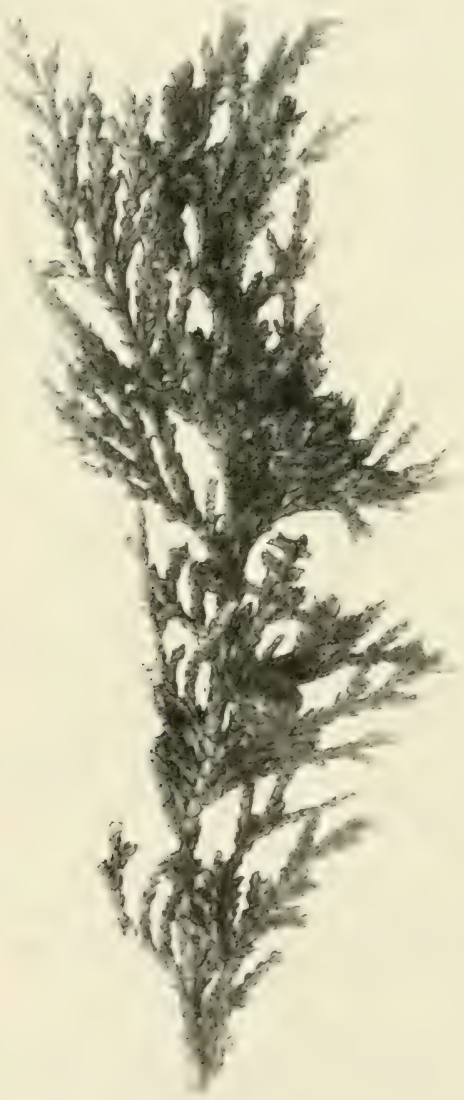

Fig. 15ว̈.

Chamaecyparis pisifera S, u. Z. wachsender Baum von 35 m Höhe, mit ziemlich wagrecht abstehenden Ästen, etwas überhängenden, breitgedrückten Zweigen und schuppenförmigen,oben abstehenden und spitzen Blättern, welche eine schmale, flache Drüse führen, oberseits glänzend hellgrüne bis bläulichgrủne Färbung und unten zwei weißliche, unterbrochen $X$ förmige Linien zeigen. Randblätter kahnfơrmig, stachelspitzig, abstehend. Die zerriebenen Blätter riechen angenehm.

Endständig stehen die einen Winter überdauernden, männlichen Blüten, auch die weiblichen Blüten sind endständig und führen 10-12 Scliuppen. Zapfen zahlreich, erbsengroß, erst grim, dann braun und runzelig: werdend.

Die selten bei uns keimfähigen Samen sind geflügelt und zeigen Harzhöcker. Der mit zwei Samenlappen versehene Keimling entwickelt zuerst nadelförmige, oben blaugrüne, unten silberweiße, ringsum gestellte Blätter.

Das angenehm riechende, 
selblich-rötliche Holz wird sowohl zu Kileinwaren wie auch zu Haus- bezw. Erd- und Wasserbauten beniitzt.

Vermehrung durch Samen und Stecklinge. Besonders die . Tugendform und die Übergangsformen wachsen vortreftlich aus Stecklingen; auberdem pfropft man auf die Stammform.

Bedauerlich ist nur, daß der Baum in lufttrockenen, oder von austrocknenden Winden heimgesuchten Gegenden so viele rote, abfallende Blätter und Zweige bildet und dadurch vielerorts ein etwas ruppiges oder humgeriges Aussehen erhält.

Formen sind:

Chamaec. pisif. Standishii Hort., kräftig im Wuchs, dunkelgrün. argenteo-variegata Hort. jap., weißbunt.

Chamaec. pisif. aureovariegata Hort, gelbbunt.

Chamaec. pisif. aurea nana Hort., goldgelb, nieder. Chamaec. pisif. lutea Hort, gelbnadelige Form.

Chamaec. pisif. stricta Hort., aufstrebend, schlank, junge Triebspitzen gelblich.

Chamaec. pisif. stricta lutescens Hort., ähnlich voriger, gelb.

Chamaec. pisif. sulphurea Hesse, eigenartiges Schwefelgelb.

Chamaec. pisif. columnaris Beißn., gleichmäßig wachsende, dicht- und kurzzweigige Säulenform.

Chamaec. pisif. II (I) squarrosa Beißn. besonders u. Hochst. (Fig.154.) $\begin{gathered}\text { feuchtent } \\ \text { Standort. }\end{gathered}$

Syn.: Chamaecyp. squarvosa leptoclada Endl.

Retinispora squarrosa Sieb. u. Zuec.

Rieptimisporaleptoclada Zuce.

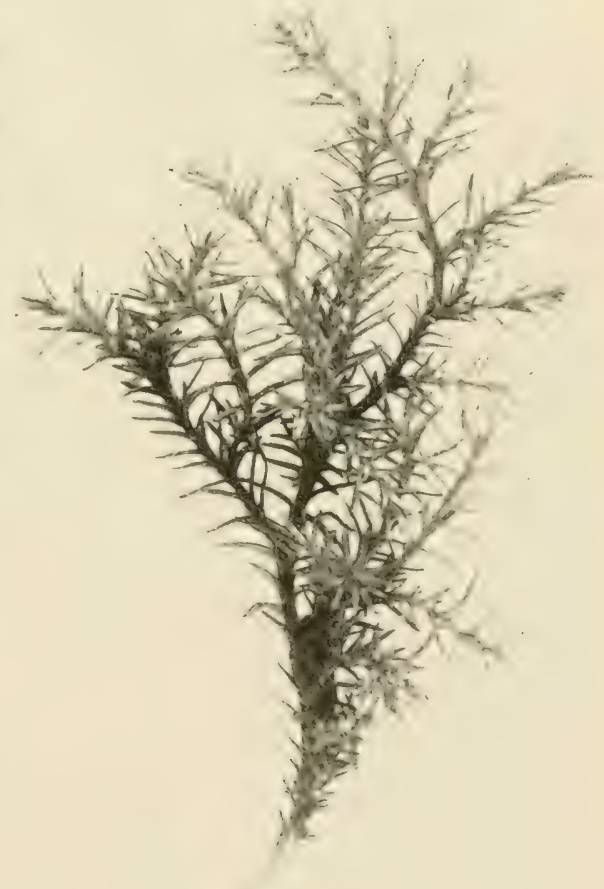

Fig. 154.

Chamaecyparis nisifera S. u. Z. squarrosa Beißn. u. Hochst.

Die durch Stecklinge fixierte Sï $\mathrm{m}$ ling gorm, mit natelförmigen, besonders unten silbergranen Blättern. Bei krättige:ı 
und älteren Pflanzen zeigen sich auch die Übergänge zur Schuppenform. Interessante Form.

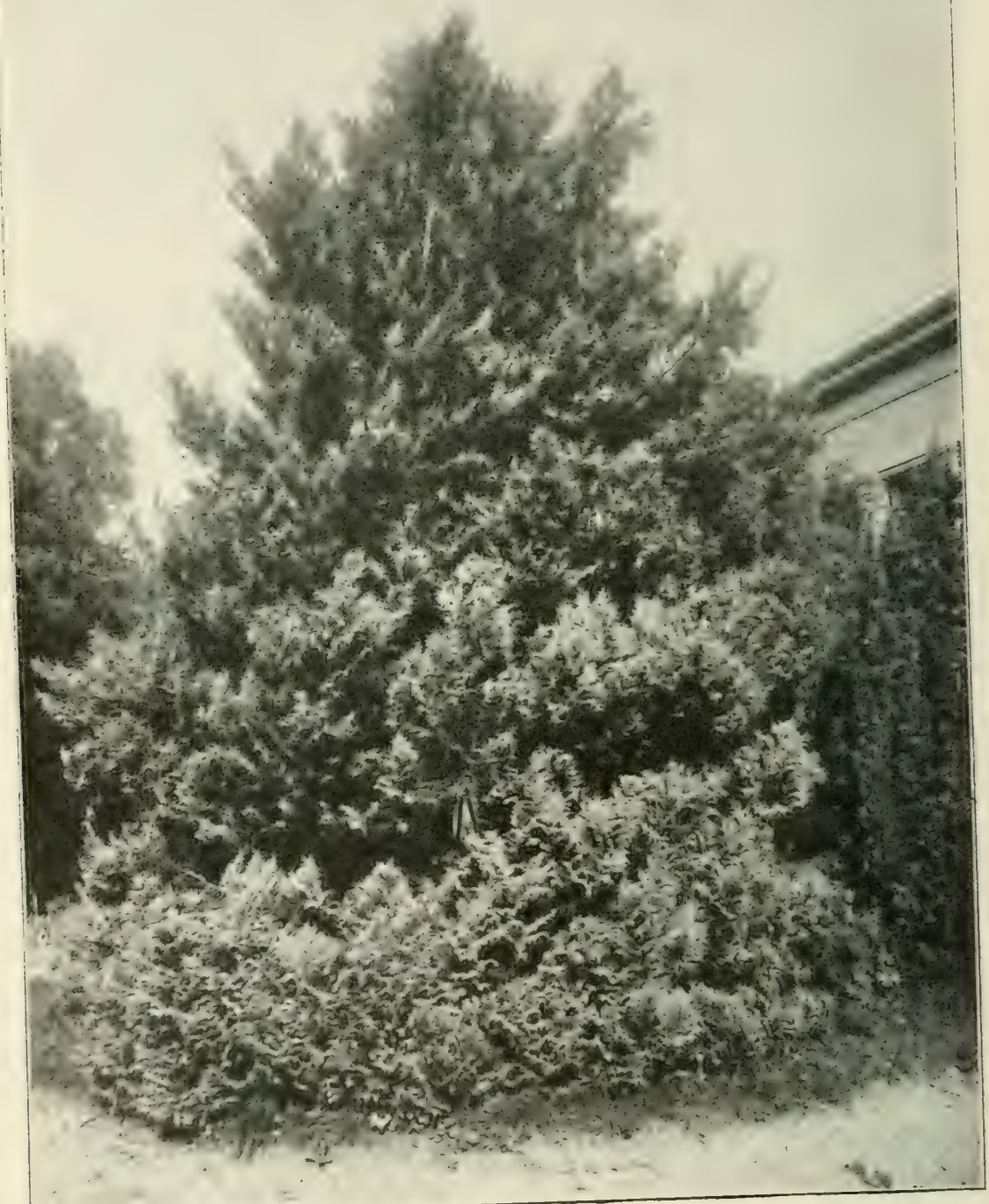

Fig. 155. Chamaecyparis pisifera S. u. Z. plumosa Hort. 
(W'ie notwendio eine cinheitliche, miighi hst kurze Bezeichnum der Koniferen ist, zeigt als Beispiel diese Form. welche lieute noch in Holland folgende Namen fuihrt:

Chamaecyp. pisit. squarrosa Veitchii sulphurea,

Chamaecyp. pisif. squarrosa Veitchii glauca Havescens,

Retinispora squar'rosa glaucescens,

Retinispora squarrosa Veitchii glaucescens sulphurea.)

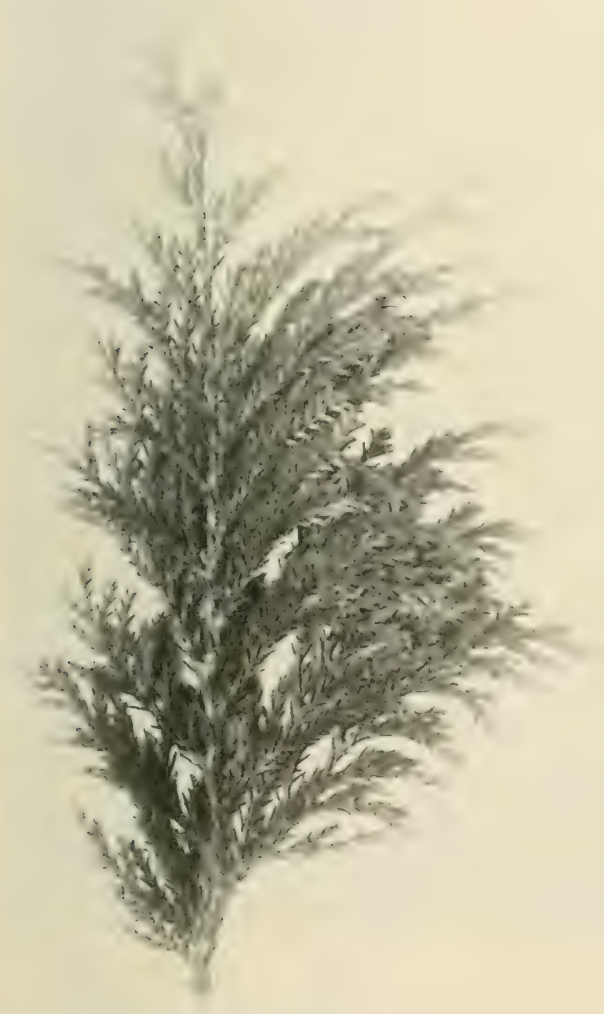

Fig. 120. Chamaecyparis pisifera S. u, Z. Filumosa Hort.

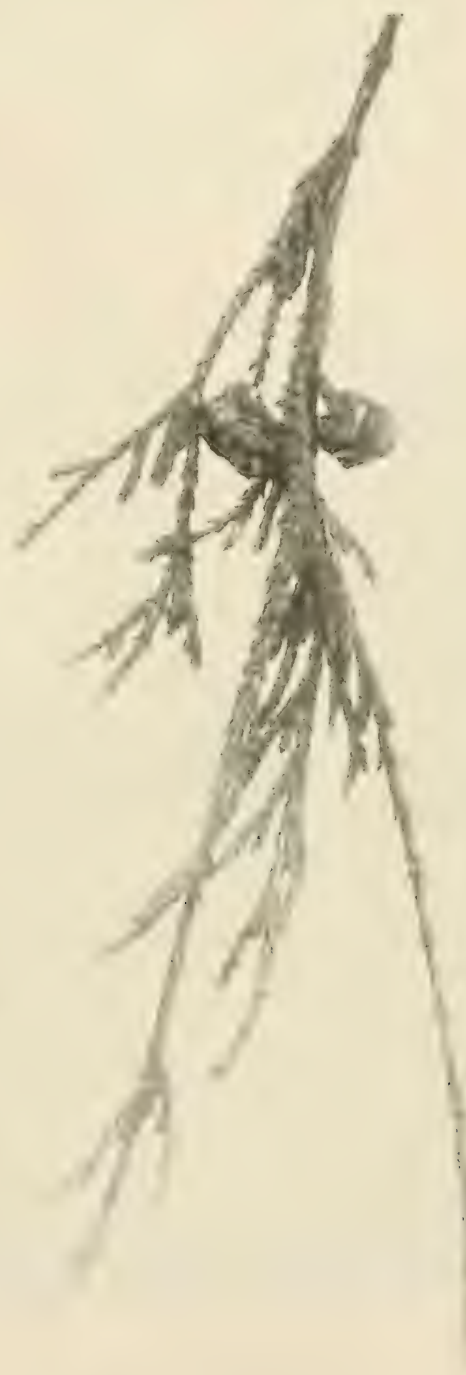

Fig. 157. Chamaecyparis pisifera S. u. Z. filifera Hort.

Chamaec. pisif. squarrosa sulphurea Beißn., wie vorige, nur im Sommer gelbe Spitzen zeigend. 
Sy11.: Chamaes. pisif. squariosa aurea Hort.

Veitchii Hort.

Chamaec. pisif. squarrosa dumosa Beißn., älnlich ersterer, aber dicht- und leichtzweigig, rundlicher. Bau.

Chamaec. pisif. plumosa Hort. (Fig. 155 und 156.) Die Übergangsform vom rein nadelförnigen zum schuppigen Blatt.

An älteren, ippigen Pflanzen zeigen sich auch Triebe der Stamnform. Die Blätter mit ihrer eigentuinlichen Kräuselung erinneru etwas an Flaumfedern.

Gegen starke Sommenbestrahlung, besonders Winters, einpfindlich.

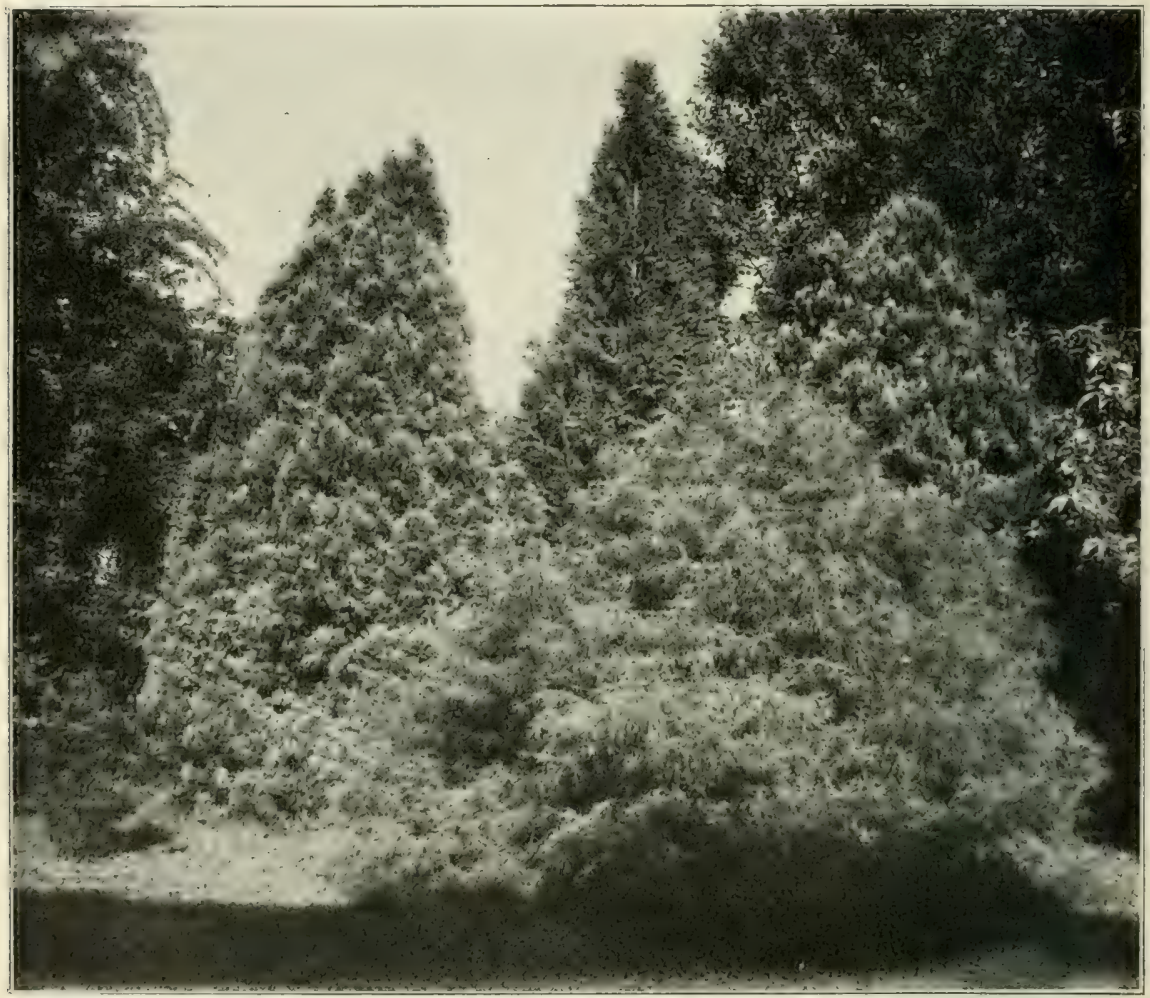

Fig. 158. Vordergrund: (hamaceyparis pisifera S. u. Z. filifera Hort.; Hinterfrund Mitte: Chamuecyparis Lawsoniann Parl. erecta viridis Hort.; Hintergrund rechts und links: Biota orientalis Endl. elegantissima Gord.; links unten: Cephalotaxus pedunculata S. u. Z. fastigiata Carr.

Chamaec. pisif. plumosa vera Hort., noch mehr gekräuselt, auch Zweigchen der Form squarrosa bildend. 
Chamaec. pisif. plumosa argentea Hort., wis erstere, silbergran. alba Hort., weißliche Färbung.

aurea Hort., junge Zweigspitzen gelb. . nana Hort, wie vorige, nieder.

Von" Japan" aus ". sind einige weitere Unterformen von phumosa, ganz besonder's monströser Art, zu erwarten. Vielleicht sind sie auch schon bei uns da und dort in Kíultur, wie z. B.:

Chamaec. pisif. plumosa cristata K. Onuma, hahnenkammartig. Wahokuhiba K. Onuma, fächerförmige, monströse Bezweigung.

Chamaec. pisif. filifera Hort. (Fig. 157 u. 158), herrliche, lang farenförmig iiberhängende Form, mit meistnadelförmigen, doch unten anliegenden, sowie teilweise mit schuppenförmigen Bliittern.

Chamaec. pisif. filifera aureo-variegata Hort,, gelbbunt. argenteo-variegata Hort, weißbunt.

schwefelgelb. flava Schelle, besonders Winters

Chameac. pisif. filifera aurea Hort., goldgelb, nieder. crispa Beißn., dichte Pyramide, gekräuselte "Bezwei"gung, "Nadelblätter.

Chamaec. pisif. filifera gracilis Hort, fein ïberhängend, nieder. breiteter," glockenförmiger Wuchs.

nana Hort. (Buittner), nieder, ausge-

Chamaec. pisif. filifera nana aureo-variegata Hort., wie vorige, gelbbunt.

Chamaecyparis obtusa Sieb. u. Zucc. Abgestumpfte L.-Z. Feuer-(Somnen-)Zypresse.Japan, frichebt Hö̀nenlage, (Fig. 159.)

Syn.: Retinispom obtusa sieb. u. Zuce. Cupressus obtusa C. Koch.

Schöne, ziemlich hohe Art von pyramidalnicht zu trockenen

Standort. Kümmert in schwerem, kalkreichem Boden und ist dann auch nicht ganz winterhart. Jung oft ziemlich empfindlich. kegelförmiger Gestalt, fast wagrecht abstehenden Ästen und dichtstehenden, fächerartig gestellten Zweigren, welche dem Baum ein ganz charakteristisches Aussehen verleilien.

Ebenso charakteristisch sind die schuppenartigen, stumpfen, hinten konvexen und mit einer rundlichen Drüse versehenen, dunkelgriinen, unten mit einer, einem liegenden Kreuze oder $Y$ gleichenden, weißen Zeichnung ausgestatteten Breitseitenblätter, sowie die einwärts geschwungen-bogigen, zugespitzten Seitenblätter.

Die Bliiten gleichren jenen der Chamaecyparis Lawsoniana. Die einzeln stehenden Zapfen sind rundlich, braun, mit 8(-10) dicken, runzeligen, holzartigen, aufwärts gekriumm-spitzigen Schuppen. Die länglichen, mit Harzhöcker versehenen Samen fiihren schmale Flügel. Mit zwei kurzen Samenlappen ent- 
wickelt sich der Keimling, um sodann im Quir' stehende, narlelförmige Erstlingshliitter zu elzeugen. Keimlinge sind gegen Kïlte und starke Sommenbestrahlung empfindlich.

Das anfen fein selhliche, innen rötliche $\mathrm{Holz}$ ist zähe und findet in der Heimat - nehen Rinde und Bast - zu allerlei Zwecken

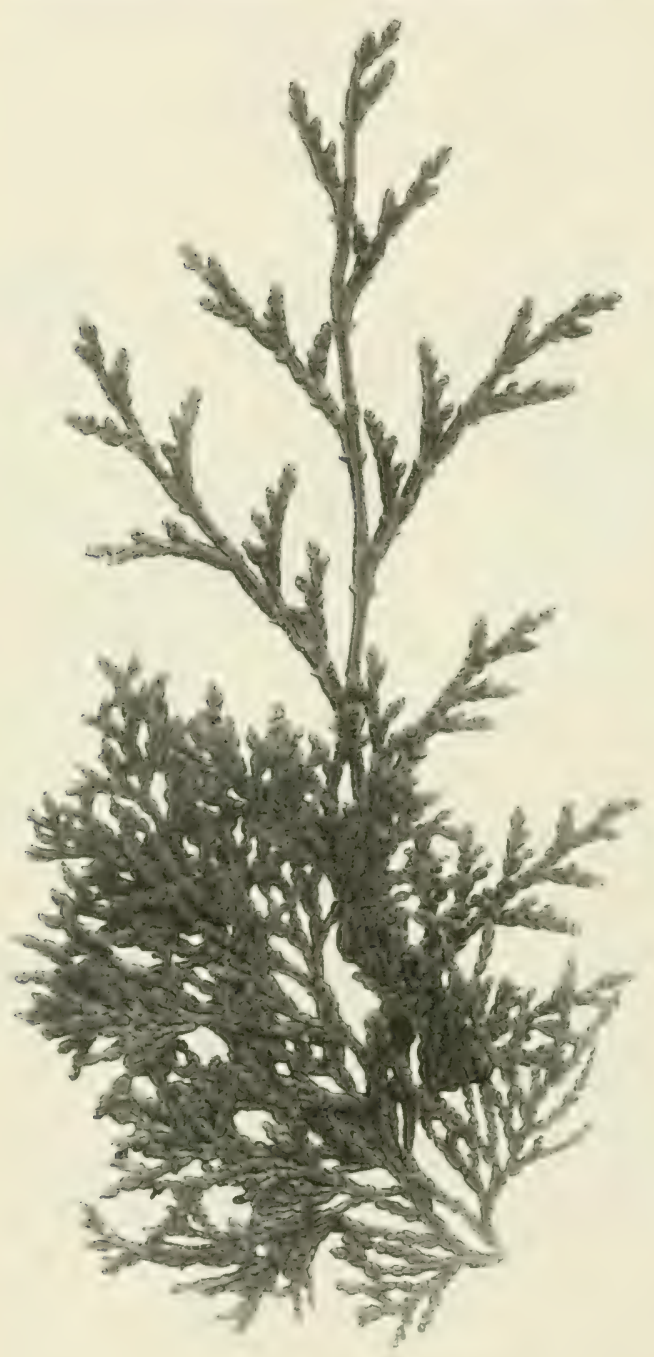

Fig. 159. Chamaceyparie obtusa S. u. Z. eine sehr starke Vel'wendung, gilt iiberhaupt dort als eines der feinsten Hölzer.

Vermelirung durch Samen, durch Stecklinge der nicht rein schuppig-blätterigen Zweige, also besonders der Jugendformen und durch Pfropfung auf die Stammform, wobei aber Zwergformen gerne starken Wuchs elhalten.

Varietäten und Formen sind:

Chamaecyp. obtusa albo-variegata Hort, weißbunt.

Chamaecyp. obtusa albo-spica Hort, weißspitzig, doch nicht immer dauernd, sondern oft wieder grün wertend.

Chamaecyp. obtusa argente 0 -variegata Hort. Groot., gleichmäßig silberbunt.

Chamaecyp. obtusa Mariesii Hort., junge Triebe hellgelb bis milchweiß gefärbt.

Chamaecyp. obtusa lutea nova Hort. Groot., goldschimmernd, feinzweigig.

Chamaecyp. obtusa Crippsii Hort. angl., gelbspitzig, etwas mehr hängend als gracilis aurea. 
Chamaecyp. obtusa gracilis aurea (aurea gracilis) Hort. galll., goldgelb, in der Jugend zierlich, leicht hängend.

Chamaecyp. obtusa magnifica Hort., breitwiichsig, kriiftiw.

Wuchs. aurea Hort., wie vorige, gelb. compacta Hort, dichter, gedrungener

Chamaecyp. obtusa erecta Hort., mit aufsteigenden Ästen. pendula Hort., herrliche, iiberhiingende Form mit fadenförmigen Zweigen. goldbunt.

Chamaecyp. obtusa pendula aurea (K. Onuma), :̈hnlich voriger,

Chamaecyp. obtusa filiformis Hort. jap., lang hä̈ngende, fadenförmige Bezweigung.

Syn.: Chameacyperis pendula Maxim.

Chamaecyp. obtusa tetragona aurea Hort. Barron, monströszweigig, fast viereckige Triebe.

Chamaecyp. obtusa filicoides Hort, farmblattartige Bezweigung, trägwiichsig.

Chamaecyp. obtusa lycopodioides Carr., zwermige Form, mit Lycopodium-artigen Zweigen.

Syn.: Retinispora lycopodivides Gord.

Chamaecyp. obtusa lycopodioides coralliformis Hort. jap.. Zrveige mehr korallenfürmig.

Chamaecyp. obtusa lycopodioides Kanaamihiba K. Onuma, gelbweißspitzige, monströse, dickliche Zweige.

Chamaecyp. obtusa lycopodioides Shamiohiba K. Onuma, weiligelblich, fächerig monströs, gekrümmt.

Chamaecyp. obtusa lycopodioides atirea. jung goligelh, dann l,lafigelb, etwas fächerig monströse, gekriumnte Triebe. (Ob) hierher gehörig?)

Hier sollten sich auch neuere japanische Formen angliedern, hauptsiichlichst Zwergformen mit meist monströsen Zweigen. Allein dieselben sind bis jetzt noch nicht (?) in dentschen Kulturen.

Clamaecyp. obtusa gracillima Hort., reizende Zwergform, mit tütenförmig gedrehten Ziveigen.

Chamaecyp. obtusa Troubetzkoyana Hort., Übergangsform, von der monströsen (lycopodioides) zur Stammform.

Chamaecyp. obtusa ericoides Hort. jap., Jugendform, nade]blätterig, eine blaue Kugel bildend.

Syn.: Juniperus Sanderii Mast.

Retinispora Sanderii Sand.

Chamaecyp. obtusa nana Carr., Zwergform, dunkelgrün. aurea Hort., wie vorige, gelb. albo-variegata Hort., weißbunt.

". gracilis Hort., feinzweigig. 
Chamaecyp. obtusa pygmaea Carr, , sehr' nierler, sich ansbreitend. gelbbunt.

aureo-variegata Hort., wie vorige,

Chamaecyp. obtusa var. treviramea Mast, mit kurzen, schmalen, dichtstehenden Nebenzweigen, an die Form filicoides erimernd. Blïtter glänzend, dick, olne weißje Zeichnung der Unterseite.

Syn.: Chamaecyparis breviramea Maxim.

Chamaecyp. obtusa var. breviramea aurea K. Onuma, ganz schmale Zweige mit goldgelben Spitzen.

Chamaecyp. obtusa var. breviramea Kamakurahiba K. Onuma, lange, fächerförmige Zweige.

Chamaecyp. obtusa var. breviramea Patsunamihiba $K$. Onuma, lange Zweige, mit noch längeren, diinnen Nebenzweigen.

In Japan werden, wie es den Anschein hat, kurzzweigige Formen stets mit breviramea bezeichuet (nach Beißner).

Chanaecyp. obtusa ist eine der Arten, welche die Japaner in sehr alten, verkrïppelten Exemplaren in Töpfen und Kübeln ziehen.

Chamaecyparis nutkaënsis Spach. Nutkaoder Sitka-L.-Z. Westliches Nordamerika, von Liebt feuchte Luft! Sitka bis Oregon. (Fig. 160.)

Syn.: Cupressus nootkatensis Lambert.

Thunopsis borealis Hort.

Ganz charakteristischer, hochstrebender, schlank pyramidal wachsender Baum, mit sich ausbreitenden und elegant iuberhängenden Ästen, enggestellten, zusammengedrückten Zweigen, sowie kreuzförmig gegenständig gestellten, schuppenförmigen, oben abstehenden, sehr spitzen Blättern. Von letzteren sind die Breitblätter flach, eine rinnenförmige Öldrïse zeigend, oben glänzend hellgrün, im Alter prachtvoll dunkelgrün, unten bläulichgrin; die Randblätter dagegen sind gekielt, konvex. Beim Zerreiben entwickeln die Blätter einen unangenehmen Geruch.

Die erst grïnen, dann bräunlichen, blau bereiften, rundlichen Zapfen sind größer als jene von Chamaec. Lawsoniana und zeigen 4-6 Schuppen, mit nahe der Mitte ziemlich starken, spitzen Höckern. Ziemlich zahlreich sind die breit-rundlichen, heiderseits geflügelten Samen, welche keine Harzhöcker führen.

Das leichte und dauerhafte Holz ist in der Heimat sehr gesucht. Als Zierbaum ist die Art, ihrer Form und ihrer auch im Winter bleibenden dunkeln Farbe wegen sehr beliebt.

Vermehrung aus meist eingefuihrten Samen, da die Stammform bei uns etwas selten keimfïhiges Material zeitigt. Stecklinge, welche aber erst spät buschige Pflanzen erzeugen, wachsen amm hesten von jugendlichen Zweigen. Pfropfung wemn irgend möglich auf die Stammform. 
Formen sind:

Chamaecyp. nutk. aureo-variegata Hort., relbbunt.

. aurea Hort., goldgelb.

Syn.: Chamaecy). mutk, lutea Hort.

Chamaecyp. nutk. argenteo-variegata Hort, weithbunt.

. viridis Hort., herrlich griin, schlankwïchsig.

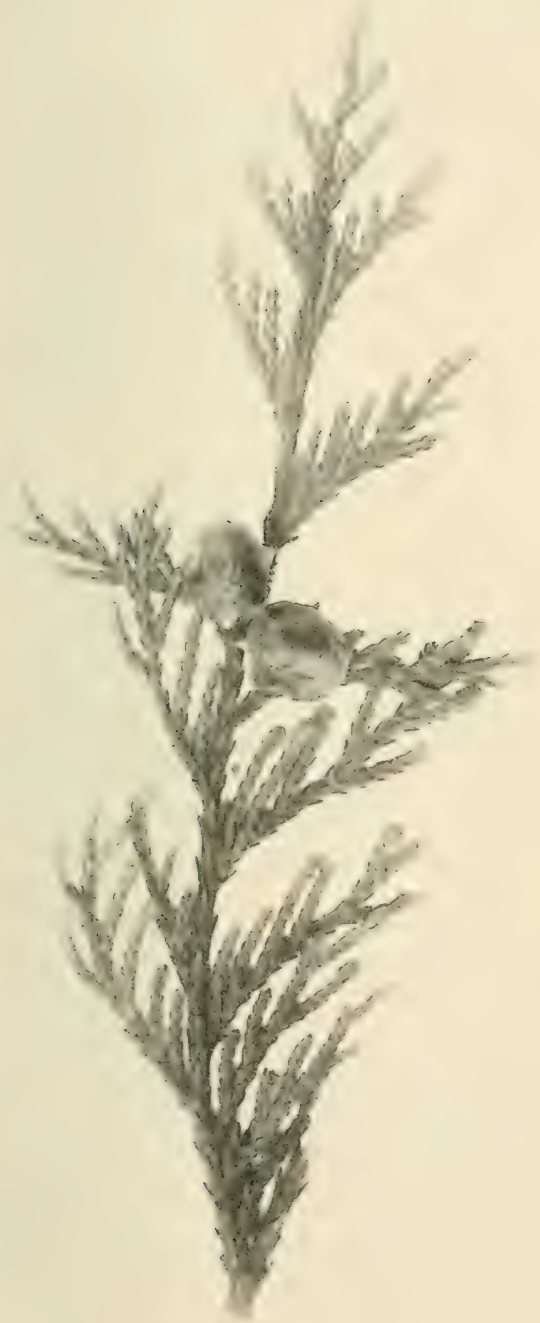

Fig. 160.

Chamaecyparis nutkaënsis Spach.

Schelle, Koniferen.

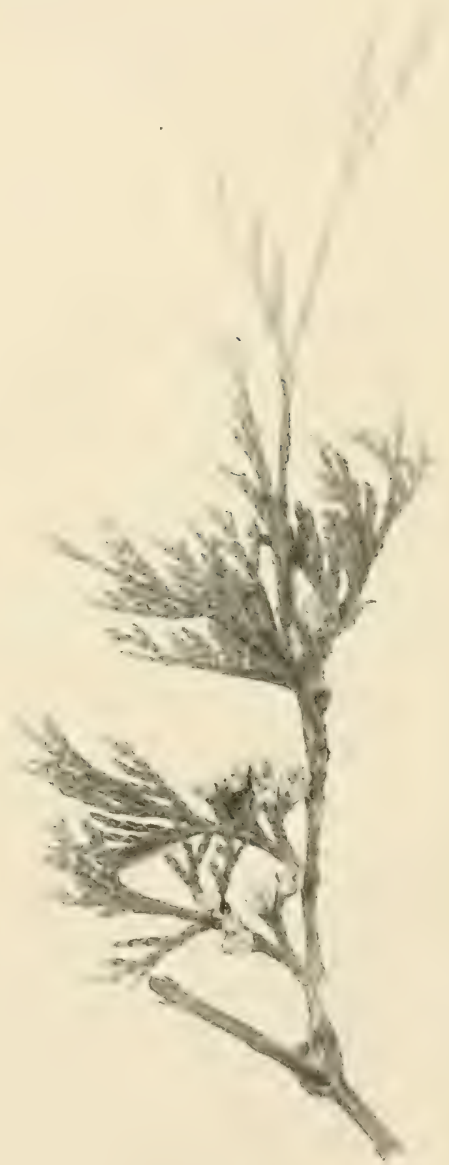

Fig. 161.

Chamaecyparis sphaeroidea Spach. 
Chamaecyp. nutk. glauca Hort, blaugrüne, überhängende Form. Wuchs. vera Hort., wie vorige, gedrungener

Chamaecyp. nutk. glauca aureo-variegata Hort., ähnlich ersterer, aber gelbbunt.

Chamaecyp. nutk. ericoides Saghi, mattblaugrün, sehr spitze, fast grannenartig ausgezogene, feingekielte Blätter.

Chamaecyp. nutk. columnaris Schelle, säulenförmiger Wuchs, mit höchstens $1^{1} / 2 \mathrm{~m}$ langen, diimnen Ästen.

Chamaecyp. nutk. pendula Hort., hängende Form. " gracilis Hort., grine, zwergige Kugel.

Wuchs.

" aurea Hort. gall., wie vorige, gelb.

n compacta Hort., gedrungener, kugeliger

Chamaecyp. nutk. compacta viridis Hort., lebhaft griine Kugel. " glauca Hort., blaugrüne Kugel. " glauca Hort., blaugrüne Kugel. nestartig. nidiformis Hort., ganz nieder, ausgebreitet,

Chamaecyparis sphaeroidea Spach. Kugelfriichtige ${ }_{\text {Liebt guten, }}^{\text {I }}$ L.-Z. Weiße Zeder. Ostliches Nordamerika. (Fig. 161.) $\begin{gathered}\text { Liebt guten, } \\ \text { fockeren und } \\ \text { feuchten Boden }\end{gathered}$ Syn.: Cupressus thyoides $L$. Kümmert auf

Bei $20 \mathrm{~m}$ hoch werdenter, aber bei uns in der schwerem oder Jugend trägwiichsiger Baum, von hoch pyramidalem Standort. Jung Wuchs, im Alter charakteristisch gedrehtem Stamm, empfindlich. ansgebreiteten Ästen, kurzen, ziemlich eng gestellten Zweigen, doppelt kreuzweise gestellten, schuppenförmigen, kleinen, hell-graugrünen Blättern, welche auf dem Rücken eine runde, etwas rötlich gefärbte Öldrüse führen und beim Reiben einen starken, doch nicht unangenehmen Geruch entwickeln. Spaltöffnungsfigur $\times$-förmig.

Die häufig an kleinen Zweigchen sich zeigenden, runden, etwa erbsengroßen, bläulich-grinen, braungrün-bereiften Zapfen haben 6-8 höckerige, wie verkrümmelt aussehende Schuppen. Die kleinen, rundlichen Samen sind schmal geflügelt, aber ohne Harzhöcker. Mit zwei Samenlappen entwickelt sich der Keimling, un sodam ganz schmale, oben konvexe, unten mit zwei weißbläulichen Linien versehene, rings um den Trieb gestellte Blätter zu elzeugen.

Vermehrung aus eingefuihrten Samen. Stecklinge von .Jugendpflanzen - schuppenblïtterige wachsen schlecht - geben buschige, aber kleine Pflanzen. Pfropfung auf die Stammform, im Notfall auf Chamaecyp. Lawsoniana.

Das gelbe Kernholz gilt als sehr wertvoll.

Ist in der Heimat eine ausgesprochene Sumpf- bezw. Moor- 
pflanze, welche also bei uns einen annähemd gleichen Standort erhalten sollte, andernfalls sie nicht ganz winterhart ist und kiimmernde, ruppige Exemplare ergibt. Das aromatisch riechende Holz ist zwar leicht und weich, aber dauerhaft und deshalb seln' ge'sucht.

Formen sind:

Chamaecyp. sphaer. atrovirens Ḱnight, dunkelgriul.

liche Form. aurea Hort, goldgelbe Form. II variegata Endl., teilweise gelbIII

Chamaecyp. sphaer. glauca Endl., blaugrüne, iibergebogene Zweige, gedrungen wüchsig.

Chamaecyp. sphaer. ericoides Beißn. und Hochst., durch Stecklinge fixierte Form mit Erstlingsblüttern, Juniperus-artig, von säulenförmigem Wuchs, im Winter sich rötlichbraun färbend.

Syn.: Retinispora ericoides Juss. blaufarben.

Chamaecyp. sphaer. ericoides glauca Hort, gleich voriger,

Chamaecyp. sphaer. andelyensis Carr., eine sogenannte Übergangsform, mit nadelförmigen und schuppenartigen Blättern, von gedrungenem, nieder-pyramidalem Wuchs und dichter Bezweigung.

\section{Syn.: Retinispora leptoclada Hort.}

Chamaecyp. sphaer. andelyensis nova, wie vorige, jedoch von ganz pyramidalem Wuchs.

Chamaecyp. sphaer. pyramidata Hort., säulenförmig, dichtzweigig.

Chamaecyp. sphaer. fastigiata glauca Hort, eine säulenförmige, blaugriine Form, welche als ein guter Ersatz der BöcklinZeder (Cupressus) in unsern kalten Klimaten zu bezeichnen ist. Zweige.

Chamaecyp. sphaer. pendula Hort., nieder, iiberhängende

Chamaecyp. sphaer. Hoveyi Hort., mit monströsen Zweigen. nana Endl., rundlich, nieder.

fast anliegende Form.

pygmaea Hort., sehr kleine, dem Boden

Eine neue, wohl noch nicht in unseren Baumschulkulturen befindliche, noch ungenügend bekannte Art ist:

Chamaecyparis formosensis NIatsumura, Formosa-L.-Z., Formosa, Hondo, von hohem Wuchs und mit feineren Zweigen.

\section{Juniperus Linné.}

Wa c h hold e r.

Immergriune Sträuches oder kleine Bäume, oft sehr veränderlich im Wuchs, mit aufstrebenden oder ausliegenden Ästen 
mod ehensolchen Zweigen. Blätter schuppenfömiæ oder nadelförnigg. Bliit'n monözisch oder diözisch: die weiblichen kugelfürmig, nnit gegenstandigen bis quirlförmig gestellten Schuppen; die mämlichen kätzchenförmig. Sanenknospen 1-2, aufrecht unter den Schuppen. Zapfen blau oder rötlich, erbsen- bis nuficrof, teils beernförmig, teils fleischig, teils steinfruchtartig. Die meist eckigen Samen, bis zu 6, sind entweder durch die Frucht eingeschlossen oder stehen bis zur Hälfte hervor; die Samenschale ist mehr oder minder hart bis steinartig.

Nur auf gutem Boden und in nicht zu kalten Gegenden er'reichen die Wachholder-Arten ihre normale Höhe bezı. Umfang. Sehr kalte Winter beschädigen auch die härtesten Arten etwas.

Termehnung durch Samen, stecklinge und Pfropfung.

Der Samen darf nicht trocken aufbewahrt werden, da er oft schon nach 7-8 Monaten, bestimmt aber nach einem Jahr seine Keimkraft verliert. Er liegt lange, d. h. geht erst im zweiten Jahr auf. Da einheimischer samen oft schlecht keimt, wird zumeist importierter zur Saat verwendet.

Stecklinge wachsen fast von allen Sorten; man entnimint dieselben mehr den unteren, noch ziemlich nadelfömigen Zweigen der Pflanzen, oder iiberhaupt jingeren Pflanzen. Pfropfung geschieht auf verschiedene Art, vielfach durch das sogen. Einspitzen. Zu Unterlagen verwendet man Sämlingspflanzen von J. virginiana, communis und chinensis. Die Formen mïssen auf die Art mepfropft werden: im Notfall dienen 2 jährige Junip. virginiana für alle Arten.

Kriechende, d. h. niederliegende Formen, besonders von J. Sabina, werden auch durch Ableger vermehrt.

\section{Abteilung: Sabina Endl.}

Sade- oder Sevenbäume.

Blätter dachziegeliø schuppenfömig, seltener dreifach quirlständig, mit einer. Oldriis e versehen. Erstlingsblätter und auch jene der unfruchtbaren Triebe nadelförmig. IVeibliche Blüten 4-6schuppig, die obersten fruchtbar. Kugelige Beerenzapfen. 1-4 hartschalige Samen.

Juniperus occidentalis Hook. IVestamerikaIV (III) nich trockenen nischer S. Britisch Kolumbien bis Nord-Kali- als zu feuchten Standfornien, Utah und Texas. ort.

Syn.: Juniperus occidentalis Hook. var. Dieclii Boll. Psendo-Cupressus Dieck. 
Tileiner, monözischer Baum oder sehr hoher Strauch von pyramidalen Aufbau, abstehenden und dabei etwas iberhängenden Ästen. Blätter @raugrin, schuppenförmig, anliegend, oben konvex, mit vertiefter, linglicher Drise und von zicmlich scharfem Geruch.

Die aufrecht stehenden, lïnglich-ovalen, 7-9 mm grofien, bram- bis bläulich-schwarzen, blauweif bereiften Zapfen fiihren 6 (auch 9) oben kurz zugespitzte Schuppen mit 1-2 eirundlichen Samen.

Eine noch immer wenig verhreitete Art, deren Holz seiner Dauerhaftigkeit wegen in der Heimat weite Verwendung findet.

Noch seltener sind die Formen:

Juniperus occid. utahensis Sarg., eine sehr langsam wachsende Form.

Syn.: Juniperus utahensis Engelm.

Juniperus occid. fragrans, pyramidal wachsend, blaugriin. Syn.: Juniperus fragrans Knight.

Weitere hierher gehörige, noch nicht genügend bekannte, oder in Deutschland kaum aushaltende Juniperus-Arten sind:

Juniperus californica Carr. Kalifornischer S. Kalifornien.

(VII ?) (VI)?

Sonniger, trockener, kalkhaltiger Standort.

Baumartiger Wuchs.

Eine Form ist:

Juniperus calif. utahensis.

Juniperus pachyphloea Torr. Dickrindiger S. Von den Gebirgen Neu-Mexikos und Arizonas stammend.

V?
Auf sonnigem, trockenem, kalkhaltigem Standort.

Schmaler, ziemlich kurzästiger Baum. Junge Triebe blangriin und blau iiberhaucht, alte Triebe blaugriin; prachtvoll.

Juniperus procera Hochst. Abessinischer S. vu? Abessinien. Wohl kaum in Kultur.

Juniperus Bermudiana L. Bermuda-S. Bermuda, Siid-Florida. Nicht in Kultur (\%). Liefert Bleistiftholz.

VII?

Juniperus monosperma Sarg. Einsamiger S. Kolorado, West-Texas, Neu-Mexiko bis Arizona. $\begin{gathered}\text { Liebt trockenen Stand- } \\ \text { ort. }\end{gathered}$

Syn.: Juniperus occidentalis Hook. var. monosperma Hort.

Kleiner Baum bis sehr hoher Strauch, mit stark ausgebreiteten Ästen, grauer, abschiilfernder Rinde und hellgrünen, schuppenartigen, oben konvexen Blättern, welche eine längliche Driise führen. Die bläulich-schwarzen, bereiften Beerenzapfen führen nur einen Samen. 
Juniperus religiosa Royle. Heiliger S. Von den höchsten Bergen des Himalaya. Wird auch als eine Form des Juniperus excelsa betrachtet. Ziemlich hoher Baum. Wohl nicht in Baumschulkultur.

Juniperus mexicana Schiede. Mexikanischer S. Gebirge Mexikos.

VII ?

$$
\text { Syn.: Juniperus gigantea Roezl. }
$$

Wohl nicht in Baumschulkultur.

Juniperus tetragona Schlechtend. Vierkantiger S. Gebirge Mexikos. Nicht in Kultur.

Juniperus flaccida Schlechtd. Schlaffer S. Gebirge Mexikos. Kalthauspflanze.

Juniperus Sabina L. Gemeiner Sevenbaum. Alpengegenden von Mittel- und Siideuropa; Kleinasien, Kaukasus, Sibirien. (Fig. 162.)

Syn: Sabina officinalis Garcke.

Weit verbreiteter und bekamnter, niederliegender aber auch sich erhebender, blaugrüner Strauch, mit aufsteigenden Ästen und Zweigen. Blätter verschieden; entweder sind solche schuppenförmig, stumpf bis spitz, am Rücken konvex, mit länglicher Driise, oder abstehend, lineal, spitz, oben blaugrün, unten grün.

Die iiber $1 \%$ cm großen, schwarzen, blau bereiften Beerenzapfen zeigen 4-6 kurz gespitzte Samenschuppen. Samen 1-4, hartschalig, stehen oft zur Hälfte aus dem Fruchtfleisch hervor.

Der Keimling zeigt kurz gespitzte Samenlappen und dam $\mathrm{N}$ a d e l blätter.

Die Zweige und Blätter, welche einen widerlichen Geruch bein Zerreiben haben, werden offizinell benuitzt und sind besonders die Triebspitzen als Abortivmittel bekannt.

Dás schöne, rote Holz findet vielfach Verwendung.

Männliche Sträucher des Junip. Sabina wachsen meist aufrechter als die weiblichen.

Vermehrung durch frischen Samen, durch Stecklinge, Ableger und Pfropfung.

In der Nähe von Obst- speziell Birmpflanzungen sollte der Sevenstrauch nicht geduldet werden, da er auf sich einen Pilz, Gymnosporangium Sabinae, trägt, welcher seinen Wirt wechselt, d. h. auf den Birnbaum iibergeht (als Rostelia cancellata) und hier Blätter und Triebe sehr schädigt.

An Unterarten und Formen sind zu nennen:

Junip. Sab. mascula, männliche Pflanze.

femina, weibliche Pflanze. 


\section{$-311-$}

Juniperus Sab. gymnosperma Schröter, mit kaum umschlossenem Samen. Junip. Sab. variegata Hort., gelbbunt.

fastigiata Hort., säulenförmig, dunkelgrün.

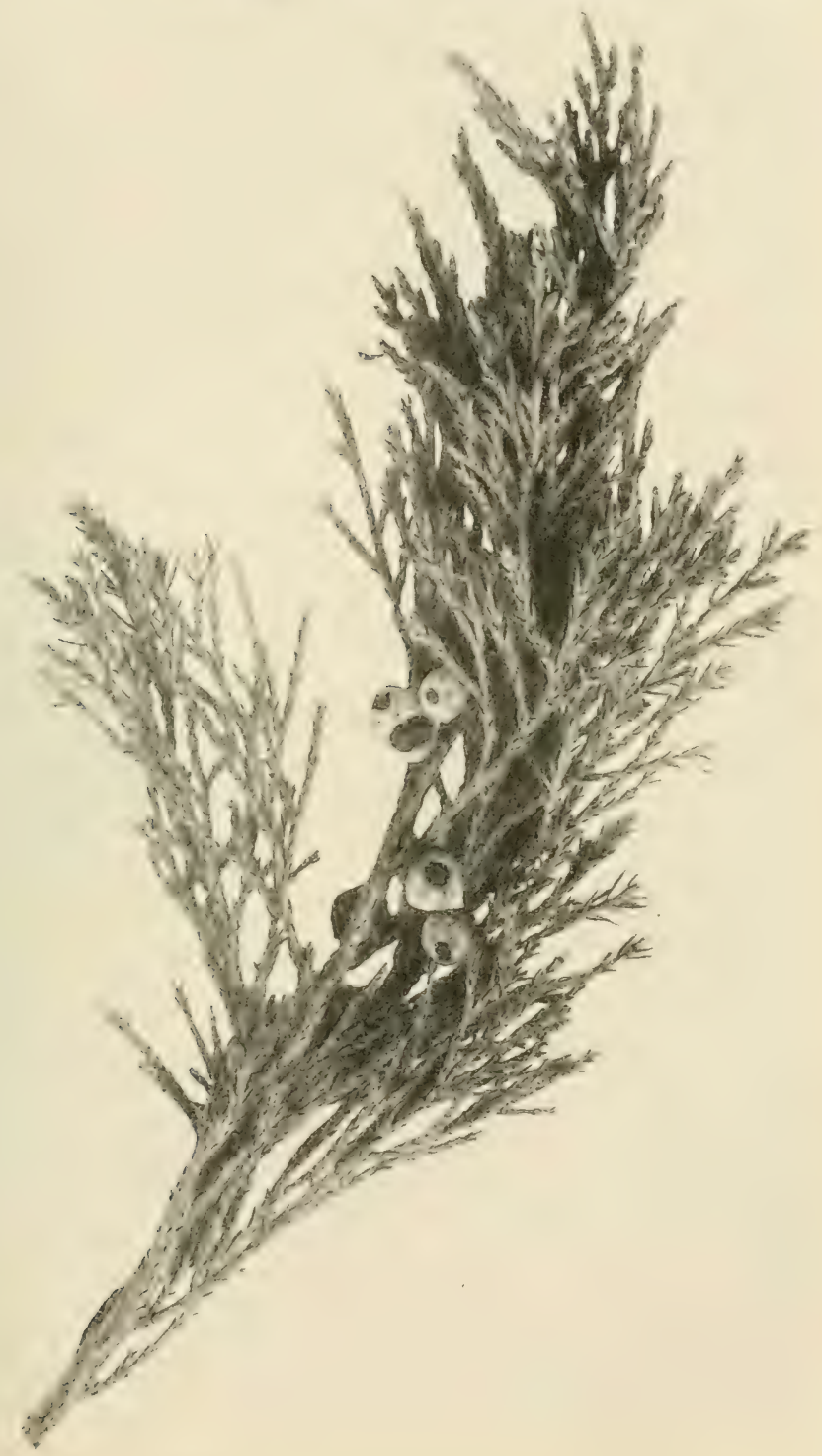

Fig. 162. Juniperus Sabina L. 
Junip. Sab. erecta Hort., aufwärts strebend, aber doch auslegend.

Junip. Sab. humilis End1., niederliegend, dickzweigig, oft auch mit nadelförmigen Blättern.

Junip. Sab. procumbens Hort., niederliegend.

var. prostrata Loud,, Nordamerika; ganz am Boden liegend, fast kriechend.

Syn.: Juniperus prostrata Pers.

Junip. Sab. Ganderii Hutter, mit nadelförmigen und schuppenartigen Blättern.

Junip. Sab. tamariscifolia Ait., suidliches Europa, blaugrüner als die Stammform, mit einwärts gebogenen, spitzen, oben weißlich-rinnigen Nadelblättern.

Syn.: Juniperus sabinoides Gris.

Junip. Sab. tamariscifolia glauca Hort., wie vorige, bläulich.

Juniperus virginiana $L$. Virginischer S., virginische Zeder, rote Zeder, Bleistift-Zeder. Öst- Jung etwas empfindliches Nordamerika, von Florida bis Mexiko und $\begin{aligned} & \text { boden, feuchter oder } \\ & \text { lelumiger Sandboden }\end{aligned}$ bis zur Hudsonbai. (Fig. 163 bis 165.) am besten.

Syn.: Juniperus caroliniana Dur.

Sehr schöner, auch bei uns bis zu 25 m hoch werdender, aber langsam wachsender Baum, von erst pyramidalem, dann mehr breitem Wuchs, ausgebreiteten und etwas überhängenden Ästen und fast viereckigen $Z$ weigen. Blätter verschiedengestaltet, entweder (an jüngeren Pflanzen) nadelförınig zu dreien gestellt, spitz, oben weißrinnig, mit schmaler Öldrüse, oder schuppenförmig, doppelt gegenständig, oben spitz, ziemlich dunkelgriin, mit etwas breiterer, rundlicher Öldrise.

Die iiber $1 / 2 \mathrm{~cm}$ großen, dunkelroten, blauweiß bereiften Beerenzapfen haben 4-6 Schuppen mit 1-2 kleinen, stumpfeckigen Samen. Die Keimlinge (der Samen bleibt oft ein Jahr liegen) zeigen 2 Samenlappen und dann - wie iiberhaupt die jüngeren Pflanzen - nadelförmige Blätter. Anzucht aus Samen und Stecklingen.

Diese Art gibt - besonders als zweijährige Pflanze die beste Unterlage zum Pfropfen sonstiger Juniperusarten.

In Deutschland schon 1664 eingefiihrt, stehen auch hier verschiedenerorts prächtige Bäune, ja hektargroße Anpflanzungen; allein ihre Träigwiichsigkeit belohnt nicht entsprechend ihren Anbau.

Das rote Holz, von aromatischem Geruch, findet einerseits zu Kleinwaren, Werkholz, Bleistifthiilsen etc., andererseits aber als Bahnschwellenholz, sowie zum Tiefbau, weil es auch in der Erde sehr dauerhaft ist und von Insekten nicht leicht angegriffen 


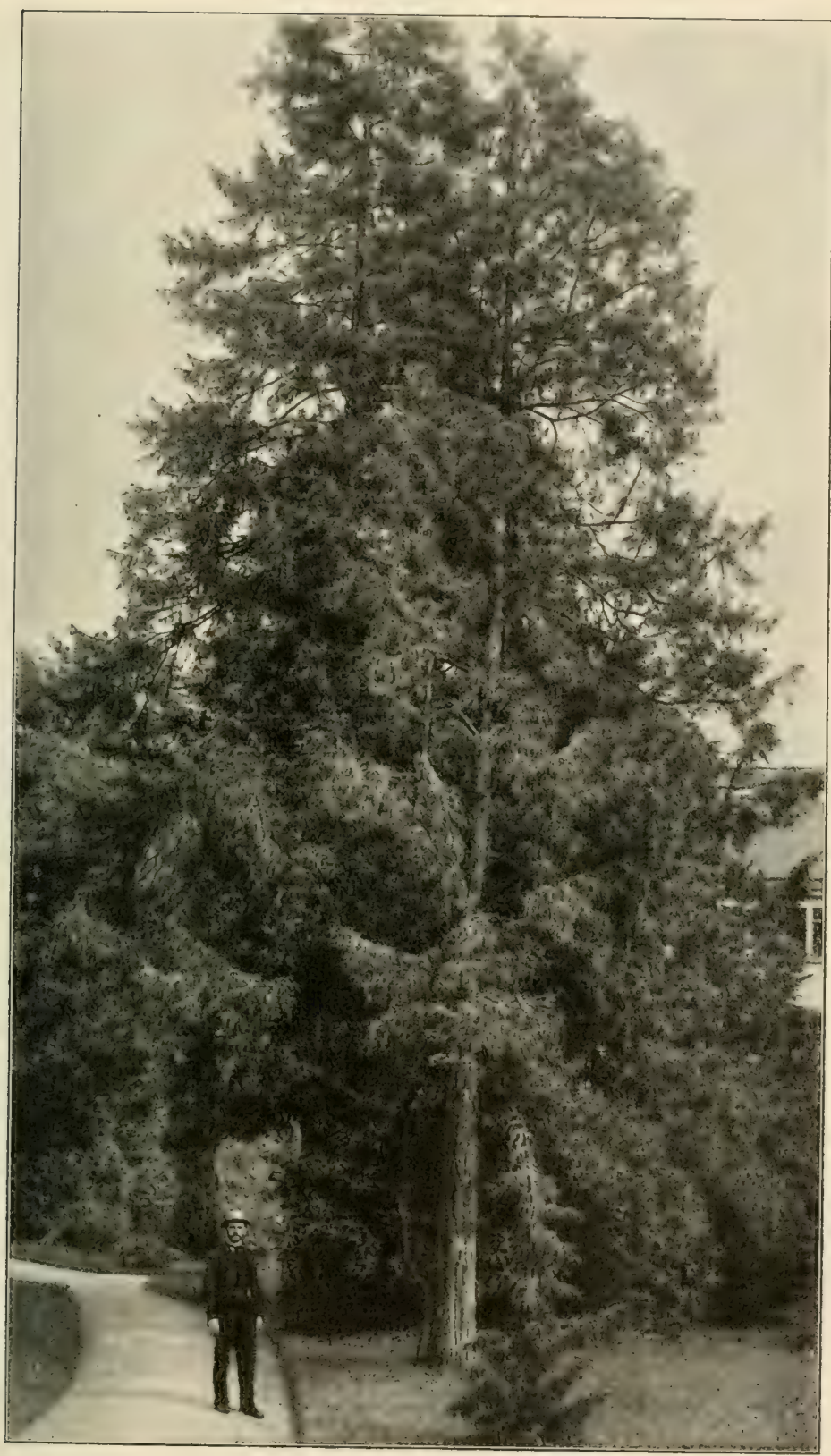

Fig. 163. Hintergrund : Picea excelsa Link.; dicht davor: Juniperus virginiana L., 80-90jährig. - Kleine Pflanze: Junip. virg. pendula Hort. 
wird. reichste Terwendung. Die Triebspitzen werden ähnlich wie jene des echten Sevenbaumes benuitzt.

Formen sind:

Junip. virg. glauca Carr.. eine prachtvolle, stahll,laue Form. .. cinerascens Carr.. grausilberig.

Syn.: Jumiperus virginiana argentea Hort.

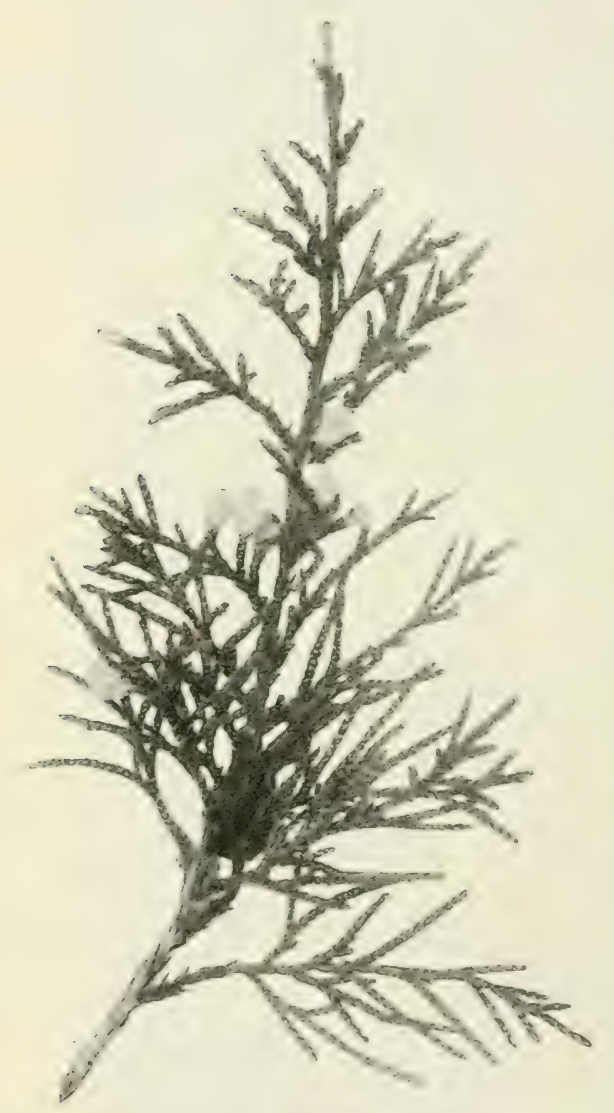

Fig. 164. Juniperus virginiana L., Zweig mit schuppigen Blättern.

Junip. virg. Iumosa alba Hort., bei der Entwicklung weiße Nadelblätter bildend. Junip. virg. plumosa nivea Schwerdt, gleich voriger, aber von kugelförmigem Wuchs.

Junip. virg. albo-spica Hort., mit weißen Spitzen. Junip. virg. albo-variegata Hort., weißbunt.

Junip. virg. variegata Hort., mit weißbunten Spitzen.

Syn.: Juniperus virginiana "Triomplee d'Angers". Junip. virg. Cunninghamii Hort, silberbunt.

Junip. virg. aureo-spica Hesse, jugendlich goldgelbspitzig.

Junip. vilg. aureo-variegata Hort., goldbunt.

Junip. virg. aurea elegans Hort, goldbunt, zierlich.

Junip. virg. elegantissima Hort., im Austrieb goldgelbspitzig, gegen starke Sonnenbestrahlung empfindlich.

Junip. virg. Bedfordiana II Knight, hochpyramidal, iiberhängende Spitzen, fast nur nadelförmige Blätter.

Syn.: Jumipenus Gossainthanea Lodd.

Bermudiana Hort. (fälschlich). virginiane Gossainthanea Carr.

Junip. virg. viridis Hort. (Barb.), mit ausgebreiteten, außen iiberhängenden Asten und silbergrau bereiften Zapfen. 
Junip. virg. pyramidalis viridis Hort., säulenförmig, griin. Syn.: Juniperus virginiana fastigiate Hort.

Junip. virg. pyramidalis glauca Hort, siiulenförmig. blaugrim. formen. " polymorpha Hort., pyramidal, beiderlei Nadelformen tragend, interessant.

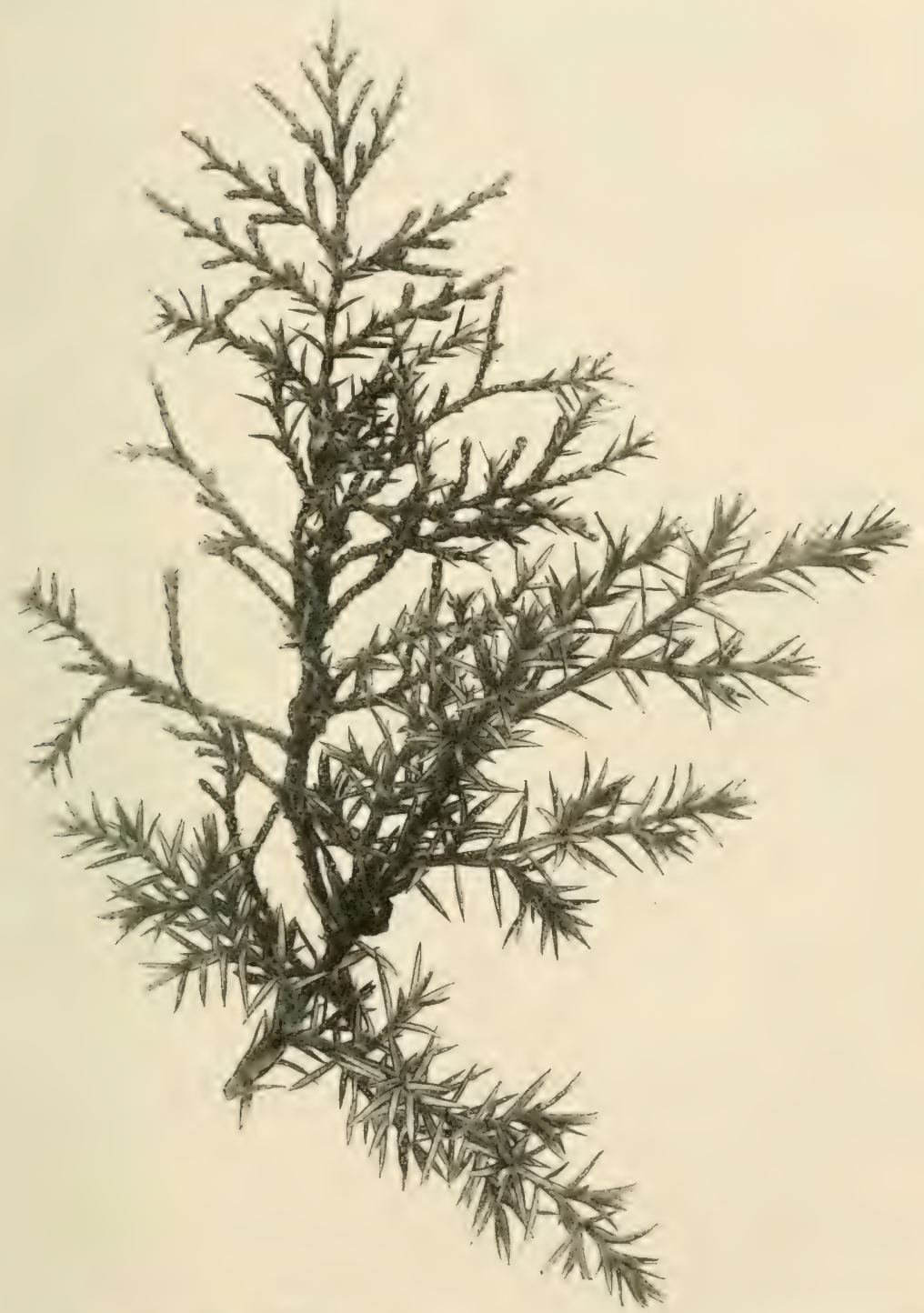

Fig. 165. Juniperus virginiana L., Zweig mit Schuppen- und Nadelblättern. 
Junip. virg. nutans Hort., pyramidal, etwas hängende Zweige. scopulorum Beifn., silberweißnadelig, prachtvoll. Syn.: Juniperus scopulorum Sarg.

Junip. virg. pendula Hort., hängezweigig; †. (Fig. 163.) Smithii pendula Hort., hängezweigig, zierlich.

. . . Clanbrasiliana Hort., hängend, feinzweigig.

mehr nädelförmigen Blättern.

Junip. virg. Cannartii Hort., gedrungen, breitpyramidal. " " interrupta Hort., nieder-pyramidal, fast nur mit Nadelblättern.

Junip. virg. dumosa Carr., ähnlich voriger.

Schottii Hort., nieder, buschig.

tripartita Hort., nieder, buschig, nur Nadelblätter.

goldbunt. aure0-variegata Hort., wie vorige,

Junip. virg. Kosteriana Hort., nieder, schirmförmig.

nana Hort, nieder.

$" \quad " \quad "$ nivea Hort., nieder, weißlich.

$"$ " globosa Hort., kugelig.

Syn.: Juniperus virginiana nana compacta Hort.

Junip. virg. turicensis Froebel, sehr nieder. reptans Hort. Jen., niederliegend.

Juniperus thurifera L. Weihrauch-S., IVeihrauch-Zeder. Höhenlagen der pyrenäischen Halb- Liebt Höhenlagen bei insel und Algiers.

Graugrüiner, mittelhoher Baum oder baumartiger Strauch, mit abstehenden Ästen, eckigen Zweigen und entweder breitlanzettlichen, abstehenden, spitzen Nadelbliattern, oder ebenfalls alstehenden, spitzen, dabei aber schuppenförmigen Blättern mit länglicher Driise und scharfem, aromatischem Geruch.

Die bei $1 \mathrm{~cm}$ großen, aufrechten, ziemlich kugeligen Beerenzapfen sind bläulich- bis schwarzbraun, dabei bläulich bereift, mit 4-6 kurz-spitzen Samenschuppen und 2-4 braunen, etwas eckigen Samen.

Juniperus excelsa M. v. B. Hoher S. Vom griechischen Archipel bis Kaukasus, NordwestHimalaya, West-Tibet.

Syn.: Juniperus macropoda Boiss.

III (II)

Geschuitzter Standort; mehr trockener als feuchter, kalkiger Lehmboden ist Vorteil.

Blangriine, schlank-pyramidal wachsende Art, mit mehr aufrechten als abstehenden Ästen und mehr kurzen als langen Zweigen. Blätter zweigestaltig, besonders an den unteren Zweigen eirundlich, abstehend, zugespitzt, zu dreien stehend, mit einer schmalen Öldriise versehen, jene der oberen Zweige 
schuppenföming, doppelt gecenstïndig, an der Riickseite konvex und mit einer breiteren Öldrise ausgestattet.

Die mon̈̈zische PHanze zeigt sehr zahheich einzeln stehende, kugelfömige, 9-12 mu slofe, schwiirzliche, bläulich bereifte, meist 1 - (selten 6) schuppige Beerenzapfen, mit 3-6 bramen, etwas eckigen Samen.

Formen sind:

Juniperus excelsa variegata Carr., weif-grelbbunt. IV stricta Hort,, schöne, blaugraue, säulenförmige, aber sch"wach wachsende Form.

Juniperus excelsa isophylla, kleinfrichtig, anliegende Blitter. Ob in Kultur? (Wird auch als eigene Art betrachtet, weil sie diözische Blïten hat.)

Syn.: Junipentes isophyllus C. Koch.

Juniperus polycarpus (.. Koch. Viclfrichtiger S. Transkaukasien.

Pyramidal schlanke, blangriue Art, mit etwas schuppenförmig bis eiförmig-rundlichen, zugespitzten Blättern und zahlleich sich zeigenden, 8-12 mm großen, schwärzlichen, blaubereiften Zapfen.

Wird ron rerschiedenen Autoren zu Juniperus excelsa gestellt.

Juniperus chinensis L. Chinesischer S. China, Japan. (Fig. 166 und 167.)

Die bunten Formen etwas empfindlicher,

Auffallender, diözischer, in Wuchs und Blattbildung iiberaus verschiedengestalteter (!) lieben geschützten, leicht beschatteten Baum oder Strauch, dessen männliche und weibliche Pflanzen gänzlich von einander abweichende Ausbildungen zeigen. In Ostasien vielfach als Topf-Zwergbaun gezogen.

Pyramidaler Wuchs, ziemlich ausladende Äste, mit langen und kurzen, dicklichen Zweigen. Blätter sehr verschieden; die unteren Zweige zeigen anliegende oder abstehende, zu zweien oder dreien gestellte, lanzettliche, spitze, oben gefurchte und weiß gezeichnete, unten konvexe und mit schmaler, vertiefter Öldriise versehene Bliatter; die oberen Zweige fiihren dagegen solche von schuppenartiger Gestalt, mehr oder minder stumpf, stachelspitzig, doppelt gegeniiberstehend, oben konvex und mit einer ein wenig breiteren Öldrüse.

Die runden bis länglichen, erst weiß-bläulichen, bereiften, dann schwirzlich-blauen, $1 / 2-1 \mathrm{~cm}$ großen Beerenzapfen zeigen 4-8 meist abgerundete Schuppen und 2-5 braune, etwas eckige Samen.

Formen sind:

Junip. chinensis mascula, die männliche, mehr säulenförmige Stamminorm, mit hauptsächlichst nadelförmigen Blïttern.

Syn.: Juniperus struthiaced Knight. 
Junip. chinensis femina, die weibliche Stammform, mit mehr ansgebreitetem, etwas hängendem Wuchs und vorherrschend schuppenförmigen Blättern.

Syn.: Juniperus cermua Roxb.

Rewesiana Hort.

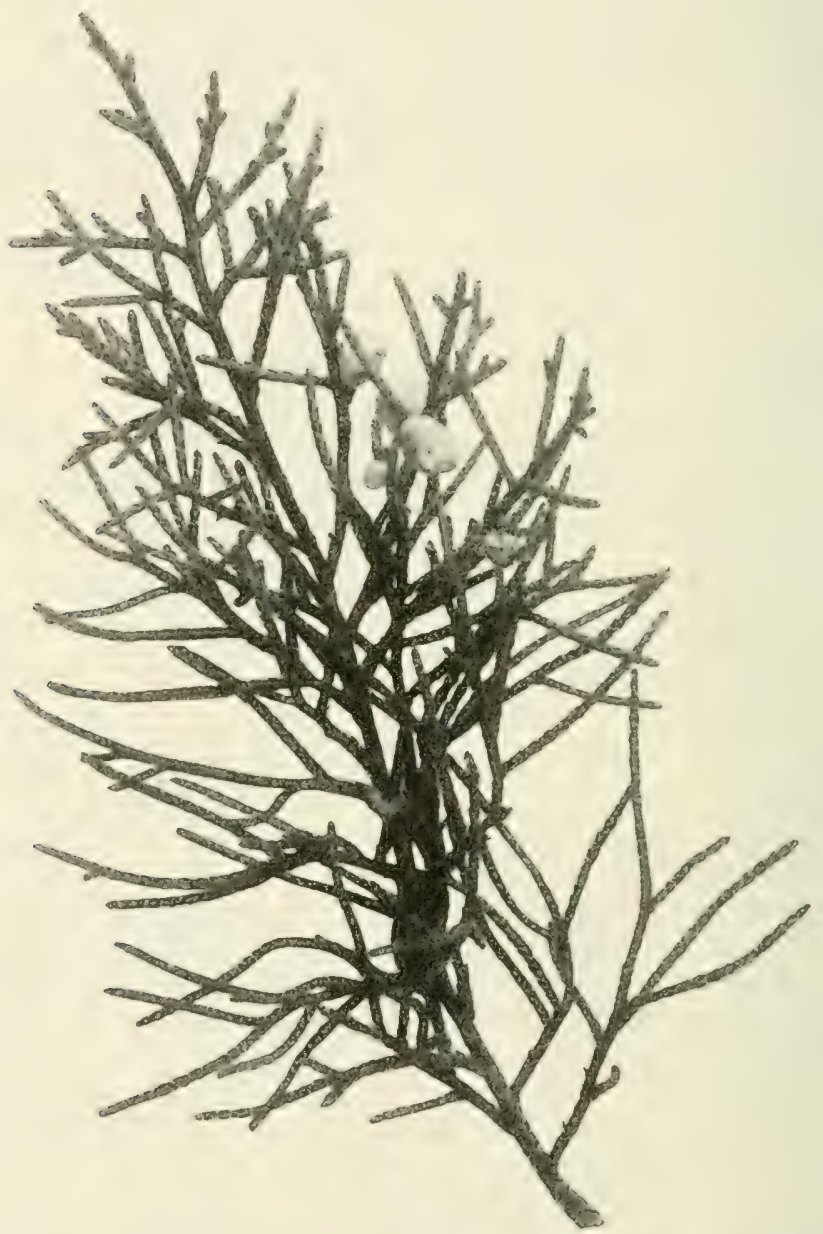

Fig. 166. Juniperus chinensis L., Zweig einer weiblichen Pflanze.

Junip. chinensis aurea Hort, ‡, goldgelb. argenteo-variegata Hort., zum Teil mit weißen Trieben, von mehr niederem Wuchse.

Junip. chinensis pyramidalis Hort., む, pyramidaler Wuchs, besonders nadelförmige Blätter. 
Junip. chinensis Jacobiana Hort., pyramidal, nur Nadelblätter erzeugend.

Junip. chinensis Leeana Hort., , schmal und schlank wathsend, beiderlei Blätter bildend.

Junip. chinensis Langoldiana Hort., schlankwiichsig, besonder's schuppenblätterig.

Junip. chinensis pendula Hort,, $\odot$, hängend.

aurea Hort., hängend, goldgelb.

Pfitzeriana Spaeth, pyramidal wachsend, außen leicht uiberhängend, sehr schön.

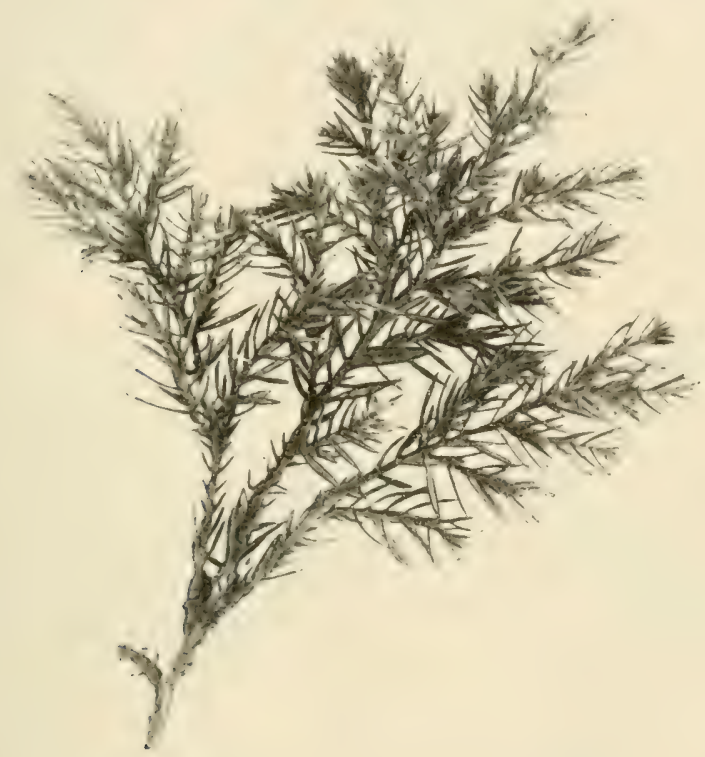

Fig. 167. Juniperus ehinensis L., Zweig einer männlichen Pflanze.

Junip. chinensis neaboriensis Hort., bläulich-blätterig, Säulenform.

Syn.: Juniperus neaboriensis Hort.

Junip. chinensis procumbens Endl., buschig breitwachsend, die unteren Zweige führen mehr Nadelblätter, die oberen mehr Schuppenblätter.

Syn.: Juniperus japonica Carr.

Junip. chinensis procumbens nana Hort., kleiner als voriger.

Syñ.: Juniperus japonica aurea Hort. aurea Hort., junge Triebe gelb.

Junip. chinensis procumbens aureo-variegata Hort., teilweise goldgelb. 
Junip. chinensis procumbens albo-variegata Hort., weifhunt. bunt. argente0-variegata Hort., silberig-

Juniperus sphaerica Lindl. Kugelfrüchtiger S. Nordchina.

Syn.: Juniperus Fortunci von Houtte.

Niederer, pyramidal wachsender Baum, mit ziemlich aufstrebenden Ästen und Zweigen. Letztere sind fast viereckig, zeigen an den unteren Trieben - wie anch an jungen Pflanzen - dreiseitig stehende, nadelförmige, spitze, an den oberen Trieben dagegen doppelt gegenseitio gestellte, schnpenförmige, kaum abstehende und mit langlich-runder Öldrise versehene Blätter.

Die etwa $1 \mathrm{~cm}$ großen, ziemlich kugeligen, einzeln stehenden Beerenzapfen sind schwarz gefärbt, doch nicht bereift und fiilnen 6 kam gespitzte Schuppen mit 3 braunen, eckigen Samen.

Eine Form ist:

Juniperus sphaer. glauca Gord., b]augriu, mit nadeliörmigen Bliattern.

Juniperus foetidissima Willd. Stinkender S.

Ton Macedonien, Griechenland bis Kaukasus $\begin{gathered}\text { Geschiitzter, trockener } \\ \text { Standort, in kalkig }\end{gathered}$ und Syrien.

III (II) lehmigem Boden.

Pyranidal wachsender, monözischer, ganz niederer Baum, mit aufrechten Ästen und vierkantigen, ziemlich abstehenden Zweigen. Die Blätter der unteren Zweige sind fein lanzettlich, spitz, am Rücken scharf gekielt, mit länglicher Driise, jene der oberen Zweige schuppenförmig, doppelt gegenseitig gestellt, hinten konvex, mit etwas breiterer Öldrüse.

Einzeln stehen die ziemlich runden, braunroten, blaubereiften Beerenzapfen; sie werden iaher $1 \mathrm{~cm}$ groß und führen 4-8 ganz wenig gespitzte Schuppen mit meist 2 großen, rundlichen Samen.

Formen sind:

Juniperus foetidiss. pindicola Forman., Schuppen an der Spitze huckelig-spitzig; Zapfen runzlig und scharf gerandet.

Juniperus foetidiss. squarrosa Medw., mit abstehenden Blättern.

Juniperus phoenicea L. Rotfrüichtiger S. Suideuropa bis Nordafrika.

Sehr selten bei uns zu findender. Strauch von pyramidalem Wuchs, mit aufrechten, dicht stehenden Ästen und Zweigen und mit besonders

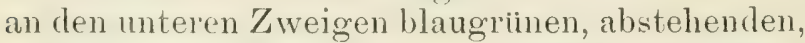
schnal-lanzettlichen, fein spitzigen Blättern, welche an den oberen Zweigen eine schuppenförmige, mehr stumpfe, hinten 
konrexe Gestalt zeigen, doppelt gegenstiindig sind und eine längliche, gepreßte Öldrïse führen.

Die rundlichen, glinzenden, rothramen, ganz wenig bereiften Beerenpflanzen sind $1-1^{1} 2 \mathrm{~cm}$ srob, werden im reifen Zustand weich (!), fiihren 6-8 gering gespitzte Schuppen und 3-6 stumpf-eckige, braune Samen.

Es liomnten aus der Stammform mehrere abweichende Formen ausgeschieden werden, inden es solche mit hauptsïchlichst nadelförmigen und solche mit besonder's schuppenförmigen Blïttern gilot; da solches jedoch auch an einzelnen Zweigen zu beohachten ist, so ist eine genaue Ahscheidung doch nicht möglich.

Wuchs-Formen sind:

Junip. phoenic. turbinata Parl., niederliegend.

filicaulis Carr., mit lang hängenden Zweigen.

Juniperus recurva Hamilt. Zuriickgekriimmter

S. Himalaya, Sikkim.

IV (?)

Liebt Schutz.

Monözischer Strauch von ziemlich pyramidalem Wuchs, mit zimmthraun berindeten Ästen und ziemlich eckigen, zuriichgekrimmten, etwas hängenden Zweigen, deren Blätter schmallanzettlich, spitz, fast ganz freistehend sind, oben eine Riefe und bläuliche Linie, unten Kielung und weißen Rand bei sonst gruiner Färbung zeigen.

Die länglichen oder länglich-runden, bei ${ }^{1}{ }_{2} \mathrm{~cm}$ breiten und $1 \mathrm{~cm}$ langen, glänzenden, griunbraunen Beerenzapfen führen 4-6 Fruchtschuppen und 1(-3) längliche Samen.

Als Form ist zu nennen:

Juniperus recurva densa Carr., buschig;

Syn.: Juniperus densa Gord.,

während als Unterart

Juniperus recurva var. squamata Parl.

Syn.: Juniperus squamata Hamilt.,

III (II)

zu hezeichnen ist, welche einen niederliegenden Strauch mit dicht stehenden Ästen und Zweigen, bläulich-grinen, sehr schmalen, wenig gekrimmten und spitzen Blättern darstellt. Es wäre vielleicht doch richtiger, diese Varietät zur Art zu erheben und ihr Juniperus recurva, sowie recurva densa als Formen unterzuorduen.

Juniperus Pseudo-Sabina Fisch. und Mey. Sibirischers. Sibirien, Altai- und Baikalgebirge, Songarei, Tibet.

Seltener, schöner, niederliegender und aufstrebender, an Juniperus Sabina erimmernder Strauch, mit grauer, abschuppender Rinde, aufrechten und etwas abstehenden Ästen und Zweigen, sorvie an ïlteren Pflanzen stumpfen, angedriickten, schuppen- 
artigen, oben konvexen Blättern mit länglicher, eingesenkter(!) Dritse, während junge Pflanzen und auch Triebe nadelförmige, feine, bläuliche Blätter zeigen.

Die einzeln stehenden, glänzenden, schwarzen Beerenzapfen sind länglich-eiförmig, s: $12 \mathrm{~mm}$ groß, und führen nur einen Samen.

Juniperus davurica Pall. Davurischer S. Sibirien bis Amurgebiet.

II

In sandigem und feuchtem Boden.

Wohl kaum in Baumschulkultur befindlicher, dem Juniperus Sabina ähnlicher, niederliegender Strauch, mit schuppenförmigen Blättern und erbsengrofen, bramen, blau bereiften Beerenzapfen.

Juniperus semiglobosa Regel. S. mit halbkugeligen Früchten. Südliches Turkestan, Tianschangebirge.

Niederliegender Strauch, ähnlich Juniperus Sabina. Mit Eucalyptus-artigen Fruchten. Nicht in Kultur (?).

\section{Abteilung: Oxycedrus Endl. \\ Echte Wachholder.}

Die in dreizählimen Quirlen abstehenden, druisenlosen Blätter sind narlelfürmig, sehr spitz, oben bläulich-griun und mit Rimne versehen, unten konvex, gekielt, grin. Weibliche Bliten, deren obere Schupen fruchthar sind, einzelnstehend. Same hartschalig.

Juniperus communis L. Gemeiner WV., Kranawitt, I Machandel. Europa, Nordafrika, Nordasien, Nordame- Sandboden. rika. Das am weitesten verhreitete Nadelholz. (Fig. 168 u. 169.)

Syn.: Juniperus communis uralensis S.-L.

Allbekannter Strauch oder Baum, von ${ }^{1 / 2}$ in - auf unfruchtbarem Boden, - bis $15 \mathrm{~m}$ hoch in Wäldern wachsend, von verschiedener Gestaltung, mit etwas abstehenden Ästen, die Zweige oft etwas iiherhän@end. A uf trockenem, sandigem Boden zeigt die Art straffen, aufrechten Bau, säulenförmigen Wuchs, auf losem feuchtem Boden dagegen einen mehr oder minder luxen Aufbau. Die graue Rinde schiilfert an älteren Trieben ab. Die Blätter, zu dreien in (quirlen stehend, sind schual, stechend, oben etwas rinnig, mit weifer Binde versehen, unten griu, an Grunde gegliedert.

In Herbst des zw citen Jahres reifen die kugeligen Zapfenheeren, welche erst wrin dann schwarzblau werden, mit bläulichem Reif, drei- his sechsschuppig sind und 3 hartschalige, schwerkeimende Samen enthalten.

Der gencine Wachholder ist ein wertvoller Nutzloam. Das leicht zu schneidende, welhe und brame, wohlriechende $\mathrm{Holz}$ ist sehr zithe mol elastisch, liefert Material zu schnitzereien, 


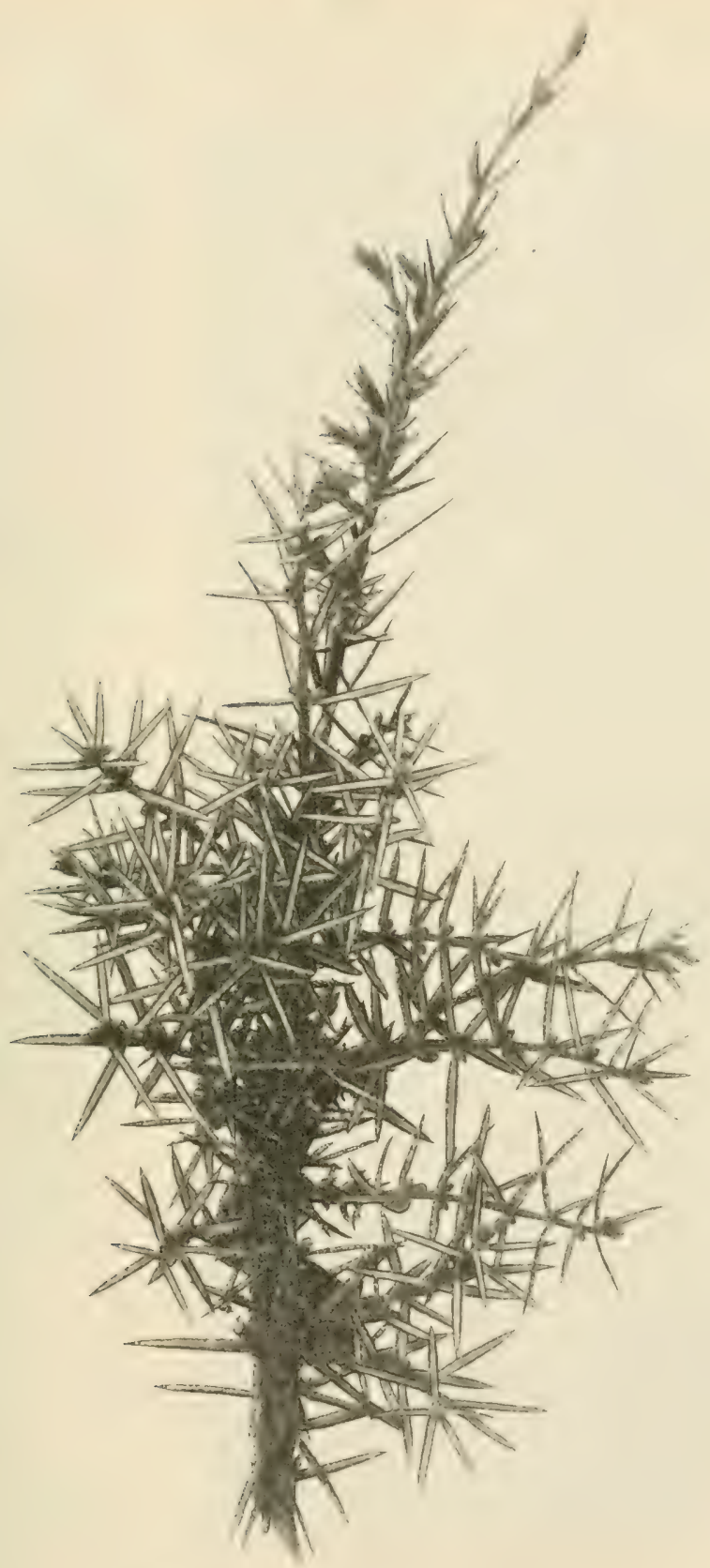

Fig. 168. Juniperus communis L. 
fiur Drechsler, zu Peitschenstöcken, Zaun- und sonstigen Kleinarbeiten. Holz und

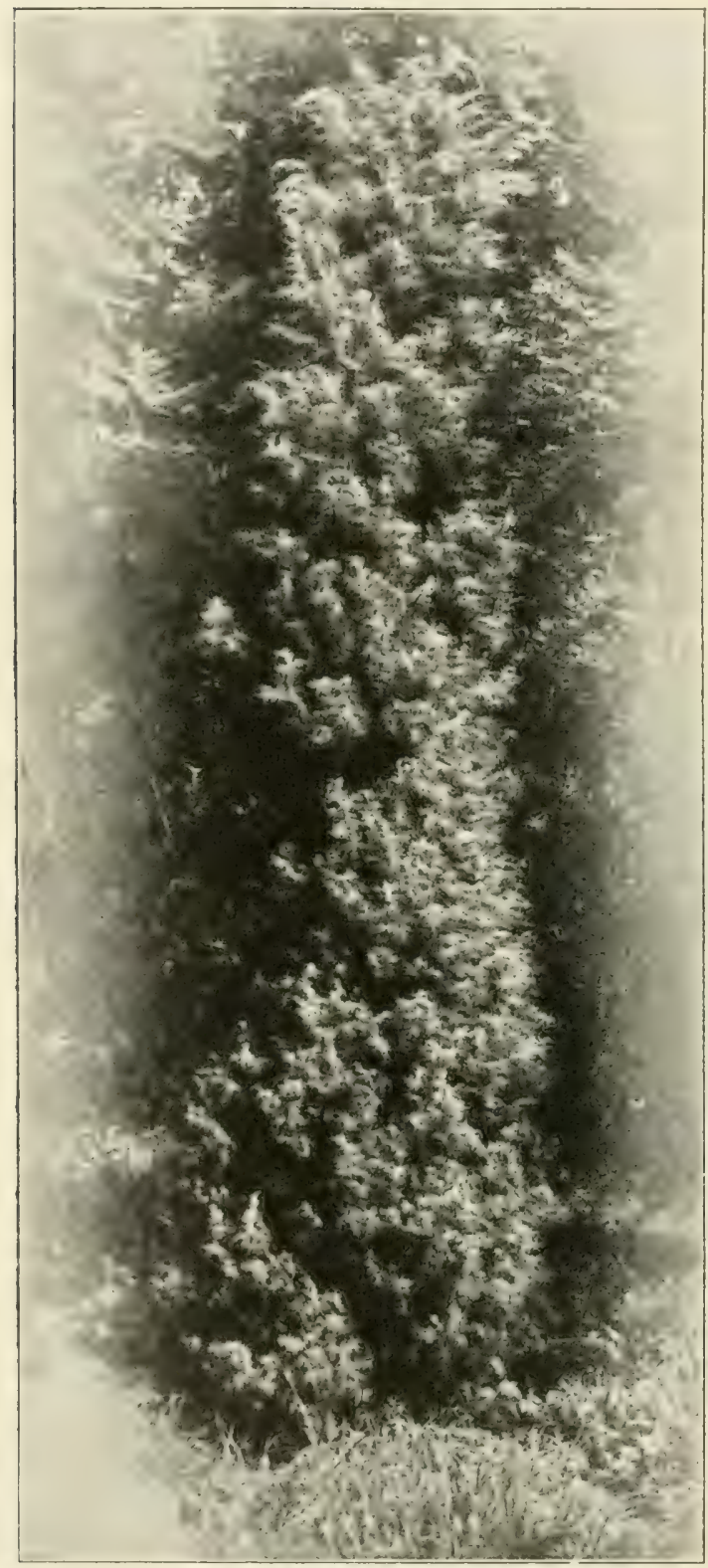

Fig. 169. Juniperus communis L.
Früchte enthalten ätherische Öle, welche medizinische Verwertung: finden, die Beeren werden außerdem als Räuchermaterial und besonders zur Bereitung eines sehr gesuchten

Schnapses, dem "Gin" oder "Genever" beniitzt. Als Zierstrauch oder Baum wirkt er äußerst dekorativ.

An Formen sind zu nennen:

Junip. communis exserta, mit hervorstehenden Schuppenspitzen an den Zapfen.

Junip. communis thyocarpa Aschers. u. Gräb., mitzedernartigen Früichten.

Junip. communis WeckiiGräb., mitzurückgeschlagenen Blättern.

Junip. communis aurea Hort., gelbliche Form.

Junip. communis aureo-variegata Hort., mit goldgelben Zweigspitzen. Junip. communis cracovica Hort., mit horizontal abstehenden Zwveigen, kurzblätterig. 
Junip. communis suecica Lond., schwedischer IV., pyramidalwachsend, mit ïberhängenden Zweigspitzen.

Syn: Juniperus fastigiala Knight.

Junip. communis species von Nordchina, ïhnlich voriger Form, mit sehr lang gespitzten Blättern.

Junip. communis oblonga Loud., kaukasischer WV., mit iileerhïngenden Zweigen und langen Bliattern.

Syn.: Juniperus oblonga M. v. B.

Junip. communis oblonga-pendula Carr., reizende, stark iiberhängende Form.

Junip. communis pendula Hort., mit lang herahhingenden Zweigen.

Junip. communis hibernica Gord., irlïndischer W., säulenförmig, für Einzelstellung, speziell GrabdekoII ration vorzuiglich.

Syn.: Juniperus pyramidalis Hort.

$$
\text { stricte Hort. }
$$

Junip. communis hibernica compressa Carr., wie voriger, doch kleinbleibend.

Syn.: Juniperus hispanica Prsl.

Junip. communis hibernica erecta Hort., lhat aufrechte Triebe. wiichsig," breiter als vorige.

excelsa pyramidalis Hort., stark-

Junip. communis hemisphaerica Parl., niederliegend, kurz und breitblätterig.

Junip. communis nana Loud., niedere Form.

" " prostrata Beißn., niederliegend.

dunkelg"rune Form, welche (zur Tafelzierde) hochstämmig veredelt wird.

Junip. communis intermedia Schur. depressa Pursch, ausgebreitet niederliegend, bis $3 \mathrm{~m}$ breit und etwa $30 \mathrm{~cm}$ hoch.

Juniperus nana Willd. Zwerg-W. Gebirge Auf Höhenlagen; auch von Europa, Asien und Nordamerika. (Fig. $170 \begin{gathered}\text { Auf Höhtenlagen; auch } \\ \text { auf Moorboden, doch }\end{gathered}$ und 171.)

Syn.: Juniperus alpina Clus.

communis L., montana Ait.

Charakteristische, niederliegende, dichtwachsende Art, mit dicken, ausgebreiteten Zweigen und ebenfalls dicken, etwas einwärts gekriimmten, hiedurch die Oberseite gewissermałen deckenden, ziemlich abstehenden, linealen Blättern, welche zugespitzt, ohen mit einem breiten, weißen Band versehen und unten glïnzend grüu sind.

Die Beerenzapfen sind etwas größer als bei Juniperus communis. 
Der Nutzen dieser Art ist so ziemlich der gleiche, wie bei roriger. Auf Felspartieen ein vortreftlich verwendbarer Wachholder.

Formen sind:

Junip. nana mascula, die männ liche, schwarzgriublätterigeForm.

" $\quad$ femina, die weibliche Form.

. . gymnosperma Schröter, mit offenen Beeren.

$" \quad$ " canadensis Carr., mehr aufrechte Form, mit dichtgestellten, stechenden Blättern.

Syn.: Juniperus canadensis Lodd.

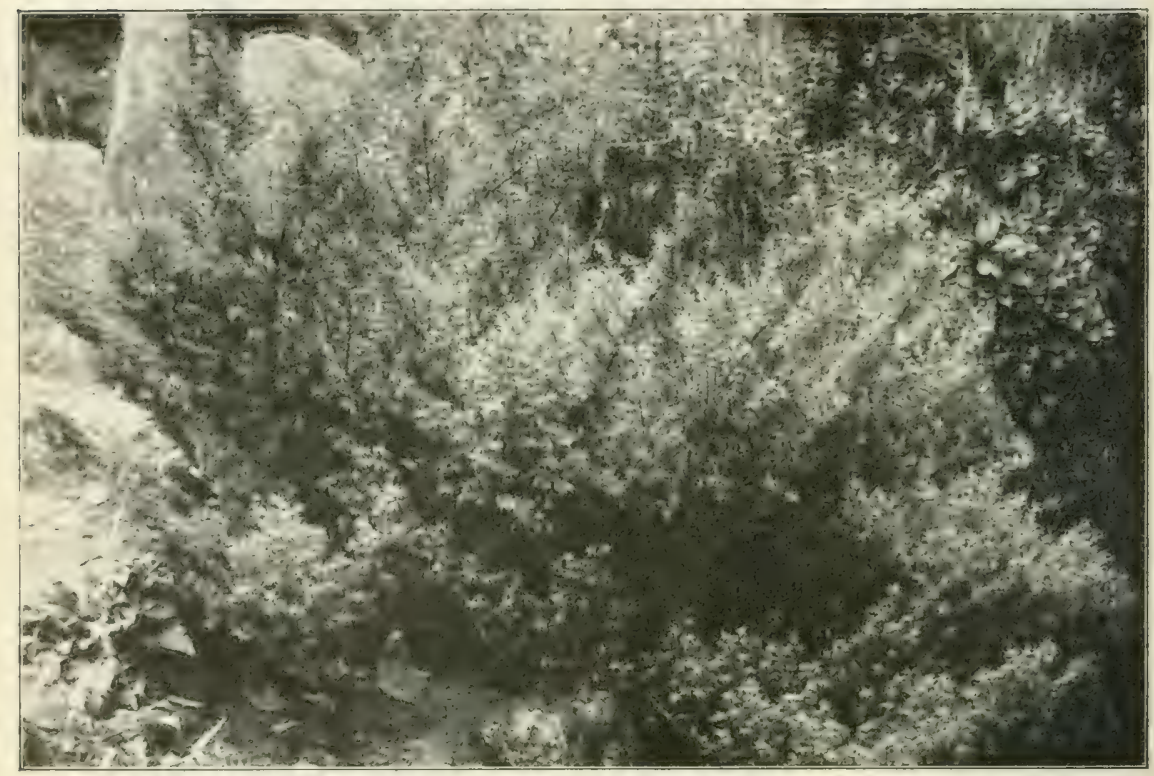

Fig. 170. Juniperus nana Willd. Junge Pflanze auf einem Alpinum.

Junip. nana canadensis aurea Hort, wie vorige, doch mit goldgelben Zweigspitzen.

Syn.: Juniperus Fremontii Hort. gall.

Junip. nana Jackii (Rehd.), niederliegend, sehr langzweigig, aber gering verzweigt, gekriinmt-blätterig und schmal-lanzettlich.

Juniperus Oxycedrus L. Baum-IV. Mittelmeer- VI (V) länder, Orient, Nordafrika; besonderss auf Höhenlagen.

Syn.: Juniperus rufescens Link.

Meist strauchfömmge, selten baumartige, diozische, reich beastete und reichzweigige Konifere, welche glatte Rinde und 
dem Junip. communis ähnliche, unten gegliederte Bliitter führt. Letztere sind ziemlich lang, bis $2 \mathrm{~cm}$, zu dreien westellt, oben etwas rinnig, weiß gezeichnet, unten gríin und gekielt.

Die einzeln stehenden, 7-12 $\mathrm{mm}$ großen, 3-6schuppigen, etwas auffälligen, roten oder braunroten, kugeligen Beerenzapfen zeigen nur an den Rändern und der Spitze der Schuppen etwas bläulichen Reif. Samen 1-4, etwas eckig.

Besonders ohne Beerenzapfen wird diese Art gerne mit Junip. communis verwechselt; deshalb auch öfters die falschen Angaben uber große Vinterhärte! Das $\mathrm{Holz}$ liefert einen offizinell gebräuchlichen, feinen Teer. Nach den Beeren werden einige Formen unterschieden.

Juniperus ma- v? (VI) crocarpa Sibth. Großfrůchtiger W. Suideuropa, Nordafrika, Cypern, Syrien.

Syn.: Juniperus neaboriensis Laws.

Strauch oder kleiner Baum, mit ausgebreiteten, oft auch .. etwas hängenden Ästen und Zweigen.

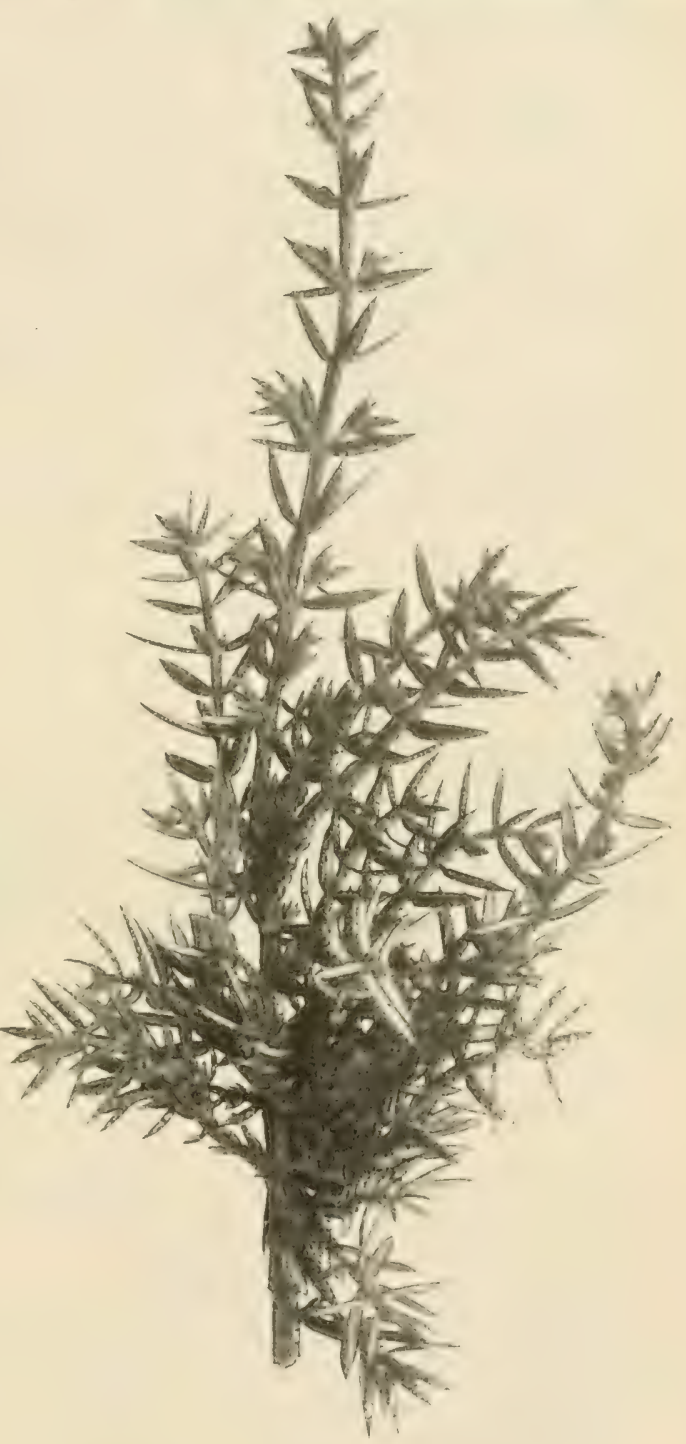

Fig. 171. Juniperus nana Willd.

Blätter lineal, scharf-spitzig, oben weiß, unten griin, gekielt, zu dreien gestellt. 
Beerenzapfen bis $1^{1 / 2} \mathrm{~cm}$ groß, lundlich oder länglich-rund, schwarzbraun, blau bereift; sie werden zu Weihrauch verwendet.

Eine groffriuchtige Form ist:

Junip. macrocarpa Lobelii Guss.

Juniperus Cedrus Webb. Zedern-IV. Höhenzüge der kanarischen Inseln.

(V1 ??)

Zur Zeit nicht in Baumschulkultur befindliche, kräftige Art, mit ausgebreiteten Ästen und zahlreichen, etwas kurzen, kantigen, dicht stehenden, blaugrünen Zweigen.

Die ebenfalls sehr dicht stehenden, zahlreichen, besonders an den Fruchtzweigen sehr derben Blätter werden 5-12 $\mathrm{mm}$ lang, bis $2 \mathrm{~mm}$ breit, besonder's an der Basis, sind spitz, konkav und blaufarbig.

Reichlich werden die rotbraumen, blau bereiften, runden, bis $1 \mathrm{~cm}$ großen, einzeln stehenden Beerenzapfen erzeugt.

Juniperus nipponica Maxim. Nippon-WV. Gebirge ? Nippons.

Der Juniperus nana ähnliche, wohl nicht in Kultur befindliche Art.

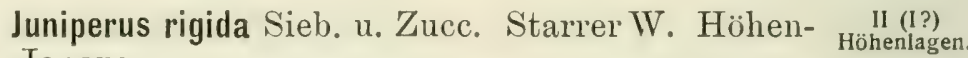
zuige Japans.

Bildet einen kleinen Baum von etwa 6-7 in Höhe, mit gelblich-roter Rinde und etwas abstehenden, wie auch oben leicht iiberhängenden Zweigen. Die Blätter sind lanzettlich, spitz, tief gerinnt, gekielt, ziemlich lang und von feiner, blaugrüner Färbung. Beerenzapfen einzeln stehend, etwa $1 / 2 \mathrm{~cm}$ groß, schwarzblau und bereift.

Diese huibsche Art führt gelbes Holz.

Eine Form ist:

Juniper. rigida spiraliter falcata Hort., mit gedrehten Nadeln.

Juniperus litoralis Maxim. Strand-W. Meeresgegenden Japans.

Syn.: Juniperus confertu Parl.

Niederliegende, kriechende, dichtzweigige Art, mit bräunlicher Rinde, dicht dachziegelig zu dreien gestellten, graugrüinen, weif gezeichmeten, linealen, sehr spitzen Blättern mit erhabener Ansatzstelle. Beerenzapfen bei $6 \mathrm{~mm}$ groß, rund, blau, bereift, mit 3 eckigen Samen.

$\mathrm{Ob}$ nicht Form bezw. Abart von Juniperus rigida?

Juniperus taxifolia Hook. u. Arn. Eibenblätteriger

W. Japan. 
Wohl nicht in Kultur befindlich. Aufrechte, hohe Art mit iiberhängenden Ästen und diinnen Zweigen, sowie anfitallend hreiten, starren, stechenten, rimnigen, dicknervigen, weißhlan gezeichneten Blättern.

\section{Abteilung: Caryocedrus Endl. Nußfriichtige Wachholder.}

Diözische Arten mit nadelförmigen Blättern, meist großen, steinfruchtartigen Beerenzapfen und holzig verwachsenen Samen.

Juniperus drupacea Labill. Stein- oder ptlaumenfritichtiger WV. Gebirge des Orients.

Eine sehr schöne, in der Heimat bis $12 \mathrm{~m}$ hoch werdende Art, mit grauer Rinde, ziemlich reich verzweigten Ästen und dicht stehenden, $1^{1} / 2-2 \mathrm{~cm}$ langen und $3 \mathrm{~mm}$ breiten, zu dreien gestellten, lanzettlichen, scharf gespitzten, oben weißen, unten griinen, konvexen, gekielten, längsnervigen Blättern.

Die Beerenzapfen gleichen einer Pflaume, sind rundlich, rotbraun, blaugrau bereift, mit eng gewachsenen Schuppen und enthalten eine dreifächerige Nuf mit länglich-runden Samen (Nuißchen).

Das Holz dieser Art ist sehr zäh und widerstandsfähig gegen Nässe, weshalb es in der Heimat reiche Verwendung findet.

Die Frucht ist ein trotz des harzigen Beigeschmacks sehr beliebtes, etwas suißes Obst, das roh genossen, sowie als Mus und Narmelade besonders in Zilizien sehr hoch geschätzt wird.

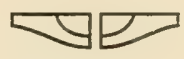




\section{Nachträge und Berichtigungen.}

Seite 18 ist bei den Lnterschriften der Figuren 4. 5 und 6 das Wort "var" zul streichen.

.. 26, Zeile $\mathbf{1 5}$ von oben ist "Mykorrhizen" zu lesen.

. 43, Zeile 3 von oben ist am Ende der Zeile 2 statt 1 zu setzen.

. 79, Zeile 4 von oben ist statt $12-20 \mathrm{~cm}$ zu lesen $12-20 \mathrm{~mm}$.

" 82, Zeile 5 von unten ist "Pyramidenform" statt "Kugelform " zu lesen.

" 91 ist bei Picea Alcockiana das Ausdauerzeichen .. " beizufitgen.

" 101, Zeile 3 von oben ist zu lesen: "Picea alba nana glauca Hort.".

. 103. Zeile 6 von unten ist zu andern: ...Neoveitchii" statt ..neoveitchii".

.. 194, Zeile 9 von oben ist "Kusseln" statt "Kuscheln" zu setzen.

.. 245 ist nach Cumninghmia sinensis wanca beizufüzen: C'unninghamia Konishii (Hayata), eine neue Art von Formosa, welche sich von voriger Art durch die weiße Färbung auf beiden Seiten der Blätter charakterisiert. Winterausdauer wohl gleich ersterer Art.

" 302 ist bei Chamaecyp. obtusa einzufigen: Cliamaecyparis obtusa aurea Hort, goldgelbe, schlankwïchsige Form.

.. 306, Zeile 12 von oben ist statt "Chamaecyp. nutk. aurea" nun "Chamaec. nutk. gracilis aurea" zu lesen.

. 309 ist bei Juniperus occidentalis einzufügen: Juniperus occidentalis Burkii Beißner, $ち$, kräftiger als die Art wachsende Form. 


\section{Alphabetisches Register.}

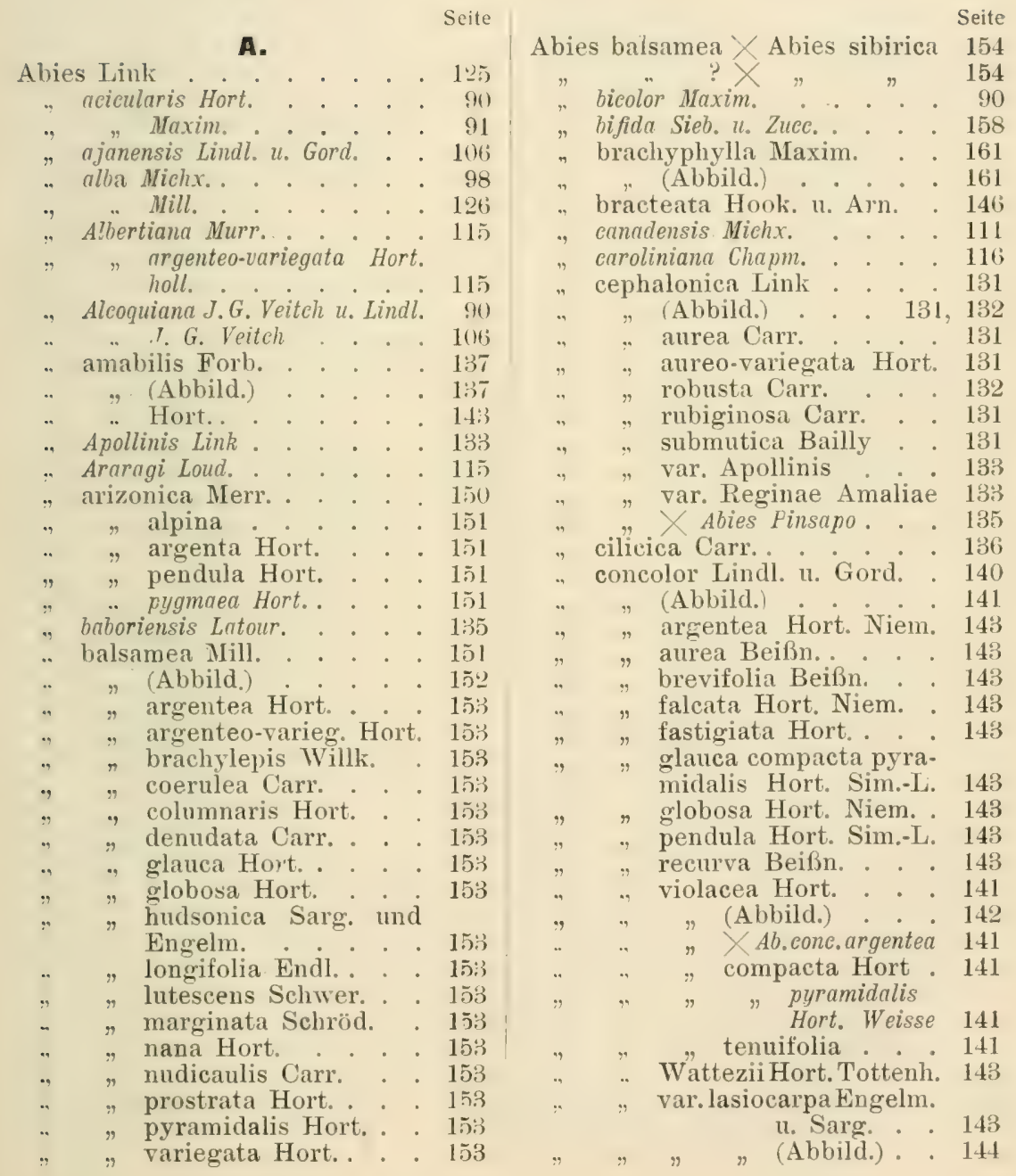


Abies concolor Seite pendula Hort. lasiocarpa cula Hort. • • . 143

conc.var.lasioc. varieg.Hort. 143

Davidiana Franch.. . . . . 164

Delavayi Franch. . . . . 156

Douglasii Lindl. . . . . . 119

Eichlerii Lauche . . . . . 155

Fargesii Franch. . . . . 162

n sutchuensis Franch. . 162

firma Sieb. u. Zucc. . . . 158

"(Abbild.) . . . 158, 159

Fortunei Murr. . . . . . . 163

Fraserii Lindl. . . . . . 151

Hort. . . . . . 151

glauca Hort. . . . . . . 123

glaucescens Hort. . . . . . 123

Gordoniana Carr. . . . . . 137

gracilis Kom. . . . . . 158

grandis Lindl. u. Gord.. . 13i

, (Abbild.) . . 138, 139, 140

" aurea Hesse . . . . 140

" compacta Hesse . . 140

pendula Hort. Spaeth. 140

"var. Lowiana Mast. . . 143

holophylla Maxim. . . . 157

homolepis Sieb. u. Zuce. . . 161

Hookeriana Murr. . . . . . 118

hudsonica Bosc. . . . . . 153

insignis Carr. . . . . . 131

jezoënsis Lindl. . . . . . 163

Khutrow Loud. . . . . . . 86

lasiocarpa Lindl. u. Gord. . . 143

"Nutt. . . . . . . . 150

"Hock. . . . . . . 150

, Hook. X Abies amalilis

Forb.

150

Lowiana Mac Nab. . . 143

magnifica IIurr.. . . . 143

argentea Hort. . . 145

" glauca Hort. . . . . 145

" prostrata Beißn. . . 140

, shastensis (Lemm.) . 145

n xanthocarpa Lemm. - 145

Mariuna Mill. . . . . . . 101

Mariesii Mast. . . . . 161

161

Menziesii Loud.. : . . . . . 109

Mertensiana Lindl. . . . . 115

Momi Sieb. . . . . . . . 158

nephrolepis Maxim. . . 157

. . elegans Hort. . . . 158

.. nigra Michx. . . . . . 101

. nobilis Lindl. . . . . . 145

.. .. argentea Hort. . . . 146

" $"$ " (Abbild.) . . 147

. $\quad$ glauca Hort. . . . 146

Abies nobilis robusta Hort. . . $\begin{array}{r}\text { Seite } \\ \mathbf{1 4 6}\end{array}$

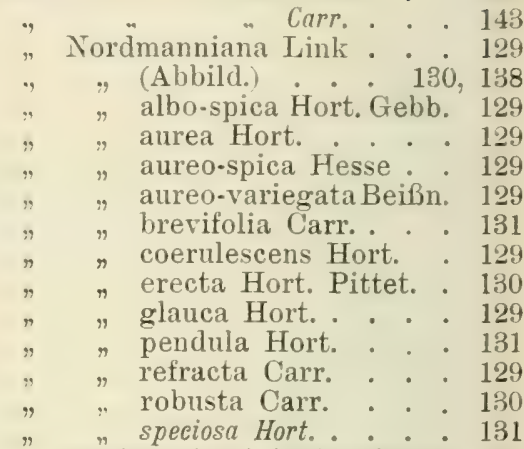

Nordmanniana \Abies Pinsapo 131

numidica de Lann. . . . 135

" (Abbild.) . . . . 135

" glauca Hort. . . . . 135

orientalis Poir. . . . . . 89

" compacta Th. Ohlend. . 84

panachaica Heldr. . . . . 131

Pattoniana . . . . . . 118

Pattonii Jeffr.. . . . . . 118

pectinata DC. . . . . 126

" (Abbild.) . . . . 15, 127

" aurea Hort. . . . . 128

" brevifolia Hort. . . 128

" columnaris Carr. . . 128

" compacta (Beißn.). . 128

" Equi Trojani Aschers.

u. Sint. . . . . 128

fastigiata (Beißn.) . . 128

, nana Hort. . . . . . 128

"pendula Hort. . . . 128

$"$ podolica Sr. . . . . 128

" pyramidalis Carr. . . 128

" stricta Hort. . . . 128

" tenuifolia van Geert. 128

" tenuiorifolia Hort. . . 128

" tortuosa Booth . . . 128

. variegata Hort. . . . 128

" virgata Casp. . . . 128

" " $\quad$ irramosa Moreill. 128

peloponnesiaca Haage . . . 133

Picea Lindl. . . . . . . 126

Pichta Forb. . . . . . . 154

Pindrow Spach . . . . . . 137

Pinsapo Boiss. . . . . 133

(Abbild.) . . . . 134

baboriensis Coss. . . . 135

argentea Hort. . . . 135

fastigiata Hort. gall. . 135

glauca Hort. . . . 133

Hamondii Veitch . . 135 
Abies Pinsapo pendula Hort. . 135

Abietinene . . . . . . 71

1333

- variegata Hort.

Ableger, Senker . . . . . .

Abies cephalonica . 135

polita Sieb. u. Zuce. .

92

Reginae Amaliae Heldr. .

133

religiosa Lindl. . . . . . 148

rubra caerulen Loud. . . . . 100

sachalinensis Mast. . . . 156

157

, nemorensis Mayr

157

" typica Mayx .

Actinostrobus Miq.

261

" pyramidalis IIiq. . . . . 261

Adansonia digitata . . . . . う

Aecidium elatinum . . . . . 25)

Äste der Koniferen . . . . . 11

Agaricus melleus . . . . . 24, 24:2

A gath-Tanne . . . . . . 68

Agathis Salisb. . . . . . . . $\quad 67$

$164 \quad$ "australis Salisb. . . . . 68

Semenowii Fedtsch. . . . . 154

shastensis Lemm. . . . . . 145

sibirica Ledeb. . . . . . 154

" alba Fisch. Scindelabrum Schö. 154

" compacta glauca Hort. 155

" elegans Hort. . . . 154

" glauca Schröd. . . . 154

" monstrosa Schröd. . 155

" nana Schröd. . . . . 155

" nephrolepis Trautv. . . 157

" parvula Schröd. . . . 154

" pendula Schröd. . . 154

" pumila Schröd. . . 155

" pyramidalis Hort. . . 154

" variegata Schröd. . . 154

spectabilis Spach. . . . . . 136

spinulosa Griff. . . . . . 110

squamata Niast.. . . . . 162

subalpina Engelm.. . . . 148

(Abbild.) . . 148, 149

" Beißneriana Hesse . 150

" coerulescens Froebl. . 150

$"$ compacta Beifn. . . 150

" glauca Hort. . . . 150

subalpina $\times$ Abies amabilis 150

Tlapalcatuda Roezl . . . . 123

Torano Sieb. . . . . . . 92

Tschonoskiana Rgl. . . . . 161

Tsuga Sieb. u. Zucc. . . . . 115

umbellata Mayr. . . . . . 160

umbilicata Mayr. . . . . 160

" (Abbild.) . . . . 160

Veitchii Carr. . . . . 155

" Dammara Rich.. . . . . 68

" obtusa (Abbild.) . . . . 68

Ajanfichte . . . . . . . . 104

Albertafichte . . . . . . . 101

Alcocksfichte . . . . . . . . 90

Aleppokiefer . . . . . . . . 2116

Alerce . . . . . . . . . 262

Allgemeiner Teil . . . . . 1

Alpen-Blatteibe . . . . . . 5 1

" Fichte . . . . . . . 79

" -Steineibe . . . . . . 49

Altaifichte . . . . . . 78

Amerikanische Rotficlite . . . 101

" Trauerfichte . . . . . 93

Andina-Steineibe . . . . . 49

Apollotanne . . . . . . . 133

Araucarieae . . . . . . . 67

Arancaria Juss. . . . . . . 68

" Bidwillii Hook. . . . . . 71

" brasiliensis A. Rich. . . . 71

" Cookii R. Br. . . . 71

"Cunninghamii Ait.. . : . 71

" excelsa R. Br. . . . . 71

" imbricata Pav. . . . . . 69

$"$ " (Abbild.) . . . 69, 70

$"$ Rulei Müll. . . . . . 71

Archers Alerce . . . . . . 263

Arizona-Kiefer . . . . . . 220

, -T'anne . . . . . 150

Armands-Kiefer . . . . . . 232

Arthrotaxis Endl. . . . . . . 249

"Doniana Maule. . . . . . 250

" cupressoides Don . . . 250

" laxifolia Hook. . . . . . 250

" selaginoides Don . . . . 249

Arve . . . . . 225

" mandschurica Maxim. . 157

" nikkoënsis Mayr. . . 157

Atlaszeder. . . . . . . . . 176

Auffallende patagonische Eibe . 49

venusta C. Koch . . . . 146

Ausläufer-Fichte . . . . . . 78

Ayacahuite-Kiefer . . . . . . 241

Vilmorinii Mast. . . : 135
Webbiana Lindl. 136

„affinis Hort. . . . . 137

" var. Pindrow Brandis 137

yünnanensis Franch. . . . . 117

Abessinischer Sadebaum . . 309

\section{B.}

Balfours-Kiefer .

292

Balsamtanne . . . . . 151 


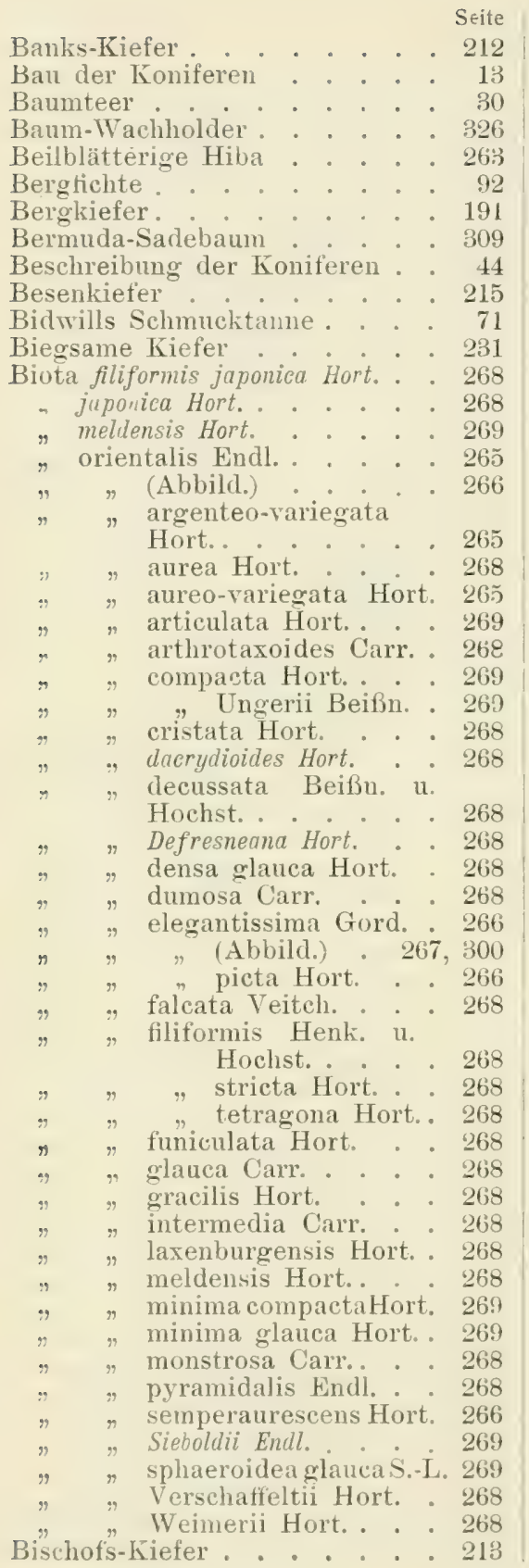

Blasenrost . $\cdot 0.0$ Seite

Blatt-Fibe . . . . . . 25

Blatt-Eibe . . . . . . . 51

Blattscheiden . . . . . . . 15

Blattkissen . . . . . . . 1\%

Blattstiele . . . . . . . 15

Blätter der Koniferen . . . . 13

Bleimennig . . . . . . . . 31

Bleistiftzeder . . . . . 312

Blite der Koniferen . . . . . $16 ;$

Böcklin-Zeder . . . . . . 286

Bockkäfer . . . . . . . . . 29

Bodenbeschaffenheit . . . . 211

Bombyx Pini . . . . . . . 29

Borke . . . . . . . . 13

Borkenkäfer . . . . . . 27

Brasilianische Schmucktanne. . 71

Brewers-Fichte . . . . . . . 98

Buckelkiefer . . . . . . . 196;

Bunges-Kiefer . . . . . . . 22.2

c.

Callitris Vent. . . . . . 261

australis R. Br. . . . . . 262

cupressoides Schrad. . . . 2062

fruticosa R. Br. . . . . 262

"quadrivalvis Vent.. . . . 262

" rhomboidea R.Br.. . . . 262

" robusta $\mathrm{R} . \mathrm{Br}$. . . . . . 262

"verrucosa R. Br. . . . 262

Canaren-Kiefer . . . . . . . 222

Caryocedrus Endl.. . . . . . 329

Caryotaxus Zuce. . . . . . . . 57

"grandis Hochst. . . . . . 58

" Myristica Henk. u. Hochst. . . 59

" nucifera Zuce. . . . . . . 58

" taxifolia Henk. u. Hochst. . . 58

Ceder $=$ Zeder . . . . . . . 174

Cedrus Link. . . . . . . . 174

$"$ atlantica Man. . . . . 175

$"$ (Abbild.) . . . . 176

.. . aurea Beißn. . . . . 176

. " $\quad$ " urevifolia Hort. . . . 176

$" \quad "$ columnaris Otin. . . 176

" $"$ fastigiata Carr. . . 176

" " glauca Hort. . . . . 176

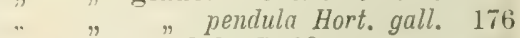

.. . pendula Beißn. . . 176

" " pyramidalis Paili. . . 176

". " variegata Hort. . . . 176

$"$ " $"$ Libani . . . . 179

" Deodara Loul. . . . . . 179

" $"$ (Abbild.) . . . . 180

$" \quad "$ albo-spica Anesley : 179

". " argentea Hort. . . . 179

. . aurea Hort. . . . . 179 
Scite

Cedrus

Deodara compacta Hort. . $1 \uparrow 1$

, crassifolia Hort. . . 181

$"$ glauca Hort. . . . . 17!

" nivea Anesley . . . 179

" pendula (Hort. gall.) . Isl

" " colummaris. . 181

" robusta Hort. . . . 1s1

" uncinata Hort. . . . 1*1

" variegata Hort. . . 179

verticillata Hort. . . 181

"glauca Hort. . . 181

viridis Knight . . . 17!

Libani Barr. . . . . 176

(Abbild.) . . 177, 178

brevifolia J. D. Hook. 178

decidua Carr. . . 179

denudata Carr. . . 178

glauca Carr. . . . 17s

hybrida Hort. . . . . 179

nana Loud. . . . 179

" pyramidata Carr. 179

pendula Knight. . . 178

stricta Carr. . . 17s

viridis Carr. . . . 178

Cembra" Spach. . . . . . . . 2.25

Cephalonische Tanne . . . . 1:31

Cephalotaxeae . . . . . 5.

Cephalotaxus Sieb. u. Zucc. . . 52

adpressa Hort. . . . . . . 616

" drupacea Sieb. u. Zucc. . . 56

"fastigiata Carr. . . . 56

" Maxim. . . . 54

" Harringtoniana Miq. . 5t;

Fortunei Hook. . . . . jt (Abbild.) . . . . j.

Fortunei-drupacea Hort. . 5̋;

Fortunei feminina . . . 54

" lanceolata Beif3n. . . 56

" masculina . . . . jt

" robusta Hort. . . . 54

Griffithii Hook, fil. . . 56

"Oliv. . . . . . 5

Hurringtonia C. Koch . . . 52

koraiana Hort. . . . . . . 5t

"Sieb. u. Zucc. . . . . 54

lanceolate Hort. . . . . . 5̋

Mannii Hook, fil. . . . . 5 t)

Olivierii Mast. . . . . . 56

pedunculata Sieb. u. Zucc. 5.2

" (Abbilu.) . . . 5.2

" fastigiata Carr. (Abbild.)

$53,267,300$

C'alr. .

54

aureo-variegata

Hort.
Cephalotaxus

pedunculata nana compacta Hort. . . . . . 54 sphaeralis Mast. . . 54

tardiva Sieb. . . . . . . 156

umbraculifera Sieb. . . . . 63

Chamaecyparis Spach. . . . . 289

breviramen Maxim. . . . . 304

formosensis Mats. . . . . 307

Lawsoniana Parl. . . . . 289

(Abbild.) . . 290, 291

alba pendula Hort. . . 294

albo-spica Hort. . . 292

Alumii Hort. . . . 29:3

argentea Hort. . . . 292

"nova Hort. . . 292

argenteo - variegata

Hort. . . . . . 293

argenteo - variegata

nova Hort. . . . . 293

atrovirens Hort. . . 292

aurea Hort. . . . 292

nova Hort. Tott. 292

aureo-spica Juriss. . 292

aureo-variegata Hort. 292

Beissneriana P. Smith 292

Bowlerii pendula Hort. 294

casuarinifolia Hort. . 295

" aureo-variegata

Hort. Ord.

295

coerulea Hort. . . 294

, erecta Hort. . . 294

compacta nova Hort. 295

conica Hort. . . . . 294

crispa J. Connink . . 295

darlyensis Hort. . . 292

Depkenii Beißn. . . 292

elegantissima Hort. . 294

epacroides Hord. Ord. 293

erecta alba Kees.. 293

coerulea glanca

Hort. . . . . 293

glauca Hort. . . 293

., viridis (IVaterer) Hort . 293

(Abbild.) . 300

viridis argentea

Hort. . . . 293

$"$ viridis argenteo.

variegata Hort. . 293

falcata Hort. Ord. . 29 a

filiformis Hort. . . 294

compacta Hort. . 294

erecta Hort. . 294

glauca Hort. IVenz. 294

pendula Hort.

294 
Seite

Chamaecyparis

Lawsoniana Forsteckiana

Hort. .

296

Cliamaecyparis

Seite

Forsteckiana variegata

Hort.

296

fragrans Hort. am. . 295

argentea Hort. . 295

" conica Beißn. . 295

Fraserii Hort. . . 294

glauca Hort. . . . . 292

elegans Hort. . 292

"Veitchii Hort. . 292

globosa Hort. . . . 295

gracilis WVat. . . 295

. aurea Hort. . . 295

. nana Hort. . . 295

gracillima Hort. . . 295

intertexta Hort. . . 294

. atrovirens Hort. 295

Kramerii Hort. . . . 296

laxa Hort. . . . . . 292

lutea Hort. . . . . 292

lutescens Hort. . . . 292

lycopodioides Hort. . 295

. aurea Hort. . . 295

magnifica aurea Hort. 293

minima argenteo-va-

riegata Hort.

295

minima glauca Hort.

$29 \tilde{5}$

monumentalis glauca Hort. . . . . 293

nova Hort. . . . 293

nana Hort. . . . 295

. albo-spica Hort. 295

" albo - variegata

Hort. . . . . 295

. argentea Hort. . 295

. argenteo-variegata

Hort. . . . 295

" compacta Hort. . 295

glauca Hort. . 295

nidiformis Hort. . 296

nivea P. Smith . . 292

Olbrichii Hort. Froeb. 294

Overeynderii Hort. . 293

patula Hort. . . . . 292

pendula Hort. . . . 294

.. alba Hort. . . . 294

., aurea Schelle . 294

" nova Hort. . . 294

"vera Hort. Hesse 294

plumosa Hort. Lieb. . 293

prostrata glauca Hort. 296

pulcherrima Hort. . 293

pulverulenta Hort.Lieb. 293

pygmaea argenteaHort. 295

a pyramidalis

P. Smith . 293

pyramidalis alba Hort. 293 glauca Hort. . . 293

Iutea Hort. . 293

" " gracilis Hort. 293

Raievskyana Hort.Lieb. 295 robusta Hort.

294

" argentea Hort. . 294

" aurea Hort. . . 294

" glanca Hort. . 294

Rosenthalii P. Smith 293

Shawii Hort. . . . . 295

shongariensis Hort. . 294

sulphurea Hort. . . . 292

"Silver Queen" Hort. . 292

stricta Hort. . . . . 294

, excelsa Hort. . 294

tortuosa Hort. . . . 292

Triomf van Boskoop

Hort.

293

Triomf van Boskoop

Hort. X Chamaecyp.

Lawsoniana aurea. 293

versicolor J. Connink 292

Weisseiana Hort. . . 295

Westermannii Hort. . 292

" aureo-variegata

Hort. .

292

Wisselii Hort. . . . . 294

Worleii P. Smith . . 293

Youngii Hort. . . . 294

nutkaënsis Spach. . . . 304

(Abbild.) . . . 305

argenteo-variegata

Hort. . . . . . 305

aurea Hort. . . . . 305

aureo-variegata Hort. 305

columnaris Schelle . 306

compacta Hort. . . . 306

"glauca Hort. . 306

" viridis Hort. . . 306

. nana Hort. . . 306

ericoides Saghi . . . 306

glauca Hort. . . . 306

" aureo - variegata 306

vera Hort. . . 306

gracilis Hort. * . 306

gracilis Hort. 'all. 306

lutea Hort. . . . . 305

nidiformis Hort. . , 306

"Hort. nonn. . . . 296

pendula Hort. . . . 306

viridis Hort. . . . 305 
Chamaecyparis

obtusa Sieb, u. Zucc. 301

(Abbild.) . . . 302

albo-spica Hort. . . 302

albo-variegata Hort. . 302

argenteo-variegata

Hort. Groot. . . . . 302

aurea Hort. . . . . 330

") gracilis . . . . 303

compacta Hort. . . . 303

Crippsii Hort. angl. . 302

erecta Hort. . . . . 303

ericoides Hort. jap. . 303

filicoides Hort. . . . 303

filiformis Hort. jap. . 303

gracillima Hort. . . 303

gracilis aureaHort. gall. 303

japanische Formen . 303

lutea nova Hort. Groot. 302

lycopodioides Carr.

" coralliformisHort.

jap. . . . 303

.. Kanaamihiba K.

Onuma . . . 303

, Shamiohiba K.

Onuma . 303

magnifica Hort. . . 303

aurea Hort. . . 303

Mariesii Hort. . . . 302

nana Hort. . . . . 303

, albo - variegata

Hort. .

303

" aurea Hort. . . 303

" gracilis Hort. . 303

pendula Hort. . . 303 aurea (K. Onuma) 303

pygmaea Carr. . . 303

" aureo - variegata Hort.

304

tetragona aurea Hort.

Barr.

Troubetzkoyana Hort. var. breviramea MLast. " " aurea K. Onuma " " Kamakurahiba

K. Onuma

Patsunamihiba K. Onuma .

pisifera Sieb. u. Zucc. . . 296

., (Abbild.) . . . 296

. argenteo-variegata

Hort. jap. . . . . 297

aurea Hort. . . . . 297

.. nana Hort. . 297

" aureo-variegata Hort. 297
Chamaecyparis pisifera columnaris Beißn. . 297 filifera Hort. . . . 301

" (Abbild.) 267, 299, 300 argenteo-variegata Hort. . . 301 aurea Hort. . . 301

", aureo - variegata

Hort. . . . 301 crispa Bei1jn. . 301

flava Schelle . 301

gracilis Hort. . 301

nana Hort.(Büttn.) 301 aureo-variegata Hort. 301

lutea Hort. . . . . 297

plumosa Hort. . . . 300

(Abbild.) . 288, 299

alba Hort. . . 301

argentea Hort. . 301

aurea Hort. . . 301

aurea nana Hort. 301

cristata K.Onuma 301

flavescens Hort. 301

" vera Hort. . . 300

squarrosa Beißn. und

Hochst. . . 297

(Abbild.) . . 297

aurea Hort. . . 300

Veitehii sulphurea 299

" " glauea flavescens . . $\varepsilon 99$

. dumosa Beißn. . 300

" sulphurea Beißn. 299

Standishii Hort. . 297

sulphurea Hesse . . 297

stricta Hort. . . . . 297

"lutescens Hort. . 297

Ungerii Hort. . . . 269

Wahokuhiba K. Onuma 301

Veitchii Hort. . . . 300

pendula Maxim. . . . . . 303

sphaeroidea Spach . . . 306

(Abbild.) . . . 305

andelyensis Carr . 307

nova. . . . 307

atrovirens Knight • 307

aurea Hort. . . . 307

cricoides Beißn. und

Hochst. . . 307

glauca Hort. . . 307

tastigiata glauca Hort. 307

glauca Endl. . . . 307

Hoveyi Hort. . . 307

nana Endl. . . . . 307

pendula Hort. . . . 307

Schelle, Koniferen. 
Chamaecyparis

" sphaeroidea pygmaea Hort.

" " pyramidata Hort. . . 307

, .. variegata Endl. . . 307

"Squarrosa leptoclada Enull. . . 207

Chermes Abietis

(Abbild.)

Chihuahua-Kieter

Chilenische Flußzeder

Schmucktame

Chinesischer Sadebaum

Chinesische Sumpfzypresse

"Steineibe

"Trauerzypresse.

Cnethocampa pinivora

Coleophora

Columbea Salisb.

Cooks Schmucktanne

Coulters Kiefer .

Cronartium ribicolum

Cryptomeria Don.

japonica Don

(Abbild.)

albo-rariegata Hort.

arancarioides Hort.

argenteo-spica Beißn.

. aurea Hort.

" compacta Hort. nana Hort.

cristata Beißn.

dacrydioides Hort.

elegans Hort.

. nana Hort.

gigantea Hort.

(Abbild.)

.. Lobbii Hort.

lycopodiiformis Hort.

monstrosa Hort.

" nana Knight. . . .

albo-spica Hort.

pungens Hort.

. selaginoides Hort.

spiraliter falcata Hort.

Cryptomerie

viridis Hort.

Cunninghams Schmucktanne .

Cunninghamia $\mathrm{R}$. Br.

, Konishii (Hayata) .

" sinensis $\mathrm{R}$. Br. .

Cunninghamie

glauca Hort.

Cupressineae

Cupressus Tournefort

" arizonica Greene . . . . . 257

" "Abbild) . . . . . 208

. cashmeriana Royle
Seite

27

28

221

271

69

317

260

49

287

29

2!)

69

71

219

25

อล)

250

51, 252

252

252

$25 \%$

253

253

253

253

252

251

252

252

253

252

253

25:3

2.53

2.3

252

253

25.2

25.2

25ั1

71

244

33:30

244

245

$24 t$

260

284

$2 \rightarrow 8$
Cupressus fastigiata $D C$. .

Sette

"

funebris Endl.

glandulosa Hook.

Goveniana Gord.

horrizontalis Mill.

Lambertiana lutea Hort.

Lawsoniana Murr. .

Nac Nabiana Murr.

macrocarpa Hartw.

"filiformis Hort.

" lutea Hort.

"sulphurea Hort. Lebr. 2\$7

nootkatensis Lam. . . . . . $30 t$

obtusa C. Koch . . . . . 301

pisifera C. Koch . . . . . 296

pyramidalis Hort. . . . . . 286

"Targ. Tozz. . . . . 256

sempervirens L. . . . . 284

" rar. fastigiata (DC.) 5,286

" (Abbild.) . 24)

". var. horizontalis (Mill.) 256

spee. Hills of Indiae . . . 287

torulosa Don. . . . . . 2-2i

. cashmeriana . . . . 2 T

$"$ Hills of Indiae . 257

\section{D.}

Dacrycarpus Endl.

49

Dacrydium Sol. . . . . . . .

Franklinii Hook. fil. . : 50

Dammara Lnmb.

ti7

alba Rumph.

australis Lamb.

obtusa

". orientalis Lamb.

Dammara-Tanne

68

(i)

198

68

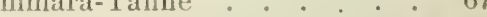

Dasyscypha IVillkommii : . 24, 29

Davurischer Sadebaum . . . . 322

Delaways-Tanne . . . . . 156

Deodar-Zeder . . . . . . 179

Dickrindige Fichte . . . . . S1

Diclirindiger Sadebaum . . . 309

Diselma Hook. fil . . . . . . . . - 1 (i)

Archerii Hook. fil. . . . . 263

Douglas-Fichte . . . . . . . 119

-Tamne. . . 119

Dracaena Draco

Dreh-Kiefer

189

Echte Eibe

.. Lebensbäume . . . . . 271

Zypresse

284

Edeltanne . 
Seite

Edte Tanne . . . . . . 145

Eibe . . . . . . . . . 60

Eibenbaum . . . . . 59, 60

Fibenblätterige Torreye . . . 58

Eibenblätteriger Wachholder . 328

Eichkätzchen

Einblätterige Kiefer .

Einsamiger Sadebaum

Einteilung der Koniferen

Elateriden .

Eldar-Kiefer

Elegante Tanne

Emodi-Kiefer

Empfindlichkeit gegen Rauch und Staub

Engelmanns-Fichte -Kiefer

Erbsenfrüchtiger Lebensbaim

Eucalyptus amygdalina .

Eutacta Link

Eupodocorpus Endl.

Euthuya Benth. u. Hook.

Eutsuga Engelm.

\section{F.}

Fegen des Wildes.

Feinnadelige Fichte . . . . . 110

Feuer-Zypresse . . . . . . 301

Fichte . . . . . . . 71

vom Harz. . . . . . . 81

Fichten-Bastkäfer . . . . . 27

$$
\text { -Kiefer . . . . . . } 211
$$

-Laus, yelbe

27

27

Filzkoppe

Fitzroya Hook. fil.

197

262

263

262

110

269

185

185

185

54

233

50

151

261

262

262

262

262

262

" verrueosa Cunningh.

Fuchsschwanz-Kiefer

Fusicoccum Abietinum

Fusoma parasiticum .

\section{G.}

Gall-Läuse . . . . . . 28

Ganzblatterige Tanne . . . . 157

Garben-Fichte . . . . . . 78

Gefalteter Lebensbaum . . . 277

Gelbkiefer . . . . . . . 216

Gelbe Kiefer . . . . . . . 211

279

218

310

322

160

222

52

44

44

$45,46,47$

laciniata Hort. . 46

pendula Hort. . . . 46

variegata Hort. . . 46

Ginkgobaum . . . . . . 44

Glatte Kiefer . . . . . 214

Glattzweigige Fichte . . . . 92

Glehns Fichte . . . . . . 89

Gleichfarbige T'anne . . . . . 140

Glieder-Fichte . . . . . 249

lockerblätterige . . 250

Glyptostrabus Endl. . . . . . . 253

"heterophyllus Endl. . . 257, 260

Gold-Kiefer . . . . . . . 216

Gold-Lärche . . . . . . . . 173

Govens Zypresse . . . . . . 289

Grannen-Kiefer . . . . . . 233

146

Grapholita tedella . . . . . 27

Graslärche . . . . . 165, 168

Grankiefer . . . . . . 188

Griechische Tanne . . . . . 131

Griffiths Kopf-Eibe . . . . . 56

Großblätterige Stein-Eibe . . . 50

Große Torreye . . . . . 58

Großfiuchtiger Wachholder . . 327

Großfrüchtige Zypresse . . . 286

Gymnosporangium juniperinum . 25

"Sabina . . . . 25

\section{H.}

Haken-Kiefer.

194,232

Halimasch . . . . . . . . 24, 292

Hängefichte . . . . . . 82

Hänge-Weißfichte . . . . 100

Harzausscheidungen . . . . . 81

Harz-Eibe . . . . . . . 50

Harzfichte . . . . . . . . 81

Harz-Riisselkäfer . . . . . . 27

Haselfichte . . . . . . . . 78 
Heiliger Sadebaum

Seite

Heilige Tanne

310

Heimat der Koniferen . . . . 3

Hemmlockstanne , . . . , 110

.. Brunons . . . . . . . 117

.. kanadische . . . . . . 111

. Karolina . . . . . . . 116

.. Mertens. . . . . . . . 115

.. Pattons. . . . . . . . 118

"Siebolds . . . . . 115

" verschiedenblätterige . . 116

Hesperopeuce Engelm · • • 117

Hexenbesen . . . . . 25,185

(Abbild.) . . . . . 186

Heyderia deutrrens C. Koch ¿ 269

Hiba . . . . . . . . . 263

, beilblätterige . . . . . 263

Himalaya-Zeder . . . . . . 179

"-Fichte . . . . . . . 86

Höcker-Kiefer . . . . . . . 222

Hohe Fichte . . . . . . 73

Hoher Sadebaum . . . . . 316

Holz der Koniferen . . . . . 11

Hondo-Fichte . . . . . . 108

Hylesinus micans . . . . . 27

$"$ cumicularius . . . . 27. 28, 29

Hylobius Abietis . . . . . . 27

Hypoderma brachysporum . . 24

Hysterium Pinastri . . . . 24

\section{3.}

Japanische Stein-Eibe . . . . 50

"Tanne . . . . . . 158

". Weymouthskiefer . . . 241

Jeffreys Kiefer . . . . . . . 218

Igelfichte . . . . . . . . . 85

Igelföhre . . . . . . . 205

Jersey-Kiefer 。 . . . . . 211

Immergrüne Sequoie . . . . 248

Jochlärche . . . . 165, 168

Trländische Säulen-Eibe. . . . 64

Irländischer Wachholder . . . 325

Juniperus Linné . . . . . . 307 alpina Clus. . . . . . . 325

Bermudiana Hort. . . . . . 314

Bermudiana L. . . . . . 309

californica Carr. . . . . 309

utahensis . . . . :09

canadensis Lodd. . . . . . 326

caroliniana Dur. . . . . . 312

Cedrus Webb. . . . . 328

cernua Roxb. . . . . 318

chinensis L. . . . . . 317

". (Abbild.) . . 318, 319

Juniperus

chinens, argenteo-variegata

Hort. . . . . 318

aurea Hort. . . . 318

femina . . . . 318

Jacobiana Hort. . . 319

Langoldiana Hort. . . 319

Leeana Hort. . . . 319

mascula Hort. . . . 317

neaboriensis Hort. . 319

pendula Hort. . . . \$19

.. aurea Hort. . . 319

Pfitzeriana Spaeth . 319

procumbens Endl. . 319

albo - variegata

Hort. . . . . 320

argenteo-variega-

ta Hort.

aurea Hort.

aureo - variegata

Hort. . . . . \$19

nana Hort. . . 319

" pyramidalis Hort. . . \$18

communis L. . . . . . 322

(Abbild.) . . 32:;, 324

aurea Hort. . ... . 324

aureo-variegata Hort. 324

cracovica Hort. . . . 324

echinoformis Hort. . 325

exserta . . . . 32t

hemisphaerica Parl. . 325

hibernica Gord. . . . 325

compressa Carr. 325

erecta Hort. . . 32.j

excelsa pyramidalis Hort.

intermedia Schur. de-

pressa Pursh. . . . 325

montana Ait. . . . 325

nana Loud. . . . . 325

oblonga Loud. . . . 325

oblongo-pendula Carr. 325

pendula Hort. . . . 325

prostrata Beißn. . . 325

species v. Nord-China 325

suecica Loud. . . . 324

thyocarpa Aschers. u.

Gräb. . . . . . 324

uralensis Sim.-L. . . . 32.2

Weckii Gräb. . . . 324

conferta Parl. . . . . . . 320

davurica Pall. . . . . 322

densa Gord. . . . . . . 321

drupacea Labill. . . . . . 329

excelsa M. v. B . . . $31 t^{\circ}$

, isopliylla . . . . \$17 
Juniperus

excelsa stricta Hort. . . . 317

"variegata Carr. . . 317

fastigiata Knight. . . . . 325

flaccida Schlechtd. . . 310

foetidissima Willd, . . :320

320

squarrosa Medw. . . 320
fragrans Knight

Fortunei van Houtte . . . . 320

Fremontii Hort. gall. . . . 326

gigantea Rnezl. . . . . . 310

Gossainthanea Lodd. . . . . 314

hispanica Presl. . . . . . 325

isophyllos C. Koch . . . 317

japonica Carr. . . . . . . 319

319

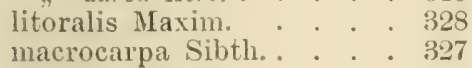

"Lobelii Guss. . : 328

macropoda Boiss. . . . . 316

mexicana Schiede . . . 310

monosperma Sarg. . . . . 309

nana Willd. . . . 325

$"$ (Abbild.) . . . 326, 327

" canadensis Carr. . . 326

" " aurea Hort. . . 326

. femina . . . . 326

" gymnosperma Schröt. 326

.. Jackii (Rehd.) . . . 326

" mascula. . . . . 326

neaboriensis Hort. . . . . 319

. Lnwe. . . . . . . . 327

nipponica Maxim. . . . 328

oblonga M. v. B. . . . . . 325

occidentalis Hook. . . . 308

" fragrans . . . . . 309

"utahensis Sarg. . . . 309

"var. Dieckii Boll. . . . 308

"var. monosperma Hort. . 309

Oxycedrus L. . . . . . 326

pachyphloea Torr.. . . 309

phoenicea L. . . . . . . 320

" filicaulis Carr. . . . 321

turbinata Parl. . . 321

polycarpos C. Koch . . 317

procera Hochst. . . . . . 309

prostrata Pers. . . . . 312

Pseulo-Cupressus Dieck. . . 308

Pseudo-Sabina Fisch.u.Mey. 321

pyramidalis Hort. . . . . 325

recurva Hamilt. . . . . . 321

"densa Carr. . . . . 321

var. squamata Parl. . 321

religiosa Royle . . . . 310

Rewesiana Hort. . . . . . 318
Juniperus

rigida S. u. Z. . . . 328

. spiraliter falcata Hort. 328

rufescens Link . . . . . . 326

Sabina L. . . . . . . 310

(Abbild.) . . . . 311

erecta Hort. . . . . 312

fastigiata Hort. . . . :311

femina . . . . 310

Ganderii Hutter . . 312

gymnosperma Schröt. 211

humilis Endl. . . . 312

mascula . . . 310

procumbens Hort. . . 312

tamariscifolia Ait. . . 312

, glanca Hort. . . 312

variegata Hort. . . . 311

var. prostrata Loud. . 312

subinoides Gris. . . . . 312

Sanderii Mast. . . . . . . 303

scopulorum Sarg. . . . . 316

semiglobosa Rgl. . . . . 322

sphaerica LindI. . . . 320

, glauca Gord. . . . . 320

squamata Hamilt. . . . . . 321

stricta Hort. . . . . . . 325

struthideea Knight. . . . . 317

taxifolia Hook. u. Arn. . . 328

tetragona Schlechtd. . . . 310

thurifera L. . . . . . 316

utahensis Engelm. . . . . 309

virginiana L. . . . . 312

(Abbild.) . 313, 314, 315

albo-spica Hort. . . 314

albo-variegata Hort. . 314

argentea Hort. . . . . 314

aurea elegans Hort. . 314

aureo-spica Hesse . . 314

aureo-variegata Hort. 314

Bedfordiana Knight. . 314

Cannartii Hort. . . . 316

Chamberlaynii Carr. . 316

cinerascens Carr. . . 314

Clanbrasiliana Hort. . 316

Cunninghamii Hort. . 314

dumosa Carr. . . 316

elegantissima Hort. . 314

fastigiata Hort. . . . 315

glanca Carr. . . . 314

globosa Hort. . . . 316

Gossainthanea Carr. . . 314

interrupta Hort. . . 316

. Kosteriana Hort. . . 316

" nana Hort. . . . . 316

" nivea Hort. . . 316

" compacta Hort. . 316 
Seite

Seite

Juniperus

Kiene ....... 185

virginiana nutans Hort.. . \$316 pendula Hort. . . . 316

313

plumosa alba Hort. . 314

Kienfichte . . . . . . . . 196

Kienholz . . . . . . . . 197

Kienzopf . . . . . . . 25

Kleinblütige Kiefer . . . . . 230

Kleinfrucht-Eibe . . . . . . 48

Knospen . . . . . . . . . 13

Königin Amaliens-Tanne . . . 183

Kopf-Eibe . . . . . . . . . 52

Korea-Kiefer . . . . . . . . 228

- viridis Hort. . . $\$ 15$

reptans Hort. Jen. . 316

Schottii Hort. . . 316

scopulorum Beißn. . 316

Smithii pendula Hort. \$316

Triomphe d'Angers . . 314

turicensis Froebl. . \$ \$16

variegata Hort. . 314

viridis Hort. (Barb.) . 314

tripartita Hort. . . 316

Körperbau der Koniferen . . . 10

Kranawitt . . . . . . . . 322

Kremsen . . . . . . . . . 197

Kreuzschnabel . . . . . . . 29

Krummholz . . . . . . . . 196

Krumpholz • . . . . . . . 198

Krummholz-Kiefer . . . . . 191

Krümpen . • . . . . . . . 168

" aureo-variegata Hort. .

\section{K.}

Kalabrische Schwarzkiefer . . 201

Kalifornische Flußzeder . . . 269

Torreye . . . . . . 59

Kalifornischer Sadebaum . . . 309

Kanaren-Kiefer . . . . . . 224

Kanadische Eibe . . . . . . 66

Kandelaberfichte . . . . . 78

Karpathen-Fichte . . . . . $8 \mathbf{i}$

Kastanie . . . . . . . 5

Kaukasischer Wachholder . . . 325

Kaurifichte . . . . . . . 68

Kegelfichte . . . . . . . 85

Keimbiälter . . . . . . . 10

Keimlinge . . . . . . . . 10

Keimlingspilz . . . . . . . 25

Kernfäule . . . . . . . . 25

Keteleeria Carr. . . . . . . 162

. Davidiana Beißn. . . . . 164

" Fabrii Mast. . . . . . 164

" Evelyniana Mast. . . . . 164

" Fortunei Carr. . . . . . 163

. sacra Beißn. . . . . . 164

Kiefer, gemeine . . . . . 185

Kiefern-Prozessionsspinner . 29

Kieferntrieb-Wickler 。 . . . . 28

Kiefer von Hagenau . . . . . 188

Kiefern-Eule . . . . . . . 29

Kiefernkultur-Rüisselkäfer . . . . 28

Kiefern-Saateule . . . . . . 29

Kiefernspinner . . . . . . . . 29

Kienäpfel . . . . . . . . . 187

Kienbaum . . . . . . . . 185

Kugelfrichtige Lebensbaum-Zypresse . . . . . 306

Kugelfrüchtiger Sadebaum . . 320

Kultur der Nadelhölzer . . . 20

Kunstdïnger . . . . . . . . 2 !

Kupfervitriol-Lösung . . . . 31

Kurzblätterige Eibe . . . . . 67

Kurztriebe . . . . . . . . 12

Kussel . . . . . . . . . . 194

\section{L.}

Lackholz . . . . . . . . 197

Langnadelige Kiefer . . . . . 22j

Langtriebe . . . . . . . 12

Lärche . . . . . . . . . 164

Lärchen-Krebs . . . . . . . 24

Lärchen-Miniermotte . . . . . 29

Lärchen-Wickler . . . . . . 29

Larix Link . . . . . . . 164

americana Michx. . . . 169

170

170

168

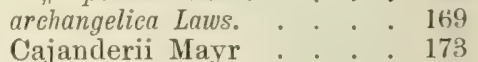

Cajanderii Mayr
chinensis Beißn.

dahurica Turez. . . . . 170

" alpina Schröd. . . 170

" chlorocarpa Schröd. . 170

" montana... . 170

"prostrata Rgl. . . . 170

"var. japonica Maxim. 172

decidua Mill. . . . . 165

, $\quad$ s rossica Henk. u. Hochst. 169

" $\beta$, Rgl. . . . 169

" $"$ s sibirien Rgl. . . . . 169

europaea DC. . . . . 165 
Seite

Larix europaea (Abbild.) • 166, 167

" . alba Hort. . . . 168

" " cervicormis Beißn. . . 169

" " compacta Hort. . . . 169

" $\quad$ fastigiata Hort. . . 168

" flore albo Hort. . . . 168

" " glauca Hort. . . . 168

. . .168

. $\quad$ Kellermannii Hort. . 169

. " " macrocarpa Beißn. . 168

" " microcarpa Beißn. . 168

. ". multicanlis Schröd. . 168

" " pendula Laws. . . . 168

:

?

" 3 rossica Beissn. . . . 169

. ${ }^{\prime}$ sibirica Loud. . . . 169

. virgata Hemp. u. Wilh. 169

. X L. leptolepis. . . 169

Griffithii Hook. fil. u. Thoms, 171

hybrida Schröd. . . . . . 170

japonica Carr... . . . . 170

Kaempferii Fort. . . . . . 174

kurilensis Mayr . . . . 172

leptolepis Murr. . . . . 170

$\rightarrow$ aureo-variegata Hort.

Dirk. . . . . 171

dumosa Beißn. . . 171

Ganghoferii Beißn. . 171

Murrayana Maxim. . 171

" pendula Hort. . . . 171

Lyallii Parl. . . . . . 171

microcarpa Bedf. . . . . . 169

occidentalis Nutt. . . . . 172

Potaninii Batal. . . . . 173

Principis Ruprechtii Mayr 173

sibirica Ledeb. . . . . . 169

, fastigiata . . . . . 169

. glauca . . . . . 169

longifolia . . . . . 169

pendula . . . . . 169

robusta . . . . 169

- Tittelbachii Schröd. . 169

" viridis Sr. . . . . 169

thibetica Franch. . . . . . 173

Latsche.

196,197

Laus, gelbe Fichten- . . . . . 27

Lawsons Lebensbaum-Zypresse . 289

Lebensbäume

Lebensbaum, abendländischer

, gefalteter . . . .

, , morgeuläindischer . . .

, riesiger . . . . .

Standish's japanischer .

-Zypresse

Lepidothamns Phil.

Libanon-Zeder.
Seite

269

271

269

270

270

270

271

270

Doniana Endl. . . . . 271

macrolepis Bentl. u. Hook. 271

papuana F. v. M. . . . . 271

tetragona Endl. . . . . 271

Liebliche Tanne . . . . . . 137

Liparis monacha : . . 27, 28, 29

Lockerblätterige Gliederfichte . 250

Lophodermium Pinastri. . . . 24

\section{M.}

Machandel . . . . . . . 322

Mac Nabs-Zeder . . . . 286

Macrothuya Benth. u. Hook. . 279

Mädchen-Kiefer . . . . . . 230

Mahin . . . . . . . . 48

Mammutbaum . . . . . . 245

Massons-Kiefer . . . . . 210

Mastbaum-Kitfer . . . . . 187

Masters Fichte . . . . . . 86

Matten-Fichte . . . . . . 78

Maulwurfgrille . . . . . . . 29

Mayrs Kiefer. . . . . . . 210

Mexikanischer Sadebaum . . 310

Mexikanische Sumpfzypresse . . 260

Microcachrys Hook. fil. . . . 48

r tetragona Hook. fil. . . . 48

Mitzumine-Tanne . . . . 160

Momi-Tanne . . . . . . 158

Morgenländische Fichte . . . 89

Morgenländischer Lebensbaum . 265

Moorkiefer . . . . . 187

Moosföhre . . . . . . . 196

Morastkiefer . . . . . . 215

Mugokiefer . . . . . . . 198

Muskat-Torreye . . . . . . . 59

\section{N.}

Nackt-Zypresse . . . . . . . 254

Nadeln der Koniferen . . . . 13

Nadelholzanpflanzungen . . . 37

Nadelschititte . . . . . . 2 24

Nageia Gaertn. . . . . . . . . 49

Nepal-Zypresse . . . . . . 287

Neuseeländische Blatt-Eibe . . 51

Nierenschuppige Tanne. . . . 157

Nikko-Tanne. . . . . . 161 


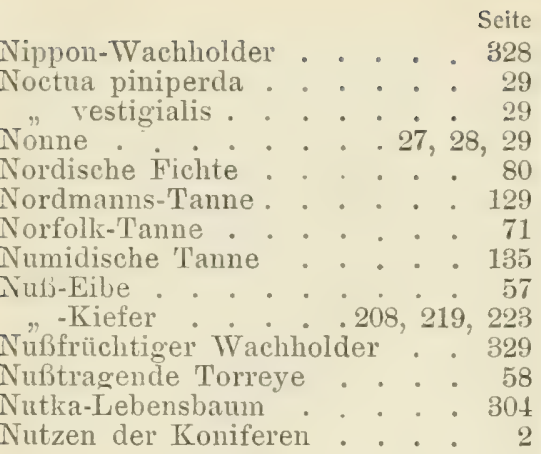

\section{o.}

Octoclinis F. von Milll. . . . . . 261

Öldrïsen 13

Österreichische Schwarzkiefer • 199

Omorica Willk. . . . . . . 104

Omorika-Fichte . . . . . 104

Orgyia antiqua . . . . . . 27

Otiorrhynchus . . . . . . 27

\section{P.}

Parrys Kiefer . . . . . . 223

Patagonische Alerce . . . . . 262

"Eibe . . . . . . . 48

Pech-Kiefer . . . . . . 214

Peridermium Pini. . . . . 25

. Pini acicola. . . . . 25

" . cordicola . . . . 25

Pestalozzia Douglasii. . . . . 24

funerea . . . . . . 24

., Hartigii . . . . . . 25

Peziza Willkommii . . . . 24, 29

Pflanzliche Schädlinge . : . . 24

Pflanzung der Nadelhölzer . 21

Pflanzzeit der Nadelhölzer . . 20

Pflaumenfrüchtiger IVachholder 329

Pflege der größeren Koniferen . 22

Pfropfung . . . . . . . . 35

Pherosphnera Arch. . . . . . . 50

Phoma Abietina . . . . . 25

Phyllocladus Rich. . . . . . 51

"alpina Hook. . . . . . . 51

" aspleniifolia Hook. . . . . 51

" hypophylla Hook. . . . . 51

" rhomboidalis Rich. . . . 51

" trichomanoides Don . . . 51

Pien

" acicularis Hort. : . : . : : 90

" Maxim. . . . . . 91
Picea

ajanensis Fisch. . . . 104

(Abbild.) . . 106, 107

aurea P. Smith . . 1117

var. japoniea Maxim. . 10s

var. mierosperma Mast.. $10 \mathrm{y}$

$\begin{array}{rr} & \text { X Picea nigra Doumettii } 111 \overline{7} \\ \text { alba Link } & 98\end{array}$

(Abbild.) . . 99, 100

acutissima Hort. . . 100

aurea Hort. • . . 10 10

aureo-spicata Hort.

Karol. . . . . 100

aureo-variegata Hort.

amer. . . . . 100

coerulea Hort. . . 100

"hudsonica Hort. . 100

"Hudsonii. . . 100

compacta pyramidalis

P. Smith. . . 100

" gracilis Breinig. . 100

compressa Hort. . . 101

echinoformis Carr. . 101

fastigiata Carr. . . . 100

splauca Hort. . . . . 101

nana Hort. . . . 101

"glauca Hort. . . 101

pendula Hort. . . 100

pinsapoides Beißn. . 100

variegato-spicata Beißn. 100

wörlitziensis Hort.

Späth. . . . . 100

Albertiana St. Brown . . 101

Alcockiana Carr. . . . 90

(Abbild.) . . . 90, 91

alpina . . . . 91

var. morindoides Mott. . 110

bicolor Hort. . . . . . . 92

Maxim. . . . . 90

brevifolia Peck. . . . 103

"Hort. amer. . . . 103

Breweriana Wats. . . . 93

Columbiana Lemm. . . . 98

commutata Hort. holl. u. Hort.

belg. . . . . . . 95

complanata Mast. . . . 110

Douglasii Link. . . . . . 119

Engelmannii Engelm. . . 98 argentea Hort. . : 98 Columbiana . . . 98 glauca Hort. . . 98 11 aurea . . .998

"pendula Beißn. : 98

microphylla Hesse. . 98

pendula Hort. Wernig. 98

excelsa Link . . . . 73 
Seite

Picea excelsa (Abbild.) 15, 73, 74, 75,

$77,144,313$

: Garbenficite . . 78

: Haselfichte . . . 78

: Kandelabertichte. . 78

: Mattenfichte . . . 78

: Pyramidenfichte . . 78

: Schneebruchichte . 78

Stelzenficlite . . Ts

: Walzenfichte . . 78

Weilifichte. . T

: Wetterfichte . . Ts

: Zargenfichte . . . Ts

: Ziegenfichte . . . 7s

: Zwillingsfichte . . is

acrocona Th. M. Fries 81

acutissima Hort. . . . 42

adnata Beifin. . . $\$ 4$

aegra myelophthora

Casp.. . . . . . 82

albo-spicata Hort. . . \$2

alpestris Bruegg: . . 79

" chlorocarpa Beifn, 79

" elythrocarpa Beißn. 7!!

altaica repl. . . . 79

archangelica Hort. . 8.)

araucarioides Beißn. . S.2

argentea Hort. . . 82

argenteo-spicata Hort.

Hesse . . . . . 82

attenuata Carr. . . 84

anrea Carr. . . . sl

" magnifica Hans.. 81

aureo-spicata Hort.

Karol.

82

Barry Hort. . . . $8 t$

borealis Hort. . . . 81

candelabrum Sr. . . S.2

capitata Croux. . . 85

carpathica Loud. . . 81

cellensis Hort. Schiebl. 85

chlorocarpa Purk. . 81

cincinnata Hesse . . 5.

Clanbrasiliana Carr. . 8.5

coerulea Breinig . . 81

columnaris Carr. . . 82

compacta Hort. . . st

"pyramidalis Hort. $\$ 4$

compressa Scliwer. . 85

concinna Carr. . . . 84

conica Carr. . . . S5

convoluta Beißn. . Sij

corticata Schröt. . . 81

Cranstonii Carr. . . 8:3

crassifolia Hort. . . $\mathrm{S1}$

crimitii Hort. gall. . . 8:3 exce

Picea excelsa cupressina Thomas 82

denudata Carr... . . 83

Diecksonii Hort, gall. 83

Diedorfiana Schwer. . S2

dumosa Carr. . . 86

echinoformis Hort. . 8 อ

elegans Hort. . . . 85

Ellwangeriana Hort. . 84

eremita Carr. . . . 83

erythrocarpa Purk. . 81

femnica Rupr. . . . 79

finedonensis Hort. . . $\$ 1$

gigantea Hort. . . . 81

glituci Si.. . . . 81

glomerulans Kihlm. . $\quad 83$

Gregoryana Hort. . . 8.̆

hercynica Hort. . . 5.

humilis Hort. . . So

integrisquamis Carr. . 81

intermedia Carr. . . 83

interrupta Beißn. . . 8:3

inversa Hort. . . . 82

lubecensis Hort. Rose Sõ

major pendula Hort. . 82

Maxwellii Hort. . . it

medioxima Nyland. . 80

Merkii Th. Ohlend. . 85

microphylla Schwer. . S2

mierosperma Hort. . . Sĩ

minuta $\mathrm{Sr} . . . . . \quad \mathrm{S} 5$

monocaulis Nördl. . . 84

monstrosa. Hort. . . 84

mucronata Carr. . 85

mutabilis Hort. holl. . 82

nana Carı. . . . 84

. aurea Carr. . . St

" conica Kihlm. . 84

" pallida Hort. . 81

". variegata Carr. 84

nidiformis Beißn. . . 86

nigra Loud. . . . . 81

Olilendorfii Späth. . 81

oligoclada Hort. . . 83

parviformis Hort. . . 85

pendula Carr. . . . 82

.. major Hort. . . 82

petrowsliensis $\mathrm{Sr}$. $\quad 83$

phylicoides Carr. . . 84

plumosa Sr. . . . 83

procumbens Carr. . . 85

pumila Hort. . . . 85

"glauca Hort. . 85

" nigra Hort. . . S5

pygmaea Carr. . . . 85

pyramidalis Hort.s.L. $\quad 82$

" gracilis Hort. . 8. 
Seite

Picea excelsa pyramidalis robusta

$$
\text { Hort. . }
$$

ramosa Pillich.

reflexa Carr. .

83

" " " reflexa Carr. . . . .

. $\quad$ " Remontii Hort. . . . .

septentrionalis Hort.

Shelesnowii Hort. .

sibirica Carr.

squarrosa Jacob. 81

tabuliformis Carr. . 86

tuberculata Schröt. - 81

uralensis Tepl. . . . 79

Uwarowii Kaufm. . 79

variegata Carr. . . 82

viminalis Casp. . . 83

virgata Jaq. . . . . 83

var. obovata C. Koch 78

, altaica (Te-

plouch.) .

" japonica

Maxim.

$"$ (Abbild.)

lapponica

(Berg.) .

: uralensis

(Teplouch.) 79

Fortunei Murr. . . . 163

Glehnii Fr. Schmidt . . 89

(Abbild.)

90

hondoënsis Mayr . . 108

(Abbild.) . . 108

japonica Hort. Petrop. . . . 90

- jezoënsis Carr. . . . . . 106

. Mastersii Mayr . . . . . 86

.. Maximowiczii Rgl. . . . . 79

. microsperma Carr. . . . . 108

"Hort. Allard . . . . 110

- Menziesii argentea Hort. . . 95

montigera Mast. . . . 92

Morincla Link . . . 86

" compacta Beißn. . 89

morindoides Rehd. . . . . 110

MLoserii MLos. . . . . 107

Neoveitchii Mast. . . . 103

nigra Link . . . . . 101

(Abbild.) . . . 102

argenteo-variegata

Hesse . . . . 103

aurea Hesse ․ . 103

brevifolia Rehd. . 103

Doumettii Carr. . . 103

fastigiata Carr. . . . 103

". Mariana Hort. : : 103

" nana Hort. . . . 103

"pendula Schwer. . . 103

Picea nigra semiprostrata Rehd. 103

obovata Ledeb. . . . . 78

Omorica Panč. . . . . 104

(Abbild.) . . 105

orientalis Link . . . 89

$"$ (Abbild.) . . 87,88

aurea Hesse : : . $\quad . \quad 89$

aureo-spicata Hort.

Spee...... 89

compacta Th. Ohlend. . 84

gracilis Hort. belg. . 89

pygmaed Hort. . . . 84

nutans Hort. Niem. . 89

Parryana Barr. . . . . 95

pinsapoides Hort. Tott. . . 100

polita Carr. . . . . . 92

(Abbild.) . . . 93

" glauca Hort. Wernig. 93

pungens Engelm. . . . 90

$"$ (Abbild.) . . . 94, 96

" argentea Hort. . . . 95

$"$ " (Abbild.) : . 94, 97

" "Fürst Bismarck 96

" " König Albert . 96

" aurea Hort. Niem. 96

" coerulea Hort. . . . 95

$"$ columnaris . . . 97

"flavescens Hort. Niem. 97

" glauca Hort. . . . . 95

" $\quad$ " aurea Hort. Petrop. 97

$" \quad "$ pendula Koster . 95

" " prostrata Hort.

Ansorg. . . . 97

Kosterii Hort. holl. . 96

pseudopungens Dieck. . . . 98

rubra Link . . . . . . 101

"Mill. . . . . . 188

" coerulea Hort. . . . . 100

" virgata Rehd. : : 101

Schrenkiana F. u. M. . . 86

"globosa Schelle . . 86

"(Abbild.) : : 87

"Loczyi Kanitz : . 86

sitchensis Trautv. u. Mey. 109

"(Abbild.) . . . . 108

"speciosa Beißn. . . 109

sitkaënsis . . . . . 109

Smithiana Belf. . . . . 86

spinulosa Griff. . . . . . 110

Wilsonii Mast. . . . . 91

Pi"nolen . . . : . : 209

Pinaceae . . . . . 67

Pinaster Endl. . . . . . . 184

Pinie . . . . . . . 208

Piniennüsse . . . . . . 209

Piniolen . . . . . . . 209 
Seite

Pinon

Pinus Linné

albicaulis Engelm.

(Abbild.)

aleppensis Mill.

altaica Led. .

amabilis Dougl.

aristata Engelm.

australis Michx.

austrinea Höss.

arizonica Engelm.

Armandii Franch.

Ayacahuite Elırenb.

Balfouriana Jeffr.

n var. aristata Engelm.

Banksiana Lamb.

Benthamiana Hartw.

brutia Ten. . . . . . . . 204

Bungeana Zucc. . . . . 222

canariensis Chr. Sm. . . . 224

caroliniana Hort. . . . . . 204

caucasica Fisch. . . . . . 189

Cembra L. . . . . . 225

(Abbild.) . . 226, 227

chlorocarpa . . . 228

columnaris Beifn... 228

". compacta pyramidalis Hort. Hell.

228

forma nova Sr. . . . 228

" monophylla Carr. . . 228

" pumila Pall.

231

228

, sibirica Hort.

228

224

cembroides Gord.

Chihuahuana Engelm. . . 221

contorta Dougl. . . . . 212

. Bolanderii Parl. . . 213

., var. MIurrayana Engelm. 212

Corteana Hort. . . . . . 205

Coulterii Don. . . . . . 219

deflexa Torr. . . . . . 218

Douglasii Sab. . . . . . . 119

densiflora Sieb. u. Zucc. . 209

" aurea Hort. . . . . 209

" pumila Hort. . . . 209

variegata Beißn. . . 209

digena Beck. . . . . . 191

echinata Mill. . . . . . , 211

edulis Engelm. . . . . . 223

Eldarica Medw. . . . . 206

Engelmannii Carr. . . . 220

Escarena Endl. . . . . 205

excelsa IVall. . . . . 237

(Abbild.) . . . 238, 239

" monophylla Carr. . . 240
Pinus excelsa zebrina Croux.

var. Peuce Griseb. . . 240

excorticata Hort. . . . . 222

flexilis James . . . . . 231

Fortunei Parl. . . . . . . 163

Fremontiand Endl. . . . . 224

funebris Komar. . . . . 214

Gerardiana IVall. . . . 222

glabra Walt. . . . . . 214

hagenaviensis . . . . . . 188

haguenensis Loud. . . . . 188

halepensis Mill. . . . . . 206

Pithyusa Stev. . . . $206^{2}$

$"$ X Yin. Finaster . . . 206

halepensi-Pinaster G. de

Saport . . . . . . 206

Hamiltonii Ten. . . . . . 205

Heldreichii Christ. . . . . 202

humilis Link . . . . . $196^{\circ}$

" X P. silvestris (Christ) 190

191

forma submon-

tana. . . 190

Jeffreyi Murr. . . . . . 218

inops Sol. . . . . . . 211

"var. clausa Chapm. . 211

insignis Dougl. . . . . . 221

var. binata Palm. . 222

koraiënsis Sieb. u. Zucc. . 228

(Abbild.) . . . . 229

" tortuosa . . . . 230

" variegata . . . . . 230

Lambertiana Dougl. . . . 240

lapponica Mayr. . . . . . 188

Laricio Poir. . . . . . . 198

austriaca Endl. . . 199

(Abbild.) 200, 201, 202

Pinus montana 203

aurea Hort. . . 199

falcata Baenitz . 199

. foliis aureis . . 199

" variegata Hort. 199

Bujotii Hort. . . . 203

calabrica Delam. . . 201

columnaris Schwer, . 203

corsicana Hort. . . 201

Heldreichii (Mast.) . 202

XP. halepensis . . . 204

italica Hort. . . . . 201

leptophylla Christ. . . 199

monspeliensis Hort. . 199

monstrosa Hort. . . 203

Moserii (Moser) 。 . 203

nana Hort. . . . . . 203

Y nigricans Parl. . . . 199

- Pallasiana Endl. . . 201 
Seite

Seite

Pinus Laricio pendula Hort. . . 203

"pindica (Beißn.) . . 202

Poiretiana Ant. . . . 201

prostrata Beif3n. . . 203

pumila aurea Hort. . 303

" pygmaea Rauch. . . 203

„ $\beta$ pyrenaica Gren.u.Godr. 199

. taurica Hort. . . . . 201

. variegata Hort. . . . 203

latifolia Sarg. . . . . . 219

leiophylla Schiede u. Deppe 241

leucodermis Ant. . . . . 203

Llaveana Schiede u. Deppe. . 224

Iongifolia Roxb. . . . . 225

luchuënsis Mayr. . . . . 225

mandschurica Rupr. u. Rgl. . 228

maritima Lamb. . . . . . 206

"Poir. . . . . 205

". C. Koch . . . . . 199

Massoniana Lamb . . . . 210

"Sieb. u. Zucc. • . . 210

$"$ planiceps A. Mur. . 211

Mayriana Sudw. . . . . 219

mitis Michx. . . . . . 211

monophylla Torr. u. Frem. 224

montana Mill. . . . . . 191

(Abbild.) . . 192, 193

gallica Rafn. . . . 197

Pinus silvestris Brügg. 190

Mughus (Scop.) . . 198

(Abbild.) : . 18, 198

• Pumilio (Hänke) . . 197

" (Abbild.) . 18, 197

" " applanata Willk. 197

" " echinata Willk. . 198

" " gibba Willk. . . 197

" $\quad$ varjegata Hort. . 197

" uncinata (Willk.) . . 194

$" \quad "$ (Abbild.) 18, 193,

194,195

aureo - variegata

Schwer. . . 195

gracilis Schwer. 195

Pseudopumilio

Willk. . . . 197

rostrata Ant. 195

, castanea

Hart. Mscr. 195

" macrocarpa

Willk.

" pendula Hart.

Mscr. . 195

versicolor

IVillk.

195

rotundata Ant. u.

Endl. . . 196

Pinus montana

"uncinata rotundata gallica (Rafn.) "rotundata gibba Willk. . mughoides Willk. pyramidata

Hart. Mscr. 196 < $P$. silvestris engadinensis (Brügg.) . 190

196

196

196

190
240

monticola Dougl. • • • . 240

Mughus Seop. Murrayana Balf. * : * : 198
213

- var. Sargentii Mayx - 213

muricata Don. . . . . 213

nigra Arn. . . . . . . . 199

Link . . . . . . 199

" X P. silvestris . . . 191

nigricans Host. . . . . . 199

Neilreichiana Reich. . . . 191

Nelsonii Shaw... . . 225

osteosperma Engelm. . . 224

Pallasiana Hort. . . . . . 201

palustris Mill. . . . . 215

Paroliana Web. . . . . . 204

Parryana Engelm.. . . . 223

parviflora Sieb. u. Zucc. . 230

" (Abbild.) . . . . 230

" brevifolia . . . . 231

. tortuosa . . . . 231

"variegata . . . . 231

pentaphylla Mayr . . . . 241

permixta Beck. . . . . 191

Pence Gris. . . . . . . 240

Picea L. . . . . . . . 126

Pinaster Sol.. . . . . 205

"Hamiltonii Parl. . . 205

"Lemoniana Endl. . . 205

" minor Lois. . . . 205

pindica Form. . . . . . . 202

Pinea L. . . . . . . 208

"(Abbild.) . . 207, 208

" fragilis Loisel. . . . 209

Pithyusa Strangw. . . . 206

ponderosa Dougl. . . . 216

" Malletii Hort. . . . . 217

$"$ pendula Hort. amer. . 218

" var. scopulorum

Engelm. 218

" " $"$ (Abbild.) . . 217

pontica" C. Koch . . . . 201

Pumilio Hänke . . . . . . 197

pumila Mayr . . . . . 231

" brevifolia . . . . 231 
Seite

Pinus pungens Michx. . . . . 214 pyrenaica Lap. . . . . . 204 brutia (Ten.). . . 204 quadrifolia Sulw. . . . . . 223 radiata Don . . . . . . 221 reflexa Engelm.. . . . . 232 resinosa Sol. . . . . 204 rhaetica Brügg. . . . . . 190 Christii Brüggg. . . . 190 Heerii Brügg. . . . 190

190

190

190 rigida Mill. ") suberuncinata pyramidalis Brügg.

214 (Abbild, . 18. 215 aurea Beißn. . . . 215 var. serotina Engelm. 215 Sabiniana Dougl. . . . . 219 Salzmannii Dun.. . . . . . 199 scipioniformis Mast. . . 241 scopulorum Lemm. . . . . 218 septentrionalis Mayr . . . 188 serotina Michx. . . . . . 215 sibirica Mayr . . . . . 228 silvestris L. . . . . . 185 "(Abbild.) . . 184, 185 „: Mastbaumkiefer . . 187 ..: Moorkiefer . . . . 187 ., : Strandkiefer . . . . 187 anguina Hort. . . . 189 argentea Stev。 . . 188 .. argenteo-compacta Ordn. 189 . aurea Kihlm. . . . . 189

. beuvronnensis Hort. . 190

". brachyphylla Wittr. . 190

Beißneriana Schwer. . 189

" columnaris compacta Croux. . . . . 190 compressa Carr. . 190

- conis aggregatis . . . 187

- crispa Schwer. . . . 189

. engadinensis Heer. . 188

" erythranthera Sanio . 187

" rubra . . . 188

"fastigiata Carr. . . . 189

. Watererii . . 190

"genevensis Hort. Sim.-

L. . 190

genuina Heer . . 188

gibberosa Kihlm. . 189

glauca Hort. . . . 189

globosa Hort. . . . 190

" viridis Hort. . . 190

" hamata Stev. . . . 188

hybrida Heer. . . . . 190

. 3 lapponica Fr. . . . 188
Pinus silvestris

Seite

macrocarpa Schröd. . 189

microphylla Schwer. . 190

monophylla Hort. . . 189

₹ montana Wahlbg. . . 196

$X$ Pinus montana uncinata 188

nevadensis Christ. . 188

X nigra Arn. . . . 191

nivea Schwer. . . 189

. parvifolia Conw. . . 190

. pendula Hort. . . . 190

„persica Hort. . . . . 189

.. pontica C. Koch . . 189

"pumila Hort. . . . . 190

.. pygmaea Hort. . . . 190

. pyramidalis glauca

Hort. holl.. . . . 190

reflexa Heer . . . . 188

rigensis Desf. . . . 188

rubra. . . . 188

septentrionalis Schott. . 188

tortuosa Büttn. . . 189

umbraculifera Hort. . 190

uralensis Fisch... 188

variegata Hort.. . . 189

virgata Casp. . . . 189

Watereriana Hort. . . 190

"Xuliginosa Neum. . . 191

sinensis Lamb. . . . . . . 210

Smithiana Wallich. . . . . 86

spectabilis Lamb. . . . . . 136

strobiformis Engelm. . . 232

Strobus L. . . . . . 233

(Abbild.) . 234, 235

alba Hort. . . . . . 237

aurea Hort. . . . . 236

brevifolia Hort. . . . 236

fastigiata Hort. . . 237

forma monophylla tortu-

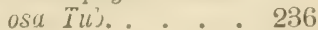
nova monophylla Tub. 236 glauca Hort. Veill. . 236 gracilis viridis Hort. . 236 monophylla (Tub.). . 236 - tortuosa (Tub.) . 236 nana Hort. . . . . 237 nivea Hort. . . . 237 pendula Wesen. . . 237 prostrata (Beißn.) . . 237 pumila Hort. . . . 237 tabuliformis Hort. . 237 umbraculifera Hort. . 237 variegata Hort. . . 236 viridis Hort. . . . 236 zebrina Zoch. . . 236 Täeda L. . . . . 216 
Finus trxifolia Lamb.

Thunbergii Parl.

$$
\begin{aligned}
& \text { monophylla Hort. } \\
& " \text { tabuliformis Hort. } \\
& " \text { tortuosa Hort. . . } \\
& \text { variegata Hort. } \\
& \text { (Iayr). Pinus densiflora }
\end{aligned}
$$

tabuliformis Hol't. . 210

tortuosa Hort. . . 210

variegata Hort. . . 210

Torreyana Parry.

- tuberculata Gord.

. Don

uliginosa Neum.

uncinata Ramd.

" rostrata Ant.

" rotundata Ant.

venusta Dougl. .

virginiana Mill.

yünnanensis Franch.

Wettsteinii Fritsch

Pissodes

notadus.

Pitch-Pine .

Podocarpeae

Podocarpus L'Her.

$$
\text { alpina } \mathrm{R} \text {. Br. }
$$

andina Pöpp.

chinensis Wall.

cuspidata Endl.

grandifolia Endl.

Nageia $R$. Br. .

Nagi (Mayr)

koraiana Sieb.

macrophylla D. Don

Pollenkoln (Abbild.)

Polyporus .

Prächtige Tanne

Prumnopitys Phil.

Psendolarix Gord.

- Fortunei Mayr.

"Kaempferii Gord.

Püpur-Tanne nana Hort.

Pseudotsuga Carrière

Davidiana Bertr.

"Douglasii Carr. .

$$
\begin{aligned}
& \text { (Abbild.) 18, } 120,121, \\
& \text { argentea Kost. . . . } \\
& \text { " compacta Hans . } \\
& \text { nova (Hort.angl.) } \\
& \text { (Beitin.) . pendula Beißn. . } \\
& \text { caesia Schwer. . . . } \\
& \text { compacta Hort. . . } \\
& \text { " glauca Beißn. . } \\
& \text { "viridis Beißn. . }
\end{aligned}
$$

Seite

119

210

210

210
210

210

220

222

221

196

194

195

196

146

211

225

203

27

28

28

215, 216

48

49

49

49

49

ธิ0

50

50

50

อั4

รั0

16

25

143

49

173

174

174

174

137

119

164

119

144

123

123

123

123

123

123

123

123
Pseudotsuga

, Douglasii denudata Carr. . 124

" " elegans Hort. . . . 123

Fretsii Beißn. . . 124

fastigiata Carr. . . 123

glaucescens Carr. . . 123

globosa Beißn... . 124

macrocarpa Engelm. . . 124

monstrosa Hort. . . 124

pendula kngelm. . . 123

"glauca . . . 123

elegans . 123

pumila Beißn. . . 123

Standishii Hort. . . 123

Standishiana . . . 123

Stairii Hort. . . . 123

suberosa Lenm. . . . 119

taxifolia Carr. . . 123

variegata Forb. . . 123

violacea Hort. holl. . 123

var. glauca (Hort.) . 122

- elegans Hort. holl. 123

" pendula Beißn. . 123

Fretsii " P. Smith . 123

124

122

123

124

124

163

Pyrenäen-Kiefer . . . . . . 204

Pyrenäen-Schwarzkiefer : . . 199

\section{R.}

Rautenförmige Blatt-Eibe . . , 51

Red Fir . . . . . . . . 122

Retinispora Ellwangeriana Hort. . . 274

" ericoides Hort. . . . . . . 274

" " Juss. . . . . . . . 307

juniperoides Carr. . . . 268

leptoclada Hort. . . . . . 307

»Zucc. . . . . . . 297

lycopodioides Gord. . . . 303

meldensis Hort. . . . . 269

obtusa Sieb. u. Zuce. . . . . 301

pisifera Sieb. u. Zucc. . . . 296

Sanderii Sand. . . . . 303

squurrosa Sieb, u. Zuce. . . 297

" " glaucescens. . . • • 299

" " phurea . . . . . . 299

Rhizinia undulata. . . . 25

Riesen-Bastkäfer . . . . 27

„-Lebensbäume . . . . . 279

Riesige Sequnie . . . . 245 
Seite

Riesiger Lebensbaum . . . 279

Schmuckzypresse . . . . . . 261

Riesige Kiefer . . . . . . . 240

Schnabelkiefer . . . . . . . 195

Riga-Kiefer . . . . . . 188

Schnecken. . ... . . . 29

Rinde der Nadelhölzer . . . . 13

Rotfäule . . . . . . . 25

Rotfichte, amerikanische . . 101

Rotfuhre . . . . . . 196

Rote Zeder . . . . . . . 312

Rotîrichtiger Sadebaum . . . 320

Rotkiefer. . . . . . . 204 japanische. . . . . . 209

Rottanne ...... 73

Schneebruch-Fichte . . . . . 78

Schnitt der Nadelhölzer . . . 23

Schottische Kiefer . . . . 187

Schrenks Jichte . . . . . . 86

Schuppenzypresse . . . . . . 26il

Schiitte... . . . . . . 24

Schutz gegen Schädlinge . . . ㄴ:3

Schwarzfichte . . . . . . 101

Schwarze Fichte . . . . . 81

Rules Schmucktanne. . . . . 71 Schwarzföhre _. . . . . . 199

Rumelische Kiefer . . . . 240 Schwarzkiefer, kalabrische . . 201

Weymouthskiefer . . . 240 " österreichische . . . . 199

Rüsselkäter . . . . . 27

" brauner, großer . . . 27

Ruten-Kiefer . . . . . 189

Ruten-Tanne . . . . . . 128

\section{S.}

Sabina Endl.

308

officinalis Garcke . . . . 310

Sabines-Kiefer . . . . . 219

Sachalin-Tanne. . . . . 156

Sadebäume . . . . . . 308

Sadebaum mit halbkugeligen Früchten . . . . . 322

Salisburia adiantifolia Sm. . . . 44

Samen der Nadelhölzer . 19, 31

(Abbild.) . . . . . 19

Sanderak-Schmuckzypresse . . 262

Sapindusfichte . . . . . . 89

Siulenfichte . . . . . . 82

Säulenförmige Zypresse . . . 286

Säulen-Lärche 。 . . . . 168

Säulen-Kiefer . . . . . . 189, 190

Saxegothaea Lindl. . . . . 48

.. conspicua Lindl. . . . . 49

Sciadopitys Sieb. u. Zucc. . . 242 . verticillata S. น. Z. . . . 242

" $"$ (Abbild.) . . . . 243

". variegata Gord. . . 244

Schierlingstanne . . . . . . 110

Schimmelfichte . . . . . . 100

Schirmföhre . . . . . . 208

Schirmtanne . . . . . . . 242

Schlaffer Sadebaum . . . . 310

Schlangenfichte . . . . . . 83

Schlangenkiefer . . . . . . 189

Schlangentanne . . . . . . 128

Schlehenspinner . . . . . 27

Schlüssel zu den WinterhärteNotizen

Schmucktanne "taurische

Schredische Fichte. . . . . 81

"Hängefichte . . . . . 83

Schwedischer Wachholder . . 325

Schwere Kiefer . . . . . 216

Selaginellaähnliche Gliederfichte 249

Senker, Ableger . . . . . . 35

Septoria parasitica . . . . 25

Sequoia Endl . . . . . . . 245

gigantea Endl. . . . . . 245

gigantea 'Torr. . . . . . 245

(Abbild.) $246,247,248$

argentea Hort. . . 248

aurea Hort. . . . 248

" columnaris Hort.(Beißn.) 248

glauca Hort. . . 2 248

"pyramidalis compacta Hort. . . 248

Holmsii P. Smith . 248

lutea Hort. . . . 248

pendula Hort. . . . 248

pygmaea Hort. . . . 248

pyramidalis Hort. gall. 248

variegata Hort. . . 248

sempervirens Endl. . . . 248

adpressa Carr . . . 249

alho-spica Hort. . . . 249

" filifera elegans Rov. . 249

". pendula Rov. . . . 249

" taxitolia Hort. . . . 249

" variegata Carr. . . . 249

Sequoie . . . . . . . . 245

Sevan-River-Schuppenzypresse . 261

Sevenbäume . . . . . . . . 308

Sibirische Tanne . . . . . . 1024

Zirbel . . . . . . . 228

Sibirischer Sadebaum . . . . 321

Silberkiefer . . . . . . . . 188

chinesische . . . . . . 222

Silbertanne . . . . . . . 145

Sitkafichte . . . . . . . 109 
Sitka-Lebensbaum $\cdot-304$

Sonnen-Zypresse . . . . 301

Spätkiefer . . . . . . 215

Spaltöffnungen . . . . . . . 15

Spanische Tanne . . . . . 133

Spießtanne . . . . . . 244

Spirke . . . . . . . . 196

Stachycarpus Encll. . . . . . . 49

Standish's japanischer Lebensbaum . . . 283

Standort der Nadelhölzer . . . 20

Starrer Wachholder . . . . 328

Stechende Fichte . . . . 9

Stechende Kiefer . . . . . . 214

Stecklinge der Nadelhölzer . . 33

Steife Kiefer. . . . . . 214

Stein-Eibe 49

Steinfrüchtige Kopf-Eibe . . . 56

Steinfrüchtiger Wachholder . . 329

Stein-Kiefer . . . . . . . 224

., italienische . . . . 208

Stein-乇ärche . . . . 165, 168

Stein-Wachholder . . . . . 329

Stelzenfichte . . . . . . . 78

Stink-Eibe . . . . . . . . . 58

Stinkender Sadebaum . . . 320

Stockfänle . . . . . . . . 25

Strandkiefer . . . 187, 20 s

Strand-Wachholder . . . . 328

Strauchkiefer . . . . 212

Strobe . . . . . . 233

Strobeähnliche Kiefer : : 232

Strobus Spach. . . . . . . 233

Sumptforche . . . . . . . 196

Sumpfkiefer . . . . . 196, 215

Sumpfzypresse . . . . . 253

$\mathbf{T}$

Taeda Endl. . . . . . . . 214

Tamne . . . . . . 125

Tannen-Borkenkäfer . . . . 28

Tannen-Rüsselküfer . . . . . 28

Tasmanische Kleinfrucht-Eibe . 48

Taxaceae . . . . . 48

T'axbaum . . . . . . 60

Taxeae . . . . . . 56

Taxtanne . . . . . . . 126

Taxodieae . . . . . . . . 242

Jaxodium Rich. . . . . . 253

. distichum Rich.. . . . . 254

" (Abbild.) . . . 255

" " compactum Hesse. . 260

. " denudatum Carr. . . 257

$" \quad$ " erectifrons Schelle : 260

" " $\quad "$ (Abbild.) . 258, 259
Taxodium distichum fastigiatum

Knight . . . . 259

imbricarium Sarg. . . 260

intermedium Carr. . 259

Knightii Carr. . . . 259

microphyllum Carr. . 259

nanum Carr. . . . 260

nigrum Carr. . . . 260

nutans Ait. . . . . 257

pendulum Carr. . . 255

(Abbild.) . 256, 257

elegans Hort. 257

novum P. Smith 25

pyramidatum Carr. . $25 \mathrm{~S}$

sinense pendulum Hort. . 257

heterophyllum Brongn. . . 260

imbricarium Nutt. (Harb.) . 260

mexicanum Carr. . . . . 5, 260

mierophyllum Brongn. . . . 259

mucronatum Hort. . . . . 260

Taxus Tourn. . . . . . . 59

adpressa Gord. . . . . . 66

Hort. . . . . . . 66

erecta Hort.. . . . 66

fastigiata Hort. . . . 66

stricta Hort. . . . . 66

variegata Hort. . . 66

baccata L. . . . . . 60

(Abbild.) . . . 60,61

adpressa Carr. . . 66

aurea Hort. . . 66

aureo-elegantissima

Hort. . . . . . 62

aureo - variegata

Hort. . . . 66

stricta Hort. . . 66

"variegata Hort. . 66

albo-variegata Hort.

Späth . . . . 62

aureo-variegata Hort. 62

brevifolia . . . 67

„Blue John" Hort. angl. 64

canadensis . . . . . 66

" aureo - variegata

Hort. . . . 67

cheshuntensis Gord. . 64

columnaris Carr. . . 64

compressa Carr. . . 64

conica Hort. . . . . 64

cuspidata Carr. . . . 62

(Abbild.) • . 62

" formosona Pilg. 63

Davisii Hort. . . 63

Dovastonii Carr. . . 63

aureo - variegata

Beißn.

63 
Seite

Seite

J'axus baccata

Taxus canadensis Willd. . . . . 66

Dorrstonii pendula variegata Hort.

elegantissima Hort. . 62

elevastonensis aurea

Hort. . . . . . 62

epacroides Beißn. . 66

erecta Loud.

64

" aureo - variegata

Hort.

64

" glauca Hort. . . 64

ericoides Carr. . . 66

expansa Carr. . . 66

fastigiata Loud. . . 64

(Abbild.) . 6 63,65

" argenteo-variegata Hort. . . 64

"aurea Stand. . 64

$"$ aureo-marginata

Beifin. . . . tit

" aureo - variegata

Hort. . . 61

, -compactaHort. 64

, nova Hort. Voll. 64

fructu luteo Loud. . . 62

glauca Carr . . . 62

gracilis pendula Hort. 64

hibernica Hort. . . . . 61

horizontalis Knight . 62

Jacksonii Gord. . . 62

inmperialis Hort. . . 64

intermedia Carx. . 62

linearis Carr. . . . . 62

macrocarpa Hort. . . 62

major Hort. . . . 62

microcarpa 'Trauty u.

Maxim. . . . 62

microphylia Jacques . . 66

minor Michx. . . . . 66

Mitehellii Hort. . . . 66

monstrosa Carr. . . 66

nana Kuight . . . 66

Nedpath Castle Hort. 64

pendula gratiosa Over. 64

"variegata Hort. S.-L. . . . 64

pyramidalis Carr. . 62

" 'aureo - marginate

Hort. angl. . . . 61

recurvata Carr. . . 62

semperaurea Ottol. u.

Hoftm. . . . . . 62

Sieboldii (Beißn.) . . 66

IVashingtonii Hort. . 62

irevifolia Hort. . . . . . 66

Nutt. . . . . . 67

Schelle, Koniferen.

'leufern . . . . . . . 196

Thunbergs Kiefer . . . . . 210

Thuya Tournefort . . . . 271

ericoilles Hort. . . . . 274

Defresneana Hort. . . . . . 268

Ellwangeriana Hort. . . . . 27t

gigantea Nutt. . . . . 279

(Abbild.) . . 280, 281, 282

Carr. . . 269

Hort. . . . . . 269

" albo-maculata Hort. . 283

, atrovirens Hort. . . 283

aurea Hort. Spaetl. . 283

"Hort. . . . . 276

aurescens Hort. . . . 276

aureo-variegata Hort. 283

fastigiata Hort. . . 283

gracilis Hort, . . . 283

incurva Beißn. . . 283

pendula Hort. Lieb. . 283

" semperaurea Hort. . . 276

filiformis japonica Hort. . . 268

funalis Hort. . . . . . 268

japonica Hort. . . . . . . 268

"Maxim. . . . . . . 28t

Lobbii Veitch. . . . . . . 279

meldensis Hort. . . . . . . 269

Menziesii Dougl. . . . . . 279

occidentalis L. . ... . . 271

(Abbild.) . . . . 27:2, 273

albo-spica Hort. . . 276

albo-variegata Hort. . 276

argenteo-variegata

Hort. . . . 276

artlırotaxoides Hort. . . 268

aspleniifolia Hort. . 276

aurea Hort. . . . . 27 õ

aureo-spica Hort. . . 275

aureo-variegata Hort. 275

aurescens Hort. . . 27 כ

Bodmerii Hort. ' . . 277

Bowthii Hont. . . . 27T

Buchononii Arb. Arn. 276

compacta Hort. . . 277

" Hort. (fälschlich) 279 
Thuya occidentalis

.Cloth of Gold" Arb.

Arn.

Columbia Hort. . . . 277

Columna Hort. Spaeth. 27

columnaris Reut..... .

cristata Hort. . . . 2

aurea Hort. . . 2 2Tit

denudata Hort. . . 27i;

Dicksonii Hort. angl. . . 27i

Douglasii pyramidalis

Hort.

Douglasii Hort. am.

$27 i$

Ellwangeriana Hort. . $27 t$

" (Abbild.)

". Rheingold" Hort.

Voll. . . . . 274

. pygmaea aurea Hort. angl.

- 271

aurea Hort. Spith. 274

erecta viridis Hort. . . .

erecta Hesse. . . . . 277

ericoides Hort. . . . . 2 274

(Abbild.) . . . 2 $2 \pi$

fastigiata Hort. . . . 277

nova Hort. . 277

filicoides Hort. . . . 2Tit

filiformis Beißn. . . 277

Froebelii Hort. . . . . 2 27T

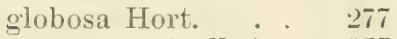

comipacta Hort. . . $27 \overline{7}$

viridis Hort. . . .

globularisLamb. u.Reit. $27 \mathrm{~T}$

l'Haveana Hort. . . . 277

hollandica Beißn. . . 277

Hoveyi Hort. . . 277

aureo-variegata

Hort. Bet.

. Little gem" Hort. .

277

277

Hoersholmiensis Lange . 277

lutea Hort.

275

.. nana Hort.

275

Ohlendorfii Hort. . . 275

pendula Hort. . . 276

"glauca Hort. . 276

plicata Loud. . . . . . 277

pumila Hort. . . . 277

pygmaea Hort. . . 277

pyramidalis compacta

Hort. gall. . . .

recurva nana Hort. . 276

recurvata Hort. . . 276

.. argenteo-variegata

Hort. . . . 276

reflexa Hort. . . . . 276

Riversii Hort. . . . 276
Thuya occidentalis

Seite

Rosenthalii Ohlend. . 277

"Silver Queen Hort. 276

Spaethii P. Smith . 275

Spihlmannii P. Smith . . 277

stricta Hort. . . . 277

tatarica Hort. . . 276

theodonensis Hort. . 276

thuyopsoides Schneid. 276

umbraculifera Beißn. . 277

Versmannii Cordes . . $27 \pi$

Vervaeneana Hort. . 276

viridis . . . 276

viridis Hort. . . 276

Wareana Hort. . . 276 aireo-variegata

Hort. . . . 276

globosa Hort. . 276

lutescens Hort.

Hesse . . 276

Wagneriana Froeb. . 277

Viegneriana Hort.

(Reuter) .... 276

orientalis $L, \ldots \ldots . .265$

plicata Don. . . . 277

(Abbild.) ..... 278

argenteo-variegata

Hort. . . . 279

aurea Hort. . . . 275

aureo-variegata Hort. . 279

compacta Hort. . . 279

dumosa Hort. . . . 279

pygmaea Hort. . . 279

Wareana Hort. . . . 276

Standishii Carr. . . . 283

(Abbild.) . . . . 283

Thuyopsis Sieb. u. Zucc. . . . 263

borealis Hort. . . . . 304

dolabrata S. u. Z. . . 263

(Abbild.). . . 264

. altissima Hort. Ans. . 264

cristata Hort. Ans. . 264

decumbens Hort. . 264

nana S. u. Z. . . . 264

plicata Hort. Ans. . 264

- robusta Hort. . . . 264

" variegata Hort. . . 264

laetevirens Lindl. . . . . . $26 t$

Standishii Gord. . . . . 284

Tierische Schädlinge. . . . 26

Tinea laricella. . . . . . . 29

Tomicus $\quad \ldots \quad 27,28,29$

" chalcographus . . . 27

" curoideus . . . . . 28

" typographus ..... . 27

Torano-Fichte . . . . . 92 
Seite

'Torreya Arn. californica Torr.

Fargesii Franch.

grandis Fort.

(Abbild.)

*

:

Myristica Hook. fil.

mucifera S. u. Z. Y Torr. grandis

taxifolia Arn.

"argentea Beißn. tenuifolia Hort. Rov.

. $\quad$ argentea Hort. Ro:.

Torreye

Torreys-Kiefer .

Tortrix

. Buoliana

. duplana

nigricans

.. pinicolana

tedella

" turionana.

Trïnenfichte

Tränenkiefer

'Tranerfichte

Trauelzypresse, chinesische .

Tremetes Pini

. radiciperda

Trichosphaeria parasitica

Triebe der Nadelhölzex

Tsuma Carr.

. Brumoniana Carr.

". (Abbild.)

chinensis Francl.

canadensis Carr.

(Abbild.)

" albo-spica Hort.

$112,113,11$

" argentea Hesse

Hort.

aurea Hort.

" columnaris Bolle

" compacta Beißn.

" " nana Hort.

fastigiata Hort.

globosa Hort.

gracilis Hort.

microphylla Hort.

minima Hesse.

nana Carr.

parvifolia P. Smith

pendula Hort.

Sargentii pendula Hort.am. 114 sparsifolia Beißn.

caroliniana Engelm. . (Abbild.)

Däidiana Franeh.
Tsuga diversifolia Marim.

stga diversifolia Maxim. • . 110

Douglasii Carr. . . . . . 119

dumosa Loud. . . . . . . . 117

heterophylla Sarg. . . . . . 115

Hookeriana Carr. . . . 118

japonica Shiras. . . . . . . 12⿺t

Mertensiana Carr. . . . 115

(Abbild.) . . . . 11

" argenteo-variegata

Beifin. . . . 115

" macrophylla Beißn. . 11\%

Pattoniana Engelm. . . . 118

(Abbild.) . . . 11

$"$ argentea (Beißn.) . . 118

"glauce Hort. . . . . . . 118

Sieboldii Carr. . . . . 115

(Abbild.) . . . . $111 ;$

" nana Carr. . . . 116

"variegata Hesse . . 116

yünanensis Mast. . . . . 117

\section{U.}

Tral-Kiefer . . . . 185

Uwarows Fichte. . . . . 79

\section{v.}

Verhalten fremdländischer Gehölze

Vermehrung der Nadeliölzer und

Pflege der jungen Pflanzen. : 0

Veitch's Tanne .. . . . 155

Verbiß der Koniferen . . . . . 29

Vierkantiger Sadebaum . . . 311

Virginische Zeder . . . . . . 312

Virginischer Sadebaum . . . . . :312 , , 12

Wachholder . . . . . . 5 : 317

Walzenfichte ... . . . . .

Warzenkiefer . . . . . . . 2.2

Wasserfichte . . . . . . . 260

Webbs Tanne . . . . . 136;

Weihrauchkiefer . . . . . 216

Weilırauch-Sadebaum . . . . :31;

Weiluauchzeder . . . . 316

Weißfichte ... . 78

Weißkiefer . . . . . . 188, 219

Weißtanne . . . . . 126

Weiße Zeder . . . . 306

Weißrindige Kiefer . . . . 2113

Weißstämmige Kiefer . . . . . 2:32)

Wellingtonia Lindley . . . . . . . . 245 


\section{$-\quad 351 ;$}

Seite

IVellingtonie ....... . . .

TVestamerikanische Tanne . . 148

Westamerikanischer Sadebaum . :31n

Wetterfichte . . . . Ts

Weymouths-Kiefer . . . . . . . . 23:3

Widdringtonia Endl. . . . . . . ¿til

.. cupressoides Endl. . . . . . 20172

Wilde Tanne . . . . . . . 1:33

Wilde Zeder . . . . . . . 1833

Wilhelmshöher Schwarzfichte . 111:3

WVurzeln der Nadelhölzer . . . 11

Wurzelschwamm . . . . . . . . 25

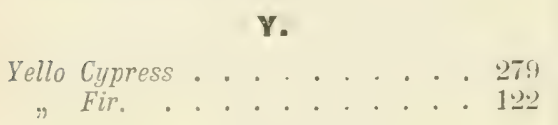

z.

Zahme Tanne ...... 133

"Zeder . . . . . . 133

Zapfen der Nadellı̈̈lzer . . . 17

Zapfensucht . . . . 19.18T

Zäpfchenfichte . . . . . sl

Zargenfichte ....... is

Zeder . . . . . . $17 t$

Zederrt-Wachholder . . . . \$2⿺s

Ziegenfichte ...... is

Zierende Kiefer . . . . . 214

Zilizische Tanne... . . 13ł;

Zirbel . . . . . . 225

", einblätterige . . . . . 2.2

"Kiefer . . . . . . 2.

$n$-Nïsse . . . . . . 22 2 .

$"$, sibirische . . . . 220

Zirme . . . . . . . . 2.25

Zitzen-Fichte . . . . . . 51

Zuckerkiefer . . . . . 241

Zunder . . . . . . . 19t;

Zurïckgekrümmter Sadebaum . . : :21

Ziirbel . . . . 22:5

Zweige der Koniferen . . . . 11

Zwergföhre . . . . . 196

Zwergkiefer . . . . 197, 234

Zwerg-Wachholder .... 32.)

Zwerg-Weymouthskiefer . . . 2:37

Zwillingsfichte ...... T

Zypresse . . . . ㄴt

Zypressenähnliche Gliederfichte. 2010.5 



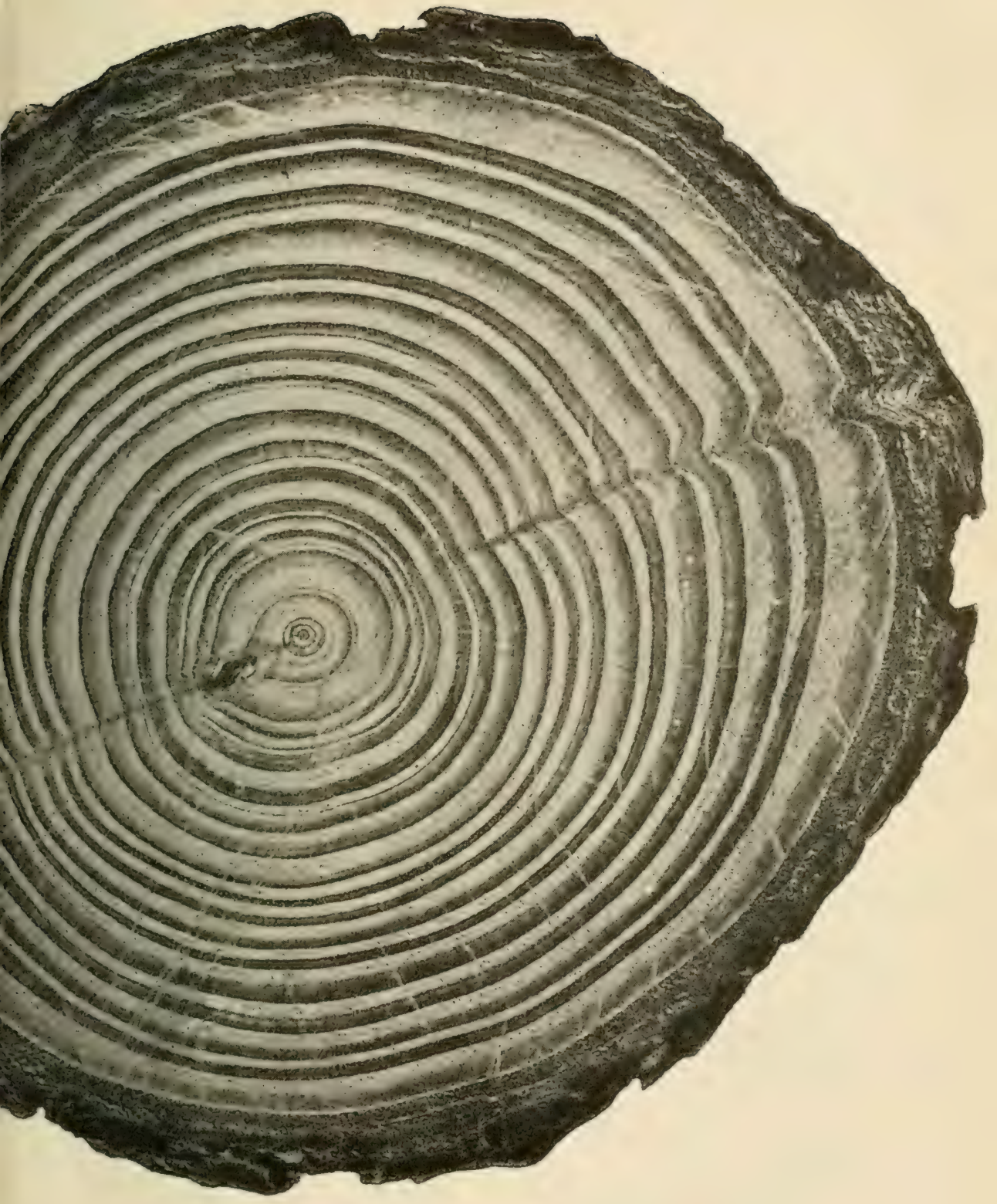

Fig. 173.

Pseudotsuga Douglasii Carr. Stamı idurchschnitt.

25 jährig.

chten Boden gewachsen. (Siehe Seite 122.) 



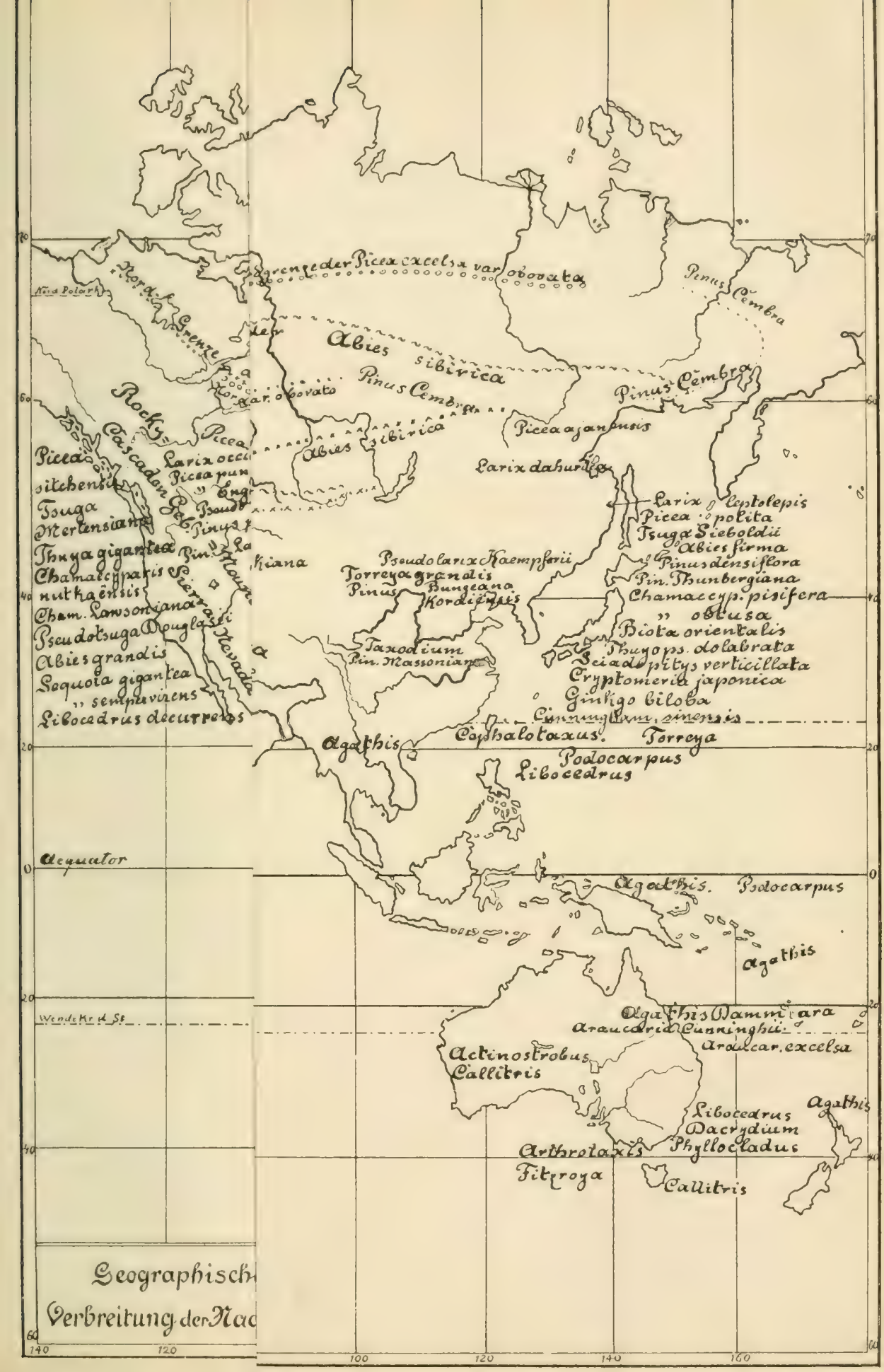




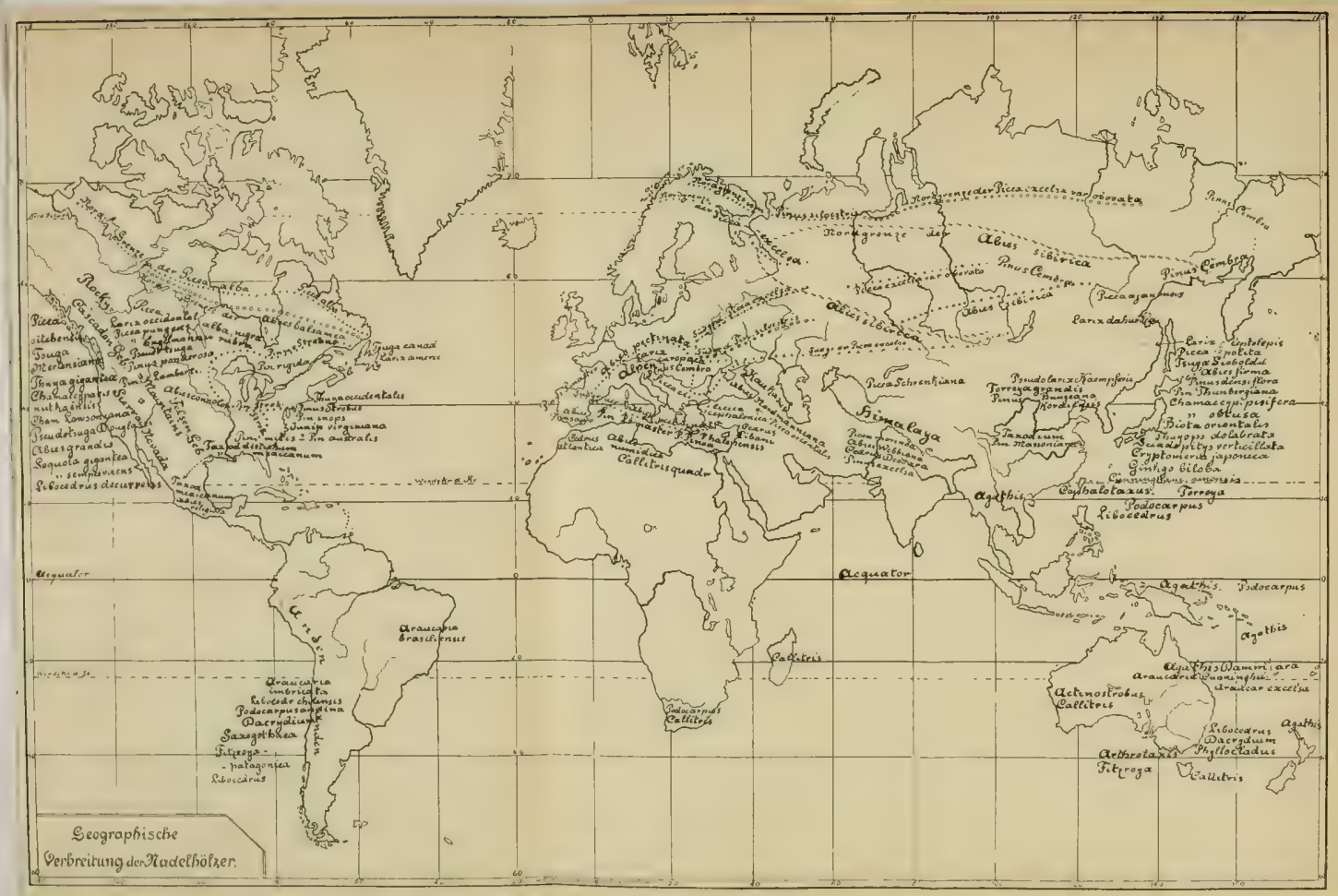


Verlag von Eugen Ulmer in Stuttgart.

\section{Die Nadelíölzer}

mit beionderer Berükfiifitigung der in Europa winterfiarten Arten.

Eine Einführung in die Nadelholzkunde für Landschaftsgärtner, Gartenfreunde und Forstlente.

Von

Dr. Kavl F'eiher' rou 'T'ubeuf',

Professor an der Universitit Mïnchen

Mit 100 nach der Vatur anferenommenen originalhildern im Text.

Preis gebunden e 16.50 .

\section{Die Coniferen und Gnetaceen Mitteleuropas}

in ifren geiamten Lebenseridieinungen mit einer allgem. ökol. Einfülirung.

Unter Mitwirkun $@$ von Dr. Rikli, Privatdozent am eidgen.

Polytechnikum Züirich herausgegeben von

Di. 0. ron Kirchner,

Prof, der Botanik an der Kgl. landw. Hochschule Hohenheim

\section{Professor Dr. Li. Loew,}

Berlin.

Kgl. Real-Oberlehrer a. D.

Dr. C. Schröter,

Prof. der Botanik am eidgen. Polytechnikum Zürich.

Nit 186 Abbildungen. Preis geb. J6. 16.-.

\section{Der Wald und dessen Betoirtifiaítung.}

Fit seitfadest fiir privatwalobeitser, Genteitdebeante, Waldmeifter,

foritiduntybeamte niw.

Don

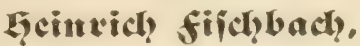

$\uparrow$ Pönial. wiattembergijdycr forftoireftor.

3. ten bearbeitete 2uflage vou forjtamtmantu Dr. Wörule. nit 42 2tbbildnugen. - Gebunton ell 1.80 .

\section{Chrilit-Lucas Gartenturit.}

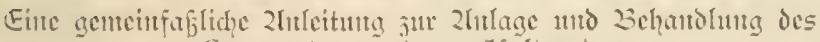
Eansgartens witio jut Zuiltur der

Blumen, Gemüie, Obitbäume u. Reøen einífil. der Blumenzunit im Zimmer. เุ็. 2ưflage.

Dolt

(i) Fonomierat Fr. Lucas

Direptor des pomoloq. Intituts in Reatlingen.

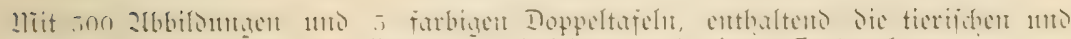

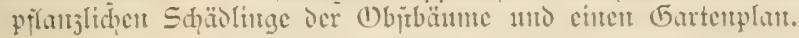

Preis in seintwatto geb. ell $4 .-$

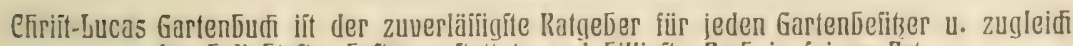
das Deliebteîte, Deîtausgeîtattete und billigite Bunt in leiner Brt. 


\section{Illustrierte Handhülcher sukkulenter Pflanzen.}

Herausgegeben von

\section{Alwin Berger,}

Kurator des Hanbury'schen botanischen Gartens zu La Mortola (Riviera).

\section{Bereits erschienen sind:}

Band I.

\section{Sukkulente Euphorbien.}

Beschreibung nnd Anleitung zum Bestimmen der kultivierten Arten, mit kurzen Angaben iiber die linltur.

Mit 33 Abbildungen.

Preis brosch. ell 2.50, geb. ell 3.-
Band II.

Mesembrianthemen und Portulacaceen.

Beschreibung und Anleitung zum Bestimmen der kultivierten Arten. nebst Angaben iber die Kultur.

Mit 67 Abbildungen. Preis brosch. At 5.-, geb. All 5.80

\section{In Vorbereitung sind:}

Aloe und verwandte Gattungen.

Agaven und verwandte Gattungen (Beschorneria, Fourcroya etc.); im Anschluh daran einige sukkulente Bromeliaceen.

Crassulaceen : Sedum, Sempervivum, Monanthes, Cotyledon
Echevera, Bryophyllum, Kalan. choe, Crassula.

\section{Kakteen.}

Stapelien und verwandte Gattungen, Compositen (Kleinia, Se: nesio).

*) Erscheint im Januar 1909.

Die ..Ilustrierten IIanlbiichers sind in erster Linic für den Gebrauch der zahlreichen Freunde der teils merkwürdigen, teils schönen Fettpflanzen (Sukkulenten) und Kakteen geplant. Sie sollen ihnen als Fürer dienen und ihnen helfen, über die Menge der Formen einen gewissen Überblick zu erlangen. Die Übersichtlichkeit soll eine solclie sein, daB es jedem gelingen wird, unbekannte Pflanzen darnach zu bestimmen.

Seit 10 Jahren hat der Herausgeber den sukkulenten Pflanzen seine spezielle Aufmerksamkeit gewidmet, hauptsächlich auf Grund der reichen, inzwischen ständig vergrößerten Sammlung lebender Pflanzen und der Bibliothek des Gartens zu Ia Mortola, der Gärten und Herbarien zu l'alermo, Berlin, Kew etc. und eines eigenen Herbars, zu dem der Herausgeber von vielen Seiten wertvolle Beiträge erhielt.

\section{Für jeden Gärtner unentbehrliche Wörterbücher:}

Salomons Wörterbuch der botanischen Kunstsprache.

5. Aufl. Neu bearb, von Garteninspektor Schelle. Preis geb. 1l 1.30. Salomons Wörterbuch der deutschen Pilanzennamen. 2. Aufl, bearbeitet von A. V o B. Geb.

Salomons Wörterbuch der botanischen Gattungsnamen.

Geb. ell 2.50. 


\section{Handbuch der Kaḱteenkultur.}

Kurze Beidireibung der meiften gegenwärtig im Handel befindliđien Kakteen, nebit Hngabe zu deren Pflege.

Sö̈ Gürtmev und Iafteenliebhaber zufanmengeftefit vou

(15. Fitlielli,

Sigl. Garteninipettor in Iibingen.

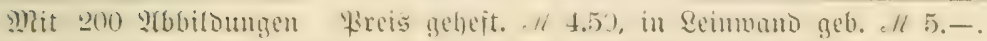

Monatsforift für Kaktecnkunde: Ias (Erjocinen Des vorfiegenten

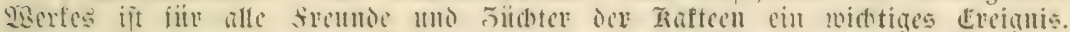

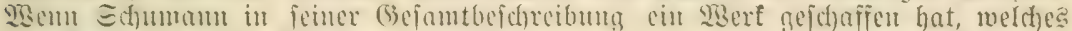

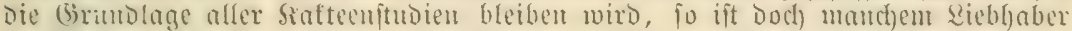

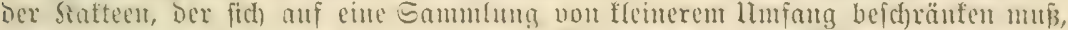

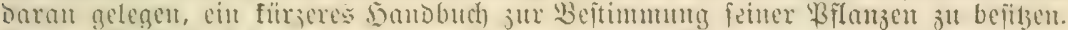

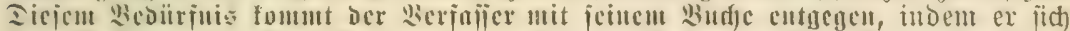

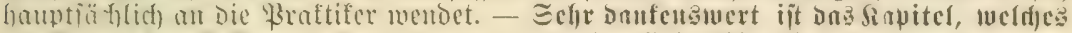

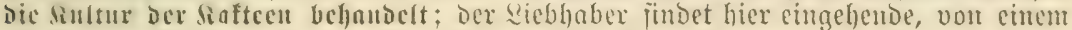

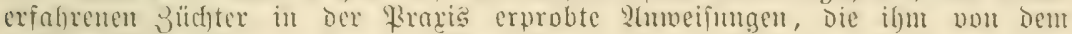

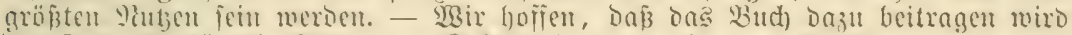

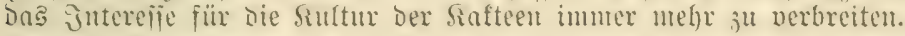

\section{Die Kultur der Pilanzen im Zimmer.}

23011

I. Brilltener,

(3) ropherzoglicier \$oigartendirettor.

2. Auflage. Mit 28 26biloumgen. preis gebuntent dl 2.-

Diese Schrift will daz̨u beitragen, das Cos der Dflanzen im Zimmer z̧u verbeffern, das Verfändnis für ihre Bedürfniffe und für ihr gebcimnisvolles Ceben žu crweitern und dadurch diefen ichönen Kindern der Natur immer mehr Eingang 3 u verichaffen, nicht nur im Salon, londern auch im einfachen đaohnraum, ja in der kleinen Dachkammer.

\section{Volíïändiges Handbun der Obîtkultur.}

+. Iuflage, neu bearbeitet und wefentfich vermebrt vou

\section{Dlonomierat fr. Eucas,}

Direttox Des \$omologifden gnitituts in Reutinger.

530 Seiten. Mit 343 Ubbilo. - Preis geb. $1 / 6 .-$

Tiejes \$ud) gibt über alles, was den Dbftbau betrifit, in flarer, ver=

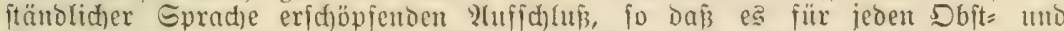
Gartenfremb cinen zuverläjingen lintgeber bildet. Für mfere bentfden Berhält= nifie bearbeitet, nimmt es ene critc Etclle in Der betrefienden Siteratur ein;

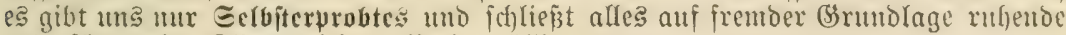
แno für unfer Slima nicht pafiende völlig aแร. 


\section{Dermehrutg unto Sthnitt der כiergehölje}

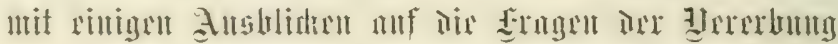

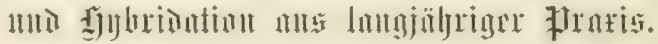

3out

Fteplan (Dluridy,

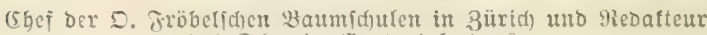
bes 巨d)wets. (Bartentalembers.

Mit 86 2lbbiloungen. Preis brofd. Mt. 3.-, geb. MA. 3.40.

\section{Hllgemeine Gärtnerzeitung caien:}

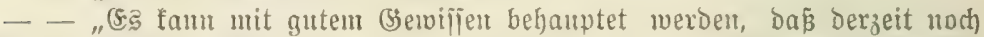

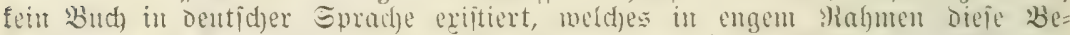

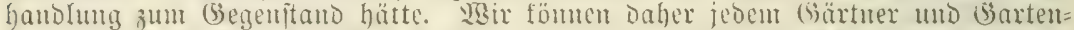

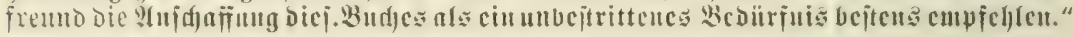

\section{Der 2kofe öutht mis Dflege.}

$30 n$

\section{Titrulym (1)llutidy,}

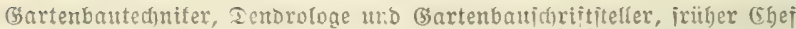

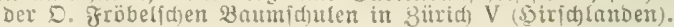

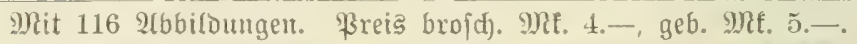

Befprechung der gärtnerifchen Rundichau:

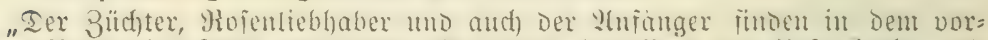

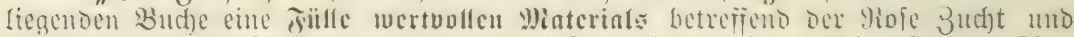

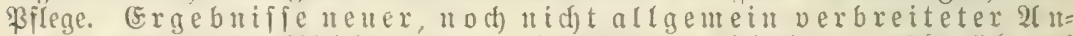

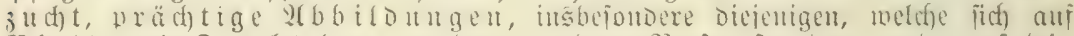
Blatt un Frud der ausdaueruben Rofenforten ud auf die unterlagenzudit beziehen, findet man in jold)ex $1 g$ eife in feiner anderen Shrift. Das Bud ift jefr cupichlensuct.

\section{Ifrantheiten mo Bejhäiolgungen der 2ints= nuto Jierpflangen des (5artenbanes.}

Frofilfor Dr. Fr. Krüger

Dozent jür \$ĭlanzentrantbeiten an ber

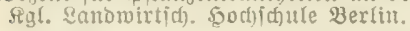

23011

Imo frotifjor Dr. 5. Rörig

Regierungşrat an Der fraij. Wiolog. 2fnjtalt Fïr Sand $=u$. Toritwirtid)aft Iablent b. SBerfin

Mit 4 Farbentafern und 221 in ben Text geducten 2bbiloungen.

Hreis in Reinmano geb. ) Mrt. 6.-

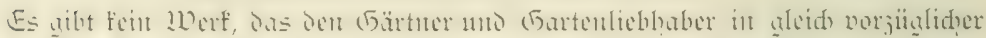

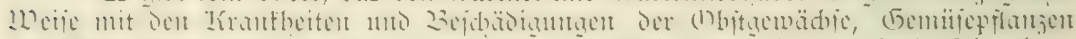

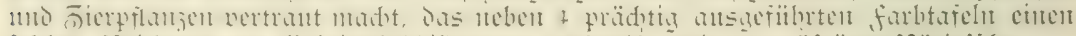

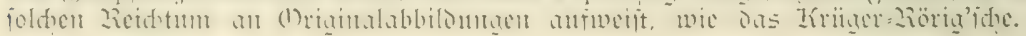




\section{खaerke iber Candwirtichaft.}

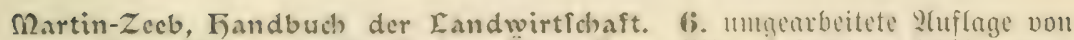

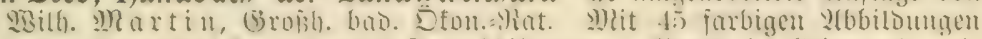

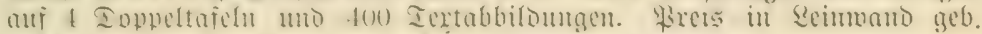
dl 8.-. (Эn \$artien von 12 (5xemplaren ant à ell 7.-.)

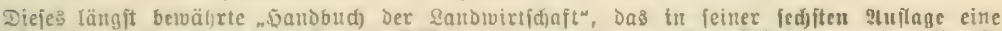

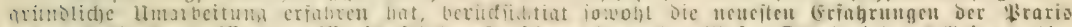

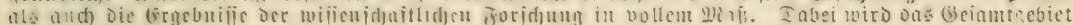

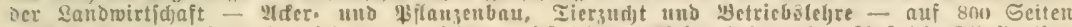

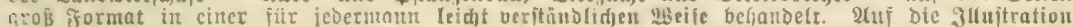

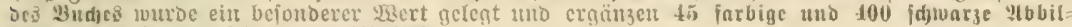
D:mneu Den Tert auf bas vorteillaftejte.

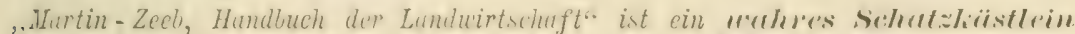
fiis jeden Lamdurin und lictet anf tunsenderlei Fragen die richtige Antwort.

Das Jabr des Candwirts in Den Worgäugen Der Yiatur mo in Den Berrict)=

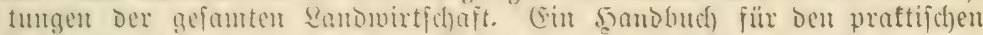

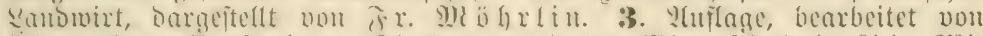

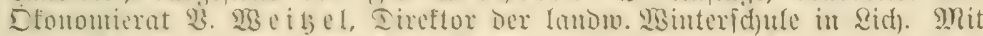
125 2lbbilo. und juei farbigen Doppeltafeln, enthaltend: tierifde nto pflanaliche Sdjäolinge dex Sbjtbämme. Preis geb. All 4.-.

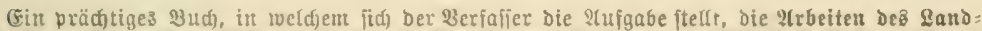

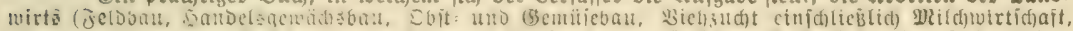

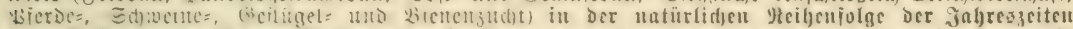

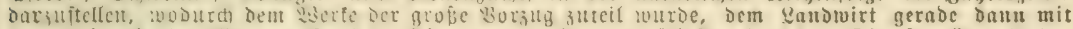

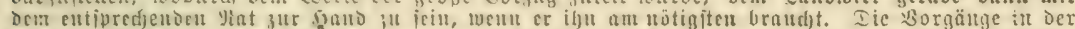

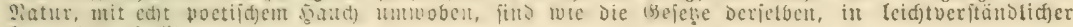
iform Darieitellt.

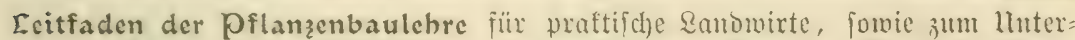

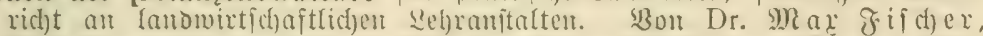

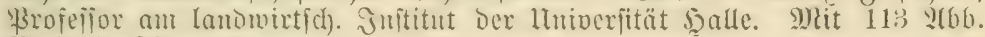
Preis brofd). All 3.-, geb. Al 3.50 .

Dic Bekämpfung der Hcker-ankräuter. Won Eton.= Hat Ma ier= B o Dc. Mit

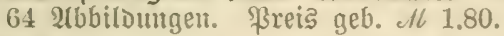

Candwirtichaftlicher Calchen= und Schreibkalender. Deraughegeben voun

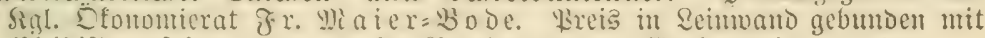

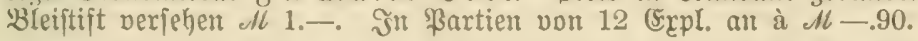

Fübling's landwirtichaftliche Zeitung. 3entralblatt jür praftifhe Sanbuirt= fd)aft. Ilnter Mritmirfung fervorragender (Selefrter und Braftifer herans:

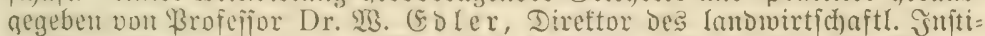

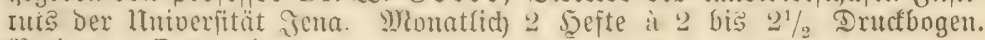
Sreis pro Sluartal $\mathbb{N} 3$. - .

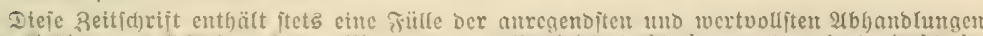

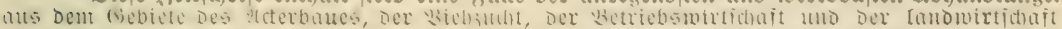

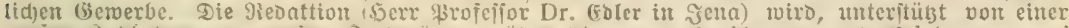

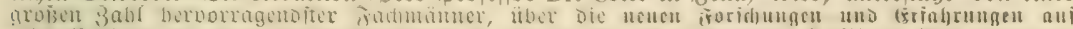

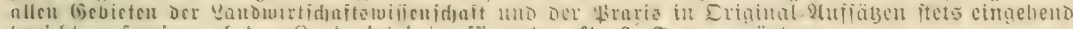
berid)ten, forie aud ben Sanomit interefficrende aftucde fragen erörtern.

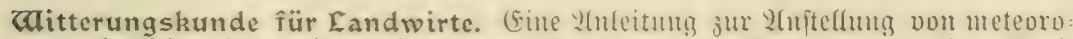

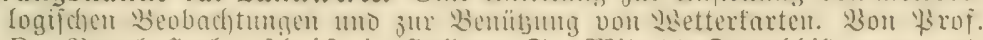

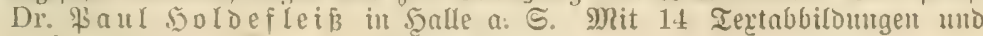
6 Metterfarten. \$reis broid). all 2.40. 


\section{Clerke über Candwirtichaft und Cierheilkunde.}

Reurcitliche Eandwirtichaft. 20) gemeinfaß̉iliche 23orträge über Maß̧ahmen

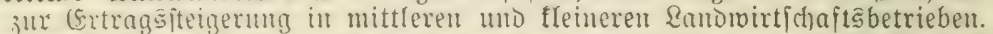

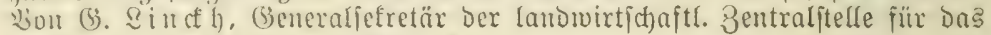
(Sropherjogtum Sachjen. (3)eb. Mt. 4.-.

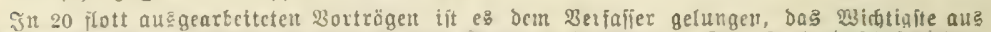

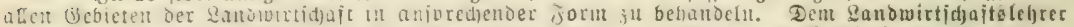

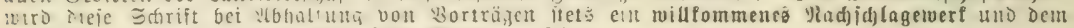
vraftifden Qanbwirt eine Euelle reidjer Befebrung feitt.

Die Eagerung der Getreide. Entitehung uno Berhätung mit bejondecer Be=

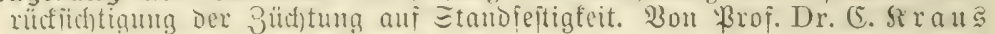
in MRünd). (Gebunden dl 13.-.

Ch. Merk's Faustierbcilkunde für Candwirte. 10. 24 flane nell bearbeitet

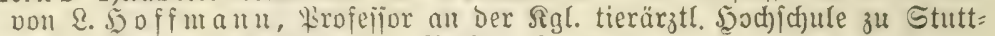

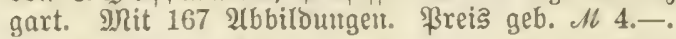

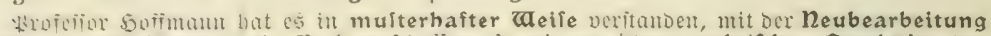

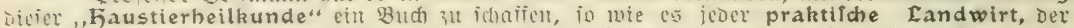

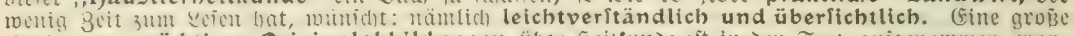
Juhl neutr prächtiger Originalabbildungen liber seilfunoe ift in bet Tert auigenommen wor=

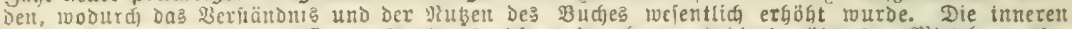

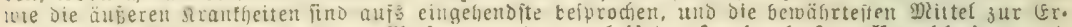

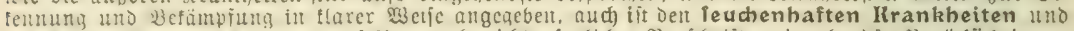

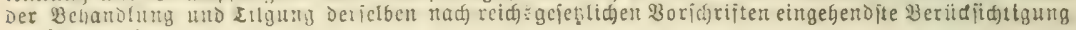
iuteil neworden.

Ciermelt und Candwirtichaft, des Candwirts freunde und feinde unter

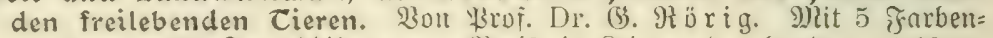
taielu und 439 Iextabbildungen. Freis in Semmand gebunden ell 10. 418 Seiter, großse Sftad= Furmat.

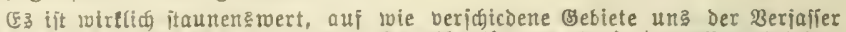

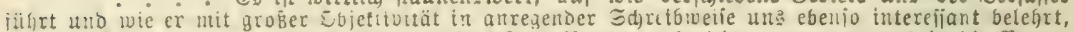

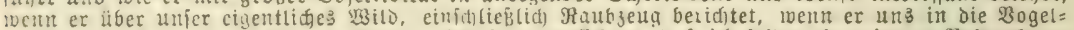

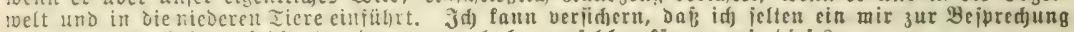

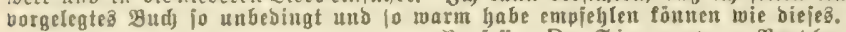

Profeffor Dr. Sim on von $\mathfrak{R}$ a $\mathrm{t}$.

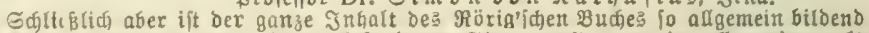

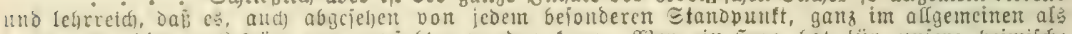

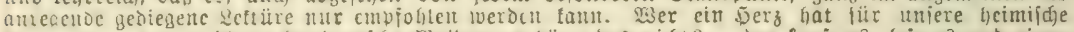

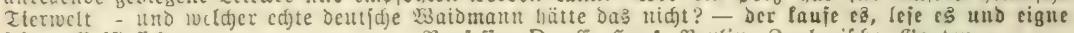
feinen (scipt fid an.

Brofefior Dr. (5. Je d, Berlin, Boologifder Garten.

\section{Schriften über fütterungslehre.}

Die fütterung der landwirtichaftlichen Nutz̧tiere. Auf Grund Der neuen

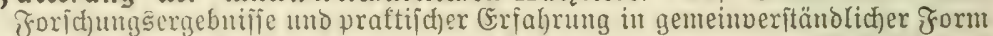
bearbeitet von (3). Lin d h, Generaljefretär Der lando. Bentraljtelle fiu das

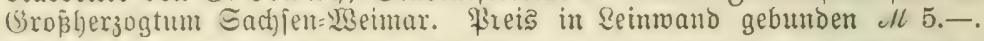

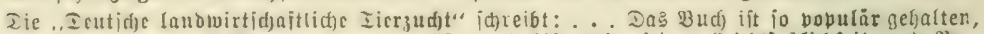

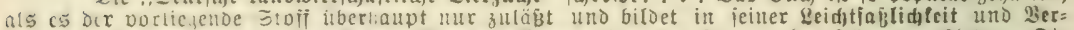

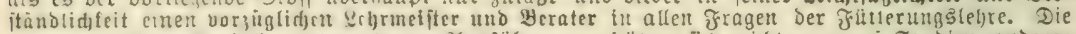

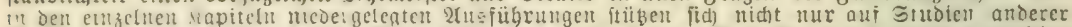

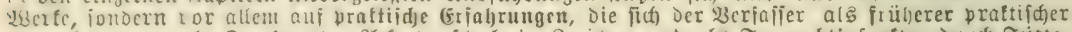

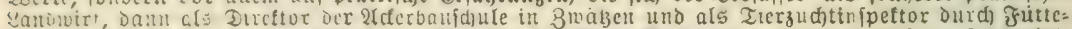

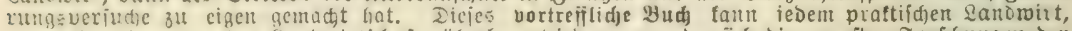

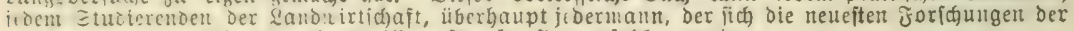
fütterungsicl)re zu eigen madjen roill, anfỏ märmite cmpioblen toerben.

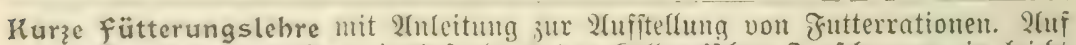

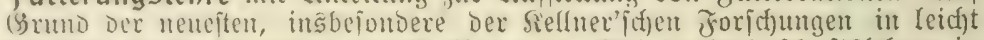

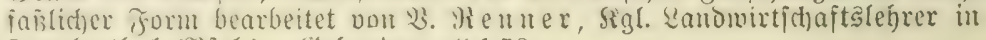

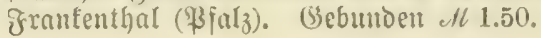




\section{Schriften über Cierzucht.}

Geburtshilfe und Geburtspflege. (Sin Mraftifher Wiatneber für Wiehbefiber.

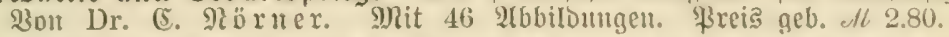

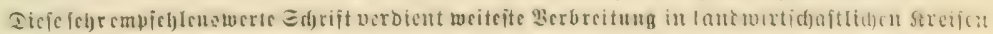

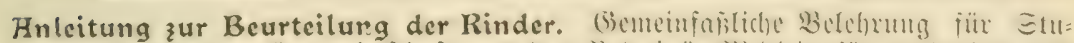

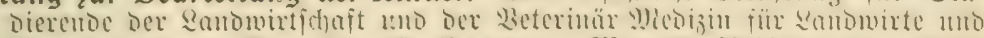

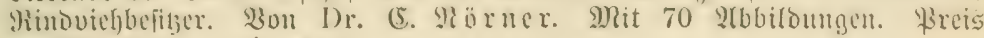
brofd). Al 5.- geb. dhe 6.-.

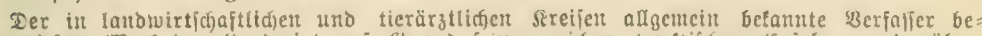

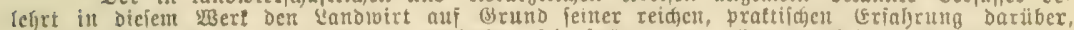

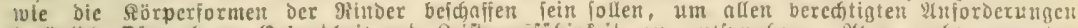

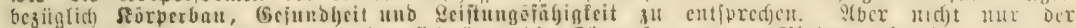

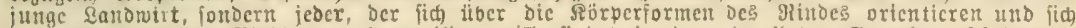

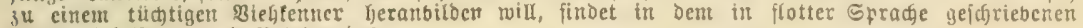
¿łudje viel शieuc: und Belehrende?.

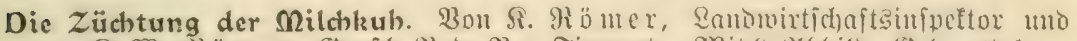

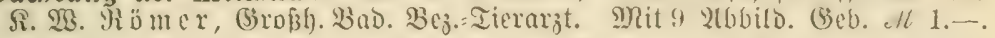

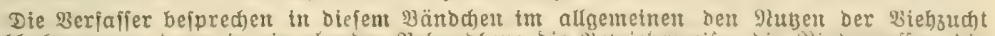

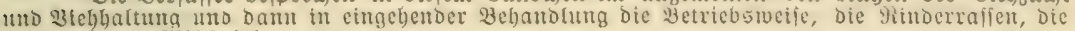

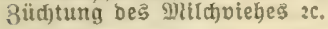

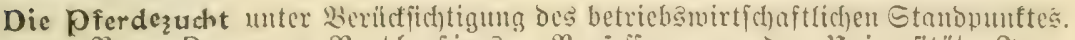

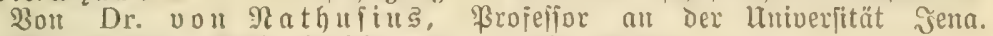

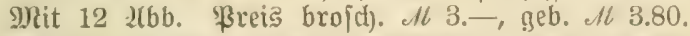

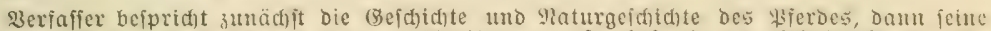

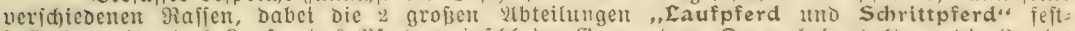

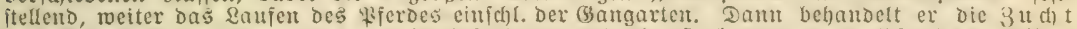
Des

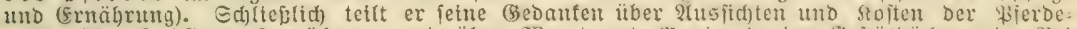

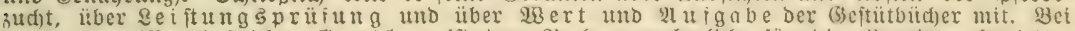

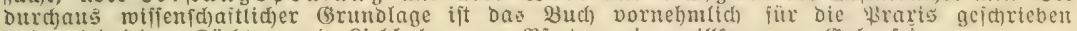

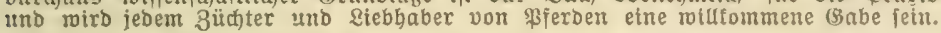

Zucht, Faltung, Maltung und Pflege des Schweines. Bearbeitet von

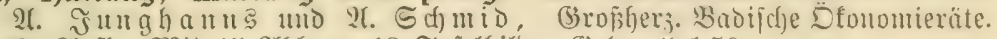
3. Ulufl. Mit 15 2tbb. u. 12 Tafelbild. (3eb. Al 1.50.

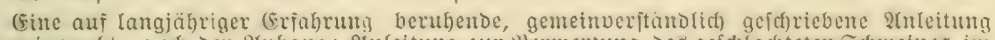

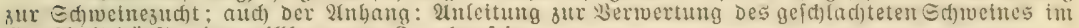
इaushalt bürite eine roillommene 3ugabe fetn.

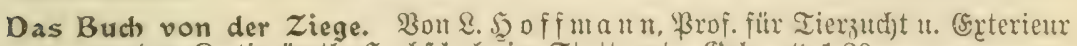

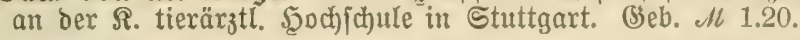

Die Nutzgeflügelzucht. (Sine 2Unleitung zum praftifd)en Betrieb dexfelben.

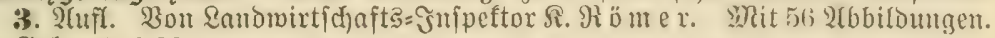
(5eb. Ill 2.80.

Der Berfaffer gibt tu Dtefer Sthrtft etue auf langiäbrige (Eriabrungen geftübte, burch=

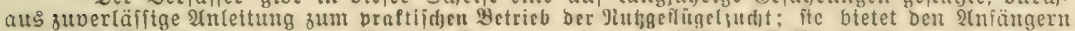

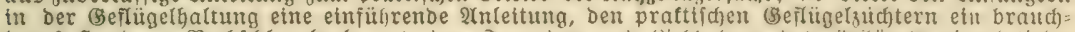

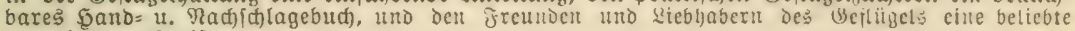
lunterfaltungafinrif!.

Praktifche Geflügelfütterung. 23on 2B. Ma iex, Lanbm. Manderlehrer uno

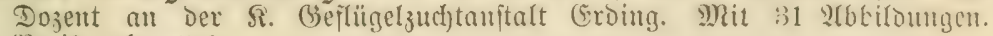
\$reis geb. ell 2.-.

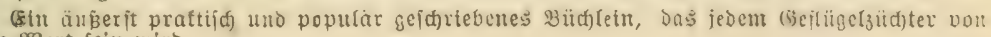
grüBtem Wert fein sotrb. 


\section{Schriften ïber Cierzucht.}

Fitlas der Raflen und Formen unierer Fausticre. Lon [r]. Simon vou giathufiug, Frofefior an dex lniverfität jena. Itad)

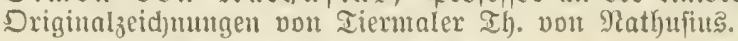

I. Eerie: Pferderaffen. 24 Iafelt mit Iext. Preis in Reimmant: Mappe 16 6.-.

II. " Rinderraffen. 28 Iafeln mit Text. ßreț in Reimwand= Mappe Al $7 .-$.

III. "Schweine-, Schaf- und Ziegenrafien. 24 Infeln mit Iect. Breis it Reimwand= Mappe eth 6.50.

IV. "Verichiedenheiten der formen, verutriacht burd) (Gefd) (ed)t,

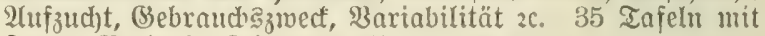
Tert. Preis in Reimmand=9Mappe th 6.50 .

Format jeder Tafel 20,5:26 cm. Jede Serie ist einzeln käuflich.

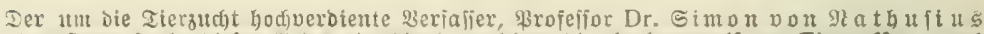

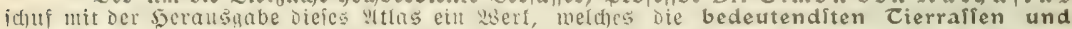

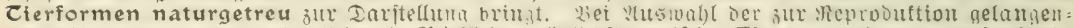

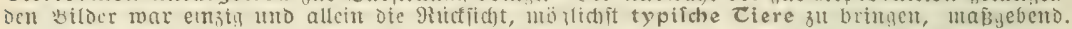
In furzent Text tít Das wichtigite über Die abgebilbeten Jlajien unter நervorbebung ibrer

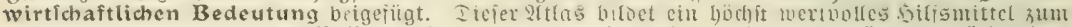

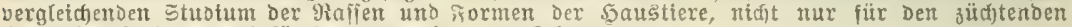
Sanowirt, fondern aud) für Den Sernenden und sebrenden.

Das Schaf. Seine wirtf(haftlidye Bedcutung, feine 3udft, Saltung und Bflege. (sin Sandbud) für mittlere uno fleme Ed)afhalter und Iandw. Seamte.

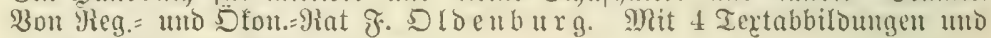
11 Mafjebildern. \$reis geb. N 1.20.

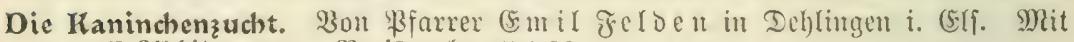
17 शtbbildungen. Freis geb. Al 1.20 .

\section{Schriften iiber Bienenz̧ucht.}

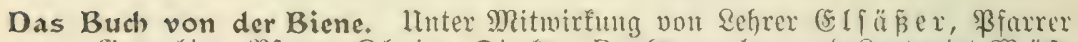

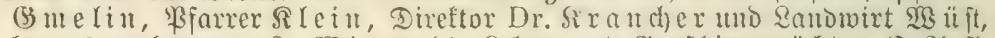

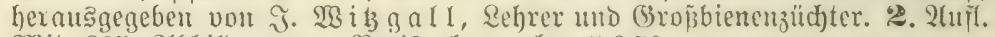
Mit 305 2lbbildungen. Prets eleg. geb. Al 6.50.

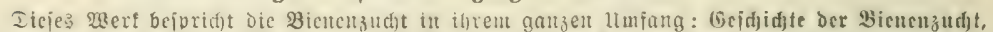

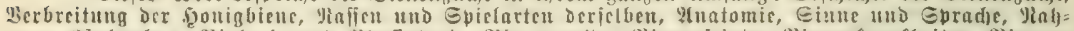

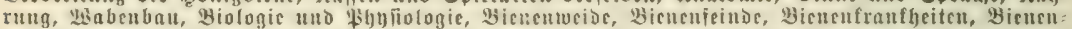

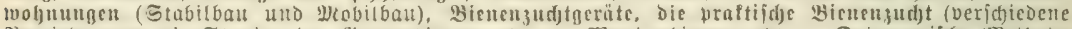

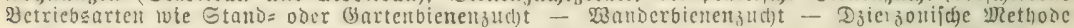
- Majazinmethode - Sdbrormmethode - Retoelmethodel. Die interei im 9jobil= u. Stabilbau,

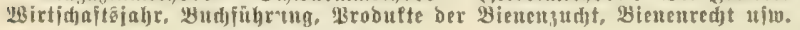

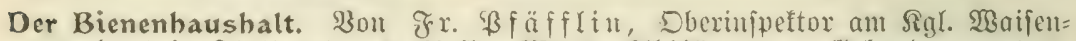

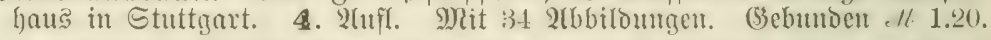

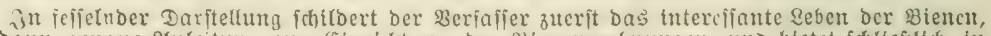

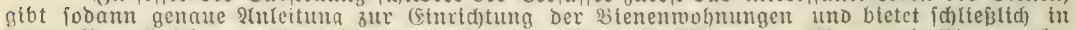

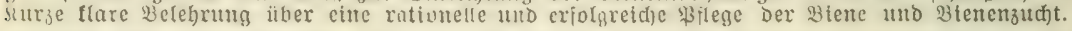

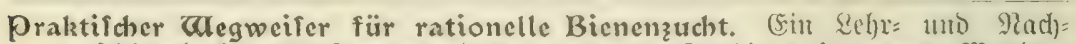

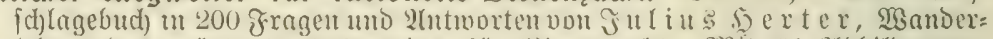

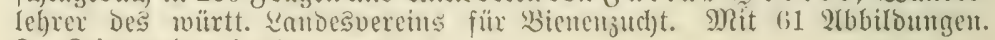
In Reimband gebumben $\mathbb{A l} 1.80$. 


\section{Schriften über Milchwirtichaft.}

Schäfer's rehrbuch der Milduwirtichaft. (Fin "ecifnben fïr Den lluterid)t m

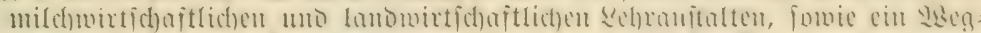

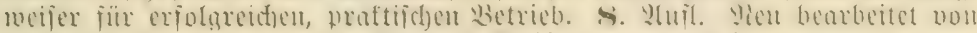

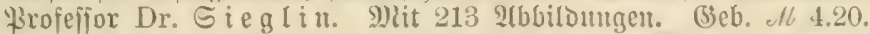

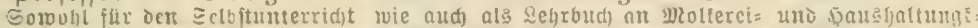

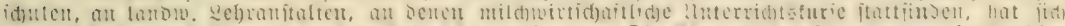
Decie Đurijt entes überang azol;

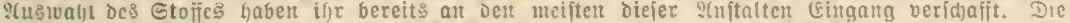

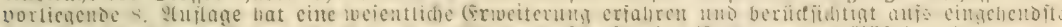
alle fortidritte auf dem Gebiete der Milchwirtidaft, der Butter-und läfebereitung.

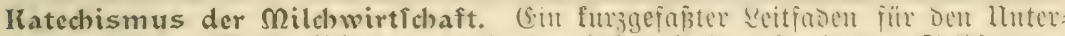

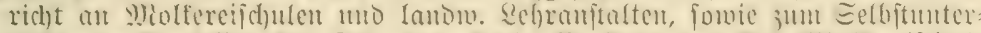

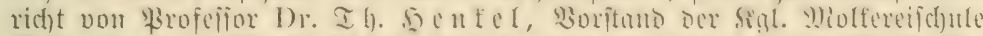

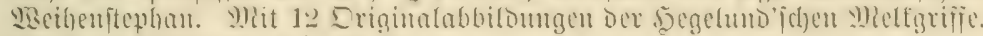

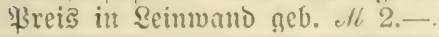

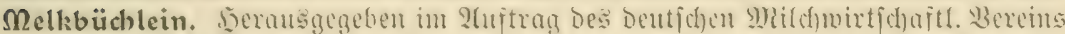

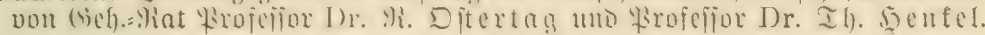
y) Xit 64 2tbbilbuntgen. Wreis geh. ell 1.30, geb. Mh 1.50 .

Der praktifhe Mildwirt. 2ion Dr. vou Silenze. :3. Whülage, bearbeitet von

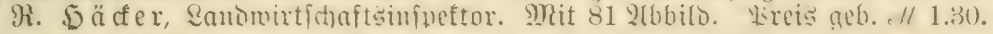

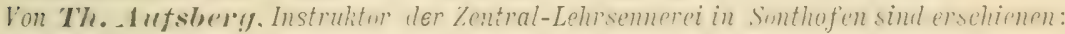

Die Bereitung von Rundkälen nach Emmentaler Hrt. I. Teif. 9nit 25) 2lbbill. Rart. all 1.-.

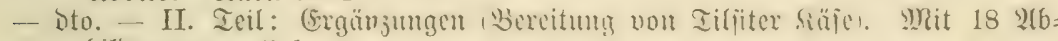
billoungen. ell 1.-.

Die Bercitung von đacichkälen im Hllgär. Mit 30 श6b. Siart. c/l 1.20.

Rabmgewinnung und Butterbereitung. Mit 56 2(bb. Siart. dl 1.20.

Stallkunde und Mildkenntnis. Mit 14 thbilbungen. Siart. d/ 1.20.

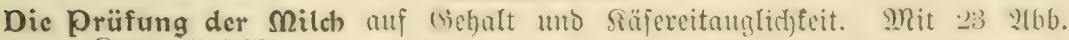
Siart. ill 1.20 .

\section{Schriften ïber Baukunde.}

Des Candmanns Baukunde. 3um (jebranct) fïr Rambleute umb länolide

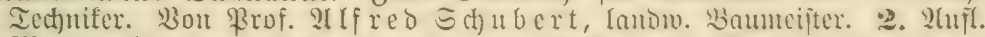
9) 22 Iafeln. (Drightalabbilo. De's Werfaffers.) Hireis geb. ell 1.-.

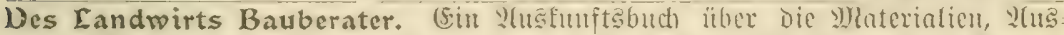

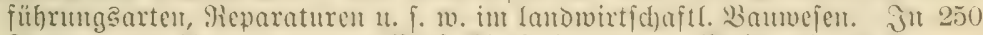

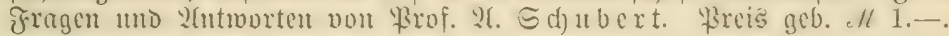

zaie baut der Eandmann Teine Ställe praktifch und billig? (Ein furjer,

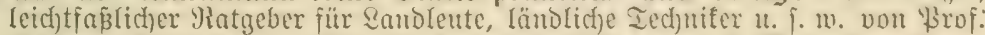
24 If

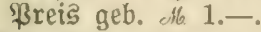

Die Dungitätte, ibre zwedzmäßige Hnlage und Husführung. Wुbn Wrof.

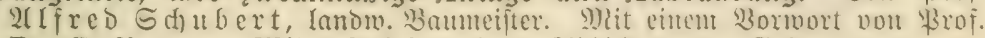
Dr. (5. Ka m m. Mit 7 Iafeln uto 14 26bildugen. (Seb. de 1.-.

Diese Schriftehen sind in leicht verstänllicher Form speziell für den Landwirt geschrieben und bilden für denselben ganz vortreffliche Rutgeber in BuuAngelegenheiten. 


\section{Schriften über Pflanzenkrankbeiten.}

Htlas der Rrankbeiten und Belchädigungen unferer landwirtTchaftlichen Rulturpflanzen. Sernuggegeh. vou Dr. D. v. Si $i \mathrm{rd}$ u er,

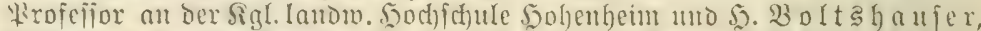
Eefmonrlehrer in 2(mrismcil. 2ollftändig in is Eerien (126 folor. Iafelm).

Preis in Mappe mit Sd)ubfarton $M$ 68.-. Preis als $\mathfrak{B a n d a f e l a n s g a b e ~ . ~ M ~ 8 5 . - . ~}$

\section{Daraus einzeln:}

I. Eerie: Getreidearten. 2() Iafeln mit Iext.) Freis in Mlappe ell 10.-

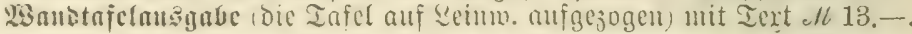

II. " Gülfenfrüchte, futtergräier und futterkräuter. 22 Tafelı mit Iext. Preis in slappe ell 12.-. Wantafictangabe (bie Iafelt auf Seinwand aufgezogen) mit Iext $M$ 15.-.

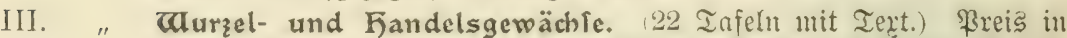

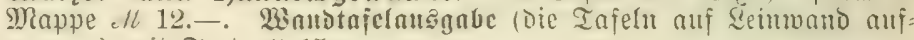
gezogen) mit Iext $\mathbb{N}$ 15.-.

11. "Gemüle- und Küchenpflanżen. 112 Infeht mit Tert.) Breis in Wappe ell 7.-. Wiandajclansgabe ide Tafeht auf Reinmand anf= gejogeti) mit Tert dit 9.-.

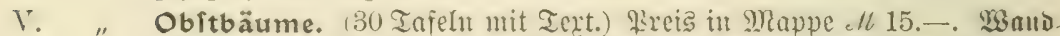
tajelnusgabe (bie Iafeln auf Seimmand anfgejogen) mit Iert on 18.-.

I. " «ueinitock und Beerenobtt. (20 Tafehn mit Tert) Breis in Mappc .ll 12.-. Wantajelansgabe (oie InfeIn auf Seimmano allfgezogent) mit Iert $M 15 .-$.

Die Krankheiten und Beichädigungen unferer landwirtidhaftlichen Kultur-

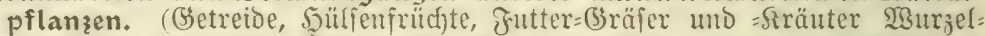

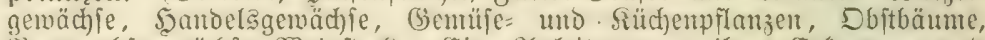

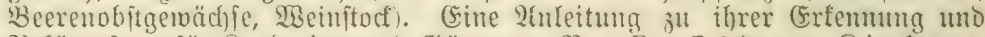

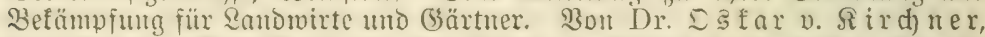

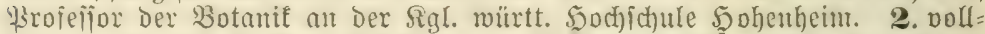
itänoig untgearb. N1tfage. 634 Seiten gr. 8". Freis brofd). ell 14., geb.e/l 15.50.

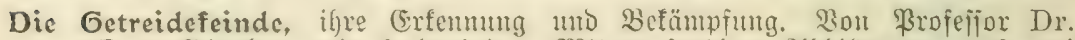

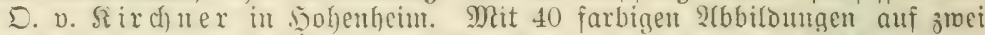

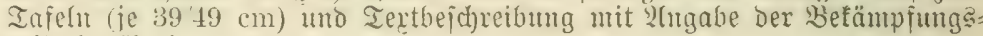
mittel. sireis en 2.-.

Krankbeiten und Befchädigungen der Nutż- und Zierpflanżen des Garten-

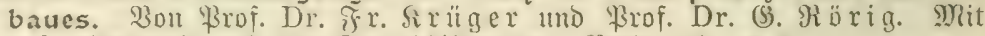
4 Farbentafelm und 224 Iertabbildungen. Freis geb. ell 6.-.

IRurzgefaßtes Kebrbuch der Krankheiten und Belebädigungen unferer Kulturgewächfe. (Ein Seitfaden sunt llnterrid)t an Ectulen, forvie jut Eelbit=

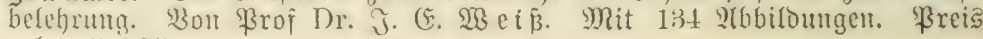
geb. Al 1.75 .

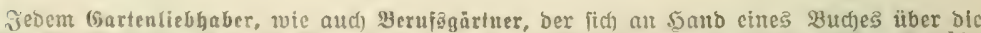

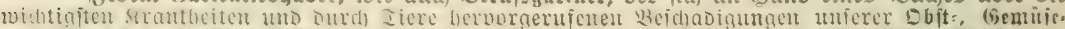

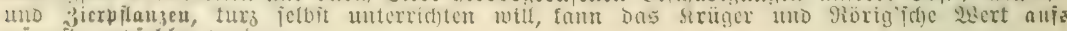
märmîte empiohlen beroeu. 


\section{Schriften über Obitbau.}

Volltändiges Fandbuds der Obithultur. 1. 2(ufl. Wearbeitet von Sfono=

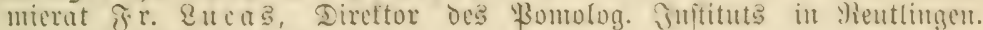
Mit 343 2lbbillo. (3)eb. ell 6.-

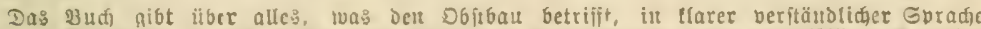

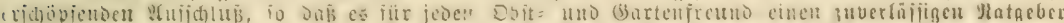

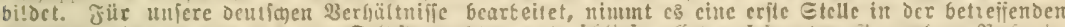

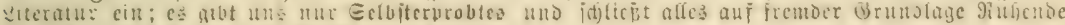
uno pïr unier nlimu nidit 13 afiende nillia aub.

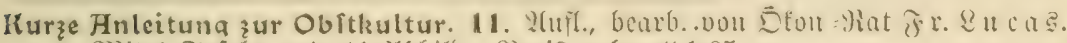
9) 4 it 4 Iajeht und 11 2)bbild. \$reis geb. ell 1.65 .

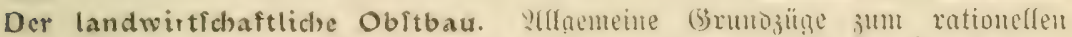

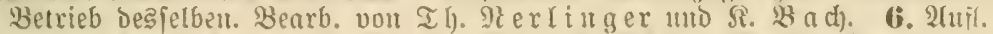

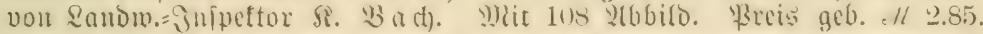

Die pflege des Obftoaumes in Rorddeutioland. y?it befonderer Beritt:

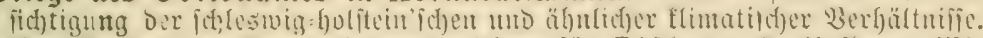

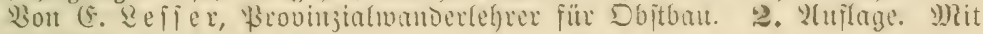
51 2(bb. Siart. ell 1.40

\section{Schriften über Oblt- und deinbereitung.}

Obit- und Küdenvorräte im Faushalt. Whleitum jux jatifhbaltumg mu

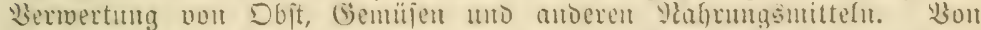

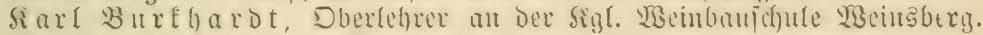
Mit 34 2lbbildungen. - \$reis gebunden th 2.40.

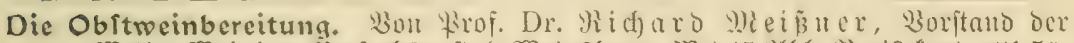

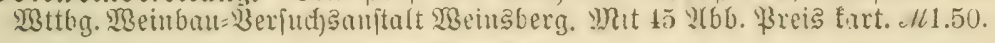

Max Barth, Dic Obitweinbereitung mit befonderer berïcfïf)tiqutg dex

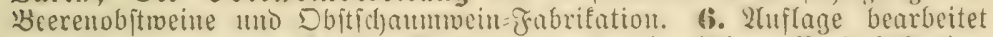

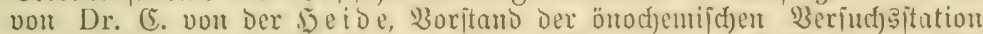

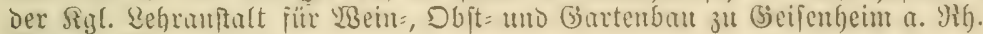
פRit 26 Ubb. Breis all 1.30.

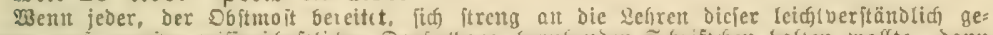

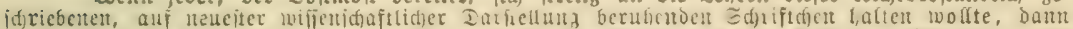

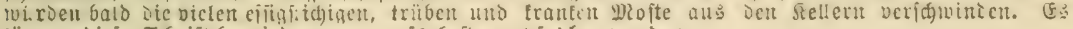
töntent dieje Sdjriftcien jedermant aufs bejte cmpfot (en merdent.

Der Johannisbeerwein und die übrigen Obit- und Beerenweine. Nebit

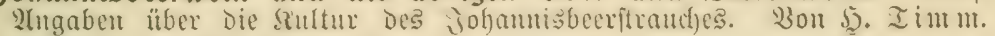

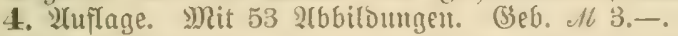

Die Bereitung, Pflege und Anterfuchung des aleines. Bout (Beh. Jofrat

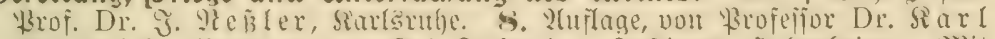
IB 134 2tbbildungen. Wretis gebumbat all 11.-

Max Barth, Die Kellerbehandlung der Craubenweine. Silligefabte 2ln loitung

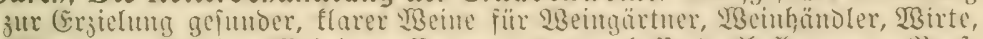

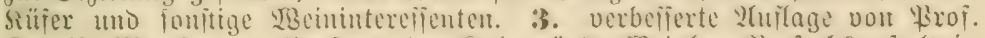

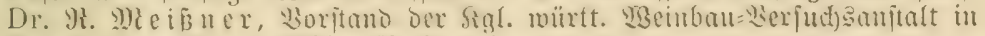
Meinaberg. Mit 53 26b. \$reis geb. 162.80.

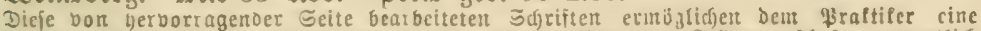

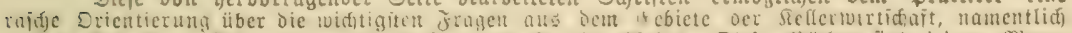
and in Betıc interificnter värmitens zu empiehlen. 


\section{Schriften ïber Gartenbau und Blumenzucht.}

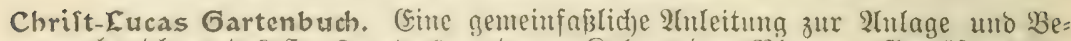

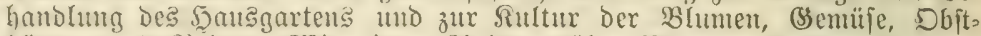

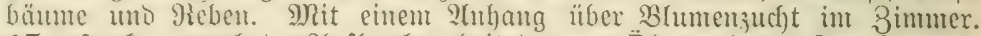
15. ftarf vermebrte 2ufl., bearbeitet von Dfonomierat ifr. Zucas.

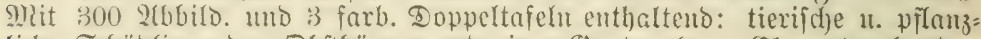
liche Grfädlinge dex Dbitbämme und cinen Bartenplan. Elegant gebumben M. 4.-.

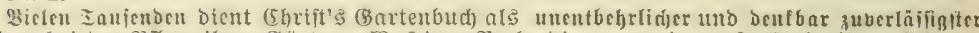

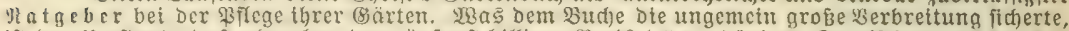

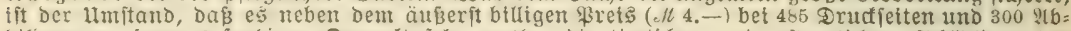
buldugen, jomte : facbigen Doppertajeln, enth.: Die tierilden mo pilanzlidjen Sctüblinge des

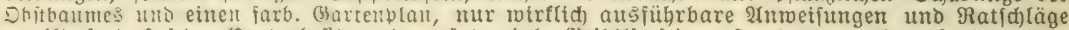

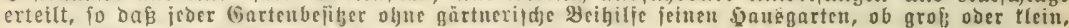
Danadj iclbit bebauen fann.

Die Kultur der pflanzen im Zimmer. Zou \&. (5) räbener, Grop̉h. \$of =

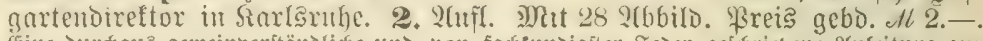

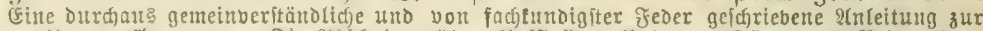

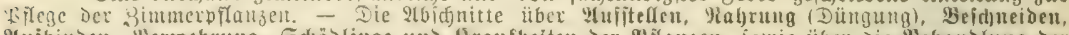

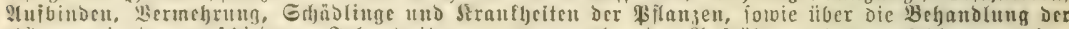

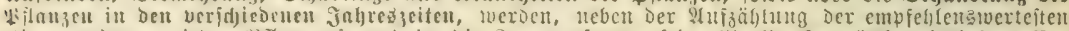

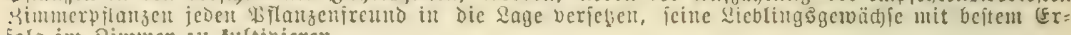
folg in Rimmer ant tultinieren.

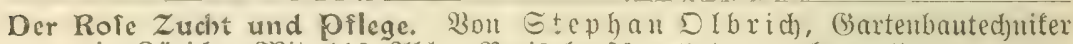

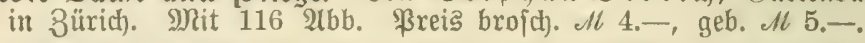

Vermebrung und Schnitt der Zicrgehölze mit einigen 9ltablicten anf Die frragen der 23ererbung und Snbribation. Bou Stephan SIbrid), (Shef

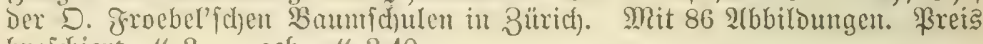
brofdjiert ell 3.-, geb. Al 3.40 .

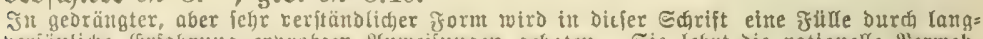

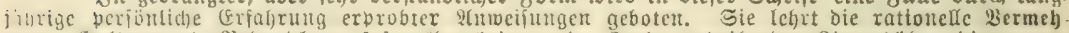

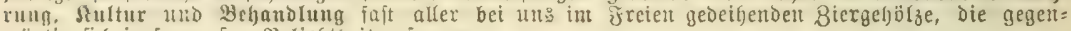
suärtig fid ja fo großer Beliebtheit erfreuent.

\section{Schriften über Obitichutz.}

Schutz der Obitbäume gegen feindliche Ciere und gegen Krankheiten. Bion firof. Dr. Iafdenberg mo Brof. Dr. Sox a uer. Mit 185 grbbilo.

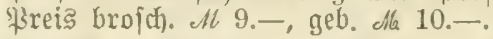

Dieses Werk ist auch in zuri, je einzeln käuflichen Bänden zu beziehen und zwar:

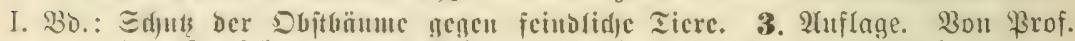
Dr. I afdenberg. Mit 75 abbild. Brofd. Al 4.80, geb. d6. 5.60 .

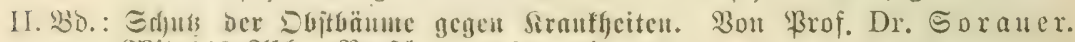
g) it 110 abb. Brofd). $\mathscr{M} 4,20$, geb. $\mathscr{A l}$ 5.-.

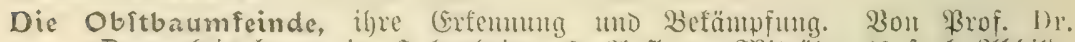

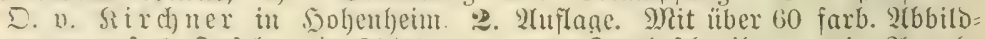
mugen auf 2 Iafeln, (je $39 / 49 \mathrm{~cm}$ ) mo Iextbefdreibung mit 2lugabe Der sBefämpfungsmittel. Bebunden $\mathscr{N} 2 .-$

Dic widhtigiten feinde der Obitbäume. Bou Dr. (5). Lü jt u er in (Geijentheint. Mit 30 abbild. (Sebutben dl 1.-.

Die Rebenfeinde, if)re (Exfemmug mo befämpfung. Bon \&rof. Dr. D. von

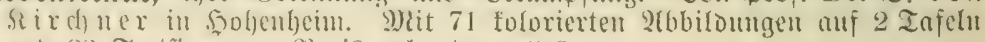
uno 22 Textriguten. \$rcis gebunden Al 2.-. 


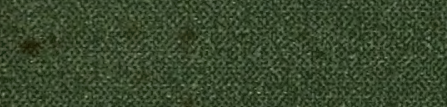

4 